\title{
OCEANOGRAPHY IN THE UNITED STATES
}

\section{HEARINGS}

BEFORE THE

\section{SPECIAL SUBCOMMITTEE ON OCEANOGRAPHY}

OF THE

\section{COMMITTEE ON}

\section{MERCHANT MARINE AND FISHERIES \\ HOUSE OF REPRESENTATIVES}

\section{EIGHTY-SIXTH CONGRESS}

FIRST SESSION

WASHINGTON, D.C.

MARCH 3, 10, 12, 17, APRIL 21, 23, JUNE 23, JULY 13 AND 14, 1959

CARDEROCK, MD.

APRIL 24, 1959

BOSTON, MASS.

JUNE 1,1959

WOODS HOLE, MASS.

JUNE 2, 1959

Printed for the use of the Committee on Merchant Marine and Fisheries

3

46

pt. 1

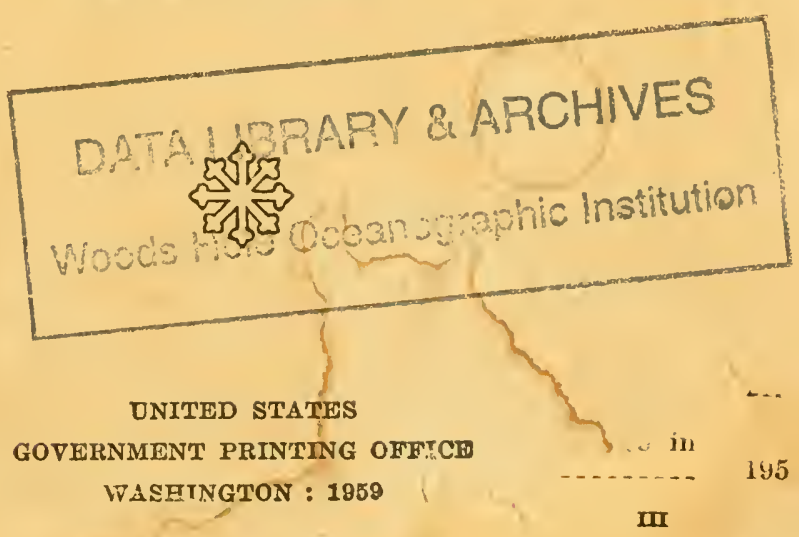





\section{OCEANOGRAPHY IN THE UNITED STATES}

\section{HEARINGS}

BEFORE THE

\section{SPECIAL SUBCOMMITTEE ON OCEANOGRAPHY}

OF THE

\section{COMMITTEE ON}

\section{MERCHANT MARINE AND FISHERIES \\ HOUSE OF REPRESENTATIVES}

\section{EIGHTY-SIXTH CONGRESS}

FIRST SESSION

WASHINGTON, D.C.

MARCH 3, 10, 12, 17, APRIL 21, 23, JUNE 23, JULY 13 AND 14, 1959

CARDEROCK, MD.

APRIL 24, 1959

BOSTON, MASS.

JUNE 1, 1959

WOODS HOLE, MASS.

JUNE 2, 1959

\section{GC \\ 3 \\ 46 \\ pt. I}

Printed for-the use of the Committee on Merchant

Marine and Fisheries

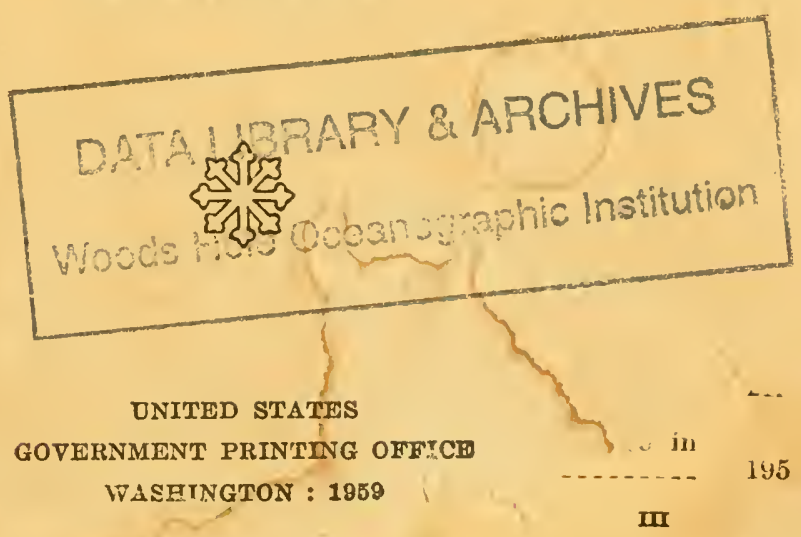




\section{COMMITTEE ON MERCHANT MARINE AND FISHERIES}

HERBERT C. BONNER, North Carolina, Chairman

FRANK W. BOYKIN, Alabama

EDWARD A. GARMATZ, Maryland LEONOR K. (MRS. JOHN B.) SULLIVAN, Missouri

T. A. THOMPSON, Louisiana GEORGE P. MILLER, California HERBERT ZELENKO, New York FRANK M. CLARK, Pennsylvania THOMAS LUDLOW ASHLEY, Ohio JOHN D. DINGELL, Michigan L. MENDEL RIVERS, South Carolina TORBERT M. MACDONALD, Massachusetts ALTON LENNON, North Carolina ROBERT N. C. NIX, Pennsylvania VICTOR L. ANFUSO, New York JAMES C. OLIVER, Maine THOMAS N. DOWNING, Virginia GERALD T. FLYNN, Wisconsin BOB C.ISEY, Texas

THOMAS F. JOHNSON, Maryland
THOR C. TOLLEFSON, Washington WILLIAM K. VAN PELT, Wisconsin JOHN H. RAY, New York WILLIAM S. MAILLIARD, California FRANCIS E. DORN, New York THOMAS M. PELLY, Washington A. D. BAUMHART, JR., Ohio H. R. GROSS, Iowa WILLARD S. CURTIN, Pennsylvania MILTON W. GLENN, New Jersey ELMER J. HOFFMAN, Illinois

\section{JoHN M. DREWRy, Chief Counsel \\ Bernard J. Zincke, Counsel \\ Robert H. Cowen, Counsel}

William B. Winfield, Chief Clerk

\section{Special, Surcommitee on Oceanograpiy}

GEORGE P. MILLER, California, Chairman

JOHN D. DINGELL, Michigan ALTON LENNON, North Carolina JAMES C. OLIVER, Maine GERALD T. FLYNN, Wisconsin
FRANCIS E. DORN, New York THOMAS M. PELLY, Washington

WILLARD S. CURTIN, Pennsylvania

JonN M. Dexwry, Counsel

II 


\section{CONTENTS}

Statement of-

Bascom, Williard, technical director,

Beatty, Capt. Walter F. formector, AMSOC committee ......... 289 Bennet, Hon. Charles E., a Representative in Congress from the
State of Florida.

Brooks, Hon. Jack B., a Representative in Congress from the State of Texas...........

Brown, Dr. Harrison, chairman, Special Subcommittee on raphy, National Academy of Sciences, etc

Casey, Hon. Robert, a Representative in Congress from the State of

Donahue, William J.

Downing, Hon. Thomas N., a Representative in Congs State of Virginia. .

Fye, Paul M., director, Woods Hole Oceanographic Institution

Hays, Earl F., physicist, Woods Hole

Hayward, Rear Adm. John T., USN, Assistant Chief of Naval Opetions (Research and Development); Capt Chief of Naval OperaUnderseas Warfare Research and Developt. Richard Holden, USN, Office of the Chief of Naval Operations; USN, Deputy Hydographer, perations; and Capt. H. G. Munson, Hess, Dr. Harry H., Department of Geology, Prince......... Hiller, Capt. Emerson H., Fairl of Geology, Princeton University.. Albatross III ........ Fairhaven, Mass., master, formerly of the

Iselin, Columbus O'D., Henry Brvant Bigelow Oceano.....

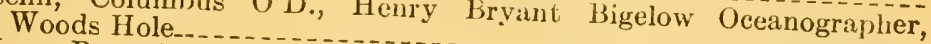

Karo, Rear Adm. H. Arnold, director, Coast and Geodetic survey, Department of Commerce._.
Ketchum, Bostwick H, senior

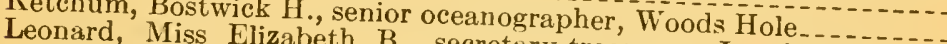
American Federation of Government

Lichtman, Dr. Martin, research direct Employees, A. F. of L. Furcolo Dr. Martin, research director, from the office of Governor

Lieberman, Dr. Joseph, Chief of the Environmental and Sanitary Engineering Branch, Reactor Develonvironmental and Sanitary ergy Commission... Reactor Development Division, Atomic En-

Lill, Gordon G., Head, Geophysics Branch office of 337

Lyman, John, Director, Division of , Office of Naval Research.Hydrographic Office. - Division of Oceanography, U.S. Navy

Malkus, Joanne S., meteorologist, Woods Hole

$\begin{array}{ll}\text { Marak, Robert R., biologist, Fish and Wildlife Service, Falmouth, } & 280 \\ \text { Mass } & \end{array}$

McHugh, J. Lawrence, Chief, Division of Biological Research, Bureau of Commercial Fisheries, Department of Interior Research, Bureau

McKernan, Donald L., Director, accompanied by Andrew W. AnderSon, Assistant Director, Bureau of Commercial Fisheries, Fish and

Metsger, Capt. A. B., Deputy and Assistant Chief of Naval Re... . 84

Morse, Clarence G., Chairman Assistant Chief of Naval Research time Administrator, accompanied byl Maritime Board, and Marinator of Research, accompanied by Charles R. Denison, CoordiConstruction, Maritine Vito L. Russo, Deputy Chief, Office of Ship Commerce... Maritine Administration, U.S. Department of

Munma, Rear Adin. Albert G., Chief, Bureau of Ships, Department
of the Navy .

Munson, Capt. Henry G., Hydrographer of the Navy and hydro rapher in command of the U.S. Navy the Navy and hydrogOceanography......... the U.S. Navy Hydrographic Office in 
Statement of-Continued

Nickerson, Samuel, Centerville, Mass., employed by Fish and Wildlife

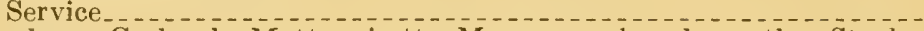

Paulsen, Gerhard, Mattapoisett, Mass., employed on the Stanley

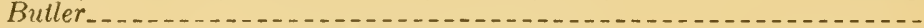

Powers, Austin J., Dorchester, Mass

Richmond, Vice Adm. A. C., The Commandant, U.S. Coast Guard, accompanied by Rear Adm. James A. Hirshfield, Assistant Commandant, U.S. Coast Guard.

Rivers, Hon. Ralph J., a Representative-at-Large from the State of Alaska...-

Rogers, Hon. Paul G., a Representative in Congress from the State of Florida

Sadler, W. M., executive secretary to Hon. Hastings Keith, a Representative in Congress from the State of Massachusetts........

Schaefer, Milner B., Inter-American Tropical Tuna Commission, La Jolla, Calif

Seymour, Dr. Allyn H., consultant, Atomic Energy Commission, and assistant director, Laboratory of Radiation Biology, University of

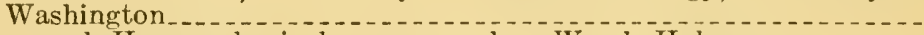

Stommel, Henry, physical oceanographer, Woods Hole

Vetter, Richard, Executive Secretary, National Academy of Sciences . von Arx, William S., physical oceanographer, Woods Hole.........

Wright, Capt. E. A., commanding officer and director, David Taylor

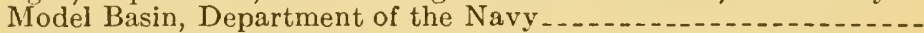
Additional information-

American Miscellaneous Society, submitted statement, and list of members

Anderson, C. L., Commissioner, State of Alaska, Department of Fish and Game, letter, June 11, 1959, and attachments _..........

Bonner, Hon. Herbert C., letter, June 23, 1959, to Ross L. Leffler, Assistant Seeretary of the Interior, re disposal of radioactive waste, and letter in reply, July 2, 1959, with statement

Bureau of Commercial Fisheries, Fish and Wildlife Service:

Inserts:

Some recent charter vessel experience

Statisties of vessels 40 feet and over

Letter, March 2, 1959 , to Hon. George P. Miller, with attachments:

February 26, 1959 letter to Hon. Leverett Saltonstall _...

Summary budgets for New England Biological Research.-

Statement of condition of Albatross $I I I$.

Coast Guard, office memo, March 10, 1959, re officers who have had oceanography training, list.

Commercial Fisheries Review, U.S. Department of Interior, Fish and Wildlife Service, article, "The Albatross $I I I$," by Willian F. Royce..

Department of the Interior, letter, July 2, 1959, letter, in reply to June 23, 1959, letter from Hon. Herbert C. Bonner, and statement.-

Fasccll, Hon. Dante B., a Representative in Congress from the State of Florida, letter, July 23, 1959

Fish and Wildlife Service, letter, July 28,1959 , signed A. W. Anderson, Acting Director . . .

Hargis, William J., director, Virginia Laboratories, letter, July 10,

Hiller, E. H., master, chief officer, Albatross III, letters, March 9, 1959, with inserts Laboratory of Radiation Biology, University of Washington:

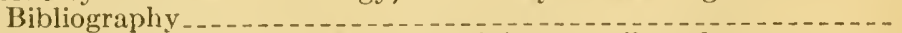

Table 1-Percent of total radioactivity contributed, etc

Leffler, Ross, Assistant Secretary of the Interior, letter, February 18, 1959, to Miss Elizabeth Leonard, with comments on letter

Metsger, Capt. A. J3., Deputy and Assistant Chief of Naval Research, memo on oceanography . . . . . . . . . . . . . . . . . . . . . . . National Aeademy of Sciences:

Report of the Committee on Oceanography, 1960 to $1970 \ldots \ldots$. Chapter 8-Education and Manpower-
Chapter 12-Marine Sciences in the United States-1958.--

10-year plan for increasing U.S. fleet of Ocennographic ships, and

tables 1-17, etc 
Additional information-Continued

Oeeanographie publications, list supplied by John Lyman, Director, Page

U.S. Navy Hydrographic Office _. .

Oceanography Research Ships, artiele by G. G. Lill and A. E. Maxwell, Officer of Naval Research ......

Patty, Ernest N., president, University of Alaska, letter, July 15, 1959.

Powers, Austin J., ex-2d officer, Albatross III, letters:

March 14, 1959, to Hon. Leverett Saltonstall, re objecting to deactivation of Albatross $I I I$, ete

June 3,1959 , to Hon. George P. Miller

Saunders, William P., director, Department of Conservation and development, Morehead City, N.C., telegram, January 13, 1959_.. Taylor Model Basin, articles by:

Cummins, W. E., "Storms and Ships, a Mutual Problem of Naval Architeeture and Oceanography" -....................

Harrison, Mark, Ph. D., "The Significanee of Oceanography to the Underwater Acoustics Program at the David Taylor Model Basin"

Jasper, N. H., "On Strength of Ships at Sea"

Johnson, E. E., "The Interrelation of Oceanography and Submarine Operation"

Marks, Wilbur:

"One-tenth Scale Model of TMB Seakeeping Basin Exhibit and Presentatiou"

"Taylor Model Basin Disposable Wave Buoy (Splashnik)",

Nelligan, J. J., "Oceanographic Survey Instrument" - . ... -

Wrench, J. W., Jr., "The Role of the Applied Mathematics Laboratory in the Solution of Oceanographie Problems" ........

Woods Hole Oeeanographie Institution:

Fields of study

Partieipants in hearing

Telegram, March 6, 1959, signed, Paul M. Fye, director...... 


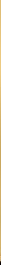




\title{
OCEANOGRAPHY IN THE UNITED STATES
}

\author{
TUESDAY, MARCH 3, 1959
}

\author{
Hotse of Representatives, \\ Special Subcommittee on Oceanography, \\ of the Compuittee on Merchant Marine and Fisheries, \\ Washington, D.C.
}

The subcommittee met, at 10 a. m., pursuant to notice, in room 219 , Old House Office Building, Hon. George P. Miller (chairman of the subcommittee) presiding.

Present: Representatives Bonner (chairman), Miller, Dingell, Lennon, Oliver, Flynn, Dorn, Pelly, and Curtin.

Staff members present: William B. Winfield, clerk; John M. Drewry, chief counsel.

Mr. Miller. A quorum being present, the committee will come to order.

This is the first meeting of the Special Subcommittee on Oceanography of the Committee on Merchant Marine and Fisheries, ap nointed February 17, and directed by Chairman Herbert C. Bonner to hold such hearings and take other actions as may be appropriate in order to fully develop the extent to which the U.S. should go to carry out a broad and effective national program of oceanographic studies.

The Merchant Marine and Fisheries Committee is vested by the House of Representatives with jurisdiction over matters pertaining to the merchant marine, fisheries, the Coast and Geodetic Survey, and the Coast Guard. Thus, we have had frequent occasion to consider separate aspects of the broad field of oceanography from time to time. In the past year or so, however, as a result of the successes of the International Geophysical Year, the importance of coordinated study of problems of this nature has been demonstrated. Moreover, new concepts of transportation, military preparedness, and exploitation of food resources have shown that detailed knowledge and understanding of the oceans and their contents are assuming even greater importance. Yet, we have come to realize that despite the importance of the oceans our knowledge of them is small when compared with the needs.

Therefore, the Committee on Merchant Marine and Fisheries, with its keen obligations with regard to matters concerning the oceans and that which is beneath the surface, has initiated this study and investigation under the immediate inspiration of the provocative report recently released by an ad hoc Committee on Oceanography of the National Academy of Sciences, established by the National Research Council in 1957. This committee of 11 distinguished scientists under the chairmanship of Dr. Harrison Brown, professor of geochemistry at California Institute of Technology, in the initial portion of its report recently released outlined the scope of research and survey work 
that needs to be done, and the facilities that will be required to achieve a thorough study in this important field over the 10-year period from 1960 to 1970 . This report clearly shows that, while man has been going to sea since before the dawn of written history, he has really acquired but little knowledge of the element that carries the trade of the world. His ignorance of what is below the surface of the sea is as dark as its abysmal depths.

It will be the goal of this committee to conduct a comprehensive study in the field of oceanography so that it can make positive and factual representations and recommendations to the Congress for guidance in carrying out a firm program.

We are pleased to hear this morning from Mr. Richard Vetter, Executive Secretary of the National Academy of Sciences, Committee on Oceanography, and Adm. H. Amald Karo, Director of the U.S. Coast and Geodetic Survey.

Chairman Bonner, we are very happy to have you here this morning. If you have anything that you would like to say before we start our hearings, we would be pleased to hear you.

Would you come forward, please, Mr. Vetter.

Our fir'st witness is Mr. Vetter, Executive Secretary of the National Academy of Sciences, Committee on Oceanography, who acted as Secretary, I believe, to the Brown committee, and is very familiar with this work.

Mr. Vetter.

\section{STATEMENT OF MR. RICHARD VETTER, EXECUTIVE SECRETARY, NATIONAL ACADEMY OF SCIENCES}

Mr. Vetter. Mr. Chairman, first of all I would like to express the appreciation of the Committee on Oceanography for the thoughtful attention you have already given to marine sciences and to our report. I would like to extend Dr. Harrison Brown's greetings at this time and to comment that he and the rest of the committee stancls ready to be of assistance and cooperation in every way possible in your studies.

I think you already have a copy of chapter 1, "Introduction and Summary of Recommendations," of the Committee's report.

At this time I have brought two other preliminary copies of chapters being prepared for the Committee on Oceanography report, chapter 8, "Education and Manpower," and chapter 12, "Marine Sciences in the United States, 1958". These two and other chapters in the report are being prepared as rapidly as time will permit and will be made available to you as soon as possible.

There may be some slight changes in the published copies but the changes will be very minor.

In addition, there is a small mimeographed two-page report that lists some of the departments of the Government that are concerned with the development of marine sciences and that are mentioned in the report of the Committee on Oceanography.

Also, for your information, there is a four-page mimeographed list of oceanographic research ships, including those engaged in the scientific activities of the various oceanographic instructions, those being used by the Navy in its program, those being used by the Coast and Geodetic Survey, and those operated by the Bureau of Commercial Fisheries. 
I hope that this material will be useful to you and I will be happy to make any other information available to you that I can.

Mr. MiLuen. Could you give this committee for the record a comparison as to the work that is being done in this country as compared to other countries that are now engaged in oceanographic research?

Mr. VETTER. I am not sure exactly in what way this comparison is best made. My own belief is that the United States is well in the forefront of the scientific exploration of the sea. We have, in the last $10 \mathrm{or} 20$ years developed considerable competence in this field and have exceeded the level previously set in the European countries for scientific activities in this area.

Our rate of advance has been good. It has not been as rapid as it has been in some other countries. The emphasis placed in our own country is on two problems, on the fisheries aspect of marine research and on the problems of defense.

It has been in the latter field that we have advanced more rapidly.

In Europe and in Japan, emphasis is placed on the fisheries problems, and in these areas they, I believe, have maintained a level of activity that is equal to ours if not greater.

Mr. Miller. How about deep-sea exploration. Who has led in that field?

Mr. Vetter. Deap-sea exploration has involved all of the major powers, the United States, Japan, Great Britain, Russia.

I think that, if you were to chart the world with little dots of different colors according to different nationalities, that you would find a fairly even distribution among observations made by our own country and observations made by Russia, Great Britain, and Japan.

The International Geophysical Year has stimulated a great deal of activity in each of these four countries in the last 2 years.

Mr. Miller. Do we need more scientists in this field? Do we need to encourage more men to go into it?

Mr. Vetter. Yes, sir; we certainly do.

Mr. Miller. Would you care to comment on that phase of the subject?

Mr. Vetter. Our greatest need is to interest larger numbers of first rate scientists in oceanography. There are now approximately 500 scientists in the United States that are devoting full time to studying the oceans. This is a very small number in comparison with the problem that they are trying to attack. They are forced to group themselves in units, oceanographic institutions that are large enough to be able to support a ship and to operate teams at sea in order to operate economically.

If we are to really step up our activities in exploring the oceans we have, of course, to train more people, get more scientists interested in the field.

Mr. Mrleter. Do you believe we should step up our activities in this field?

Mr. VETIER. I do, sir.

Mr. Miller. In spite of the fact that you indicate we are still pretty much in the lead in the field, is there need to make additional effort to secure information? 
Mr. Vetrer. I do not want you to misinterpret my previous statement. I think that we are scientifically well in the forefront but we are not advancing as rapidly as Russia in this field, for example. We are not advancing as fast as we should independently of any other country in view of the problems that our own people, our own country has to solve for its economic welfare and for its security.

I think that we can make a case for advancing marine sciences in the United States without regard to comparing our activities with any other country. We have our own needs and, based on these alone, there is a tremendous need for additional work.

Mr. Miller. I think that all of the members of the committee are familiar with Dr. Brown's report, but, for the record and in order to better advise us, would you care to sketch the background of some of the men on his Committee? You are familiar with it. Would you give a brief résumé of their accomplishments, who they are, and what they have done in this field?

Mr. Vetrer. First I would like to name the members of the Committee who are prominent as directors of oceanographic institutions and leaders in marine research. These are Maurice Ewing, Columbus Iselin, Roger Revelle, and Fritz Koczy. Each of these individuals is identified with a long history of scientific activity in the oceans. Dr. Ewing is director of the Lamont Geological Observatory. His major interests are in marine seismology. He has received awards from the Department of the Navy for his contributions to marine science and to programs of interest to the Navy. Several of his findings in this area have resulted in development of techniques and equipment that the Navy uses in its operations in detection and communication with submarines.

Columbus Iselin has been the director of the Woods Hole Oceanographic Institution for several years. He has now retired from that position. He has served on many committees with the Navy, has been involved in several international oceanographic activities and is a member of the Special Committee for Oceanic Research.

Dr. Revelle is director of the Scripps Institution of Oceanography and has been for several years. His main interests are in marine meology. He is a man of extremely broad capabilities and interests. He is chairman of the Special Committee for Oceanic Research and has been active in many committees both in and out of the Gorer'ninent.

Dr. Koczy has recently come to this country from Sweden. His particular competence is in marine geochemistry. He has done work recently on the diffusion of radium from the sediments underneath the oceans up into the water above. His work is important as a measure of vertical diffusion and deep circulation.

Dr. Gordon Riley, while a biological oceanographer for many years, is associated with a small oceanographic activity at Yale University, the Bingham Oceanographic Laboratory. He has conducted studies of productivity of the oceins to determine ways of estimating the various areas where production is taking place and the rate at which it is taking place.

'The other members of the Committee are not as closely associated with oceanography and this was arranged intentionally so that the Committee could approach its studies as objectively as possible. 
Mr. Sumner Pike is well known in Washington for his services with the Atomic Energy Commission. He was at one time a Commissioner of the AEC. He has considerable interest in the living resources in the sea being involved in the herring fishery in Maine.

Dr. Colin Pittendrigh, of Princeton University, is primarily a biologist of considerable stature. Before coming to the Committee on Oceanography, his interests were mainly centered on problems of establishing controlled experiments that would re-create the environment for relatively small biological communities.

Dr. Milner B. Schaefer is the director of the Inter-American Tropical Tuna Commission, and has participated in many international activities. He was one of the U.S. advisers to the recent Geneva convention on the law of the seas.

Athelstan Spilhaus is the dean of the Institute of Technology at Minnesota. He has long been interested in the exchange of energy between the atmosphere and the oceans. He is primarily a meteorologist. He is the inventor of the bathythermograph, an instrument which has very wide use now and has had for many years since the war to measure the temperature structure in the surface of the ocean.

Dr. Harrison Brown, before being asked to be Chairman of this Committee, had no connection with oceanography. His primary interests are in geochemistry. He is head of the Department of Geochemistry at the California Institute of 'Technology.

Mr. MrLuer. Mr. Chairman, have you any questions?

The Champiran. No.

Mr. Milleer. Mr. Dorn?

Mr. Dors. I think at the outset we should have a definition of oceanography.

Mr. Veтter. My own definition is that oceanography is that which involves any scientific work at sea including biological, geological, physical, and chemical problems.

In the oceans these problems all have to be studied in connection with one another.

Mr. Dons. Then would not oceanography probably be the study of the ocean and the land under it?

Mr. VeTter. This is a good definition, yes. I would call it the scientific study of problems in the oceans.

Mr. Dons. Have you thought at all about the work this committee can do to extend the study in the United States, implement it?

Mr. Vetter. Yes, I have.

Mr. Dons. What do you think we should do?

Mr. VeTtrar. I think the committee should first consider the problem on the broadest possible basis, that you should attempt to determine for your own satisfaction the extent to which a national program should be implemented, what all the agencies are doing, how much this amounts to in terms of manpower and dollars and in fields of interest. I think this is absolutely necessary before the next step can be made.

The next step, I should think, would be to determine to your own satisfaction whether this amount of activity in these fields is adequate. If not, I would think it appropriate to decide what part of this total program would come under the cognizance of this group and determine then what should be done about increasing the activity in this part of the field. 
Mr. Dors. Do you think that the total program is adequate at the present time?

Mr. VETTER. No, sir; I do not.

Mr. Dons. What do you think should be done about it?

MIr. TeтTER. I think, first of all, it is necessary to make money available for fellowship programs. The greatest roadblock in proceeding with this is to get the people into the system that we need. It takes a rather long time to take a man ont of one field of science and familiarize him with the problems he can and cannot solve in the oceans, so that the first step is to try to do something about the manpower problem.

One of the fastest ways to proceed would be to make postgraduate fellowships available so that topflight people from other areas of the scientific interest, from mathematics, from biology and chemistry, could be attracted into the field.

Coupled with this, I think it is extremely important that we do something about replacing the old inadequate ships that are now being used for marine sciences thereby providing a mechanism for doing more work, for doing it more efficiently, and also for attracting more people into the business.

If we can provide better ships, better laboratory facilities, the problem of attracting new people into the field will become somewhat lessened.

I think there are really two urgent problems. One is manpower and the other is ships and laboratory facilities.

Mr. Dons. I have no further questions.

Mr. Mirler. Mr. Dingell?

Mr. Dingell. Yes, Mr. Chairman.

I have been very interested in this and I would like to have the witness tell this committee some of the practical benefits that can come to this country as the result of an increase of study in this field. In asking this question, I would like to say this: There are many, of whom I am not one, who feel that the only justification for the expenditure of Government money is, let us say, some practical immediate result that is visible for all to see.

I am sure there will be this practical result from this and I would like to hear the witness tell us some of this immediate practical benefit that will flow from the expanded program in this field.

Mr. VeTter. It is much easier to point out practical benefits that have occurred,

Mr. Dingell. I would be willing to accept that.

Mr. VeTrer. It is very dangerous to try to promise that a certain research project will have a practical end product. Tho rery nature of scientific activities is that the practical results come from something completely unexpected.

One example that comes to mind involves a program which is now underway for routing ships across the North Atlantic and North Pacific in such a way that their passage time can be reduced. They are routed to avoid ocean waves that will cut down their transit crossing.

This is analogous to the practice that aircraft have of finding the appropriate elevation to pick up favorable tailwinds in flying back and forth across the country. Each ship has its own reaction to ocean 
waves. Depending on the size of the ship and the speed at which it progresses, some will respond very unfavorably to waves of certain frequency and height.

Mr. DingelL. Is that a saving of both time and money?

Mr. VeTTER. Yes, sir. This ship routing system based on wave forecasts now is in use by the Military Sea Transport Service. In a trial run which has been underway for about $1 \frac{1}{2}$ years and involves approximately 70 ships they have succeeded in reducing the scheduled passenger transit time in the North Atlantic by 1 day. Even with this reduction in schedule ships routed by this system have never been late even by 1 hour and many have been early.

Mr. Dingell. It is an increase in efficiency?

Mr. Tetrer. Yes, the MSTS estimates that this has saved about $\$ 11 / 2$ million in the trial run so far.

I would like to point out that the basic research that led to the ability to use this system was done by two or three oceanographers who were just interested in wave forecasting and the problems of describing what real ocean waves are like. They had no idea that this would then be turmed into a ship routing system as a practical end product.

The first piece of basic rasearch came from a mathematician who was not even interested in ocean waves but who was concerned with a way of describing the background noise in a transmitted radio signal. Some of the mathematics that he worked out came to the attention of one of the oceanographers at New York University who noted the potentiality of using similar equations to describe the chaotic, irregular motion of ocean waves.

He reworked the mathematics and dereloped a new wave forecasting system.

One of his students saw the possibility of writing a doctoral thesis on this wave forecasting method and slanting it toward the problem of routing ships so as to cut down on passage time.

This man is now at the Hydrographic Office assisting in developing this system.

The point is that this whole capability which has saved about $\$ 11 / 2$ million just in the trial run is based on the work of two or three people over the past 5 years.

Mr. DingenL. What about the potentiality of exploiting fishery resources?

Mr. Vetrer. Well, I think this is rery great. Our present situation, if I can speak very casually, is analogous to the early hunter as far as exploiting the living resources of the sea are concerned.

We are way back in the dark ages where human beings got their food by going out and shooting with a bow and arrow or catching it with nets. I believe that it is perfectly within our capability within the next generation to become farmers of the oceans, to actually introduce trace elements into the seas so that we can increase the productivity, to perhaps cultivate species, perhaps even to develop new species that will be particularly suitable for living in various parts of the ocean, perhaps even to fence off in some way parts of the ocean so that we can control populations.

I think right now that we have the capability of catching all the fish that the people in the United States want to eat. I think this will change in the next 50 or 100 years. 
Mr. Dingetil. How about the relation of ocean currents to this?

Mr. VETTER. The fish go where the nutrients go and the nutrients are moved from place to place in the ocean by currents.

Mr. Dingell. Do you know anything about these currents?

Mr. Verter. We know quite a bit. We are just beginning to find out how much we do not know about the currents.

We have a very good idea of the general circulation of the ocean, sort of the study of climate. What we do not know very much about are the variations of this climate and the details of the circulation and, of course, it is the details that affect the disposition of nutrients and the growth of populations of fish.

Mr. Dingerc. How about exploitation of minerals in the ocean proper and on its bottom? Is that going to come out of this?

Mr. VetTer. This, I believe, is primarily a question of economics. We know that there are tremendous deposits of manganese nodules in both the Atlantic and Pacific which contain a fairly high content of cobalt and nickel and copper and manganese.

If we need to get this material and if we decicle to build the equipment to do it, I think we certainly can.

There are some problems as to whether this is more expensive to do at sea than on land and in addition there are problems of the ownership of these materials.

Mr. Dingell. How about the effect on the weather by controlled currents or by diking the Bering Strait? Is this a consideration that will com out of the study?

Mr. I TTrR. We are not thinking of building a dike across the Bering strait.

Mr. Drngell. I have seen studies about the possibilities of making dikes here and there that would affect the weather by increasing rainfall and so forth. This is something that we could study, is it not?

Mr. Vetter. These are things than can be studied.

I believe, however, that the first payoff is not in control of ocean currents by building dikes or anything else to divert them but in being able to understand what they are doing and perhaps predict what will happen so that we can then in turn see how this affects the climato and the weather.

Our ability now to forecast climate is nil. We have no idea what the climate is going to be like on earth 50 or 100 years from now or 10 years from now.

In the system of heat energy coming into the earth from the sun and affecting the atmosphere and the oceans, the ocean is the great flywheel that really affects the climate and it is only by understanding the oceans that we can ever liope to be able to predict climate as opposed to being able to predict weather a fow wcels in advance.

Mr. Drngeri.. 'Thank you very much, Mr. Chairman.

Mr. Mrluer. Mr. Pelly.

Mr. Pully. Thank you, Mr. Chairman.

Doctor, there is every reason to believe, is there not, that there can be a free flow of information between all nations on scientific information regardless of the troubled conditions in the world?

Mr. Vryvres. I certainly hope so. In the case of the oceanographic, part of the IGY, this has certainly proven to be the case.

Mr. Pelly. In other words, if we can induce more scientists to go into this field wo would have not only our own information available 
to study and develop but also the information that is developed in other areas of the earth?

Mr. Vetter. Yes, I believe so. In fact, I thing we should encourage other countries to develop their programs so that we do not have to tackle the whole problem by ourselves.

The ocean is a pretty formidable obstacle and it is a wonderful opportunity to develop international cooperation among nations in studying the oceans.

Mr. Pelly. Do we not have a very close community of interest with our good neighbor, Canada, in this field?

Mr. Vetter. Yes, we do.

Mr. Pelly. Are we exploiting that association as well as we might be?

Mr. Vetrer. I believe so. To the best of my knowledge there is a steady flow of scientific joumals, periodicals, and reports to and from our colleagues in Canada.

Mr. Pelly. One of our great interests is, of course, that blind spot, I guess, underneath the ice north of Canada, is it not?

Mr. Vetter. Well, I do not quite understand your question, sir.

Mr. Pelly. In other words, we do not know much about the oceanography under the ice in that part of the world in which we have a tremendous interest. We work with Canada there, certainly; do we not?

Mr. Vetter. Yes, there have been cooperative expeditions in the Arctic Ocean on our side in which Canadian scientists have gone aboard our icebreakers and we have gone on theirs.

Mr. Pelly. I was wondering if, in the work of this committee, there should be any relationship with the Canadians; whether we should develop that community of interest more as a responsibility of this committee.

Mr. Vettrer. I think it is a very good idea to cooperate with the Canadians insofar as possible.

Mr. Pelly. Would you comment on the gaps now, the blind spots that are particularly serious as far as marine scientists view it today?

Mr. VetTer. Now we are not talking about United States-Canadian relationships but are back to marine sciences?

Mr. Pelly. In what fields do you think greater emphasis should be placed where we have less knowledge and there is more urgency for us to explore?

Mr. VeTter. All fields are interrelated. The most immediate problem, I believe, is to obtain an adequate description of the oceans-a road map, if you will, of what is in the oceans in as great detail as possible. We need to know a great deal more about the bottom topography of the oceans, about the variations in the circulation from one part of the oceans to the other and about the effects of these variations on the marine biological environment.

Mr. Prely. The suggestions that the committee made regarding the need for new vessels took into consideration that particular urgency that you just mentioned; did they not?

Mr. VetTer. Yes, sir. I believe that the starting point for the committee's estimate of what we ought to do in the next 10 years centers around the need for an adequate description of the oceans. 
We feel that this is really the first step that has to be taken; that if the recommendations set forth are followed we will have at the end of 10 years the necessary ships for surveying the oceans, the necessary ships for doing oceanographic research so that we can do a reasonable share of the total job.

We estimated that the U.S. share of surveying the oceans should be about 30 percent, with the other major powers splitting up the difference.

Mr. Pellr. In other words, you have a coordinated global plan for the road maps or whatever you call them of the oceans.

Mr. VetTer. No, we do not yet have a plan.

Mr. Pency. There is no allocation to each nation of a certain phase in the overall project?

Mr. Vetter. We have not done that in this report.

However, I think that SCOR, the Special Committee for Oceanic Research, has plans for exploring various parts of the ocean and pulling in various countries to various degrees.

In the near future, in the next year or two, there are plans for an intensive oceanographic investigation of the Indian Ocean that would involve all of the major countries. There are fairly well detailed estimates as to how much this would cost, as to how many ships would be required, as to what countries would participate and to what extent.

Mr. Pelly. What is the international body that sponsors a group project like that?

Mir. Vetter. SCOR, Special Committee for Oceanic Research, is part of the International Council of Scientific Unions. Their own operations are sponsored by each member country. Up to now they are only a committee operating with travel expenses.

As far as a projected survey of the Indian Ocean is concerned, the source of funds to do this is still undertermined, but I think it would be appropriate for the countries involved to consider seriously spending the necessary money.

Mr. Pelcy. There are from time to time, then, meetings in which representatives from certain interested nations gather together and form an opinion as to projects such as you have referred to?

Mr. Vetter. Yes, sir.

Mr. Pelly. Then everyone goes home and tries to implement it in some way; is that correct?

Mr. VETTER. That is correct.

Mr. Pelly. It will take considerable funds for that purpose.

Mr. VETTER. The funds for the meetings are very minor. However, the funds for a large survey program of a piece of the ocean like the Indian Ocean are considerable.

Ve estimate the U.S. share would be something like $\$ 2$ million.

Mr. Pelcy. Do you anticipate that this committee would have any part in helping along with that project?

Mr. VeTrter. Well, sir, I have not done any anticipating in this regard. I certainly think we conld use all the help we could get.

Mr. Peluy. That is all, Mr. Chairman.

Mr. Miluter. Mr. Lennon?

Mr. Lisnnon. I have no questions.

Mr. Miller. Mr. Curtin?

Mr. CukTrs. 'Thank yon, Mr. Chairman. 
Sir, you said there is a free interchange of ideas and data between the scientists of the various nations. Does that include the Russian scientists?

Mr. Vetter. Yes, sir.

Mr. Curtin. There is no reluctance there to exchange information from them to us or vice versa?

Mr. Vetter. No, sir; not that I know of. To the best of my knowledge the Russians are very proud of their recent accomplishments in marine sciences and very anxious to show off this accomplishment to the Western World.

Their research ship, the Vityaz, recently stopped off both at Vancouver and at San Francisco and later at Hawaii and the Canadian scientists who went aboard the Vityaz and talked to the Russians in their laboratories at Vancouver and our own scientists who went aboard at San Francisco were very much impressed with the eagerness that the Russians seemed to have to show what they had done recently. They have just in the past few years achieved enough stature in their field so that they are proud of it and want to show what they have done in as great detail as possible.

There may be aspects of the program that they are not talking about but I think that the best estimate is that they are being open and above board as far as the IGY part of their activities is concerned.

Mr. Curtin. That is all, Mr. Chairman.

Mr. Miller. Do you know whether all of their activities are confined to that? There has been speculation in other places that this ship has gotten off course and disappeared in the ocean for a while and we did not know just what she was doing.

Mr. VeTTER. I cannot comment on that authoritatively.

Mr. Mirler. I know that you cannot do it authoritatively.

Mr. Veтter. 'To the best of my knowledge, they have done what they said they were going to do and have made all this information available.

Mr. Miller. Mr. Oliver.

Mr. Oliver. 'Thank you, Mr. Chairman.

Mr. Vetter, I, of course, along with the other members of the committee, have read this report which your group recently published. I have been tremendously impressed by what I have thought was a sense of urgency expressed therein by your group. Is that correct? Do you feel that this is a matter of urgency so far as our Nation is concerned?

Mr. Vetter. Yes, I do.

Mr. Ouiver. Would you care to compare it, for example, with what we may be doing with regard to the exploration of space as to its degree of urgency?

Mr. VetTer. First of all, space is a very exciting, stimulating, scientific, and I think we ought to go ahead vigorously in this field.

It is a characteristic of science that rapid progress in any part of scientific capabilities and technology is reflected in increased capabilities throughout the rest of science.

I think that we cannot help but benefit directly and indirectly from the vigorous program for exploring outer space and developing these devices. 
However, I believe that our own practical problems of defense, of resources, fuel, and food for the human populatinn, will involve the earth and not outer space. The ocean is a great source of many of these materials, of food, energy, transportation, communication.

We have to be practical about it. 'The amount' of energy that it takes to operate in outer space or even in what might be called semiouter space in the immediate area around the earth is tremendous and I believe that a dereloping population will find that the most efficient and economical way of utilizing energy will result in a stronger nation.

What I am trying not very effectively to say is that the oceans and other resources on land can be had and utilized with much less expenditure of energy than we are forced to use to go away from the earth, and I think that we have to use our resources and our energy as efficiently as possible in order to maintain a strong and healthy Nation.

Mr. Oliver. Is it your feeling that the potential resources of the ocean that have been spoken about here this morning are great enough so far as we know almost to an unlimited degree and would more than compensate by far any expenditures of money that we might put into bringing about a result of knowing more about them and of utilizing them? Is that a correct assumption?

Mr. VETTER. Yes, it is.

Mr. Ourver. In this IGY activity that we participated in, is it your feeling that the United States contributed to this to such a substantinal degree that perhaps our relative position with regard to the other nations who participated showed up successfully and well in terms of oceanography?

Mr. VeTter. I think so. I think we made a very good showing on the international level for the IGY.

Mr. Olrver. Have I not read somewhere recently that in checking with the Russian research ships with particular regard to fisheries that they seemed to have more specific data than we?

Mr. Vetter. I guess so. I do not know. I have not read this.

Mr. Oliver. I saw that somewhere. Do you think that that may be the actual situation or do you think that our knowledge and data is fully as good or better than what they may be coming up with or have come up with?

Mr. VetTre. I would not underestimate their determination to get a great deal of data from the oceans particularly from the standpoint of fisheries and military applications of the oceans. As to their data being better or our data being better. I think they are both good. If we have to make a comparison I think it is best to say that their efforts now seem to be devoted toward the routine examination, surveying of the oceans, conducting large worldwide cruises in a similar way to the effort that the European countries condueted in the past 20 years of running long worldwide cruises for exploring the oceans. The great phase of running expeditions into the oceans is one that the Russians seem to be in now. I think we are at the stage of having built up enongh understanding of what is going on in the oceans to be able to formulate a hypothesis to explain something we have observed and then go ont into the oceans with detailed and plinned experiments to test with our hypothesis. 
In other words, I think we are a little bit more mature in our approach to oceanographic problems than the Russians are but, as to how long this will last, I would not care to predict.

As one example, one of our theoretical oceanographers from studying the dynamics of the circulation of the North Atlantic Ocean postulated that there had to be a current under the Gulf Stream flowing in the opposite direction.

At approximately the same time a scientist in Great Britain, Dr. Swallow, developed an aluminum tube which could be designed and preset to sink to a certain level in the oceans and stay there.

The reason this is possible is that the compressibility of an aluminum tube is somewhat less than the compressibility of sea water so that the tube can be ballasted to go so deep and no deeper. You put inside of this tube an acoustic transponder which would send out a signal when it heard a signal so that it is possible to track this tube at great depths.

By using this device called the Swallow buoy, the hypothesis that there is a countercurrent under the Gulf Stream was recently tested and found to be true.

This is an example of the stage we are at now where we are able to formulate questions about what is going on in the ocean and then go out on a specially designed cruise to see if they are true or not.

I do not think that the Russians are at this stage yet in the sophistication of their concepts about the oceans but they are moving very rapidly.

Mr. Oliver. Have we any centralized operation in the Government that coordinates and works together toward the common objective of trying to get all the progress we possibly can in this field? I realize that we have individual efforts on the part of departments but I was wondering if there is any coordinated or concentrated effort?

Mr. VETTER. Well, sir, there is an informal group at the working level that has met together about once a month ever since the Committee on Oceanography of the Academy of Sciences was organized. These individuals are not at the policymaking level but at sort of the "Indian" stage of organization. They exchange information about their problems, their progress, and programs.

Mr. Ouiver. Do other nations have a centralized group that work toward this end?

Mr. Vetter. I am afraid I am not qualified to answer that. I would like to have opportunity to do a little research before answering that question.

Mr. MILLER. I wonder if you are in a position to get that information, Doctor? Would you get it for us and furnish it for the record? I think it would be quite important.

Could you suggest where it might be obtained? I refer to this information as to what other nations have it under centralized coordinated control.

Mr. Vetter. This is something I ought to try to get for my own information and I would be happy to try to get it for you.

Mr. Miller. Thank you.

Mr. Orfver. The other question I had here, Mr. Vetter, that bothers me at the moment is this: I believe the Albatross III is a research vessel, is it, that is operating out of Woods Hole in Massachusetts, is that correct? 
Mr. Vetter. Yes, sir.

Mr. OLIVEr. It has recently been decommissioned, is that correct?

Mr. Vexter. Yes, sir.

Mr. Oliver. I have received some correspondence with regard to it. I am wondering what the real basis for that decommissioning is. Do you happen to know?

Mr: Vetrer. Well, my own information is that the Albatross III is a very old ship and that she is very expensive to operate and maintain. Beyond this I would not care to comment.

Mr. OLIVEr. My information indicated that it not only had been certified as seaworthy but at least some people think it is necessary that it should be still operated in view of the scarcity of other available vessels that we may have at the moment.

I was interested to know what the picture really amounts to, whether this is just a self-serving statement that I have had or whether or not there was actually some eventual loss that this country would suffer from not using it in view of the scarcity of other vessels for this purpose.

Mr. VerTer. I would rather not comment any further on this. My only knowledge of this is all indirect but it is my impression that she was decommissioned because of the expense to maintain the ship and the relative ineficiency of operation at sea.

Mr. Oliver. So that, as a practical result, we have one less vessel in this research work.

Mr. VeTter. Yes, sir.

Mr. Milder. We will eventually have a witness on that.

Mr. Oliver. Thank you, Mr. Chairman, very much.

Mr. Miller. Mr. Flynn.

Mr. Flyn N. Does your definition of a study of oceanography include the Great Lakes and other inland lakes?

Mr. Vetren. No, sir. The Great Lakes and all lakes have some things in common with the oceans and in some cases they can serve as small models of the oceans.

However, for our own frame of reference in studying this problem, it does not include any fresh water lakes.

Mr. Fly s . Those people located in the midsection of the American continent could not expect any value from this study in, for instance, gaining more knowledge on the control of the lamprey that has practically ruined the million dollar trout fishing industry? That would not come under the scope of this study?

Mr. Veтter. It is hard to say. I would not like to guarantee whether it would or would not.

The lamprey is an eel that spends part of its life in the oceans and part of its life in fresh water. Any scientific gain in either of these areas would be useful in trying to determine how to control it.

Mr. FLYNN. But to date various committees studying oceanography have not studied the inland lakes or included these lakes in their studies?

Mr. VeTter. Well, there are cases in which for simplicity we will take an oceanographic problem and do an experiment in an inland lake to see what the relationships are.

However, in most cases there is not very much interchange between the limnologist, the fresh water scientist, and the salt water scientist. 
Mr. FLYNN. I was interested in your one reference to the sea when you call it the highway of the sea. I think that has long been the actual situation in this country that the sea has serred as a highway to bring both men and industry and business and commerce to this Nation.

It would appear that that meaning is directed to a preliminary meeting largely to see whether or not, financially speaking, the expenditure of money necessary for this study can be justified.

In the sense that the sea is the highway which will serve the people, business, and industry of this country, do you believe that this study would provide for the sea to become a faster highway, a safer highway?

Mr. Vetter. Yes, I do. I think that the oceans provide a very vital and efficient way of transporting materials from one part of the earth to another and I should think that any increase in this efficiency would benefit the entire Nation, not just the coastal States, and I believe that by studying the oceans we can increase the efficiency as my other illustration earlier this morning pointed out.

Mr. Flyns. Might one of the end results of the study be that we would find a faster means of using the highway and a cheaper means of using the highway and a safer means of using the highway?

Mr. VetTer. Yes, sir.

Mr. FlynN. And would this, in your opinion, result economically in a saving to the people generally, to those who use the sea?

Mr. Vetter. Yes, it would, a tremendous saving.

Mr. FLYNN. Do you believe that that saving would justify the expenditure of money that would be needed to carry on this study?

Mr. VetTer. Well, I believe that the savings from only this one application of oceanographic wave research to problems of routing ships that belong to our country can and will pay back all of the money that is being asked for in this report. This is just one isolated case.

Mr. FlY s . Doctor, I agree with Mr. Dingell that this should not have to be justified from the financial position alone. However, I believe that many people are going to attempt to have us justify the expenditure from a financial gain point of view and I was trying to seo if we could get into the record enough financial gain to justify this expenditure of money.

In this regard, I have noted in my home area, which is on the shores of Lake Michigan, that the lake was the highway that originally brought the white man there to settle and develop the lake shore on which the great cities have grown and today, with the St. Lawrence Seaway coming through, it is the direct cause of the most tremendous development that there is any place in the country outside of possibly California.

I was wondering whether or not the study that we are making of the sea would not cause the sea to become a faster, safer and speedier highway so that it would benefit the entire country similar to the way the lake ports are being benefited by the St. Lawrence Seaway?

Mr. Vetter. Yes, I believe it will. I do not see how it is possible not to benefit the entire country by increasing the efficiency of our merchant marine, and particularly with the opening of the St. Lawrence Seaway in effect we now have that much more coastline to utilize. 
The cities on the Great Lakes are seaports now.

Mr. FuYNN. That is all.

Mr. Miller. Do you have any questions, Mr. Chairman?

The Chamman. You say it has been agreed by your group and similar groups of other nations to make a study of the Indian Ocean?

Mr. Verter. This is a tentative plan that has been discussed by the scientific representatives from other countries on this Special Committee for Ocean Research. I do not think there has been any commitment by any nation, or by any of the participants in this group to do this.

The Curamman. How did they happen to select the Indian Ocean for this study?

Mr. VeTter. I think there are several reasons. First of all, the Indian Ocean is probably the least understood of all of the oceans except possibly the South Pacific.

Secondly, the Indian Ocean is not as big as the South Pacific, so that you could hope in a year or two of intensive effort to find out enough about it to understand it.

Thirdly, it supplies sort of a neutral ground for the various nations to meet and get together and study.

Finally, there are some peculiar scientific problems involving the circulation of the Indian Ocean that result from the monsoon seasons and from its own size and shape that we would like to study.

The northern part of the Indian Ocean is probably one of the best places we could go to do work to try to find out how the atmosphere affects the circulation of the ocean and in turn how the circulation of the ocean affects the atmosphere simply because of the periodic monsoon wind reversals across this area.

There are several practical reasons, and it is interesting scientifically.

The Cramman. As to your observation about the lack of ships to carry on the desired studies, who would operate the ships?

Mr. VeTTEr. I think the ships should be operated by the scientific institution that is performing the study. This is the way it is now being done. The Woods Hole Oceanographic Institution runs and operates its own ships as do the Scripps Institution of Oceanography and other institutions.

The Navy in pursuit of its own problems operates its own ships as do the Bureau of Commercial Fisheries and the Coast and Geodetic Survey.

I do not see the value of changing this method of operation. In fact, I think it is important that the vessel and the crew on the ressel has its first loyalty to the oceanographic institution that is conducting the work, otherwise this could operate as a handicap toward the flexibility of the system and toward the efficiency in removing control of the vessel from the scientific director of the expedition.

I would not visualize the need for changing the method of operating ships just because of the construction of more ships.

The Crinmaras. Who would operate additional ships? Iet us pin it down.

Mr. VetTler. Ilow far can we pin it down?

The Cirnirman. Somebody has to have supervision over the operation of a ship. Would it be a replacement of the ship that has been retired at Woods Hole, or what would it be? 
Mr. Vetrer. I think that the oceanographic institution that is most desperately in need of a new ship now is the Woods Hole Oceanographic Institution, and I would visualize that this ship would be operated entirely by that institution.

As succeeding ships become available, they should either supplement or replace existing ships both in the Navy and at the university laboratories and the Coast and Geodetic Survey and the Bureau of Commercial Fisheries.

The Chamrurax. That is all, Mr. Chairman.

Mr. Miluer. Thank you, Mr. Chairman.

Thank you very much, Mr. Vetter.

Knowing your intense interest in this work, we will be calling on you from time to time perhaps for advice and assistance.

Without objection, the report of the Brown committee, the supplemental reports and other data supplied by Mr. Vetter will be made part of the record.

('The documents referred to follow:)

OCEANOGRAPHY, 1960 TO 1970-A REPORT OF THE COMMITTEE ON OCEANOGRAPHY OF THE NATIONAL ACADEMY OF SCIENCES

\section{[February 1959 (final approved copy)]}

The complete report of the committee will consist of the following chapters:

1. Introduction and summary of recommendations.

2. Basic research in oceanography during the next 10 years.

3. Ocean resources.

4. Oceanographic research for defense applications.

5. Artificial radioactivity in the marine environment.

6. New research ships.

7. Engineering needs for ocean exploration.

8. Education and manpower.

9. Oceanwide surveys.

10. International cooperation.

11. History of oceanography.

12. Marine sciences in the United States, 1958.

Chapter 1. Introduction and Summary of Recommendations of the Committee on Oceanography, National academy of Sciences and National ReSEARCH COUNCIL

Harrison Brown, California Institute of Technology, Pasadena, Calif.

\section{INTRODUCTION}

Two-thirds of the earth's surface is covered by the waters of the seas. The waters thenselres greatly affect our lires-they play a major role in governing our climate; they provide inexpensive transportation; from them we derive important quantities of nourishment; they have traditionally provided protection against military attack. Beneath the surface a myriad of wonders is concealed. There are trenches, the floors of which are as much as 7 miles below sea level. Mountains which approach MIt. Everest in height rise up from the ocean floor. Sediments in the ocean deeps contain detailed records of earth history-and, associated with it, life history. The mole than 300 million cubic miles of water contain huge assemblages of living matter of fantastic variety.

As our technological civilization increases in complexity, as human populations grow more and more rapidly, as problems of military defense become increasingly difficult, as man pushes forward with his lelentless quest for greater understanding of himself, his origins and the universe in which he lives-as all of these changes take place, detailed knowledge and understanding of the oceans and their contents will assume ever greater inportance.

Man's knowledge of the oceans is meager indeed when compared with their importance to him. Recognizing that neglect in this area of endeavor might 
well result in our being placed in a precarious position from the scientific, technological, and military points of view, the National Academy of Sciences and National Research Council decided in 1957 to form a Committee on Oceanography. ${ }^{2}$ In May of that year President Detle 5 Bronk appointed Harrison Brown, professor of geochemistry at the California Institute of Technology, chairman of the Committee. The Committee itself was formed during the following months and its first meeting was held in Norember $195 \%$.

The members of the Committee are:

Harrison Brown (chairman), California Institute of Technology, Pasadena, Calif.

Maurice Ewing, Lamont Geological Observatory, Columbia University, Palisades, N.Y.

Columbus O'D. Iselin, Woods Hole Oceanographic Institution, Woods IIole, Mass. Fritz Koczy, Marine Laboratory of the University of Miami, Miami, Fla.

Sumner Pike, Lubec, Maine, formerly Commissioner, U.S. Atomic Energy Commission.

Colin Pittendrigh, Department of Biology, Princeton University, Princeton, N.J. Roger Revelle, Scripps Institution of Oceonography, La Jolla, Calif.

Gordon Riley, Bingham Oceanographic Laboratory, Yale University, New Haven, Conn.

Milner B. Schaefer, Inter-American Tropical Tuna Commission, La Jolla, Calif. Athelstan Sphilhaus, Institute of Technology, University of Minnesota, Minneapolis, Minn.

Richard Vetter (executive secretary), formerly with the Geophysics Branch of the Office of Naval Research, Washington, D.C.

The work of the Committee was made possible by the sponsorship of several Government agencies, all of which have interests in the oceans:

Atomic Energy Commission.

Bureau of Commercial Fisheries.

National Science Foundation.

Office of Naval Research.

The Committee was organized as a part of the Divison of Earth Sciences of the National Academy of Sciences-National Research Council.

At the request of President Bronk, the Committee has made a surrey of the present status of the marine sciences in the United States. It has attempted further to assess the major problems of operations, administration and funding in this area and to evaluate the probable needs for oceanographic knowledge in the years ahead. On the basis of its findings, the Committee has drawn up a series of recommendations which, if followed, can result in a strengthening of the marine sciences during the next 10 years to a level which is consistent on the one hand with the assessed needs, and on the other with limitations such as the rates at which ships and laboratories can be built and new oceanographers can be trained. It should be stressed, however, that the Committee consider's its recommendations minimal ones. Action on a scale appreciably less than that recommended will jeopardize the position of oceanography in the United States relative to the position of the science in other nations, thereby accentuating serious military and political dangers, and placing the Nation at a disadrantage in the future use of the resources of the sea.

The deliberations of the Committee were complicated by a number of factors: oceanography embraces many sciences-indeed "oceanography" encompasses the scientific study of all aspects of the oceans, their boundaries and their contents; research is undertaken in a variety of private and Government laboratories; numerous Govermment agencies have direct but differing interests in tle oceans: funds are derived from many sources. In order to expedite the formulation of

1 This is the third NAS/NRC Committee on Oceanography. The first was established In 1927 under the chalrmanshlp of Dr. Frank R. Lllic. The second, chaired hy Dr. Detlev Bronk, was established in 1949. The reader is referred to the following publications for additional background material on these two Committees.

(1) "Occanography," Henry B. Blgelow, Boston and New York; Houghton Mimin Co., 1931.

(2) "International $\Lambda$ spects of Ocennography," Thomas W. Vaughn et al., Washington, N.C. National Academy of Sciences, 1937.

(3) "Oceanography, 1951, NAS/NRC Publication 208," Washington, D.C., 1952 (out of print). 
recommendations under these circumstances, several specialized panels ${ }^{2}$ were formed for the purpose of making specific studies :

Oceanographic Research Ships.

New Devices for Exploring the Oceans.

Ocean Resources.

Radioactivity in the Oceans.

International Cooperation in the Marine Sciences.

The memberships of the panels are listed at the end of this summary. The Committee on Oceanography is greatly indebted to the panel members, who gave extensively of their time to these studies, and without whose help the recommendations could not have been formulated.

The complete reports of the panels have been incorporated into the final report of the Committee. Chapter headings of the final report are listed inside the front cover of this summary. Individual chapters will be made available separately through the National Academy of Sciences as soon as possible. In addition, a condensed rersion of the Committee's report shortly will be made available for widespread distribution. The reader is referred to individual chapters of the report for more detailed discussion of the background, facts and reasoning which have led to the recommendations summarized in Section III, General Recommendations.

\section{THE IMPORTANCE OF THE PROBLEM}

The Committee has found that relative to other areas of scientific endeavors, progress in the marine sciences in the United States has been slow. There has been a substantial amount of excellent work, more often than not undertaken under extremely difficult and trying eircumstances. But generally speaking progress has not been rapid when compared with the essential and exciting information yet to be obtained by probing the vast and dark, but penetrable, depths of water which cover so much of the earth's surface.

The seas present a challenge to man which in magnitude approaches that of space. At least we have been able to observe the moon, planets and stars directly with our telescopes. But the ocean depths, shrouded in darkness, have been obscured from our view. We know less about many regions of the oceans today than we know about the lunar surfaces. Yet we have learned enough to know that the major features of the ocean flood-35,000-foot-deep trenches ; 2,000-milelong fracture zones; flat-topped undersea mountains; broad ocean long ridges; abyssal plains as flat as a calm sea-are uniquely different from anything either on the surface of the moon or on the land surfaces of earth. How and when were these features formed and why are they so different? An answer to these questions is essential if we are to decipher the history of our planet and its sister planets. Part of the answer lies in the records of ancient earth history locked in deep sea sediments; part will come from an intensive study of the rocks under the ocean. These studies, combined with studies of the waters and the living creatures of the sea, will also tell us much about the origin and evolution of life on earth.

During the last few rears, four great subsurface ocean currents-rivers in the depths of the sea 1,000 times greater in flow than the Mississippi-have been discovered using newly developed current measuring techniques. We suspect that others exist and we need to know where the waters come from and where they go.

On the practical side the problems to be solved concerning the oceans are at least as urgent as those of space. How many fish are in the sea? No man knows, nor do we know what determines the numbers of fishes in different regions, the quantities of plant and animal material on which they feed, or what could be done to increase these numbers. We must learn these things if we are to help solve the increasingly acute problems of providing animal protein food for the growing numbers of underfed people in the world. Given more study man can economically harvest considerably more food from the seas than is now possible. Considering the position of the United States in the community of nations, it seems appropriate, eren essential, that we lead the way in this respect.

About a third of the energy of sunlight is used to evaporate sea water. This evaporation and the subsequent condensation are the primary means by which

\footnotetext{
2 The Committee as a whole acted as a panel on basic research, on education and manpower, and on problems of operations, sponsorship, and funding.
} 
solar energy is absorbed in the atmosphere. There is good reason to believe that changes in the location where interchange of matter and energy takes place between sea and ail affect persistent weather patterns. We lnow that the arerage weather conditions we call climate can change over a few decades, and we suspect that changes in the storage of gases and heat in the oceans will profoundly influence the process. Studies of the mechanisms of interchange between the air-sea boundaries of regions wher'e intense interchange occurs and of the slow mixing between the ocean deeps and the surface which controls storage of heat and gases are essential for further understanding, hence for prediction and possibility of control.

From the point of view of military operations there is no comparison between the urgeneies of the problems of the oceans and those of outer space. The submarine armed with long-range missiles is probably the most potent weapon system threatening ou security today. It seems clear that the pressures of establishing effective bases, and of protecting ourselves frow attack, are relentlessly driving us into the oceans.

The problems inrolved in military operations in the sea are enormous. We will not be able to navigate under the oceans with adequate precision until our knowledge is greatls expanded. Nor will we be able to detect submerged submarines efficiently unless we learn far more about the ocean depths than we now know. We will not be in a position to negotiate an adequate international submarine control and monitoring system until we have the ability to make the oceans transparent so that we can track all submarines in the oceans, both our owll and all others. To accomplish this, we must place greater national emphasis on research in the marine geophysical sciences, on surveys of the ocean background against which tracking must be accomplished, and on the development of effective devices to achieve such aceanwide surveillance. The Committee's recommenlations constitute an essential first step in these directions.

With these problems and prospects in mind, this Committee has attempted to assess the steps which should be taken in order that the Inited States might possess ontstanding capabilities in the nceanographic field, and in order that we might obtain suffieient knowledge in time to avert a "crash" proglam-which would be wasteful in terms both of money and valuable technical manpower.

The cornerstone of our oceanngraphic endeavors is basic research. We need to understand waves and the interactions between the atmosphere and the oceans. We need to know more about ocean eurrents and upwellings. More intensive studies should be made of the properties of sea water and of processes of sedimentation. We should systematically study the life forms in the oceans in three dimensions. We should study the sea floor with instruments and we should send men down to look at it in manv localities.

In view of the complexities of these problems the Committee has recommended that the level of basic research in these fundamental areas be substantially increased during tle next 10 years. This will require increases both in manpower and in facilities. Of particular importance among the facilities are ships, which are to the oceanographer what cjclotrons or reactors are to the nuclear ph.jicist. He simply cannot undertake adequate res arch without them.

Our oceanographic research ships are inadequate ior the job which must be done. Most of the ships are old and outdated. Many are obsolcte and should be replaced by ships of modeln design which will be more efficient to operate and from which a greater variety of scientific observations can be made. In addition, the number should be increased.

The oceanographer also needs improved instruments if he is to penetrate the water barrier and learn in detail about conditions at great depths. Thus far oceanozraphers have not been able to take full advantage of recent technological developments and, accordingly, the Committee has recommended the establishment of a program of broad scope, aimed at developing and using new instruments and devices for exploring the sea. Using new deep-diring rehicles, for example, it is now possible for man to observe directly the occin de'ps. It seems highly likely that within the next 10 years men will descend through the water nearly 7 miles to the deepest point oh eirth.

In integral aspect of a program for learning about the oceans involves our surveying tlem more or less routinely. The topography of the ocean floor should be malped in detail. We should arrive at a complete picture of gravitational and magnetic forces and of ocean currents in three dimensions. Sufficient biological information should be gathered so that we can prejare accurate maps of the distribution of life in the sea. 
All of these studies, together with others like them, will have bearing upon the more immediate practical problems which confront us in the military area and in the area of ocean resource development. In addition to this, however, it is clear that the applied research and derelopment programs in these areas should be expanded.

In the Committee's attempts to give quantitative indications of the relative amount of effort which it believes should be placed upon various aspects of the proposed program by individual Govermment agencies, suggested budgets have been compiled for a 10-year period. These suggested budgets, in the committee's opinion, present a reasonable representation of the magnitude and kind of effort and the degree of interagency cooperation which will be required if the recommendel goals are to be achieved. In addition, a budget permits a direct comparison of efforts in this field relative to the efforts in other fields of scientific and technological endeavor.

\section{GENERAL RECOMMENDATIONS}

The key to the growth of oceanography in the United States lies in basic research-research which is done for its own sake without thought of specific practical applications. The very nature of basic research is such that the problems which will be attacked and the results which will be obtained cannot be predicted. The rery nature of applied research is such that its success depends upon the size of the reservoir of fundamental knowledge upon which it must draw. The rate of progress in the applied marine sciences will be determined in the long run by the rate of progress in the basic marine sciences.

The Committee has concluded that both the quantity and quality of basic research in the marine sciences can and should be increased substantially during the years ahead. Specifically the Committee recommends-

1. The U.S. Government should expand its support of the marine sciences

at a rate which will result in at least a doubling of basic research activity during the next 10 years. ${ }^{3}$

It should be emphasized that doubling the basic research activity will require more than doubling the total expenditures.

A large part of the deliberations of the Committee were devoted to discussions of the conditions under which basic research can flourish. First and foremost, progress depends upon the interests, experience, and creative imaginations of individual scientists. But the individual scientist does not work in a vacuum. He must have instruments and facilities. He must live in an atmosphere which is conducive to creative actirity. These necessities in turn give rise to problems involving marine research laboratories-problems of leadership, financial stability, flexibility, growth, academic associations, and physical facilities.

Not only for research but in order to exploit and use the oceans we need more detailed knowledge which can only be obtained through systematic surveys in three dimensions. These surveys should include such features as depth, salinity, temperature, current velocity, wave motion, magnetism, and biological activity. It is essential that these survers be conducted on an ocennwide ocean-deep basis as quickly as possible. Our knowledge is now largely limited to waters 100 miles from shore and even here it is inadequate for present and future needs. Accordingly, the Committee recommends-

2. The increase in support of basic research should be accompanied during the next 10 years by a new program of oceanwide surveys. This will require a twofold expansion of the present surveying effort.

We believe that, on a long-range basis, basic research coupled with systematic ocean surveys are of paramount importance in solving a number of urgent practical problems involving military defense, the development of ocean resources, and possible future increases of radioactive contamination of the seas resulting from the rapid development of atomic energy. However, research and surveys must go hand in hand with a vigorous and imaginative applied research and development program. Accordingly, the Committee recommends-

3. The United States should expand considerably its support of the applied marine sciences, particularly in the areas of military defense, marine resources, and marine radioactivity.

In 1958 about $\$ 23$ million were spent by applied and basic nceanngranhic research. The baslc research share of the total was not over $\$ 9$ million. About $\$ 8$ million of this, Including the 1958 share of IGY expenditures, was Federal funds. 
The implementation of these general recommendations requires action upon a number of broad fronts. More marine scientists must be educated. Additional ships and shore facilities must be built. New instruments and techniques must be developed. International cooperation in the marine sciences must be strengthened.

To achieve these aims in the next 10 years will necessitate many agencies of the Federal Government working togethel both in planning and in providing the moneys." Taking into account the relative degrees of interest and importance of oceanography to individual agencies, the Committee recommends-

4. The Navy and the National Science Foundation should each finance about 50 percent of the new basic research activity except ship construction. The Navy should finance 50 percent of the new research ship construction with the Maritime Administration and the National Science Foundation sharing the remainder. The Navy, through the Hydrographic Office, should finance 50 percent of the deep ocean surveys, while the Coast and Geodetic Survey should finance the balance. The Navy should sponsor completely all military research and development operations. The Bureau of Commercial Fisheries should finance the greater part of the recommended ocean resources program. The Atomic Energy Commission should finance the major part of the research dealing with the problems of radioactive contamination of the oceans. The National Science Foundation and the Office of Education should sponsor jointly the proposed program for increasing scientific and technical manpower in the marine sciences. Efforts aimed at fortering international cooperation in the marine sciences should be sponsored by the Department of State, the International Cooperation Administration, and the National Science Foundation. Other agencies should take responsibility for certain aspects of the proposed program, particularly the Public Health Service, the Geological Survey, and the Bureau of Mines.

Although the bulk of oceanographic research and survey work must of necessity be financed by the Federal Government, the value of State and private funds cannot be overestimated. Such funds are especially helpful for supporting initial exploratory basic research and for starting new laboratories. Accordingly, the Committee recommends-

5. Private foundations and universities, industry, and State governments should all take an active part in the recommended program of expansion.

\section{SPECIFIC RECOMMENDATIONS}

\section{Education and manpower}

1. The universities now providing graduate education for oceanographers should be encouraged to increase the numbers and quality of their output. Some institutions which now teach oceanographers in only certain branches of oceanography should add professors in other fields to their faculties. These measures will require financial support.

2. Institutions which undertake considerable research, but provide no regular formal teaching in oceanography, could contribute greatly to the education of oceanographers at the higest level by close formal affiliations with universities. Conversely, universities should recognize their responsibilities in the educaton of oceanographers. They should welcome this affiliation with marine laboratories and arrange for the interchange of facilities. This will require financial support.

3. It may be desirable to develop occanographic education at new centers. However, a "critical mass" of faculty in the basic sciences is essential for successful teaching of oceanographers. Such new centers should, therefore, be developed at universities which possess strong faculties in the sciences.

4. In order to finance new faculty in oceanography at existing or new teaching centers, the U.S. Government should provide funds on long-term commitments. This committee recommends that about $\$ 500,000$ per year be appropiated for salaries and the equipment and indirect costs associated with such positions. This program could be operated through the Office of Education.

S One method suggested for developing more effective interngency cooperation is through the jronosed Federal Council for Science and Technology. This Council is described iu "Strengthening American Science," a recent report of the President's Science Advisory Committec. 
5. In order to attract competent graduate students to the long and somewhat arduous schooling required of well-qualified oceanographers, it will be necessary to provide substantial long-term fellowships. It is believed that 80 fellowships should be supported on a 5-year basis and at an average stipend of $\$ 3,500$ to $\$ 4,000$ per student each jear. This will produce 12 to 15 new $\mathrm{Ph}$. D's per year (allowing a reasonable attrition factor) at an annual cost of about $\$ 300,000$. This would provide approximately one-third of the student support that will be needed in order to double the number of oceanographers at the Ph. D. level during the next 10 years.

It is desirable that fellowships permit students to attend more than one university. This can provide students with well-rounded educations in all branches of oceanography without each university having to provide a full curriculum. Such a program should be handled throngh the National Science Foundation.

6. Efforts should be made in research and surves programs to use larger numbers of assistants at the bachelor and master's level in order to utilize more efficiently the limited number of persons available at the doctoral level.

7. Oceanographers should undertake more active recruiting of prospective oceanographers among undergraduate students of physies, chemistry, biology, and geology.

New ships for research, development, and surveying

1. A shipbuilding program should be started aimed at replacing, modernizing, and enlarging the number of oceangoing ships now being used for research, surveying, and development. Specifically in the period 1960-70 the research, development, and survey fleet should be increased from its present size of about 45 ships to 85 ships. Taking into account the replacement of ships which must be retired during the next decade, this means that 70 ships should be constructed at a total estimated cost of $\$ 213$ million.

2. The size ranges recommender for new oceangoing ships are: About 500 tons, 1,200 tons, and 2,200 tons displacement.

3 . The conversion of vessels, which were originally designed for other purposes, into research, development, or survey vessels is to be discouraged. Such converions are generally uneconomical.

4. The recommendations for the construction of ships for specific purposes (basic, research, military research and development, oceanic surveys, resources and fisheries) are given in table 1.

5. The recommended size distribution for new ships is given in table 2 .

6. The Nary should provide about 50 percent of the financing for the construction of new ships for basic research, all of the financing for new ships for military research and development, and 50 percent of the financing for new ships for oceanic surveys. The Coast and Geodetic Survey should provide 50 percent of the financing for the construction of new ships for oceanic surveys. The Bureau of Commercial Fisheries should finance the construction of all the new ships for marine biological resources and fisheries studies. The National Science Foundation and the Maritime Administration should each provide about 25 percent of the financing for new ships for basic research. The numbers of ships in each size category which should be built by each of the sponsoring agencies are given in table 3 .

7. Detailed recommendations for the scheduling of ship construction by each of the sponsoring agencies are given in table 4 . Estimated capital costs by year and by ageney are given in table 5, based upon the assumption that a 500ton ship will cost about $\$ 1.65$ million, a 1,200 -ton ship will cost about $\$ 3.8$ million and a 2,000-ton ship will cost about $\$ 5$ million.

8. The Maritime Administration should be consulted in the designing of all ships paid for from public funds and used for marine studies.

9. Research ships operated by private institutions like those operated by the Nary, Coast Guard, and Coast and Geodetic Survey should be exempt from those existing legal requirements for living accommodations, safety, and the licensing of crews, which are practical and sensible only on large (3,000 tons) merchant ships.

10. All noncombatant surface ships used for research, development or surveying should be operated by the laboratory or agency directly concerned and should have civilian crews. 
11. In most cases the annual costs of operating ressels for basic research by non-Government laboratories should be paid for separately from the other expenses of research: for example, through a long-terın facilities contract distinct from any research contracts.

12. The costs of ship operations paid by the Federal Government should be subdivided as follows: The Navy should pay for 50 percent of the operational costs of ships nsed for basic research, all of the operational costs of ships used in military research and development, and 50 percent of the operational costs of ships used for oceanic surreys.

The Coast and Gendetic Survey should pay for 50 percent of the operational costs of ships used fur surveys. The Bureau of Commercial Fisheries should pay for the operations of ships used for resource and fisheries studies. The National Science Foundation should pay for 50 percent of the operational costs of ships used for basic research.

13. Estimated costs of ship operations, both by function and by agency, are given in tables 6 and 7 .

10-Yhar Plan for Increasing U.S. Fleet of Oceanographic Ships

TABLE 1.-Function of ships

\begin{tabular}{|c|c|c|c|c|c|}
\hline & Research & $\begin{array}{l}\text { Military re- } \\
\text { search and } \\
\text { develo, ment }\end{array}$ & Survey & $\begin{array}{c}\text { Resources } \\
\text { and fisheries }\end{array}$ & Total \\
\hline $\begin{array}{l}\text { Present fleet } \\
\text { To be replaced } \\
\text { Still operational in } 1970 \\
\text { Additional new construetion. } \\
\text { Total construction }\end{array}$ & $\begin{array}{r}11 \\
5 \\
6 \\
11 \\
16\end{array}$ & \begin{tabular}{r}
9 \\
9 \\
\hdashline 11 \\
20
\end{tabular} & $\begin{array}{r}18 \\
9 \\
9 \\
11 \\
20\end{array}$ & $\begin{array}{r}7 \\
7 \\
7 \\
14\end{array}$ & $\begin{array}{l}45 \\
30 \\
15 \\
40 \\
70\end{array}$ \\
\hline Total flect in 1970 & 22 & 20) & 29 & 11 & 35 \\
\hline
\end{tabular}

TABLE 2.-Recommended size distribution of new ships

\begin{tabular}{|c|c|c|c|c|c|}
\hline Size & Research & $\begin{array}{l}\text { Military re- } \\
\text { search and } \\
\text { development }\end{array}$ & Survey & $\begin{array}{l}\text { Resources } \\
\text { and fisheries }\end{array}$ & Total \\
\hline $\begin{array}{l}500 \text { tons } \\
1,200-1,500 \text { tons } \\
\text { Larger than } 2,000 \text { tons. }\end{array}$ & $\begin{array}{l}5 \\
9 \\
2\end{array}$ & $\begin{array}{r}10 \\
6 \\
4\end{array}$ & $\begin{array}{r}4 \\
11 \\
5\end{array}$ & $\begin{array}{r}12 \\
2 \\
-\end{array}$ & $\begin{array}{l}31 \\
28 \\
11\end{array}$ \\
\hline Total & 16 & 20 & 20 & 14 & 70 \\
\hline
\end{tabular}

TABLE 3.-Recommended sponsors of newo ships

\begin{tabular}{|c|c|c|c|c|}
\hline & 500 tons & $\begin{array}{c}1,200 \text { to } 1,500 \\
\text { tons }\end{array}$ & $\begin{array}{c}\text { Larger than } \\
2,000 \text { tons }\end{array}$ & Total \\
\hline $\begin{array}{l}\text { Coast and Geodetie Survey } \\
\text { Bureau of Commereial Fisheries. } \\
\text { National Science Foundation. } \\
\text { Maritime Administration. }\end{array}$ & $\begin{array}{r}12 \\
2 \\
12 \\
3 \\
2\end{array}$ & $\begin{array}{r}18 \\
6 \\
2 \\
2\end{array}$ & \begin{tabular}{c|c|c|c|}
8 \\
2 \\
-1 \\
-1
\end{tabular} & $\begin{array}{r}38 \\
10 \\
14 \\
4 \\
4\end{array}$ \\
\hline - & 31 & 28 & 11 & 70 \\
\hline
\end{tabular}




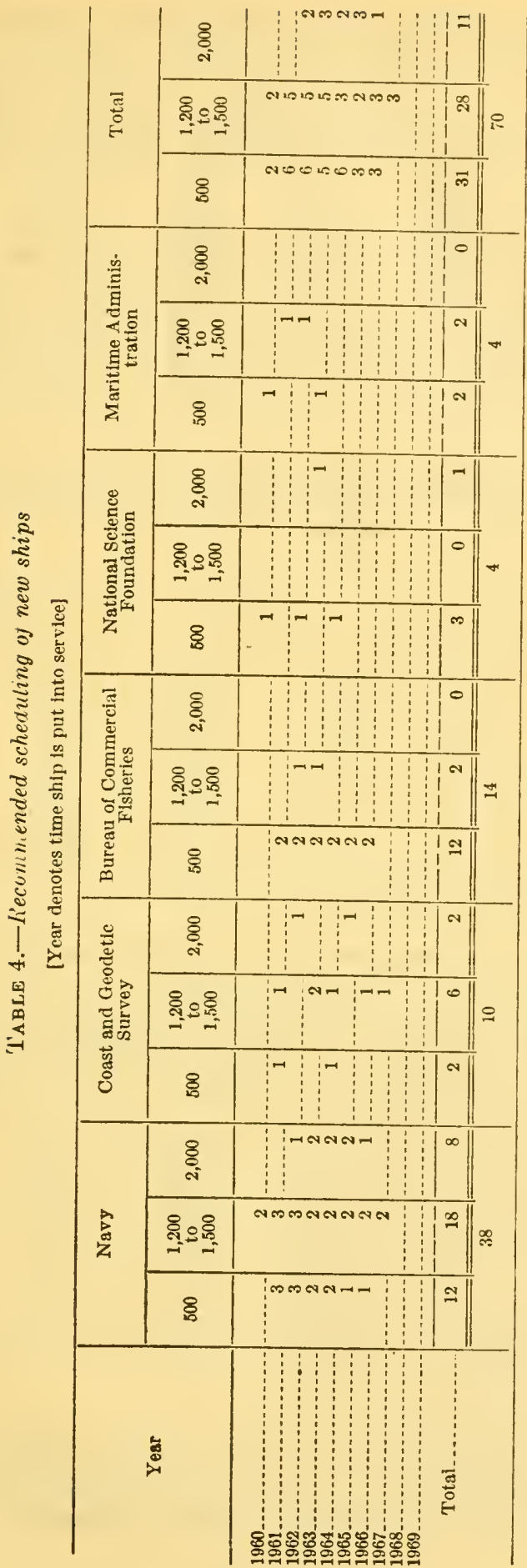


TABLE 5.-Estimated capital costs for newo oceanographic ships by agencies

[Millions of 1958 dollars ']

\begin{tabular}{|c|c|c|c|c|c|c|}
\hline & Navy & $\begin{array}{c}\text { Coast and } \\
\text { Geodetic } \\
\text { Survey }\end{array}$ & $\begin{array}{l}\text { Bureau of } \\
\text { Commereial } \\
\text { Fishelies }\end{array}$ & $\begin{array}{l}\text { National } \\
\text { Sclence } \\
\text { Foundation }\end{array}$ & $\begin{array}{c}\text { Maritime } \\
\text { Administra- } \\
\text { tion }\end{array}$ & Total \\
\hline 1060 & 23.95 & 5.45 & $3.3 u$ & 1.65 & 5.45 & 39.80 \\
\hline $1961 \ldots$ & 21.35 & 5.00 & 7. 10 & 1.65 & 3.80 & 39.90 \\
\hline 1962 & 20. 90 & 7. 60 & 7. 10 & 5. 00 & 1.65 & 42.25 \\
\hline 1963 & 20.90 & 5.45 & 3.30 & 1. 65 & $\mid$ & 31.30 \\
\hline 1964 & 19.25 & 5.00 & 3.30 & -....... & -................ & 27.55 \\
\hline 1965 & 14. 25 & 3.80 & 3.30 & $m-2-2-2-2-2$ & - non. & 21.35 \\
\hline 1966 & 7. 60 & 3.80 & (n) & non & and & 11.40 \\
\hline $1967 \ldots \ldots$ & n.n. & 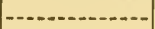 & n-non & 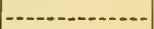 & non & n-non \\
\hline 1968 …ten & -1.2. & - . & - & - & - & $\ldots+\ldots$ \\
\hline 1969 & - nnen & -non- & -non & - nnen & - & - \\
\hline Total ........ & 128.20 & 36.10 & 27.40 & 9.95 & 10.90 & 212.55 \\
\hline
\end{tabular}

Budget allocat Jons have bcen assigned to the year immediately preceding that in which the ship is to be puti nto service.

\section{TABLE 6.-Estimated ship operations costs above present level by function}

[Millions of 1958 dollars]

\begin{tabular}{|c|c|c|c|c|}
\hline Year & Research & Survey & $\begin{array}{c}\text { Resources } \\
\text { and } \\
\text { fisheries }\end{array}$ & Total \\
\hline $\begin{array}{l}1960 \\
1961 \\
1962 \\
1964 \\
1966 \\
1967\end{array}$ & $\begin{array}{l}0.60 \\
1.20 \\
1.80 \\
2.35 \\
2.95 \\
3.55 \\
4.15 \\
4.15 \\
4.15\end{array}$ & $\begin{array}{r}0.65 \\
1.30 \\
2.00 \\
2.60 \\
3.30 \\
3.90 \\
4.60 \\
4.60 \\
4.60\end{array}$ & $\begin{array}{r}0.30 \\
.55 \\
.85 \\
1.15 \\
1.40 \\
1.70 \\
1.70 \\
1.70 \\
1.70\end{array}$ & $\begin{array}{r}1.55 \\
3.05 \\
4.65 \\
6.10 \\
7.65 \\
9.15 \\
10.45 \\
10.45 \\
10.45\end{array}$ \\
\hline Total $\ldots$ & 24.90 & 27.55 & 11.05 & 63.50 \\
\hline
\end{tabular}

1 Excludes military research and development ship operations.

TABLE 7.-Estimated ship operations costs above present level by agency

[Millions of 1958 dollars]

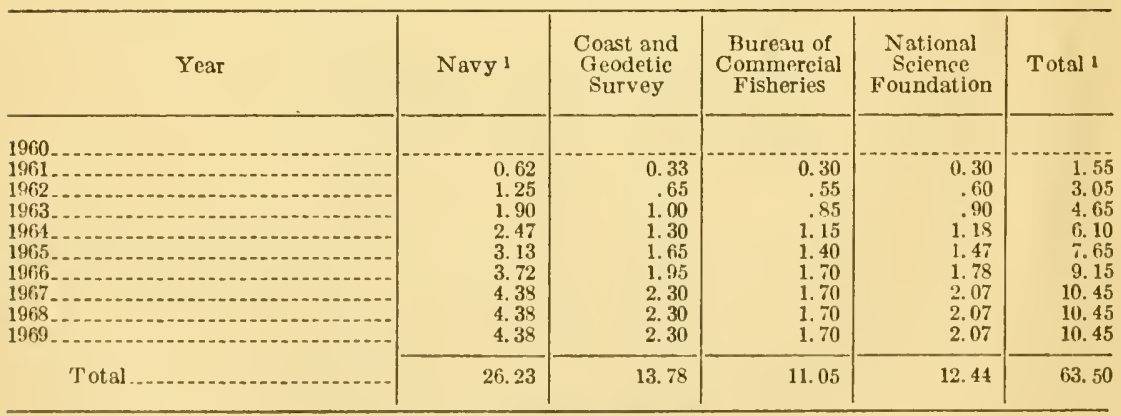

1 Excluding Military Research and Development Ship Opcrations.

\section{Shore facilitics for basic rescarch}

In order to derive the maximum knowledge from observations and collections made at sea, it is estimated that 60 technical persons must be available for the average ship involved in high seas research activity. Most of these persons are involved in land-based activities which require laboratories and associated facilities. 
1. It is recommended that for every additional oceangoing research ship put into operation, an average investment of $\$ 1.5$ million be made for essential shore facilities. These costs should be divided between the Nary and the National Science Foundation.

2. It is estimated that the costs of research other than ship operation will average about $\$ 1.2$ million per ship per year. The committee recommends that Federal funds for this purpose be divided between the Nary and the National Service Foundation.

The costs to each agency, by year, are given in table 8 . Capital allocations are assigned to the year preceding the placing of a new research ship into operation. Although table 8 shows no increase in the operating costs of shore-based facilities for basic research until 1961 when the first new ships are completed, we expect that plans now being made by various Federal agencies (mainly the National Science Foundation and the Nary, involving budgets for basic oceanographic research will be able to maintain the 1958 level of activity and allow for some buildup of staffs. Such plans should be strongly supported by the agencies, the Bureau of the Budget, and the Congress in order to avoid a serious relapse of our present capabilities.

TABLE 8.-Capital and operating costs of basic research other than ships (over and above present level in millions of 1958 dollars)

\begin{tabular}{|c|c|c|c|c|}
\hline \multirow{2}{*}{ Year } & \multicolumn{2}{|c|}{ Navy } & \multicolumn{2}{|c|}{$\begin{array}{l}\text { National Science } \\
\text { Foundation }\end{array}$} \\
\hline & Capital & Operating & Capital & Operating \\
\hline $\begin{array}{l}1960 \\
1961 \\
1963 \\
1964 \\
1965 \\
1967 \\
1968\end{array}$ & $\begin{array}{r}0.75 \\
.75 \\
.75 \\
1.50 \\
2.25 \\
1.50 \\
.75 \\
\\
\hdashline\end{array}$ & $\begin{array}{r}0.60 \\
1.20 \\
1.80 \\
3.00 \\
4.80 \\
6.00 \\
6.60 \\
6.60 \\
6.60\end{array}$ & $\begin{array}{r}0.75 \\
.75 \\
.75 \\
1.50 \\
2.25 \\
1.50 \\
.75 \\
\\
\hdashline\end{array}$ & $\begin{array}{l}0.60 \\
1.20 \\
1.80 \\
3.00 \\
4.80 \\
6.00 \\
6.60 \\
6.60 \\
6.60\end{array}$ \\
\hline Total & 8.25 & 37.20 & 8.25 & 37.20 \\
\hline
\end{tabular}

\section{Oceanwide surveys}

The capital and operating costs for ships involved in surveys of the world ocean have been given in a previous section. However, it is estimated that substantial shore facilities are required for the purpose of evaluating the data collected at sea. It is estimated that capital costs for shore facilities for each new survey ship will average about $\$ 0.75$ million. It is further estimated that operating costs for shore facilities will amount to about $\$ 0.75$ million per survey ship per year.

1. The committee recommends that for every new survey ship put into operation an investment of about $\$ 0.75$ million be made for essential shore facilities.

2 . It is recommended that an average of $\$ 0.75$ million be allocated each year for the operation of shore facilities for each new survey ship placed in operation.

These costs should be divided between the Navy and the Coast and Geodetic Survey. The costs to each agency, by year, are given in table 9. Capital allocations are assigned to the year preceding the placing of a new survey ship into operation.

3. Consideration should be given to conducting some aspects of the survey program through contracts with commercial organizations and private institutions. 
TABLE 9.-Capital and operating costs for shore facilities for survey work (over and above present level in millions of 1958 dollars)

\begin{tabular}{|c|c|c|c|c|}
\hline \multirow{2}{*}{ Year } & \multicolumn{2}{|c|}{ Navy } & \multicolumn{2}{|c|}{ Coast and Geodetic Survey } \\
\hline & Capital & Operating & Capital & Operating \\
\hline 1960 & 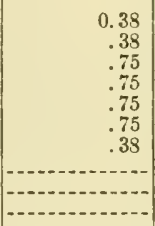 & $\begin{array}{r}0.38 \\
1.75 \\
2.25 \\
3.00 \\
3.75 \\
4.13 \\
4.13 \\
4.13\end{array}$ & \begin{tabular}{r}
0.38 \\
.38 \\
.75 \\
.75 \\
.75 \\
.75 \\
.38 \\
\hdashline$-1.2-$ \\
\end{tabular} & $\begin{array}{r}0.38 \\
.75 \\
1.50 \\
2.25 \\
3.00 \\
3.75 \\
4.13 \\
4.13 \\
4.13\end{array}$ \\
\hline Total & 4. 14 & 24.02 & 4. 14 & 24.02 \\
\hline
\end{tabular}

\section{Engineering needs for ocean exploration}

1. A vigorous program should be conducted for the development of manned submersibles that can onerate down to and on the bottom of most of the ocean:

(a) An improved bathyscaph using the best materials and techniques available should be designed and built immediately.

(b) Following up the recent commendable ONR action in bringing the bathyscaph Trieste to the United States, it is recommended that funds be made available for a mother ship ${ }^{5}$ together with auxiliary equipment in order to make maximum use of this deep submersible.

(c) A continuous design and development program should be initiated aimed at building deep and middepth manned vehicles as the need arises and as the state of the art progresses.

2. The need for open-ocean manned research platforms which are stable, and which can remain in place so that time studies can be made, seems essential and the design for such a buoy should be started.

3. A major program should be supported aimed at developing and using anchored and drifting buoys for obtaining space and time coverage of ocean characteristies.

4. It seems likely that aircraft can be used effectively for some research and surveys on the open ocean, particularly for studies involving the joint problems of oceanography and meteorology. Nearly all laboratories will need single engine planes; several will need twin engined amphibious planes; some will need four-engined commercial-type aireraft.

5. Surface icebreakers are of limited value to Arctic oceanographic research compared to properly equipped submarines. Ffforts should be made to develop a submarine capable of breaking into and out of the ice.

6. Instrmments should be developed for survey purposes which are more accurate, effective and trouble-free than those now in use. The techniques needed to use them more effectively should be developed. Specialized derices such as loran $\mathrm{C}$, inertial narigation equipment, gravity meters and stable platforms should be made available for research as well as surveys as soon as possible.

7. A major program aimed at developing new high-seas engineering techniques should be started. Our abilities to handle heavy equipment and to conduct such operations as drilling and bottom sampling at sea limit our operations at present. Many of these difficulties would be appreciably lessened given proper effort. We have not included the very important problem of drilling to the Mohorovicic discontinuity in our budget because another academy group is studying this problem.

8. Machine aids to computation and data storage have much to offer and should be budgeted.

9. High pressure facilities to permit controlled physical and biological experiments in the laboratory are needed.

10. Efforts slould be male to secure the active participation of private industry in the development and manufacture of new devices and instruments for oceanographic research and surveying.

Bhis is listed in the section on new ships. 
11. The unpredictable aspects of new derices makes difficult the formulation of an exact budget over a 10 -year time scale. The committee recommends that $\$ 48$ million be allocated during the next 5 years. It further recommends that a minimum of $\$ 10.5$ million be allocated each year thereafter. The cost of this program should be divided between the bureaus of the Navy and the National Science Foundation.

Budget breakdowns are given in tables 10 and 11 .

TABLE 10.-Estimated annual budget for engineering needs for ocean exploration

[Millions of 1958 dollars]

\begin{tabular}{|c|c|c|c|c|c|}
\hline & 1960 & 1961 & 1962 & 1963 & 1964 \\
\hline Deep-manned vehicles.. & 2.0 & 2.0 & 3.0 & 4. 0 & 4.0 \\
\hline Large-manned buoys... & .3 & 2.0 & 1.3 & .2 & \\
\hline Unmanned buoys................... & .8 & .8 & .9 & 1.0 & 1.0 \\
\hline Aircraft . . . & .6 & 1.3 & 1.0 & 2.0 & 1.2 \\
\hline Other specialized vehicles & 2.0 & 1.0 & 1.0 & 1.0 & 1.0 \\
\hline Development of new instruments & .6 & 1.2 & 1.2 & 1.5 & 1.8 \\
\hline Other & 1.1 & 1.2 & 1. 2 & 1.2 & 1.3 \\
\hline Total & 7.4 & 9.5 & 9.6 & 10.9 & 10.5 \\
\hline
\end{tabular}

TABLE 11.-Estimated annual budgets for engineering needs for ocean exploration by agency

[Millions of 1958 dollars]

\begin{tabular}{|c|c|c|c|c|c|}
\hline Year & $\begin{array}{l}\text { Navy } \\
\text { bureaus }\end{array}$ & $\begin{array}{l}\text { National } \\
\text { Science } \\
\text { Foundation }\end{array}$ & Year & $\begin{array}{c}\text { Navy } \\
\text { bureaus }\end{array}$ & $\begin{array}{l}\text { National } \\
\text { Science } \\
\text { Foundation }\end{array}$ \\
\hline $\begin{array}{l}1960 \\
1961 \\
1962 \\
1963 \\
1964\end{array}$ & $\begin{array}{l}3.70 \\
4.75 \\
4.80 \\
5.45 \\
5.25\end{array}$ & $\begin{array}{l}3.70 \\
\text { 4. } 75 \\
\text { 4. } 80 \\
\text { 5. } 45 \\
5.25\end{array}$ & $\begin{array}{l}1966 \\
1967 \\
1968\end{array}$ & $\begin{array}{l}5.25 \\
5.25 \\
5.25 \\
5.25\end{array}$ & $\begin{array}{l}5.25 \\
5.25 \\
5.25 \\
5.25 \\
\end{array}$ \\
\hline 1965 & 5.25 & 5. 25 & Total..... & 50.20 & 50.20 \\
\hline
\end{tabular}

\section{Radioactivity in the oceans}

The widespread use of nuclear energy for peaceful or military purposes necessitates studies to determine the effects of radioactive contamination upon the oceans and the life therein. The Committee on Effects of Atomic Radiation on Oceanography and Fisheries in its report to the National Academy of Sciences made certain general recommendations concerning national policy in this area. Both the Committee on Oceanography and the Committee on Effects of A tomic Radiation on Oceanography and Fisheries believe that more specific and detailed recommendations can now be made.

1. A single agency should be given the overall responsibility and authority for regulating the introduction of radioactive materials in the oceans. Monitoring of disposal sites should be done by some agency other than the regulating agency. It is recommended that either the Coast and Geodetic Survey or the Public Health Service be made responsible for engineering studies in and near disposal areas, for routine monitoring of disposal areas and their surroundings and for a continuing assessment of the effects on the environments of added radioactive materials.

2. Vigorous programs should be started for the purpose of determining the circulation and mixing processes which control the dispersion of introduced contaminants in coastal and estuarine environments and in the open ocean. These studies represent the major part of the proposed budget in this area.

3. A program should be pursued aimed at determining the inorganic transfer of radioactive elements from seawater to the sediments.

4. Studies should be made of the effects of living organisms on the distribution of radioactive elements introduced into the sea.

5. The genetic effects of radiation upon marine organisms should be studied. 
6. A rariety of biological field experiments should be conducted utilizing radioisotopes.

7. The proposed budgets for the programs are given in tables 12 and 13 . The greater part of the program should be financed by the Atomic Energy Commission.

\section{TABLE 12.-Radioactivity in the oceans-Summary of budget estimates}

[Annual cost in 1958 dollars]

\begin{tabular}{|c|c|c|c|}
\hline & $\begin{array}{l}\text { Without } \\
\text { shiptime }\end{array}$ & Ship time & Total \\
\hline $\begin{array}{l}\text { Control and monitoring } \\
\text { Estuarine and coastal studies. } \\
\text { Research in open ocean } \\
\text { Sedimentation processes. } \\
\text { Effects of the biosphere } \\
\text { Genetic e fects. } \\
\text { Biological field experimentss }\end{array}$ & $\begin{array}{r}\$ 370,000 \\
1,920,000 \\
1,000,000 \\
1449,000 \\
678,000 \\
100,000 \\
100,000\end{array}$ & $\begin{array}{r}\$ 880,000 \\
400,000 \\
35,000 \\
260,000 \\
- \\
-\end{array}$ & $\begin{array}{r}\$ 370,000 \\
2,800,000 \\
1,400,000 \\
2484,000 \\
938,000 \\
100,000 \\
100,000\end{array}$ \\
\hline $\begin{array}{l}\text { Total 1st year } \\
\text { Total subsequent years. }\end{array}$ & $\begin{array}{l}4,617,000 \\
4,432,000\end{array}$ & $\begin{array}{l}1,575,000 \\
1,575,000\end{array}$ & $\begin{array}{l}6,192,000 \\
6,007,000\end{array}$ \\
\hline $\begin{array}{l}\text { Net cost of new program: 1st year } \\
\text { Subsequent years } \\
\text { If } 2 \text { large open-sea tests are conducted, } 1 \text { in } 1962 \text { and } 1 \text { in } 1966 \text {, } \\
\text { the additional costs in those years will be }\end{array}$ & $\begin{array}{l}3,078,000 \\
2,954,000 \\
1,400,000\end{array}$ & $\begin{array}{r}1,050,000 \\
1,050,000 \\
600,000\end{array}$ & $\begin{array}{l}4,128,000 \\
4,004,000 \\
2,000,000\end{array}$ \\
\hline Total in those years..... & $4,354,000$ & $1,650,000$ & $6,004,000$ \\
\hline
\end{tabular}

$1 \$ 264,000$ after 1st year.

$2 \$ 299,000$ after 1 st year.

TABLE 13.-Radioactivity in the oceans-Summary of budget estimates for new research

[Millions of 1958 dollars]

\begin{tabular}{|c|c|c|c|c|c|c|c|}
\hline Year & $\begin{array}{l}\text { Cost } \\
\text { without } \\
\text { ship time }\end{array}$ & Shiptime & Total & Year & $\begin{array}{l}\text { Cost } \\
\text { without } \\
\text { ship time }\end{array}$ & Ship time & Total \\
\hline $\begin{array}{l}1960 \ldots \ldots \\
1961 \\
1962 \ldots \ldots \\
1963 \ldots \ldots \ldots \\
1964\end{array}$ & $\begin{array}{l}3.08 \\
2.95 \\
4.35 \\
2.95 \\
2.95\end{array}$ & $\begin{array}{r}11.05 \\
11.05 \\
1.65 \\
1.05 \\
1.05\end{array}$ & $\begin{array}{l}4.13 \\
4.00 \\
6.00 \\
4.00 \\
4.00\end{array}$ & $\begin{array}{l}1966 \ldots \ldots \\
1967 \ldots 68 \\
1969\end{array}$ & $\begin{array}{l}4.35 \\
2.95 \\
2.95 \\
2.95\end{array}$ & $\begin{array}{l}1.65 \\
1.05 \\
1.05 \\
1.05\end{array}$ & $\begin{array}{l}6.00 \\
4.00 \\
4.00 \\
4.00\end{array}$ \\
\hline 1965 & 2. 95 & 1.05 & 4.00 & Total.. & 32.43 & 11.70 & 44. 13 \\
\hline
\end{tabular}

1 Primarily through use of ships now In service.

\section{Occan resources}

Lack of adequate understanding of the occurrence, behavior and potential harvest of fish and other marine organisms serves as a serious barrier to extensive economic development and utilization of marine biological resources. Existing knowledge is inadequate to evaluate the feasibility of creating a marine mineral industry.

1. The sea aud its contents should be studied on a broad basis to enlarge our knowledge of its potential resources.

2. In order to elucidate the problem of population fluctuations of commercial fish stocks, which in large part is due to variable infant mortility, laboratory studies of the survival requirements of larval and jurenile stages of commercially important fish and shellfish are needed urgently.

3. There is an urgent need for facilities for studies of fish behavior in the laboratory under controlled conditions. This will require aquarium facilities of sizable physical dimensions.

4. Greater atteution should be giren to studies of the geneties of fish and other marine organisms.

5. Investigations should be made of the feasibility of adding nutrients to the euphotic zoue of the sea in order to increase the productirity of marine organisms. 
6. A program to investigate the possibilities of transplanting useful organisms from one region of the sea to another should be conducted.

7. More research is needed on the nature of the aggregations of organisms in the sea.

8. Biological surveys in the seas should be intensified, and programs should be initiated aimed at utilizing new devices such as unmanned buoys and the mesoscaph.

9. A data center for all oceanographic research should be established for the storage, routine processing and "read-out" of such information as sea surface temperatures, currents, and meteorological data. This data center would not perform the functions of more specialized computing centers such as will be required for oceanographic forecasting.

10. There is a need for scientific, sociological, and engineering studies directed toward the wider utilization of marine products in protein-deficient areas of the world.

11. There is a pressing need for studies of the economic and legal aspects of commercial fisheries, especially in comparison with other industries, in order to provide a basis for national policy decisions.

12. A scientific study of salt-water fishpond culture should be started aimed at providing a basis for greatly increasing the efficiency and productivity of this industry and thereby increasing the protein food supplies in protein-deficient areas such as southeast Asia.

13. Many aspects of the potential mineral resources on the deep-sea floor should be inrestigated. Such work should be supported through the Bureau of Mines.

14. An expanded program of estuarine research is recommended in order that we can make most effective use of this habitat of important resident stock of foodfish and shellfish and the nursery areas for other stocks which are later harvested from the open ocean.

15. Many lines of marine research depend upon precise definition of species. The stuly of species is centered in research museums which generally have been supported very poorly. It is recommended that established museums having significant study collections be given financial support so that this kind of work can be carried forward.

16. It is recommended that a program on diseases and other toxic effects in the marine environment be established.

T'lie proposed budgets for these recommendations are given in tables $14, \mathbf{1 5}$, and 16. The mineral resources investigation should be sponsored by the Bureau of Mines with the balance being supported by the Bureau of Commercial Fisheries through grants, contracts, and in its own laboratories and with the assistance of other branches of the Department of the Interior. Plograms involving international cooperation and technical assistance to other countries budgeted under this beading should be supported at least in part by the International Cooperation Administration and the State Department.

TABLE 14.-Capital costs for nev ocean resources studies ${ }^{1}$

[Millions of 1958 dollars]

\begin{tabular}{|c|c|c|c|c|c|c|c|c|c|c|c|}
\hline & 1960 & 1961 & 1962 & 1963 & 1964 & 1965 & 1966 & 1967 & 1968 & 1969 & Total \\
\hline $\begin{array}{l}\text { Laboratory survival studies } \\
\text { Fish behavior studies... } \\
\text { Supplementary data collection. } \\
\text { Uninanned buoy utilization. } \\
\text { Mesoscaph utilization } \\
\text { National data center } \\
\text { Disease and related studies. }\end{array}$ & $\begin{array}{c}0.50 \\
-.04 \\
-. .-2 \\
-.25 \\
\cdots\end{array}$ & \begin{tabular}{c}
2.10 \\
\hdashline .20 \\
$\cdots$ \\
\hdashline$\ldots$ \\
$\cdots$
\end{tabular} & 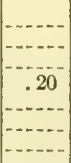 & \begin{tabular}{c}
1.90 \\
. .30 \\
\hdashline .80
\end{tabular} & $\begin{array}{r}0.30 \\
1.00 \\
\cdots\end{array}$ & $\begin{array}{r}0.04 \\
50 \\
\hdashline \\
\hdashline \\
\hdashline\end{array}$ & 0.50 & 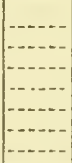 & 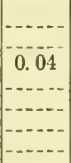 & 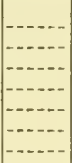 & $\begin{array}{r}0.50 \\
4.00 \\
.12 \\
2.00 \\
1.00 \\
.25 \\
.80\end{array}$ \\
\hline Mineral resources investigation. & $\begin{array}{l}.79 \\
.10 \\
\end{array}$ & 2.30 & .20 & 3.00 & 1.30 & $\begin{array}{c}.54 \\
--.-- \\
\end{array}$ & .50 & (n-n & .04 & - & $\begin{array}{r}8.67 \\
.10 \\
\end{array}$ \\
\hline Total. & & $\ldots$ & & & & & & & & & 8.77 \\
\hline
\end{tabular}

I Does not include capital costs of ships, which will be found in the section on new ships. 
TaBle 15.-Operating costs for new resources studies ${ }^{1}$

[Millions of 1958 dollars]

\begin{tabular}{|c|c|c|c|c|c|c|c|c|c|c|c|}
\hline & 1960 & 1961 & 1962 & 1963 & 1964 & 1965 & 1966 & 1967 & 1968 & 1969 & Total \\
\hline Laboratory survival studies..... & & 0.24 & 0.24 & 0.24 & 0.24 & 0.24 & 0.24 & 0.24 & 0.24 & 0.24 & 2. 16 \\
\hline Fish behavior studies & & & .48 & .48 & .95 & .95 & $\begin{array}{r}.95 \\
.95\end{array}$ & $\begin{array}{r}.2 . \\
.95\end{array}$ & $\begin{array}{r}.24 \\
.95\end{array}$ & $\begin{array}{r}.25 \\
.95\end{array}$ & 6.66 \\
\hline Genetics of marine organisms.... & 0.20 & .20 & .20 & .20 & .20 & .20 & .20 & .20 & .20 & .20 & 2.00 \\
\hline Nutrient increase studies . . . . . & .12 & .12 & 12 & 15 & 15 & 15 & 15 & 15 & .15 & 15 & 1.41 \\
\hline Organism transportation studies. & .05 & .05 & .05 & .05 & .05 & .05 & 05 & .05 & .05 & .05 & .50 \\
\hline Organism distribution & .05 & .05 & .05 & .05 & .05 & .05 & .05 & .05 & .05 & .05 & 50 \\
\hline Biological surveys & 1.80 & 1.80 & 1.80 & 1.80 & 1.80 & 3. 60 & 3.60 & 3.60 & 3.60 & 3. 60 & 27.00 \\
\hline Supplementary data collection. & .11 & .11 & .11 & .11 & .11 & .22 & .22 & .22 & .33 & .33 & 1.87 \\
\hline Unmanned buoy utilization ..... & - n-..- & .03 & .06 & .11 & .15 & 23 & .30 & .30 & .30 & .30 & 1.78 \\
\hline Mesoscaph utilization & & & & & & .64 & .64 & .64 & .64 & .64 & 3. 20 \\
\hline National data center & .10 & .11 & .12 & .13 & .15 & .16 & 18 & .20 & .22 & .24 & 1,61 \\
\hline Marine product utilization & .30 & .30 & 30 & .30 & .30 & 1. 00 & 1.00 & 1. 00 & 1.00 & 1.00 & 6.50 \\
\hline Economic and legal studies..... & .20 & .20 & .20 & .20 & .20 & .20 & .20 & .20 & .20 & .20 & 2.00 \\
\hline Pond fish culture & .10 & .10 & .10 & .10 & .30 & 30 & 30 & .30 & .30 & .30 & 2. 20 \\
\hline Estuarine studies & .20 & .20 & 50 & .50 & .50 & 50 & .50 & .80 & .80 & .80 & 5.30 \\
\hline Taxonomic development. . & .55 & .55 & 55 & .55 & .55 & 1.00 & 1.00 & 1.00 & 1.00 & 1.00 & 7.75 \\
\hline and related studies...... & & & & .20 & .20 & .20 & .50 & .50 & .50 & .50 & 2,60 \\
\hline Special development fund ...... & .10 & 10 & .10 & .10 & 10 & 10 & .10 & 10 & 10 & .10 & 1.00 \\
\hline $\begin{array}{l}\text { Total for Bureau of Com- } \\
\text { mercial Fisheries }\end{array}$ & 3.88 & 4. 16 & 4.98 & 5.27 & 6.00 & 9.79 & 10.18 & 10.50 & 10.63 & 10.65 & 76.04 \\
\hline Mineral resource investigation & & & & & & & & & & & \\
\hline (Bureau of Mines) & 5 & .25 & 25 & .25 & .25 & .25 & .25 & .25 & .25 & .25 & 2.50 \\
\hline Total & 4. 13 & 4. 41 & 5.23 & 5.52 & 8.25 & 10.04 & 10.43 & 10.75 & 10.88 & 10.90 & 78.54 \\
\hline
\end{tabular}

1 Excluding ship operations.

TABLE 16.-Capital and operating costs for new resources research ${ }^{1}$

\begin{tabular}{|c|c|c|c|c|c|}
\hline \multirow{2}{*}{ Year } & \multicolumn{2}{|c|}{$\begin{array}{c}\text { Bureau of Commerciai } \\
\text { Fisheries }\end{array}$} & \multicolumn{2}{|c|}{ Bureau of Mines } & \multirow{2}{*}{ Total } \\
\hline & Capital & Operating ${ }^{2}$ & Capital & Operating & \\
\hline $\begin{array}{l}1960 \\
1961 \\
1962 \\
1963 \\
1965 \\
1966 \\
1967 \\
1968\end{array}$ & $\begin{array}{r}0.79 \\
2.30 \\
.20 \\
3.00 \\
1.30 \\
.54 \\
.50 \\
.04\end{array}$ & $\begin{array}{r}3.88 \\
4.16 \\
4.98 \\
5.27 \\
6.00 \\
9.79 \\
10.18 \\
10.50 \\
10.63 \\
10.65\end{array}$ & 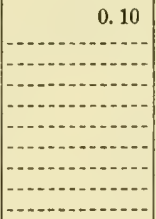 & $\begin{array}{l}0.25 \\
.25 \\
.25 \\
.25 \\
.25 \\
.25 \\
.25 \\
.25 \\
.25 \\
.25\end{array}$ & $\begin{array}{r}5.02 \\
6.71 \\
5.43 \\
8.52 \\
7.55 \\
10.58 \\
10.93 \\
10.75 \\
10.92 \\
10.90\end{array}$ \\
\hline Total & 8.67 & 76.04 & .10 & 2. 50 & 87.31 \\
\hline
\end{tabular}

1 Excluding ships and ship time.

2 Programs involving International cooperation and technical assistance to otier countries budgeted under this heading should be supported at least in part by the International Cooperation Administration and the State Dcpartment.

\section{International cooperation}

It is clear that, as in other seiences, a very large part of the pioneering research and new ideas concerning the oceans must come from individual seientists or small groups working independently. But international cooperation in work at sea is essential in several kinds of marine research and should also greatly facilitate surveys of the ocean floor and of the waters.

There is at present a high level of international cooperation among physieal and ehemical oceanographers of different countries resulting from the International Geophysical Year. This cooperation should be maintained and broadened throughout all aspects of the marine sciences, partieularly ineluding biology. To this end, the committee recommends :

1. The United States through the National Science Foundation should give its proportionate share (amounting to perhaps $\$ 20,000$ per year) of financial and other support to the Special Committee on Oceanic Research of the Internittional Council of Scientific Unions. The Committee on Oceanography has been 
designated as the United States National Committee for this long-range cooperative program.

2. Grants should also be sought from foundations and governmental sources to support special projects such as the proposed year-long international expedition to the Indian Ocean by covering the increased expenses to United States oceanographic institutions and by making the participation of other countries possible. Special funds needed for the Indian Ocean project are estimated at about $\$ 2$ million.

3. An intergovernmental conference of the maritime countries should be called, after suitable preparation, to discuss means by which the governments can cooperate in increasing man's knowledge of the oceans. Specifically, agreements should be sought regarding the means of carrying out ocean-wide surveys, including allocation of responsibility to different countries, intercalibration of techniques, and free exchange of data. It would be expected that the United States' proportion of this international responsibility for surveys would be about the same as its proportion of financial responsibility for support of United Nations agencies. This conference should be a first step toward the establishment of a World Oceanographic Organization; a United Nations specialized agency corresponding to the World Meteorological Organization.

4. In the study and conservation of the living resources of the sea, regional international organizations, such as the various international fisheries commissions, have proven effective.

In developing formal intergovernmental cooperation in the marine sciences, the Federal Government should give special emphasis to the establishment and adequate support of such regional organizations, and should seek to broaden their charter to allow an integrated research program on all aspects of a particular oceanic region.

5. In order to increase the effectiveness of cooperation between United States marine scientists and laboratories and marine scientists in other countries, the United States State Department should be prepared to assist positively, sympathetically and promptly in facilitating research ship operations and the exchange of information, persons, equipment, and supplies.

6. The need for increased protein foods from the sea is especially urgent in underdeveloped countries. The International Cooperation Administration in its programs of technical assistance should give greater emphasis to marine resources surveys and to research projects and training programs in the marine sciences. The Federal Government should also encourage United Nations specialized agencies such as UNESCO and FAO in their efforts to aid underdeveloped countries to achieve greater utilization of marine resources. The funds needed for both these purposes have not been budgeted separately in this report but are included in the budget for ocean resources studies.

\section{Budget and operations}

The total recommended budget for the period 1960-70, broken down by category and agency, is given in tables $\mathbf{1 7}$ and 18. It should be emphasized that although the budget includes the capital costs of ships involved in strictly military research and development, it does not include the other costs which are involved in such work.

Concerning the actual funding and operations, the committee recommends:

1. A higher percentage of longer-term funding must be made available in oceanographic research. Past funding has been inefficient, and has held back much longer-term imaginative research. A reasonable portion ( 30 to 50 percent) of the annual operatiug budget should include 5-year money which is refreshed annually. Existing laws permit allocation of many funds on a 5-year basis. The military is accustomed to making long-term commitments of 5 to 10 years when they adopt a new weapons system and it is equally essential that they make long-term commitments for research.

2. Administrators of research and laboratory directors must have a higher percentage (25 to 50 percent) of their fundlng free to spend on those good research problems which emerge without the benefit of planning.

3. Government organizations which presently fund or carry on extensive research and development in oceanography should continue to do so in the field of their special interests. For example, the Navy, the Atomic Energy Commission, and the Bureau of Commereial Fisheries all have their own Important oceanographic problems. It is recommended that each bureau and organization sponsor and finance much of the research which it needs to meet the demands 
of its present and future objectires. Any duplication of effort which might be involred appears trivial compared to the value of insuring that scientists are in close touch with changing Bureau problems.

4. There will still remain a need for a great deal of research which should be funded by the National Science Foundation. This agency should carry a much hearier portion of the long-term basic research in the Nation. A reasonable percentage of grants should be made to individuals and a reasonable portion should be allocated for long-term funding of institutional activities such as rehicles, facilities, and major expeditions.

5. Foundations, States, and industries should take an actire part in the support of marine research. Their support is particularly valuable in new and unusual research programs, in filling technological gaps, and, through appropriate assistance, insuring that private laboratories and academic groups do not become solely dependent on Federal assistance.

TABLE 17. -Summary of budgets for new oceanographic activity ${ }^{1}$

\begin{tabular}{|c|c|c|c|c|c|c|c|c|}
\hline Year & $\begin{array}{l}\text { Education } \\
\text { and man- } \\
\text { power }\end{array}$ & Ships & $\begin{array}{c}\text { Shore facili- } \\
\text { ties (re- } \\
\text { search) }\end{array}$ & $\begin{array}{c}\text { Shore facili- } \\
\text { ties } \\
\text { (surveys) }\end{array}$ & $\begin{array}{l}\text { New } \\
\text { devices }\end{array}$ & $\begin{array}{l}\text { Radio- } \\
\text { activity? } \\
\text { in oceans }\end{array}$ & Resources & Total \\
\hline $\begin{array}{l}1960 \\
1961 \\
1962 \\
1963 \\
1964 \\
1965 \\
1966 \\
1967 \\
1968 \\
1969\end{array}$ & $\begin{array}{l}0.80 \\
.80 \\
.80 \\
.80 \\
.80 \\
.80 \\
.80 \\
.80 \\
.80 \\
.80\end{array}$ & $\begin{array}{l}39.80 \\
40.45 \\
45.30 \\
35.95 \\
33.65 \\
29.00 \\
20.55 \\
10.45 \\
10.45 \\
10.45\end{array}$ & $\begin{array}{r}1.50 \\
2.70 \\
3.90 \\
6.60 \\
10.50 \\
12.60 \\
13.50 \\
13.20 \\
13.20 \\
13.20\end{array}$ & $\begin{array}{l}.076 \\
1.52 \\
3.00 \\
4.50 \\
6.00 \\
7.50 \\
8.26 \\
8.26 \\
8.26 \\
8.26\end{array}$ & $\begin{array}{r}7.40 \\
9.50 \\
9.60 \\
10.90 \\
10.50 \\
10.50 \\
10.50 \\
10.50 \\
10.50 \\
10.50\end{array}$ & $\begin{array}{l}3.08 \\
2.95 \\
4.35 \\
2.95 \\
2.95 \\
2.95 \\
4.39 \\
2.95 \\
2.95 \\
2.95\end{array}$ & $\begin{array}{r}5.02 \\
6.71 \\
5.43 \\
8.52 \\
7.55 \\
10.58 \\
10.93 \\
10.75 \\
10.92 \\
10.90 \\
\end{array}$ & $\begin{array}{l}58.36 \\
64.63 \\
72.38 \\
70.22 \\
71.95 \\
73.93 \\
68.89 \\
56.91 \\
57.08 \\
57.06 \\
\end{array}$ \\
\hline Total...... & 8. 00 & 276.05 & 90.90 & 56.32 & 100.40 & 32.43 & 87.31 & 651.41 \\
\hline
\end{tabular}

1 Not including special funds for basic research projects involving extensive international cooperation such as the proposed year-long international expedition to the Indian Ocean (extimated cost: $\$ 2$ million).

2 Plus ship time charges of $\$ 11.70$ million to be subtracted from other categories. 


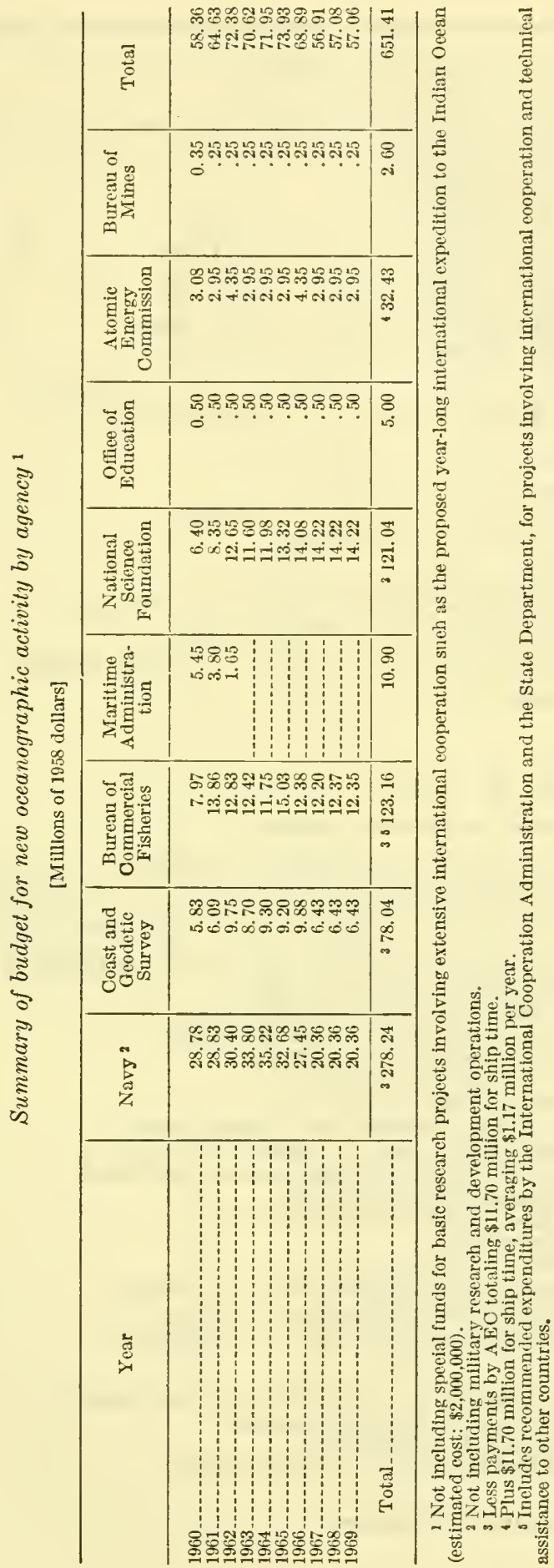


MEMBERSHIPS OF PANELS OF THE COMMITTEE ON OCEANOGRAPHY

I. Panel on Oceanographic Research Ships:

Clifford A. Barnes, University of Washington

Arlmiral L. O. Colhert (retired), Arctic Institute of North America

John Isaacs, Scripps Institution of Oceanography

Columbus O'D. Iselin (chairman).

Vito Russo, Maritime Administration

Herbert Seward, Yale University

II. Panel on New Derices for Exploring the Ocean:

Robert Frosch, Hudson Laboratories, Columbia University

James Lipp, Lockheed Aircraft Corp.

Philip Mandel, Massachusetts Institute of Technology

Andreas Rechnitzer, the Navy Electronics Laboratory

Athelstan Spilhaus ${ }^{\circ}$

Allyn Vine (Chairman), Woods Hole Oceanographic Institution

Rear Adm. George Weaver (retired), George Washington University.

III. Panel on Ocean Resources:

Richard L. Meier, University of Michigan

H. W. Menard, Scripps Institution of Oceanography

John R. Menke, Nuclear Development Corp.

Milner B. Schaefer ${ }^{\circ}$

Oscar E. Sette, Bureau of Conımercial Fisheries

Robert G. Snider (chairman), the Conservation Foundation

Lionel A. Walford, Bureau of Commercial Fisheries

IV. Panel on International Cooperation in the Marine Sciences

Columbus O'D. Iselin ${ }^{\circ}$

Fritz Koczy ${ }^{\circ}$

Roger Revelle ${ }^{\circ}$

Milner B. Schaefer ${ }^{\circ}$

Athelstan Spilhaus (chairman) ${ }^{\circ}$

V. Panel on Radioactivity in the Oceans

(This group continues to be active as the Committee on the Effects of Atomic Radiation on Oceanography and Fisheries of the National Academy of Sciences' Study of the Biological Effects of Atomic Radiation. It responds to inquiries from but is not officially a part of the Committee on Oceanography.)

Howard Boroughs, Instituto Interamericano De Ciencias Agricolas

Dayton Carritt, the Johns Hopkins University

Walter Chilman, Bureau of Commercial Fisheries

Harmon Craig, Scripps Institution of Oceanography

Lauren Donaldson, University of Washington

Richard Fleming, University of Washington

Richard Foster, General Electric Co.

Edward Goldberg, Scripps Institution of Oceanography

John Harley, U.S. A tomic Energy Commission

Bostwick Ketchum, Woods Hole Oceanographic Institution

Louis Krumholz, University of Louisville

Charles E. Renn, the Johns Hopkins University

Roger Revelle (chairman) ${ }^{\circ}$

Milner I3, Schaefer ${ }^{6}$

Allyn C. Vine, Woods Hole Oceanographic Institution

Lionel A. Walford, Bureau of Commercial Fisheries

Warren S. Wooster, Scripps Institution of Oceanography

Consultants :

Theodore IR. Folsom, Scripps Institution of Oceanography

Arnold Joseph, Atomic Energy Commission

Robert Reid, 'Texas A. \& M. College

Donald P'ritchard, the Johns Hopkins University

- Committee on Oceanography Members. 
Oceanographic research ships (200 tons displacement or more)

[d-Displacement]

\begin{tabular}{|c|c|c|c|}
\hline Name & Tonnage & Length & Operated by- \\
\hline $\begin{array}{l}\text { Atlantis. } \\
\text { Crawford. } \\
\text { Bear } \\
\text { Chain } \\
\text { Brown Bear. } \\
\mathrm{R} / \mathrm{V} \text { Hidalgo } \\
\mathrm{R} / \mathrm{V} \text { Vema. } \\
\text { Spencer F. Baird. } \\
\text { Horizon } \\
\text { Orca... } \\
\text { Velero IV }\end{array}$ & $\begin{array}{l}298 \mathrm{~d} \\
250 \mathrm{~d} \\
260 \mathrm{~d} \\
1,800 \\
270 \mathrm{~d} \\
243 \\
533 \mathrm{~d} \\
505 \mathrm{~d} \\
505 \mathrm{~d} \\
200 \mathrm{~d} \\
400\end{array}$ & $\begin{array}{l}142 \\
125 \\
100 \\
214 \\
114 \\
136 \\
202 \\
143 \\
143 \\
100 \\
110\end{array}$ & $\begin{array}{l}\text { Woods Hole Oceanographic Institution. } \\
\text { Do. } \\
\text { Do. } \\
\text { Do. } \\
\text { University of Washington. } \\
\text { Texas A. and M. College. } \\
\text { Lamont Geological Observatory. } \\
\text { Scripps Institution of Oceanography. } \\
\text { Do. } \\
\text { Do. } \\
\text { Hancock Foundation. }\end{array}$ \\
\hline
\end{tabular}

Military research and developments ships

[d-Displacement]

\begin{tabular}{|c|c|c|c|}
\hline Name & Tonnage & $\begin{array}{l}\text { Length } \\
\text { (feet) }\end{array}$ & Operated by - \\
\hline $\begin{array}{l}\text { San Pablo } \\
\text { Rehoboth } \\
\text { Gibbs. } \\
\text { U.S.S. Allegheny A TA-179 } \\
\text { Epce (RP) 856 } \\
\text { Epce (R) 857 } \\
\text { U.S.S. Rockville } \\
\text { U.S.S. Somersworth } \\
\text { U.S.S. Hunting }\end{array}$ & $\begin{array}{l}2,700 \mathrm{~d} \\
2,700 \mathrm{~d} \\
2,700 \mathrm{~d} \\
700 \\
818 \mathrm{~d} \\
818 \mathrm{~d} \\
800 \mathrm{~d} \\
800 \mathrm{~d} \\
800 \mathrm{~d}\end{array}$ & $\begin{array}{l}310 \\
310 \\
310 \\
146 \\
184 \\
184 \\
180 \\
185 \\
200\end{array}$ & $\begin{array}{l}\text { Hydrographic Office. } \\
\text { Do. } \\
\text { Hudson Laboratory. } \\
\text { Do. } \\
\text { Underwater Sound Laboratory. } \\
\text { Navy Electronics Laboratory. } \\
\text { Naval Research Laboratory. } \\
\text { Do. } \\
\text { Do. }\end{array}$ \\
\hline
\end{tabular}

Oceanographic survey ships operated by U.S. Coast and Geodetic Survey

\begin{tabular}{|c|c|c|c|}
\hline \multirow{2}{*}{ Sosbee } & $\begin{array}{c}\text { Displacement } \\
\text { tons, loaded }\end{array}$ & \multicolumn{2}{|c|}{$\begin{array}{c}\text { Displacement } \\
\text { tons, loaded }\end{array}$} \\
\hline & 46 & Patton & 150 \\
\hline & & Bowie & \\
\hline$g h t_{-}$ & 4 & Hod & 26 \\
\hline & ; & Hy & 1,10 \\
\hline & 5 & Explorer & 1,9 \\
\hline & & Pat & \\
\hline$e s$ & & Pioneer & \\
\hline$-\ldots$ & & revenar & \\
\hline
\end{tabular}

Resources and fisheries ships

[g-Gross tons. n-Net tons]

\begin{tabular}{|c|c|c|c|}
\hline Name & Tonnage & Length (feet) & Operated by- \\
\hline MV Oregon & 254 & 100 & Bureau of Commercial Fisheries, Pascagoula \\
\hline $\begin{array}{l}\text { MV Silver Bay } \\
\text { Albatross } 11 I_{-}-\ldots \\
\end{array}$ & $\begin{array}{l}239 \\
525\end{array}$ & $\begin{array}{r}96 \\
180\end{array}$ & $\begin{array}{l}\text { Laboratory. } \\
\text { Do. }\end{array}$ \\
\hline MV Hugh M. Smith... & $392 \mathrm{~g}(190 \mathrm{n})$ & 128 & Bureau of Commerctal Fisheries, Pacific \\
\hline $\begin{array}{l}\text { MV Charles H. Gilbert......- } \\
\text { Black Douglas........ } \\
\text { Alaska }\end{array}$ & $\begin{array}{r}196 \mathrm{~g}(88 \mathrm{n}) \\
370 \\
240 \mathrm{~g}\end{array}$ & $\begin{array}{l}122 \\
150 \\
100\end{array}$ & $\begin{array}{l}\text { Do. } \\
\text { International Pacific Fishery Investigation. } \\
\text { California Department of Fish and Game. }\end{array}$ \\
\hline
\end{tabular}


DEPARTMENTS OF THE GOVERNMENT CONCERNED WITH THE DEVELOPMENT OF MARINE SCIENCES AND DISCUSSED IN DETAIL IN THE REPORT OF THE COMMITTEE ON OCEANOGRAPHY

\section{Department of Commerce}

The Coast and Gcodetic Survey operates a small but efficient survey fleet, has a long tradition of high quality survey work in Continental Shelf areas, is viewed by the Committee on Oceanography as highly suited for conducting a major part of the ocean survey program recommended by the Committee.

I aritime Administration is considered as having an important part of ship design and construction program.

II. Department of Defense

The Navy has an urgent requirement for the development of a program of oceanographic research. Major emplasis is on waves, currents, underwater sound propagation, effectiveness and design of weapons systems, submarine detection, location and identification, mine countermeasures, ship construction, navigation, and communication.

\section{Department of Interior}

The Bureau of Commercial Fisheries present programs in support of fisheries' interests require strengthening. Future responsibilities for vigorous and imaginative support of basic research required for effective development of marine resources.

\section{Independent offices}

Atomic Energy Commission present activities in marine research are on a small scale. Recommendations for support of specific research programs are discussed in detail in the Committee's report.

National Science Foundation present support of marine sciences is on relatively small scale. The Foundation has a vitally important role in the future support of basic research, construction of special facilities (ships and laboratories), and derelopment of fellowship programs.

\section{$\nabla$. Other agencies and departments mentioned in the report}

A. The Department of Agrieulture.-Desalting of water, climatic control.

B. The Air Force.-Concerned with survival and location of downed flyers, navigation over the sea, the shape of the earth, radar performance, and missile ranges.

C. The Army.-Significant interest in amphibious operations, beach erosion, oversea transportation, and movement of troops and supplies.

D. The Coast Guard operates the International Ice Patrol (and associated oceanographic surveys) and ocean reseue stations. An important supplement to our total U.S. effort in oceanography.

E. The Geological Survey is concerned witl offshore oil and mineral resources.

F. Department of Health, Education, and Welfare.-Radio active contamination of the ocean resources.

G. The State Department.-U.S. international leadership and competence in maritime technology and international cooperation.

H. The Weather Burcau.-Weather forecasting, hurricane information, weather modification.

\section{Chapter 8. Education and Manpower}

\section{STATUS}

The recruitment of highly trained professional oceanographers is barely adequate to meet the requirements of existing research programs in the United States, and is less than adequate in the field of pliysieal oceanograpliy. A substantial increase in the support of oceanography will result, therefore, in a serious manpower shortage unless action is taken to inerease the number of stuclents in this field.

At present there are 12 universities in the United States providing graduate education in oceanography leading to the $\mathrm{Ph}$. D. degree. Of these, four offer $\mathrm{Ph}$. D.'s only in biological oceanograplyy, four in one or mole of the nonbiological fields (physical, cliemical, geological oceanography), and four in all fields of oceanography. In addition, three univerities provide substantial graduate edu- 
cation in oceanography but not at the $\mathrm{Ph}$. D. level. 'Two of these are expected to begin a doctoral program in the near future.

The combined total of the professional staffs of organizations offering graduate education is 150 or more. Howerer, many of these are engaged almost exclusively in research. Only about 50 people are actively engaged in graduate teaching, or less than 10 percent of the 520 professionally trained personnel in the country.

The type of graduate education varies widely. Some universities offer a full course and a degree in oceanography. Others offer a degree in a basic scientific discipline with the oceanographic program consisting of two or three courses and thesis supervision. Opinions differ as to whether the major emphasis at this lerel of training should be on the basic discipline or on the more specialized professional aspects of oceanography. Thus, the young oceanographer is not a standardized product. This is probably a healthy situation in any interdisciplinary profession, leading to dirersification of knowledge, interests, and technical skills. Howerer, it must be admitted that thorough education in both oceanography and basic science cannot be accomplished within the usual span of graduate study. Postgraduate study and on-the-job training are generally necessary.

Accurate data have not been obtained on the rate of production of oceanographers, but almost certainly no more than $20 \mathrm{Ph}$. D.'s are graduated per year. A small but significant number of $\mathrm{Ph}$. D.'s come into the field from basic sciences or from related interdisciplinary fields such as limnology and geophysics.

A much larger number of recruits are taken on as technical assistants and junior scientists with little or no prior knowledge of oceanography. They range from people with a bachelor's degree in a basic science to those with virtually no scientific training. Thus, while 90 percent of the oceanographers are not actively engaged in graduate teaching, many are fulfilling an important and necessary function in teaching oceanographic and laboratory operations to the apprentices and journeymen who are put in their charge.

\section{THE PROBLEM}

The research program envisaged by other chapters of this report will require an approximate doubling of the number of professional oceanographers at the doctoral level and an increase of rather greater magnitude in personnel of lower categories over the next several years. Obviously, this necessitates doubling the educational program as rapidly as possible.

\section{CONCLUSIONS AND RECOMMENDATIONS}

1. The universities now providing graduate education for oceanographers should be encouraged to increase the numbers and quality of their output. Some institutions which now teach oceanographers in only certain branches of oceanography should add professors in other fields to their faculties. These measures will require financial support.

2. Institutions which undertake considerable research, but provide no regular formal teaching in oceanography, could contribute greatly to the education of oceanographers at the highest level by close formal affliations with universities. Conversely, unirersities should recognize their responsibilities in the education of oceanographers. They should welcome this affiliation with marine laboratories and arrange for the interchange of faculties. This will require financial support.

3. It may be desirable to develop oceanographic education at new centers. However, a "critical mass" of faculty in the basic sciences is essential for successful teaching of oceanographers. Such new centers should, therefore, be dereloped at universities which possess strong faculties in the sciences.

4. In order to finance new faculty in oceanography at existing or new teaching centers, the U.S. Government should provide funds ou long-term commitments. This committee recommends that about $\$ 500,000$ per year be appropriated for salaries and the equipment and indirect costs associated with such positions. This program could be operated through the Office of Education.

5. In order to attract competent graduate students to the long and somewhat arduous schooling required of well-qualified oceanographers, it will be necessary to provide substantial long-term fellowships. It is believed that 80 fellowships should be supported on a 5-year basis and at an average stipend of $\$ 3,500$ to $\$ 4,000$ per student each year. This will produce 12-15 new Ph. D.'s per year (allowing a reasonable attrition factor) at an annual cost of about $\$ 300,000$. This would provide approximately one-third of the student support that will be needed in order to double the number of oceanographers at the Ph. D. level during the next 10 years. 
It is desirable that fellowships permit students to attend more than one university. This can provide students with well-rounded educations in all branches of oceanography without each university having to provide a full curriculum. Such a program should be handled through the National Science Foundation.

6. Efforts should be made in research and survey programs to use larger numbers of assistants at the bachelor and master's lerel in order to utilize more efficiently the limited number of persons available at the doctoral lerel.

7. Oceanographers should undertake more active recruiting of prospective oceanographers among undergraduate students of physics, chemistr, biology, and geology.

\section{Chapter 12. Marine Sciences in the United States, 1958}

\section{INTRODUCTION}

The main purposes of this report are to examine the present status and past history of the growth of basic and applied research in the marine sciences in the United States and to analyze some of the current problems of supporting oceanographic research.

Oceanography is a very young area of activity in the United States. It has developed from a handful of laboratories in 1920 to its present status of about 70 laboratories of various sizes. Part of the story of this growth is shown in table 1. The total number of laboratories doubled in the postwar years and has increased nearly tenfold since 1920. The total financial support and personnel has also increased, for most of the existing institutions have increased their staffs and new laboratories have been established.

TABLE 1.-Number of marine laboratories in the United States and territorial possessions, listed according to sponsoring agency and period when founded

\begin{tabular}{|c|c|c|c|c|c|c|}
\hline & $\begin{array}{c}\text { Before } \\
1920\end{array}$ & $1921-30$ & $193 i-45$ & $1946-50$ & $1951-58$ & Total \\
\hline $\begin{array}{l}\text { State } \\
\text { Federal } \\
\text { University } \\
\text { Other } 1\end{array}$ & $\begin{array}{l}0 \\
2 \\
4 \\
2\end{array}$ & $\begin{array}{l}2 \\
2 \\
3 \\
2\end{array}$ & $\begin{array}{l}1 \\
8 \\
7 \\
0\end{array}$ & $\begin{array}{r}5 \\
71 \\
1\end{array}$ & $\begin{array}{l}1 \\
7 \\
5 \\
0\end{array}$ & $\begin{array}{r}9 \\
26 \\
30 \\
5\end{array}$ \\
\hline Total & 8 & 9 & 16 & 24 & 12 & 70 \\
\hline
\end{tabular}

1 Mainly corporations funded by private contributions or by endowments provided by foundations.

'The problems of acquiring a first rate staff in a competitive market, of financing their research, and of getting and maintaining additional ship and shore facilities have been severe. They have led in some cases to difficult and precarious financing of oceanographic laboratories.

Some of the data used in this discussion came from the "Directory of Hydrobiological Laboratories and Personnel in North America" edited by Robert W. Hiatt and published in 1954 under the auspices of the Advisory Committee on Hydrobiology to the Office of Naval Research. For present purposes the Conimittee on Oceanography found it necessary to bring this information up to date. Accordingly, in the spring of 1958 a questionnaire was sent to existing marine laboratories in the United States asking for detailed information concerning their programs, financial support, staffs, facilities, and future capabilities. This report summarizes the responses received from 60 laboratories.

Each laboratory was asked to describe its present program and to estimate the percentage of the total laboratory program that was devoted to oceanography. Oceanography was defined as being "*** primarily concerned with describing and understanding the oceans: its surfaces, estuaries, shoreline, and dceps." The intended application of this knowledge to a particular practical problem, such as underwater acoustics or fisleries population studies need not, it was emphasized, rule out this definition of oceanography. The responses to this first question are not summarized here. However, the descriptive answers to this question were used to verify or modify the estimated percentage of each laboratory's progran which the directors estimated to be devoted to marine scienees. 


\section{FINANCIAL SUPPORT}

Each laboratory furnished information on the amounts and sources of financial support for the fiscal year 1958. The totals are summarized in table 2 . An attempt was made to classify the laboratories into logical groups according to their primary function and size. It is helpful to divide them into two size categories according to whether their budgets are greater or less than $\$ 300,000$. In almost all cases this criterion separated laboratories capable of operating in the deep ocean from those which specialize in investigations of inshore environments. They were also divided into university, Navy, State fishery, or Federal fishery laboratories. A few nonuniversity laboratories such as the Woods Hole Oceanographic Institution and the Bermuda Biological Station were included in the university classification because of essentially similar research functions. Three other laboratories which could not be put readily into any of these groups were not considered in the comparisons that follow.

TABLE 2.-Sources of financial support in various kinds of oceanographic laboratories

[Fiscal year 1958; monetary figures in thousands of dollars]

\begin{tabular}{|c|c|c|c|c|c|c|}
\hline & $\begin{array}{c}\text { Large } \\
\text { university }\end{array}$ & $\begin{array}{c}\text { Small } \\
\text { university }\end{array}$ & $\begin{array}{l}\text { Large } \\
\text { fishery }\end{array}$ & $\begin{array}{l}\text { Small } \\
\text { fishery }\end{array}$ & Navy & Total \\
\hline Number of laboratories.... & 6 & 19 & 6 & 24 & 5 & 60 \\
\hline $\begin{array}{l}\text { U.S. Government: } \\
\text { Bureau of Commercial Fish- } \\
\text { eries. } \\
\text { Office of Naval Research } \\
\text { National Science Foundation. } \\
\text { Atomic Energy Commission.- } \\
\text { Other. } \\
\text { State funds. }\end{array}$ & $\begin{array}{r}\$ 248 \\
3,598 \\
1,277 \\
196 \\
983 \\
581\end{array}$ & $\begin{array}{r}\$ 526 \\
379 \\
130 \\
149 \\
1 \\
567\end{array}$ & $\begin{array}{r}\$ 2,895 \\
35 \\
20 \\
\hdashline 36\end{array}$ & $\begin{array}{r}\$ 1,617 \\
9 \\
325 \\
213 \\
594\end{array}$ & $1 \$ 4,808$ & $\begin{array}{r}\$ 5,286 \\
4,012 \\
1,436 \\
670 \\
6,005 \\
1,778\end{array}$ \\
\hline 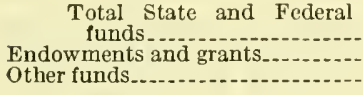 & $\begin{array}{l}6,883 \\
1,001 \\
2,281\end{array}$ & $\begin{array}{r}1,752 \\
360 \\
318\end{array}$ & $\begin{array}{r}2,986 \\
353\end{array}$ & $\begin{array}{r}2,758 \\
16 \\
110\end{array}$ & $\begin{array}{r}4,808 \\
\end{array}$ & $\begin{array}{r}19,187 \\
1,377 \\
3,062\end{array}$ \\
\hline Total.. & 10,165 & 2,430 & 3,339 & 2,884 & 4,808 & 23,626 \\
\hline
\end{tabular}

1 Does not include shlp operating costs. The oceanographic work at 3 Navy operated laboratories and 2 laboratories operated under contract by a single Navy agency is included in this category.

The contributions to marine research in industrial laboratories have not been included in this survey. Although their participation in geophysical exploration of offshore and Continental Shelf areas is large, the results of this work are not commonly made public. Some grants and contracts are given to marine laboratories by various industries. These funds are included.

Some additional comments may be made about the contributions from various sources of support. Only two laboratories reported that combined endowments and private grants provided more than half of their total support. Both of these were small, private laboratories. State funds were the sole source of support for four laboratories and the major support of seven others. Twentytwo laboratories received almost all of their support from the Bureau of Commercial Fisheries, and five were financed solely by Navy funds. Six laboratories reported that they received more funds from the Office of Naval Research than any other source. Federal and State funds totaled 70 percent of the university budgets. With minor exceptions, private universities were as dependent on Government funds as the State universities.

\section{PERSONNEL ENGAGED IN OCEANOGRAPHIC WORK}

Data on laboratory staffs are compiled in table 3. In addition to listing the various categories of staff members, the average cost of supporting the staff is tabulated in items 12 through 15. The questionnaire also requested information on visiting scientists computed on a man-year basis. These totaled $61 \mathrm{I} h$. D.'s, 41 with the master's degree or equivalent, 242 summer students, and 36 visitors in other categories. It was estimated that 35 percent of the scientific output of the visitors could be considered oceanographic, as contrasted with 89 percent of the work of permanent staffs. 
TABLE 3.-SUmmary of budget and personnel data from 5 groups of laboratories

[All monetary figures are listed as thousands of dollars per year]

\begin{tabular}{|c|c|c|c|c|c|c|}
\hline & $\begin{array}{c}\text { Large } \\
\text { university }\end{array}$ & $\begin{array}{c}\text { Small } \\
\text { university }\end{array}$ & $\begin{array}{l}\text { Large } \\
\text { fishery }\end{array}$ & $\begin{array}{l}\text { Small } \\
\text { fishery }\end{array}$ & Navy & Total \\
\hline 1. Number of laborato & & 19 & 6 & 24 & 5 & 60 \\
\hline 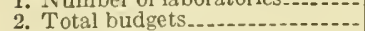 & $\$ 10,165$ & $\$ 2,430$ & $\$ 3,339$ & $\$ 2,884$ & $\$ 4,808$ & $\$ 23,626$ \\
\hline 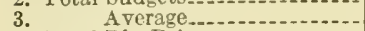 & $\$ 1,700$ & $\$ 128$ & $\$ 556$ & $\$ 120$ & $\$ 960$ & $\$ 394$ \\
\hline 4. Total Ph. D.'S & 219 & 79 & 35 & 49 & 47 & 429 \\
\hline 5. Average & 37 & & 6 & 2 & 9 & \\
\hline 6. Total masters plus Ph. D.'s. & 324 & 124 & 92 & 120 & 124 & 784 \\
\hline 7. Average & 55 & 7 & 15 & 5 & 25 & \\
\hline 8. Total seientific staff........... & 595 & 228 & 201 & 198 & 323 & 1,548 \\
\hline 9. Average & 100 & 12 & 34 & 8 & 65 & 26 \\
\hline 10. Total staff. & 1,250 & 285 & 298 & 314 & 517 & 2,664 \\
\hline 11. Average & 208 & 15 & 50 & 13 & 103 & 44 \\
\hline 12. Cost per Ph. D & $\$ 46$ & $\$ 32$ & $\$ 93$ & $\$ 60$ & $\$ 107$ & $\$ 56$ \\
\hline 13. Cost per Ph. D. plus master & $\$ 31$ & $\$ 18$ & $\$ 37$ & $\$ 24$ & $\$ 39$ & $\$ 30$ \\
\hline $\begin{array}{l}\text { 14. Cost per scientific staff mem- } \\
\text { ber }\end{array}$ & $\$ 17$ & $\$ 11$ & $\$ 16$ & $\$ 15$ & $\$ 15$ & $\$ 15$ \\
\hline 15. Cost per employee & $\$ 8$ & $\$ 8$ & $\$ 11$ & $\$ 9$ & $\$ 9$ & $\$ 9$ \\
\hline
\end{tabular}

A large share of the total number of oceanographers are working at the few large oceanographic institutions. If we consider how many of the largest laboratories one must count in order to account for over half of the personnel in each of several groups, we have:

Groups

Number of laboratories

Ph. D.'s

Master's degrees

Junior scientists and technicians

Support staff (secretarial, assistants, ship crews, etc.) --_---_-_------

Total all personnel

Each of the four larger institutions have extensive open ocean programs requiring ships and a strong support staff as well as a large number of Ph. D.'s. The smaller laboratories are relatively weak in numbers of support staff members.

\section{Financial problems}

\section{DISCUSSION}

Among the university-sponsored organizations, only the large ones have been able to maintain an extensive blue-water operation and large departments in specialized categories such as physical oceanography and geochemistry. In order to support their large ships and technical staffs, most of these laboratories have found it necessary from time to time to conduct relatively large applied research programs for the Government. In some cases such work has necessitated sacrificing more basic research projects In others, the stimulation provided by applied problems has been helpful. However, laboratories should not have to undertake large applied projects primarily as a means of solving financial problems.

The small university laboratories represent two somewhat different categories. Some are summer seaside laboratories with major emphasis on teaching and marine biological investigations. Others are sear around oceanographic operations in estuarine and coastal waters. There are some intergradations. On the average, only 38 percent of the support of the smaller university laboratories is obtained through Federal funds. They depend mainly on general university funds, derived either from private or State sources. They are less dependent on specific research grants than the larger organizations and hence have maintained a larger measure of financial stability. However, this has been accomplished only by severe limitation of the scope of their activities.

Each laboratory has its own particular problems, but some general patterns are discernible. The large laboratories with heavy Federal support need financial stability and predictability to rescue them from their present hand-to-mouth existence on short-term contracts. The insecurity of this existence is a constant worry to administration and staff alike; it interferes with long-range planning; and it sometimes results in taking on routine survey tasks that are not the proper work of a research organization and contribute little to the laboratory except as a financial stopgap. They desperately need ship replacements and additional 
shore facilities. They need the kind of general institutional support that will permit them to maintain their salary scale at the current market value and provide reasonable stability to their operations.

The small laboratories also need ship-and-shore facilities but generally not so desperately. Often their chief material need is for modern scientific equipment, and in this respect their work tends to be limited in scope because they cannot hope to acquire the large stock of expensive instruments that are more or less standard equipment in larger organizations. However, their most pressing need is for growth and diversification of their staffs. The small laboratories consist almost exclusirely of biologists and biological oceanographers. They hare learned a few techniques of physical and chemical oceanography to supply background for their biological studies, but specialists in these subjects are essential both for teaching and for solving the particularly difficult problems of coastal circulation and nutrient cycles.

We find ourselres looking at the two faces of the same coin. The small laboratory has to grow in order to solve its problems effectively, and having done so it finds a whole new set of problems waiting for it. Perhaps some laboratories have overexpanded, but it is clear that gradual expansion is necessary in order to meet the increasingly exacting requirements of modern oceanography.

\section{Government laboratories}

The federally operated laboratories, both Navy and fishery, also have serious financial problems. They have a more stable situation than the large university laboratories, but their budgets fluctuate unpredictably. It is commonly considered that their primary function is to be service organizations conducting routine survess and applied research. Some basic research is undertaken, but when budgets are curtailed the basic research is the first to suffer. This is one reason why Federal laboratories do not attract large numbers of highly trained scientists. Table 3 shows a disproportionately large ratio of total scientific staff to $\mathrm{Ph}$. D.'s in these laboratories as compared with the universities. It is not a healtlyy situation, and it probably cannot be corrected until legislators become aware that it is a good investment to maintain a stable, long-term program of basic research in Federal laboratories.

\section{Comparison of laboratories}

One way of comparing the problems and organization of various laboratories is to examine the cost of the operation per staff member, as shown in table 3. The size of the staff is a crude measurement of the research product, but it is a practical way of looking at the matter because the management has to think in terms of cost per unit of accomplishment.

In seaside laboratories of a seasonal nature which pay only the summer salaries of their staff, the cost per staff member is usually about two to five thousand dollars. It is seldom larger unless the laboratory supports a considerable number of visiting investigators who are not listed as staff members.

At the opposite extreme are the large, deep water operations that cost $\$ 50,000$, more or less, per senior staff member. This reflects both the high cost of operating large ships and the relatively large number of junior scientists and nonscientific staff members at these institutions.

The cost per scientist is distinctly lower in the small university laboratories than in any other group. In part this is due to the lower cost of coastwise operations, but it also is to some extent an indication of inadequate equipment and supporting staff. The number of technicians and nonscientific staff members is undoubtedly too low for an efficient use of trained scientists.

The small fishery laboratories have field programs more or less similar to those of the small universities, so that the financial problems of these two groups are somewhat comparable. The very high cost of $\$ 60,000$ per Ph.D. in the fishery laboratories simply reflects the very small number of people in this category. More reasonable figures for comparative purposes are the cost of $\$ 24,000$ per master or $\mathrm{Ph}$. D. and $\$ 15,000$ per scientific staff member. Each of these is $\$ 1,000$ more than the corresponding figures for university laboratories, and it is suspected that they are more realistic for this kind of operation.

\section{Total support}

While making this study, we tried to estimate that portion of the total budgets of the laboratories that is actually spent on oceanographic research. Our best estimate is that this is about 63 percent of the total. This figure contains subjective elements as indicated earlier. However, it should also be recognized 
that oceanography is directly or indirectly benefited by research in many institutions that are not included in the present tabulation. This includes work in basic disciplines and also in related interdisciplinary fields such as geophysics, geochemistry and meteorology. The contribution from such sources is probably about equal to the missing 27 percent in the subjective estimate mentioned above. The figures included in this report established the amount that oceanographic institutious spend on activities that they consider worth supporting, and this, after all, is the only practical way to look at the matter.

\section{Growth of oceanography}

Fiually, it is of considerable interest to determine the rate of growth of oceanography in the immediate past as an indication of what might be expected in the future. Information was obtained from Hiatt's "Directory of Hydrobiological Laboratories" which was compiled during the fiscal sear 1953 . As an additional check an abstract of the comparative information for 1953 and 1958 was sent to the directors of 28 of the laboratories for which data from both years were available. Each director was asked to confirm or change the data to represent as nearly as possible the real change over this 5-year period.

The laboratories in question listed a total expenditure of about $\$ 8$ million in 1953 and $\$ 14$ million in 1958 -an increase of 76 percent. The question immediately arises as to how much of this increase represents real growth and how much is simply inflation. Some data on the 1953-58 inflationary factor can be obtained by examining research proposals in the files of the Office of Naval Research. They indicate that the increase in salaries for various grades of staff members at various laboratories ranged from 20 to 80 percent during this time interval with the majority of percent increases for the largest number of staff members ranging between 30 and 40 percent. A similar review of ship operating costs showed an increase of between 40 and 50 percent. The study further rerealed that the funds spent by private research laboratories are devoted approximately one-third to ship operating costs; one-third to salaries; and onethird to equipment, travel, overhead, and other items. In the latter group, inflation has been slightly less extreme than in the first two. Nevertheless, the analysis suggests an inflationary factor of at least 30 percent and possibly more, and the real growth might therefore be of the order of 30 to 45 percent in 5 years. This is probably a slower rate of growth than that of the early postwar years when the formation of new laboratories (table 1) occurred more rapidly than in any other period before or since. The present rate of growth is more in keeping with the ability of the science to produce new oceanographers and to supply the ship and shore facilities that they require. An increase of 30 to 45 percent in 5 jears is equivalent to 70 to 110 percent in 10 years. The recominendation for doubling of oceanographic research in the next 10 years contained in the first chapter of this report therefore seems well within our capabilities and in line with a moderate acceleration of our present rate of growth.

Mr. Mrluer. Admiral Karo, we are very lappy to welcome you here. You come as an old friend. This committee is not new to you. We are very happy to see you.

\section{STATEMENT OF REAR ADM. H. ARNOLD KARO, DIRECTOR, COAST AND GEODETIC SURVEY, DEPARTMENT OF COMMERCE}

Admiral Karo. Chairman Bonner, Chairman Miller, and members of the committee, I am Rear Adm. H. Arnold Karo, Director of the Coast and Geodetic Survey of the Department of Commerce.

Incidentally, Secretary Allen, one of your old colleagues, asked me to present his compliments to the committeo and his best wishes for success.

Just as a matter of interest to some of you whom I have not met before, I am a native Nebraskan. I was graduated from the University of Nebraska in 1923 in civil engineering. I immediately entered into the service of the Coast Survey, which almost totals 36 year, and I have had 23 years at sea, so thait I feel I know a little of some of the problems facing us. 
Mr. Miller. You are really a Nebraskan, Admiral?

Admiral Karo. That is right.

Mr. Mulcer. We had a colleague on this committee some years ago who made those older member's Nebraska admirals, so we will welcome you.

Admiral Karo. I am an admiral in my own right.

Nebraska has never honored me that way, sir. Maybe it is because I do go to sea.

Mr. Mruler. I will guarantee you that our commissions which may not have the depth that yours has are much more beautiful than anything you have ever had.

Admiral Karo. Thank you, sir.

I have this prepared statement from which I would like to speak, $\operatorname{sir}$.

I greatly appreciate the invitation to appear before you today-to assist you in whatever way I can. For the subject of oceanography is one which has been studied and given deep and serious consideration by the Coast and Geodetic Survey for over a century and a cyuarter. Certain phases of oceanography form an integral part of hydrographic surveying. In the process of our hydrographic surveys and investigations we make many oceanographic observations and studies, some of which have ultimately led to significant discoveries and uses of far-reaching importance.

Strange as it may seem, lack of information concerning the oceans or the science dealing with the earth's water mantle, has been both a hindrance and a motivating force concerning man's relationship with the seas and his desire to conquer them. To the timid or weak man, the unknown facets of oceanography have appeared as barriers to progress or exploration, but to the strong and daring with a desire for knowledge these mysteries of the great water frontiers of the world not only appeared as a challenge to his progress, but also as another facet of nature that must be subdued in the course of exploration.

'The ocean is a vital part of any nation's economy. The term "oceanography," meaning the study of the oceans, is relatively new in our language. Basically oceanography is inseparable from hydrography, the science by which the secrets of the oceans are revealed. This great field of science may be divided into three branches-physical, geological, and biological oceanography. The branch of physical oceanography dealing with the physics of the oceans is that which is most pertinent to Coast and Geodetic Survey operations. This branch deals with tides, currents, and waves, the physical processes in operation, and the distribution of variables such as temperature and density of sea water. Geological oceanography deals with the geology of the continental shelves, structure of the ocean floor, and the deep ocean beyond the continental margins.

Benjamin Franklin might be considered the father of oceanography in the United States, or at least one of its first patrons, for his efforts in directing attention of the scientific world, about the middle of the 18 th century, to the existence of the Gulf Stream. The second Superintendent of the Coast Survey, Prof. Alexander Dallas Bache, a direct descendant of Franklin, inaugurated the first orderly investigation of the Gulf Stream, undertaken during the summer of 1846. American 
seamen navigating the historic clipper ships attained world superiority in Atlantic crossings by being the first to discern the existence of the wide river of the sea, which was used effectively on eastern voyages but was to be avoided on the return trips to American ports. Extensive observations of the Gulf Stream by Pillsbury in 1880 brought the discovery of a south-flowing countercurrent beneath the Gulf Stream in the vicinity of southern Florida and the Great Bahama Bank. This interesting oceanic phenomenon was recently "rediscovered."

Oceanographic activities of the Coast and Geodetic Survey were of immediate concern to the new agency of Government, Survey of the Coast, established by President Jefferson more than 150 years ago. Systematic oceanography in the United States originated with the first surveys by the Coast Survey in 1934-35. 'The necessity of making oceanographic studies was an initial requirement if we were to learn the secrets of the restless ocean and the forces affecting its movements. Over the years untold benefits have accrued to industry, science, engineering, and requirements of national defense through the great progress achieved in this branch of the physical sciences.

The Coast and Geodetic Survey is a recognized world leader in physical oceanographic work. Experience and background gained over 15 decades of sustained effort, together with the establishment of sound organizational concepts, carefully trained personnel, and scientific understanding, qualify the Bureau to perform oceanographic work in a highly efficient manner.

Intensive studies of our continental shelves through greatly accelerated hydrographic surveying operations and supporting oceanographic research are essential before effective exploitation of undiscovered natural resources can be undertaken in the great underwater frontiers of the Nation. This vast underwater domain presents a great challenge to the modern hydrographer equipped with all the new techniques of this modern technological age. The military posture of the Nation is as much affected in this modern age by the more than 70 percent of the earth's surface covered by water as by the outer atmosphere now dramatized by visions of space travel. Now data must be collected on the nature and composition of the sea, of the sea bottoms, undersea mountains, and complicated ocean currents for the effective use of the globe-ranging atomic powered submarine, and for defense against enemy submarines.

I have a little different idea that I wanted to insert at this point.

Current oceanographic activities include continuing surveys of ocean waters of the Gulf of Alaska in which sounding lines are run en route to and from summer survey areas in western Alaska and Aleutian Islands. The sounding lines are interrupted to make limited surveys of major features. The gulf floor is dotted with immense seamounts which have been discovered over a period of many years. They are grouped or alined over extensive distances. Large numbers are detached volcanic cones, while others are peaks on extensive ridges. Many of the seamounts rise 2 miles above the ocean bottom. Discovery of these seamounts and other extensive features in the Gulf of Alaska has created considerable scientific interest in this area. Much more survey work is required to obtain a more complete knowledge of the submarine topography in this region. The opera- 
tional use of nuclear powered deep-running submarines, i.e., the Polaris type, and the development of countermeasures against these, including detection, identification, tracking, and attack, will inevitably require a far greater knowledge of the location and definition of these seamounts. It has been most fortuitous that the Coast and Geodetic Survey has been able to cover the ocean waters of the Gulf of Alaska and to delineate so well the underlying sea floor. However, other and perhaps more strategic ocean areas should be surveyed with the same degree of thoroughness and accuracy.

Last season, at the request of the Atomic Energy Commission, oceanographic observations were made by the Coast and Geodetic Survey in an offshore area designated for the disposal of low-level packaged radioactive wastes. Other areas for this purpose have been designated and a proposal has been made to the Bureau to participate in a program for monitoring these additional areas. Under this proposal the Survey will send ships out to the areas to obtain such data as sediment, water, and biological sampling, plus measurements of currents at various depths. As a special investigation in one area, it is proposed that Coast and Geodetic Survey divers will be utilized to observe and photograph the effects on dummy packages so that they hit the bottom in a series of field experiments.

Basic to any oceanographic study or research project is the gathering of the physical data necessary for the projected study. Many types of studies are of necessity repetitious in nature. This means that the ability to collect data at identical locations at different times, this is all-important.

In both the collection of data and the ability to collect these data at the same location, time after time, the Coast and Geodetic Survey is without question the leading agency, either private or governmental. The nature of our operations and responsibilities have made this necessary, with output limited only by available personnel and equipment. The ability to take repeat observations at the same location in the ocean, time after time, is of paramount importance in the monitoring of the atomic waste disposal areas.

The Bureau has pioneed in the development of equipment and techniques for making oceanographic observations, including depth measurements, water samples, bottom samples, and the development of special equipment for making these observations. Knowledge of the nature of the magnetic field over oceans is pertinent to modern oceanographic research. The Coast and Geodetic Survey has collaborated with the Navy in the development of an induction magnetometer for airborne use over the oceans and for use in magnetic submarine detection work.

Methods of determining water depths have been under constant change since the early years when soundings were made with the hand lead. Soundings that formerly required as much as 4 hours in depths of 2,000 fathoms are now made by electronic echo-sounding equipment that makes the same sounding in a few seconds. The early equipment, using audio and visual techniques, has been replaced by automatic recording devices which provide a continuous profile of the ocean floor showing ridges and depressions on a permanent visual graph.

Precision navigation systems and methods have been progressively developed in step with new and improved methods of depth recording. 
Precision navigation, to be of surveying accuracy, requires a continuous accurate knowledge of the vessel's position at all times while at sea. It is this type of navigation which is employed by the Coast and Geodetic Survey for its hydrographic and oceanographic activities.

Radio acoustic ranging (RAR) was developed in the 1920's for accurately determining the position of the survey ship when out of sight of land, day or night, in clear or foggy weather. Position of the ship is determined by measuring the time for an explosive underwater sound to travel from the survey ship to underwater hydrophones placed at known locations.

Since it was essential to have an accurate knowledge of the velocity of propagation of the sound through the sea water, the survey ressel took many samples of the water and measured the physical properties to establish the sound velocity. These data have proven extremely valuable to other oceanographic bureaus and to the Navy in the antisubmarine warfare.

Several important instrument developments came through the Bureau's use of RAR, the most prominent being a sono radio buoy. This is a portable station which eliminates the use of an expensive vessel or ground station installation. The Navy patterned their sono radio buoy after this design and made use of it for antisubmarine warfare.

Another important development was the discovery by Comdr. O. W. Swainson and Dr. Carl Dyk of the phenomenon of long distance sound transmission at deeper depths. Discovered in 1934 in the course of oceanographic investigations concerned primarily with the transmission of sound in sea water, this phenomenon was to have important future application in the development of SOFAR, a longrange signaling method over great distances at sea and used primarily for location of ships in distress.

RAR gave way to electronic positioning adapting World War II developments such as shoran to our use in hydrographic positioning. Due to shoran's approximate line of sight limitation, the Bureau developed its own electronic position indicator, which we call EPI, in order to carry accurate positioning to greater distances offshore, up to 500 miles and more. The Bureau is also using a commercially developed navigational system and makes use of loran.

In the field of tidal hydraulics notable achievements were made in investigating forces and factors involved in the tidal regime. Early discoveries and inventions form the basis of present day investigations in coastal geomorphology.

Sigsbee, in his explorations almost 100 years ago, added materially to our oceanographic knowledge, at the same time inventing and developing many of the instruments and techniques for gathering and measuring oceanographic data. The improved Sigsbee sounding machine added immeasurably to oceanographic investigations. Another Sigsbee invention was a clam-bucket-type bottom simpler. The bottom sampler is a device to obtain information on bottom materials so that the bottom characteristics may be shown on the nautical chart. Sigshee also developed a multiple container that provided for simultaneous water temperature and water samples, with an automatic registering device. 
For more intensive study of the bottom sediments, coring devices are used. Studies of core samples disclose a wealth of important scientific data from the 72 percent of the surface of the earth which is covered with water and which, until recently, has remained hidden from the investigator. The additional fact that the approximate limits of the ocean basins are believed to be unchanged since early geologic times also makes studies of these areas of scientific importance. The sedimentary layers have been deposited in historic sequence. In the middle of the ocean basins they remain undisturbed and have been deposited very slowly, so that a vertical core a few feet long represents a very long period of time.

'The geologist obtains important information from the character and thickness of the successive layers. From core samples an idea may be obtained of variations in the depth of the ocean in the past and also changes in climatic conditions from a study of the fossils of microscopic animals or foraminifera.

Many minute particles of magnetic materials that have settled to the bottom are found in bottom core samples, oriented along the line of magnetic force. A study of these minute particles, with delicate electric apparatus, to determine the shift in orientation through the length of the core, reveals the cyclic change of the lines of magnetic force throughout the period of time represented by the deposits in the core.

Every continent rests on a so-called submarine base which extends seaward at varying distances from shore. To this submerged extension of the visible continent has been given the name Continental Shelf. More specifically, it may be defined as the submerged margin of a continent, which slopes to seaward to a point where a substantial break in grade occurs. Or if we approach the matter from seaward rather than from landward it would be the first well-defined rise from the ocean floor, which in the majority of instances would be in the nature of the 1,000-fathom curve.

The Continental Shelf is not everywhere of uniform width. In the United States it varies from a few miles off parts of California to over 200 miles off Cape Cod. In parts of the Gulf of Mexico it has a width of over 200 miles.

The Continental Shelf comprises an area of more than 300,000 square miles in continental United States and 550,000 square miles in Alaska.

In recent years, the Continental Shelf has assumed increasing importance with the discovery of oil and gas. A littoral nation's right to explore and exploit the natural resources of the subsoil and seabed of the Continental Shelf and beyond to its limit of competence has been given international approval at the recent United Nation's Conference on the Law of the Sea.

The Coast and Geodetic Survey has been working in the area of the Shelf for many years in furtherance of its statutory responsibility of providing nautical charts and related information for safe navigation. But many byproducts have resulted therefrom of interest both to the scientist and the engineer and the public generally. Detailed surveys of these areas have in the past opened up new fishing banks to commercial exploitation, and have furnished evidence of potential oil reserves in the offshore areas. Additional surveys (hydrographic and oceanographic) may open up new sources of food 
supply and bring to light promising areas of other natural resources.

'The role of the Coast and Geodetic Survey in the study of currents in the oceans and estuaries has traditionally been in the direction of navigational aid to augment the nautical chart. However, as this country turms to the oceans more and more as a source of food and minerals and as a dumping ground for radioactive wastes, a knowledge of circulation below the surface becomes mandatory. Similar studies in our various harbor estuaries are proposed or already underway because of the increased pollution associated with our industrial and population growths. 'The Coast and Geodetic Survey has done far more than any other agency in this field, but our data are totally inadequate for today's requirements and even more so in the light of the presently known future requirements. Last summer experimental offshore current surveys were made on Georges Shoal in anticipation of our role in patrolling dumping areas of radioactive wastes.

The continuing development of atomic energy will progressively produce greater amounts of radioisotopes, and with them increased amounts of radioactive waste material. Rapidly developing private use of radioactive materials demands adequate control of radioactive waste discharge from nuclear reactors, uranium mills, research laboratories, and the like. Since the oceans cover 72 percent of the earth and ultimately receive the drainage of the land, they are the ultimate reservoir where most of radioactive waste will finally accumulate. The only place on earth where the disposal of the wastes can be considered practical is in the oceans. However, the dispersal of radioisotopes in the ocean must proceed very carefully with additional investigations in areas where knowledge is now limited.

Great potential danger is present in the indiscriminate introduction of wastes into coastal waters, especially in the upper layers. This is the habitat of most of the important commercial fish. The major fishery resources of the world are concentrated near the coasts and could be contaminated. Coast waters enter harbors and bays and could carry waste material with them.

This Bureau has recently initiated a survey project in the New York Harbor for the Atomic Energy Commission and the Maritime Administration. The program in New York is being carried out by the survey ship Marmer, the first survey ship to be assigned full time to current surveys. This project will provide data on the variations in the direction and velocity of surface and subsurface currents and also the temperature and salinity of the water in the harbor area. Data obtained during the survey are being used by the AEC and the Maritime Administration in joint activities pursuant to the development of nuclear power for merchant ships.

Direct measurements of deep currents are extremely meager. To date much of these data are obtained by indirect measurements based on precise measurements of temperature, salinity, and density. Last year, actual direct observations were made with current meters by the Bureau's oceanographers at the edge of the Continuental Shelf off the Massachusetts coast. This year in Alaskan waters further investigation will be made by following a number of underwater drogues set at predetermined depths to determine by direct measurements the velocity and direction of these deep ocean currents. 
Variations in the level of the sea attain increasing importance with the development of coastal areas. Data obtained by the Coast and Geodetic Survey at a number of key control tide stations distributed along oul coasts provide basic data covering more than half a century for the determination of short period as well as progressive changes in sea level. Our studies have disclosed that secular changes in sea level differ on our two coasts. On our Atlantic coast there has been a rise of the sea with respect to the land at a rate of about 1 foot per century. On the Pacific coast, however, the rate has been only half of that on the Atlantic. This summer we are making an investigation in southeast Alaska where the land as measured from sea level appear's to have risen as much as 5 feet in 60 years.

As the need for accurate tidal predictions has increased over the years we have increased the scope of oul predictions from a handful of stations in 1867 on the east and west coasts of the United States, to 4 volumes containing daily predictions for 5,000 places distributed over the world. The accuracy of predictions has also been increased by improved observations, greater density of station distribution, and improved instrumentation. The prediction process has been changed from the slow, laborious curve and equation method to fast automatic tabulation of tide predicting machine computations. Predictions of the ebbing and flooding of the tidal currents are also made by the same automatic equipment. Advance information on currents is not only essential for safeguarding navigation along our coasts. but is also invaluable in many oceanographic activities.

Following the disastrons seismic sea wave at Hilo in 1946, the necessity for protecting life and property in the Hawaiian Islands against such natural catastrophes was forcefully impressed on all. Under this impetus the seismic sea wave warning system was conceived and organized. The system basically requires the quick detection and location of submarine earthquakes which may or may not create such waves. Approximately 10 seismograph stations and 21 tide stations in the Pacific area provide the primary information for detecting and verifying the occurrence of an actual seismic sea wave. Data from all stations are promptly fed by communication facilities of the Department of Defense and the Federal Aviation Administration into the central headquarters of the system at the Honolulu Magnetic Observatory, which issues the necessary advisories and alerts.

The warning system is the response to the need of the people of Hawaii and of the Pacific military commands for such protection. While the public may be concerned about the system only when a destructive wave is imminent, it requires constant work and vigilance to keep such a far-flung and seldom used organization ready for instant action in time of need.

Subsequent to these successful alert actions, the Bureau computed travel time charts to Neah Bay, Crescent City, San Francisco, San Pedro breakwater, and La Jolla to facilitate estimates of seismic sea wave arrival times on the west coast.

Another phase of the overall oceanographic research program to be considered is the study of sedimentation, particularly as it relates to our coastal areas. Continual changes are occurring in the submerged lands of coastal areas. Areas of sedimentation and shoaling require resurveys for up-to-date charting. But in addition to proper 
charting of these marginal areas, there should be concurrent studies to determine causes and methods of correction. In many areas considerable funds are expended each year by the Government in dredging and maintaining navigation in the main shipping channels. Additional studies of these marginal lands as they relate to the total natural resource potential of the Nation should also be concurrently undertaken. A comprehensive oceanographic program should include the collection, compilation, and analysis of basic data on sedimentation in these coastal areas.

I have dealt almost exclusively with the more practical phases of oceanography; those visible phases which affect our everyday living. There are many other areas which must be considered in any comprehensive oceanographic program. Among these are such areas as heat and moisture exchanges between the oceans and the atmosphere, for such transfers affect our weather. Also to be considered are the heat transfers between the oceanic waters and the underlying earth mantle.

The deep sea current information, which has been mentioned before, is vital in the study of bulk water transfer, which in turn affects the supply of plankton or fish food. This in turn affects the commercial supply of fish. The interrelationship or correlation between meteorological phenomena and ocean currents is a matter for intensive study. I am sure you all remember the exceptionally warm waters along the California coast a year ago which in turn brought new species of fish in great abundance to our coastal waters. Oceanographers of the Coast and Geodetic Survey traced this phenomenon to a sustained change in offshore wind patterns for several months which in turn changed current patterns of long standing. The result was warmer water and a superabundance of fish.

The subject of oceanography is most interesting, and one which has many facets. This is only natural considering that it deals with the oceans, covering about three-fourths of the earth.

Mr. Muller. Admiral, I want to thank you for that statement. It is a very fine one. Time is rather running out on us. There are a lot of questions which we would like to ask.

We might induce you to come back again.

Do you feel that there is a need at this time for a study of the kind that this committee is undertaking to try to coordinate, correlato and investigate this field?

Admiral Karo. Well, as I mentioned in my prepared statement here, oceanography, of course, goes hand in hand with our own more prosaic work of charting, and we have always felt that we should make these oceanographic investigations not only for our own need but for the need of the public in general.

I might mention that last week, just a week ago today I believe, there was a meeting in the Pentagon of the various interested agencies and they have established a conmittee which will study the problem of correlation of eflort and to come up, I believe, with a coordinated program.

Mr. Minler. TVe hope to have members of that committee before us at the proper time.

We want to confine our initial efforts to those people with whom we are well acquainted and who know the work of this committee. 
Admiral Karo. Yes, sir.

Mr. Mrller. I have no further questions.

Do you have any questions, Mr. Pelly?

Mr. PELLY. I have no questions.

Mr. Miller. Mr. Curtin?

Mr. Certin. No, sir.

Mr. Minler. Mr. Chairman, excuse me. You are hidden over there. You should be here where I can see you.

The Crampiras. This is an interesting subject. I came here to hear about something that I know very little about.

Do I gather from your statement that if there were united in one agency a broad expansion of the subject before this subcommittee that it should be placed in the Coast and Geodetic Survey?

Admiral KAro. No, sir. I did not mean to leave that impression, Mr. Chairman. I merely meant in this statement to point out that it is a subject with which we have dealt ever since our existence, that we have competence in it and have realized the importance not only to the national economy but to the defense effort, and it is a subject which I think bears very close study and implementation if we are to get the most of it.

The Champuns. That was the reason I asked you that question. It appears that somewhere along the line there must be a correlation of the various agencies that participate in oceanography.

Admiral Karo. I feel that the interested agencies will come up with perhaps a coordinating committee to be sure that there is no duplication.

The Chamman. Who is going to head up the coordinating committee? Under whose jurisdiction would they be?

Admiral Karo. I would say that that would perhaps be up to the Congress to decide who would have the overall responsibility.

The Chamman. While I had the opportunity I wanted to ask you the question.

Admiral Karo. That is right. I mean the problem is so big. I certainly do not mean to leave the impression that I wanted to mastermind it at all.

The Chatrman. Who is better qualified then, from the background and history of your agency? What other agency is better qualified?

Admiral Karo. Modesty forbids my answering that.

Mr. Mrller. I was going to say this, Mr. Chairman.

Is this not correct, Admiral: You pointed out that there were three basic phases?

Admiral Karo. That is right.

Mr. Mrtuer. You are dealing with physical oceanography and that is the one in which you claim proficiency. If we wanted to go into the biological phase of it, I think you would be the first to say that your agency has no interest or competency?

Admiral Karo. In other words, I do not advocate anything like that because it would mean that to really have competency in it you would have to build duplicate facilities.

I think there are enough private and Government facilities available so that we can get on with the job if it is properly coordinated.

Mr. Miruer. There is no question that you can coordinate the physical oceanography along with biological oceanography without coming in conflict with the work of the Fish and Wildlife Service? 
Admiral Karo. That is correct. I must in all fairness mention the Hydrographic Office of the Navy. Our main work has been concentrated along the U.S. coastal waters and territories and possessions, whereas the Navy, by its responsibility, has taken off where we left and gone into the foreign areas.

Mr. Miller. So that, in our own governmental setup there is no conflict?

Admiral Karo. That is correct.

Mr. Miller. But we do want to coordinate these and dovetril them so that the data collected by you, the data collected by the Hydrographic Office, the data collected by the Fish and Wildlife Service, the data in which the Maritime Administration may be interested, can all be used to supplement one another and to build the complete structure or to help solve this very intricate problem that presents itself hidden by the surface of the sea.

Admiral Karo. That is correct, sir.

I might add that our relationship with the Hydrographic Ofice has been one of very close coordination.

In fact, a few years back we undertook along the coastal waters of the east coast of the United States a detailed oceanographic investigation program for them which was of a classified nature. We also have one of our ships now which has been operating under contract with the Nary on the west coast of the United States and the Southwest Pacific in another classified project so that there has been no duplication between our efforts and those of the Hydrographic Office. We get together and decide which is the best method of approach.

Mr. Miluer. You are in the process of getting a new ship now, are you not?

Admiral Karo. We have one being built in San Diego; yes, sir.

Mr. Miller. I know you have read this report of this committee.

Admiral Karo. Yes.

Mr. Mruler. Do you subscribe to the thesis that we need more people skilled in the sciences, grouping them all?

Admiral Kino. I would say that that is right along with our general emphasis on all things scientific in our education, and in our endeavors today that the technology has advanced to the point where we must have more and better skilled people.

The number required would depend upon the amount of implementation if any that Congress, after its complete study, determines should be made, but I think we all know that when we try to recruit people in these certain fields, oceanography, mathematies, geodesy, that there are just not enough to go around.

We are continually being called upon to furnish people that we have trained, part of our own organization, for specific jobs in other Government services on loan or they hire them away from us.

Mr. Miller. I know that this is a question that perhaps you can answer becanse of your close association in this field at the time of the war. In the event of an emergency, would there not be a demand for these people that we could not fill right now?

Admiral Karo. Well, I think before we get into an emergeney we ought to have a lot of this material at hand and digested because that is one of the things that we hope will come out of this oceanographic study, particularly in the research angle. One is how are we going to look through the water and see the enemy as it approaches? 
I think that has been brought out by a special committee of the other Congress that put out a report on undersea warfare last year.

It is a problem that has a very great value to the economy of the country in the development of marine resources and also in its defense posture.

Mr. Mrluer. I may say that the Commission on Fish and Game of the State of California has made some studies on atomic waste, the disposals that have disturbed them, and are still disturbing them.

Are you familiar with some of those?

Admiral Karo. I know in general the problem as to the pollution of our streams and if we put it out to sea we have to be sure that we put it where it will not come back in and adversely affect our seaside economy.

Mr. Mrluer. I am told that in some of the early packing of this material surrounded by concrete that was supposed to carry it to great depths that in cases it has been known that these would burst before they got to these depths and could release isotopes into these fishing waters. That is possible, is it not?

Admiral Kano. That is correct. We are discussing a program with the Atomic Energy Commission as to shore depths where we can get our divers down to, say, 100 feet, to get photographs of these packages to see what happens and to see whether the drift of the sand will cover them up or whether they migrate. It is most important that we come back year after year to check on that phase and to see whether there has been any radioactive leakage. Thatentails the ability to get in the same spot. That has been our business to know where we are at at sea. You have to know precisely if you are going to check these atomic waste disposal areas.

Mr. OuIver. Mr. Chairman, I hesitate to prolong this but I have a brief question which I would like to ask the Admiral, if I could, please.

Mr. Muler. Go ahead.

Mr. Oliver. The question is this: It occurs to me that you suggested that there has been some calling together of a centralized group representing the various agencies of Government interested in this subject.

Admiral Karo. Yes, sir.

Mr. OLIVER. That has been rather recent, has it?

Admiral Karo. Yes, sir. A week ago today Admiral Bennett, head of the research in the Navy, had a group together of those who had an interets in oceanography, and we discussed the report, and then a smaller working group was appointed to go into the problem in a more specific manner.

Mr. Oliver. Does this take in all of the agencies of Government interested in the subject?

Admiral Karo. Mentioned in the report, yes.

Mr. Oliver. From all angles?

Admiral Karo. As far as I know; yes, sir.

Mr. Otrver. That particular group has no authority to move ahead as far as expansion is concerned?

Admiral Karo. No, absolutely not. No one has any authority to move.

Mr. Mrleer. 'This is just a discussion group? 
Admiral KARo. 'That is right, to try and correlate any plamning.

Mr. Miluer. Counsel?

Mr. Drewry. Admiral, I have just one question to follow up on something you said earlier. You mentioned that you are engaged in the physical oceanography, that there are other groups in the biological and geological, and that you have worked very closely with the Hydrographic Office.

As I mderstand it, each branch of this science goes hand in hand with others?

Admiral Karo. There is a gray area there. One spills over into the other.

Mr. Drewry. You are a Government agency. How have you been working on the problem of getting the maximum use out of facilities, for instance, by coordinating with other agencies with your coast survey work? The Hydrographic Office has its problems in the deep oceans. Woods Hole is looking at commercial fisheries.

Is there an interchange of persomnel or when you go on a survey mission are there provisions either through informal or statutory arrangement for one or more scientists from another group to go with you?

Admiral Karo. Normally there has not been; no, sir. In the matter of gathering the bottom specimens and water specimens and so forth, we have many times on a specific project bottled those up and sent them to Scripps Institute for analysis there.

A few years back, we were working on agreement with the Bureau of Fisheries and then it was dropped and I understand later that they made some sort of a contract with, I believe, the Department of Oceanography and Fisheries of the University of Washington in Seattle for work.

But I feel that with this emphasis that is being put on oceanography and all things connected with it, that a coordinating committee will obtain fuller use of the facilities that each of us has so that they can really get more out of our efforts. Because the cost of any of these operations is in getting to the spot, the cost of your ships, and overhead, I feel that we should use the equipment when it is there to the maximum.

Mr. Drewry. That was one of the main features about the hearings we had last year involving the atomic icebreaker which was to be a Coast Guard facility and not only for breaking ice and not only for military preparedness work with the Navy but much emphasis was placed on the availability of that type of facility for scientific work which would, of course, bring people in from other agencies.

'There was no difficulty discussed but on the other hand it was not too clear just what kind of arrangements might have to be made by new legislation or otherwise to provide for that coordination.

Admiral Karo. I do not believe that legislation would be needed for coordination. In fact, I remember back in about 1949 or 1950 on one of the ice breakers up in the Aretic that they put some of our technicians aboard to help them position it out there and to get some of the information they were after, and that we have a servieing agreement with the Navy on servicing EPI equipment that they use on some of their special projects so that, the matter of coordination, 
I think, is just the will to coordinate and I believe that, with the emphasis that has been placed on oceanographic information, everybody will cooperate much more closely because they realize the necessity of it. The field is so big and there is so much to be accomplished that it would be foolish not to do all that we can by cooperating with each other.

The Chamman. Will you yield, please?

Mr. Drewry. Certainly.

The Chamman. Much stress has been given by the previous witness of additional ships for scientific study.

You were authorized two new ships, were you not?

Admiral Karo. Yes, sir.

The Champran. And you say you are only building one?

Admiral Karo. Yes, sir.

The Chamran. What is the matter with the other ship?

Admiral Karo. Well-

The Champran. All this stress is being put on the need for additional ships to make this study by this group which has just made this interesting report on the need of oceanography, and then we have the retirement of a ship, and this question can be fairly asked: Evidently there was not sufficient effort by the administration in the Bureau of the Budget to grant you the money for the two ships?

Admiral Karo. Well, of course, that ship was anthorized and the construction on the one started about 2 years ago.

Of course, this report and the emphasis on oceanography was not made apparent until just recently, long after the present budget cycle and the bills were formulated that are before Congress now.

The Chatrman. Do you have a request in the deficiency appropriation or in the new budget?

Admiral Karo. That would depend, as a result of what this study comes out with, as to what the administration policy would be.

The Chatrman. Do you have a request in for the new funds?

Admiral Karo. This year; no, sir.

The Chammax. Then this committee has done its part in trying to furnish the proper number of ships, to increase the number of ships that are needed and authorized?

Admiral Karo. Well, I say that authorization came before this emphasis came along. We are working on a new program.

The Chamraran. The committee was then a little ahead of the light that has been thrown on this subject now?

Admiral Karo. That is correct, sir.

The Chatratan. That is all.

Mr. Milcer. We thank you very much, Admiral.

I hope that this is not the last time we see you here.

As things develop we may want to see you again.

Admiral Karo. It will be a pleasure to be here, sir.

Mr. Muller. Perhaps at a later date you might come back.

Do you have this equipment in Washington that we conld see? Maybe some of the members of the committee would like to visit some of the installations. 
Admiral Karo. We would be happy to have you come and see the office and how we make the charts.

The equipment itself is not in Washington.

Mr. MrLeEr. Thank you very much.

Admiral Karo. Thank you, Mr. Chairman.

Mr. Mrluer. The subcommittee will now adjourn.

(Whereupon, at 12:15 p.m., the subcommittee adjourned, subject to the call of the Chair.) 


\title{
OCEANOGRAPHY IN THE UNITED STATES
}

\author{
TUESDAY, MARCH 10, 1959
}

Hotse of Representatives, Spechal Sebcomittee of Oceanography, of the Committee on Mercerant Marine and Fisheries,

Washington, D.C.

The subcommittee met, at 10 a.m., pursuant to adjournment, in room 219, Old House Office Building, Hon. George P. Miller (chairman of the subcommittee) presiding.

Present: Representatives Bonner (chairman), Miller, Dingell, Lennon, Flynn, and Pelly.

Staff members present: John M. Drewry, chief counsel, and William B. Winfield, clerk.

Mr. Miller. The committee will be in order.

This morning we are privileged to hear from the Coast Guard and the Maritime Administration. We had also programed the Navy for this morning but our scherlule became filled and we have decided to postpone hearing them until next week.

I also understand that we have Dr. Schaefer with us, who is a member of the Committee on Oceanography.

Doctor, I hope that before we get through, although it is rather short notice, that we will be able to talk to you and hear a bit from you.

The first witness will be Vice Adm. A. C. Richmond, the Commandant of the Coast Guard.

We are very happy to have you here, Admiral, because we know the very extensive work that has been done in some phases of oceanography by the Coast Guard. Our hope is that we will be able to expand some of the activities in which you are now engaged.

\section{STATEMENT OF VICE ADM. A. C. RICHMOND, THE COMMANDANT,}

U.S. COAST GUARD, ACCOMPANIED BY REAR ADM. JAMES A. HIRSHFIELD, ASSISTANT COMMANDANT, U.S. COAST GUARD

Admiral Richmond. Mr. Chairman, at first I would like to apologize for the fact that I do not have copies of my statement which was just recently prepared. I would like to read it into the record.

I would also like to mention that I brought with me the Assistant Commandant, Admiral Hirshfield, who is here in case there are questions.

Mr. Miller. I am very happy to see Admiral Hirshfield. The last time I saw him was under different circumstances on Oahu last September.

Admiral Richmond. Mr. Chairman, in appearing here this morning, I should like to emphasize to the committee that in testifying on 
the subject matter which is the prime concern of this special subcommittee, the Coast Guard has not had the opportunity to devote any great amount of study or thought to the requirements of the Coast Guard in this field, or to the place that the Coast Guard might take in the development of the subject matter. Therefore, anything that I may say is, I confess, a very superficial review of what is admittedly a very broad field, and that a more detailed study by the Coast Guard might develop areas of research in the field of oceanography that would be of particular value to the Coast Guard in the discharge of its duties.

At the outset, I am sure this committee recognizes that the Coast Guard is a service organization discharging specific statutory duties laid down by Congress after careful review of those duties by the Merchant Marine and Fisheries Committee. Therefore, in the past it has been customary and mandatory to limit research in any field to those areas that could specifically lead to the more efficient and economic discharge of the specific statutory duties imposed by Congress. Even in using the word "research" I am using language loosely because, in fact, the Coast Guard, through its limited size, has been precluded from engaging in pure research. Personnel and budgetary limitations geared to day-to-day operational efficiency have been an effective bar to such endeavor. We have, in recent years, developed in our corps a small group of personnel engaged in activities allied to research work, but in order to make the distinction between pure research and the work carried on by this personnel, we have referred to onr activities in this field as testing and development rather than research. This may appear to be a very fine distinction in semantics, bu the concept has been that basic research must be left to others and we merely take the results of their efforts and through testing, develop these items for our own better use, always keeping in mind that those things tested must generally be an extension of our statutory duties.

Oddly enough, the only field in which we have probably approached true research is in.the area of oceanography, the matter of principal concern to this committee. This has come about, I would say, largely because of our being charged with the duty of maintaining the international ice patrol. We recognized over 30 years ago that the proper and efficient discharge of this responsibility required more knowledge on the part of the officer in charge of the ice patrol than the mere locating and counting of the icebergs in a given area during the ice seasons. We therefore undertook to train a limited number of our officers in oceanography, and this practice has been continued to date. We also maintain on our rolls a civilian oceanographer, and have had his services available for a number of years.

As part of the program of conducting the ice patrol, we have through the years, particularly since the war, authorized a number of postseason, and occasionally preseason, cruises to make studies of the Labrador currents as well as the areas around Greenland where the bergs that constitute a menace in the shipping lanes are generally calved. 'The result of these cruises, as well as the report on the conduct of the ice patrol, is a matter of public record which has for years contributed to the general knowledge in the field of oceanography.

The small staff that correlates and prepares this information, following the actual gathering of it, is located at the Woods Hole In- 
stitute, so there is a very fine correlation between what we are doing in this field and the general work of the Woods Hole Institute. It may also be a matter of interest to this committee to know that the first officer trained by the Coast Guard as an oceanographer was, after retirement, the director of the Woods Hole Institute for 5 years.

In addition to the above, during the years following the war a number of our officers have become quite interested in, and in many instances on their own made a considerable study of wave motions primarily for the purpose of analyzing the effect of wind and sea, and arriving at the most desirable heading to land an airplane in the unhappy circumstances where it is necessary to ditch a plane at sea. In this particular field, I would suppose that these officers might well have wished for a more exhaustive means of pursuing their studies, even to the point of actually researching this activity. Due, fortunately, to the rather infrequent number of times when the problem of ditching an airplane, commercial or otherwise, arises, and the fact that in these cases the circumstances may dictate arbitrary considerations on the pilot in choosing his ditching heading apart from the wave motion, the Coast Guard to date has not seen the wisdom, nor could it afford to conduct a full-scale research study into this problem, even though, as I say, it has been a matter of considerable individual study by a number of officers of the service engaged in search and rescue. I mention this phase as one that, as the committee contimues its study, it may want to pursue further.

One other area in which the study of oceanography might offer direct benefits to the Coast Guard in the application of its statutory duties arises, it appears to me, in the matter of oil pollution of our coastal waters. As the committee is aware, for a number of years many of our coastal areas have been plagued by deposits of oil on their beaches. Such deposits are not only harmful to the fish, shellfish, and bird life, but can be exceedingly annoying to the many bather's along our shores. The beaches along the Florida coasts are a particular example of this. The source of this oil can usually not be traced directly to its source, though the general consensus of opinion is that it stems from the pumping of bilges, particularly of tankers, at sea. In fairness, I should say first, so long as the vessel is outside of the territorial waters of the United States, there is no offense against the laws of the United States, and secondly, that the companies engaged in transporting oil have fully cooperated in attempting to minimize this problem by issuing stringent orders against the practice of discharging bilges in areas where the sludge deposits would in all probability be thrown up on the beach.

In addition, the oil companies have even employed a special investigator to patrol certain beaches with the idea of tracing the source of oil, insofar as practicable, and attempting to find a solution to the situation. It is possible that if the law were broadened to make it an offense to discharge bilges in an area where the normal trend of ocean currents would be likely to deposit the sludge on the beaches, and the prosecution provisions eased to permit the assessment of a penalty or prosecution without the necessity of actually witnessing the discharge of oily bilge water or ballast, as is presently the case for effective prosecution, research in this area could be well justified. However, it seems to me it would be fruitless to spend funds in re- 
searching the current and wind effect on the drift of sludge oil unless the enforcing agency could do something effective to prevent the discharge of the oil even though the point of discharge was outside the limits of the territorial water's of the United States.

Before closing, I think I should mention the recent report of the Committee on Oceanography of the National Academy of SciencesNational Research Council, of which I am sure this committee is quite conversant. It is, as you are aware, a most comprehensive report, and certainly anyone who is interested in the sea and maritime matters could not do less than applaud the objectives set out therein. I would like to emphasize, however, that even the National Academy recognized that such research as it set as the objective should be allied to the agencies named in the report through the statutory responsibilities of those agencies.

For example, under "General Recommendations," they stated, in paragraph 3, that-

The United States should expand considerably its support of the allied marine sciences, particularly in the areas of military defense, marine resources, and marine radioactivity.

They go on from that point and find that the $\mathrm{Navy}$, in the interest of national defense, should bear a considerable portion of the overall costs, and I quote their language from paragraph 4 :

The Navy should sponsor completely all military research and development operations.

They recognize, further, that in the matter of deep ocean surveys the Coast and Geodetic Survey, which has a statutory responsibility in this area, should contribute its share. They go further and say that the Bureau of Commercial Fisheries should finance the greater part of the recommended ocean resources program. They find that the Atomic Energy Commission should finance the major part of the program dealing with the problems of radioactive contaminations of the ocean.

I mention this to emphasize what I said at the earlier part of my statement-that any research that the Coast Guard should recommend must be properly contributive to the discharge of our statutory duties.

With respect to the study conducted by the National Academy of Sciences, the Coast Guard did not know that this study was going on, nor were we consulted as to this particular report. 'Therefore, for the Coast Guard to come before you now and suggest areas of responsibility for research not already covered by this very exhaustive report is almost presumptuous. This is not complacency on our part, but I think that we must accept that the report of the Committee is exhaustive, very carefully thought out, and, as I have indicated, tied to the specific statutory requirements of certain agencies of the Government. I would presume that the Committee was definitely a ware of the Coast Guard's activities, and, rightly or wrongly, discounted any contribution that we might make. Certainly, insofar as the report is concerned, we are only incorporated by indirection.

In paragraph 4 I find this statement:

Other agencies should take responsibilities for certain aspects of the proposed program, particularly the Public Health Service, the Geological Survey, and the liureau of Mines. 
On the assumption that we come under the heading of "Other Agencies," I can assure this committee that we are prepared to take responsibility for such parts of the program that might well belong to us under our present statutory responsibilities or in such other areas that the Congress might decide properly fall within our jurisdiction.

The only specific reference to the Coast Guard in the report is in paragraph 9 under "New ships for research, development, and surveying," where it states that-

Research ships operated by private institutions like those operated by the Nary, Coast Guard, and the Coast and Geodetic Survey should be exempt from those existing legal requirements for living accommodations, safety, and the liceusing of crews, which are practical and sensible only on large merchant ships.

Aside from the inclusion of the Coast Guard at this point, only as an example, I might suggest that as the work of this committee progresses, you may, as members of the Merchant Marine and Fisheries Committee, care to consider this recommendation very seriously with the idea of modifying certain sections of title 46, United States Code, to implement this recommendation. Without prejudgirg the question unless some such exemption is incorporated in law, the chances are that vessels operated by private institutions could well be in difficulty with the statutory requirements as implemented by the Coast Guard.

In closing, I would like to say that the Coast Guard stands ready under statutory authority authorizing cooperation with other agencies to do anything practicable to further any research program adopted either on the basis of the Academy of Sciences Committee report, or on the work of this subcommittee. Such cooperation could, as indicated, be extended by carrying out assigned tasks in our own behalf or as in the case of the ocean stations providing a medium of transportation and a platform for scientific personnel to perform their observations, as we currently do for Weather Bureau personnel on the stations just mentioned.

Thank you very much, Mr. Chairman, for the opportunity to present these statements.

Mr. Miller. Thank you very much, Admiral. I want to thank you for a very fine report on this subject. I know that the Coast Guard is ready.

May I say that many of us found this report of the Academy of Sciences a ver'y challenging thing.

Now, we realize that presently there are certain statutory limitations as to what the Coast Guard, what the Maritime Administration, what all of those agencies that come under the jurisdiction of this committee can do with respect to this work. On the other hand, our objective in calling representatives of all of the agencies before us is to find out what your work is, what you have done, what the potentionals of the organization are, and then I believe it is going to be put to us to determine whether or not we should recommend legislation that would implement the carrying out of some of the objectives or perhaps other objectives that may develop during the course of the hearings. I think it speaks well that you, in your remarks, very definitely point up where the Coast Guard, although unofficially, has met a challenge because this challenge was something new since the law creating this old and honorable agency was written into the statute books and last amended. 
You speak of the unofficial study made by members of the officers of the Coast Guard recognizing a very vital problem of determining the wave action as a part of sea rescue work. This is a very fine thing that perhaps this committee should get into and say, "Has enough been done in this field? Should we do more in this field?"

I think the very fact that one of your officers, after leaving your service, could head up such an institution as Woods Hole indicates the great potential capability of the Coast Guard to do a great deal of work in this field.

Where we are going to divide the work, where we are going to define what must be done, where we are going to get the money to do it are some of the things that the subcommittee must seek to answer.

The work of the Ice Patrol is of great importance. If we get an atomic icebreaker, as we hope to do, surely it would play a great part in the studies in the future.

Do you think so?

Admiral RichmoNo. I would say such an icebreaker very definitely would. There is no question that it would particularly in the aretic region, which is all a part of the overall subject of oceanography.

Mr. MnLer. I do not know a thing about currents but it just seems to me as a layman that a thorough knowledge of the oceans in the Arctic and Antarctic must be very pertinent to that subject, are they not?

Admiral Richyond. I think the chairman will remember that last year when we had the hearings on the atomic icebreaker bill that one of the witnesses appearing before this committee was a retired officer of the Coast Guard, Admiral Thomas who has, largely on his own, contributed quite a great deal to, you might say, the study of arctic conditions. He was in command of our icebreakers and, because he had a particular penchant for that type of research, he did it on his own as an extracurricular activity because the ressel was not engaged in scientific research but in operational commitments. On his own he has gone forward with his studies and, of course, he would be quite an enthusiastic witness, I might mention, because he has tried to convince me over the last several years that we should send our icebreakers into the ice carrying scientific crews from private institutions and otherwise, which we would be very happy to do except for the fact that our icrbreakers are very busy on official commitments and operational commitments and we cannot spare them for that purpose.

He feels that there is a tremendous amout to be done, particularly in the Arctic as well as the Antarctic.

Mr. Mirler. I believe that your testimony today sums up the fact that maybe we should expand the activities of the Coast Guard to give you some responsibilities and money to carry out the work in this field.

You would not object to that?

Admiral Ricmiond. No; I certainly definitely would not.

Mr. Miruer. Should we perhaps have some governmental committee at this time composed of representatives from those agencies of Government to try to correlate and evaluate the activities of the several agencies and try and bring out some lines of demarcation and assign specific duties which would then be brought to the Congress to have enacted into law to expand and bring this work about more quickly? 
Admiral Richmond. Well, I would hesitate to give a direct answer because anything I would say now would be purely curbstone. It does seem to me, after reviewing the report which has been put out by the National Academy of Sciences group and looking at the work that I think is before this subcommittee, that at some point there is going to have to be a coordinating agency. I would not like to say just what that coordinating agency would be but feel that these objectives cannot be accomplished without some coordinating agency or group having the responsibility for carrying the objectives forward.

I would not want at this point to venture an opinion as to who or what or how that would be done, but I think that your committee, sir, if I may suggest, is going to have to consider that very, very carefully to this extent: that I feel that the big gap, as I see it now, is in assuring that this program, assuming that it was accepted as any program, whether it is the program as set forth in the committee or modified up or down mores forward as a coordinated effort and not by fits and starts as any particular agency that is able to obtain funds or to implement a part of a program.

I think at the very inception of the thing that it must be a very coordinated effort and, from experience in Government of a number of years in obtaining budgets and implementing a thing like this, it cannot be done, I believe, by individual agencies operating on their own.

Mr. Mrrler. Do you feel as one who knows the sea and loves the sea that we have been perhaps negligent in not doing enough in this field in the past?

Admiral Richmond. Of course "negligent" is a harsh word, sir. Let me put it this way, sir. I think we know very little about the sea. I think what we know about the sea is most superficial. It has been brought to the fore very forcibly in the last few years largely by the Navy in their underwater sound experiments and that sort of thing.

Thirty or forty years ago, the only interest in water was that it was a means of transportation. We knew that there were great depths but had very little knowledge of what the waters contained.

Mr. Mrller. Mr. Pelly.

Mr. Pelly. I have no questions.

Mr. Mrller. Mr. Lennon.

Mr. Lennon. Mr. Chairman.

Admiral Richmond, I came in a little late after you had already gotten into your statement.

Did I understand you to say that the Coast Guard did not know of the study being made by this committee until the report was made?

Admiral Richmond. Well, we, of course, did not contribute. Frankly, if it was called to my attention when it started it certainly escaped my memory. We had no relation to it. I will put it that way.

Mr. Lennon. You, of course, have read the report and particularly the general recommendations and the specific recommendations of the report. Are you inclined on the basis of those general and specific recommendations to agree in substance that we ought to project into the future a serious study of this problem, if we can call it a problem?

Admiral Richmond. I do not think there is any question about it 
and I so stated in my statement, sir. I do not think that anyone can quarrel with the objectives as set out in the report, sir.

Mr. Lennon. Has the Coast Guard, over any reasonable period of time, in the last 5 or 10 years recognized the need for such an objective study as this?

Admiral Richmond. Well, the objective study is in general terms. I have pointed out in my statement the Coast Guard has in its own right been limited. We have thought only in terms of how it would serve the Coast Guard in the discharge of its duties.

Mr. Lennon. It is your thinking, certainly, that in the future this committee or whatever committee has the legislative jurisdiction over this overall problem and its many facets would have to think in terms of a coordinating committee of Government agencies affected by such a survey?

Admiral Richmond. I can see no other answer to it myself, sir.

This is not in criticism of the report, but in the actual operating procedure of how you would implement this report there are a great many gaps in how it is going to be worked out, sir.

Mr. Lennon. Do you believe that the Coast Guard would be interested in participating to any appreciable degree in such a program as has been indicated by the report of this committee?

Admiral Richmond. I do not think there is any doubt about it, sir. As I have indicated, in one way we are already in the field; true, in a very limited way. It is a very small part but I think that the studies that we have made in the conduct of this ice patrol and in performing a better ice patrol have already contributed to the knowledge of oceanography.

Mr. Lennon. That is the very reason that I was a little bit surprised to hear you say that so far as you knew the Coast Guard had not been brought into this study by this committee. Naturally, in my limited knowledge, I would think that your organization or agency would be the first one that I would want to contact to get the background of your knowledge and experience and experiments that had been made over the period of years even though limited.

Admiral Richmond. Well, as I have also indicated, such information as we have been able to gather in our rather limited research are a matter of public record and all of the members that sat on this committee were, I am sure, fully conversant with those reports.

Mr. Lennon. Would you be willing to assign someone in your Department to give some study to the type of committee and as to what agencies should be represented on the coordinating committee for this subcommittee's consideration?

Admiral Ricimond. I agree with you that that has to come if we are going to do anything about it. We have to have a coordinating committee at the top level representing these affected agencies.

Mr. Lennon. Would you be in position to assign someone in rour staff the study of it so that you can make recommendations to this committee as to what agencies would be included in an overall coordinating committee?

Admiral Ricirmond. Certainly, sir.

Mr. Lennon. And give some background material as to why you think that those agencies onght to be brought into this committee?

Admiral Ricimond. We can do that very readily, sir. 
Mr. Lennon. I think that is all.

Mr. Militer. Mr. Flynn.

Mr. Flynn. I have no questions.

Mr. Miller. Counsel?

Mr. Drewry. Admiral Richmond, as I understood your colloquy with Congressman Lennon, the coordinating committee that was being discussed was something in the nature of a personal group, but is it not true that at the present time there is presently in being an informal or interdepartmental group that is representing the various agencies that are concerned with different facets of this subject?

Admiral Richmond. Yes.

Mr. Drewry. Are you the Coast Guard representative in that group?

Admiral Richmond. Yes, sir.

Mr. Drewry. Who is the Chairman or Director?

Maybe someone else can answer it.

Did I understand that Dr. Reichelderfer, of the Weather Bureau, is the Chairman?

Admiral Richmond. It might be, sir. I would have to check.

Let me make this point: that this interdepartmental committee as such, as I see it, is concerned, you might say, with common problems or matters of general interest.

The thing that disturbs me is the mechanics. Assuming that you were going forward with any program the mechanics of how you were going to be assured that you were going to budget for it and run it and control it, not talking about setting the type of program and that sort of thing, but things just do no run themselres. That is the type of control that I think has to be very seriously considered.

Mr. Miller. Being in the Department of the Treasury, we realize how you are much more conscious of the difficulty of getting a few dollars than anyone else.

Admiral Richmond. I do not think it is only that, sir.

As you know, I think it was a week ago Monday there was a meeting of representative agencies at which the Coast Guard was present to discuss this particular program. I did not attend. I had a representative there but I understand that the general reaction of all of the parties who attended, and maybe I am stating this incorrectly, was a bit of confusion as to how do we go or where do we go from here, because, as I say, particularly from the budgetary aspect, it is one thing to say that the Navy or some other agency shall contribute 30 percent of the thing and at the same time to get a definite commitment from the Navy that they are going to be able to contribute 30 percent against it.

Mr. Drewry. The point I was leading to, Admiral, was that at this stage it is very early for all of us. As I see our program here with this committee, we are endeavoring to find out just what is being done at present in oceanography and what related fields will benefit from it. So that in a sense we are groping too, and after making our survey in the field of what is being done, we will then proceed to find out how we go from there.

As I understood, this present more or less informal interdepartmental group was in the administrative level doing a similar thing in trading views and putting heads together to see how a program can be shaped up. 
I wanted to know whether you are participating in that group.

As you say, you knew nothing or were not very fully aware of the work of the Academy group and you are an operational service organization for the most part, but in view of what is presently before us, would you be inclined in your organization to make a review of the whole picture and see where not only you might participate more but also where work might be done by others which will aid you in your work whether it be setting out buoys or charting icebergs or whatever?

This subject having now come up as a matter deemed to be of considerable importance, is it not time for the agencies that are in any way concerned to make a deliberate determination of what they can use or what they need irrespective, in the first instance, of where the money is going to come from or who is going to do it?

Admiral Richmond. We certainly can do that.

As I indicated in my statement, I tried to pull together the immediate things that I could see both from the report that we presently have before us and, as I indicated, a more detailed study on our part might develop some others, although I have to confess at this point, after going over the report fairly thoroughly, that at the present time what I have listed here today are the existing contributions that we are making, if you can call them contributions, and the possible areas where I feel that oceanographic studies, whether conducted by us or others might help us.

Mr. Drewry. I have one more question. Do you know, offhand, whether the Academy at New London carries a course, either required or elective, in oceanography?

Admiral Richmond. We do not, sir.

Mr. Drewrr. Not physical oceanography.

Admiral Richmond. It has been our practice to assign for postgraduate work officers, I would say, on the order of about every 2 or 3 years, and I would have to put this in the record later, to the Scripps Institute. I am not sure that they all went to Scripps Institute.

Mr. Drewry. That would be specialized education.

Admiral Richmond. Specialized postgraduate training of oceanography with the idea that they would serve as a junior officer and as assistant to the officer in charge of the ice patrol, and eventually as they progressed in rank we would have an officer who was fully capable of being the officer in charge.

Mr. Drewry. In connection with the ice patrol, the chairman suggests that we inquire how many officers have been assigned to that postgraduate work.

Admiral Ricumond. I would have to put it in the record.

Mr. Mrruer. You may supply it.

Admiral Ricimond. I am not sure. I think we have about four or five still on active duty.

Admiral Hirschfield tells me we probably have a dozen still on active duty but I would like to correct that if necessary.

Mr. Miluer. You may supply that.

(The information referred to follows:) 
Office Memorandum-U.S. Government

MARCH 10, 1959.

To: Commandant.

From: Chief, Office of Personnel.

Subject: Officers who have had oceanography training.

ACTIVE

Capt. Richard M. Hoyle (1114), Harvard.

Capt. William P. Hawley (1255), Harvard.

Capt. Garrett V. A. Graves (1261), Harvard.

Comdr. Leroy A. Chaney (26S4), Scripps Institute.

Lt. Comdr. Armand J. Bush (3287), Scripps Institute.

Lt. Coindr. Harry H. Carter (3227), Scripps Institute.

Lt. Comdr. Peter S. Branson (3444), Scripps Institute.

Lt. Comdr. Robertson P. Dinsmore (3715), Scripps Institute.

Lt. Comdr. Rudolph E. Lenczyk (3728), Scripps Institute.

Lt. Comdr. John E. Murray (3747), Scripps Institute.

Lt. Richard M. Morse (4450), University of Washington.

Lt. Peter A. Morrill (4977), University of Washington.

RETIRED

Rear Adm. Edward H. Smith, Harvard.

Comdr. Noble G. Ricketts, Harvard.

Rear Adm. Charles W. Thomas, Washington University.

The above are officers who have had special training and does not include all officers who have been commander, International Ice Patrol.

R. MI. Ross.

Mr. Drewry. In connection with the ice patrol, for instance, has there at any time been any request from other services or agencies that they be allowed to have one or more scientists along during the ice patrol season for any type of scientific work?

Admiral Richmond. I will put it this way : If there has been I have never heard of it. I do not believe so.

Mr. Drewry. Do you know of any objection to it?

Admiral Richmond. No; there would be no objection.

As I indicated in my statement, we have, particularly since the war, tried to run, if not a preseason cruise, a postseason cruise, and there may have been some observers not connected with the ice patrol aboard on that. I would doubt very much that anybody has requested to be on the ice patrol itself. Of course, as you know, even in that we do not run it as we previously did. In the years when the ice is light we may never even send a vessel out on actual patrol. We have a vessel standing by but insofar as practical we find that we can more efficiently cover the area as a general thing, particularly in a light year, by plane so that it is now a combined patrol of plane and vessel.

I may add just to make the record clear that I would say most of the contribution to the science of oceanography has come from the preseason-postseason cruises that we have been able to engage in rather than the actual observations made on the Grand Banks themselves during the conduct of the patrol.

Mr. Lennon. I have another question.

Mr. Mrrler. Yes, Mr. Lennon.

Mr. Lennon. Admiral, since this report of the Academy's Committee on Oceanography was released, do you know whether or not that committee from the Academy has met with the various governmental agencies on the governmental level to discuss the impact of this report 
and what they wanted to bring to this or any other legislative committee in the form of recommendations?

Admiral Richmond. No, sir, I do not know. I know that a week ago Monday there was a meeting of Government agencies at which some members of the committee, I am quite sure, were present.

Mr. Lennon. Some members of the Science Committee?

Admiral Richmond. That is right, sir. Some members were present but, answering your question specifically as to whether they have met with any Government agencies, I do not know, sir.

Mr. Mrluer. Thank you very much, Admiral. I am certain that from time to time we will be calling on you for more assistance.

Admiral Ricirnrond. Thank you for the opportunity to appear, sir.

Mr. Mrtrer. We are very happy to see the Honorable Clarence G. Morse, Chairman of the Federal Maritime Board, here.

We always welcome you here, Mr. Morse, whether it is on a subject as technical as this or on the more practical phases of maritime operation. You are the favorite of this committee. I am happy to see a fellow Californian and particularly one from the Bay District here.

STATEMENT OF CLARENCE G. MORSE, CHAIRMAN, FEDERAL MARITIME BOARD, AND MARITIME ADMINISTRATOR, ACCOMPANIED BY CHARLES R. DENISON, COORDINATOR OF RESEARCH, AND VITO L. RUSSO, DEPUTY CHIEF, OFFICE OF SHIP CONSTRUCTION, MARITIME ADMINISTRATION, U.S. DEPARTMENT OF COMMERCE

\section{Mr. Monse. Thank you very much, Mr. Chairman.}

This opportunity to appear before you today and to express the views of the Federal Maritime Board and Maritime Administration on the subject of oceanography and its relation to the U.S. merchant marine is appreciated. The Maritime Administration in the discharge of its duties of fostering a merchant marine adequate for mobilifiation and commercial pur poses realizes that knowledge of the ocean environment and its effect on shipping is fundamental to improving the efficiency of ocean transportation.

Our research and development work at the present time involves development of seakeeping instrumentation, cooperative investigations with the Navy relating to stresses induced into ships' hulls by sea state, methods for obtaining data with respect to wind and sea state by remote-controlled buoys, and the automatic transmission of such data by radio in order to permit optimum routings so that the ships will arrive at destination in the least time with the least damage to cargo. The informaion now available does not allow this to be done satisfactorily.

The Maritime Administration is interested in obtaining fundamental information relating to ocean currents, sea temperature, sea state (wave conditions), and direction and intensity of winds and the extent of storm areas, including areas of low visibility due to fog and snow. Information is desired on ice conditions both with respect to floating and anchored ice. The $\Lambda$ dministration is interested in sea life that fouls ship hulls. Our interest extends to the levels of radiation in the sea at the present time and the possible effects of increased radiation in sea water due to mammade radiation and the possible effects of nuclear contamination resulting from nuclear-propelled ships. 
The Maritime Administration agrees that-

(1) The Maritime Administration should be consulted in designing of all ships paid for from public funds and used for marine studies.

(2) The Maritime Administration should be charged with the supervision during construction of Government-owned oceanographic survey ships operated by others in pure research.

The oceanographic survey and research ships proposed in the report of the National Academy of Sciences are intended to be manned by civilian crews and to be built to merchant marine standards of construction. This will reduce considerably the cost of construction and operation of these ships. The Maritime Administration is well qualified to supervise this type of ship design, construction, and operation.

'The developmental work of the Maritime Administration which depends on other sources for fundamental knowledge about the ocean is being hampered at the present time by not only the lack of knowledge but the lack of organized procedures and mathematical systems for communicating information to engineers who desire to incorporate fundamental knowledge into the improvement of ships. For example, there is a lack of instruments and data processing devices for measuring sea phenomena and for communicating data to scientific persons for study and analysis. The Maritime Administration, therefore, endorses the proposition that the field of marine sciences encompassing oceanography should be improved through the training of qualified persons, the investigation of the many scientific aspects of the waters of the sea, the atmosphere above the sea and the earth beneath the sea. The Administration is presently supporting this oceanographic research through its own direct efforts and in coordination with the other Government agencies and will continue to support it to the extent that funds are available for such fundamental research purposes.

Now, specifically, on our Liberty ship instrumentation for seakeeping qualities, we have used $\$ 100,000$ of our research and development funds in conjunction with an additional $\$ 100,000$ which is being supplied by the Navy through the David Taylor Model Basin.

In addition, we are in the process now of allocating $\$ 65,000$ of our funds for the development and installation of automatic seakeeping instrumentation. The Navy here again will contribute a like amount of $\$ 65,000$. We are contributing to the Office of Naval Research $\$ 25,000$ in fiscal 1959 and a like amount in fiscal 1960 for studies in recording wave conditions.

All of these things are of substantial interest and substantial value to us and we are enthusiastic in the development of this whole subject.

I have with me today Mr. Charles Denison, who is the Chief of our Office of Research and Development, and Mr. V. L. Russo, who is the Deputy Chief of the Office of Ship Construction. They are better qualified than I when we start getting off into the technical aspects of this field.

Mr. Miller. Would you care to have them make any statements at this time touching on the general field or subject of oceanographic research as it specifically affects their duties?

Mr. Morse. Mr. Denison. 
Mr. Denison. I can say generally that we know little about the sea and to get along with our scheduled research and development activity we should have a lot more information than we do have. We are not an agency large enough to support fundamental research, so we must depend for basic research on other sources, either academic or governmental. When we go to them for particular information it is not there. IVe would say that a great deal of work should be done if we are to get along with our desires to make ocean shipping more effective, that is, to design ships better.

Mr. Mrluer. Do you know whether any other nations in the world are doing anything in this field?

Mr. Denison. I know there is a certain amount going on. It is supposed to be coordinated to a certain extent through this IGY. I do not know well enough to report, sir.

Mr. Miller. Mr. Russo?

Mr. Russo. I would be reiterating the same points, sir.

Mr. Mrller. Then I take it, Mr. Morse, that you and your staff feel that there is a real need for coordinated and comprehensive study to be made in this field and that it would be to the advantage of the Maritime Administration if this knowledge that is lacking was available to it through such an effort?

Mr. Monse. Certainly insofar as it affects our activities we are doing research to a limited degree as it has a direct impact upon our activities and we do not begin to have the necessary information that we require to improve our efficiency.

Mr. Minler. Of course, in the field of science, are we not going into this thing to get the complete picture of the ocean, the things above it and below it so that you cannot narrow it down and say, "We are only going to study this particular phase that affects us" because if you go into it you will find that you have to use data that seem far afiield from the point that you are seeking. Is that true?

Mr. Russo. That sounds reasonable to me.

Mr. Denison. I think Mr. Morse's statement said we were interested in the atmosphere above the sea, the water surface and the land beneath it. We never know nor can we forecast at what time we will want information which someone else is going to think is important and we at the moment think is unimportant.

Mr. Miller. Am I presuming in saying that the information you want or that you need at a specific time or maybe information you need today was apparently gathered by people in the field who at the time they gathered it had no direct thought that it might apply to, say, the design of a ship?

Mr. Denison. Yes, sir.

Mr. Mrlu.er. In other words, you cannot limit scientific investigation to any narrow channel, is that true?

Mr. Denison. No, sir. It is fundamental knowledge and you need fundamental knowledge.

Mr. Miruer. It is fundamental knowledge. That is right.

Do you think that this committee should continue this investigation stimulated and brought about by the report of the Committee on Oceanography of the Academy of Sciences?

You have read that report, I presume?

Mr. Monse. Yes, sir. 
Mr. Miller. Do you think that we should continue this study and try to resolve all of the questions and differences that come up and see if we can bring something out of it?

Mr. Monse. Expressing my personal views, I think it is very desirable.

Mr. MrLcer. You think that there is a need in this field, that there is a great void in the knowledge that we have, is that correct? Do you feel that way?

Mr. Morse. Yes, I do.

Mr. Miller. Do you know of any work that has been done by other nations in this field? What has England done in connection with its merchant marine?

Mr. Monse. I personally have no knowledge.

Mr. Russo may have some.

Mr. Russo. There has been an activity which is in progress now in all the maritime countries to develop facilities, experimental facilities like the Davis Taylor Model Basin and make them suitable for the study of ships in waves. To this extent it is my knowledge that countries like England, Holland, France, and this country, have been very active in developing these facilities. They are predicated on an experimental way of dealing with the problem. These facilities basically consist of trying to duplicate, scaled down, the ocean conditions which exist in the field, to run models and determine the behavior of ships under those given sea conditions.

One of the first points where we come to be in need of some assistance from other branches of science is to define the sea in the open so that we can duplicate it in the experimental facilities so that we can study our ships and determine the behavior of the ship in that sea.

That seems to be a very simple proposition but it implies the ability to define the sea. The sea can be defined quantitatively by the oceanographers who have been attempting and are still attempting to accomplish the fact.

In the Maritime Administration we do not have direct concern in deterimning the sea but we are vitally concerned in the results and that is the reason we would like to support this, Mr. Chairman.

From the merchant marine viewpoint, our interest in seakeeping or oceanography is simple. We would like to know enough to be able to design better ships to run more efficiently, the merchant ships.

Sea transportation has moved to faster and faster ships and it seems futile to design faster ships if we do not know how to make them run fast in seaways.

Our interest, as I say again, is geared and based on this basic point.

Mr. Miller. How long have these studies by people interested in ship construction and operation with respect to the seaway motion or action been going on?

Mr. Russo. Mr. Chairman, I was studying the mathematics of seaways 30 years ago when I was in school. This is a very old problem. The question now is that it has been more or less in the field of speculation and we would like to make it tangible. We would like by concerted effort to render the problem soluble so that we can learn something.

I already mentioned that our primary interest is to identify full scale conditions so that we can duplicate them in the experimental 
tanks. This activity, to my knowledge, has been going on for I would say the last 5 or 6 years and maloe longer.

Mr. Mrller. If we can solve some of those problems it would have a very practical effect upon the operation of ships, would it not? In other words, it would have a dollar and cents effect?

Mr. Russo. Definitely so. If we have to slow down a Liberty ship which is designed for $101 / 2$ knots to 5 knots or 6 or 7 and we still have to slow down a 20 -knot ship to 5 or 6 knots in the same sea, it is better that we leam how to design ships to navigate in seaways.

The result can be visualized immediately. The ships turn around faster. They render better service.

Mr. Miller. We have been using the sea as the high road to commerce, and for the interchange of ideas since before the memory of man recorded these things. The airplane is a comparatively new means of transportation.

Would you say that in the short years that we have had the airplane that the intensive study that has been made of weather conditions and which is still going on in this field alone to assist this mode of transportation has overtaken comparative knowledge in the design and operation of ships?

$\mathrm{Mr}$. Russo. I am afraid the question is too broad because you are comparing two modes of transportation which render two different services.

Mr. Miluer. The thing I want to bring out is that, the airplane being new, we have not hesitated to spend a lot of money to establish weather stations to determine where we get into the air stream to save gasoline and get an airplane there much faster.

We correspondingly have really just begun to apply that same sort of thinking to the sea, have we not? We have just taken the sea for granted. It has been our old friend.

Mr. Russo. That is correct. I am not an expert on airplanes so that I cannot testify on that, but by hearsay only I understand that the airplane industry has been very effective in improving the method of weather forecast so that they can route the airplanes around the weather rather than plunging through the weather. They have much more speed and can perhaps be more versatile in relation to the weather.

That is one of the things we are trying to do by means of correct forecasting.

I may say this is not an idle speculation. There have been attempts to establish this mode of routing ships by Military Sea Transportation and even ourselves.

Mr. Miller. After all, you cannot hope to predict results on the experience of a few years, but do you feel that the limited experience you may have had so far because of the few years you have been at it indicates that in terms of dollars and cents it is going to pay off?

Mr. Russo. I am expressing my views only now. My feeling is that it is due to two factors. First, up to 10 or 15 years ago, we were moving slower ships. It did not matter much whether we had to slow down or not.

The second one is that to solve the problem it requires the concerted effort of allied sciences. 
No agency alone can come to grips with the sea in the sense of a scientific or mathematical clefinition of the sea. It is far beyond our means and limits.

That is the reason why there has been limited activity in this problem.

As a corollary to this, we might say that if this concerted effort by all the sciences involved in oceanography could be channeled in a way that would lead to practical results, maybe we could get the answer we want.

Mr. Miller. Do you feel, then, that if we had some coordinated agency it could define the different areas, give rather broad guidelines to the different areas of research in this country?

Mr. Russo. Mr. Chairman, I am a ship designer, and I see this problem essentially from the technical aspects. To me any system that works would be satisfactory. That is not an answer to your question. I would say, as an amateur speculating in the field, that by the mere fact that several sciences have to coexist in order to come up with some practical results, then a means of coordinating these activities should be devised.

Mr. Miller. Are you familiar with this report of the Academy of Sciences?

Mr. Russo. I represented the Maritme Administration as a member of a panel of this committee. The committee organized itself and instituted some panels. The panel in which I participated was naturally the one that had to do with the types of ships that would be desirable, the cost of these ships, and so on. To that extent, I am familiar with the activities of this committee.

Mr. Miller. Do you think it is timely that this challenge be thrown before us now or should we delay?

Would it have been better if we had undertaken this 5 years ago?

Mr. Russo. The first answer is "better late than never."

The second thing is that I have participated in this activity. I have been instrumental in instituting or fostering whatever research in the field of seakeeping we have done in Maritime. As a naval architect, I think the problem of learning how to design ships to be efficient in a seaway is the next advance.

Mr. Miller. That is your immediate problem?

Mr. Russo. That is right.

Mr. Miller. Mr. Pelly.

Mr. Pelly. Thank you, Mr. Chairman.

I wonder, is there a free exchange of scientific data as between nations in ship design as far as you know?

Mr. Russo. I cannot answer that question.

Mr. Pelly. Do not engineers and scientists publish books and are not those books and papers available to us?

Mr. Russo. To the extent that we have access to technical papers; yes.

Mr. Pelly. Who discovered the stabilizer, for example? Was it invented in this country?

Mr. Russo. In this country, you say?

Mr. Pelly. Yes.

Mr. Russo. Well, the stabilizer principle is as old as physics. The stabilizer applied to ships has been tried in a small scale for a long 
time. The first large-scale stabilizer that I know of was developed by Sperry in this country and was installed on a big transatlantic superliner of the 1930's, the Conte di Savoie. I do not know whether you want a further dissertation on stabilizers.

Mr. Pelly. Is it a patented device on which a royalty is paid?

Mr. Russo. Yes.

Mr. Pelix. And could it be improved, in your opinion, if we had more knowledge of the waves and other scientific data?

Mr. Russo. Not necessarily the stabilizer. The stabilizer copes with only one motion, that is, the rolling of the ship. If we had better knowledge of the seas we could perhaps attempt to correct pitching. In fact, in this country we have a considerable amount of information developed on that at the Massachusetts Institute of 'Technology. There is a research activity going on there of which one of the ingredients is to define the spectrum of the sea, which is a mathematical definition of the sea.

Mr. Pelly. I was interested in reading some time back that a British port, I believe it was, was trying to break the action of the wives by releasing air bubbles and having a breakwater, you might say, to provide them with calmer inside water.

Mr. Russo. I would say that this device is not in the nature of a device yet. It is in the nature of a dream, if I might define it that way.

Mr. Pelly. I think that that in itself must be related to the very subject which this committee is thinking of implementing.

Mr. Russo. Yes; I would say so. If you define the sea, you simplify a very great deal problems which have to do with ships in relation to the sea.

Mr. Pelly. Mr. Morse, have you been consulted at all with regard to an international program to study the Indian Ocean?

Mr. Morse. Not to my knowledge.

Mr. Pelly. A previous witness indicated that there was afoot a program, perhaps a dream, but, nevertheless, it has been talked about, to make a comprehensive study of that one area because of its particular interest.

Mr. Monse. No; I am not a ware of that, Mr. Pelly.

Mr. Pelly. Thank you, Mr. Chairman.

Mr. Mrller. Mr. Flynn.

Mr. Frynd. I have no questions.

Mr. Miller. Counsel.

Mr. Drewry. Mr. Morse, to follow up Mr. Pelly's inquiry about the exchange of information between foreign technical groups, what about the exchange of technical information between our own governmental groups? Do you, for instance, have readily available technical data developed by the Navy Department or any of its branches?

Mr. Russo. I can answer that question.

We have a system which has been improvised as we went along of interlocking membership in committees of the Society of Naval Architects, the National Academy of Science, and such. We have to that extent access to research activities of other Government agrencies.

Mr. Drewwry. Does the Society of Naval Architects in which you are very active, I believe, or does any other group have a program for analyzing papers presented by foreign naval architects and marino 
engineers or translating them to make them available in English to American naval architects?

Mr. Russo. Well, essentially it is left to the individual to do his own looking for the information he wants. There are publications both by the British and ourselves which are synopses of technical papers.

Mr. Drewry. That is just British and American which are already in English. I wondered if there was any eflort in the naval architectural field to try to analyze papers produced by other nationals in their own foreign language, Norwegian, Russian, whatever it might be?

Mr. Russo. I do not know but I would not be surprised if there was an organization heavily involved in research of that kind. I do not know.

Mr. Drewry. You do not know of any of it being made generally public?

Mr. Russo. I do not know.

Mr. Drewry. You mentioned that MSTS and yourself had been working on weather studies in connection with the routing of ships. A witness last week mentioned that MSTS participation and said that there was evidence that by this pilot program they had that over a million dollars had been saved already by a reduction of time by routing of ships around storms rather than through them.

To what extent has Maritime been participating in that program?

Mr. Russo. I cannot answer that. We do not operate ships.

Mr. Monse. It is done primarily by the operators themselves. Some of them participate or buy the services from commercial forecasters. We operate few if any ships of our own at the present time.

Mr. Drewry. What $I$ was trying to develop was the extent to which Maritime had looked into the subject and had, shall we say, encouraged operators.

Mr. Monse. Mr. Denison can answer that.

Mr. Dexison. This was thought of and reported on in a study which was the first study by our first research effort with the Maritime Cargo Transportation Conference of the National Academy of Sciences. One of the local weather forecasters who has a service in this regard, volunteered to set forth the system in this report. Our Operations Division has, on certain ships which we have operated by general agency, engaged this service and at the present time is accumuPating operating experience which is made available to operators.

I assure you it has real value. A report on Maritime Administration experience was published in the proceedings of the Society of Naval Architects and Marine Engineers Technical and Research Bulletin, No. 4-1, December 1957. Mr. Allen, of the Operations Office of Maritime, is in charge of this work.

Mr. Drewry. What is the maritime industry itself doing in the way of research? They have these problems that involve the elements on the various routes that they serve.

Are any of the operators or any of the shipbuilders engaging in any kind of research program either individually or collectively?

Mr. Russo. The Society of Naval Architects has a research and development committee which is divided into several subcommittees each one involved in problems of hydrodynamics, ship structure, and such. 
The hydrodynamics committee has a panel on seakeeping which is a short term for ocemography, short in the sense that it is oceanography as applied to ships.

The industry supports that through voluntary contributions.

Mr. Drewry. Do you feel that it is adequate?

Mr. Russo. I would say that for a long time it has been practically the only thing that we have done in the merchant marine field.

Mr. Drewry. I asked Admiral Richmond this question, Mr. Morse, in regard to the Coast Guard Academy at New London. Do you know whether oceanography or any aspect of it is given as a required or elective course at Kings Point?

Mr. Monse. No, it is not.

Mr. Drewry. You have a trainee program. Is that used in a manner in which a contribution either is or can be made in this field ?

Mr. Morse. I think so. Mr. Russo can answer that.

Mr. Drewry. Would you explain a little about the program?

MIr. Russo. In the trainee program we have attempted to recruit college graduates preferably in naval engineering or architecture or allied fields and encourage them to develop a higher technical level of education in subjects which deal with the advanced phases of hydrodynamics oceanography in terms of ships. We call it seakeeping.

We channel some our trainees toward these particular courses and they specialize and get higher academic training in those subjects which would be valuable to us in the furtherance of the research programs we develop.

Mr. Drewry. How long have you had the training program?

Mr. Russo. The training program has been since the inception of the Maritime and is included in the 1936 act. It followed the vicissitudes of the World War. We resumed it again after the war. If you take an approximation it would be about 1950 or 1951 or 1952 . I do not have the exact date.

We already have a graduate of the University of California. We have now a student at the University of California, one at Stevens Institute of Technology. Stevens Institute students are particularly specializing in seakeeping.

Mr. Drewry. I have just one more question, Mr. Chairman.

As I read and understand your statement, Mr. Morse, there are two respects in which you feel that Maritime is very heavily involved in whatever program regarding oceanograplyy might develop.

One is in the field of applied research and I suppose, of basic research, both in connection with subjects such as seakeeping and these matters of instrumentation and so on, and the other is in relation to the overall aspect in the design and construction of whatever oceanographic vessels there may be whether operated by one agency or another.

Am I correct in that?

Mr. Morse. In both fields, yes, sir.

Mr. Drewry. You state that the Maritime Administration is well qualified to supervise this type of ship design construction and operation. I assume that the point on your qualifications is based on the fact that the vessels, according to the Academy of Sciences report, are to be manned by civilian crews and to be built according to merchant standards. But in addition, have you had experience with 
the construction of specialized scientific ships as against solely merchant vessels? this.

Mr. Monse. We have, and I would like to have Mr. Russo speak to

Mr. Russo. We have designed and are building now a 3,000-ton ship for the Coast and Geodetic Survey. That is a survey ship. However, it is still basically a ship, that is a small ship, that is equipped to do this kind of work. It meets conditions which are not identical with those of oceanographic research ships but similar.

We have done preliminary design work for smaller-sized ships, again for the Coast and Geodetic Survey, but the key in that statement is the standards, the commercial standards of construction and operation. That, in our judgment, makes the Maritime Administration qualified, not necessarily the only agency qualified to undertake the program of design, construction and operation of ships predicated on commercial standards for construction and operation.

Mr. Drewry. What is the status of this survey ship? When will it be completed?

Mr. Russo. In August.

Mr. Morse. August of this year.

Mr. Drewry. That is one of the two ships that were authorized by this committee a couple of years ago?

Mr. Monse. Yes, sir.

Mr. Mrllen. Where is she being built?

Mr. Monse. At National Steel \& Shipbuilding in San Diego.

Mr. Miller. Mr. Morse, I would like to close with this note. This is a very complex problem. It can be divided into many divisions. Roughly, it is the physics of the sea, the chemistry of the sea, the biology of the sea. The hydrodynamics, I presume, come under the physics of the sea. These are all important. I notice in your statement here that you say, among other things, that you are interested in the sea life that fouls the hulls of ships. That is part of the biology of the sea.

I did not expect you to express the view of the Administration because I should give you time to discuss it, but in your own personal opinion, do you feel that this subject is of sufficient importance that we should have some coordinating agency to lay down the guidelines and to get it before the people or get it before Government so that there will not be overlapping and so that we can do the best job in learning some of the secrets of that which is beneath the surface of the sea?

Mr. Monse. I personally think it would be very desirable that there be close coordination and supervision of these broad fields of research.

Mr. Miller. Thank youl very much, sir.

Dr. Schaefer, a member of the Committee on Oceanography, happens to be present. We had not known that you were going to be here, Doctor, or we would certainly have invited you to appear before us. Would you like to come forward and perhaps tell us some of the things that actuated the committee? We had hoped to have Dr. Brown back. We will not pass up the opportunity now that we have you here to ask you to tell us something about your work. 


\section{STATEMENT OF MILNER B. SCHAEFER, INTER-AMERICAN TROPICAL TUNA COMMISSION, LA JOLLA, CALIF.}

Mr. Schaerer. Thank you very much, Mr. Chairman. Actually I came here this morning to learn rather than to talk.

Mr. Miller. Before you proceed, would you please for the sake of the record identify yourself?

Mr. Schatefer. I am Dr. Milner B. Schaefer of the Inter-American Tropical Tuna Commission located at the Scripps Institution of Oceanography, La Jolla, Calif.

This Committee on Oceanography was formed at the request of some of the Government agencies who were nost concerned with oceanography, its support and its applications.

Dr. Bronk, of the Academy of Sciences, appointed Dr. Harrison Brown, professor of geochemistry of the California Institute of Technology, as chairman, and he in turn with the assistance of Dr. Bronk and others, selected a number of persons who they thought were qualified in various of the fields of oceanography to serve on the committee.

The committee met periodically-mostly on weekends since we have other professional responsibilities-for about the last year and a half and attempted to review as well as we could all of the aspects of oceanography in the United States, to identify those areas of oceanography that particularly were in need of increased support and to make some recommendations as to what Government agencies, in our opinion, would be the proper ones to carry on certain of these researches, both basic research and applied research.

It is fairly easy to identify the problems, that is, to look at the oceans and to say what things need further study. It becomes a great deal more difficult when you say how you should go about doing this.

It was impressed on me this morning in listening to the testimony of the previous witnesses that apparently this is one of the things in which your committee, sir, can be of the greatest help if you can work out some methodology of determining how this work is to be done.

In the summary report, we have outlined in general the sort of thing that we think needs to be done, and have made fairly detailed estimates of the cost of doing it.

There are in preparation detailed chapters on certain areas, explaining the background of the basis of the estimates in a great deal more detail, but the thing that impressed us as we got further into this study was the great number of Government agencies that have either a direct or an indirect interest in the ocean and its contents and the very great need for somehow obtaining a proper degree of coordination. In fact, within the committee we, of course, think we have some expert knowledge in oceanography. We realize that we have vory little expert knowledge in Government. However, we debated at great length within the committee as to what our own personal opinions are on how this thing ought to be done.

Some of the members thought perhaps a central bureau, a burean of marine sciences, might be the most expeditious way of accomplishing this sort of thing.

However, it was realized that the varions agencies of the Government, such as the Navy, the Bureau of Commercial Fisheries, the 
Atomic Energy Commission, and the State Department have very particular interests of their own and have particular statutory responsibilities that they need to carry out, for which they require certain specific knowledge and, of the totality of knowledge that is required in the general subject of oceanography or the totality of knowledge that is required in a small field such as, say, the marine resources, the fisheries resources, different agencies have specific needs for certain parts of this knowiedge.

Therefore, it seemed to us most appropriate that the agencies that had these statutory responsibilities should actually participate in the organization of, and the support of, the research program rather than trying to put it in a single bureau.

As I say, I came here this morning to learn, and I think that the hearings of this committee may bring out the best means of organizing to get this job done.

Mr. Miller. Of course, that is what we are trying to do.

We have to stumble along because we are not fortified by the technical knowledge that you have.

I am glad you were here to see some of the ramifications that we have to go through.

I presume that our best procedure is to continue to hear these agencies. Then we will have to sit down among ourselves and resolve what must be done and perhaps out of that will come some legislation and then we can begin to call the agencies back and ask them to submit very definite plans as to how the matters are proceeding.

Are there any questions of the doctor?

We are happy to have had you here to get your reactions as to what we are doing and to tell you that I know nothing which has created the interest that your report has created. It has been provocative and the members of this committee are all to a man very much interested in what will come of it.

We will do our best.

Thank you very much, Doctor.

Mr. Schaefer. Thank you, sir.

Mr. Mrller. Without objection, the committee will recess until next Tuesday at 10 o'clock when the Navy will be heard.

(Whereupon, at 11:40 a.m., the committee recessed until 10 a.m., Tuesday, March 17, 1959.) 



\title{
OCEANOGRAPHY IN THE UNITED STATES
}

\author{
THURSDAY, MARCH 12, 1959
}

\author{
House of Representattues, \\ Spectal Subcommitee on Oceanography, \\ of the Commituee on Merchant Marine and Fisheries, \\ Washington, D.C.
}

The subcommittee met at 10 a.m., pursuant to recess, in room 219, Old House Office Building, Hon. George P. Miller (chairman of the subcommittee) presiding.

Present: Representatives Bonner (chairman), Miller (chairman of the subcommittee), Oliver, Flynn, Dorn, Pelly, and Curtin.

Staff members present: John M. Drewry, chief counsel, Bernard J. Zincke, counsel, and William B. Winfield, clerk.

Mr. Miller. The committee will please come to order.

A few weeks ago, almost coincident with the release of the first portion of the comprehensive report of the Committee on Oceanography of the National Academy of Sciences, the Bureau of Commercial Fisheries announced that the biological and oceanographic research ship, Albatross III, was being deactivated. This circumstance was highlighted by recent reports disclosing the fact that the United States has very few research vessels engaged in the increasingly important field of oceanography. Our shortage of such vessels is such that recommendations have been made for early replacement of existing vessels with specially designed new ones, and a considerable increase in the total number of such vessels.

Thus, the news of the deactivation at this time of an active operating research vessel raises certain very obvious questions.

Protests regarding the deactivation of the Albatross III have been raised in the press and made to a number of Members of Congress. This hearing has been called this morning in response to such protests, to hear from the Bureau of Commercial Fisheries, Fish and Wildlife Service, an explanation of the action which has been taken in this case, and to ascertain the effect the loss of the vessel will have on important current research programs.

We have limited time this morning, since the House meets at 11 o'clock. Therefore, we will confine attention as closely as possible to this one matter. We will have a further appearance from the Fish and Wildlife Service to receive a more comprehensive understanding of their various activities in the field of oceanography later.

The witness this morning is Mr. Donald L. McKernan, Director, Bureau of Commercial Fisheries, Fish and Wildlife Service, who will be accompanied by the Assistant Director, Mr. Andrew W. Anderson.

Mr. McKernan, will you and Mr. Anderson come forward together. 


\section{STATEMENT OF DONALD L. MCKERNAN, DIRECTOR, ACCOMPANIED BY ANDREW W. ANDERSON, ASSISTANT DIRECTOR, BUREAU OF COMMERCIAL FISHERIES, FISH AND WILDLIFE SERVICE}

\section{Mr. Mrluer. Have you a statement, Mr. McKernan?}

Mr. McKernax. I have no prepared statement, Mrr. Chairman.

Mr. Murer. You have heard the statement that I have just made. I am certain that you have had some correspondence on this subject.

Mr. McKernan. Yes, Mr. Chairman.

Mr. Mirler. Will you proceed from there and tell us why the Albatross was decommissioned?

Mr. McKernan. Yes, Mr. Chairman. It is a privilege to again address this committee especially on such an important matter as the marine resources of our Nation.

We have recognized for a number of years that our research vessels are becoming more and more obsolete and are becoming more expensive to operate. This is not only true of those vessels in the New England area but it is true of other vessels with which we are carrying out marine oceanography and marine biological research. Increasing costs and increasing age of these vessels, plus the fact that, for all practical purposes, none of them was constructed for the type of work that they are conducting at the present time has all piled together to make an almost impossible task of gathering data, processing it, and making reports to Congress, and also to other scientists, that is the objective of our particular Bureau.

The Albatross itself is a vessel which was constructed in 1926. It was converted for use by our Bureau in 1948, I believe, but it was an old vessel at that time. It has done quite well until recent years when what we consider to be prohibitive costs have reduced its effectiveness and have reduced the effectiveness of our New England research program to the point where it meant that either we further curtail the biological research program or we lay up the boat.

Having had considerable experience in my own career extending over 20 years with the operation of research vessels, one of the first things I noticed in coming to my present job was that this particular vessel was obsolete and should have been decommissioned.

Finally, we have found it necessary to do so or we would further reduce our biological research program in New England.

In New England we consider that we have perhaps the most serious fisheries problem in the United States. There are other serious problems but nevertheless the New England ground fisheries are in need of research work.

To continue to operate the vessel in anything like an efficient manner would have meant that we would have been compelled to further reduce our work. In tying up the Albatross and hoping that the economic climate of the United States will soon be such that we can design and construct a vessel worthy of this portion of the country and of theso great fisheries of New England, we felt that we can do our work better with the funds that we now have through chartering, within our own particular Bureau, for the vessel, Delaware, which is also in New England and by chartering with outside fishing boats.

That is about the sum and substance of it. 
I would like to add one thing. There has been a lot written and a lot said about our activities in New England in this regard and I am very pleased and feel it is a real privilege to be able to appear before you and attempt to set the record straight.

There is a great deal of misinformation that has been put out on this boat, a great deal of it that we have not been in position to properly answer. We will appreciate giving the committee any information and any facts in this matter within our control.

We believe that we have people who are expert in the operation of fishery research and oceanographic vessels. In fact, I believe I am an expert in this particular field. I operated research boats in Hawaii, in Alaska, and in the Pacific Northwest for practically all of my 20 years of my professional fisheries work. T'nder no circumstances would I tie up an important phase of our research arm without thorough and considered thought by not only myself but by other experts that we hire for this purpose.

Mr. Miller. Mr. McKernan, let us give you an opportunity to start presenting the background of facts. Was the Albatross recently rehabilitated and some length added to her as late as 4 years ago?

Mr. McKinnnan. The length was added by the Navy in 1941, almost 20 years ago. We reliabilitated the boat, or I should say converted her, to biological purposes in 1948. We have been operating her the 11 years since that time.

Mr. Mriler. Then the additional length was added in 1941?

Mr. McKernan. Yes.

Mr. Miller. When was any material or major work done on her engines?

Mr. McKernan. Now, a major boat of this kind needs a major engine overhaul approximately every 5 years and, if we had been working on that boat properly, it would have been within the past 5 years.

In 1958 there was some bearing work done on the vessel.

Vessels of this kind and especially of this age need rather constant work. There are ordinarily several or many thousand dollars a year which go into the upkeep of these reserach vessels. The older they get the more work it requires.

Mr. Miller. They are like an automobile. When we do one little piece of work we do not consider that major overhaul. I was told that within the last 5 years there was a major overhaul done on the engines of this boat and that they are in very good condition today. Is that correct?

Mr. McKernan. There undoubtedly was a major overhaul done on the engines of the Albatross and it is my understanding that the engines are in fair condition for their age.

Mr. Miluer. They are in fair condition for their age?

Mr. McKernan. Yes.

Mr. Mrluer. Do you consider the boat then as being entirely obsolete for this work?

Mr. McKernan. Of course, let us establish this: No boat converted for this purpose is ever satisfactory.

That is correct.

Mr. Miller. So that we have to start on the premise that this was a converted ship, that you are using other converted boats today. 
Mr. Mchernan. That is right.

Mr. Millen. How many of your ships were specifically built for fisheries research purpose?

Mr. McKernax. Of our major fleet of research boats, I can think of only two, the Charles $H$. Gitbert and the John $N$. Cobb.

Mr. MrLier. How many boats do you presently operate?

Mr. McKernan. About nine offshore vessels, Mr. Chairman.

Mr. Miller. Weighing the efficiency of the Albatross against the other converted boats, is she in the lower or upper category?

Mr. McKernan. She is in the lowest category that we have; that is, she is the most inefficient research boat we are operating, to my knowledge.

Let me give you an example of this so that the committee will have facts. The Albatross has been operating in the last 3 or 4 years about 150 days per year.

The Delaware, her sister ship up there, a smaller boat, not a twin but a boat that operates in New England, has been operating at about 180 days per year except in 1958 when we ran short of funds. She has been operating at from 180 to 185 days a year.

I consider this a minimum operation for a research boat. I consider operations between 200 and 220 days a year are appropriate for a research vessel doing marine biological research in oceanography.

Mr. Mirler. I have before me a copy of a letter signed by you. It is a letter you wrote to Senator Saltonstall. You were nice enough to send me this copy. I notice that in one paragraph you say :

If not deactivated the operation of the Albatross III would have had to be curtailed this spring because its funds for the fiscal year would have been exhausted by then. Attempting to operate on such a part-time basis is unwise, financially, in our present situation.

Now, that indicates that your money may have run out and that is the reason you are deactivating the vessel.

I would like you to explain that paragraph to me.

Mr. MCKernaN. Well, Mr. Chairman, there are two factors involved. With a vessel of the age of the Albatross it is simply inherent that the costs increase and the costs of the Albatross have increased. TVe had anticipated that next year further reductions in our research in New England wonld have had to occur in order to operate her full time. In fact, the operating expenses of the boat have increased beyond what we expected this year alone so that we were short of funds for that particular purpose.

We anticipated a further increase next year in the operating expenses and, since right at the moment anyway our budget is the same as it was last year and we anticipate in the President's budget about the same budget next year, it simply meant further reductions in our scientific work in New England. TVe felt we could ill afford to do that, Mr. Chairman.

Mr. Miller. Then the budgetary picture plays a very important part in this scheme?

Mr. McKernan. Well, it plays a part.

Mr. Miluser. Are you getting any more money or anticipating getting any more money in fiscal 1960 than you have in fiscal 1959 for research work? I assume that your research work, as far as Congress is concerned, is a line item and you justify to your own people 
in the Bureau of the Budget and perhaps to the Appropriations Committee the elements that go into making up that line item. Is this line item going to be greater in 1960 than it was in 1959 ?

Mr. McKennan. No; it remains the same.

Mr. MrLler. You have had an increase in salaries since that time which you have to absorb?

Mr. McKernan. The increase in salary, at least part of it, is being made up by a special item of appropirations by Congress. That is in our regular appropriations from Congress.

Now, the colnmittee will remember that we operate some of our research functions, and in fact the Albatross, from the SaltonstallKennedy funds. They are what we call permanent funds and in those funds we were obliged to absorb the salary increase which did reduce the Saltonstall-Kennedy funds available for research projects.

The Albatross is being financed out of these Saltonstall-Kennerly funds so that essentially what you say is correct for that particular item.

I did not quite finish my answer to your previous question, Mr. Chairman, about the other factor involved in the Albatross situation. That is, a boat as old as the Albatross going to sea from 140 to 150 days a year and costing an increasing amount of funds simply seems to me, is in my experience, inefficient. As I said before, I consider 180 days at sea a very minimum that I would like to see a research boat at sea. When you drop below that, because of the large costs for operating research boats since they are expensive, it just appears to me that it is not a very good expenditure of our funds.

I might add that it would be my recommendation that, if any other of our vessels become in the position where they drop consistently below 180 days a year, they should be replaced so that we can go back to between 200 and 220 days a year at sea. A good fishing boat will operate between 250 and 300 days at sea so that the fishing fleets operate many more days that this.

Mr. Miller. I can appreciate your problem in operating boats as obsolete as this in this service. Without going into the report submitted by the Ad Hoc Committee on Research Sciences, because we hope to have you before us on that later, we will just say that it recommends that we increase materially this fleet, that we have vessels especially designed for that purpose.

Do you feel that your laying up this vessel might adversely affect the results sought in that report? You are familiar with the report.

Mr. MoKernan. I am very familiar with it, Mr. Chairman, and I think it is a fine report.

We considered this but, since re are limited in our budget and since we have the responsibility for achieving the very maximum in results with this budget, we felt that it was necessary for us to do the thing that was right. It was the unanimous opinion of every expert who studied this particular problem in our Burean that the Albatross be laid up at the present time. There was no disagreement in this. In fact, the only disagreement had been in past years when even then a majority of our people for several years felt that the Albatross was an inefficient research vessel and should have been laid up.

It was unfortunate and purely a coincidence, I assure you, that it occurred at the time when this subcommittee report happened to be 
released. It was not done for any reason whatsoever to draw attention in one way or another to this very fine report that has been completed by the subcommittee of the National Academy of Sciences.

Mr. Muluer. I have two more questions. I do not want to take up too much time when we are rather limited.

You are going to do this work now by contract, I understand. You are going to contract with trawler owners and other people for ships to do this work?

Mr. McKernan. Yes.

Mr. Miluer. Will that be more costly than operating the Albatross?

Mr. McKernan. No, it will not. We will be obliged to reduce to some extent our sea work but this will allow us to catch up to some extent on the shore work because the operation of the Albatross has actually reduced the amount of shore work that we have carried out. It has been expensive and we have had limited funds so that we will be able to catch up to some extent on the shore work.

This is not a good operation permanently and we in Government we are not in favor of a permanent reduction in the oceanographic ressels operated in this important section of the North Atlantic. But, for the time being and with the funds available to us, this appears to be the most efficient way of getting our work done.

Mr. Mruler. Mr. McKernan, I know that you were not prepared for that question. I wonder if you could gather some data and quote some figures and put together a statement that you can supply for the record on that basis?

Mr. McKernan. Yes, I would be pleased to.

(The information referred to follows:)

Some Recent Charter Vessel Experience, Bureau of Commerctal Fisheries

\section{Pacific}

Mitkof: Halibut schooner-dragger out of Seattle. Used two seasons. Daily rate $\$ 335$, all costs including five-man crew. Season, $41 / 2$ months, total cost approximately $\$ 45,000$. Use: gill-netting for salmon; dragging for king crab, oceanography, International North Pacific Fisheries Commission research program. Carried two or more Bureau personnel. Range: approximately 2,500 miles. Length 72 feet, 62 tons, 9 knots, 200 horsepower. Electronic equipment: radar, loran, fathometer and radio. Wooden construction, built in 1932. Used in central North Pacific, May to September.

Paragon: Halibut schooner-dragger out of Seattle. Used two seasons, 1956 and $1957,2 \frac{1}{2}$ months. Rate approximately $\$ 350$ per day, covering costs and five-man crew. Season cost approximately $\$ 26,250$. Use: gill-netting for salmon, oceanography in central North Pacific for INPFC research program. Carried two Bureau personnel. Range: approximately 3,000 miles. Length 90 feet, SS tons, 8 knots, 165 horsepower. Wood construction, built about 1930 . Electronic equipment: radar, loran, fathometer, radio. Season, July to September.

Tordenskjold: Halibut schooner-dragger out of Seattle. Used two seasons and under charter for the 1959 season. Daily rate from $\$ 330$ to $\$ 375$, all costs including five-man crew. Season cost, $4 \frac{11}{2}$ months, May to September, approximately $\$ 45,000$. Carries two to four Bureau personnel. Used in salmon gillnetting, king crab dragging oceanography, INPFC research program, central North Pacific. Range: approximately 2,500 miles. Length 70 feet, 57 tons, 8.5 knots, 150 horsepower. Wood construction, built 1911. Electronic equipment: radar, loran, fathometer, radio.

Ccltic: Halibut schooner ont of Seattle. Used 1956 season, July to September. Daily rate $\$ 325$, covering costs and five-man crew. Carried two Bureau personnel. Approximate season cost $\$ 25,000$. Used in salmon gill-netting, oceanography, INPFC research program, central North Pacific. Range approximately 2,500 miles, length 70 feet, 57 tons, 8.5 knots, 135 horsepower. Wood construction, built about 1925 . Electronic equipment : radar, loran, fathometer, radio. 


\section{Gulf of Mexico}

Silver Bay: New England side trawler used for exploratory fishing and developing and testing of traml gear in the Gulf of Mexico and adjacent areas. Chartered for 2 years at $\$ 30,000$ per year, bareboat basis. Fuel, mess and gear provided by the Government. Vessel is 96 feet in length, carries a crew of nine, and can accommodate up to six Bureau personnel. Built in 1946, the ressel is of steel and has a range of 3,000 nautical miles.

\section{Atlantic}

Dartmouth: Scalloper out of New Bedford. Used September 1958, total cost $\$ 2,513$, cost per day $\$ 359$. (This was to have been a 2-year contract, with 50 days' use estimated, but the ressel changed hands and the new owner canceled the contract.) Crew of 11 men included in hire of boat. Type of work was dragging and sea-scalloping. The range of the vessel is unknown but it was an offshore boat which could go to Georges Bank. Fuel capacity 36,000 gallons. Length 85 feet, Carried three Bureau personnel. Electronic equipment: radar, loran, depth indicators, and radio.

Jacquelyn: Inshore dragger used for industrial fish project and sea scallop project. Cost $\$ 1,500$ or $\$ 300$ per day for five 1-day trips. Three in crew. Range: inshore. Length 43 feet. Carried 3 Bureau personnel. Electronic equipment: radio, echosounder. Time used, May to October 1958.

Silver MIink: Inshore dragger out of Provincetown used for haddock ecology studies for 1 day once a month. Thirteen 1-day trips made, costing about $\$ 5,000$ at $\$ 380$ a day, including crew of five or six. Bureau personnel carried, three or or four. Length, 62 feet. Range, not as far as Georges Bank, medium-range offshore. Electronic equipment: radar, loran, radio direction finder and radiotelephone. Time used, all of 1958 and to February 1959. This was an old shrimp trawler, now a medium-size New England dragger.

Unnamed vessel, used for Eastport redfish studies. Cost $\$ 30$ per day, including crew of one. Length 40 feet. Carried one to three Bureau personnel. No electronic equipment. Total cost $\$ 1,770$, for 59 1-day trips. Used July 1957 to October 1958.

Whaling City: Scallop dragger used before chartering the Dartmouth. Used June to August 1957, for two 10-day trips at $\$ 500$ a day plus fuel. Total cost $\$ 10,500$ ( $\$ 500$ for fuel). Cost included erew of 7 . Type of work-deep scalloping. Length 83 feet. Range: offshore. Carried three or four Bureau personnel. Electronics equipment: radar, loran, direction finder, echosounder, radiotelephone.

Silver Bay: Otter trawler, chartered for 3 months by Biological Laboratory at Boothbay Harbor. Cost $\$ 300$ per day, including crew and food, oil extra. Range: 3,000 miles. Carried four Bureau personnel. Electronics equipment: loran, radio, radar, echosounder. Use of vessel: plankton survey.

Mr. Miller. What is going to be the effect of laying up this ship on civil service employees who operated her? What is going to happen to them? You just cannot say that we need scientists and need people to build up an agency without the captain taking care of the troops or perhaps saying the chiefs taking care of the Indians. What is going to happen to the Indians in this case?

Mr. McKernan. We are doing quite a little bit in this regard, $\mathbf{M r}$. Chairman. I do not wish to give the committee the impression that we are going to be able to find jobs for everybody on the crew but, as you know, we have a daily fisheries news bulletin that we put out in New England as well as some other important fishing ports. In this particular bulletin we have run every day for about 13 days or so a notice which, in effect, indicates that there are a number of well qualified, experienced, loyal people. We enumerate the positions themselves and indicate that if anybody has any such positions we would be pleased to communicate with the employees and attempt to act as liaison between the employees and new employers. This has already brought about some effects. 
We know that there is at least one offer at the present time for one of these crew members and we have considered and have actually hired some of these displaced men for the increased crew on the Delaware, so that we certainly have the welfare of these people as one of our concerns.

We recognize our responsibility and we shall do what we can to attempt to see that their livelihood is upset as little as possible.

Mr. Mruler. About how many are adversely affected?

Mr. McKernan. Seventeen.

Mr. MILLer. Mr. Dorn.

Mr. Dorn. What exactly did the Albatross do?

Mr. McKernan. She went to sea, Mr. Dorn. In some cruises she ran oceanographic sections. 'This meant that she would go out and make plankton tows in a certain manner with plankton nets and drop oceanographic bottles to different depths and sample the water.

When these data are analyzed in the labolatory, they give us an idea of the currents and changes in current patterns. Some of our important problems in New England are the matter of the disappearance and recurrence of various fish populations along the coast and also the locating of any changes in the general environment of fish.

Of course, since fish are cold-blooded animals, they are completely subject to their environment. These great populations of fish inhabiting the bottom areas of New England-for the New England resource is really a bottom fishery-these great fish populations are subject to changes in where they occur and in what numbers they reproduce successfully. The study of their environment, of course, plays a very important part in forecasting their occurrence and the success of proper reproduction. In fact, they are far more subject to their environment than any warmblooded animals that we normally study, so that one of the things we do is study the climate of the water, the climate of the environment.

Another thing is to sample the fish populations and effect of the fishing itself on the populations for, in addition to the environment affecting the populations, the fishing itself, of course, crops and harrests these fish and we wish to ascertain at what population levels these fisheries will produce to the very maximum extent.

Thirdly, we have an important function which is in carrying out in certain areas and in certain matters both the biological and hydrographic work I just described to you.

We have an important function with the Northwest Atlantic Fisheries Commission, a Commission of some 12 nations now with the advent of Russia accepting this particular convention during 1958. We do have important responsibilities with respect to this Commission.

Then there are other very important fisheries in the North Atlantic, the great herring fisheries of Maine, and the great scallop fisheries out of New Bedford. Data on all these are collected on our research vessel giving us information upon which to base predictions and by which we understand both the future and past of these great fisheries resources.

Mr. Dorn. You say that the work of the Albatross has been replaced by hiring trawlers. Has that curbed any of this activity at all? 
Mr. McIinanan. Ies, there will be a curb in some of this activity. Wo expect, for example, in fiscal year 1960, that fiscal year beginning in July, to do a great deal of this work through chartering the Delaware; in other words, to more efficiently use our vessel, the Delaware. To are anticipating that our sea work will be somewhere in the neighborhood of 110 chys during the next fiscal year, whereas we had anticipated about 150 days this year with the Albatross or a net reduction of somewhere in the neighborhood of 40 days.

The funds from that net reduction will be spent in attempting to analyze the data that have been collected in a more complete manner than has been possible in the past few years.

Mr. Dorx. How many trawlers have you hired?

Mr. McKernax. Now, in general, as I recall the figure, we have nartered about four, I think, up there recently at varions times. These are short-term charters when we have a cruise and then, as I said before, we will charter our own boat and operate it $2+$ hours a day by increasing the crew. Therebr we are increasing the nse of the Detavare. She has been operated on a 1.2-hour-a-day basis recently.

Mr. Donn. Do you have any triwlers that have been chartered at the present time?

Mr. Mckervax. Right at the moment I do not think we have, but in the very recent past we have chartered some trawlers. Iast fall, Mr. Eckles of our Research Division informs me, we chartered a trawler for scallop research.

Mr. Dons. Actually you have not chartered any trawlers to replace the work that the 176 atross did do?

Mr. McKrenax. At the present time we have not. The Albatross was decommissioned on the 9 th of this month so that there have been no charters at the present time.

Mr. Dons. So that your answer to the chairman that you chartered trawlers to replace the work that the Albatross was doing is not entirely exact.

Mr. MCKervax. Well now, I am very sorry if I misinformed the chairman. The Delaudre is a trawler type boat. It operated as a trawler before we took her over and she is our exploratory fishing boat in New England.

We have right at the moment, for example, cruises during this coming month planned for the Delaware to handle some of the work that the Albatross was doing so that I attempted, as best I could, to answer the chairman's question correctly. I did not mean to mislead him.

Mr. Miluer. I may say, Mr. Dorn, that maybe I did not put it correctly becanse I did not mean to imply that any work had actually been done and contracts entered into but in this letter to Senator Saltonstall, which perhaps you have not seen, they pointed out that they would charter trawlers. I should have put it that way.

IIr. Dors. This action was not contemplated when you requested funds for this fiscal year, was it?

Mr. McKernan. "The decision to deactivate the Albatross had not been made at that time, Mr. Dorn. Action on the Albatross has been consiclered every year since I have been back here, which is only 2 years by the way, but a consicleration of the A7batross and her expensive operation and less-than-efficient operation has been considered 
every year by me since I have been back here. However, it was not a decision that had been taken when we budgeted for 1960. You are correct.

Mr. Dors. Going back to some of the answers that you gave me in the discussion we have had up to now, you mentioned something about chartering the Delaware. Is not the Delaware your ship?

Mr. McKernan. Yes. This is in a sense a figure of speech, but it is operated by our Branch of Exploratory Fishing and has its own program laid out for the year after a careful programing preceding the fiscal year.

By the way, it was short of funds also and what we have done now is that the Research Division has contacted our Exploratory Fishing people and they have planned the work together.

Now, we have felt that it was advisable to keep the Delaware under her present managrement and so what we are doing is an intrabureau charter, which is perhaps not a very good word because what it will amount to is a transfer of funds on the basis of the days at sea that the research people use the Delaware. That is planned now and there is a program which is being put into effect at the present time.

Mr. Dorn. In your budgetary plans, have you started on an idea of actually replacing the Albatross?

Mr. McKernan. Yes.

Mr. Dons. What is that idea that you have started on?

Mr. McKernan. In fact, we have had an idea for some time to replace the Albatross but, of course, we have budgeted within the limitations of the overall Federal budget and our plans at the present time are still subject to the limitations that are given all Federal departments at the present time. Within those limitations and within the general balance of the Federal budget, we are planning that in our turn, we will construct a research vessel which will be appropriate and will be designed specifically for the kind of oceanographic and experimental fishing that the Albatross has been carrying out.

Mr. Donn. That sounds like 1985.

Mr. McKernan. I hope before that, Mr. Dorn.

Mr. DorN. Well, is that thinking for 1980 then?

Mr. McKernan. I certainly hope it is before that?

Mr. DonN. Then does it bring us to 1970 ?

Mr. McKernan. I hope it is before that.

Mr. Dons. Now, what I am trying to get at from the circumspect language that you use is, When will it be?

Mr. McKernan. It will be as soon as my superiors give me permission to include it in my budget.

Mr. DonN. You would like to include it in your budget immediately, would you not?

Mr. McKernan. I would have liked to have included it in the budget in the past.

Mr. Dons. You think it is essential to include in your budget, do yoll not?

Mr. McKernas. I think that for the time being we can do a great deal of good research work without it, but I certainly think that it is an essential part of a full research program that is needed in Now England.

Mr. Dorn. Then, the answer to my question really would have been "yes"? 
Mr. McKennan. Within the limits of my prerogatives to set such policy, yes, that is correct.

Mr. Dors. So that, summing up, in order to have proper functional scientific research, it is essential to have the Albatross replaced immediately?

Mr. McKernan. No.

Mr. DonN. How do you differentiate?

Mr. McKernan. We have a back log of scientific data in our laboratory in Woods Hole and there will be a loss in the collection of scientific data and there will be some interruption. My "no" perhaps should have been qualified to that extent, but nevertheless the essential parts of our New England program can be carried on effectively with the present arrangements. We were assured of this by the director of the laboratory, Dr. Graham, before he helped us make the decision to deactivate the boat.

Mr. Dons. I think, though, that you would feel very decidedly that the limitations incurred are curbing scientific research?

Mr. McKernax. I am sure I could not answer that in any other way but "yes."

Mr. Dons. That is all.

Mr. Mirler. Mr. Oliver.

Mr. Oliver. Thank you, Mr. Chairman.

Mr. Director, I have a great interest, of course, in the work that your Bureau or Department is doing, primarily of course because of coming from Maine, as I do.

Your reference to the herring catch there is of prime importance to us.

Mr. McKernan. Yes, sir.

Mr. Oliver. Also another problem that confronts us or has confronted us for some time is the matter of offshore dragging of lobsters. This local interest of mine, however, is perhaps overshadowed I may say by the great problem of how are we going to get more research so far as our oceanographic goals and objectives are concerned, and I would gather from your testimony as of this time that it is your feeling that oceanographic research in terms of the recommendations perhaps of the committee of scientists is going to be cramped and stifled and delayed by reason of the inability of the Bureau to meet the monetary requirements of such increased research.

Is that a correct statement or a reasonably correct statement of the situation?

Mr. McKernan. Well, considering the report of the subcommittee, of course, these things cost a great deal of money and, when those funds are not made available, obviously the increases recommended to the extent recommended by any committee cannot be carried out.

We still will carry out both in New England and other parts of the United States important and absolutely essential oceanographic and marine biological work to the very maximum extent possible with the funds made available to us.

Mr. Oliver. To make a direct inquiry, are you going to be able to carry on the necessary work, the essential work with regard to information concerning the herring catch for this next season, for example?

Mr. McKernan. Yes. 
Mr. Oliver. You are going to be able to carry on as much work as you have last year, for example?

Mr. Mchernan. Yes.

Mr. Oliver. What about this business of offshore dragging for lobsters? Has your Bureau been in that picture at all?

Mr. McKensix. Yes. I think we have. In fact, the Detaurare has been doing that particular work. We will anticipate that she will carry on those very important offshore exploratory efforts during the coming year.

I do not mean to imply that I think that more should not be done because this is not the case, and I furthermore do not, on the other hand, wish to imply that we do not have funds to do important work which wo feel will contribute directly to the benefit of the New England fisheries and of other coastal fisheries of the United States, because I do not feel that way. In other words, I do not feel that we are so stifled that our efforts are ineffective. I certainly do not feel that.

I feel that onr efforts are very effective and that we will, during 1960 , bo able to carry out effective and essential parts of this program.

Mr. Ouner. May I ask you this: With regard to the budgetary allotments for the Albatross specifically, is it your statement that the Albatross has been operated within its budgetary allotments up to now?

Mr. McKernan. The Albatross was operating on a deficit when we closed her down. In other words, had we contimued operation for the rest of the year as it was plamned with no increass, we would have had a deficit in her operating budget which would have had to have been made up out of our research budget.

Mr. OLIver. I have some information, and I do not know whether it is correct or not, which indicates that the last balance sheet, dated January 31, 1959, showed that the A7batross was well within her maintenance work and average repair budget for fiscal 1959.

Mr. MoKervax. That information is incorrect.

Mr. OLIVER. That is incorrect?

Mr. MoKernan. Yes.

Mr. OLivel. What has been the repair expense on the Albatross during the years 1957,1958 , and 1959 ? Have you those figures arailable?

Mr. Mrchelinan. Yes: I do.

Shipyard repairs were $\$ 25,000$ in $1956, \$ 51,000$ in 1957 , and $\$ 24,000$ in 1958 , and $\$ 24,500$ so far in 1959 .

Does that give you the information? Those were shipyard repairs.

$\mathrm{Mr}$. OLIVER. If my arithmetic is correct, that means an average annual expense of $\$ 33,000$.

Mr. McKernan. Yes.

Mr. Otsver. Is that comparable to some degree perhaps with the operation of a comparable sized boat or vessel in the private industry, we might say?

Mr. MCKinnas. I think it is higher.

Mr. Orrvek. You think it is higher?

Mr. MrKiman. Yes.

Mr. ()wrve. I have information which indieates thit the avelare anumal overhanl costs for a 100-foot towboat, for example, run between $\$ 30,000$ and $\$ 40,000$. 
Mr. McKernas. I have no information on towboats.

Mr. Oriver. I should expect you would not.

Mr. McKernan. My experience is in oceanographic and fishing vessels.

Mr. OLiver. I was wondering if there was any similarity there so far as average costs are concerned or whether there could be any similar amount involved in a vessel operating under your supervision and one operating in private industry.

Mr. MeKenvas. There would be if they were doing similar work. For example, fishing vessel operations are more like ours except that we are required to keep our boats in much better condition than fishing boats. For example, none of the fishing boats is moler Coast Guard inspection.

We keep ours up at considerable extra expense to meet Coast Guard and American Bureau of Shipping standards and many of the fishing boats do not.

Mr. Oliver. By the way, this Albatross, as I understand it, has been declared seaworthy by the U.S. Coast Guard.

Mr. McKernax. That is correct. She is seaworthy.

Mr. Ourver. When they say "seaworthy," does that mean that it is capable of taking on any particular work that is necessary out in a deep ocean in off'shore work?

Mr. McKernax. At that time: yes. In other words, I would be willing to sail on the Albatross if she were operating right now. It might break down but I do not think it would sink.

Mr. Oliver. Would that not be true with the Delaware, too? Might the Delaware not break down?

Mr. McKinnax. Ies; except that the Delaware is a much younger vessel.

Mr. Otiver. Was not the Albatross given a major repair job by the Navy? They were using it, were they not, during the war?

Mr. MoKernan. I do not think they ever used it. All they did was get it ready for use and tested it for a number of hours and I do not think they ever used it. I have seen some of the information that you may have had. I had a letter to that effect. I do not believe that information is quite correct. I think we overhauled it at a cost of about $\$ 125,000$ but this does not affect the hull and other essential parts of the structure itself. We put on a new superstructure and made her usable for research work to the best that her basic design would allow.

Mr. Oliver. I see. What would be the comparative operating cost between the Delaware and the Albatross per month?

Mr. McKernan. The Albatross probably cost $\$ 3,000$ or $\$ 1,000$ per month more than the Delaware.

Mr. Oliver. Now, on the $\$ 3,000$ or $\$ 4,000$ additional cost, how much larger scientific personnel force conld be carried or has been carried on the Albatross as compared to the Delaware?

Mr. McKernan. The Albatross has carried 17, because she has been used for oceanographic research work.

The Delaware has been operated as much as possible as a fishing boat so that she carries the same crew as a fishing boat and she is operated with 11.

The scientific crew is your request?

Mr. Oliver. Yes. 
Mr. McKernan. I am sorry. 'The Albatross can carry up to eight or does carry up to eight.

The Delaware can carry six.

Mr. Oliver. The Delaware can carry six scientific personnel with her present accommodations?

Mr. McKernan. Yes; she has 23 berths on board. At the present time she has $11 \mathrm{crew}$ members. We expect to increase her crew to 17 which would leave 6 berths.

Mr. OLiver. Will that call for additional expense of operation of the Delaware?

Mr. McKernan. Absolutely not. If we want to increase that above six, it will require some revision which is absolutely minor to add some new bunks to her, but at the present time she will carry six extra personnel without any difficulty in addition to the some six extra people that we will need for the crew.

Mr. Oliver. 'To get back to this business of chartering fishing boats for carrying on this additional research work that you say you have planned or programed out, is the fishing industry at the present time reasonably well occupied? I mean, are they using a large portion of the fleet that is available for private fishing operations?

Mr. McKernan. Yes, to a considerable extent. However, we always get quite good vessels to bid and it is not true that only obsolete vessels bid on our charters. In fact, we do not take them if they will not do the work and will not do it well.

Mr. Oliver. Is the cost of that chartering going to be comparable perhaps in any way to the operating costs of the Albatross?

Mr. McKernan. I think it will be cheaper. We will not be able to do quite as comprehensive work because the equipment will not be on these commercial boats, but we expect the charter will be cheaper.

Mr. Ourver. For example, when these seamen who operate the Albatross are thrown out of work because of this deactivation of this vessel, I think you stated in the letter that they probably could find jobs in the fishing industry because the fishing industry is now fairly good. Are they going to be able to find jobs? Are you trying to get them placed?

Mr. McKernan. Yes, we are certainly helping. I would be very hopeful that they would be able to find jobs.

Mr. Oliver. Are these fishermen that can go out and find a job, we will say, in private industry, experienced hands that you are going to have to replace at some time for work on a research vessel that you may be operating? Do you have to go out and train other people to be as competent as they have been?

Mr. McKernan. These people are certainly competent on our vessels. They are all trained as fishermen and they are all New England fishermen insofar as I am aware. I might be wrong about one or two, but I think this is the case, so that they can step into the fishing industry in New England.

Mr. Oriver. In effect, could it not be true that by losing them now you may have difficulty in replacing them with men as good later?

Mr. McKernan. It could be true.

Mr. Oliver. Is that good business?

Mr. McKernan. No, not if it could be helped, but $I$ think it is much worse business to have a boat lying at the dock and simply paying for 17 people and not using the boat. 
Mr. Oliver. You mentioned this business of days at sea with the Albatross. I have some figures here which indicated that in fiscal 1957 there was a record of 137 days at sea and in fiscal 1958 a record of 149 days at sea and in a portion of fiscal 1959 the record is 102 days at sea.

I assume those are fairly accurate figures.

Mr. McKernan. Those are correct.

Mr. Orrver. In talking about the portion of the year 1959, does that include the 25-day Christmas holiday period that the ship would have been at the dock in any event?

Mr. McKernan. I do not know how many days it was, Mr. Oliver, but I am sure that through 1959 it was 102 days that the vessel was at sea up to March 9 when it was deactivated.

Mr. Oliver. March 9 of this year?

Mr. McKernan. Of this year, yes.

Mr. Oliver. You think that there would have only been a matter of only about 30 more days?

Mr. McKernas. With funds that we had there would have been less than that.

Mr. Oliver. But so far as the condition of the vessel is concerned?

Mr. McKernas. Had we had unlimited funds to operate the vessel regardless of her efficiency, I suspect we would have done about the same as we have done in the past 4 years, about 150 days.

Mr. Oriver. You think it would not have run over 150 days if you had the funds to keep it operating or had wanted to use the funds to keep it operating?

Mr. McKernas. I cannot be certain about that. It would depend, of course, upon some other factors but, just looking at the record, I would say that she would be expected to operate at about 150 days.

Mr. Oliver. I am taking too much time, Mr. Chairman, but these questions, to me, should be clarified.

I have just a few more.

Mr. Millar. Go ahead.

Mr. McKernan. 'The Delaware has operated about 180 days in contrast to this 150 or 145 days that the Albatross has operated.

Mr. Oliver. Do I understand from your previous replies to questions that you feel that we should have more research facilities if we are going to carry on a real program of oceanographic research?

Mr. McKírnan. I would hope so.

Mr. Oriver. Did I understand you to say that during your regime that additional funds have not been asked to get the tools with which to work, namely, vour research vessels?

Mr. McKernan. Our Bureau has had a fair allotment of the Department's budget with respect to research. There was no increase in research allowed in the President's budget for this year. In general, since the Saltonstall-Kennedy funds became available from import duties in 1955, I believe there have been little or no increases in our research budget. I am saying that right off the top of my head, Mr. Congressman.

Mr. OLIver. You and your associates have not been too aggressive in fighting for additional budgetary funds.

Mr. McKernan. This is not necessarily true. I am, of course, not at liberty to indicate our efforts in this respect, but we have aggres- 
sively attempted to put our case and I think if the records of the Department of the Interior were examined, it would show that our Bureau has been getting a fair allotment of funds, too. That is, we have not been cut short and our ellorts and our justification with respect to research has allowed us what appear to me to be a fair share and perhaps even in some instances a little more than some of the other bureaus of the Department. That is, I do not feel that we have been treated unfairly.

Mr. Ourver. I am happy to have you give me that reply. I felt, in looking over some of this information that I have, that there has not been too aggressive an effort made by the Bureau to get its proper share of funds.

Mr. McKern.s. I have been accused a great many times of the opposite.

Mr. Oliver. That is very good. I hope that that means that up in New England, particularly off the Maine coast, we are going to get more work done on herring production and also that we are going to be able to get out and study further the impact of that deep sea dragging for lobsters which bothers us rery much.

Mr. McKernax. Sometime I would like to tell you about our herring research up there. It is very interesting.

Mr. Oliver. To close, as far as I am concerned, Mr. Chairman, for the moment, I sent a telegram on my own. I might say, to the Director of the Woods Hole Institute, and I would like to read the last sentence of his reply and then insert it in the record at this point.

Mr. Miller. Withont objection that may be done.

(The telegram referred to follows:)

Representative JAMES C. OLIVER,

Woons Hole, Mass., March 6, 1959.

Washington, D.C.

This institution has not used research vessel Albatross $I I I$ since the summer of 1952 hence deactivation will not affect our operation, our understanding is that scientific personnel are not affected by this action, however, laving up of research vessels such as the Albatross makes it mandatory that positive action be taken to create a research flect as proposed by the National Academy of Sciences report on oceanography.

\section{PAUL M. FYe, Dircetor.}

Mr. Oriver. I asked him two or three questions, whether or not the deactivation of the Albatross is going to interfere with the scientific research at Wroods Hole, and he replied that it would not affect "our operation."

I suppose that means the Woods Mole Institution itself not the Federal effort, is that correct?

Mr. McKernan. Yes.

Mr. Oriver. It-

will not affect our operation. Our understanding is that scientific personnel are not affected by this action. However, laying up of research resscls such as the Albatross makes it mandatory that positive action be taken to create a research fleet as proposed by the National Academy of Sciences report on oceanography.

signed "Paul M. Fye, Director."

I assume you would go along with that statement? At least, that is the implication I have of what you said here today.

Mr. MeKmens. 'That is correct.

Mr. Orwan. Ini other work, the more that we can all do together to get more funds for this particular purpose making our oceano- 
graphic research more effective and more expansive would probably be in the interest of the country as a whole.

Mr. McKernan. Yes.

Mr. Oriver. Thank you very much.

That is all I have.

Mr: Miller. Mr. Pelly.

Mr. Pelur. Mr. MeKernan, are we going to go through this in connection with Alaska, too? Are you transferring any vessels to the new State or discontinuing any operations up there?

Mr. McKersax. We are transferring our management vessels to the new State for their use and we have deactivated two rather obsolete ressels in Alaska.

Mr. Peluy. Are those vessels operated with civil service employees?

Mr. MeKernan. Yes.

Mr. Pelly. In other words, there are no openings available for transfer?

Mr. MeKernan. No.

Mr. Pelur. Do you anticipate that you will have further reductions in the Alaska operations in ressels?

Mr. McKernax. Yes, we will, Mr. Pelly.

Mr. Pelur. Are those budgetary or in connection with the State?

Mr. McKensax. Those are in connection with the transfer and, of course, the budgetary picture for us changes with the transfer of functions as it well should.

Iere again we are attempting to work with the new State and again bring about a painless transfer of these personnel everywhere possible but, as yet, there are problems involved in the pay scales and benefits and various other matters. I am sure that the new State will take the position that they wish to pick and choose with respect to the employees and will not. want to take them over in toto. They have indicated such.

Mr. Pelly. You had prior to statehood how many ressels there?

Mr. Mchersax. I think we had a total of about 30 . I am pulling this out of my memory, Mr. Pelly, because I am not prepared to answer in detail. I think there are about six major vessels in Alaska, one or two of which have been carrying on research and will remain with us.

Mr. Peluy. How many have you transferred to the new State?

Mr. MCKerNax. We have made arrangements to transfer all of the remainder that are not used for research, but you may remember that that transfer of authority has not taken place, so that most of those vessels are still being used by us.

There were two of them that were old and we felt were inefficient to operate and we have decommissioned those.

One, I think, is being loaned to the State of Washington.

Mr. Percy. TVere those ressels all manned with civil service persomnel?

Mr. Mclínsax. Yes, they were excepted personnel exactly in the same classification as the New England people.

Mr. Pelly. What is the budgetary situation, then, as far as the management of the Fish and Wildlife Commercial Division in 1960 as aginst 1959 ?

Mr. McKenndx. It remains approximately the same. 
Mr. Pelly. And you are going to operate less vessels with about the same anticipated amount of money?

Mr. McKírnan. Approximately, yes.

Mr. PeLLy. Are the vessels there obsolete like the Albatross?

Mr. McKennan. Yes. There are probably two or three others that the State will want to lay up. In connection with those that we are laying up, we cooperated and coordinated our actions with the officials of the new State and, in fact, simply asked them if they wanted them in their present condition, and reached complete agreement with them that they should be deactivated.

Mr. Pelly. Will the overnight closing of fish traps eliminate any management work and save any money?

Mr. McKernan. No.

Mr. Pelly. Then, as I understand it, actually getting down to research you will have two vessels in the Alaska waters; is that correct?

Mr. McKernan. It depends a little bit on the size and I think we will have one large research vessel in Alaska and in fact two smaller ones. Then, plus that, we will have one large one, the John N. Cobb, stationed in Seattle which works the Pacific Northwest and Alaska so that there probably will be two boats working part time in Alaska.

Mr. Pelcy. You do not anticipate that there will be any less research work or less effective work during the next fiscal year?

Mr. McKernan. No; there will not be less.

Mr. Pelly. But you will probably have in your mind that there would be some need to ask for funds to construct new vessels for the Pacific as well as New England?

Mr. McKernan. In research?

Mr. Pelly. Yes.

Mr. Mchínnan. Yes; our entire research fleet is pretty obsolete. Even our new vessels are not in very good condition and the report of the National Academy of Sciences properly assesses the condition of the American oceanographic research vessels in general, and those include ours and our vessels I might add, even the best of them, are in my opinion worse than probably the worst that a country like Japan has.

Mr. Miller. Will you yield for just a minute because I may as well do this now.

Mr. Pelly. I yield.

Mr. MiLLER. Will you prepare for the record a complete list of your rescarch vessels showing pertinent data referring to them, their size, location, length, power, the date on which they were built or launched. and the date of their last major overhaul?

Mr. McKernan. Mr. Chairman, would you like that limited to some size since we have a number of small motorboats.

Mr. Mirmer. Yes. I would limit that not to small craft but to craft that are capable of going to sea offshore and staying offshore.

Mr. McKernan. Yes, we will be pleased to do that.

Mr. Mrrcer. I have merely indicated some of them but I would like a complete history.

You can talk to counsel and get together on the type of data that we want.

(The information referred to follows:) 


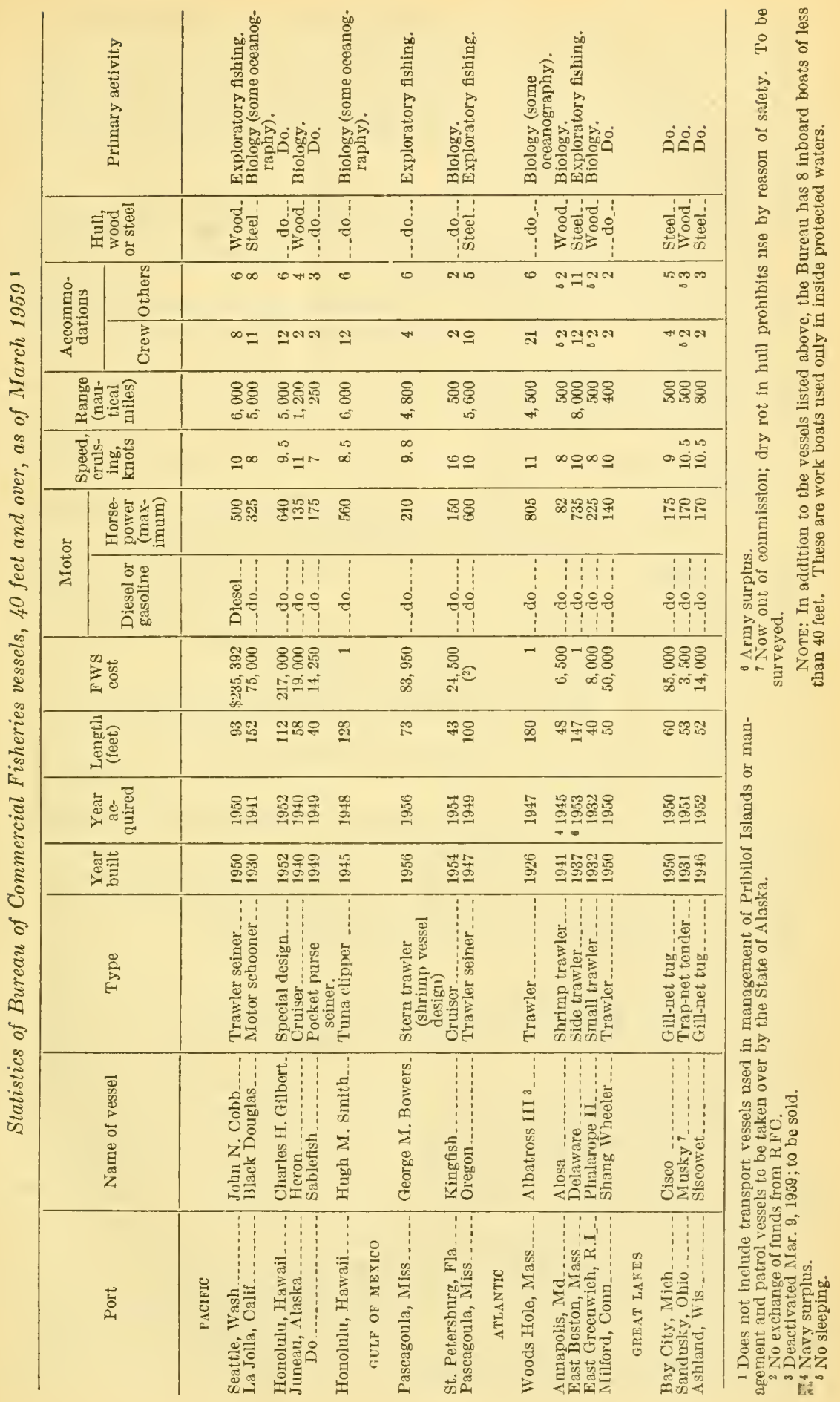


Mr. Miller. Excuse me. That was a good place to insert this.

Mr. Curtin. Will the chairman yield?

Mr. Milluer. Yes.

Mr. Curtiv. Do I understand that this witness was going to supply you with information as to the cost of chartering these trawlers?

Mr. Milleer. Yes.

Mr. Pelly. I was all through.

Mr. Miller. Mr. Flynn.

Mr. FlynN. I have just a couple of questions. You mentioned your operating limitations on your budget. Will you tell us who put on that limitation and what the limitation is?

Mr. McKernan. I think every Federal agency is working within the limitation of the President's budget and we are no exception to that, Mr. Flynn.

Mr. FlynN. Do you have a budget of your own or does yours come under your parent department?

Mr. McKernan. Well, we have a budget of our own as a Bureall of the Department of the Interior and this comes under the Department's budget.

Mr. FLYNN. And you present your budget before the budget hearing or is that presented by the Department of the Interior?

Mr. McKernan. I present the material at the congressional appropriations hearing.

Mr. Firns. And that is the Burean of the Budget hearing?

Mr. McKernan. Yes, my staff and myself appear before the examiners before the Burean of the Budget hearings.

Mr. FLYNN. And also before the President's Board?

Mr. McKernas. Well, the Bureau of the Budget is the President's Review Board for all administrative departments.

Mr. FLYNN. Then you also appear before the congressional bodies?

Mr. MoKennan. Yes, sir.

Mr. FLYNn. As far as the Bureau of the Budget is concerned, what did you ask for that they failed to give you?

Mr. MCKernan. I do not believe that I am allowed to give out that information without permission from my superiors, Mr. Flynn.

Mr. Miller. What was the nature of the question?

Mr. FLYNN. With this boat being out of operation, I asked him what he asked for.

Mr. Mulwis. That is very true. He cannot give that out to you at this time. $\Lambda$ s a Member of Congress individually you can write to the Bureau and ask for it. You will not get it until after the Bureau of the Budget has put its mark on it but after the Bureau of the Budget as approved, then they can come and tell you as a Member of Congress what they asked for.

Mr. Fryns. In any event, because of the anticipated reduction in this year's budget, your Department made a decision to lay up the Albutross?

Mr. MoKminan. Notentirely, Mr. Flynn.

Mr. FLYNN. What other factors then entered into it, sir?

Mr. MCKrirnan. 'The obsolescence of the boat.

Mr. FIYNN. In comparison with the Delaware, which boat is in the best condition?

Mr. McKirnan. 'The Delaware. 
Mr. Flyxs. Which is the newer boat?

Mr. McKennan. The Delaware.

Mr. Fly

Mr. McKernan. I cannot give you the detail of those, Mr. Congressman. I am not at all sure that there are any repairs that you can put your finger on right at the present time, but, as I mentioned to the chairman, the Albatross is an old boat and repairs simply mount up like they do in any old piece of machinery and this boat is about 10 to 15 years beyond the normal replacement time. You normally would replace a steel ressel like this in between 15 and 20 years.

Mr. FlyNx. But it is seaworthy?

Mr. Mrínran. It is seaworthy but it is old.

Mr. Flyns. And it has been doing oceanographic research?

Mr. McKernan. Right, inefficiently during the past several years.

Mr. Flysx. Do you have any boat to take its place in this research work?

Mr. McKersax. As I said before, we are operating the Delaware to a greater extent and to that extent it will replace the Albatross.

Mi: Flyxs. But the Delaware has been limited pretty well to fishing?

Mr. McKersax. To exploratory fishing but it is capable of doing oceanographic work also.

IIr. Flyxx. In any event, you are substantially reducing the amount of research that would be done if you operated the Albatross in addition to the Delaware?

Mr. MrKervan. We are substantially reducing the sea work at the present time, yes.

Mr. Flyxi. And by reducing the sea work you are reducing the research work?

Mr. MCKenxax. No, we are actually going to be able to increase the analysis of research work by the diversion of funds that would be spent for the excessive costs of operating the Albatross to additional research work on shore.

Mr. Flyxis. You used the word "analysis." Does that mean you are going to spend more of the budget in the office and less of the budget on the water? Is that right?

Mr. McKensas. We will spend more of the budget in the laboratory dealing with the data that have been collected at sea, yes.

Irr. Fursw. Do you have substantial data that have not been worked out?

Mr. McKennax. A great deal, yes, sir.

Mr. F Fryx. For how many years past has that been gathered?

Mr. McKrrsan. Well, we have been operating for a grood number of rears and I am told by the Laboratory Director, Dr. Graham, that there is a backlog of data and that it is essential that this be canght up and that, while the loss of the use of the Albatross will certainly affect our program, and I would not mean to imply anything else, nevertheless a great deal of this, for the time being, will be made up for by an increased efficiency in the operation in the laboratory in the analysis of the data.

Mr. Flyxs. But your main reason for laying up the Albatross is the fact that your budget did not provide adequate funds to operate
it? 
Mr. McKernan. No. I am of the opinion that no matter what the budget was that very shortly or at the present time I would recommend laying up the Albatross anyway because we need a research boat in New England that is designed for the purpose of oceanographic and marine biological work and the Albatross is not. It has never been a good research boat. These conversions never are and the Albatross is worse than most of them that we have in this regard, so that it has never been a good boat. It is far beyond its useful age and its effective operations have been limited in comparison to our other good research boats which are also old, by the way, most of them. Most of them are conversions. So that, if we had the funds, Mr. Congressman, at the present time I would recommend laying up the Albatross, so that the funds problem is important but it is not the real factor. These things pile up on you.

We have delayed laying up the Albatross now for about 3 or 4 years, and at some time or another this particular decision must be made.

It so happened that at the present time we were confronted with budgetary problems with these increasing costs. We felt that we could more effectively operate the Delaware than it has been possible to operate her by chartering her in an intrabureau manner and get the very maximum use out of one boat. Then, by more efficienly using our scientific staff, work up back data and the data that the Delaware will collect.

It seems to us with the present funds this is the best way to operate.

Mr. Flyns. By the same reasoning, why did you not lay up the other outmoded vessels that you speak off ?

Mr. McKernan. In no instance that I know of are the vessels operating in the same inefficient manner and with the same budget problems that we had in New England at this time.

Mr. FLYNN. For the record, so that you will know the reason for my question, I am deeply concelned over what I believe is a tendency to have inefficient operation of necessary departments under the guise of a balanced budget. I am interested in determining whether or not we are getting an efficient and a proper operation of the Department or whether it is being sacrificed because of an attempt to save money and balance the budget.

Do you feel, in the nature of my question, that you have had allotted to you in your budgret enough money to efficiently and competently operate your Department for the year?

Mr. Mclíernan. Yes.

Mr. Flyns. Do you feel that your Department can do all of the oceanographic research that you should do?

Mr. Mclíernan. No.

Mr. FLYN . Do you feel that if you had a greater budget you could perform a greater service in this oceanographic research?

Mr. McKernan. Yes.

Mr. Flyns. Do you feel that you need another boat to perform this work?

Mr. McKernax. Eventually we do. For the time being $I$ think that the present plans that our stafl have organized and have presented to me are sufficient to carry on the essential work and to allow efficient operation, and I want to assure you, Mr. Congressman, that 
not only myself but everybody I come in contact with in my Department is interested in exactly the same thing you are and we are not interested in inefficient operations or any kind of waste and this present action was designed particularly to correct that kind of a thing.

Mr. FLYNN. Thank you.

Mr. Miller. Mr. Curtin.

Mr. Curtin. Thank you, Mr. Chairman.

Do I understand that the Albatross is the oldest of the vessels engaged in this kind of work?

Mr. Mchíervan. I think it is the oldest oceanographic vessel in the United States.

Mr. Curtin. How old is it?

Mr. McKennan. It is 33 years old.

Mr. Cortin. Do I understand that it is your intention to charter four trawlers to do part of the work that was being done by the Albatross?

Mr. McKennan. Mr. Curtin, not specifically. The question that was put to me, as I recall it, was how many vessels have we chartered, or at least I answered that question.

The answer was that we have in about the last year chartered four different vessels and you know we put those out on bids. We ask for bids and tell them what we are going to do and the length of the cruise and we put out the specifications needed. 'Then these various vessel owners answer our bids and bid on this particular cruise or this particular project so that this is somewhat indefinite-and I do not mean, under any circumstances, to be evading your question, but it is not possible to give the precise number of vessels or cruises that will be chartered during the next 4 or 5 months.

Mr. Curtis. Then you are not in a position to say how much the cost of this charter service is going to be for the next fiscal year as compared to what it would cost to keep the Albatross in operation?

Mr. McKernan. Yes, I am, because when we do not charter outside vessels we will have an intrabureau charter of the Delaware so that I am in a position to say that the approximate cost of vessel operation next year, I think, is about $\$ 110,000$ for the biological portion of our program. That compares with an estimated budget of $\$ 192,000$ for operation of the Albatross.

Had we operated the Albatross at $\$ 192,000$ next year, which was the estimate that it would have cost us, this would have meant that the scientific work in New England would have dropped $\$ 67,000$ in order to meet those estimated increased costs.

Mr. Cortin. But if you use these trawlers you will not do the same amount of scientific work on the high seas, will you?

Mr. MoKernan. No; we will not.

Mr. Curtin. You will do a lot more work in the laboratory on information you have previously assembled?

Mr. McKernan. Yes.

Mr. Curtin. Is it your thought that these trawlers are more effciently designed so that they can better do the work formerly performed by the Albatross?

Mr. McKernan. In connection with the fishing portions of these charters, a charter of the fishing vessels themselves is even more efficient, but with respect to any aspects of oceanography and any as- 
prets of on marine hiological work requiring precise navigat ion right down to almost the yard, the answer is that the fishing ressels are not as eflicient and in the long haul fishing ressels are not good ressels to use for ocemographic or maline biological work. They do not rephace oceanogiaphic ressels and we would hope that this is an interin replacement.

Mr. ('untr. I got the inpression from you that the Albutrose was senworthy, is that true?

Mr. MCKensax. It is seaworthy at the present time; yes, sir.

Mr. ('crtix. I also got the impression that the power plant was Satisfactory.

Mr. MCḰrenan. They are not in bad shape for their age.

Mr. Curtis. Then is the inefinciency due to the equipment that is now in the ressel?

Mr. MoKmaxax. Well, the inefficiency in general is just due to the age of the boat and the firct that the ressel was never designed to do oceanographic and marine biological work and the fact that for most of our work she is a little large; and all of these things combined make her rather ineficient for the purposes that we need.

Mr. Curtin. How many years have you used her for this purpose, since you got her in $19 \div 8$ ?

Mr. McKernax. She has been in actual operation for us for 11 years.

Mr. Crmten. Why did you just decide that she was not efficient?

Mr. MaKrenas. "We did not decide that just now, Mr. Curtin. We knew she was inefticient as general knowledge back in $195 \frac{1}{2}$ or $195 \mathrm{~s}$. Along in there I molerstand that it was recomized that she was ineficient and there were general plans laid at that time to consider the construction of a new research boat.

Mr. Curtin. Has it cost $\$ 192,000$ to operate it in any previous fiscal year?

Mr. MeKerinax. It cost $\$ 177,000$ in $195 \%$.

Mr. Crutrix. That was the highest?

Mr. McInerax. 'That is the highest in the last 6 years.

Mr. Milder. Just a minute, Mr. MeIiernan. Let us not mislead anyone.

ivill you excuse me?

Mr. Cirtin. Surely.

Mr. Miller. I was going to ask you some questions.

In 1957 your shipyard repairs costs were $\$ 51,000$, which were in that $\$ 177,000$. In 1956 , you spent $\$ 25,000$, which made it $\$ 145,000$ to operate her, and in 1958 you spent $\$ 24,000$, which made it $\$ 164,000$.

Fon are not trying to mislead us by telling us that this $\$ 17 \%, 000$ was the high year whereas in that particular year you have about $\$ 25.000$ above the average ship repair between the years 1955 and now?

Mr. MoKmenan. 'That is correct.

Mr. Milusr. Then it cost you about actually $\$ 152,000$, if you take that extraordinary expense out, to operate her for that year; is that correct?

Mr. Mokneran. 'That is right, but the total expense includes this extra cost of repairs.

Mr. Muskr. What were those extra repairs in that year? 
Mr. McKensax. These were a number of items that after Coast Guard inspection were found to be substandard on the Albatross and that we put in to bring her up to Coast Guard standards.

As I recall, before that time she had not been under Coast Guard inspection and, at that time, we brought her up to Coast Grard standards.

Mr. Mutur. Because for the next sncceeding 2 years or next succeeding year, the cost of repairs fell from $1956 ; 1956$ was $\$ 25,000$; 1958 was $\$ 24,000 ;$ and 1959 to date was $\$ 24,500$.

Mr. Mchernax. Jes. There have been items which were not budgeted in our 1959 budget. That is, although the total is the same as last year. for example, the costs of repairs so far in the fiscal year have already exceeded our budgeted costs for that comparable perior of time.

Mr. Miular. Do you have any further questions?

Mr. ('URTाх. I have just a few questions, sir.

Do I understand that the average daily use of the ressel was 180 days during the last fiscal year?

Mr. Mchervax. The Detaware has been about 180 days.

Mr. ('crins. I mean the Albatross.

Mr. MrKervax. 'The Abatross in the last full year she was in operation has been at sea 149 days.

Mi. Crums. How many days would there be for the contemplated Jeasing of these trawlers?

Mr. McKernax. Te are plamning on approximately 110 days of sea operation in biological research, at least a minimuni of 110 days for 1960 .

Mr. Ccoms. That a verages abont $\$ 1,000$ a day. Is that coincidental or is that a basis on which you can figure it? You said 110 days, $\$ 110,000$.

Mr. MrKenxax. This is about right. This is about what it will cost.

Mr. Certix. That is all, Mr. Chairman.

Mr. Mnufr. Mr. Chairman, have you any questions? We are very happy to see you here.

The Cindrisax. I have no questions.

Mr. Oliver. Mr. Chairman, could I be indulged for a couple more minutes?

Mr. Millier. Yes.

Mr. Olrver. I would like to ask the witness, Mr. Chairman, if it can be done within the jurisdiction of his official position, whether or not when he sends up for the record the figures as to the present condition of those varions vessels which are now being operated, it would be possible for him to send up also information as to what he thinks the requirements of a real oceanographic program would call for in terms of ressels for the Bureau to operate.

Mr. Mitur. We will get into that when Mr. McKernan is up here in connection with our other phase of our work so that we are confining this today to the Albatross matter.

Mr: Ourrer. All right. Could I ask the witness a couple of more questions?

Mr. Minder. Yes. 
Mr. Ourver. You have been talking about the inefficiency of the Albatross. Do you mean inefficiency as a vessel or do you mean also perhaps that the crew itself has not been as competent as it should be?

MIr. Mícinernan. I do not mean the latter. It is a very good crew.

Mr. Ourver. You are talking about the vessel's inefficiency?

Mr. McKernan. Yes; it has a very good crew.

Mr. Oriver. They have been very interested in their work and in the the objectives that you have been trying to reach?

Mr. MoKernan. Very much so.

Mr. Oliver. So that this decision could in no way be considered to be a punitive move against personnel on board that vessel ?

Mr. McKennan. Absolutely not. This is no reflection on the excellent crew. The present crew of the Albatross is perhaps the best we have ever had and the present master is an excellent skipper.

Mr. Oliver. I have one other question, Mr. Chairman.

As a basic philosophy, I am wondering whether or not in this decision there has been consideration given to moves which have been made in other fields of Government operation to turn over to private industry operations which previously have been carried out through the Government agencies themselves.

Mr. McKernan. This was not a consideration.

Mr. OLIVEr. In other words, it is your position that private industry or private enterprise, for example, is not being favored at the sacrifice of efficient personnel and efficient operation taking into consideration only the fact that you call this an inefficient vessel?

Mr. McKernan. That is my position and I would go further and say that private fishing vessels can in no way replace an efficient oceanographic Government operated research boat.

Mr. OLIVEr. I gather from what you say the impression that you feel that you are going to use a more inefficient operation under private charter in trying to do a job that you feel that the inefficient Albatross is not able to do.

Mr. McKernan. I am not sure I followed that but if I get the question correctly, it is our decision that with the funds we have allotted we can do a more efficient operation in carrying out our objectives of research and oceanography in New England with the plan that we have adopted.

Mr. Oriver. That is all I have, Mr. Chairman.

Mr. Miller. Mr. Counsel, do you have questions?

Mr. Drewry. Mr. McKernan, going back to this question of inefficiency of the Albatross, was she inefficient from the very beginning?

Mr. McKernan. Yes, the Albatross was never considered to be a good boat.

Mr. Drewry. She was never considered to be a good boat?

Mr. McKinrnan. Never considered to be a good research boat.

Mr. Drewry. Do you know why the decision was made to use her as a research boat?

Mr. McKernan. Well, she was the best that was available to us and we got her for a dollar and the costs of reconversion were somewhere in the neighborhood of $\$ 150,000$ or so to begin with, and $I$ expect we probably have a half million dollars in actual conversion in her. I am guessing at that, by the way. 
The Government and the country has gained a great deal of information and a great advancement that it would not have been able to make otherwise but this still does not make for an eficient operation or eficient oceanographic and marine biological research.

$\mathrm{Mr}$. Drewrx. What is the reason for that inefficiency?

Mr. McKínnan. Well, she was designed for other purposes. For example, the position of winches for the operation of various kinds of experimental fishing gear and for the conduct of ocean research is not the best. For example, it is much better to have laboratories on research vessels right directly amidships so that the roll of the vessel will not detract from chemical tests and reading burettes. It is not possible on a boat that is ready made for another purpose to redesign it to get the proper uses.

The matter of fresh water, the matter of general accommodations for scientists and crews which have to carry out their functions in unique ways on research vessels is never good in these converted boats. I have had this experience on the west coast also and I think it is the general opinion of scientists throughout the world that these conversions are poor second choices.

Our Government had a lot of these vessels in the early forties and there was a great temptation to get these vessels by research agencies that were otherwise strapped for funds.

We were no exception. That is, we thought we were getting a good bargain by getting a boat for a dollar and I think that we have made good use of this vessel, and I say that in all seriousness, but nevertheless, all of us realize now that at best you get pretty second rate efficiency in operation from the very beginning.

Then as the boat gets older and older, the little things that are sort of bothersome at first when the vessel is newer but that you put up with become more and more cumbersome and efficient operations become more and more difficult.

Mr. Drewry. She was lengthened, was she not?

Mr. McKernan. She was lengthened.

Mr. Drewry. The lengthening process was by cutting her through the middle and putting in the new midsection?

Mr. McKernan. Yes.

Mr. Drewry. Did I understand you to say that that conversion work was done by you?

Mr. McKernan. No; not that lengthening. The conversion work from a Navy boat to an oceanographic boat was done by us but the section was put in there in 1941. This was before we had her. The conversion to a research boat, however, was 1948, and we did that.

Mr. Drewrx. You kept her up to Coast Guard standards and subject to Coast Guard inspection?

Mr. McKernan. Yes.

Mr. Drewry. In fact, I believe you mentioned that this larger amount in 1957 was due to a Coast Guard survey.

Mr. McKernan. Yes.

Mr. Drewry. I believe you also mentioned that you kept her up to American Bureau of Shipping standards?

Mr. McKernan. Yes, I believe we have American Bureau of Shipping Certificate.

Mr. Drewry. Is she actually classed by the American Bureau? 
Mr. McIírnax. I cannot tell you exactly how they have rated her; but normally they do not with these ressels.

What they do is actullly make a report on her condition. What we do is simply hire American Bureau of Shipping inspectors to inspect our lesearch boats and this is rery helpful because their inspections are very thorough and are classed by mariners everywhere as being good inspections.

Mr. Drewry. Son that even though it did not have an actual classification under the rules of the Bureau. as far as you were concerned you wonld comply with the advice of the Bureau inspectors? did.

Mr. McKnavaix. To the extent that our funds would allow we

Mr. Drwwry. How old is the Delavare? You stated it was newer.

Mr. Molianndx. She was built in 1935. That would make her 21 years old.

IIr. Drwwr. What do you consider to be the maximum useful age for it vessel of that type?

Mr. McKennax. Of that general style, I would say between 15 and 20 years is about the maximum that she should be operated and the Delaware is at an ang now where she should be replaced, too, before very long:

iIr. Drrwry. I mention this age question in connection with rour reference to the general debility that seems to be taking place as time has gone on.

The Coast Guard itself, according to information furnished by the Commandant last year, considers around 35 years to be useful life of most of its craft, such as buoy tankers and patrol boats and things of that sort.

You call on them for inspection. I would assume that they would? apply the same standards to you that they do on their own craft.

Mr. MCKERNax. I am applying the genelal standards that are of the classe of ressels that we are dealing with. In general, that is far older than the reneral consideration.

In fact, insmance companies will simply not insure vessels of anywhere near the age or at least do not like to. 'They consider the replacement age in wooden vessels of about 15 years and of ressels of steel hull of the nature of the Albatross of about between 15 and 20 years.

Mr. Drewry. You said that conversions are usually inefficient in the first place. When inquiry was made, I believe by Mr. Dorn. concerning your plans for replacement of this vessel, you said you did have in mind the reconstruction of an existing ressel. How does reconstruction compare with conversion and what vessel do you hase in mind that you will reconstruct?

Mr. McKirinas. If I said that, I made a misstatement. I meant new construction. If I said "leconstruction," I misstated it.

Mr. Drwwry. I may have misheard you, too.

While you said you would have liked to have replaced this ressel in the past, I do not get a very clear picture that you feel that it is even necessary to be concerned about replacing her at present because you can carry on necessary work, essential work, you said, without her. 
Mr. Mchernax. I recognize that your question is a good one and my answel's mat not have been too specific in this respect. Essentially what it amounts to is that with respect to the general limitations of budgets and with respect to our overall program, we can well delay for a short time the replacement of the Albatross. IVe do need a new vessel to carry out essential oceanographic and marine biological work in New England and our present interim plan will not be adequate for any great length of time so that my answer is along those lines. I am not in a position to say that the administration will approve the construction of the Albatross in fiscal 1961 but I am sure that it is given a high priority in the Department and I am assured that at the very earliest opportunity and consistent with other plans in Government it will be given fair consideration for replacement.

Mr. Mulder. Am I right when I put this interpretation on your answer: that when you get through evaluating these present data that you have collected in the past, during which time the gathering of new data conld be allotted to some charters of private vessels, that unless you have a boat to replace the Albatross there will be a deterioration in the amount and quality of the data you can gather and the work that you can do in this field?

Mr. McKernan. That is true, Mr. Chairman.

Mr. Drewry. Mr. Mickeruan, money has been budgeted for research. Have you actually used up all the money that would have gone to this ressel or will what is left go to carry out this backlog work that you are going to clean up on shore?

Mr. McKernas. We have a small amount of money remaining that will go into chartel work this spring, mostly the intrabureau charter of the Delaware, and probably a small amount for the remainder of the fiscal year will go into some accelerated shore work, probably not very much because we have pretty well used up all of our funds.

Mir. Drewry. Mr. Chairman, there are perhaps more questions but they are involved questions where probably Mr. McKernan would have to consult his records.

May I be permitted to ask him those and ask that he supply them for the record?

Mr. Mruler. Yes, without objection, that will be the order. We will also leave the record open with respect to the matter of the complete data that we want on these boats.

We can get it now because we want it later anyway in another committee. I pulled some of it out of the air and I think that you and Mr. Drewry together can arrive at that.

The Chainmax. May I ask one question?

Mr. Miller. Yes, Mr. Chairman.

The Chamman. Have you surveyed the reserve fleet to ascertain whether there might be in the reserve fleet a vessel that you could convert to replace the Albatross?

Mr. McKernan. Yes, Mr. Bonner, we have and we have not found one that we feel would satisfactorily do the job.

The Chammax. I have one other question which I would like to ask if you bear with me. Of course, I am interested in the studies that are made in all the localities, the Pacific, Atlantic, and so forth. Why is it more advantageous to explore the north Atlantic than the central or south Atlantic? 
Mr. McKernan. We are hoping to eventually extend comprehensive surveys all along the Atlantic coast and we have done some in the central and south Atlantic and are hopeful that within a short time these can be explored.

I think the real answer to your question, Mr. Bonner, is that the more urgent problems have arisen in the New England area where you have this old-established fishery, so that what it amounts to is that we have put the first things first, in a sense. That may not even be right but I think essentially one must admit that that is the case and we have attempted to put emphasis in this area where there was this old and established and large fishery but there are some excellent potentials in the middle and south Atlantic and we have great hopes for exploring those and further development of these offshore fishing areas.

The Chatrman. Thank you.

Mr. Mruler. Is Congressman Keith here?

STATEMENT OF W. M. SADLER, EXECUTIVE SECRETARY TO HON. HASTINGS KEITH, A REPRESENTATIVE IN CONGRESS FROM THE STATE OF MASSACHUSETTS

Mr. SAdLer. No, he is not. My name is W. M. Sadler. I am Congressman Keith's executive secretary. He was in his own committee this morning and could not be here. He sent his regrets.

Mr. MrLler. I wanted to make sure. He was invited.

Mr. Sadler. He is extremely interested in this, Mr. Chairman.

Mr. Mrluer. I have a letter with certain attachments which, without objection, will be made part of the record.

(The documents referred to follow:)

\section{DEPARTMENT OF TIIE INTERIOR,}

Fish and Wildlife Service,

Buread of Commercial Fisheries, Washington, D.C. March 2, 1959 .

Hon. George P. Miller,

House of Representatives, Washington, D.C.

Dear Mr. Miller : In accordance with your telephone conversation with this office on February 27, we are forwarding copies of correspondence and statements which were prepared for Senator Saltonstall who has been extremely interested in our operation of the research vessel Albatross III. We believe this material will explain fnlly the Bureau's position on deactivation of the vessel and in addition will show the budgetary situation on which the action is based.

Sincerely yours,

A. W. ANDErson, Assistant Director

(For Donald McKernan, Director).

DepartMeNT OF THE INTERIOR,

Fish aNd WiLdiffe, Service.

burfau of Com Mischal Fisilertes,

Washington, D.C., February 26, 1959.

Hon. Leverett Salotonstali,

U.S. Senate,

Wrishington, D.C.

Dear Senator Saltonstall: In response to requests from your office, we hare reviewed the liurean of Commercial l'isheries' decision to deactivate the Albatross $I I I$, which is hased at Woods IIole, Mass., and have confirmed this deeision as the most appropriate one which ean be made in the light of the efficient expenditure of the funds available, the condition of the ressel, increased operating costs, and the status of the research progran in the area. 
We are well aware of the severity of the fisheries problems facing New England at the present time. Our regular programs are substantial and diversified to meet the most important needs. In recognition of the seriousness of these problems, we have allocated to New England for its most urgent requirements more than 20 percent of the funds available each year under the SaltonstallKennedy Act. More than 42 percent of the loans approved under the fisheries loan fund have been made to New England fishing craft.

The Albatross III is a 33-year-old vessel. It is a converted trawler, far beyond its normal replacement age, exceedingly costly to operate, and subject to major breakdowns beyond routine maintenance. In recent years it has cost well over $\$ 1,000$ for each day it operated at sea. Increased operating costs and heavy repair bills have contributed to the drain upon our research budget as well as curtailing the number of days at sea. These facts make it imperative that the vessel be deactivated and amply justify the decision not to expend more funds on it or its operation, especially when arrangements have been made for conducting the essential parts of its program using other vessels.

If not deactivated, the operation of the Albatross $I I I$ would have had to be curtailed this spring because its fund for the fiscal year would have been exhausted by then. Attempting to operate on such a part-time basis is unwise financially in our present situation.

The essential features of the Bureau's biological research 'program in New England waters can be continued by a greater use of the vessel Delaware which is also stationed in New England. This ship can be operated for considerably less per day than the Albatross III. She has adequate accommodations for a larger crew and can carry experimental and fishing equipment necessary for the total program. Smaller fishing vessels will also be chartered for special research, so that as nearly as possible a complete sea program for biological purposes will be effected. While some sea time will be lost, the essential features of the New England biological program will be carried out, and without fail the Bureau's immediate major responsibilities will be met.

Use of the Delaware also permits it to operate the full fiscal year, since funds available for its operation would have also been exhausted this spring.

The possibility of utilizing surplus Navy vessels also has been investigated. The costs and time required for conversion, in addition to the general dissatisfaction with such craft for research and fishing, precludes this means of alleviating the situation.

We are sorry that it is necessary to lay off the crew. We are informed, however, that there is a good demand for fishermen in the Boston area at this time.

While we regret the need for deactivating the Albatross $I I I$, we are convinced that the revision of our program is in the best public interest and in the long term will also be in the best interest of the New England fisheries. We will continue to give special attention to this area and hope to increase our effectiveness in helping the New England fisheries maintain their importance to the national economy.

Sincerely yours,

DONALD L. MCKERNAN,

Director.

Summary Budgets for New England Brological Research

Woods Hoie-Trawlfish research

\begin{tabular}{|c|c|c|c|c|}
\hline Fiscal year & Regular & S-K & Construction & Total \\
\hline $\begin{array}{l}1955 \\
1956 \\
1958 \\
1959\end{array}$ & $\begin{array}{r}\$ 218,000 \\
218,000 \\
225,000 \\
228,000 \\
252,200 \\
268,000\end{array}$ & $\begin{array}{r}\$ 406,000 \\
294,000 \\
2414,000 \\
3413,000 \\
325,000 \\
4325,000\end{array}$ & $\begin{array}{r}\$ 143,000 \\
930,000\end{array}$ & $\begin{array}{r}\$ 624,000 \\
655,000 \\
\mathbf{1}, 569,000 \\
641,000 \\
577,200 \\
593,000\end{array}$ \\
\hline
\end{tabular}

I $\$ 200,000$ contract with Woods Hole Oceanngraphic Institution for 3 years.

Nonrecurring expenditures: Alabatross III repairs, $\$ 30,000$; sea scallops, $\$ 50,000$.

3 $\$ 80,000$ contract with Woods Hole Oceanographic Institution for 2 years.

Estimated. 
Milford-shellfish research

\begin{tabular}{|c|c|c|c|}
\hline Fiscal year & Re'gular & $\mathrm{S}-\mathrm{K}$ & Total \\
\hline $\begin{array}{l}1955 \\
1959 \\
1957 \\
1959 \\
1959\end{array}$ & $\begin{array}{r}\$ 40,800 \\
40,800 \\
43,800 \\
46,200 \\
46,200 \\
48,200\end{array}$ & $\begin{array}{r}\$ 69,200 \\
25,000 \\
229,000 \\
25,500 \\
398,500 \\
195,500\end{array}$ & $\begin{array}{r}\$ 110,000 \\
65,800 \\
71,800 \\
72,700 \\
141,700 \\
143,700\end{array}$ \\
\hline
\end{tabular}

$\$ \$ 4,200$ contract with Oyster Institute of North America for 3 years.

$2 \$ 3,000$ nonrecurring for small firejroof storage building.

$3 \$ 20,000$ contract with Oyster Institute of North America for 1 year.

1 Estimated.

Boothbay II arbor-Herring researeh

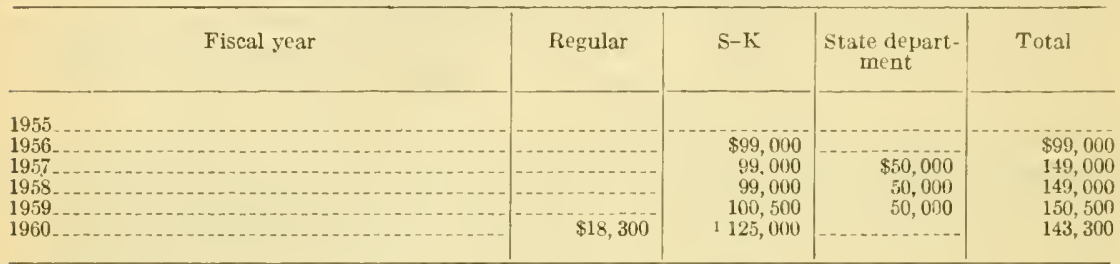

1 Estimated.

Boothbay Harbor-Shellfish research

\begin{tabular}{|c|c|c|c|c|}
\hline Fiscal year & Regular & $S-K^{-}$ & Construction & Total \\
\hline $\begin{array}{l}1955 \\
1956 \\
1957 \\
1958 \\
1960\end{array}$ & $\begin{array}{r}\$ 85,000 \\
83,000 \\
163,000 \\
65,400 \\
71,200 \\
77,600\end{array}$ & 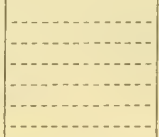 & $\left(-25,009^{2}\right.$ & $\begin{array}{r}\$ 85,000 \\
83,000 \\
63,000 \\
65,400 \\
96,200 \\
77,600\end{array}$ \\
\hline
\end{tabular}

1 Combined with Chesapeake shellfish investigations, some personnel and funds transferred to Annapolis, Md.-no reduction.

\section{Statement on Condition of "Albatross III"}

As a result of continued repairs and shipyard work the Albatross III is in safe operating condition. A Coast Guard inspection was completed last September 4, 1958. A certificate was issued then which expires in October 1960.

The American Bureau of Shipping inspected and passed the ressel in August 1958.

While the Albatross $I I I$ is considered safe for sea, bringing her to and keeping her in this condition has placed a severe strain on the researeh budget. Overhall costs have been: $1957, \$ 51,000 ; 195 \$, \$ 24,000 ; 1959,824,500$ (through January 30$)$.

Part of these costs have heen for major repairs: replacement of the tailshaft, main engine bearings, deck and hull repairs. We had hoped that once the ressel was in shape she could be kept un without such major expenditures. For a new'r vessel these costs mould he only half the amounts spent. l'ast history tells us these high costs will continue. When one part is repaired the ship breaks down some place else. For example, there are new leaks in the mitin deck, even though there was eonsiderable deck repair work done this palst year.

\section{RFFET OF VESSEL CONHITION ON WORK SCHEDLE}

'Joo much time in the repair varl and dolays in eruises for repairs las lud a Irastic effect on the work sehedule. For 'xample, days at sea were: 1957, $137: 1958,149 ; 1925), 10^{\circ}$ ( to date, 1!) w was the goal) ).

This is a very poor schedule, making the days at sea very costly; on the average in excess of $\$ 1,000$ Irer day. 
The Bureau has made a preliminary study into the feasibility of using small naval ressels for fishery research in New England and possibly in other areas should ships need replacement.

The Nary has told us about three ships which will soon be available as surplus to their needs. Two of these are within the size range which could be operated in offshore areas. However, there are a number of factors which need careful consideration before launching into a Irogram of conversions to supply research ressel needs.

Each vessel would have to be converted as follows:

1. From military to civilian use, which would include improvement of living spaces. increasing water capacity, and arranging for sanitary facilities.

2. Provision for resarch space such as wet and dry laboratories and gear storage; addition of winches and modifications to booms.

3. Conversion for fishing.

Discussions with the $\mathrm{Fayy}$ did not reveal that there were relatively new vessels which could be made available for research purposes. Those which can be released now were constructed in $19 \longleftarrow 3$ or 1944. making their age anproximately 15 years. Conversion of vessels of this age would not appear logical. In addition, previous experience by two California agencies has shown that use of two similar type hulls for oceanographic research has proved a costly and rather short-term operation. The Scripps Institution of Oceanography converted a minesweeper for general oceanograplic work. While the ensts of the conversion are not immediately available, we know that they were very high. During the course of operations considerable main engine trouble develoned and the vessel defaulted on many cruises. After about 6 years' operation the vessel was laid up.

California Fisly and Game modified a small Army transport ship similar to another trpe the Nary could make available to the Bureau. This ship was condemned after 7 years' operation because of dry rot.

One of the most serious drawbacks in using naval vessels for research purposes is that after conversion they will not adequately meet all the research requirements. For example, it would be very difficult to conduct experimental fishing or trawling from a converted transport vessel or minesweeper. The towing characteristics, freeboard and general deck arrangements preclude fishing from these ressels in an efficient manner. Hence it is entirely possible that after spending rather large amounts for conversion the vessel produced would be less than satisfactory.

To support this point we wish to quote from a report prepared by the National Academy of Sciences on research ships:

"Conversions should be kept to a minimum.-The matter of conversions versus new construction has been studied. The Committee concluded that conversions will be more expensive (in the long run) than new construction in terms of research accomplished per dollar. For some survey-type operations conversions can be quite satisfactory. Indeed practically all the ships being used in this country for marine science today are conversions. Nevertheless, it is believed that from the standpoint of orerall costs, conversions should be kept to a minimum."

In summary, we believe the most sound procedure would be to carry on fishery research in New England with our one major vessel, the Delavare, plus fishing vessel charters as necessary. Such operations would have to be carried out until we can budget for, design, and construct a modern research trawler which will allow us to effect the research and survers necessary for the benefit of New England fisheries and which will allow us to lead the industry in the development of efficient fishery methods. In the long run the Government will be ahead in the quality and amounts of information produced and will expend less money for ship time if the policy of new construction is followed.

\section{POSTTIONS FOR DISPLACED FISHERMEN}

Information from the Bureau's regional office in Gloucester rereals that there are now plenty of vacancies for fishermen in the New England fishing fleet. In fact some crews have been reduced because of a shortage of fishermen. Hence, men from the Albatross $I I I$ should have no difficulty in locating jobs. 
Summary expenditure Saltonstall-Kennedy funds, Woods Hole, Mass.

\begin{tabular}{|c|c|c|c|}
\hline Fiscal year & $\begin{array}{c}\text { Albatross } \\
\text { III }\end{array}$ & $\begin{array}{c}\text { Non- } A l b a- \\
\text { tross } I I I\end{array}$ & Total \\
\hline $\begin{array}{l}1955 \\
1956 \\
1958 \\
1959\end{array}$ & $\begin{array}{r}\$ 97,000 \\
145,000 \\
177,000 \\
164,000 \\
1124,500 \\
192,000\end{array}$ & $\begin{array}{r}\$ 309,000 \\
149,000 \\
237,000 \\
249,000 \\
200,500 \\
2133,000\end{array}$ & $\begin{array}{r}\$ 406,000 \\
294,000 \\
414,000 \\
413,000 \\
325,000 \\
325,000\end{array}$ \\
\hline
\end{tabular}

1 Operation to Mar. 9, 1959.

I Estimated.

"Albatross III" operations-Paid for from Saltonstall-Kennedy funds

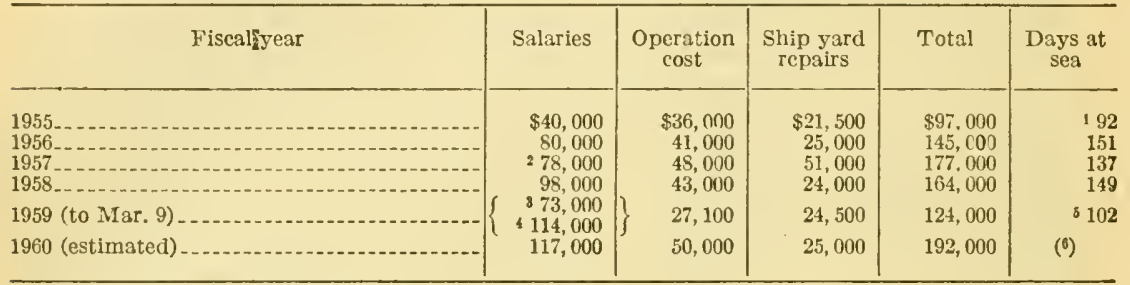

1 First cruise was in January 1955.

2 Reduced crew for part of the year.

3 Through Mar. 9, 1959.

- To complete fiscal year 1959 at new rate established Feb. 4, 1959.

5 Goal 198 .

G Goal 200.

SUMMARY OF 1959 FiNANCING, "DEL.A WARE" AND “ALbatross III"

The Delaware operation would have a $\$ 23,000$ shortage in 1959 if operations were continued as previously. Costs for the Delaware run about $\$ 10,000$ per month. At this rate the operation would have to be stopped or refinanced the latter part of April 1959.

The Albatross III operation would have a $\$ 43,000$ shortage if operations were continued as previously. Costs for the Albatross have been running at least $\$ 14,000$ per month. At this rate this operation would have to be stopped or refinanced at the end of March 1959.

An example of increased costs is given by the Delaware salary schedule:

Cost of erew (approximate) $M / V$ "Delaware" (12 men)

\begin{tabular}{|c|c|c|}
\hline Year & Total & Increase \\
\hline $\begin{array}{l}1956 \\
1958 \text { (April) } \\
1959 \text { (November) } \\
1959 \text { (February) }\end{array}$ & $\begin{array}{r}\$ 65,126.10 \\
78,458.00 \\
79,258.50 \\
80,934.00 \\
93,703.00\end{array}$ & $\begin{array}{r}\$ 13,331.90 \\
800.50 \\
1,675.50 \\
12,769.00\end{array}$ \\
\hline Total.... & & $\begin{array}{r}28,576.90 \\
165,126.10\end{array}$ \\
\hline
\end{tabular}

1 Equals 43.8 percent inerease over 1956 wages.

Mr. Miller. There are certain data that you will supply that will be part of the record and there is certain information that has just come to us that I think should be screened. I will instruct counsel to screen out that part of it that he believes is pertinent to the record and submit it for the record. 
Mr. Oliver. Mr. Chairman, might I request permission to include in the record any information that might come to me within the next 2 or 3 days with respect to the Albatross?

Mr. MirLer. Without objection, so ordered.

(The following was furnished for insertion.)

DORCHESTER, MASs., March 14, 1959.

Hon. Leverett SALtonstall,

Senate Office Building, Washington, D.C.

Dear Senator Saltonstall: My reasons for objecting to the deactivation of Albatross III are as follows:

In 1938 Russia had 2,727 boats. In 1958 Russia had 12,387. Poland built a fishing motorship for Russia, 515 feet long, 65 feet wide, to operate in any waters. She carries a helicopter, also. Russia had 20 large trawlers built at the Lowestoft yards. England completed 20 large trawlers for Russia. One shipyard in Germany employing 5,000 people was taken over to build nothing but trawlers for Russia. At a meeting in Halifax in June 1958 the Soviet Cnion's scientific spokesman described research work carried ont by his country in the convention area and indicated that this was to be increased this year. Three trawlers, the Odessa, the Kreml, and the Novorossiysk will carry out research work in the region of the Grand Banks, Flemish Cap, Labrador, and along the west coast of Greenland. Soriet fish landings from two banks off Newfoundland in 1957 totaled 70.000 metric tons.

England is building 500 trawlers over a 10-year period. 81 have been completed and 149 have been approved. Offshore craft, 309 have been completed with 43 under construction. England also grants a subsidy or a support price on some species of fish. They also grant as much as $\$ 17.80$ per day toward the expenses of large trawlers.

Canada just completed a research ressel costing $\$ 1,750,000$. She was built to operate in any waters. Canadi also is appropriating $\$ 130.000$ and hired four trawlers to destroy dogfish. They are also paying the fishermen 10 cents a pound for dogfish livers. She is also spending $\$ 500,000$ on improvements in Newfoundland. Canada has purchased 1 million pounds of bait from the United States to help her fishermen. She also helps her lobstermen and small-boat men.

Norway built a research ressel named the John Hjort, delivered in March of last year, earrying a crew of $32 \mathrm{men}$ and 8 research workers.

Germany has a modern research ressel. England has sereral modern research ressels. A West Germany trawler named the Falkland in the fall of 1958 returned to Bremerhaven, Germany, with 259 metric tons taken 120 nautical miles up the south coast of Labrador on Hamilton Bank. As far back as June 1956, at a meeting held in Halifax, N.S., Dr. L. A. Walford, at that time chief of the branch of fishery biology of the Fish and Wildlife Service of the United States and chairman of the Standing Committee on Research and Statistics, stated that because of increased population and resulting demands for fish, the problems of fully utilizing the sea resources in the northwest Atlantic are likely to grow in complexity and are not likely to be solved in a hurry. Broadly, these complexities consist of the effective use of men and materials for the needs of the whole Commission. In planning research programs for the convention area, and in judging needs of men, material, and equipment, therefore, certain inescapable facts must be faced. The convention area is large, nearly 1 million square miles: the hydrographic conditions of the environment are exceedingly complex; the fisheries in this area are among the most valuable in the world; over 4 billion pounds annually are taken. He further quoted from the report of the Standing Committee on Research and Statistics as follows: "Understandings of the mechanism of replenishment and of the identity and degree of independence of stocks is essential to the scientific direction of North Atlantic fisheries in order to obtain maximum utilization."

(The foregoing facts were gathered from the "Commercial Fisheries Review.")

Above I have outlined some of the things which other countries are doing to aid the world's food supply.

. What is the United States doing?

At the present time our trawlers operating out of Boston average 20 years in age. In 1958 we landed 123,800,000 pounds of fish in Boston, the lowest in 36 years. But we did import 144 million pounds, which is almost 22 million pounds more than we ourselves landed in Boston. 
The only real research vessel which we possess is the Albatross $I I I$, and that boat is tied up and scheduled for the junk heap. We do also possess one otlier so-called research ressel, the Dclaware, which is being kept in operation, but that boat will only operate 10 hours per day y5 percent of the time. So far as hiring boats is concerned, to do research work, this in my opinion is a waste of funds, because the only arailable boats are low-earning and are not equipped to do resuach work. Thes only operate in the summer months, and I know from my past experience with biologists and scientists that in order to keep up with research, boats must be operated on a sear-round, 24-hour-a-das basis and be properly equipped to go in any waters.

In view of the foresoing facts, does it not seem to you that the proposer scrap ping of the 1 lbatross $I I I$ is vel'y, very ill-advised?

Very truly yours,

Austix J. Powers,

Ex-2d Officer, Albatross III.

DEPARTMENT OF THE INTERIOR,

OPFICE OF 'THe Sieclet ARY,

Wrashington, D.C., February 1S, 19.5.9.

Miss ElrzabetI LEONARD,

Secretary, American Federation of Govcrnment Employees, Lodge 1729, L.S. Fish and Ililalife Scrvice, Woods Hole, Mass.

DeAr Miss Leonard: This will acknowledge four telegram of February 9, 1959. to Secretary Seaton, Commissioner Suomela, and we concelning the Atbutross III.

Onr decision to deactivate the Albatross $I I I$ was talien, reluctantly, after we hat consideled many factors. Basically we are seeking a mole efficient overall operation in New England, with the aim of accomplishing our total mission with presently available funds.

In the future we plan to make greater use of the Delauarc and of charter vessels to provide for research purposes. While there will be some loss of sea tilue, essential parts of the biological plogram will be accomplisled.

The Albatross $I I I$ is an old ship. Maintenance and opelating costs are very high and have reached the point where her continued operation gives too little return per researeh dollar expended. Thus we believe it best to deactirate and sell her. Our action is based upon the needs for both economs and efficiencr.

We realize a number of hardships will result from our decision and that unam questions are in your minds ahout the future of your jobs and related activities at the Woods Hole Laboratory. I am sure Dr. Graham will be pleased to rliscuss them with you and your lodge members. He will call upon Mr. Puncuchar or the rentral office staff for additional information should he not be able to answer al! of your questions.

We a jpreeiate you keen interest in improving the Bureau's research activities. Sincerely yours,

Ross LefFler, Assistant Sccretary.

Comments on Statements in Ml. Lejflel's Lettek of Ferruary 18, 19j!) DESCRIPTION OF "ALBATROSS III"

length overall : 179 feet.

Beam: 24 feet.

Draft: 1' feet.

Displacement : 310 tons.

Main power: Diesel.

Stcering: l'ower (electrotelomotor).

Type: 'I"lawler.

Sperol : 14 maximum, 11 eruise.

Complement: 27 ( 21 crew, 6 scientists $)$.

Cruising rance: 4,50 (1 niles.

Food and water: 20 days.

Yeir built: 19:26 (reluijt 1941).

IIull: Metal (steel).

(Information from: "Oceanographic vessels in the United states, April 19.r3." Issucel by the Oflice of Naval Researeh). 
“Abutross $I I I$ is an old ship." - I am forwarding separate No. 200 which gives a fairly good history of the Albatross. The "Conmercial Fisheries Review" is an official publication of the Fish and Wildlife Service.

"Operatin!" costs are very high."-Costs are high from what point of riew, and in comparison witl what? Admittedly, it costs money to run a vessel, but it costs money to run anything. Peried. It is reliably reported in Woods IIole, that the operating budget of the $R$. V. Atluntis, owned and operated by the Woods Hole Oceanographic Institution, is a round $\$ 200,000$ a year. The Atlantis is a smaller vessel (142 feet) and her wage scale is lower than that of the Albatros. Incidentally, it easily costs between $\$ 50,000$ and $\$ 100,0010$ a year to operate a racht. (Tachts are commonplace in Woods Hole). Wages? The present wage for the Albutross crew is $\$ 6, \$ 00$ per annum, the eaptain gets alound $\$ 8,000$, and the first and second officers and tlie engineers, are somewhere in between. Sixty-eisht hundred per annum is nothing remarkable, but it figures vut to about $\$ 131$ a week before deductions. And these men are pail for what they know, not for what they do. Recently, the crew of a trawler out of Poston cleared $\$ 700$ apiece for a 10-day trip. (The price for the catch is fisured on a pro-rata basis, after taking out the operating costs of the trip; the usual practice on a fishing vessel.)

And in the January 9, 195?, number of the English Fishing News, mention is made of the gross earned by the drifter-trawler Fellowship. This fishing vessel rrossed $\$ 12,870$ (US\$36,036). Fishermen on the better (financially) trawlers fresuently rlear IS\$11,000 or US\$12,000 a 5ear. And, it is also reliably reported that the master of one of the big trawlers out of Boston rereives an annual salary of $\$ 30,000$.

Foof? - Food does cost, no two ways about it. Food costs could be cont, if the Albatross steward were permitted to buy staples at Otis AFB. (The station is about 14 miles from Otis $A F B$ ). For some reason, unknown to me, this piactice is not permitted. And probalbly there is some waste. Incidentally, the usual food budset for a fishing vessel out of Boston. is around $\$ 700$ a week. The finure for 15 men on the Albatruss covering a similar period, vould run between $\$ 400$ and $\$ 125$.

"Mrintemule costs are ver!l high."-Considerable money has har to he spent to hring the Albatloss up to par because she was allowed to get into a poor condition. No major reconditioning is in sight. The september 195s haul-out rost alont \$3,000. It is reliably reported in Woods Hole that the last haulout of the IRV Atlantis was around $\$ 50,000$. A $\$ 15,000$ maintenance figure is considered moderate in marine circles, and the ammal haul-out is a must for any vessel. large or small. And to think there will he practically no maintenance for a new vessel is wishful thinking. Maintenance costs for a new vessel will be much higher for 2 or 3 years than the present cost for the Albutross, in order to elininate the "Ings" any new vessel has. The automobile industry gets around this by exhaustive road tests: this is not feasible for a ressel. And why sirend all this molley to get the Albatross in good condition, and then sell her"

"Too liflle return per reseurch lollar expended."-First and foremost, it shomld be recognized that research in and of itself is expensive, and to some extent, at least. wasteful. The return on research cannot be compared to the return one would naturally expect from a stock market transaction. The results are not immediatels apparent, and more closely resemble a mosaic or a parquet flor, i.e., a piece at a time. Research must not only prove what is true, it must also prove what isn't. It happens that I worked at one of the Navy's research activities for several years. There I learned that an experiment which didn't work out could easily cost $\$ 100,000$. In Mr. Leffler's view that money was wasted. But the Nary didn't think so because it proved what rouldn't be done in regard to the specific problem.

"Nore efficient planning * * *". -There is no argument on this point ; we are all for it. If there appears to be an insufficient return on the work of a particular cruise or cruises. this is not the fault of the ship and her crew. This is due to lack of proper planning in order to utilize the Albatross to the fullest extent. This is the responsibility of the Director of this Laboratory.

The master and crew of the Albatross are convinced that the operating costs of the ship could be pared if the ressel operation and maintenance were in the hands of a marine superintendent (or port captain) who was a graduate of one of the malitime academies, and who had put in several rears as master on "hlue water." 
[From the Commercial Fisheries Review, U.S. Department of the Interior, Fish and Wildife Service, Separate No. 200]

TIYE "ALBATROSS III"

\section{(Bj William F. Royce ${ }^{1}$ )}

The only ocean fisheries research vessel of the U.S. Government, Albatross III, was dedicated on March 19, 1948, at the Boston Fish Pier, Boston, Mass. Federal and State officials and leading members of the fishing industry took part in the ceremonies.

The Secretary of the Interior, J. A. Krug, speaking from the quarterdeck of the converted trawler to more than 300 people, stated:

"The dedication of the Albatross III for fishery research in the North Atlantic is an event which justifies widespread consideration of the important problem of fishery conservation in the North Atlantic area.

"While the commissioning of the Albatross $I I I$ is a start toward nationwide conservation and development of marine resources, we need similar facilities for the great Pacific coast fisheries, the central Pacific, for the unexplored areas of the Gulf of Mexico, and for the enclosed domestic waters of the Great Lakes."

The vessel has been named Albatross III to carry on the traditional name of the major fishery research vessel of the United States. Albatross $I$ was a 234foot twin-screw, iron steamer. She was commissioned in 1882 and decommissioned in 1921. During her 39 years of fishery and oceanographic research, she visited both coasts of the United States, Alaska, South America, Central America, the Galapagos Islands, the Hawaiian Islands, Japan, the tropical Pacific islands and the Philippine Islands. Many distinguished scientists sailed with her and their scientific work vastly increased our knowledge of the oceans. Her not-so-glorious successor, the Albatross II, was a 148-foot ex-Navy tug. She operated from 1926 to 1932 and during this time was engaged in research on the mackerel fishery, explorations of the haddock fishery grounds, and preliminary experiments with savings gear.

Acquisition of Albatross III has occupied about 14 years. In 1934, President Roosevelt authorized a fishery research vessel for the North Atlantic, but no funds were made available. Five years later, the Harvard, a steam-driven trawler, was given to the Bureau of Fisheries by the General Seafoods Corp. for the sum of $\$ 1$. In late 1941, after about 2 years of planning the couversion to research and obtaining necessary funds, the Harvard entered a shipyard and reconstruction began. War broke out and the Navy requisitioned her. She was transferred to the Coast Guard, named the C.G.C. Bellefonte and completely rebuilt as an Atlantic patrol vessel. She was reconstructed from keel to masthead and put in top condition. Plates and frames were replaced and excellent machinery installed. This conversion was completed in 1944, but as the urgent need for an Atlantic patrol vessel had passed, she was returned to the Fish and Wildlife Service. She was laid up at Woods Hole, Mass., in a semioperating condition until the summer of 1947. During this time, the plans were redrawn to fit the changes made by the Coast Guard and funds for her reconversion to a research vessel again obtained. Iast July, she entered the yards of a shipbuilding corporation and reconversion got underway.

The basic lines of the Albatross III are very similar to those of the large Boston otter trawlers. She has a high head with a Maierform bow, a clear main deck about midships for the handling of fishing gear and a deckhouse from midships aft, housing the laboratories and officers' staterooms.

IIer length overall is about 179 feet. She has a bean of about 24 feet and a draft of 12 feet. Her displacement is about 525 tons. She will be able to cruise about 4,500 miles without refueling.

She is of welded steel construction throughout. The main deck is covered with planking set in mastic. The outside bulkheads are all insulated with fiherglass. She is heated by an oil-burning furnace and a circulating hot water system. All quarters, laboratories, etc., are provided with forced-air ventila. tion systems.

The Albatross III is powered by a 7-cylinder, 805-horsepower diesel engine. A temporary 4-hlade propeller is installed pending delivery of an adjustable pitch propeller. With this temporary propeller she cruises at about 11 knots.

${ }^{1}$ Chief, New England Fishing Banks Investigations, Division of Fishery Blology, Woods घole, Mass. 
The electrical system is 110-volt d.c.; 140 kilowatts are provided by 3 diesel motor-generator sets. The engineroom is fitted with a small machine shop containing a drill press, grinder, and lathe. The galley equipment includes an oil-burning range, a 12-cubic-foot refrigerator, a coffee urn, and a drinking fountain. The room used for storage of bulk galley supplies is mechanically refrigerated.

The chartroom and wheelhouse are fitted with the most modern navigational equipment. A partial list of the equipment follows :
Radiotelephone, 75 watt
Sonic depth recorder
Engineroom telegraph
Patent $\log$
Loran receirer
Underwater recording log
Magnetic compass
Gyro compass and repeaters
Chronometers
Radio direction finder
Aneroid barometer
Searchlight

Electrotelemotor steering gear

The fishing equipment consists of a large electric winch with a capacity of 600 fatloms of $7 / 8$-inch wire on each drum, which permits operation in 200 fathoms of water. The deck has been fitted out with the staudard fishing arrangement of bollards and gallows frames, which will permit the use of full-size trawling nets with the speed and efficiency of the large Boston trawlers. The fish hold is necessarily small, because the space is required for other equipment and because large storage capacity is not needed. It is divided into two sections. The first is a standard hold fitted with pen boards for storing fish in ice. It has a capacity of about 50,000 pounds of fresh fish. Forward of this section are two refrigerated compartments for freezing and holding fish. The smaller room, for quick freezing, is capable of maintaining temperatures of $20^{\circ}$ below zero. The other rooln will hold temperatures at about zero. The whole fish hold is insulated with sheet cork.

The laboratories are located in the main deckhouse just aft of the fishing winch. The wet laboratory opens onto both the port and starboard decks through Dutch doors. It is fitted with a stainless steel sink in the center, suitable for handling and examining fish. Two small sinks are located in the cabinets on the outside bulkheads. These will be used for chemical and hydrograylic work. Adequate shelving, cupboard, and drawer space is provided throughout the laboratory for the storage of apparatus. The dry laboratory or library is located aft of the wet laboratory. This room is provided with a large work table, chains, bench, and shelves. It will be used as an office for scientists for the preliminary study of the data collected at sea.

Attached to the bridge deck just outside of the wet laboratory on either side are the booms for the lowering of hydrographic apparatus. The winches for these booms are located on the bridge deck. These booms feature a traveler to which the lowering block is attached and which is used to regulate the distance of the lowering wire from the rail.

On the portside of the forecastle is the plankton room. This room will be used to facilitate the handling and lowering of plankton nets used to capture the minute animals and plants found in the water. It has a Dutch door and a working platform built into the side of the ship, which is lowered when towing nets. Directly over this door is the plankton boom used to make the plankton net lowerings. It also has a traveler similar to the hydrographic booms. The plankton winch is located in the trawling winch room, port side.

The living quarters provide comfortable accommodations for the ship's personnel. The master's stateroom is Iocated aft of the chartroom. The officers', mates', and engineers' rooms are located aft of the engineroom on the main and lower decks. The scientists have four staterooms located around the wa'droom on the lower deck forward of the galley and crew's mess. A stateroom for the steward and cook is located on the starboard side just forward of the crew's mess. The crew's quarters are located in the forecastle lower deck.

The operating crew of the Albatross III will consist of 21 men. These are as follows :

MASTER

Deck :

Chief officer

Second officer

Third officer

Fishermen (6)

Ordinary seamen (3)
Engineroom :

Chief enginer

First assistant

Second assistant

Third assistant
Commissary :

Steward

Cook

Messmen (2) 
In addition to the above, the ship will carry six scientists in her normal complement. These will be a chief scientist, two aquatic biologists, and three biological aids. Space for eight extra men is available. This allows for additional scientists, who may be engaged on special problems, and more crew if such is necessiry to efficient operation.

The Albatross $I I I$ will be used to learn the facts necessary to maintain and increase the production of the fisheries of the northwest Atluntic. The research will be directed at problems of immediate and particular value to the fishrries. The problems receiving immediate attention will include:

(i) Census of the fish populatiuns on the New England Banks.

(2) Learning the effect of otter trawling on the bottom.

(3) Imiroving fishing gear.

(4) Improving method of handling and preserving fish.

QUESTIONS TO BE ASKED

1. The Bell Teleyhone Laboratories of New York City paid the Fish and Wildlife Serrice $\$ 50,000$ for 3 cruises: 1 on the Albatross, and 2 on the Drlaware. How was this sum allotted to the station? And why wasn't it used to keep the Abatross running? Iow did Washington juggle this sum?

2. The Delaware cannot do half the Nork the Albatross can do. IIow much more does it cost to rum the Delauare in comparisun with the operating cust of the Albutross? In rien of the cautit obtained if the Albatross were kept in service, the cost would not be much more.

3. Who nakes the decisions on the vessels? Do they hare the proper background for it? Why not get somenne to boat and ressel operations realistically?

4. A total of $\$ 2 \$ 0,000$ was awarled to the Woods Ifole Uceanograplic Institntion on FW'S contract No. 11-19-008-2377 (July 1, 1955-June 30, 19.58) and contract No. 14-17-005-62 (July 1, 1958-June 30, 1960). A major portion of the work on these contracts was working up and analyzing data obtained by Woods IIole FW' personnel on Albatross cruises. This work could have been done by station personnel if two fishery biologists (GS-7 grate) had been engaged to do the daily microscope grind. This would have left the regular personnel free to work up and analyze the data they themselves had collected.

Estimated cost : $\$ 6,000$ per man per annum for 5 years : $\$ 60,000$, as against $\$ 280,000$.

(Handwritten: This was sent to me by mal from Woods Hole. Biologist made this out but jefused to give his nanc. Please give a cony to Tom Gerber.)

Fairitaven, Mass., March ?, 195?.

Mr. JoHN McCART,

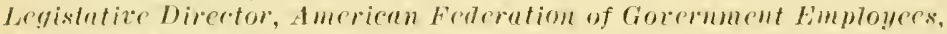

Washington, D.C.

DeAr Mr. McCART: I am forwarling herewith, a 2-page comparison of the facilities of the Albatross $I I I$ and the Delaware. This shomld be attached to the summary of information being forwarded to sou todas, under sevarate cover, by Mr. Anstin Powers.

I hope that with the information we have furnished, you will at least be able to get a thorough investigation of the Albatross $I I I$ deactivation.

Very truly yours,

E. HI. HIILEK. 
Comparison of facilities

\begin{tabular}{|c|c|c|}
\hline & Albatross 111 & Delaware \\
\hline $\begin{array}{l}\text { Mess facilities: } \\
\text { Galley } \\
\text { Crew mess } \\
\text { Wardroom } \\
\text { Food storage } \\
\text { Laboratory facilities......... }\end{array}$ & 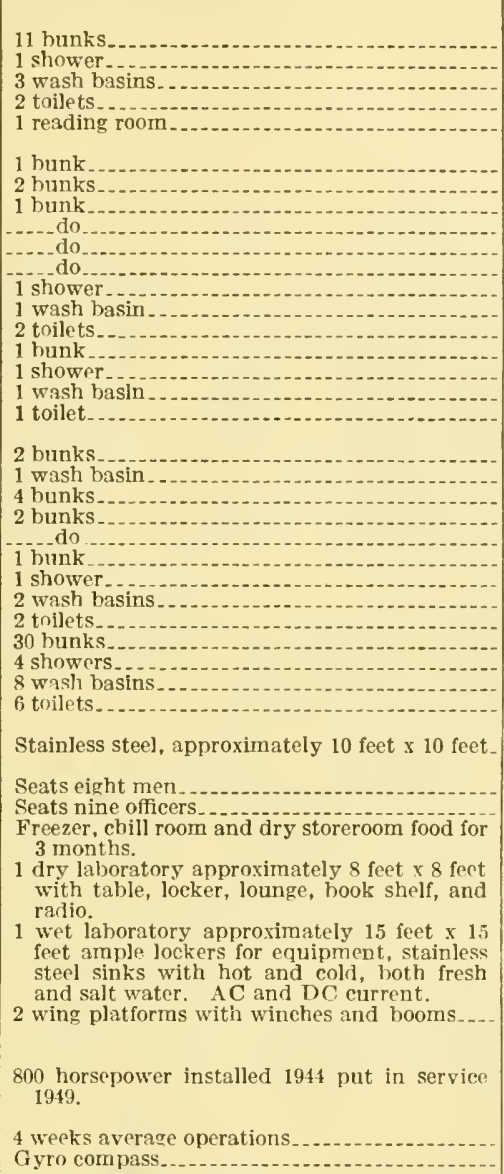 & 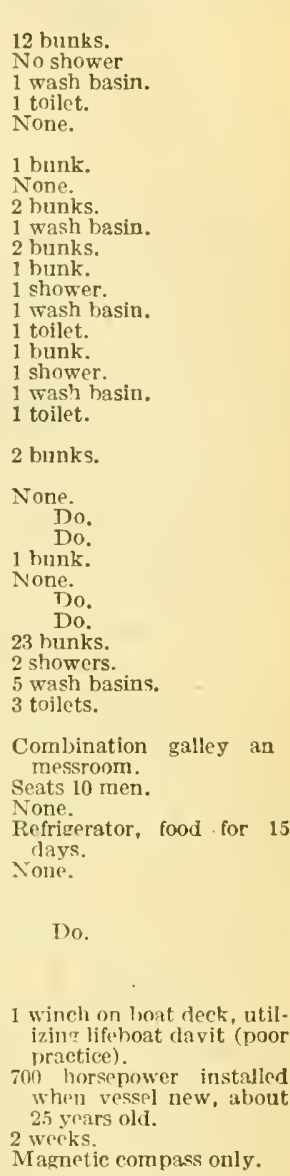 \\
\hline
\end{tabular}

Mr. JoHn McCart,

Fatrhaven, Mass, March 9, 1959.

Ic gislative Director, American Federation of Govermment Employces, Washington, D.C.

Dear Mr. McCart: Attached is a summary of information furnished by the master, chief officer and second officer of the research vessel Albatross III which is, in effect, a rebuttal to the report issued by the U.S. Fish and Wildlife Service, concerning the deactivating of the Albatross $I I I$.

This summary represents the beliefs of the crew of the vessel, some of whom have been attached to the Albatross since it was activated in 1949 . It is not intended as a personal gripe of one or more crew members, but rather a desire to make known all the facts by persons genuinely concerned and critically involved in an action effecting the very economy of our country. 
Not having access to service files, it is not possible to substantiate all the figures contained in this summary. They are however, to the best of our knowledge, true, and of such variance to the Fish and Wildlife Service report that we feel that a complete and exhaustive investigation is warranted.

Very truly yours,

\author{
E. H. HiLler, \\ Master, Chief Officer. \\ AUstin J. Powers, \\ Second Officer.
}

MARCH 9, 1959.

Subject: Report on deactivation of Albatross $I I I$, submitted by U.S. Fish and Wildlife Service, dated February 25, 1959.

The statement on the conditions of the Albatross III, contained in subject report, is very misleading and, in part, something less than factual. Take the very first statement in the report, for instance: "As a result of continued repairs and shipyard work the Albatross $I I I$ is in safe operating condition." It is only as a result of continued maintenance and annual overhauls that any ressel is kept in a safe operating condition. Repairs and shipyard work is not unique in the case of the Albatross III, as this sentence would have you believe.

It is a provable fact that considerably less than average amounts of money have been spent on repairs to keep the Albatross III at sea. A recent check of Boston shipyards indicates that the annual overhaul costs for a 100-foot towboat ranges between $\$ 30,000$ and $\$ 10,000$. Yet subject report, which shows an annual outlay of $\$ 33,000$ for Albatross III overhaul costs, would have you believe this is exorbitant.

Even if the figures shown for shipyard repairs, on page 3, were accurate and actually represented expenditures made solely for repairs and maintenance, this would still be well below the amounts spent by other Government services and private companies to keep their vessels in shape.

But these figures are misleading. During the years 1955 through 1957 the records will show that a considerable portion of the money, itemized as shipyard repairs in the report, actually was spent on structural changes and safety equipment to comply with U.S. Coast Guard and American Bureau of Shipping recommendations. Some of these items, which run into many thousands of dollars, include: two new metal lifeboats and launching equipment, an escape hatch from the crew's quarters forward, extra fire hydrants, a new general alarm system, and other items totaling 42 deficiencies found to exist on the Albatross III. Ironically, most of these deficiencies have never been corrected on the Dclaware, which the Service proposes to continue operating with a double workload.

Also included in the "shipyard repairs" must be the several thousand dollars put into designing, building and installing a new winch for the Scallop project. Due to faulty design, this winch has never been operated, nor will it ever be operated without extensive and expensive alterations. There she sits, "a $\$ 20,000$ piece of ballast."

No; if the actual upkeep costs of the Albatross $I I I$ were itemized for all the years she has been operating since 1949, the results would be so low as to be downright embarrassing to the Fish and Wildlife Service. For actually it was other Government services and a private institution that have, over the years really put the money into the Albatross $I I I$.

The Woods Hole Oceanographic Institution spent some $\$ 80,000$ on her in 1951, making extensive alterations and improvements. When the vessel was drafted into military service during the war, she was refastened from stem to stern, a new powerplant was installed, bottom plates replaced where necessary, and frames and longitudinal members reinforced throughout the vessel. It was due to these repairs, made by others, that the Albatross III met classification requirements of the American Bureau of Shipping in 1957. It is for the same reason that she is in a seaworthy condition today. Not because of exorbitant repair bills paid by the Fish and Wildlife Service.

In all the years she has been operated by the Fish and Wildlife Service, the Albatross III has experienced but one major breakdown. That was when her main bearings burned out in 1957 . This can happen to any ship, old or new, and certainly should not be construed to indicate old age and high upkeep costs.

Referring again to page 1 of subject, the new deck installed in 1958 was a joh that should have been done a year ago or so earlier. It would have been, too, if it had not been for the engine breakdown, which fact shows that the expense 
of engine repairs came in lieu of annual upkeep costs, not in addition to them. The deck job, which cost $\$ 4,200$, did not, of course, consist of new deck plates, but rather the replacement of the old wood sheathing with a modern, waterproof, nonskid deck emulsion. When the steel plates were bared during this work, they were test-drilled by ABS representatives and found to be in excellent condition. There are no new leaks in the deck, contrary to the report.

During the past 12 months the schedule of the vessel has never been delayed, nor have any scheduled cruises been omitted, due to breakdowns or other causes which could be attributed to the vessel's condition. In years past, certainly the engine breakdown caused considerable delay, but beyond that there have been no major repairs or out-of-the-ordinary repairs or layups causing undue delays in the work schedule. Indeed, no condition exists aboard the vessel today to keep her from going to sea for 300 days per year, if the work schedule required it. According to subject report, the Albatross III has been at sea for 102 days during the first half of fiscal year 1959. This, of course, equals an annual rate of 204 days. And this rate was accomplished with a scheduled idle period of 25 days over the Christmas holidays! The figures in the report just do not add up to the conclusion that the Service draws from them.

Ou page 5 of the report, it is stated that costs for the Delaware run about $\$ 10,000$ per month, compared to $\$ 14,000$ per month for the Albatross III. From these two cold, uninformative figures, someone would infer that the Delaware was more economical to operate $\$ 4,000$ per month cheaper, if you please.

A look at the attached sheet, showing a comparison of research facilities and personnel accommodations aboard the two ressels, and considering the fact that the Albatross $I I I$ has been working almost entirely on a 24-hour, aromind the clock, watch and watch basis, whereas the Delaware has been operating on a strictly daylight basis, then these figures present a different picture:

Albatross III: Carries average of six scientific personnel each working an average of-

Hour's per dav

Days per month at sea

Hours per month

Scientists

Research hours per month III

$\$ 14,000-1,080$ equals $\$ 13$ per hour of scientific research done on the Albatross

Delaware: Carries average of two scientists each working an average of-

Hours per day

Days per month at sea_... 15

Hours per month

Scientists -

Research hours per month.....-..- 300

$\$ 10,000 \div 300$ equals over $\$ 33$ per hours of scientific research done on the Delaware.

On a typical fishing cruise the Albatross $I I I$ will average better than 10 tows per day, fishing round the clock. On a recent cruise report, figures show that the Delaware averaged less than four tows per day. If the Albatross III can accomplish more than twice as much work for less than one-third more operating cost one might expect to believe she would be judged more economical. The fact is that not one man aboard either of the two vessels, or the biologists and technicians who go out on them, not one experienced seaman, given a similar choice would choose the Delaware. It is a most illogical move. It is a decision arbitrarily made by someone totally unfamiliar with the operation of the two vessels. The statement of increased costs shown on page 5 of the report cer. tainly represents a drastic increase in the wages of vessel personnel. But here again the figures lead you astray. There was no review of wages made until 1957 and the results of that survey showed that the men were drastically underpaid. Hence the increase. During the period 1957 through November 1958 , subsequent surveys resulted in a slight increase. In February 1959 the Wages Reviewing Committee again reviewed the wages, and in a surprise move, insti- 
tuted, in record time, another substantial pay raise. And, incidentally, they advised the Albatross erew of the new wage rates at the same time that they announced the deactiration of the vessel. In the same breath, literally, the crew were given a substantial wage increase and fired! Actually, in the case of the Albatross $I I I$, it has been pointed out that as a result of a drastic reduction-in-force order, reducing the number of crew members substantially, the subsequent pay increases effected the overall salary budget for the vessel considerably less than the report would tend to make us believe.

The layup of the Albatross on such short notice is a real catastrophe for some of the men involved. Sure, they can find other work, in time. But they have gotten away from commercial fishing, lost their contacts, and passed up higherpaying jobs for the ultimate security and satisfaction that they expected from Government service. Several men who hare been hospitalized for injuries or illnesses suffered in Government service now find themselves out of a job and owing the U.S. Government several hundred dollars for adranced sick leave. They have been ordered to sign releases permitting the Gorernment to withhold accumulated retirement benefits and annual leave payments.

In one instance, a man sick in Brighton Marine Hospital was mailed papers to sigu permitting the Service to advance him sick leave to corer his extended period of illness. He signed them in good faith, not expecting the ressel to be laid up scarcely two weeks after he returned to work. Certainly responsible men within the Service contemplated the deactivation of the Albatross months before the crew and public were advised. This being the ease, it seems highly illogical and most careless of those in management to encourage the man to take advanced sick leave.

When the vessel's erew were called together to receire their final separation papers, men owing sick leave were requested to sign away their pension fund and accumulated annual leare. This is money they will need to support their families while looking for work. In the case noted above the man was told it would go hard with him if he did not sign the release on the spot, after he had requested permission to take the form home to discuss with his wife a method of paying over $\$ 400$ back to the Government. After signing away all the benefits he had coming, the man admittedly could not give the Gorernment a check or money order to fulfill the claim. But he was forced to sign the release over a handwritten statement, dictated by a regional administrative officer, to the effect that he needed additional time in which to pay the Gorernment claim.

At this same separation meeting each of the crew members was handed a blue form No. 52 and told to sign his name anywhere on the back. In response to questions about the form, the regional administrative officer said it was not important, "Don't bother to fill it out, just sign your names on the back so we'll know where to send your checks and how to reach jou in the event we have a job for you." On closer inspection, it was discovered that form No. 52 is a request for personnel action, in short, a resignation form. When several men questioned the signing of this form, all were told they did not have to sign the form, plain paper would do as well. Was this subterfuge?

In the case of the chief officer of the Albatross, the arbitrary action of deactivating the Albatross came less than a month before the completion of his fifth year of service, thus depriving him of his riorht to a future annuity. This injustice is even more odious when considered in the light of the man's age, which is 65. Certainly arrangements could have been made to keep this man on duty for another montl.

The master of the vessel is 2 weeks short of completing a full year of active duty. His retention points are $1+$. He has not received a performance rating, although this could conceivably increase his retention points to 3 . Why?

The statement on page 10 of the report to the effect that the Delaucere will be able to accommodate additional crew members without difficulty is a strange and irresponsible one. A poll of the officers and erew of either vessel, the research biologists, or any impartial observer would belie the statement, most emphatically. A vast amount of moner must he spent to increase her accommodations and install the most meager facilities. No amount of money could make her equal to the Albatross as a rescurch vessel.

Certainly the Scrvice needs new research ressels. Attempting to convert a naval ship, except in an emergency, as a stopgap measure, would be too costly and rery unrewarding. But on second thought, does the Service need research vessels at all? Or, indeed, is it equiphed with the lnow-how to operate oceangoing vessels? The largest and best equipped, yes, the only fully found deep sea research vessel the Government owns is now being dismantled in Boston, 
for lack of foresight. And this action is taking place at the very time men who know, men of vision the world over are emphasizing the importance of undersea research. Says the National Academy of Science, "a greatly expanded undersea research program is needed." And, "ocean research is as important to us as space research." "Deactivate the Albatross $I I I, "$ echoes the Fish and Wildlife Service.

Perhaps the Albatross is too large a vessel for the Woods Hole Laboratory. Perhaps an 80 -foot inshore trawler will meet their requirements. If so, the Albatross should be operated as an oceangoing research vessel-at-large, to be put at the disposal of any laboratory on the Atlantic or gulf or Pacific coast, Alaska or anywhere else that a properly oriented program can justify her use.

Perhaps a whole new research program should be built around the Albatross $I I I$ to utilize her exceptional facilities, extended cruising range, and experienced crew. She should be made availabe for specific types of offshore research in any area of the world. Certainly she should not be taken out of service.

The Service proposes to use fishing vessel charters wherever necessary to augment the work of the Delaware. This has been the policy in the past, even when the Albatross was operating. In an effort to save money, this way, the Service accepted bids from the boat owners and invarably the boats quoting the lowest prices were those that were either unsuccessful for fishing, or laid up with engine trouble, or at best, were the lowest of the lowly craft. As a result, the research biologists hare been sent to sea in inferior boats, not at all represtative of the commercial fishing fleet. And it is a know fact that the best of the boats do not meet the minimum standards for life saving equipment, manning, or seaworthiness as set up by the U.S. Coast Guard. In addition, the facilities offered our biologists in the way of accommodations and research equipment are inadequate. One gear and equipment specialist reported he had to sleep on the lower shelf of a food locker on one chartered vessel.

The fishing vessel Dartmouth, chartered for scalloping, found it was losing money on the charter, so requested permission to fish commercially, at night, when the scientists were not working. This request was granted. The Dartmouth crew cast aside the Fish and Wildlife Service scallop dredges, stating that they were rigged wrong and did not fish well. They rigged up their own gear and used it. The expressed purpose in using the Dartmouth on this project was that a typical commercial scalloper was needed to give the scientist an authentic sample of scallops and scalloping operations. It has been inferred by the Fish and IVildlife Service project leader that the Albatross was too large for the work and would not produce realistic results. Fishermen contend that, using the proper gear, the Albatross would be ideal for the work.

Because they are small and ill equipped for research and, above all, uncertified by the U.S. Coast Guard, the commercial fishing boats are often held in port by the weather, thus tying up the time of several biologists, awaiting better conditions. Even under ideal weather conditions, such boats are uncomfortable, so it is questionable if the scientists can accomplish as much work as they would on the Albatross.

If a commercial vessel is in good condition, such as a well found Hiliner, fishing regularly with an experienced crew, it can ill afford to accept a charter from the Fish and Wildlife Service. They are earning too much money on their own.

It is, in fact, false economy to lay up the Albatross $I I I$. It is possible that what is needed at this time is a complete and thorough investigation of man. agement operations of all of the Service vessels. A research biologist should not be expected to be an expert out of his own field. He has had no marine education or experience required to operate a vessel, manage its schedule, or to understand the problems of fishing and shipping. Responsibility for research vessels for each region should be segregated under an authority completely separate from laboratory administration. If the maintenance, provisioning, manning, and budgeting of vessel operations were put in charge of a competent marine superintendent charged with keeping the vessels in shape and ready to meet the work schedules required by the various laboratories, then there would be 110 occasion to call the Albatross $I I I$ a $\$ 175,000$ headache. Operating a vessel is not a headache to men experienced in handling seamen or conversant with the costs of various phases of ship maintenance and management.

Thousands of dollars worth of equipment-nets, trawl doors, wire, and other gear have been damaged or destroyed entirely for lack of proper care of stowage. On the dock at Woods Hole is a mountain of fishing equipment rusting and 
rotting away for lack of proper care and protection from the reather. Perbaps enough of this equipment has been carted away to the dump already, to cover the salary of a competent marine superintendent for a year.

A closer cooperation between the activities of the two research vessels in this region would result in lower costs of gear and a more integrated work schedule. In a few instances, one research vessel could do the work of two, if care were taken in planning the cruises. One or two competent maintenance men, working in a single gear shed to serve the two vessels would save countless hours of delay aboard the vessels by mending nets, repairing gear, and making up new equipment. Money is needlessly being spent to purchase completed nets and trawl gear, whereas the required materials could be bought in bulk quantities and made up by our own maintenance men, or equipment specialists.

This term, "equipment specialists" should be scrutinized. It is the title of numerous classified employees connected with our laboratories. Some of these employees are truly expert gear specialists and many are not. Our real specialists are aboard the vessels, working at their trade 12 hours a day. But these men who have been working at their trade for 40 years or more, are never asked for advice, nerer consulted about new gear or contemplated fishing activities. They have, in many cases, reached a point where they will not even offer unsolicited suggestions, for experience has taught them that their ideas are not wanted. Many thousands of dollars worth of equipment has gone by the board for lack of proper rigging, or understanding of the ordinary practices of seamanship.

The men on the Service's research vessel are not encouraged to offer their ideas and suggestions. In many instances they have been discouraged from taking any interest in the development of new gear. And this within the branch of Fisheries called Exploration and Gear Research. Even private industry has found it profitable and to its advantage to encourage employee interest in improving equipment and operations.

We have men on our vesscls who have spent hours of their own time and many dollars of their own money in pursuing an idea for new equipment, only to find their superiors ashore uninterested and unenthusiastic, probably because of their lack of understanding of the problem.

Men, and most especially fishermen, with their heritage of independence and self-sufficiency, do not like to be supervised br shoreside personnel totally unfamiliar with ship gear and equipment. It is like throwing salt on an open wound when such shoreside personnel are rated as gear and equipment specialists.

The budget set up for the Albatross $I I I$ at the start of the fiscal year 1959 was sufficient to operate the vessel for a year, with a minimum of maintenance work and average repairs. Each month the ressel bas received a budget sheet showing expenses to date and balance in the appropriation. The last such sheet received was dated January 31, 1959. It showerl that the vessel was operating well within its budget and had sufficient funds to operate the rest of the year. If the Service is in fact without funds, then where did these budget figures come from?

Although the welfare of the actual men involved in the deactivation of the Albatross $I I I$ is of little importance when compared to the jeopardization of the country's research program, America has had a long background of standing for and fighting for the ralne and dignity of each of its individual citizens. To summarily deactivate the Albatross III without careful examination of all the ramifications of the situation can only be called a bluncler. It is unthiukable that this vessel should be deleted from our already insufficient research program, curtailing the bilogical research so important to our national welfare at this critical time when maritime nations the world over are exploring the waters washing our very shores in ultramodern research vessels.

It is the recommendation of the undersigned, that before the U.S. Gorernment's only major research vessel is taken out of service, further study by responsible and impartial authority be undertaken, to determine the truth of the myriad claims and counterclaims, reasons and excuses put forth to justify this action.

$$
\begin{aligned}
& \text { I. H. HiliER, } \\
& \text { MIaster, Albatross III. } \\
& \text { WILLIAM J. BRUCE, } \\
& \text { Chief ODicer. }
\end{aligned}
$$

Austin J. Powers,

Sccond Officer, Vice President, Loeal 1799, American Federation of Government Employees. 
Mr. Drewry. Might I say, Mr. Chairman, that this material just handed to me appears to be a statement by Mr. E. H. Hiller, master of the Albatross, Mr. William J. Bruce, first officer, and Mr. Austin J. Powers, second officer.

I have not had a chance to look at that yet.

Mr. Mrller. I want to thank you, Mr. McKernan, for being here and tell you that I think that you have done a very good job under these circumstances and we look forward to seeing you at proceedings of the Committee on Oceanography in the future.

I want to thank you, gentlemen, for being here.

Without objection, the committee will recess.

(Whereupon, at 11:45 a.m., the committee recessed, subject to the call of the Chair.) 



\title{
OCEANOGRAPHY IN THE UNITED STATES
}

\author{
TUESDAY, MARCH 17, 1959 \\ House of Representatives, \\ Siecial Subcommittee on Oceanography, \\ of the Comimitee on Merchant Marine and Fisheries, \\ Washington, D.C.
}

The subcommittee met at 10 a.m., pursuant to call, in room 219, Old House Office Building, Hon. George P. Miller (chairman of the subcommittee) presiding.

Present: Representatives Bonner (chairman), Miller, Lennon, Oliver, Flynn, Tollefson, Pelly, and Curtin.

Stafl' member's present: John M. Drewry, chief counsel, and William B. Winfield, clerk.

Mr. Miller. The committee will be in order.

This morning we are privileged to hear Adm. John T. Hayward, Assistant Chief of Naval Operations for Research and Development.

It has been our high pleasure to have seen and heard Admiral Hayward before. I almost said "Doctor" Hayward. I am certain that he deserves that title. I think that he is one of the foremost scientists in the country today.

We are very happy to welcome you here.

I want to say that this committee at present is groping. We have had the very important subject of oceanography referred to us by the chairman. We realize that, whereas it is of maximum interest to Government, no specific ageury of Government is charged with all of its ramifications. Perhaps one of the things we have to do is to come up with some formula for coordinating the work of other agencies. We know of the great work that the Navy has clone in this field and are very happy to welcome you here, sir.

STATEMENTS OF REAR ADM. JOHN T. HAYWARD, USN, ASSISTANT CHIEF OF NAVAL OPERATIONS (RESEARCH AND DEVELOPMENT); CAPT. RICHARD HOLDEN, USN, UNDERSEAS WARFARE RESEARCH AND DEVELOPMENT PLANNING DIVISION, OFFICE OF THE CHIEF OF NAVAL OPERATIONS; AND CAPT. H. G. MUNSON, USN, DEPUTY HYDROGRAPHER, HYDROGRAPHIC OFFICE

Admiral HaYward. I have a statement which I will present if that is satisfactory.

I greatly appreciate this opportunity to appear before your special subcommittee to present the Navy's programs in oceanography and to assist you in any way possible.

During the past seemingly short 10 years, oceanography has achieved an importance in the deliberations of scientists and govern- 
ments which was unforeseen at the close of World War II. This status has come about largely through the Navy's interest in the oceans. Even prior to the famous cluise of the Challenger in 1873 , which is usually considered as the beginning of modern oceanography, the Navy had carried out several scientific expeditions in the Atlantic, Pacific, and Antarctic Oceans. The Navy's formal interest in the oceans began in 1842 when Lt. Matthew Fontaine Maury was appointed Superintendent of the Depot of Charts and Instruments, which later became the Hydrographic Office. Today all active ships of the fleet and some MSTS ships collect somndings and bathythermograph information during transits and forward this information to the Mydrographic Office. The number of ships which supply this type of information is approximately 900.

Prior to the last war, the Navy carried out a program in oceanographic research through the Bureau of Ships and later through the National Defense Research Council. During the war this program became vital in combating the German submarine wolfpacks because of the effects of the ocean on the transmission of underwater sound. The bathythermograph which was useful to submarines in diving and evasive tactics came directly from the inventive mind of the oceanographer and without a doubt was one of the most valued auxiliary marine instruments used during the war. After the war, the Bureau of Ships sponsored oceanographic research for many years and emphasized the more applied aspects of oceanography in antisubmarine warfare. In 1946 a Division of Oceanography was established by the U.S. Navy Hydrographic Office. In 1947, the Office of Naval Research established a program in oceanography which has been expanded to the point that nearly all oceanographic institutes are sponsored to some extent. In addition to sponsoring the research program, ONR has assumed a position of leadership in this field. In 1957, together with the U.S. Fish and Wildlife Service and the Atomic Energy Commission, The Chief of Naval Research requested the National Academy of Sciences to form a committee on oceanography to advise the Government on a coordinated national program in oceanography and to act as a focal point for international cooperation.

Within the Department of Defense, the Navy has the major responsibility for research at sea, for looking after many of the marine interests of this country, for intermational discussions about the oceans, and for controlling commerce on the sea when dictated by war conditions.

Since the oceans are the Navy's primary domain and since the Navy must move ships about in the oceans, under the oceans, and aircraft in the air over the oceans, it goes without saying that a complete understanding of the oceans, the ocean bottom, and the atmosphere above must be obtained if the Navy is to wage modern war successfully. In the design of ships and aircraft, the oceanic enviromment must be taken into account and its effects on these instruments of war must be understood. By understanding the environment we mean that the current systems must be known from the surface to the bottom, the bottom topography must be known in detail, the temperature structure from day to day must be known, sea and swell forecasting must be efficient, the formation and breakup of Arctic Ocean ice must 
be predicted, weather conditions must be predicted, gravity and magnetic conditions must be lnown, beach conditions, and the land areas around these seas must be known.

Specific areas of military operations affected by the oceans are:

(a) Antisubmarine warfare.

(b) Mine warfare.

(c) Amphibious operations.

(d) Offensive submarine operations.

(e) Surface ship operations.

I would like to comment briefly on each of these.

The ASW problem can be clearly defined as the detection, identification, and destruction of the enemy submarine. In all three of these areas the oceans act in favor of the submarine. For example, with the exception of the transmission of sound, the oceans are nearly opaque to the transmission of all forms of energy. Even the sound transmission is distorted, reflected, scattered, and absorbed by environmental conditions such as temperature differences, chemical properties, marine life, sea surface conditions, and the nature of the sea floor. All systems of detecting submarines including airborne, surface ship, submarine, and fixed installations must take these vagaries of the sea into consideration.

Once a target is detected there still remains a problem of identifying it as an enemy submarine. False contacts such as whales, schools of fish, and abnormal sound conditions have to be minimized. These environmental problems are being investigated. After the target is detected and identified the oceans still protect it from any reapons system.

In mine warfare, we find that marine animals foul our mines to an extent that the mines eventually become inoperative. Bottom sediments may bury mines and unknown oceanic currents may sweep them away. In many cases, the design of the triggering mechanism is complicated by the fact that oceanic environment exhibits properties that are similar to those properties of ships that trigger mines. In mine warfare countermeasures we find that the ocean again interferes with our ability to detect mines, so that often our first notice of a minefield is the destruction of one of our own ships.

Our World War II experience illustrated the necessity of being able to predict ocean waves and surf as well as having a knowledge of beach conditions for amphibious assaults. Fundamental research on ocean waves has resulted in the publication of a prediction manual which is currently in use by the fleet.

There are two aspects to our offensive submarine warfare-one inrolving the missile carrying submarine of the POLARIS type, the other being the more conventional use of the submarine. In both cases, the true submersible requires a precise method of narigation while remaining underwater. Ocean currents, bottom topography, magnetic an gravitational fields are all important in this respect. Surface currents and sea state conditions are also important to the POLARIS submarine and we must be able to predict these with sufficient accuracy. A knowledge of ambient noise conditions, bottom topography, and the thermal structure is useful for evasive tactics.

For surface ship operations, we must know about the weather and sea surface conditions. The Hydrographic Office has been predicting 
these for several years and has successfully routed ships around storms in the North Atlantic and Pacific Oceans. The savings in time alone has been estimated by MSTS to be worth $\$ 2$ million over the past 2 years. Similarly, since 1952 , millions of dollars have been saved in the resupply of the DEW-line stations by the prediction of the ice conditions in the Artctic Ocean. More recently the Navy has and is participating in underice cruises in the Arctic Ocean and is collecting oceanographic information.

Thus far I have discussed some of the reasons why the Navy considers oceanography to be so important. Next I would like to describe the Navy's program in oceanography.

The Navy presently supports about 80 percent of the total oceanographic research in the United States. Approximately 300 full-time scientists of the doctors and masters or equivalent experience level are under contract. These scientists are distributed throughout 12 civilian oceanographic laboratories located on the east, west, and gulf coasts of the United States and have approximately 20 research ships varying in size from 50 to 2,700 tons at their disposition. 'The personnel are employed in both basic and applied aspects of oceanographic research. The entire field of oceanography including physical, chemical, bilogical, and geological research on the oceans is represented. In addition, the Navy supports a large program in underwater acoustics which is closely related and materially contributes to our understanding of the oceans.

Aside from the research at the civilian laboratories the Navy maintains nine large Navy laboratories, each of which has its own specific interest in the oceans. These laboratories have eight ships, two submarines, and a bathyscaph available for research in the oceans. Most of this research is directly applicable to Navy problems.

The oceanographic research program is considerably enhanced by the oceanographic program of the U.S. Navy Hydrographic Office. Facilities include eight major survey ships and inshore survey vessels. This effort is devoted solely to applied military oceanography with emphasis on (1) oceanographic publications, (2) surveys in support of military operations, and (3) research on the effect of the environment on military operations and means of predicting these effects.

Even though the Navy is engaged in a vigorous oceanographic research program we have realized this effort must be increased to solve the complex problems of modern warfare. Accordingly, the Office of the Naval Research prepared a long-range program of expansion in oceanography. This program, called TENOC, was endorsed by Adm. Arleigh A. Burke, Chief of Naval Operations on January 1,1959 . He stated that the Navy will support project TENOC within budgetary limitations in the Navy's research and development, shipbuilding and military construction programs. He has assigned a priority to this project commensurate with the antisubmarine warfare program in the Navy. Project TENOC includes a substantial increase in the research program, the construction of research ships, additional shore facilities and provision for the education of new oceanographers.

TENOC specifically covers the Navy's contract research program in oceanography. Studies are in progress to develop a similar program for the Navy laboratories. It is well known that research and sur- 
reying go hand in hand and in some instances the two overlap. Oceanographic surveying is fundamental to Navy operations, and the Hydrographic Office has been encouraged to expand and intensify its work in a manner comparable to that recommended for the research program.

IVhile the Navy is pursuing its own program in oceanography, the problems are so large and involve so many other groups that it has been found necessary to coordinate our research within the Department of Defense and other Govermment agencies. Within the Department of Defense formal coordination is achieved through the Committee on Science which has designated service representatives to deal with oceanography. Coordination among interested Govermment agencies is accomplished informally through the Coordinating Committee on Oceanography established by the Office of Naval Research in 1956. This Committee, consisting of representatives from all Federal agencies concerned with the oceans, has met regularly every month to discuss problems of mutual interest. The usefulness of the Coordinating Committee on Oceanography is attributed to its informality and to the rotation of the chairmanship among the member agencies. It is this group that will insure that a national program in oceanography is properly managed and well coordinated throughout the Federal agencies concerned.

The Navy has also participated in the international aspects of the science through scientific committees, meetings, and joint research expeditions. Through this participation we have maintained close scientific cooperation with the Western countries and have kept a vigilant watch over the scientific effort of the Soviet Union. The important work of the other Western nations is led by Great Britain whose oceanographic effort compares favorably with the United States, U.S.S.R., and Japan. Their equipment and personnel are excellent. Their program is well balanced with some effort in all physical fields of oceanography. Military, storm surge damage, and fishery requirements near the home waters are emphasized.

Japan has a large oceanographic research potential and probably ranks second or third in the world. Marine research knowledge is widely diffused throughout the educated population. The major part of the program suffers from insufficient funds and a lack of military research.

French activities are tied closely to fisheries, with some work in coastal engineering, port development, and protection. France supports more marine laboratories both public and private than any other European country.

Dutch accomplishments are of very high quality in marine geology and the theoretical aspects of physical oceanography. Coastal engineering services and equipment are outstanding. Research is concentrated in the contiguous coastal areas.

West German oceanographers are placing Germany in a position of international importance. Most of the important prewar personnel are located in West Germany or West Berlin. While most of the effort serves navigation and fisheries, there is a solid foundation for future expansion into deep sea work. A recent directory listed 68 oceanographers. Two vessels are employed with a third expected soon. 
Danish scientific contributions in oceanography have been significant. Three research vessels are employed on a worldwide scale to obtain biological and physical information on fishery and scientific programs. There is very little military effort.

Norway was once a world leader in oceanography. Equipment and personnel shortages have forced a decline.

Canadian work is concentrated in local waters and the Arctic Sea. Six research ressels, about a dozen scientists, and two dozen technicians are employed full time. The program is responsive to both defense and fishery requirements.

Argentina is the leading South American country doing oceanography, with Chile and Peru performing good but limited research. Cuban research in this field is moderate and excellent.

Soviet effort in oceanography is massive, of a high caliber, and is designed to establish and demonstrate world leadership. The objectives appear to be fourfold: (1) To accumulate masses of data equivalent to that possessed by Western nations, (2) to exploit the fishing industry as a major food source to offset deficient meat production, (3) to support naval operations and increase undersea warfare capabilities, and (4) to increase navigational use of the Northern Sea route for strategic and logistic reasons.

It is estimated that the U.S.S.R. employs as many as 800 professional oceanographers plus a similar number of support personnel. Approximately 65 merchant vessels and 40 naval vessels, including submarines, are employed full or part time. The Soviet IGY oceanographic effort was greater than that of any other country.

The activities discussed in this report indicate an extensive and growing national and worldwide interest in the oceans. It is the belief of the Department of the Navy that the real exploration of the sea is just beginning. Within the next 10 years, we expect the oceans to become more fully utilized to all depths. We further expect the United States to play a leading role in this new development and the Navy will carry its full share of this load.

I hope this has given you an appreciation of the great importance which the Navy attaches to oceanographic research and a general picture of the programs upon which we are embarked. All activities concerned with this research will be happy to give you the details of their programs at any future time at your convenience.

Thank you, Mr. Chairman.

Mr. MrLler. Thank you very much, Admiral.

I want to thank you for a very fine statement, one which will eroke a lot of thought.

In our own country in Government there are a number of agencies that have a major interest in the sea and I am glad to know that they are now at least informally coordinating their effort.

I think that the statement that you make with respect to this coordinating committee is very enlightening. You feel that this committee has functioned well in its informal capacity. Has there been an exchange of thought and ideas within the committeo that makes it a good institution with which to work or should it be more formalized?

Admiral IA Yrward. I feel that the informality, $\mathrm{Mr}$. Chairman, is an advantage. Is a matter of interest, I do not know whether the com- 
mittee is familiar with all of these agencies involved, but you have the U.S. Fish and Wildlife Service. You have the U.S. Geological Sulvey, the Director of the Trust Territories who is concerned with the problem of oceans which affect the Pacific coasts. Tou have the U.S. Weather Bureau, the Coast and Geodetic Survey, the U.S. Bureau of Standards, the Department of Justice which is working on the immediately forthcoming meeting on the law of the sea. You have the AEC on the disposal of radioactive waste. You have the National Science Foundation and the Department of Health, Education, and Welfare. You have the U.S. Air Force and the Navy and Army involved.

This gives you an idea of the number.

Mr. MitLer. About four of those agencies are under the jurisdiction of this committee.

We are privileged at having those four before us.

We hope as we go on with the investigation to call in other agencies so that we can get their reaction.

You are, of course, familiar with the report of the Committee of the Academy of Sciences which was headed by Dr. Harrison Brown, who is present?

Admiral Hayward. Yes, sir.

Mr. Miller. Of course, that was the basis which inspired Mr. Bonner to set up this subcommittee.

Dr. Brown's committee made some very fine recommendations as to the number of ships that we need in this field. We know that some ships in other agencies are obsolete and have to be replaced but one of the problems that is going to confront this committee is to determine how these are going to be funded and in what agencies some of them are going to be placed.

This is really the first chapter of its report that we have but the Academy report has been silent on that feature so that it is a question of great concern to the committee. We do not expect you or any one else to solve it but at the present time we are trying to accumulate enough data on which to come forward later with a very definite program and at perhaps future times have people in here to justify bills that I know will be introduced in the Congress on this subject.

I have nothing more right now.

Mr. Tollefson, do you have questions you would like to ask?

I may say that we are very happy to have Mr. Tollefson here as an ex officio member of the committee who has a great interest in the sea and everything to do with it. The name "Tollefson" at this time implies this.

Mr. Tollefson. Thank you, Mr. Chairman.

I know so little about this subject, $\mathrm{Mr}$. Chairman, since this is my first session with your subcommittee that I scarcely know what to ask.

I do have two or three questions which came to mind from listening to your testimony, I gather that without any question our various departments of Government have done a lot of research work in connection with oceanography generally. Do I get the impression that this work is going to be stepped up as a result of the cooperative effort between the various agencies? 
Admiral HaYward. Well, definitely we are going to step it up. To give you some figures, and this is just talking about the Navy support in oceanography, in 1951 we put in $\$ 51 / 2$ million. It went down in 1952 to $\$ 4.3$ million. In 1953 , it was up to $\$ 5.2$ million and then went down to $\$ 4.1$ million in 1954 . In 1955 , it went to $\$ 5.1$ million, and in 1956 to $\$ 7.9$ million, and in 1957 it came down to $\$ 6$ million again and in 1958 and 1959 it will run roughly between $\$ 7.5$ and $\$ 8$ million.

Mr. Tollefson. Do you know what the budget request for the next fiscal year is?

Admiral Hayward. Yes, sir; the Navy's request is $\$ 9.1$ million. One of the things about this business and all research really is that the one-shot approach is very poor. You must have a continuing program in research and it is better to have a modest program for 5 years, say $\$ 1$ million a year than to put in $\$ 5$ million in one year and nothing in the following years.

We feel that this program and our long-range program should go ahead and it involves considerable sums of money, particularly on ship construction.

Incidentally, I have here a preliminary design for an oceanographic ship that we are going to pass out. This has been one of our hard problems in the Navy. You have to decide whether to build a research ship or a combatant ship and we are going ahead with a regular construction program of research ships.

Mr. Tollefson. Do you know whether the other agencies are stepping up their work also?

Admiral Harward. The Maritime Commission is stepping up its work. I actually do not have the figures. I am sure we can get them for you over the past years just the same as we have given ours.

Mr. Tollefson. I get the impression from what you have said today and from publicity $\mathrm{I}$ have read in connection with this subject that there are various departments and agencies of Government which are more concerned now than they have been perhaps for some time.

Admiral HaYward. That is correct.

Mr. Tollefson. How does your work compare with the Russian work in the sense of effort expanded?

Admiral Hayward. They have much more effort than we have in just the number of ships. We see them on our morning briefs every day and their oceanographic ships are all over the world. I was aboard the one in San Francisco and I think they have a very excellent effort.

In talking to the oceanographers from Scripps and Paul Fye from Woods Hole, however, they said we had some better instrumentation than the Russians. As a matter of fact, they use some of our instrumentation.

Mr. Tollefson. I noticed that you say in your statement that even in the 1800's you did some work in the Antarctic.

Admiral Hayward. Yes, sir.

Mr. TorLefson. I assume that you are doing work there and also in the Aretic?

Admiral Harward. Yes, sir; very much in the Arctic.

With our nuclear submarines we plan to do as much as we possibly can. A submarine is much better under the ice up there, much better than an icebreaker, for instance. 
Mr. Tollefson. Do you know whether the Russians have done anything under the ice?

Admiral HaYward. I am sure they have. They have done a lot of Arctic research. They have put ships across the northern part of Russia for a good many years. It would be silly for me to assume that they have not done work there. I am sure if they had gone under the pole we would have known about it.

Mr. Tollefson. They would have boasted about it.

They are also doing work in the Antaretic, are they?

Admiral Harward. Yes, sir.

Mr. Tollefson. Have you heard anything in connection with their icebreaker? Is that going to be sent to the Antarctic or is it down there?

Admiral Harward. No, sir, it is not down there. I heard that they had a little difficulty with the nuclear engines on it. It has been delayed. There has been no deployment of it, to our knowledge.

Mr. Tollefson. Do you make any use of our own icebreakers in that work at all?

Admiral Hayward. For instance, the North Wind was down at Palmer Peninsula the last time I looked at the chart. She was helping the British resupply. We get the normal reports from those people, yes.

Mr. Tollefson. Do you feel an icebreaker is an efficient help for research in connection with oceanography?

Admiral HaYward. I feel that a submarine would be a more vahuable vessel. If I had the choice I would pick a submarine in the Aretic.

Mr. Tollefson. How would you like to have one of each?

Admiral HaYTard. I would say yes, certainly.

Mr. Tollefson. I have just one other question, admiral. Obviously, you exchange information with all of our agencies. How about exchange of information between our Nation and foreign nations? Do we exchange information with them?

Admiral HaYward. The western nations, yes, sir. Actually I do not know what the status of the IGY oceanographic information is. Maybe Dr. Brown knows whether we have gotten it or not. They are in the IGY committed to exchange all of this.

Mr. Tollerson. Mr. Chairman, I think I have no further questions.

Mr. Miller. Mr. Lennon.

Mr. Lennon. Mr. Chairman, there is one inquiry I would like to make.

Since the admiral has indicated that the Navy was one of the three Government agencies that requested that this Committee on Oceanography be formed by the National Academy of Sciences, I assume, admiral, that certainly the Navy has studied and considered the conclusions and recommendations made by this National Academy of Sciences committee?

Admiral Hayward. Yes, sir.

Mr. Lenson. I wonder if you would care to comment on the long range objective set forth in that report and its recommendations as to the practicability of it and how this committee, as one of the legislative committees that does have jurisdiction orer several of the governmental agencies, could implement that suggested program and

$381700-59-10$ 
those recommendations of the National Academy of Sciences Committee.

Would you comment on your impressions of the report and its recommendations?

Admiral HaYward. Well, frankly, I think it is an excellent report. As to their recommendations, if the Navy had to do it I would be caught in my same old budget argument, really, as you know. We are weighed between being ready to fight in the Berlin crisis or something of this kind and how much we will put into the research and development effort.

I feel that our 10-year program, which is the TENOC program of which you may have a copy, has the endorsement of the National Academy of Sciences. I think that is an excellent report.

Mr. Lenson. I notice here that you say that the Navy is presently supporting about 80 percent of the coastal oceanographic research. Under this projected program or recommendation of the National Academy of Sciences Committee would the Navy continue to bear that relationship to the total?

Admiral HaYward. No, we would not because, as I recall, that figure was around $\$ 643$ million.

Mr. Lennon. Over a 10-year program I believe it was. The Navy, of course, would continue to bear the same percentage of that overall program as it is presently carrying?

Admiral HaYward. No, if that program went into being we would not have the 80-percent level.

Mr. Lennon. I note here in your statement, on page 5, that actually there are 20 ships varying in size from 50 to 2,700 tons which are now presently engaged in the jurticular type of program under contract, I assume, with these private concerns. At least your scientists, you say, are under contract.

Admiral HAYward. Yes, sir. These cover everything from converted $A R$ 's to the little yachts and this particular preliminary design we have is one that the oceanographers have participated in actually to get what they want in a ship. Most of the ships that we have have been other ships converted for oceanographic work.

Mr. Lennon. Does either the Navy or these private concerns have any modern equipped vessels for this type of research work now?

Admiral HaYward. Any modern equipped ones?

Mr. Lennon. Yes, or are they all practically reconverted from other type ships?

Admiral HAYWARD. We are building one in the 1960 program, of course, but of the present ships, to answer your question, no, there has not been one built. They have a lot of modern instrumentation but the ship itself has usually been a conversion.

Mr. Lennon. Do you find that even a ship that has been converted but which has modern technical equipment can do a realistic practical job?

Admiral Haywand. Yes, according to Dr. Fye and Rogrer Revelle. As a matter of fact, the ships that we converted for them were picked out by those laboratory gromps. They went into the actual conversion and they are very useful vessels. Tust because they are converted does not mean they do not have any use. They will serve a very useful life, too. We have a converted seaplane tender and two rescue vessels that were converterl. 
In our 10-year program, of course, we are going to build 18 modern oceanographic ships.

Mr. Lennos. Will you excuse me, sir?

When you refer to the 10-year program, are you alluding to the program that is projected by the National Academy of Sciences Committee or the Navy's own program?

Admiral HAYward. 'The Navy's own TENOC program that I referred to and it runs from fiscal 1960 to 1968.

The first ship to be built is this one that you see up there. These ship are small. They will have a trial speed of 13 knots and an endurance of 12,000 miles. They have an overall length of 209 feet and 1,370 tons is their displacement.

Of course, they have their laboratories, wet and dry, aboard and combined drafting room and study space. They will be equipped with deep sea winch and boom over the stern capable of supporting 30,000 pounds. The cost of this ship is $\$ 3.7$ million. This ship will provide for a crew of 22 , including officers, and a scientist complement of 15 . It will be civilian manned by crews planned for by the parent oceanographic institution. These are not large like the U.S.S.R. ships have been. However, the smaller size that we are building is preferable to the U.S. scientists' since it entails a much lower operating cost crewwise. They get more scientists and they actually want to run the ship with a minimum number of people.

Also we have a larger research ship in this TENOC program which runs between 2,000 and 3,000 tons and this will have 29 officers and can carry a team of 39 scientists. You will have a larger boom capacity.

I have not any cost estimates but it would run in the neighborhood of about $\$ 5$ million.

Now, this program of ours recommends that the three oceanographic laboratories, Scripps, Woods Hole, and Lamont, each be equipped with two of the small ones and one of the larger research ships.

It also recommended that the Hudson Laboratory get one small one and one large ship, the University of Miami would get one small one, Texas A. \& M. would get one of the small ones and actually the overall effort recommends the building of an average of two of those a year from 1961 to 1966 and one of the larger ones per year commencing in 1963 and continuing through 1966.

Now, in addition to these there are three 80-foot boats and one 300 -ton ship for which no design specifications have been drawn but whose costs total about $\$ 11 / 2$ million.

The entire shipbuilding costs in this program come to $\$ 58,600,000$ for an annual expenditure of around $\$ 7$ million for shipbuilding.

The program is modest and we are planning, of course, what I call seed corn. Compared to the Russians we are actually getting many more mobile research stations and can cover more areas for considerably less lost. We think it makes sense to do it this way rather than building fewer large ships, and the oceanographers and scientific people who run the program agree with us.

Mr. Lennon. There is one other question.

You referred to the Committee representing the several Government agencies who had the community of interest in this proposed program. Since the Academy of Sciences report has been publicized 
and its recommendations publicized, has this coordinating committee of the Government agencies met with the Academy of Sciences Committee to discuss its recommendations and reports and try to correlate them and make specific recommendations to this or any other legislative committee that would be interested in this matter?

Admiral HaYward. They met. Dr. Brown was there in the departmental meeting. I do not know the recommendations of that meeting yet. I have not seen them. They recommended, I know, that they wanted to use the informal committee arrangement but I have not seen the minutes of that meeting.

Mr. Lenvos. There is no suggestion that grew out of that conference that a more formalized coordinating committee should be established by legislative action?

Admiral Ha Yward. No, sir'; not to my knowledge.

Mr. Lennon. Thank you.

Mr. Miller. Mr. Pelly.

Mr. Pelly. Mr. Chairman.

I am interested to have Admiral Hayward here today because I recall that a few years ago he was taking command of the great carrier, the Franklin D. Roosevelt, in Bremerton Navy Yard and at that particular time I because a little familiar with his record and from his graduation on I know that he has made a definite demonstration of the fact that he is a fine naval officer and we can feel confident at least that this program under his leadership is going to be well handled.

Admiral, does the Office of Naval Research actually sparkplug the coordinating committee?

Admiral Harward. Yes, sir. Actually, the Chief of Naval Research has the problem and job and he also has to initiate the action for us. In the Navy, Admiral Burke has given it to Admiral Bennett to make sure that our program is coordinated completely with all of the other Government agencies. The Office of Naval Research really started and sparked the rest of the agencies, I feel.

Now I cannot say too much in praise of what the Office of Naval Research has done in this field and it is true across a lot of the other basic sciences as you know, physics, low energy nuclear physics, that they have sparkplugged this.

Mr. Pelly. From a practical standpoint, does it mean that you will be building over a period of years 10 new vessels at approximately $\$ 5$ million apiece?

Admiral HaYward. We will actually build 18 all together. Mr. Peldy. Eighteen?

Admiral HaYward. Yes, sir. It will be over that period of years, as I said. The first one will be built in 1960. That is that small one. Then actually we hope to get two a year and then we hope to get the large ones. Commencing in 1963 throngh 1966 we will build one of the large ones and one of the small ones each year.

Mr. Pesty. Do the other arencies, such as the Fish and Wildlife Service, seem to have a need for more modern vessels? Some of theirs are pretty old. Iats the Nary any ships that they cam turn over to these other anencies to help them oint?

Admiral Harward. Yes, sir. We do have them in the mothball fleet now. 'The way we handled it with Woods IJole and Scripps 
was to give them a rundown on everything we had and let them pick what they thought made good sense from their scientific and technical standpoint and then they were converted.

Mr. PeLLy. They were leasing a trawler or two up there and I wondered whether or not you might have something better that they could take over and utilize to better advantage.

Admiral HaYward. Yes. Of course, in our case they would have to be converted. You would have to look at the conversion cost as to what they wanted to do with it. All of those ships that we have in that category would be available to any agency that wanted to do this.

Mr. Pelly. Would the interchange of information come through the Office of Naval Research or through the Committee on Sciences, the coordinating committee?

Admiral HaYward. Through the coordinating committee but if this is what they wanted done, the Chief of Naval Research would come to me and would go over the ship side of it.

Mr. Pelly. I cannot see why, if an ordinary fish trawler is adaptable for the type of work that the Fish and Wildlife Service is doing, they should necessarily have to lease a fishing boat and why you would not have something that would be better then without converting.

Admiral HAYWARD. It is the operating cost really, probably. I do not know how long they lease them for. When they lease them the man whom they lease them from usually has the upkeep, I imagine, and the overhaul of the ship. They probably do it cheaper this way, Mr. Pelly, I am quite sure.

Mr. PELLY. The other day we learned that there is an international plan whereby they will study the Indian Ocean as one area in which all nations engaged in this research work concentrate their work. Would the Navy participate in that general collective program?

Admiral Hayward. Certainly we would. One thing you will find with this program in the teclinical world is that everybody knows what the other people are doing and they go to the areas. It is pretty well coordinated. You will find most scientists do not like to repeat what other scientists are doing.

Mr. Pelly. I can only say for myself that I feel very much encouraged by your testimony that really we are in the infancy of a new rather extensive program. I again say that I ain sure that with your background it will mean that the program will be well handled and go forward.

Thank you, Mr. Chairman.

Mr. MilleR. Thank you.

Mr. Oliver?

Mr. Oliver. Thank you, Mr. Chairman.

Admiral Hayward, did you happen to read in the Washington Star, I think Sunday, the statement with regard to the future of oceanography so far as this country is concerned?

Admiral Hayward. No sir, I did not read it, Mr. Oliver.

Mr. Oliver. I was quite intrigued by what the article had to say. I thought it was a very imaginative statement.

I was wondering whether it was a practical situation that was outlined as to the future possibilities of oceanographic work of operations. 
If you have not read it, of course, you cannot comment.

I think, Mr. Chairman, that it might be well, if it meets with your approval, to insert that statement in the record at this point.

Mr. Miller. Do you have a copy?

Mr. Oliver. I clipped it out of the paper Sunday, I do not have it with me.

Admiral HaYward. I am sure the first time we discover an oilwell halfway between New York and Bermuda, we will have a lot of interest in oceanography.

Mr. Oliver. I was tremendously interested in this pamphlet that you have sent up here outlining the specifications and data with regard to these proposed oceanographic research vessels. That program is to be continued on, you say, over a 10 -year period?

Admiral Hayward. Yes, sir.

Mr. Oliver. And the first ship will be available in 1960 ?

Admiral Hayward. It is in the 1960 program.

Mr. Oliver. It will not be available until 1961 or 1962 ?

Admiral HAYWARD. It will be available in 1961.

Mr. Oliver. These, of course, are going to be the most modern ships available for that particular purpose, is that correct?

Admiral HaYward. That is correct. Yes, sir.

Mr. Oliver. I notice that in the meantime you have stated that converted vessels are going to be the only source of research work that you have.

Admiral HAYward. That is right.

Mr. Oliver. That interested me because of a hearing which we held here within the past several days with regard to the deactivation of a ship in the northeastern area of the country operating out of Woods Hole, the Albatross III. Are you familiar with that vessel at all?

Admiral HaYward. I am familiar with it. The Albatross III, yes, is the Fish and Wildlife Service ship, a rebuilt trawler built in 1926 and is 340 tons, 179 feet long. It has a range of 4,500 miles and the daily operating cost is about $\$ 650$. I do not know the background of the matter.

Mr. Olrver. What I was particularly interested in, Admiral, is in the light of your statements here that the Navy is using converted ships for research work in some oceanography, I am a little bit concerned over the statements which we have had that this particular conversion has practically lost its efficiency so far as oceanographic research is concerned. I find it difficult to reconcile those points of view.

Admiral HaYward. Well, I have a very good publication here of Gordon Lill, who is the Director of our Geophysics in the Office of Naval Research, and the title of it is "Oceanographic Research Ships." It is of interest to note that the ships of the U.S. Fish and Wildlife Service listed here were all originally constructed for a purpose other than research. The Albatross III, the Black Douglas, and the $H$. M. Smith, one is a rebuilt trawter, one is a schooner, and one is a tuna clipper. All of them are 600 tons or smaller. 'This is a rather' small ship.

Mr. Oliver. Apparently it is the only one that is being operated so far as Fish and Wildlife is concerned that is capable of oceangoing research. 
Admiral HaYward. Well, if they need a trawler, they have not come to us, let me say, to ask. For instance, of our ships which we just converted for this, the San Pablo is a seaplane tender. It is 2,700 tons and it has a 10,000-mile range. The Rehoboth, which is also a seaplane tender, has the same characteristics. This gives you some idea of the difference in the tonnage.

Mr. Ouvver. But the Navy's attitude apparently, in this field, is that it is necessary for the moment, in order to get oceangraphic research work done, to carry on with converted vessels?

Admiral HaYward. Yes, sir. We have no other way to do it.

We are going to build new ones. If the Fish and Wildlife Service came to us and said that they had a requirement for one of the small ships, such as this that was laid up, we would certainly consider it, but they never have done this.

Mr. OLIVER. I am glad that Congressman Pelly brought out that particular possibility in his statement here just a moment ago. It particularly intrigues me because this Albatross III having been deactivated in an area that $I$ am representing seemed to me to be, on the face of it at least, a rather ill-advised action. I am very happy to note that the Navy does have available craft which could be had by the Fish and Wildlife Service if they saw fit to request it.

Admiral HaYward. Well, I do not know what particular research the Albatross III was doing. If it is a trawler, I would recommend, from the cost point of view, that they lease another trawler rather than spend the money to convert.

Mr. Oliver. Of course, their program is one of chartering private draggers or trawlers or whatever they may be to do the work that the Albatross III was doing but there was some question in my mind yet as to whether it will be an efficient operation. I realize that that is perhaps beyond the scope of your jurisdiction and, therefore, I will let the matter drop as of this time.

I want to say in closing, Admiral, that I am very, very encouraged to note that the Navy is setting its program up on the basis that it is and I certainly will anticipate whatever results you are able to get during these next several years.

That is all I have, Mr. Chairman.

Mr. Miller. Mr. Curtin.

Mr. CurTin. Thank you, Mr. Chairman.

Admiral, do your scientists and those of the Fish and Wildlife Service collaborate on your findings in this oceanography?

Admiral Hayward. Oh, yes, sir.

Mr. CURTis. You do not work independently of one another?

Admiral HAYWARD. No, sir. It is one area that is very well coordinated.

Mr. Chairman, actually I recommend that the committee get this pamphlet in the record which is "Oceanographic Research Ships," and it has the picture of the Albatross and tells of all the ships that are in operation and their daily cost of operation and covers the various types of ships. It is a very thorough and complete article on oceanographic research ships.

Mr. Miller. Who publishes that?

Admiral Hayward. This was the Office of Naval Research. It was the Underway Acoustics Journal and we can get copies. 
Mr. Milier. Could you leave that copy for the reporter? Admiral Hayward. Yes, sir; I will.

Mr. Miller. Could you get additional copies for members of the committee?

Admiral Hayward. Yes, sir.

Mr. Miller. Without objection, we will make that part of the record.

('The pamphlet referred to follows:) 


\title{
OCEANOGRAPHIC RESEARCH SHIPS
}

\author{
G. G. Lill and A. E. Maxwell
}

Office of Naval Research

Washington, D. C.

\section{INTRODUCTION}

Modern oceanography is considered by most scientists to have begun with the unprecedented round-the-world cruise of the HMS CHALLENGER from 1872 to 1876 . There had been notable cruises prior to this, such as the voyage of the HMS ENDEAVOUR under the leadership of Captain Cook and the scientific direction of Sir Joseph Banks in 1768 to 1771 and the voyage of the BEAGLE from 1831 to 1836 under Darwin, but no scientific cruise prior to that of the CHALLENGER ever provided so much new scientific information. The HMS CHALLENGER (Fig. 1) was a spar-deck corvette of 2306-ton displacement and auxiliary engines of 1234 horsepower. In three and one half years she travelled 69,000 miles in the Atlantic and Pacific and penetrated as far south as the Antarctic ice barrier.1 The voyage of the CHALLENGER opened

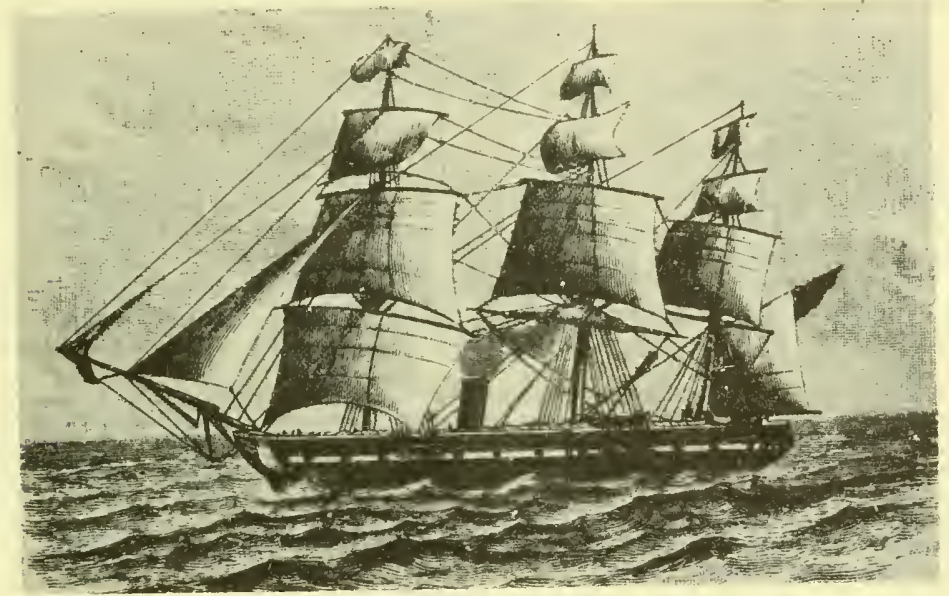

Fig. 1. HMS CHALLENGER -- 1872-1876

The "first" oceanographic research ship

\footnotetext{
ISir William A. Herdman, The Founders of Oceanography and their Work (Edward Arnold \& Co., London, 1923).
} 


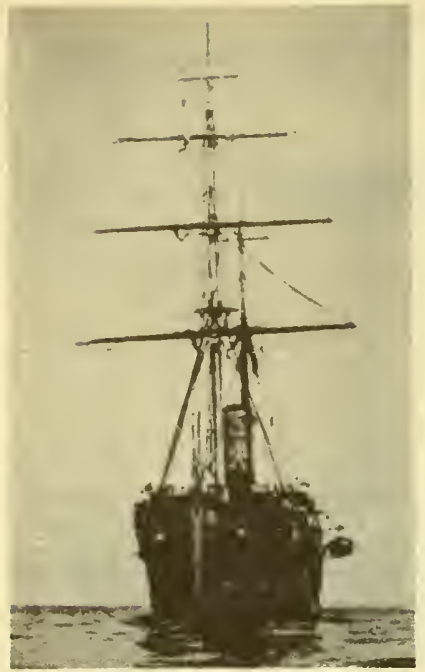

Fig. 2. METEOR. German (Hydrographic Department) research ship of the late $1920^{\prime} \mathrm{s}$. the era of exploratory oceanographic cruises, which in a certain sense is now coming to an end, 82 years later.

The expedition of the German research ship, METEOR (Fig. 2), in the North and South Atlantic from 1925 to 1927 established our knowledge of the general circulation in the Atlantic. The METEOR was an auxiliary steamer of 1200 displacement tons and carrying a total crew of 114.2 Together with other famous ships, such as the DISCOVERY, DISCOVERY II DANA, EXPLORER, and WILLIAM SCORESBY, she was a part of the grand era of oceanic exploration when oceanic expeditions were fitted out by governments, sent on long cruises, and dismantled upon their return, whereupon the scientist's attention was given over to working up the scientific results of the trip.

Since World War II, with the exception of the cruises of the ALBATROSS and GALATHEA out of Scandinavia, shorter individual crulses of a continuing nature and for particular scientific purposes are the fashion in oceanography, both in the United States and abroad.

In all of the crulses mentioned, the Navys of the particular countries involved were vitally interested in the work and often provided the ships. The United States Navy first took official notice of the oceans when, at the recommendation of Lleutenant L. M. Goidsborough, a "Depot of Charts and Instruments" was set up at the seat of the government. This Office was established as the Hydrographic Office in 1866.3

To show the intimate and vital connection of the U.S. Navy with the sclence of oceanography, in particular for the last 30 years, this quotation from Vaughan's "International Aspects of Oceanography" is presented:

"On April 27, 1927, the National Academy of Sciences adopted a resolution which read as follows: THAT 'The President of the Academy be requested to appoint a Committee on Oceanography from the sections of the Academy concerned to consider the share of the United States of America in a world wide program of oceanographic research and report to the Academy...'

"In the hope that the United States Navy might find it feasible to extend its activities in oceanographic investigations, the members of the National Academy Committee on Oceanography called on the Secretary of the Navy, at that time the Honorable Charles Francis Adams. The conference led to the appointment of a Naval Committee on Oceanography under the chairmanship of Rear Admiral Frank H. Schofleld, now retired. This Committee made several recommendations, one of which was that Naval vessels equipped with sonic-sourding apparatus should, when feasible, follow routes which would carry them over oceanic areas for which information on oceanic depths was inadequate. This recommendation was adopted and it has led to probably the most extensive systematic program of sounding for bottom configuration undertaken by any country. Since about 1928 most of the North Pacific north of a line from the Callfornia coast to the Hawailan Islands and thence to the Philipplnes has been covered by a series of closely spaced lines from east to west and these lines have been crossed by other lines, north and south between the Aleutian and the Hawalian Islands and toward the northeast

2Thomas Wayland Vaughan (and othera), International Aspects of Oceanography (National Academy of Sciences, Washington, D.C., 1937).

${ }^{3}$ Thomas Wayland Vaughan, Op. cit. 
from the Hawaiian Islands to Puget Sound. United States Naval vessels have also run many other lines of soundings. In addition to the soundings, the Navy Department has endeavoured to assist investigations in many other fields, so that it has now become one of the world's major agencies in oceanographic research. Serial sections for subsurface temperatures and salinities, the plotting of sea surface temperatures and surface drift and the utilization of submarines for the determination of gravity at sea are noteworthy."

The U. S. Navy Hydrographic Office has been responsible for carrying out the work described above. Since the publication of Vaughan's report in 1937, so much more work in oceanography has been accomplished by that agency that it would take volumes to describe it. Soundings have been added to and improved, temperatures at depth have been added to the surface temperatures, special surveys of convoy routes and other particular areas have been completed, new and accurate bottom-contour charts have been produced, and sound-velocity charts and bottom-sediment charts have been published, together with innumerable volumes on oceanographic and navigational subjects. It is a record of which the Navy is proud and one which should never be allowed to drift without the constant replenishment of new scientific ideas, equipment, and facilities.

Since 1947, the Office of Naval Research has taken over the support of oceanographic research for the Navy. Considerable research had been accomplished by the Bureau of Ships during the war and afterwards, which contributed immeasurably to our knowledge of the oceans as it applied to the many problems of submarine and mine detection. The importance of Navy support, in terms of this paper, is that the operation of research ships has been sponsored along with the research. As a general rule, about one quarter of all research funds during the last 10 years have gone for the operation of ships, including such maintenance and fitting out as has been accomplished. About $\$ 11,500,000$ has been spent in support of ships working on the Navy's research program for the last 11 years. This figure does not include funds expended on the governmental ships listed in Table I, which are employed on surveys and special projects rather than fundamental research.

In view of the long history of the Navy in oceanographic studies, and because of the Navy's vital need for oceanographic information in antisubmarine warfare, mine warfare, and amphiblous warfare, the Office of Naval Research has argued that the Navy should provide the scientists with proper facilities for collecting the information. These facilities include research ships. Furthermore, because of the threat of the Russian submarlnes, the possession of a suitable research fleet by the United States is of burning importance. Legally, and without special permission from Congress, the Navy can construct ships for the use of Navy contractors, so long as these ships are civilian manned and do not appear on the Navy register. The question of whether the ships should be constructed with Research and Development funds or Ship Construction and Maintenance funds has not been settled; but the settlement will be a matter of policy rather than of legality, since either kind of money may be used.

\section{THE FUNCTION OF A RESEARCH SHIP}

The mission of a research ship is to carry scientists to sca for the purpose of research. In the Navy the research has its ultimate application to naval warfare. The ships are employed in the following tasks in order to meet this application:

a. Performing basic and applied research at sea which will lead to new mllitary applications, particularly in undersea warfare.

b. Studying the effect of the environment on sound transmission in the ocean.

c. Carrying out scientific investigations in oceanic areas of naval interest.

d. Testing the environmental effects of the ocean on the ship and on scientific and naval instruments.

e. Obtaining the oceanic data necessary for the installation and improvement of oceanic surveillance systems of both a scientific and military nature. 
In carrying out this mission and the assigned tasks, the research ship is employed in studying: the current structure of the ocean; oceanic temperatures; environmental effects on instruments and techniques; bottom topography, sediments, and structure; heat flow through the bottom; sound transmission and velocities; ambient noise; biological activity and specimens; nuclear components; and water samples for salinities, phosphates, oxygen, nitrates, etc.

The mission, tasks, and employment of research ships form the broad base for submarine and antisubmarine warfare research work without which modern naval warfare would be severely handicapped. For instance, submarines cannot function properly in strategic areas without adequate knowledge of currents, bottom topography, sound velocities, ocean temperature, and weather. We are now ill equipped to provide the knowledge because we lack ships capable of working in the north east Atlantic, the North Pacific, and the Indian Ocean.

\section{PRESENT STATUS OF U.S. SHIPS}

The status of ships in use in the United States today is indlcated in Table I. Photographs of some of the ships are given in Figs. 3-14. The R/V ATLANTIS is the only one of these which was originally designed for research purposes. The others are conversions from yachts; warships, tugboats, and fishing vessels. Because they were designed for those purposes and not for research, they have inadequate facilities for crew and scientific work. Many of them have limited range or are unsafe for oceanographic work in sea states greater than 3 or 4. They are noisy, making it difficult or even impossible to perform sound-propagation studies. The larger ships have improper scientist-to-crew ratios, that is, they have many more crew members than scientists, which in the research business is economically unsound. Most of the ships are too slow, which is costly in scientists' time and in Navy funds.

There has been no program for the replacement of our research fleet as the ships become old and unsafe, either on the part of the scientific institutions contracting with the Navy or on the part of the Navy itself. If we are to get ahead of the Russian submarine menace and stay there, a 10-year ship-replacement program should be implemented. We have a 25-year replacement program to accomplish within the 10 years.

\section{THE STATUS OF FOREIGN RESEARCH SHIPS}

Selected foreign ships are listed in Table II. In addition, photographs and characteristics of three of the better ships are presented in Figs. 15-17. It is noteworthy that the Russians and Japanese are building new research ships. The Russians started with conversions and have graduated to specially constructed research ships such as the MIKHAIL LOMONOSOV which completed her first cruise in the North Atlantic late in 1957. The Japanese have one of the finest research fleets in the world which has been built largely for oceanographic research in connection with their fisheries. These nations are conducting much the same type of research at sea as we are, and they have better ships with which to do it. We may assume that nations which are willing to invest large sums of money in research ships also have the skilled scientists necessary to use them properly. Assumptions to the contrary are not well taken.

\section{THE NEED FOR NEW OCEANOGRAPHIC RESEARCH SHIPS IN THE UNITED STATES}

The urgent need by the United States for new and carefully obtained oceanographic information has been known for many years and has been recommended and pointed out to the Navy by some of the country's best scientific talent in the following studies:

HARTWELL Report - a study of overseas transportation problems

LAMPLIGHT Report - a study of the Navy's role in continental defense

NOBSKA Report - a study of the Navy's problems in antisubmarine warfare. 
Table I. Principal oceanographic laboratories and ships in the United States ${ }^{\text {a }}$

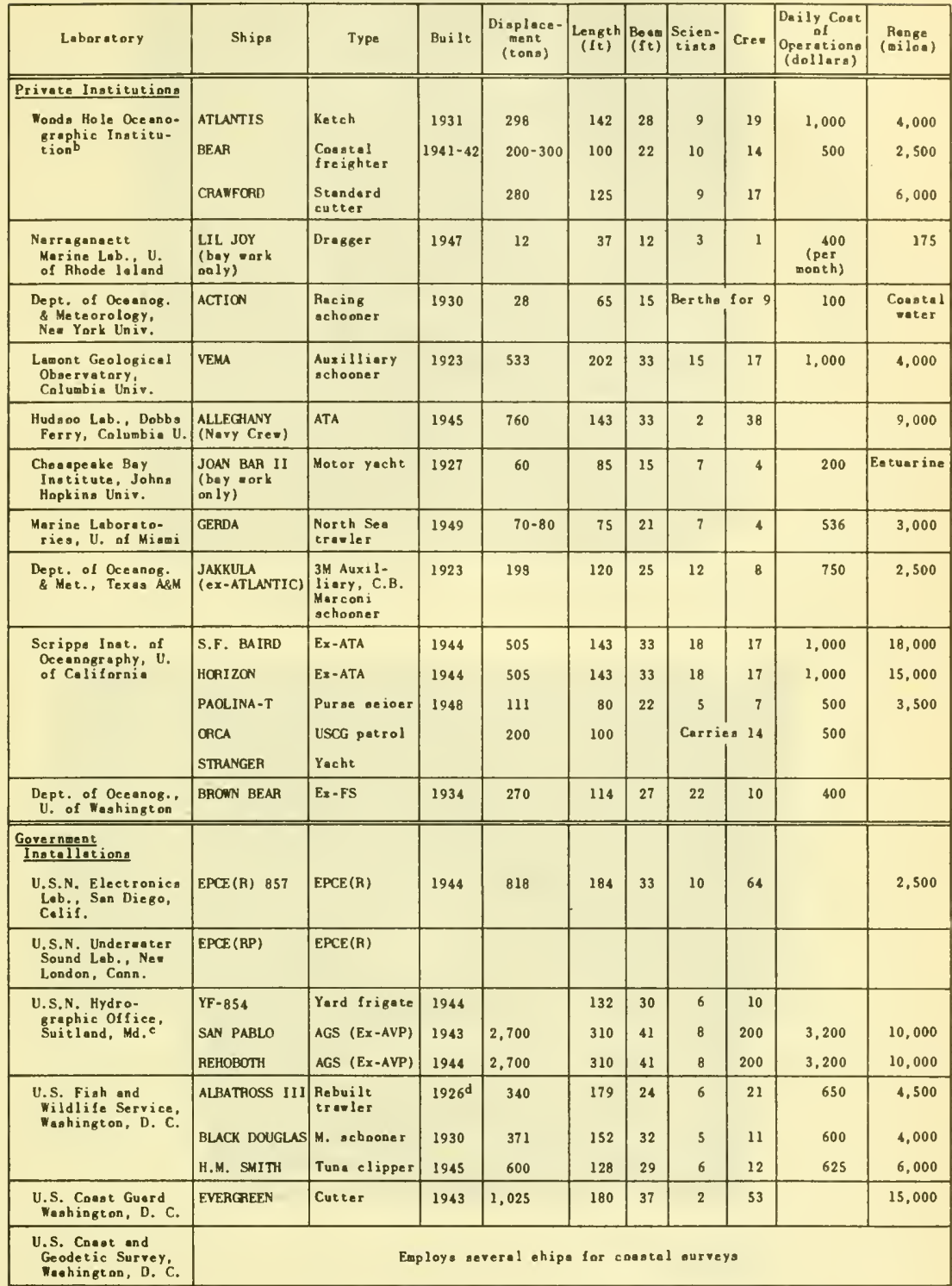

'From Milliem V. Kielhorn, Oceanographic Veasele in the Uaited Statea (Office af Naval Reaenreb, 1953 ).

banage ONR' Laboratory of Ocenography.

'Operates other hipa, but theee three do moat of deep-sea ncenography.

Roboilt in 1941. 


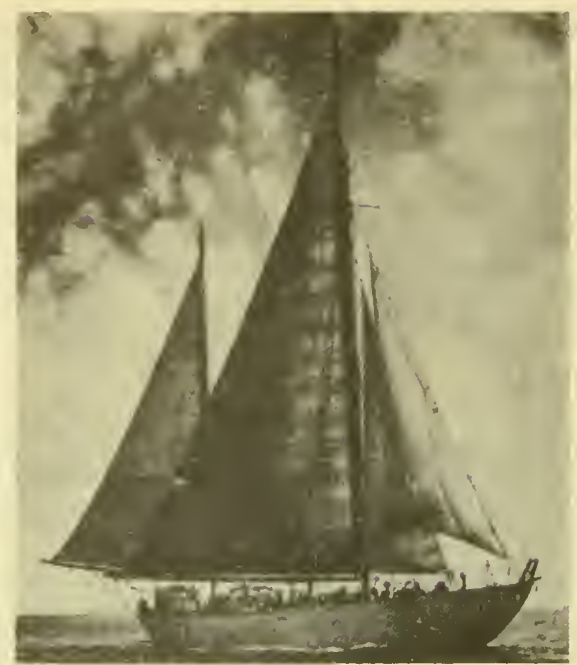

Fig. 3. ATLANTIS, Woods Hole Oceanographic Institution

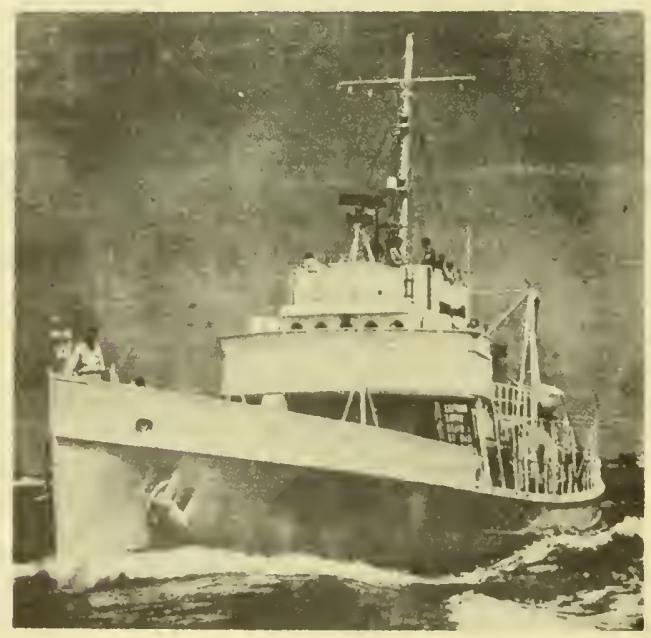

Fig. 4. CRAWFORD, Woods Hole Oceanographic Institution 


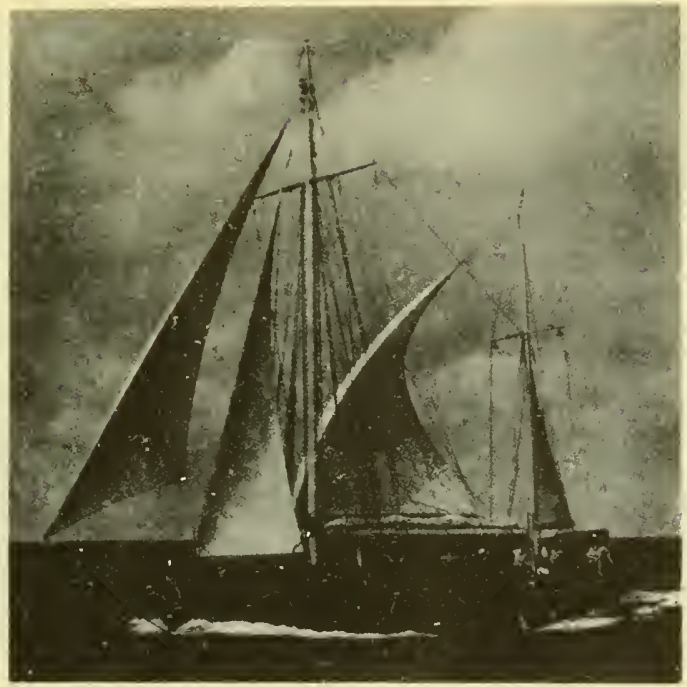

Fig. 5. CARYN, Woods Hole Oceanographic Institution

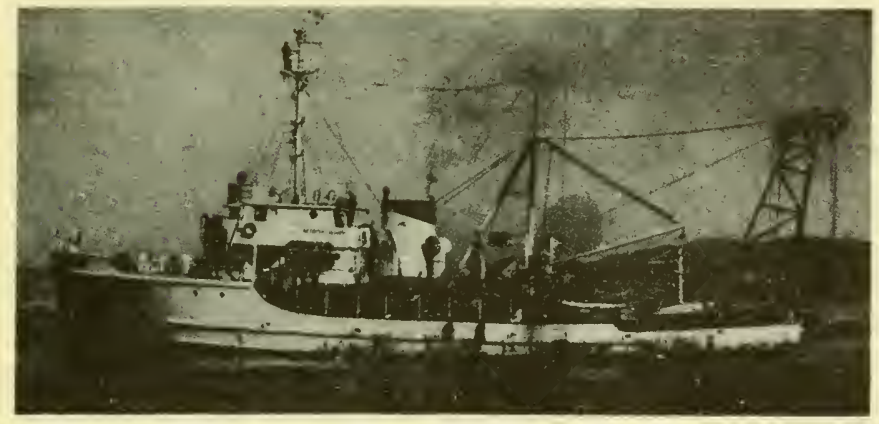

Fig. 6. SPENCER F. BAIRD, Scripps Institution of Oceanography. The $A$-frame on the tern allowg oceanographers to use very heavy equipment, which can be sent to the deepest parts of the ocean. The BAIRD's great winch carries more than six miles of secially designed teel cable. 


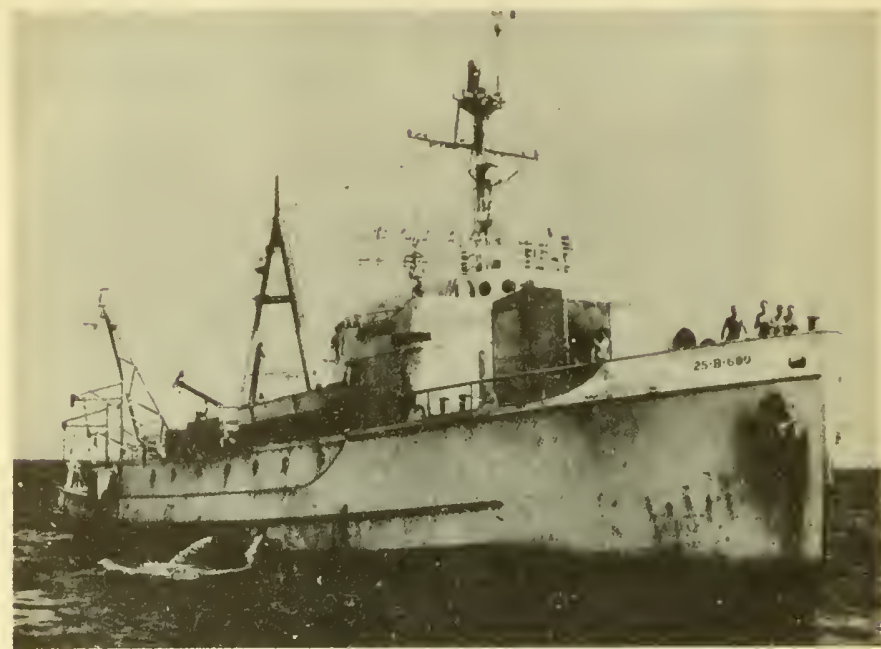

Fig. 7. HORIZON, Scripps Institution of Oceanography. The HORIZON is a converted oceangoing tug, steel hulled and Diesel-electric driven, with a cruising range of 15,000 miles at a 8 peed of 10.5 knots. For a complement

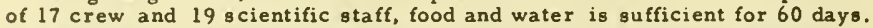
On a relatively clear, open-deck area abaft the laboratory is mounted a large A-frame rising some 28 feet above the deck, which permits bandling of any heavy, bulky weights such as Kullenberg corers or midwater trawls. A meteorological laboratory containing radiosonde and other equipment is located on the bridge deck.

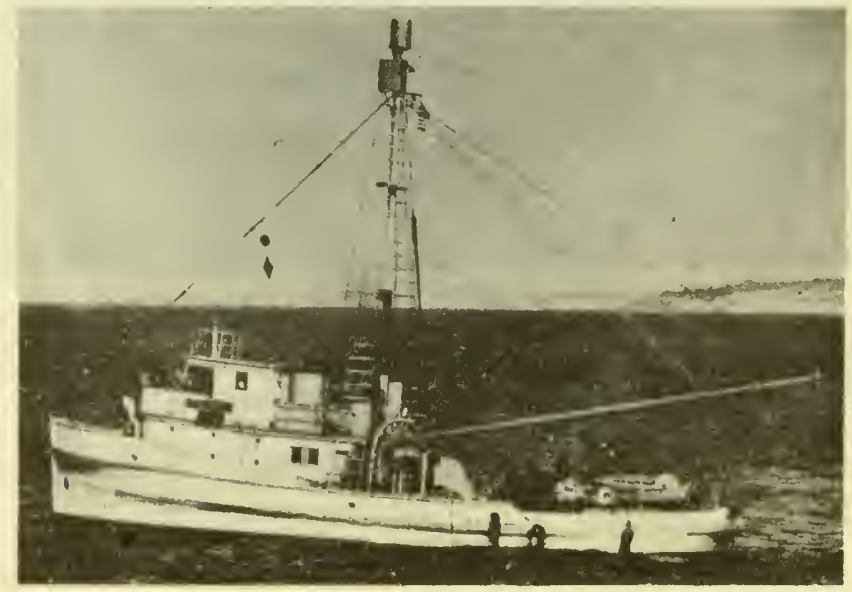

Fig. 8. PAOLINA-T, the smallest seagoing research vessel in Scripps ' tive-ship fleet 


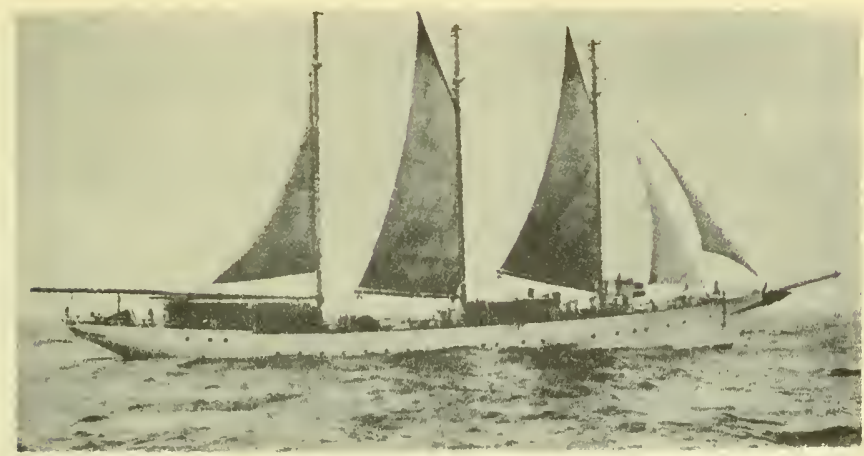

Fig. 9. VEMA, Lamont Geological Observatory of Columbia University

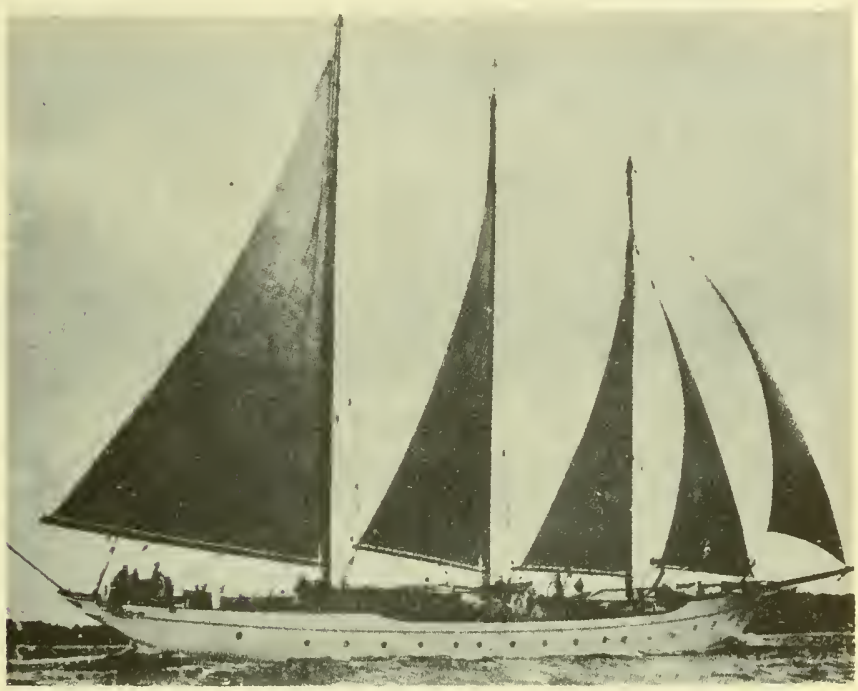

Fig. 10. JAKKULA, Texas A\&M Research Foundation 


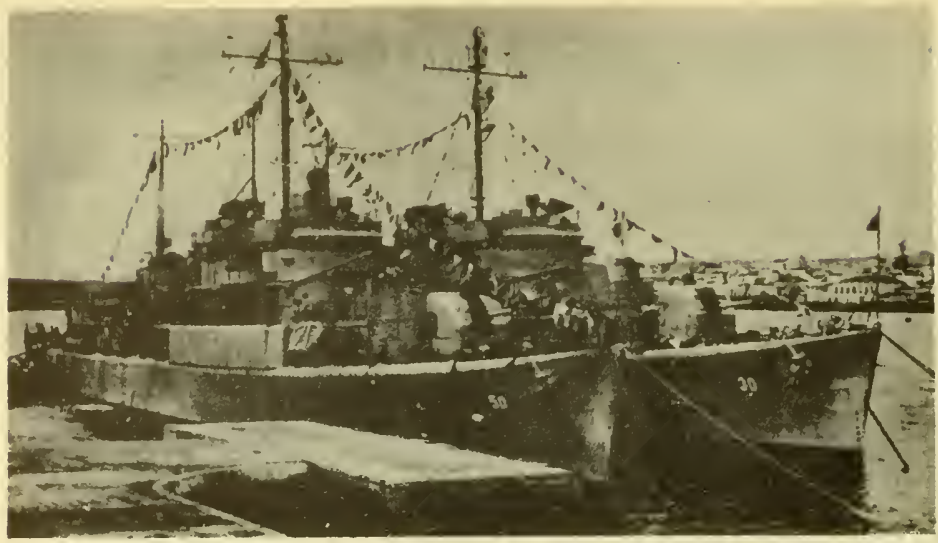

Fig. 11. REHOBOTH (AGS-50) and SAN PABLO (AGS-30), U. S. Navy Hydrographic Office

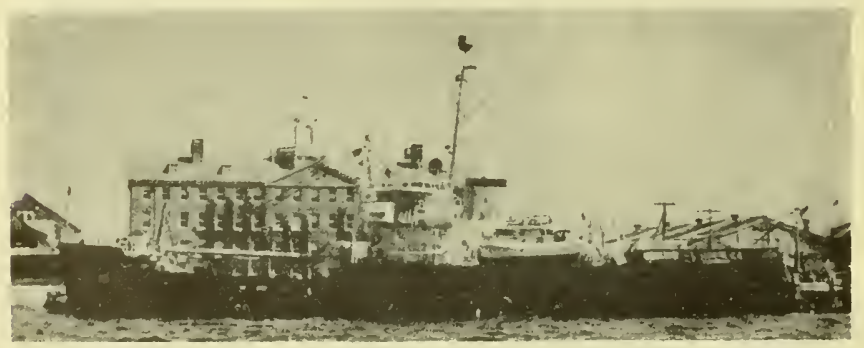

Fig. 12. CGC EVERGREEN, U. S. Coast Guard

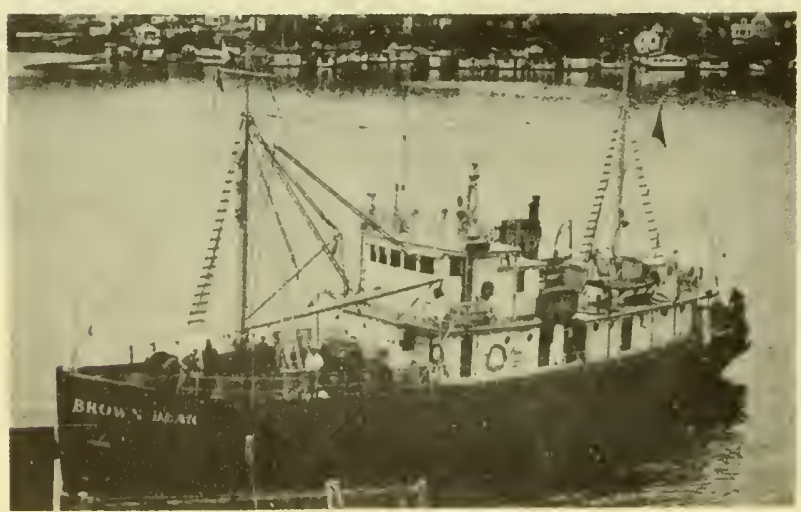

Fig. 13. BROWN BEAR, Oceanographic Laboratories, University of Washington 


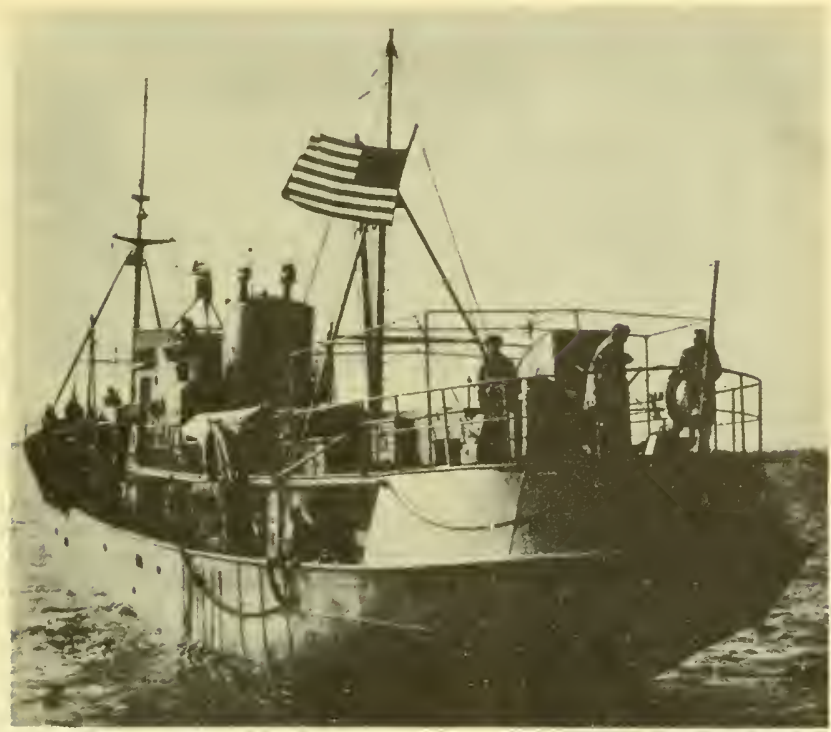

Fig. 14. ALbATROSS III, U. S. Fish and Wildlife Service

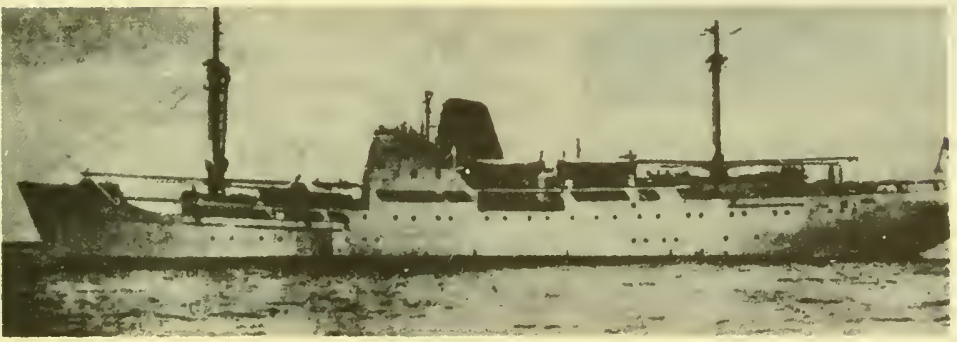

Fig. 15. MIKHAIL LOMONOSOV, built for oceanographic research by the U.S.S.R. and operated by their Academy of Sciences. She was commissioned in 1957 and has already completed her first research cruise in the North Atlantic. She has 16 8 cientific laboratories and single - and double-berthed cabins for $62 \mathrm{crew}$ and 69 scientists. Scientific equipment includes: deepwater anchor winch with $15,000 \mathrm{~m}$ of cable; eight hydrological winches with $10,000 \mathrm{~m}$ of cable; two sonic depth recorders of $5,000 \mathrm{~m}$ and $10,000 \mathrm{~m}$, respectively; helicopter platform; radio; and balloon equipment. Her major characteristics are:

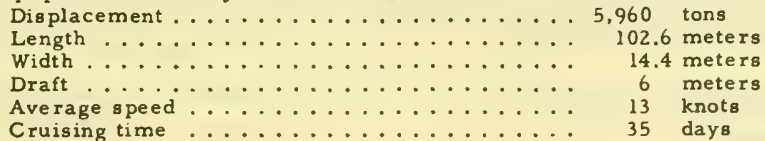


Table II. Tonnage comparison of selected research ships.

\begin{tabular}{|c|c|c|c|c|c|c|c|}
\hline \multicolumn{2}{|c|}{ United States } & \multicolumn{2}{|l|}{ USSR } & \multicolumn{2}{|c|}{ Jopen } & \multicolumn{2}{|c|}{ Great Britain } \\
\hline Ship & $\begin{array}{c}\text { Nisplocement } \\
\text { (tons) }\end{array}$ & Ship & $\begin{array}{c}\text { Diaplacement } \\
\text { tona) }\end{array}$ & Ship & $\begin{array}{c}\text { Displece went } \\
\text { (tons) }\end{array}$ & Ship & $\begin{array}{c}\text { Displecemeot } \\
\text { (tons) }\end{array}$ \\
\hline SPENCER F BAIRO & 505 & MIKHAIL LOMONOSON & 5,960 & IMITAKA MARU & 1,387 & JOHN BISCOE & 2,250 \\
\hline HOR1ZON & 505 & VITYAZ & 5,546 & RYOHO MARU & 1,100 & DISCOVEAY 11 & 1,736 \\
\hline VEMA & 533 & POLE & 5,000 & TUGARU & 1,050 & SIR WM HARDY & 418 \\
\hline ATLANTAS & 298 & SEVASTAPOL & 3,000 & OSHORO MARU & 618 & SARSIA & $250-300$ \\
\hline CRANFORD & 295 & DIAMOND & 1,500 & SHINYO MARU & 260 & & \\
\hline BROWN BEAR & 270 & EQUATOR & 1,500 & & & & \\
\hline JAKKULA & 198 & LENA (Icebreaker) & 12,000 & & & & \\
\hline PAOLINA T & 111 & OB (lcebreaker) & 12,000 & & & & \\
\hline & & OKEAN & 3,000 & & & & \\
\hline
\end{tabular}

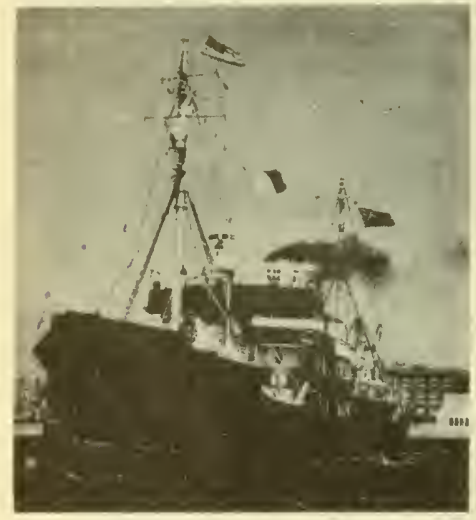

Fig. 16. The Royal Research Ship DISCOVERY Il, of the British National Institute of Oceanography, leaving the Woods Hole Oceanographic Institution after a joint IGY cruise with the $R$. V. ATLANTIS. Major characteristics are:

Length ..... 220 feet

Beam..... 36 feet

Depth...... 16 feet

Dis placement. 1,736 tons

Speed...... 13 knots

Complement... 41 crew,

9 scientists

Our research fleet is not capable of obtaining the information demanded by the first two reports. The NOBSKA report carefully points out the need for well-designed research ships.

New construction is needed to meet the following requirements:

a. The research ship must be quieted for acoustic work. For acoustic experiments at 10 $\mathrm{kc}$, the auxiliary equipment of the ship must be at least as quiet as the ambient noise of a sea state 1.

b. The ship must have an efficient scientistto-crew ratio, or a ratio of about 1 to 1 .

c. The ship must be able to maintain heading at very slow speeds; this requires a carefully considered main propulsion plant, propellers, and perhaps some type of bow propulsion.

d. The ship must have adequate deck, laboratory, office, berthing, messing, helicopter, and sonar spaces. The need for a center well has not been accepted by all oceanographers, but there are many reasons why one should be included, perhaps the most important of which is to allow work in rough seas.

e. The ship must be designed so that work can be performed in a normal manner in a sea state 5 . It must be stabilized with antiroll tanks and have the proper lines to minimize pitch.

Plates I, II, and III present an 1100-ton research ship which has been designed by the Bureau of Ships with the assistance of the Ship Design Committee of the Office of Naval Research. She is under Navy consideration as Ship's Characteristics' Board project No. 185. Her princlpal characteristics are as follows:

Length over-all ....................... 200 feet

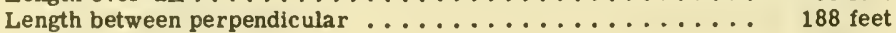

Beam, molded....................... 37 feet 


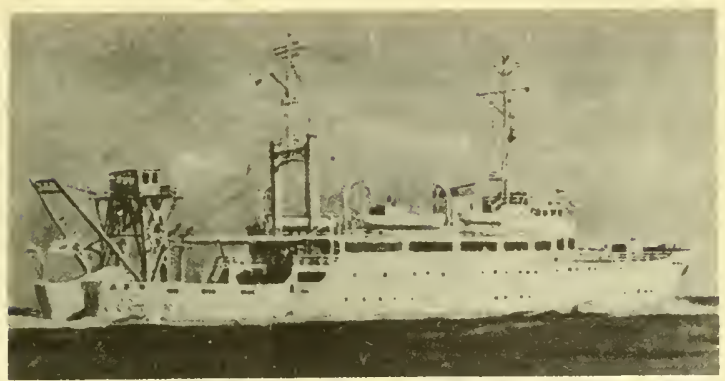

Fig. 17. UMITAKA MARU, training and research ship of Tokyo University of Fisheries, completed in August 1955. Major characteristics are:

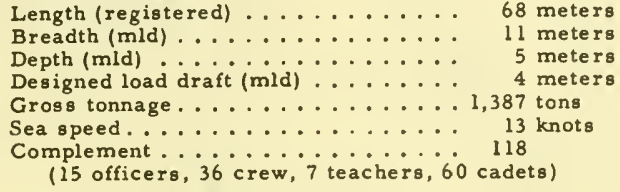

Depth to main deck amidship at side .................... 21 feet

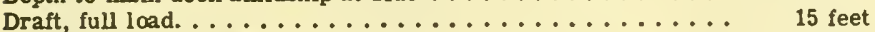

Displacement, full load ... . . . . . . . . . . . . . 1200 tons

Speed, sustained. . . . . . . . . . . . . . . . . . . 13 knots

Endurance at 12 knots. . . . . . . . . . . . . . 12,000 mlles

Propulsion plant: single screw (diesel electric)

Accommodations:

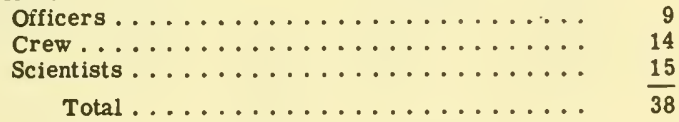

Care has been taken in the preliminary studies thus far conducted to see that these requirements listed here are included in the design. In so far as possible in a ship of this size, it is planned to include the concept of Independence at sea, so that as much of the data as possible is worked up on board ship before return to the laboratory.

\section{RNADEQUACY OF CONVERSIONS}

Many difficulties arise when conversions are substituted for new construction. First and most important is the fact that if all of the desirable requirements are included in a conversion, it means practically rebullding the ship. This is nearly as expensive as new construction, yet does not yield the desired results. A compromise on the requirements is reflected in a compromise of the research.

Major modification to Navy ships is not allowed because the ships must aiways be in condition for immediate availability in case of emergency. And most ships available for conversion are already aged beyond the time when they can be economically used. Repairs and upkeep are abnormally high, and considerable time is lost in the yard.

M. Rosenblatt \& Son, in a study for the Woods Hole Oceanographic Institution on the conversion of the Coast Guard Cutter, CRAWFORD, concluded that: 


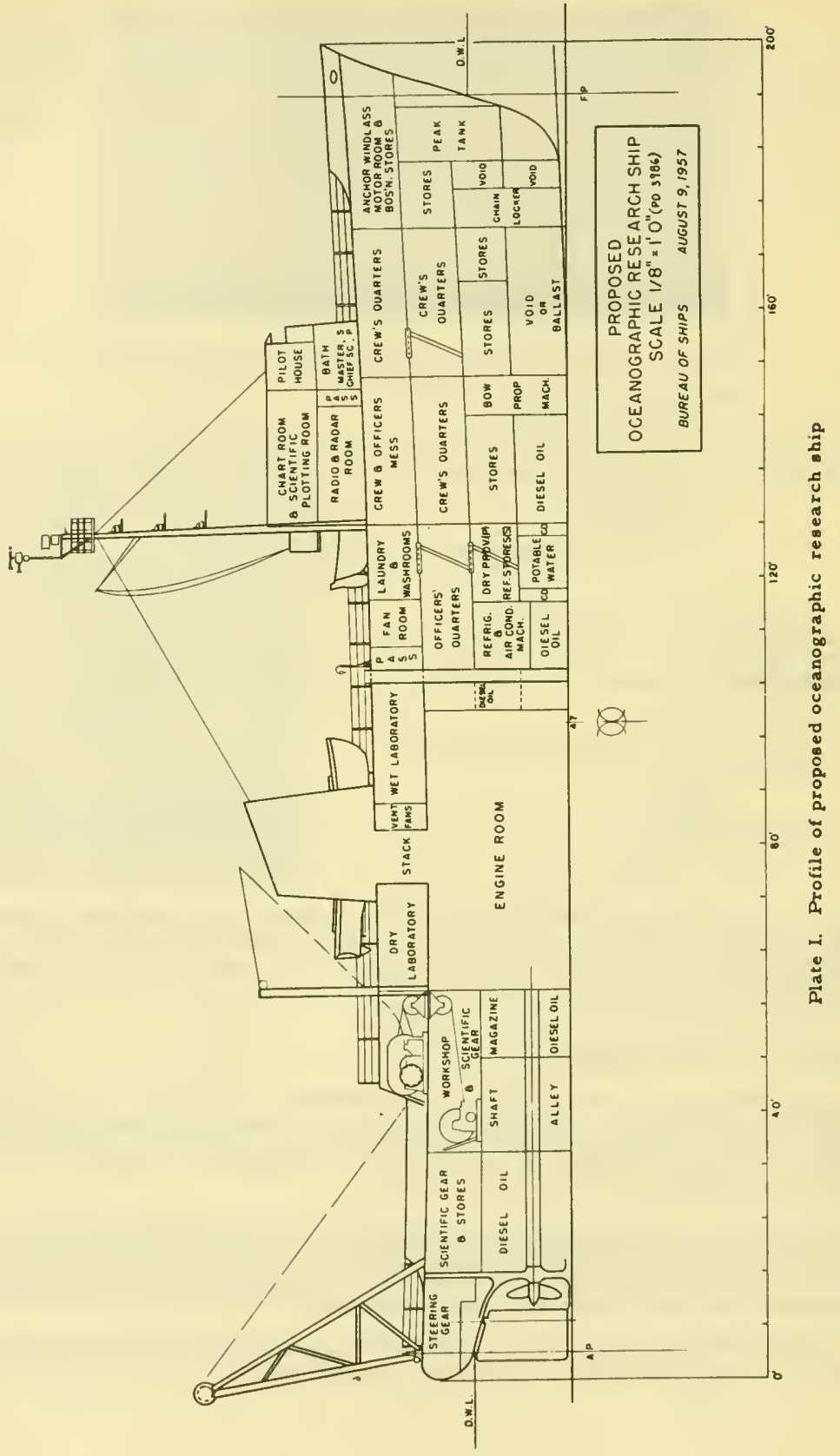




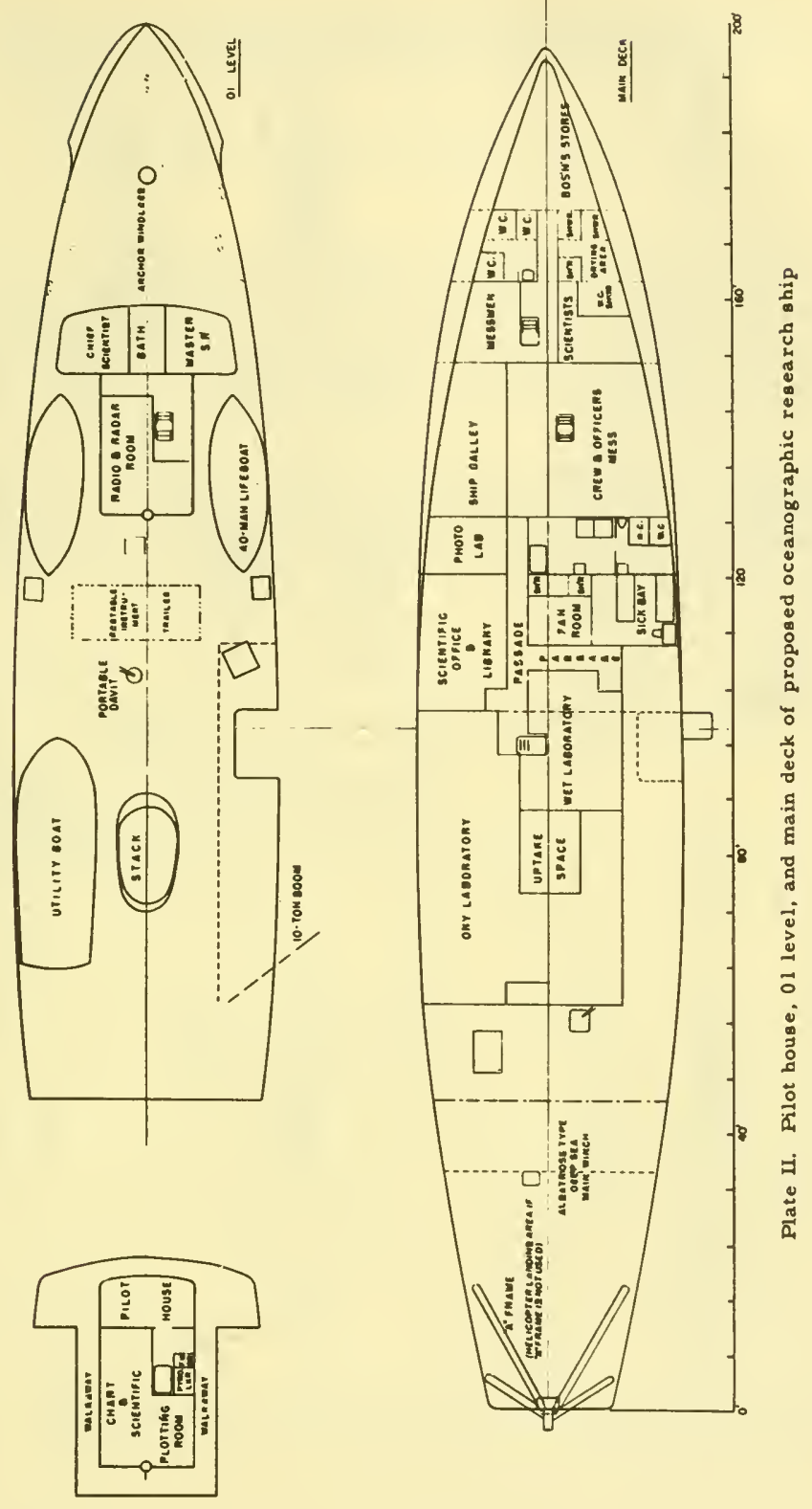




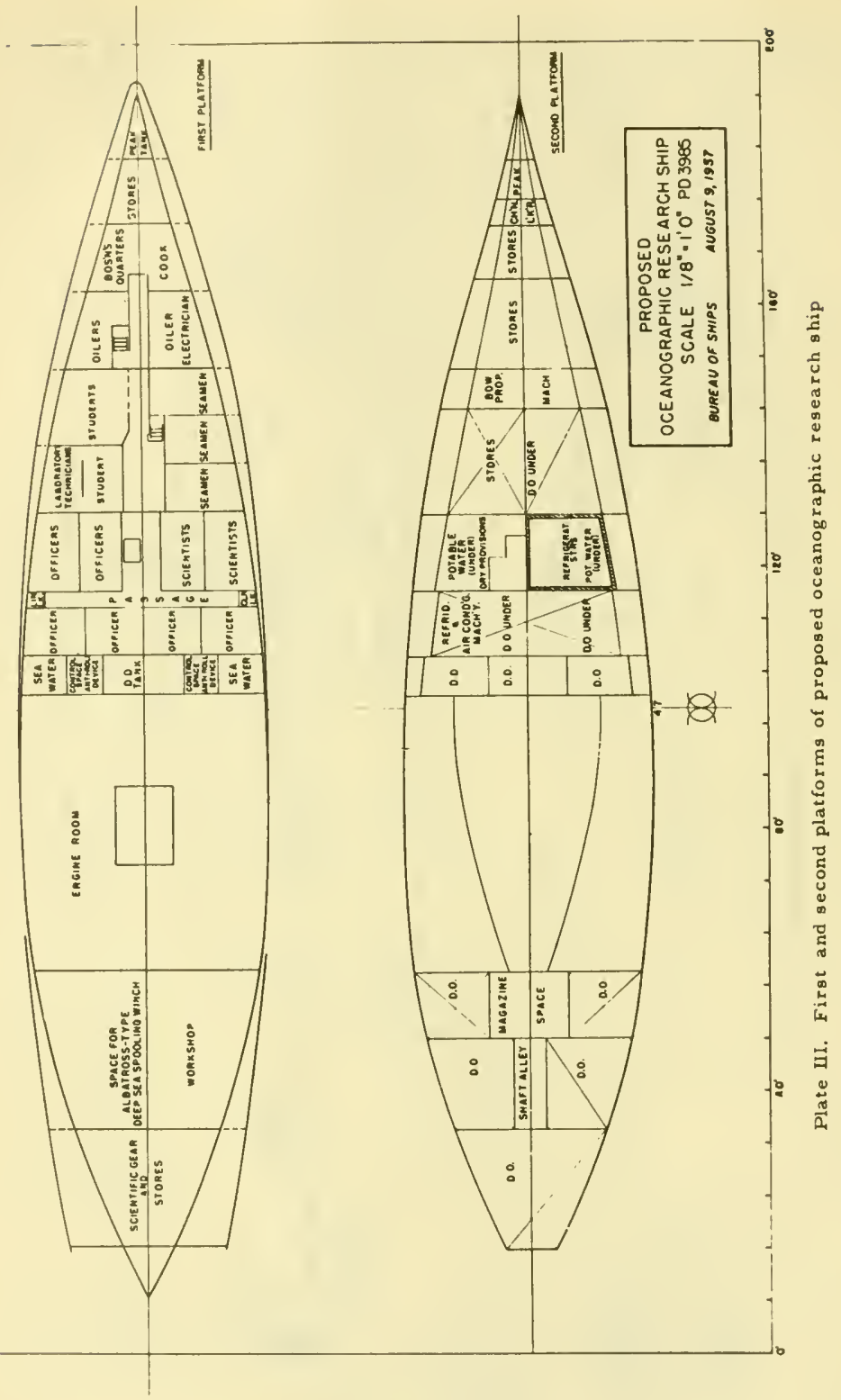


"This investigation and the difficulties encountered have strikingly shown that only in a new ship, designed specifically for oceanographic study and research work can all of the desired features be incorporated... Such features as form and primary ariangements cannot be changed without large expenditures."

We believe that the above conclusions are valid in any type of conversion.

\section{CONCLUSIONS}

Over the past six years, ONR has suggested a program whereby the obsolete research ships will eventually be replaced by new construction. Much has been accomplished during this period, although the U. S. Navy and its contracting oceanographic institutions are still without ships designed for research. In view of the accelerated oceanographic programs in other countries, time is becoming a critical factor. If new research ships are not forthcoming in the immediate future, the United States' lead in the field of oceanography will be overtaken by both Russia and Japan.

We have urged that the Navy take steps to avoid this situation by conversions to replace present ships, as a stop-gap move, and the immediate construction of several new oceanographic research ships of the type described above. Two ships of the type shown in Plates I, II, and III have been tentatively approved for the 1960 construction program, but they must still meet the stiff competition of other construction. It is too early to estimate their chances of survival.

\section{ACKNOWLEDGMENTS}

Sources for the photographs and plates appearing in this article are as follows:

Jan Hanh, WHOI: Figs. 1-9, 11-12, 14, and 16

Texas A\&M, Dept. of Oceanography: Fig. 10

Univ. of Washington, Dept. of Oceanography: Fig. 13

A. Vine, WHOI: Fig. 17

BuShlps: Plates I, II, and III 
Mr. Curtin. I have no other questions.

Mr. Miller. Mr. Lennon.

Mr. Lenson. Admiral, I would assume that the Navy, the Coast Guard, the U.S. Fish and Wildlife Service, and the Coast and Geodetic Survey would be the four principal Government agencies that would be interested in this prolonged study of oceanography, would they not?

Admiral Harwarn. Yes, sir. I think those would be the main ones, the Fish and Wildlife Service, the U.S. Coast and Geodetic, the Navy.

Mr. Lennon. Do you know to what extent the Coast Guard since World War II has been interested in the program?

Admiral HAYward. Well, I know under their ice patrols, their ice reports and everything are all fed in to us. The information we get from Woods Hole and Scripps, and what the Hydrographic puts out is definitely available to them, but they have their own responsibilities for an oceanographic program, to my knowledge.

Mr. Lennow. I got that impression, too. Although I knew that they had a need for such a study, I was a little bit surprised to hear the Commandant of the Coast Guard say just 3 days ago that, so far as he personally knew, he did not know that there was such a committee as the National Academy of Sciences Committee on Oceanography or that a study had been made.

I was just wondering how closely coordinated the Coordinating Committee of the Government agencies were, in which the Coast Guard had a representative, if they did not know that such a study had been made until the report was published.

Admiral HaYward. Well, of course, you know there are two types of people in Washington. There are the Chiefs and the Indians and his Indian was in the departmental meeting and, if he did not tell the Chief, that is the reason that he did not get the word. They were at the meeting.

Mr. Lennon. Of course, they likely did know and participated in these conferences. He just did not have that information perhaps when he made that statement.

Admiral HaYward. No, sir.

Mr. Lennon. You work closely, I assume, with any agency of the Federal Government that is interested in this program?

Admiral Hayward. Yes, sir.

Mr. Lennon. Whatever phase of it they may be interested in?

Admiral Hayward. Yes, sir.

Mr. Lennon. That is all, Mr. Chairman.

Mr. Miller. Mr. Chairman, do you have any questions?

The Chairman. I have no questions.

Mr. Milleri. Counsel? that:

Mr. Drewry. Admiral Hayward, on page 1 you make the statement

Today all active ships of the fleet and some MSTS ships collect soundings and bathythermograph information during transits and forward this information to the Hydrographic Office.

Admiral Harward. Yes, sir.

Mr. Drewry. I take it that these soundings and bathythermograph information are types of information that can readily be secured by the ship proceeding on whatever is its regular mission? 
Admiral HaYward. Yes, sir. When I went around the Horn to the Antarctic with the Franklin. Roosevelt, as in the case of any ship we made a track of soundings. This is done as you are underway, of course, and it is of great value. Even to this day we find of lot of things not previously known.

Mr. Drewry. Does that require very elaborate instruments?

Admiral HAYward. No, sir. We have the instruments available anyway. It does not require any great instrumentation from the Navy's point of view.

Mr. Drewry. Then is this done only within the Navy? The Coast Guard has vessels out also?

Admiral HAYWARD. They furnish information to the Hydrographic Office. You will find on all the charts, that all of the seagoing fraternity furnish the Hydrographic Office with all types. of information that they can possibly gather with the equipment they have on their journeys. Weather reports, all of the soundings and things of that kind. Any special circumstances, where it is found that something is wrong on the chart. For instance where the sounding reads 20 fathoms instead of 200 . These reports are all sent in by the seagoing fraternity.

Mr. Drewry. That includes the commercial operators as well?

Admiral HaYward. Yes.

Mr. Drewry. Is that through a regular program that the Hydrographic Office or the Coast Guard maintains?

Admiral Hayward. Well, Captain Munson is here, the Assistant Director of the Hydrographic Office. Maybe he can answer.

Captain Munson. Ever since the inception of the Office, the Hydrographic Office has encouraged the merchant marine to exchange data. We have a series of distributing offices known as branch hydrographic offices in principal ports of the United States and over 100 commercial outlets or offices throughout the world. The merchant mariners visit these offices and we have professional scientists visit the ships for the purpose of exchanging information. The majority of ships officers, at least one officer on each American ship is officially designated as a cooperating observer. They furnish us information on weather, oceanographic information, current, soundings where their equipment permits them to be taken. The merchant marine, generally speaking, is not equipped to take soundings in deep water. They are restricted to shoal areas but this information is priceless and valuable.

I might say that through this medium of exchange of information, we reward them by replacing the charts and furnishing the forms and furmishing certain navigational assistance in payment for their services.

I might say that through the medium of this program, we have succeeded in collecting the world's largest file of hydrographic and oceanographic data.

Mr. Drewry. This is one area where there not only is but has been cooperation for a long time?

Captain Murson. That program has been in effect for, one might say, a century and a quarter.

Mr. Drewry. I have just one other question. Reference was also made to the weather routing system which MSTS has been working 
with for the past year or so. When we had our inquiry into safety of life at sea following the Andrea Doria-Stockholm collision, one of the principal points was the question of the North Atlantic tracks and the point was made that perhaps there should be not only a tightening up of the requirements regarding the existing tracks in the North Atlantic but that there also be established tracks agreed upon elsewhere; but it occurs to me that with this weather routing that possibly the fixed track concept might be outmoded today.

Admiral HaYward. Well, of course, having been captain of a large ship, I would say the fixed track really does not have any legal significance in the rules of the road. With a fixed track, and this is the thing that always used to worry us, the burden is still on me to comply with the rules and, if the visibility is such, I have to slow down.

I have gone into the Andrea Doria case, as most captains would, to find out the facts in case they should find themselves in the same position, and there was complete violation of the law regardless of fixed tracks or radar or anything else. The law requires that you slow down so that you can stop within the limits of the visibility and that was not done.

This storm prediction thing, in the late summer months, in the hurricane paths and things of this kind, this is most important and it conld be most important from a military operation point of view. This is of more and more value as we get more and more information.

Our satellite business gets in it.

If we really get our cloud cover experiments and know the weatherand you probably have seen the picture of the hurricane from 150.000 feet-this would permit you to predict. Any prediction would pay off in dollars in time saved.

Mr. Drewry. This is something that should figure very largely when they get the next international safety convention.

Admiral Hayward. Yes, sir.

Mr. Drewry. To whatever extent, the tracks have certainly been upset by this new development in weather routing. You mentioned that a submarine is so much better as a research vessel in the polar regions. I wonder if you would tell me one or two basic reasons why. Is it because a submarine can collect more data in a shorter period of time?

Admiral HAYward. Yes; it can collect more data. There are a lot of holes up there, we found out. The submarine has much more flexibility. It is in a very good position to chart the bottom. It is probably the most useful tool we have. A surface ship would be in continual danger, could be in terrific trouble unless you really built it, as a first class icebreaker and could get stuck up there in one place for months on end so that a submarine has tremendous advantages.

Mr. Drewry. That is all, Mr. Chairman.

Mr. Mrister. Admiral, I want to thank you for coming here and at a future time we would like to have some of your people from the staff back here.

Dr. Brown has to get a plane at 1 o'clock, so that I would like to put him on now and reserve the right later on to have Captain Obermeyer and Captain Munson and some of the others back here to give us some specific information.

Admiral HAYwam. Mr. Chaiman, I would like to extend an invitation to the subcommittee to make a trip to Woods Hole. I will 
arrange to get an airplane to take them up so they can actually talk to Dr. Fye and see one of these oceanographic setups and get a briefing from the working people.

Mr. Miller. That is a very nice invitation, Admiral, and we will take advantage of it at some time. I want to make sure that we get a time when Mr. Bonner and Mr. Tollefson can go with us. I know that they would be interested along with us.

I would like to be able to extend it to some of the other members of the full committee, too, because they are all interested and it would be a fine chance for them to get acquainted with you.

Admiral HaYward. I will have Captain Holden get together with the staff.

Mr. Miller. Fine. Thank you very much.

Dr. Brown, we are very happy to have you here this morning. Would you come forward and take the witness stand, please.

\section{STATEMENT OF DR. HARRISON BROWN, CHAIRMAN, SPECIAL SUB- COMMITTEE ON OCEANOGRAPHY, NATIONAL ACADEMY OF SCIENCES (PROFESSOR OF GEOCHEMISTRY AT THE CALIFORNIA INSTITUTE OF TECHNOLOGY)}

Mr. Miller. I do not know whether you gentleman have all had the pleasure of meeting Dr. Harrison Brown, who is chairman of the committee which prepared the Oceanographic Report which has had such an impact upon the people of this country and contributed to the formation of this subcommittee.

Doctor, we would like to have you talk to us informally and then perhaps we will have some questions. We are very much interested in implementing the report which we realize is not completed as yet since you are still working on it, but we would like to have your thoughts on how we can best implement what your committee has brought forth.

As I said at the beginning, you suggest the expenditure of certain amounts of money. Somebody has to say who will spend the money. I realize that that is not your business but we have to look to you for guidance in this field and we want your advice.

Will you proceed in your own way, please, Doctor?

Incidentally, Dr. Brown has to get a plane at 1 o'clock, so that we. will try to get him out of here quickly.

Dr. Brown. Thank you very much, Mr. Chairman. I am very grateful for the opportunity of appearing before you. I believe that a little background concerning the origins of this committee would be in order together with a very brief discussion of how we went about the process of arriving at these recommendations.

The committee, as Admiral Hayward has already told you, was formed at the specific request of several Government agencies. The National Academy of Sciences, as you know, is a quasi-governmental body which was chartered originally under Abraham Lincoln and it has the specific responsibility of giving advice to the Government and to its agencies when asked. I was then asked by Dr. Bronk to chair this committee. I should stress at the outset that I am not an oceanographer by profession. That is one of the reasons I was asked.

In forming the committee, we purposely formed it, arranged its 
composition to be roughly half trained oceanographers and roughly half scientists in other fields who would be able to look objectively at the problems, say perhaps take a somewhat longer look at the problems which confront us than the oceanographer's proper who are of necessity intimately embroiled in their own immediate problems.

Our committee made a study of a number of our institutions. We held meetings in various places. We had one in Seattle, one in Miami, one at Woods Hole. We have met down in Texas and so forth, and at La Jolla. We met over a period of about 1 year and finally set about the task of drafting our recommendations.

The report which you have received is a summary which includes all of the basic recommendations. This is going to be followed by a series of chapters which will go into each of these recommendations in considerably more detail than was possible in the summary.

I think perhaps you might like to have a rough estimate of the times of appearance of various of these chapters. The one on basic research in oceanography during the next 10 years will be out in about 2 months, the one on ocean resources will be out in about 1 month; the one on oceanographic research for defense applications will be out in 2 months. Artificial radioactivity in the marine environment will be out in about 3 weeks. The chapter which deals with the specifics and the timing of new research vessels will be out in 1 month. The engineering needs for ocean exploration will be out in 3 weeks. Education and manpower in the marine sciences will be out in 1 week. Oceanwide surveys will be out in about 3 months; international cooperation in the marine sciences in 2 months; a history of oceanography will be out in 6 months, and the status of marine sciences in the United States will be out in about 3 weeks.

As you see, we have had to do quite a bit of writing, but did not want to wait until all of these were out before putting out the summary of our recommendations.

Following the formulation of these recommendations, we naturally became concerned about the problem of implementation. In our recommendations proper, you will note we make suggestions concerning the relative amounts of effort we believe individual Government agencies should place in this overall program. These are purely suggestions but they do give an index as to the opinion of the committee as to how much interest the individual agencies ought to have in the marine sciences.

In my own case, I have gone through quite a process of education. It so happens that this chairmanship of this committee and our activities coincided with my having the finger put on me to be a member of the Space Science Board as well. This involved quite a bit of work but it did enable me to get a pretty good overall picture of the status of our activities in two major fields of endeavor.

I must say that in spite of the good work which has gone on in the past, in spite of the fact that the Nary, for example, has really made an effort to face up to its responsibilities, I am personally quite distressed by the lack of suflicient rate of growth of research efforts in this area.

When we look at the knowledge which we need we really should go along more rapidly than we recommend in this report.

I am afraid it is not possible to go along any more rapidly for the reason that the main rate limiting factor is that of trained technical 
people. You just cannot turn out Ph. D.'s in oceanography overnight. It takes time and so our program rate of growth is based essentially on how rapidly, given the proper effort, we believe that young people can be trained and turned out into good oceanographers capable of working on the oceans.

We are going to be faced during the years ahead with some very critical problems that will require a vast amount of knowledge and the exact kind of knowledge that will be required simply is not predictable. What you have to do is just go out and learn all that you can about the ocean floor and so forth.

I think a very good example of how a field of scientific endeavor that did not occupy very much attention has suddenly blossomed forth been going along for years and years and year's on rather small budgets. They have learned a great deal considering the budgets that gets. They have learned a great deal considering the budgets that they have had at their disposal. Suddenly we are faced with a whole problem of detecting underground nuclear explosions. This requires a knowledge of seismology greatly exceeding that which we now have, one which is obtainable but nevertheless exceeding that which we have. Had we had the foresight to back up seismology, let us say 5 years ago, we would not be in this position today and I fear that, unless we do take a vigorous step forward in the marine sciences, we are going to be faced with, let us say, the necessity for another crash program and crash programs, as all of us know, are terribly wasteful and expensive in terms of both manpower and expenditure of funds.

Therefore, this program, as we lonk upon it, is really a minimum program. We realize that there are many changes that will perhaps be necessary and desirable but we do believe that the scope of the overall program as outlined here is essential from the point of view of the economy of your fisheries, from the point of view of adequate exploitation of marine resources, and from the point of view of military defense.

I believe that that is all I have to say as a preliminary.

Mr. Mrller. Doctor, one of the significant things you tell us, I believe, is the fact that we are going to need trained manpower in the field which is not available at the moment.

What can this committee or any committee of Congress do to meet that challenge? We have through the Science Foundation money available for scholarships and that sort of thing. Whose responsibility is it going to be to try and get the young men into this field?

Dr. Brown. That is an extremely difficult question.

Mr. Muncer. It is a difficult one. That is why I am asking it. It is the thing that I think bothers all of us. We would like to have your views on that as an editor and as an outstanding member of the field of science.

Dr. Brown. The National Science Foundation has rather a large fellowship-scholarship program but it is handled in such a way that it does not select any particular field of endeavor for favoritism, so to speak. All applications for scholarships and fellowships are handled on a competitive basis irrespective of the field that the person wishes to enter. There is no mechanism at the present time for an impartial group to say, "Well, we are lagging behind in this particular area. We need more men in it. Therefore, we should provide more scholarships in that particular area." 
Mr. Miller. That is what the Russians would do.

Dr. Brown. That is exactly what they are doing.

Mr. Miller. That is what they are doing. If they want men in a certain area whether or not a man feels the spark to get into that field he must do so. He may want to become a physician but he has the background and they are going to make an oceanographer out of him.

Dr. Brown. There are other methods available, however. For example, the Bureau of Commercial Fisheries and Office of Naval Research, in giving contracts to individual oceanographic institutions for basic research in certain areas, can provide funds for research assistantships at the predoctoral level and the postdoctoral level which can then be given to students and this will permit the student to live and at the same time conduct his research.

Mr. Miller. I am conscious that in certain large industries in this country in the airplane field, for instance, and I know you are familiar with that, some of these big companies have set aside money for scholarships for men, some working in their plants, some of them students who can qualify, and they are sending them on to college in that particular field. I think you are familiar with some of those.

Dr. Brown. At the California Institute of Technology, where I work, we have many such fellowships which are given out by private companies and so forth.

Mr. Miller. Should not the fisheries people in this country and perhaps the people who operate the merchant marine, the marine industry itself, be encouraged to start some sort of program?

Dr. Brown. I certainly believe that they should, yes. I do not know just what form the encouragement will take but something like that certainly ought to be done.

There is one other avenue also. Since the appearance of our report three large foundations have become interested in this area and there are discussions now underway aimed at the provision by foundations of scholarships and fellowships in this particular area.

A foundation does have the flexibility where it can do this kind of thing.

Mr. Mirler. I had in mind that it takes so long to train these people, it takes so long to get the Government operating some of the facilities if we could start picking them now it would be the desirable thing so that we would have trained men when the facilities are ready.

Dr. Brows. Yes, sir. Getting back to the governmental aspects, I believe that, quite legitimately, an agency like the Burean of Commercial Fisheries, an agency like the Maritime Administration could, as a legitimate part of research, which it contracts to private organizations like Scripps or Woorls Hole, include money in their budgets for research assistantships and postrloctoral fellowships and things of that sort.

Mr. Muluer. That is a very interesting suggestion. I know that you have to get away. I know that the subcommittee would like to question you because of your leadership in this field.

Mr. Chairman, do you have quest ions?

The Chummax. I have no questions.

Mr. Minleer. Mr. Pelly? 
Mr. Percy. Doctor, just following up on what the chairman has been bringing out, I would be interested to get your views as to how specifically we can develop some scientists in this field. There was testimony in the last session of the defense education bill by the dean of the engineering school of the University of Washington to the effect that there were in this country 78,000 enrollees in engineering schools from our high schools going into college, which was adequate to provide all the engineers that we needed if we had been able to encourage sufficient of those students when they were through with their 4-year normal course to stay on and take their higher training, but that they were tempted by private industry and the natural inclination to get married and be independent, and so forth, to abandon their career. This particular testimony was to the effect that a fellowship was not enough, that it did not amount to enough money, that there should be several thousand dollars a year to any individual to encourage him to go on and take his doctor's or Ph. D. degree or some other means of giving the more able, more competent students a chance at development to fill the need that we have.

Would that be the picture that yon see or do you think we have to start with the first grade and work upward counseling students to get into oceanography?

Dr. Brown. I think that one has to operate at all levels. From the point of view of fulfilling the immediate needs, the most important approach is to bring young persons who have just received their Ph. D. degrees from their own field into the field of oceanography. Now, we do the equivalent of this all of the time at Cal Tech where we have a system of what we call postdoctoral fellowships designed especially for the fresh $\mathrm{Ph}$. D. He will get his chemistry degree, let us say, at Northwestern. We bring him to our division at Cal 'Tech working as a chemist in the earth sciences and then he works with us for 3 years or 2 years. He learns the earth sciences. He brings chemistry to it. He is a very broad individual as a result. He goes out and becomes a staff member in, let us say, an oceanography institution.

Mr. Pelly. He has a fellowship when he is with you?

Dr. Brown. He has a fellowship when with us.

Mr. Pelly. How much?

Dr. Brows. Not very much. The man really has to work for the lore of the work. It amounts to about $\$ 5,000$ a year. We are now talking about raising that becanse it is rather difficult competitively.

Mr. Pelly. What I am trying to get at is how much a year in the way of a fellowship is necessary in order to give the incentive to more of these teacher-learners, I suppose you would call them, to go on in their field and not go ont into private industry and never finish their full training?

Dr. Brown. I believe that you can get some idea about this when I tell you of the experience of a student of mine who is getting his $\mathrm{Ph}$. D. in June. He has received something like 10 offers, 5 of them are from industry, averaging between $\$ 11,000$ and $\$ 12,000$ a year. This is for a fresh Ph. D., mind you. One of them is from a large Government research laboratory which has offered him $\$ 9,000$ a year, and the balance are from universities and colleges, averaging $\$ 6,000$ a year. 
Now, fortunately, this man has tremendous love and interest in basic research and in teaching and he has accepted a job at $\$ 6,000$ a year at Connecticut Wesleyan University, but it places an enormous strain upon a young boy to take a salary of roughly half what he is offered in industry.

Mr. Pelly. But you say we do not have enough presently of those individuals in order to fill the need that there is and to go on and get enough information to really put this Nation where it should be in the oceanography field.

Dr. Brown. That is correct, yes.

Mr. Pelly. I can see there is a real problem as far as money is concerned.

Dr. Brown. Now, of course, in the case of the Soviet Union, they handle this in quite a different way. If they want to build up oceanography, they put a lot of effort in that area, and pretty much ignore other competitive areas, and a man is persuaded to go into the field of oceanography quite successfully as a result.

Mr. Pelcy. Did your study have any specific recommendations in that respect?

Dr. Brown. With respect to scholarships and fellowships?

Mr. Pelly. Yes.

Dr. Brown. Yes, indeed. We are specifically making a recommendation that our Government scholarship-fellowship program should be modified so that it would be possible for us to take areas where we know we are weak and build them up by offering more scholarships and fellowships in that area than in certain others.

Mr. Pelly. Do you mean by that that the National Science Foundation would be on a purely competitive basis and that you would have the authority to concentrate in certain fields?

Dr. Brows. I believe that under normal circumstances, the National Science Foundation should handle its affairs as it is now on a strictly competitive basis but when an emergency arises where you see clearly that we are falling behind in a particular area, where we have insufficient manpower, we are not sufficiently strong, then it should have the ability to strengthen the scholarship-fellowship program in that particular area.

Mr. Pecly. Does that take any legislative authority, or is it just a matter of policy?

Dr. Brown. 'This is a matter of policy, I believe.

Mr. Lennon. Doctor, do you happen to recall about how many universities or colleges in America have either a school or department of oceanography?

Dr. Brown. I know there are many, many schools which teach oceanography in one way or another. There are only three or four which actually give advanced degrees in oceanography.

Mr. Lennon. 'The testimony of Admiral Hayward seems to indicate clearly that the Navy, certainly since World War II, has recognized the necessity for a study of oceanography in its many aspects. It occurred to me that the Navy having recognized this and the Coast Guard apparently not, to the extent that they have not established a department in the Coast Guard Academy, perhaps the field of commercial fisheries and merchant marine is where we are going to have to interest industry into encouraging these young men to go into this field. Is that your thinking abont it? 
Dr. Brown. Yes, indeed.

Mr. Lennon. So far as the national defense aspect is concerned, it would appear from the admiral's testimony that the Navy is going to do the job, it has to do the job from the point of national defense, but from the point of the merchant marine and our fisheries program and problems, it seems that the Govermment has to move in somehow or other to encourage young men who have an inclination toward this sort of program to go into this program.

I have the impression from the witnesses that I have heard here, since we started considering this overall program, that we need not worry so much about national defense, that the Navy is going to find a way, and the other departments of Government are going to find a way to get the funds to do their part of the job, but that when it comes to the merchant marine and fisheries aspect of it, we are going to have to lend a helping hand in some way.

Dr. Brown. I would only argue with you about one point here. That is when you say you would not worry about the national defense aspects.

Mr. Lennox. We always worry about them but I have confidence enough in our Department of National Defense, based on this testimony of the admiral this morning, that they have recognized this and are going into this program in a rather wholehearted way, and we are delighted to see it. It is essential to our own safety. I do believe we are going to have to give somebody a lot of help to encourage people to get into it from another aspect of this related subject.

Dr. Brown. I would agree with that.

Mr. Lennon. That is all.

Mr. Oliver. Mr. Chairman, I have one question.

Dr. Brown, it is my understanding that the program which has been recommended by the committee of scientists, of which you are the chairman, is based upon a total appropriation of some $\$ 600,000$ some-odd over a 10 -year period; is that correct?

Dr. Brown. Yes; over and above the current annual rate of expenditure.

Mr. Oliver. I would like to know whether or not you have any information which would indicate that the various departments of Government interested in the subject have requested for 1960 fiscal year amounts of money necessary to implement the program which your committee has recommended.

Dr. Browr. Unfortunately, our recommendations were formulated too late to have any major impact on the 1960 budget. 'These things, as you know, are started quite a long time in advance. However, the Navy, I know, independently arose with project TENOC, which fits in with our own recommendations remarkably well. Superimposed upon that I do know that individual Government agencies on the basis of our report are looking forward to 1961 and I believe that the 1961 budget is going to be critical in this respect.

Mr. Oliver. In other words, you feel that we can afford to lose this next year's activity in which it could be carried on if we had the dollars to do it with?

Dr. Brows. If we had the dollars to do it with I would certainly push ahead with full vigor. I hate to see this first year lost. I think it is a real tragedy that it be lost. At the same time, in my own wan- 
derings around both the executive and legislative branches and the Budget Bureau, and so forth, I feel that to really do anything about 1960 at the present time would be extraordinarily diflicult.

At the very least I should point out we should see to it that those items which are in the budget, which have a bearing upon this program, should be retained.

Mr. Oliver. In other words, what you are saying is that you feel that perhaps there should not be any effort made because of the urgency of the situation to get a program underway in 1960 ?

Dr. Brown. No. I am saying, sir, that we should do everything that we can to get our program underway starting right now. We should keep everything in the 1960 budget which has a bearing upon this program and we should start a vigorous drive immediately to see to it that the 1961 budgets are commensurate with the needs as outlined.

Mr. Oliver. Thank you.

Mr. Miluer. Mr. Flynn.

Mr. Flyns. I have no questions.

Mr. Miller. Doctor, there are many questions that come to mind but we know that you have to get out inmediately.

We have to get over on the floor.

I want to thank you for coming here and tell you that Mr. Vetter has been cooperating with us very nicely and that from time to time we may call on you again because we think you can help us.

Dr. Brown. Thank you.

Mr. MrLLER. The committee will adjourn, subject to the call of the Chair.

(Whereupon, at 11:50 a.m., the subcommittee adjourned, subject to the call of the Chair.) 


\title{
OCEANOGRAPHY IN THE UNITED STATES
}

\author{
TUESDAY, APRIL 21, 1959
}

House of Representatives, Sipectal Strcommittee ox OCEaxography

of the Committee on Merchint Marine and Fisueries,

Washington, D.C.

The subcommittee met at 10 a.m., pursuant to call, in room 219, Old House Office Building, Hon. George P. Miller (chairman of the subcommittee) presiding.

Present: Representatires Miller, Dingell, Olirer, Dorn, Pelly, and Curtin.

Staff members present: John M. Drewry, chief counsel; Bernard J. Zincke. counsel, and William B. Winfield, clerk.

Mr. Minlm. The committee will be in order. This is a resumed meeting of the Subcommittee on Oceanography, of the Committee on Merchant Marine and Fisheries.

Let the record show that we have a quorum.

The first witness will be Capt. A. I. Metsger, Deputy and Assistant Chief of Naval Research, who is here pinch-hitting for Admiral Bennett.

All right, Captain. Will you proceed, sir?

\section{STATEMENT OF CAPT. A. B. METSGER, DEPUTY AND ASSISTANT CHIEF OF NAVAL RESEARCH, DEPARTMENT OF THE NAVY}

Captain Metsaer. It is a great pleasure to be here this morning, Mr. Chairman. Admiral Bennett especially regrets not being able to be here with you this morning to discuss our programs in oceanography. He is this morning testifying on naval appropriations.

Mr. Miller. We appreciate how important that is to Admiral Bennett and to all of us.

Captain Metsger. If the appropriations hearings are over he will come on over here to join you, sir, and if there is anything further you would like to have from Admiral Bennett he would be most happy to come at a later moment at your convenience.

Mr. Mrruler. Thank you. Tell the Admiral that if there is we shall be very happy to call him.

Captain MetsGer. In considering the interest of this committee in the field of oceanography it was felt that a brief summary of the general history of oceanography in the Navy would be interesting and informative.

In the broad sense of oceanography the Navy has been extremely interested since early in the last century. Beginning in 1842, the work of Lieutenant Maury in charting the ocean currents, which con- 
tributed so much to the expeditious routing of merchantmen, constitutes the Navy's first formal entry into this particular field of science. It is interesting to note that even today, over 100 years later, the pilot charts still bear the notation "Based on the research initiated by Lieutenant Maury."

In the connotation of antisubmarine warfare the derices of World War I were so crude that variations in the ocean were never considered to be particularly significant. However, starting about 1935 , we began to tie antisubmarine observations into the general problem of the physics of the ocean. By 1937 the role of refraction, that is, the bending of sound waves due to temperatures existing in sea water, was clearly tied to problems of interest to the Navy. Later it was realized that there were time and space variations in the thermal structure of the ocean which influenced this problem.

In the meantime, our oceanographers were devising instrumentation for their own studies which turned out to be of value to the Navy. Notable among these was the bathythermograph devised by Dr. Spilhaus in 1937, and adapted for military use by Dr. Ewing. The bathythermograph principle has turned out to be a very versatile means for determining the temperature characteristics of sea water. This type of instrumentation is used by oceanographers for many of the various purposes of oceanography.

The urgent requirement for better submarine detection in World War II led to the rapid development of an extensive Navy oceanography program which was tied to the antisubmarine warfare problem. At that time we began to use the bathythermograph as a device for assisting in the prediction of antisubmarine oceanographic warfare conditions. At the same time pilot charts for general indications of expected seasonal and geographic ocean phenomena were compiled. Further, an oceanographic data program was instituted. Starting in 1940 the National Defense Research Commitee formed research groups at several of our institutions of higher learning which were coordinated by the Navy into one national program.

In handling this national program the oceanographers of the country were mobilized, and it can be safely said that the results of their efforts contributed materially toward our ultimate solution of submarine warfare.

At the end of World War II oceanographic research at civilian institutions was continued on a reasonably large scale basis. The major portions of this continuing program have been carried out at the Woods Iole Oceanographic Institution, Lamont Geological Observatory of Columbia University, and the Scripps Institute of Oceanography of the University of California. This postwar program differed from the wartime program in that it was directed much more specifically toward understanding the basic phenomena of the ocens from which are drawn the byproducts of better information of use to Defense.

'This limited background information should serve the committee's immediate purpose. Wre are now prepared to discuss some of the postwar work with special reference to the future program if the committeo has no questions on this particular part of the presentation.

I would be glad, Mr. Chairman, to respond to any questions you might care to direct to me.and, of course, we have the distinguished 
oceanographer, Mr. Gordon Lill, who handles the oceanographic scientific work for the Navy here with us today.

Mr. Mrluer. Captain, I notice that in your next to the last paragraph you mention the fact that the-

postwar program differed from the wartime program in that it was directed much more specifically toward understanding the basic phenomena of the oceans from which are drawn the byproducts of better information of use to defense.

That implies that there is still a great lack of knowledge in this field that can be developed.

Captain Metsazr. There certainly is, sir. Perhaps you have heard it said that we know far more about space millions of light years above us than we know about the earth 1,000 feet beneath us, or the ocean bottoms beneath our ships. This is literally true.

Mr. MImLer. Is there any question in your mind that in the future for both defense and in the matter of more peaceful pursuits that a thorough knowledge of the oceans is desirable?

Captain Metsaer. I feel, sir, that both for our national security and our national economy we absolutely must learn more about our oceans.

Mr. Miller. I have been interested in some things that have come to my attention. For instance, I was handed a translation of Radio Vilnius: According to the monitoring service for November 2, 1958, Radio Vilnius in Soviet Lithuania announced on that date that the designing institute of the fishing industry in Klaipeda had started working on the design of a miniature submarine, which they announced would be called a bathystat. The bathystat was expected to lend itself for watching nets and fish at depths up to 600 meters $(2,000$ feet $)$. The first bathystat was to be pulled by a ship; the subsequent one was to have its own engine.

The model of the first bathyscaph was already built and ready for testing at that date.

Have you ever heard of such a development?

Captain MeTsGer. We are familiar with that bathyscaph. In general, sir, and I think Mr. Lill will have an opportunity to talk a little more about bathyseaph operations later.

Mr. Mrluer. I understand that the Russians are going to use this among other things to determine the efficiency of netting operations of fish nets in the surface of the ocean.

I am not conscious of anything that we have done in that line. We may have been doing it or may have contemplated it, but as an old fish and game man, and I was at one time executive officer of the California division of Fish and Game, I am conscious of the fact that we know very little about the efficiency of netting operations in the ocean and carry them on as we have carried them on traditionally for hundreds of years.

The only real material advancement that we made was when you put power on ships and could put out bigger nets. This was very interesting to me. I just bring it up for the general information of the committee.

Are there any questions? Mr. Dorn.

Mr. Dorn. Do you have any suggestion as to what this committee might do to aid the work that you say should be done? 
Captain Metsger. Mr. Dorn, any actions that this committee can take to increase the national interest and support in the oceans surrounding us will be of great benefit.

I feel that our country has not understood sufficiently how important the oceans are to us in many aspects; and not only defense but fisheries, too.

From my point of view, of course my primary purpose is national security.

Mr. Dons. This question is rather broad. Is there any type of legislation which could come out of this committee which would aid you either materially or to a minor degree in the work which your department is carrying on?

Ciptain MeTsGer. I am not prepared to answer that question at this moment, sir.

Mr. DonN. I would appreciate it if, after thinking about it and talking about it, you did reach a conclusion and there is a type of legislation that you contact the counsel to the committee and inform him.

Captain Metscer. Thank you, sir.

Mr. Mrller. Mr. Dingell.

MIr. Dingell. Thank you, Mr. Chairman. I have no questions.

Mr. Miller. Mr. Pelly.

Mr. Pelly. Captain, I would just like to ask you one question. Do you know of any connection between the Soviet oceanographic ressel which made quite a tour of the Pacific, I think visiting California, and the recent Soviet fleet of 73 fishing vessels which suddenly to our surprise began operations off of Alaska?

Captain Metsaer. I would like to be excused from answering the question, sir.

Mr. Pelly. I think, Mr. Chairman, that you brought out a most interesting subject when you discussed the use of the bathyscaph for finding out what happens to fishing. There has been evidence in our fisheries work in this committee that the Japanese nets, some of which are five or ten miles long, break in storms and they continue their devastating effect upon salmon by going on and getting the fish caught in these nets; and it does seem to me that it opens up an avenue which conld contribute greatly to the conservation of our great fisheries resoures.

I hope, Mr. Chairman, you will bring that up in connection with the Fisheries Subcommittee, too, because it would be of terrific value.

Mr. Miluer. I intend to.

Mr. Oliver?

Mr. Otrver. Captain, this question may be too broad in its implications for you to answer, but I think for iny own satisfaction I shonld like to put it to you.

I understand the Navy has taken the learl or at least perhaps a leading position as a coordinating agency so far as an informal interageney committee is concerned on ocenographic questions.

Is that an accurate statement of the situation?

Captain Metsane. Yes, sir. I believe that is.

Mr. OrIver. This is entirely informal, is it not, so filr' as there is no Jerislation anthorizing it but it is a matter of different agencies getting together who are interested in this subject? 
Captain Metsaer. Yes, sir.

Mr. Ocrver. And the Navy has taken the lead in that?

Captain Metsaer. Yes, sir; that is true, and Mr. Lill is very active in that work.

Mr. Oliver. Is there any indication that if it were made a more formal organization that there might be more constructive efforts toward getting something done sooner about the expansion of oceanographic research work in the Gorernment?

Captain METsGer. I feel that this committee is adequately formal and that indeerl much of its effectiveness comes from the voluntary interest that exists in the committee. I feel that it is probably as well established now as it conld be.

In any event, a legislative basis would be no help for it, sir.

Mr. Otiver. Would it make a stronger and more effective base from which to try to effectuate increased appropriations based upon the recommenditions, for example, of the committee of scientists, namely, to the extent at least of, I think, something like $\$ 60$ million a year for the next 10 years as the program that they had outlined? Would a more direct approach, a more formal approach make more possible perhaps the dollar results that are necessary to get more expansion in this research effort?

Captain Metsaer. It might be possible, sir. However, I would like to have a try along the present lines.

I think that we are making good progress as we are going and I hope we can continue in this way mitil we find either that we succeed or fail.

I think we should succeed. If we do not, then wo must try another approach.

Mr. Oliver. What was bothering me was whether or not the approach is too scattered, whether or not we should concentrate moro through some formal legislative setup to press forward perhaps the dollar appropriations that are obviously required.

Captain Mersaer. I wonder if I might ask Mr. Lill to give you his feelings on this subject while the question is up, sir.

Mr. Oriver. Very good.

Mr. Milier. Wait a minute. Will you withhold that until Mr. Lill testifies? We have Mr. Curtin over here, Captain, who may want to ask you questions, and we will keep the continuity.

Mr. Curtin. I have no questions.

Mr. Milular. Coumsel?

Mr. Drewry. I have no questions.

Mr. Mrluer. Captain, following what Mr. Oliver has said, we know that the Brown committee recommended expenditure of a sum of money over the next 10 years. We know we can get good cooperation among Government agencies until it comes to saying, "Who is going to put up the money?" There is no question in my mind that this voluntary committee is working now but who is going to determine who is going to supply the number of boats, the equipment, the laboratories that are necessary to carry ont this job? How are we going to divide that budgetwise?

When you get down to that very practical aspect, I would like you to tell us, not today, but you can send a memorandum to the committee, if you will, as to whether or not a voluntary committee is going to be effective under those conditions. 
I think that is what Mr. Oliver is getting at. I have seen them work and you have seen them work, but we have also seen the place where we get down to "this is not exactly our duty, this is the limit of our responsibility in a certain field and we are having a hard enough time to get money to get along with what we have to have and we have not any to devote to a program of that nature because dollars are so hard to get."

Yet, to my anind, from what I have seen so far, this is going to resolve itself into how we are going to get the proper financing to carry on the program. That is going to be the big question.

Perhaps you could give that some thought on behalf of the Bureau and let us have a memorandum on it, please.

('aptain Metsger. I certainly will, sir.

('The information referred to follows:)

\section{OCEANOGRAPII}

The Office of Naval Research belieres that a formal organization established by legislation is unlikely to carry forward more effectively than the present informal committee the Government's expanding oceanographic research program.

A formal organization has its merits for promoting a scientific program where interest is scattered equally among several Government agencies, with no single agency having enough predominant interest to take the lead in directing and pushing the program. In the field of oceanography, however, the reverse is the case.

The Navy is both the largest customer for oceanographic work and, through the Office of Naval Research, provides the great bulk of all support for oceanography. Therefore, we hare a deep interest in furthering a fuller oceanographic research program. For example, oceanography is the scientific foumdation for innovations in antisubmarine warfare, which is a major concern of the Navy. In the Navy's oceanographic program we are able to transmit information from the scientists directly to the users, which are the Navy's technical bureaus. This is because through ONR we have the scientists and the users close together both administratively and physically.

The present informal committee sponsored by the Nary and formed to coordinate nationwide oceanographic activities has obtained superb cooperation from other Government departments and other activities outside of Gorernment, especially through the agency of the National Academy of Sciences. This Committee on Oceanography is working well, and a more formal arrangement would serve no purpose at the present time. In fact, much of its effectiveness stems from its voluntary nature since those who participate do so from an entlusiastic interest rather than because it is an assigned duty.

The scientists on the committee are not only desirous of solving basic scientific mysteries, but they are also impelled by the urgent practical needs of the agencies they represent. This makes for an active, dynamic committee, infusing in it a spirit of initiative and a sense of purpose that cannot be legislated.

Captain Metsger. Perhaps I could make an essentially one-sentence reply to give you the impression I have received in the work we do to obtain funding for this kind of work.

Antisubmarine warfare in all its aspects, and especially the scientific foundation, which is ocennography, receives the very serious consideration of the Nary from the Secretary and Admiral Burke on down. We at the Oflice of Naval Research determine what we feel is needed, sincerely needed, and we place this in the initial program; but this must go into competition with all the many other things which the Navy needs to provide national security at sea and, of course, we never get, all we think we really need of anything. We do not get all we think we need in oceanography, but it takes its proper proportion in comparison with all the other $i^{2}$ ma in our vast widespread list of responsibilities. 
Mr. Muller. I can subscribe to what you say and that is one of the things, frankly, that bothers me.

Now, in this field, the Navy is concerned with one or two phases and naturally that should be your prime interest.

On the other hand, how about the biology of the ocean which you are not concerned with but with which other people are concerned? Yet, in doing this job if we do it on a cooperative basis we can get it done on the whole cheaper than if we devote one part of it to the defense angle and another part to the biology and another part to the physics at sea in order to determine how we are going to send our merchant ships across, and maybe through this committee we can come in with a program of how this can be done and done more economically and with a little law, if it becomes necessary, than we can do it independently.

I am conscious of the fact, serving also on the Committee on Science and Astronautics, of how we have the peaceful phases of space exploration and the military phases, but we have set them up and you have NASA working hand in glove with ARDA in the Department of Defense, N.SA being the National Astronautical and Space Agency, and $A R D A$ being the Adranced Research and Development Agency for the Department of Defense. So that re are bringing along in that field the defense phases of it and the civilian phases or peaceful phases in close cooperation.

It strikes me that, because of the very importance of this in this field of oceanography, that if we can lay the proper background wo can come out with something like the fine cooperation of the Navy and other agencies where re can be assured of getting money to do this job. As it is now, as I understand it, there is one oceanographic boat that I believe is due for launching this year. How many others are projected or the keels laid down? Do you have any coming up?

Captain Metsger. Mr. Chairman, our program in that will be covered a little later by Mr. Lill.

May I respond to some of your fine, helpful comments, sir?

The great bulk of all the support of oceanography is made by the Navy Department and indeed by the Office where I am. This really turns out to be the most effective way to do it because this also is by far the largest customer for oceanographic work.

It strikes me, after some years in the Office of Naval Research, that our greatest problem is getting the information which is produced by science to the users. The best solution to this problem is to have the scientists and the users as close together as possible administratively and even physically. In oceanography we have happily achiever this and this is one example of immediate feeding of results to the user. This is because the scientific work and the users are intimately associated in the Office of Naval Research. Mr. Till represents both.

Now, in other areas where there are several equal participants, it may be that a committee structure such as you mentioned is useful.

I respectfully submit that a question might be raised even here but I would prefer not to raise it.

In the case of oceanography we shall do far better by keening everyone in the business in this greatest portion of it all together as they are now, with the exing superb cooperation which we do 
achieve with the other Government departments and other activities outside of Gorernment, especially through the agency of the National Academy of Sciences.

Mr. Nirluer. I do not want to give you the impression nor do I think that any one on this committee has jumped at any conclusions that there is any way of doing a shortcut on this thing. We are after information and we do not want to orerlook any phases of it.

We are going to try to develop it as across the board as we come along.

If there are no other questions of the captain, we thank you, Captain.

Tell Admiral Bennett how sorry we are that he could not get here.

We look forward to seeing him at some other time.

Ciptain Mersger. I thank you, sir.

Mr. Mrluer. Mr. Lill, are you ready, sir?

\section{STATEMENT OF GORDON G. LILL, HEAD, GEOPHYSICS BRANCH, OFFICE OF NAVAL RESEARCH, DEPARTIENT OF THE NAVY}

Mr. Lisl. Mr. Chairman, I consider it a privilege to appear before your special subcommittee and thank you for the opportunity you have given me to discuss oceanographic research in the Navy. While my remarks will emphasize the research program of the Office of Naval Research, various other aspects of the Navy's program will be alluded to and mentioned where appropriate.

I would like to go back 12 year's to 1947 , in order to pick up the trenc: of Captain Metsger's remarks. It that time, it was my privilege to work with Dr. Roger Revelle, who was the first head of the Geophysics Branch of ONR. TVe formulated several matters of policy with regard to oceanography, during those early days of the Office of Naval Research.

Because our military use of oceanographic knowledge had been exhausted in overwhelming the German submarine fleet during WVorld War II, we made fom important decisions. These were:

1. To lay the groundwork for future understanding of the oceans required by a maritime nation such as ours;

2. To initiate financial support for the oceanographic laboratories in existence at the close of WVorld IVar II;

3. To establish or influence the establishment of new laboratories: and

4. To encourage the entrance of additional scientists into the field of oceanography.

With regard to the first of these policy objectives, it became obvious that the cost of exploring the sea would be so large, and encompass so many branches of science, that only the Ferleral Government could afford to consider the matter. Since the Department of the Navy is one of the greatest users of oceanographic information, it was decicled that there must be an oceanographic program in the Oflice of Naval Research.

The second objective, the establishment of a system of financial support, was given caleful consicleration. It was decided that the few laboratories we had, would have to be supported in toto lather than project by project with hmolreds of separate contracts covering all individual scientists. 'This was done to incorporate the guidance of 
the laboratory directors in helping to plan the program for the future.

In the establishment of new laboratories, the third of our early objectives, ONR influenced the organization of the following activities: Chesapeake Bay Institute, Jolnns Hopkins University.

Narragansett Marine Laboratory, University of Rhode Island. Department of Oceanography, Yew York University.

Marine Laboratories, University of Miami.

Chesapeake Bay Institute, Johns Hopkins University.

Department of Oceanography, UTiversity of Washington.

Department of Oceanograpliy, Texas A. and M. College.

Department of Oceanography, Oregon State College.

Only this year, the addition of Oregon State College to the list illustrates that this policy aim is still active. The United States now has an imposing number of excellent oceanographic facilities in geographic locations which encourage the study of all aspects of oceanography. These are staffed by scientists who are highly competent, but far too few in number.

The last of our early objectives, to encourage additional scientists to enter the field, is still being worked on. It has been roughly estimated that the United States has but 500 scientists who are interested in understanding the oceans.

When it is considered that the world's total number of oceanographers is only about 1,200 to 1,500 we do not appear to be so badly off, but 500 oceanographers are by no means enough to meet the problems now confronting this Nation. "The serere shortage of competent scientific personnel is one of the greatest and most urgent problems in oceanography.

With these few introductory remarks, I should like now to turn to the work at hand, which is the scientific oceanographic program of the Oflice of Naval Research.

In setting out to understand a natural phenomenon as large as the "world ocean," the first thing that must be attempted is to obtain an adequate description of that phenomenon as it exists in nature. It is not enough to describe the ocean as it might be under some average condition, it must be described as it is. This objective means, of course, that a rather large system of exploratory expeditions must be established, preferably composed of two or more ships working together on each cruise. For the past 12 years, research ships under contract to the Navy have explored the "world ocean" poking into every corner to which they conld gain access.

The first slide which I have to show you is a view of the Woods Hole Oceanographic Institution.

This laboratory is located on Cape Cod near Falmouth, Mass.

The second slice is the Scripps Institution of Oceanography, which became a part of the University of California, I believe, in 1912.

These two institutions have been responsible for much of our oceanic exploration in the two big oceans. The third and fourth slides show the types of ships which are being used in research today. The first of these is the research ship Vema. The Vema was built in 1923, has a wrought iron hull, and is operated by Columbia University through the Lamont Geological Observatory.

The second research ship is the Spencer F. Baird, operated by the University of California through the Scripps Oceanographic Lab- 
oratory. The Baird is an ex-Navy tug altered for the purposes of research, and is operated by Scripps. It is with ships such as these that we have been exploring the oceans. Even now, the Vema is on the return leg of an exploratory and scientific cruise which has carried her completely around the South American Continent, while the Baird. is working in the Gulf of California.

From these exploratory cruises, which have been designed to work on particular problems, has come a general understanding of several broad features of the oceans.

We now understand better the general circulation of the oceans which is the controlling factor in the distribution of marine life, physical and chemical characteristics of the water, the movement of some of the sediments and some of the temperature characteristics. A knowledge of the distribution of marine life is important to the Navy since myriads of forms of marine animals are noise makers and provide an important share of the background noise of the sea. 'This noise often interferes with our efficient use of acoustic detection equipment and mystifies those who listen, in the oceans, for passing submarines. We know now the general distribution of lone mountains sticking up toward the surface of the sea which we call sea mounts. Coupled with this we have located features of the mid-Atlantic ridge, a submarine mountain range running from 60 degrees north to 60 degrees south down the middle of the Atlantic Ocean, and we have discovered a comparable but larger range in the Pacific called the mid-Pacific Mountains which stretch from Hawaii toward Kamchatka and southerly toward the Tuamotu Archipelago. As a part of the bottom studies, we have learned of the distribution of bottom serliment types such as clays, sands, manganese nodules and rocks. These features are important for their applicability to submarine navigation and their usefulness in laying out deep diving programs of a more extensive exploratory nature.

As $I$ liave indicated, these exploratory cruises are specifically programed to investigate special problems. Each cruise is led by a chief scientist on board the ship who has priority for his work over any other general oceanographic work which may also be accomplished. Out of this type of program have come the answers to specific questions which I would like to mention next.

A large portion of our oceanographic program is involved with a special field which, for lack of a better term, we call marine geophysics. This field encompasses the measurement at sea of the following earth features:

(a) The earth's magnetic field:

(b) 'The earth's gravity field; and

(c) The structure of the earth beneath the ocean (which I would especially like to mention).

The earth's structure is ineasured in several ways, the most important being seismic. Seismic work at sea is accomplished by two ships one of which rletonates an ('xplosion, langing in size from 2 to 300 pounds of 'I'N'I', while the other' ship, miles away, records the sound as it is reflected and refracted by the bottom structure. From this work we have proved that there is no granite under the sea floor as there is under the continents. We lave learned that the earth's crust, under the oceans is relatively thin as compared to the crust of 
the continents. Is valuable side effects from this work, we have garnered information on the transmission of sound through the sea floor sediments, and sound velocity in sea water at different depths and temperatures. This has contributed extensively to the Navy's antisubmarine warfare program. Marine seismic work has also shown us that it will be possible to drill a hole through the earth's crust, in some oceanic area, and bring up samples of the next portion of the earth which is called the mantle. By doing this, we may settle an entire host of questions, long puzzling to geologists and astronomers alike, which have principally to do with the history and origin of the earth, the rate at which the earth is losing heat, the origin and history of the permanent ocean basins, and the physical and chemical nature of the rocks of the earth's interior.

The gravity and magnetic work is usually performed in conjunction with the seismic shooting and is useful in locating structural features of the earth which might otherwise be overlooked through difliculty of interpreting seismic records.

In the special field of oceanic circulation, one of the most significant discoveries in 1958 was the mapping of the equatorial undercurrent, which is now called the Cromwell Current in honor of its discoverer. This current underlies the South Equatorial Current in the Pacific Ocean. It was measured to be at least 3,500 miles in length, having a thickness of approximately 700 feet and a breadth of 250 miles. At a depth of 300 feet the current averages almost 3 knots toward the east compared with 1 knot toward the west of the overlying South Equatorial Current. The discovery compares in significance to the wartime discovery of the jet stream in the atmosphere. This particular feature is of practical use to the Navy in submarine warfare.

Prior to the work in the Pacific the existence of a comntercurrent under the Gulf Stream of the Atlantic was postulated by Mr. Henry Stommel at Woods Hole and later was proved to exist by a two-ship cruise similar to the one which worked on the Cromwell Current. This work contributed directly to the success of the study in the Pacific.

I have mentioned a few of the highlights of our extensive basic research program, and I would like now to turu your attention to one of our more important applied research projects which utilizes the bathyscaph as a research vehicle.

'The accompanying paper which I have made available for distribution explains some of the uses of the bathyscaph and describes one of our projects in the Mediterranean during which unique acoustical information was gathered.

Since that time, and about one year ago, the Office of Naval Research purchased the bathyscaph Trieste from its inventor, the Piccurds.

Slide number 5 is a picture of the Trieste in operation in the Mediterranean Sea, while slide number 6 shows the craft as it appears in full view out of the water. The tank which you see above the sphere is filled with gasoline, which is used for buoyancy control. The people are in the sphere which is suspended neath the gasoline tank.

The Trieste will carry two men to operating depths of about 20,000 feet for the purpose of making firsthand observations of the sea floor, observing the behavior of oceanorraphic instruments at great depths, 
recording the animal life at the sea floor, and for making a host of physical measurements under the supervision of a scientist, so that on-the-spot decisions can be made with respect to the taking of data which has heretofore been collected in a "blind" fashion.

The Trieste is now located at the Navy Electronies Laboratory in San Diego where it is being readied for a series of dives off the west coast. The dives will be oriented toward acoustical studies of interest to the Nary in its ASIV program.

Aside from some of the more obvious military uses of a craft such as the Trieste, we are witnessing the opening of a new era of exploration. I fully expect, before too many years have passed, that deepdiving craft of several types will be exploring the ocean fully in its third dimension, that is, with depth. This will make available threequarters of the globe which has hitherto been denied us because of the intervening water.

In the next slide, number 7, we see illustrated a model of the Reynolds Aluminum Co. bathyscaph Aluminaut, which undoubtedly will be but the first of a series of improved, manned deep-diving devices. While the Navy has functioned thus far only in an advisory capacity on the design and use of the Aluminaut, its development and construction is being carefully observed. Please note that several improvements over the Trieste have been incorporated. The most important of these is the fact that gasoline will not be used for buoyancy and that the Aluminaut will carry more scientists over a longer range.

The main work of the bathyscaph lies somewhat in the future, so while we are thinking ahead, I would like to make a few remarks about our administrative plans for the future of research at sea.

By this time, the Subcommittee on Oceanography is well aware of the impression the National Acaderny of Sciences Report on Oceanography has made on the country. There is no doubt but that the major recommendations made in that report must be carried out.

You have seen our preliminary document called Project TENOC which was entered in the Congressional Record a few weeks ago. We consider TENOC to be our share of the Academy's recommendations. However, a few points of comparison are in order.

The National Academy report cover's all aspects of oceanography while the TENOC recommendations are only concerned with Navy support in research. By selecting the recommendations of the Acadeny report dealing exclusively with Navy supported oceanographic research, it is possible to make a good comparison. On that basis the enclosed table has been compiled. The figures represent funds in millions of dollars. Although, it appears from the table, TENOC recommends a much larger expansion in oceanographic research, it should be remembered that the Acarleny recommendations for the Navy support in research represent only half of the total suggested expansion.

The National Science Foundation is recommended to support the other half, thus resulting in a total expansion of $\$ 270.8$ million dollars in oceanowraphic research and total shipbuilding program of 16 research ships.

In the introduction to the NASCO summary, it was stressed that tho resommendations are minimal. The comparison with TENOC indicates that this is true. In compiling the recommendations in 
TENOC, it was assumed that with the Navy taking the lead, other organizations would contribute to the expansion over and above that supported by the Navy. This indicates that TENOC is recommending a slightly greater expansion than the Academy of Sciences:

(1) Capital implovements (shore facilities) :

Million

TENOC

$\$ 12.81$

NASCO

(2) Capital improvements (ships):

TENOC

51. 60

NASCO____

Comparison of number of ships:

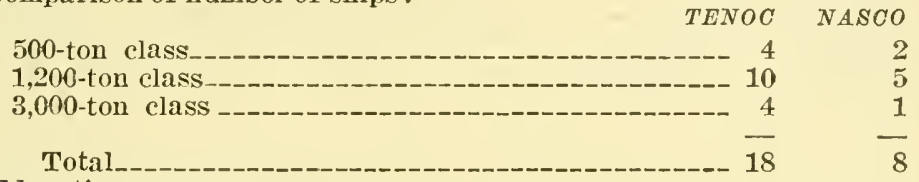

(3) Education program:
TENOC (to produce $175 \mathrm{Ph}$. D.'s in 10 years

NASCO (recommends a program sponsored by the National

Science Foundation)

(4) Research budget:

TENOC (includes ships and aircraft operation new devices research )

TENOC 10-year Navy total for research.

NASCO:
New devices
Ship operation
Shore operation
$\quad$ Total

NASCO, 10-year Navy total for research

135. 40

In addition, the NASCO report recommends the following expenditures of Navy funds for survey work and for military research and development:

NASCO (survey) :

Million

Capital (ships)

$\$ 41.10$

Capital (shore)

4. 14

Operations

'Total

83. 04

NASCO (military R. \& D.) : Capital (ships)

59. 30

NASCO 10-pear total Navy funds for all oceanography

277. 74

In the TFNOC report, it was recommended that the Hydrographic Ofice and the Navy Laboratories submit their own recommendations for expansion. 'These are in preparation.

To summarize the comments, I consider the NASCO report to be a realistic and necessary program of expansion that is desirable not only from the Navy's standpoint, but also from a national aspect. To do anything less than has been recommended would seriously jeopardize our international position in the field of oceanography.

In addition to meeting the challenge of the NAS report on oceanography, the Department of the Navy through the Office of Naval Research has been active in organizing interclepartmental coordination in this field. In 1956 we established the informal Coortinating Committee on Oceanography which is now examining the NAS report and is to make recommendations to the Federal Conncil on Science and $38170-59-13$ 
Technology; we therefore can truthfully say that intergovernmental coordination in oceanography is well in hand. I would like now to close this testimony with a few remarks regarding the international situation in oceanography.

To the Navy, the oceans contain little romance; their study is hard work, and they provide a hiding place for possible enemy submarines, so we shonld eximine the facts confronting us.

The next slide, No. 8, shows the Russian research ship Milihail Lomonosov. The most striking feature of this ship is, of course, its size, which allows it to carry about 20 different, but completely equipped, laboratories and a scientific complement of from 50 to 60 oceanographers. A comparison of the research ships of the United States, Russia, Japan, and Great Britain are shown in slide No. 9. The United States is seen to lag far behind the other nations in large research ships. Wre, in this country, do not agree that research ships must be large in order to be efficient. This is demonstrated by slide No. 10, an artist's conception of a new ship which we plan to build in fiscal year 1960 .

In 1961, two more ships of this type are planned and there are plans to produce 18 research ships by 1966 .

They will not all be like this one, however. This ship is 209 feet long with a 37-foot beam and about 1,400 displacement tons. She will carry 15 scientists over a period of 60 days and 12,000 miles range. She contains 1,600 square feet of laboratory space. Although this new ship is small compared to those used by the Russians, she will be the best research ship in this country.

The Russians successfully completed dnuring the International Geophysical Year the largest program of any nation and there were 27 countries participating in oceanography. Slide No. 10 shows the area covered by the Russians, which cover's practically all the oceans of the world, including some work in the Arctic and a very great amount of work on the continent of Antarctica.

While slide No. 11, the last slide, shows the area covered by the United States, the artist who produced this slide left off some ship tracks in the Atlantic which go back and forth between the continents of North America and Europe and South America and Africa.

In addition, the cruise which you see terminating at the tip end of $\Lambda$ frica was continued up into the Indian Ocean, so our program does look somewhat better than this slicle shows.

We are not too alarmed at this unfavorable comparison when we consider that our work in the marine sciences is generally conceded to be of higher quality than that of the Russians. 'The point is that the Russians have decided to compete in oceanography, and that they are competing very well. Their scientists are well trained. With a few years of experience at handling huge quantities of data they will be as good at it as we are, and the size of their effort will antomatically place them in the lead. The Russians are in oceanography for obvious military and economic reasons, and it appear's to be their objective to stay in and to excel.

'This brings to a close my formal, written testimony.

At this time, I would like to present a short documentary movie which shows in an excellent fashion some of our methods of doing research at sea. 'The film was produced ly the Troods Itole Ocemographic Institution, and was kindly loimed to us for this presentation. 
Mr. Miller. Mr. Lill, before we go into the film, there may be some questions we would like to ask of you.

On page 10, you say:

In the TENOC report, it was recommended that the Hydrographic Office and the Nary laboratories submit their own recommendations for expansion. These are in preparation. To summarize the comments-

and so forth. When do you think those publications will be completed?

Mr. LiL.. I should think within a few weeks, sir. We have received some information already from some of the Nary laboratories. The material is coming in at the present time to the Chief of Naval Research. Is soon as we get it all in we will add it to our 'TENOC report.

Mr. Mrucer. Then what do you propose to do with it? Will any of the financing be recommended for next year's budget? Will it be considered over a period of years as a master plan?

Mr. Lill. We will submit the amended TENOC report to the Chief of Naval Operations for his approval.

The part which we have already submitted has been approved by Admiral Burke. I would rather imagine that it will be considered over a period of years as we go through each year's appropriations.

Mr. Minler. I think that this committee could be most helpful in implementing that report although naturally the authorizations are going to fall within the jurisdiction of the Committee on Armed Services, yet we could be helpful with that committee and later on working with the Committee on Appropriations and I am going to ask you if you can formally keep us advised as to the progress of this report and its implementation as it can be released. I realize that when authorizations come up that there is something that can be released quite readily.

On the other hand, when it comes to the matter of appropriations you cannot tell us very nuch about it until it has passed the Bureau of the Budget.

At that time we can request you to tell us what your budget requests were and perhaps we can be helpful in pleading your cause with the Appropriations Committee.

Personally I think that for the present time that is one of the places where this subcommittee can be helpful if you will, within the regulations laid down, keep this committee advised along with the others. I am certain that it will be very glad to do what it can to assist you in that way.

Mr. Dorn?

Mr. Dons. I have no questions.

Mr. Mrlueer. Mr. Dingell?

Mr. Dingell. I have no questions.

Mr. Mrller. Mr. Oliver?

Mr. Oliver. I have no questions.

Mr. Míller. Mr. Pelly?

Mr. Pelly. I have no questions.

Mr. Miller. Mr. Curtin?

Mr. Curtis. I have no questions:

Mr. Miller. Thank you very much for a very fine and provocative paper, Mr. Lill. 
I think before we get through we may want to discuss sone of these features with you either individually or collectively.

It opens up new fields to us.

TVe will now proceed with the movie.

[Showing of the movie.]

MIr. NILLER. I want to thank you very much for that picture. It tells a great story.

Hare you any questions, Mr. Dorn?

Mr. Donx. I have no questions.

Mr. Millier. Mr. Dingell?

Mr. Dragell. No, thank you, Mr. Chairman.

Mr. Mirler. Mr. Pelly?

Mr. Pelur. I have no questions.

Mr. Miluer. Mr. Oliver?

Mr. Ourver. I have no questions.

Mr. Miluer. Mr. Curtin?

Mr. Curtix. I have no questions.

Mr. Miller. Mr. Counsel?

Mr. Drewry. Mr. Lill, on page 4 of your statement you referred to the Vema which is operated by Columbia University.

Does the Navy foot the bill for the operation of that vessel?

Mr. LiLl. Yes, sir.

Mr. Drewry. How long has she been a research ressel?

Mr. IILL. I think approximately for 8 years.

Mr. Drewry. Prior to that time, what was she?

Mr. Litu. I will see if I can remember this correctly. Professor Ewing at Lamont Geological Observatory found the Vema in a junk heap around New York in a graveyard for ships and recognized that the 1 ema had a wronght iron hull which does not rust and he bought her for something like $\$ 78,500$. Prior to being junked she was a private yacht. I am not sure who owned her.

Mr. Drewry. I do not know that it makes much difference, but you referred to her hull as cast iron. Now you say wrought iron. Which is correct?

Mrr. LrLL. That should be corrected. Wrought iron is correct.

Mr. Drewry. Has she done raluable work?

Mr. LiLt. Yes, indeed. She has been all over the world.

Mr. Drewry. Do you have any intention of scrapping her at the present time?

Mr. Lilu. Not so far as I know. She does need new engines but if she had new engines she could be on forever. Her hull is in good shape.

Mr. Drewny. She was a yacht initially?

Mr. Lill. Yes, sir.

Mr. Dlawry. How extensive was the conversion work necessary?

Mr. LiLt. The conversion of the Vema has actually been going on over a period of years. New things have been adkled to her when they were needed. Exactly what they had to do to her to fix her up in the first place, I an not sure.

$M r$. Dnwm. She is used for all types of oceanographic research?

Mr. LAt.. That is right, sir, principally for marine geophysies but also for straight physical and biological oceanography.

Mr. Drewry. And she has laboratories on board? 
Mr. Lill. Yes, sir.

Mr. Drewry. How many scientists does she carry normally?

Mr. Litu. Between 10 and 15 , I believe.

Mr. Drewry. Then you mentioned the Spencer F. Baird. which is of a diflerent type. I see the Baird was an ex-Nary tug. Has she been working out well?

Mr. Lill. Yes, sir; very well. She is one of our best ships. She is somewhat limited in the number of people she can carry with the accommodations that they have. She has been working ever since the war ended; since roughly 1947.

Mr. Drewry. Was she a war-built ressel?

Mr. LiLl. Yes, sir.

Mr. Drfwry. Except for the limitation, you hare had no difficulty in adapting the ressel to research purposes?

Mrr. Linl. That is right. There has been no difficulty. Te feel we can do much better if we have ships which are designed for this work, however.

Mr. Drewry. But until you get ships that are designed for the work, there are other types that can be made to do and perform effective service?

Mr. Lill. That is right. Te are now using one converted aircraft tender, an ex-Navy $\mathrm{AVP}$ and two ex-Navy salvage ships which were converted for this use. One is still to be converted. 'The other two have been converted for oceanographic research.

We look upon these three ships as interim measures to get launched into a bigger program.

Mr. Drewry. When you showed your chart of the other countries, the Russians and Japanese and British, you showed no very large ships in the American fleet but you said that we had to depend on and in fact you generally preferred smaller ones and you showed an artist's rendering of the new one. What tonnage was that?

Mŕ. Lill. 1,400 ton.

Mr. Drewry. The screen picture of oceanographic vessels in the United States is not limited only to the Vema and the Baird and the 1,400 tonner you hope to get or are expecting to get. In other words, there are quite a number of vessels of assorted types that are being used at the present time?

Mr. Lill. Yes, sir. That is right. Of ships that can actually work in the deep sea there are something like 12 in rough numbers in operation.

Mr. Drewry. Mr. Chairman, I bring this up only because it seems to me to be pertinent to the earlier consideration that we gave of the Albatross III which has been operated by Woods Hole in the past in connection with the Burean of Commercial Fisheries, and I think that the contrast between the story we heard there about the use of an older vessel and the story we hear now about the use of older vessels being better than nothing is rather interesting.

Mr. Lill, are you in position to make any comment about the Albatross $I I I$ as to its usefulness as an oceanographic vessel?

Mr. LrLl. I am afraid I am not. All I know is hearsay and I do not think it is very good to repeat.

Mr. Drewry. I did not know but what you might be personally familiar with the ship. 
Mr. LrLL. I know about the ship. I know that scientists who haveworked on her have never been very satisfied with her.

Mr. Drewry. They have not been?

Mr. Lill. They have not been.

In the first place, when the ship was taken over she was 20 feet shorter than she is now. They cut her in half and made her 20 feet longer from the middle out. She has never worked out well as far as sea worthiness is concerned. She behaves badly in the sea.

That is about all I really know about the ship.

Mr. Drewry. I would not want to press you further just on hearsay.

That is all, Mr. Chairman.

Mr. Miller. Mr. Lill, you showed us a picture of the proposed bathyscaph by the Reynolds Co. For whom are they building that?

Mr. Lilu. It is not too clear, Mr. Chairman. The Reynolds Co., of course, has their own purpose in building it. That is to promote the use of alnminum, through worthwhile advertising. They are looking to the Office of Naval Research for advice on what the ATuminaut should do and they have made contracts with the Sonthwest Research Institute for design.

The Navy Department has made contracts with Southwest Research Institute on some of the metallurgical problems involved so that there has been rather close cooperation. Whether Reynolds wants the Navy to take this over and operate it or not or who he plans to have operate it is really not decided as far as I know.

Mr. Miller. Do you know whether Reynolds was encouraged to build this by the Navy or did they do it as a venture of their own?

Mr. Lill. As far as $\mathrm{I}$ know it was their own idea. The Nary has no money in it except in the research end of metallurgy and we have been giving advice.

The first time $I$ heard of it was out of a clear blue sky.

Mr. Miller. Do you think it will be more efficient than the one that we purchased?

Mr. Irild. Yes, sir. I think so. It has at least double the range. It will have more power and carry more pcople. It will go almost as deep. perhaps not quite as deep, as the Trieste, but the other aspects of it, I think, will make it much better.

Mr. Mrumer. Do youl know whether we in this country have ever tried to or have ever built a bathyscaph?

Mr. Lir.. We have not. There have been some backyard designs built by individuals which they call private submarines but they really do not amount to much.

Mi. Mruler. Did not the French subsidize this boat for the Piccards?

Mr. Tillt. The French Navy took over the first one which was called the FNRS 3, the first bathyscaph Prof. Auguste Piccard designed and built.

'This device was given to the Fund for Research in Belgium, who in turn gave it to the French Navy. At that time Professor Piccard moved his operations to Italy where he built the one I have shown here.

Mr. Mudwr. As I recall, there was quite a piece in the National Gengraplic about the first one.

Mr. Tilu. 'That is the one the French have. 
Mr. Miluer. Out of his experience there he built this one which we have now taken over.

Mr. Curtin. Mr. Chairman, do those bathyscaphs have windows for visualization?

Mr. LiLr. They have windows for visualization.

Mr. Miluter. Thank you very much, gentlemen.

I want to saly that it is very constructive information that you gave us this morning.

Wre will have a meeting on Thursday and then Friday we are going to visit the David Taylor Model Basin. We will leave here at 9:30. I think we will find it very interesting to go out in the field.

I have been here 15 years and promised myself that I would visit this institution each year and I have never gotten ont there.

I do not know how many of you have been out there.

I think you will find it guite interesting.

Thank you, gentlemen.

The committee stands adjourned.

(Whereupon, at $11: 35$ a.m., the subcommittee adjourned, subject to the call of the Chair.) 



\title{
OCEANOGRAPHY IN THE UNITED STATES
}

\author{
THURSDAY, APRIL 23, 1959
}

House of Reiresentatrves,

\author{
Special Subcommittee ON ()CEa Nograpity \\ of tile Comantree on Merchant Marine and Fisheries, \\ W ashington, D.C.
}

The subconmittee met at 10 a.m., pursuant to call, in room 219, Old House Oflice Building, Hon. George P. Miller (chairman of the subcommittee) presiding.

Present: Representatives Bonner (chairman), Miller, Dingell, and Curtin.

Stafl members present: John M. Drewry, chief counsel; Bernard J. Zincke, counsel; and William B. Winfield, clerk.

Mr. Miller. The committee will be in order. This moming we have the privilege of hearing from Capt. Henry G. Munson, U.S. Navy, Hydroglapher of the Navy and Hydrographer in Command of the U.S. Navy Hydrographic Office in Oceanography.

Captain, we are very glad to welcome you back here and we would be very glad to hear from you.

STATEMENT OF CAPT. HENRY G. MUNSON, U.S. NAVY, HYDROGRAPHER OF THE NAVY AND HYDROGRAPHER IN COMMAND OF THE U.S. NAVY HYDROGRAPHIC OFFICE IN OCEANOGRAPHY

Captain Munsor. Good morning, gentlemen. Mr. Chairman, I deeply appreciate the opportunity to appear before you and stand ready to assist you in every way possible.

The Hydrographic Office, which I am representing here this morning, has behind it a long record of achievement in the field of oceanography, particularly with respect to problems concerning the merchant marine and fisheries.

Matthew Fontaine Maury, who, as Admiral Hayward told you last month, was appointed Superintendent of the Depot of Charts and Instruments in 1842, was the world's first professional oceanographer. That is, he was the first man in the world to make his living working full time on scientific problems commected with the ocean. Oceanography is still a very small profession, and there are certainly fewer than 1,000 oceanographers in the country today. Probably there are not more than 500 .

Maury's analysis of log-book data resulted in two sets of findings of great value to shipping and fisheries. One was incorporated in his Pilot Charts, which set forth the optimum routes for sailing vessels to follow in ocean voyages. Very valuable savings in time resulted from the use of his routes. Before all the markets of the world were 
linked by telegraph cable, a few days' difference in arrival time might mean the diflerence between profit and bankruptcy. Thus the other maritime nations of the world quickly set up similar organizations, whose work was coordinated by a conference held at Brussels in 1853. International cooperation and coordination in oceanography is therefore over a century old.

The other result of Maury's log book analyses was a series of charts showing where and in what months the various kinds of whales were to be foumd. The development of the Pennsylvania oil-fields, after which kerosene replaced whale-oil in lighting American homes, ended the whale fishery before the value of these charts could be fully tested. The relationship between oceanography and fisheries has not been forgotten, however.

The Hydrographic Office was formally established by Act of Congress, approved June 21, 1866, which charged it with--

improrement of the means for naritating safely the ressels of the Nary and of the mercantile marine, by providing, under the authority of the Secretary of the Nary, accurate and cheap nautical charts, sailing directions, navigators, and manuals of instructions, for the use of all ressels of the United States, and for the benefit and use of navigators generally.

There are no geographic restrictions on the operations of Hydrographic Office. Traditionally, however, the U.S. Const and Geodetic Survey surveys and charts the coasts of the United States, its Territories and possessions. The Hydrographic Office does not duplicate the work of the Coast and Geodetic Survey in these waters, but confines its efforts to oflshore and foreign waters. Therefore most yachtsmen and fishermen, who mainly operate in coastal waters, are more familiar with the products of the Coast and Geodetic Survey. The American merchant marine, on the other hand, depends wholly on Hydrographic Office products for information on foreign waters.

Up to 1928, oceanographic information obtained by the Hydrographic Office was confined to bathymetric somdings and to such information on the ocean's surface as could be obtained without special gear. The cooperation of merchant ships, begun by Maury, was continned, with the result that hundreds of thousands of observations of waves, sea surface temperatures, and ocean currents were obtained. In 1928, as a result of inquiries by the first Committee on Oceanography of the National Academy of Sciences, Secretary of the Navy Wilbur set up a board under Rear Admiral Schofield to investigate the possibility of further contributions by the Navy to ocenography. The Schofield Board recommended two programs. One was the commissioning of a full-time research vessel by the Navy. The other was broader participation by civilian scientists in routine voyages of naval vessels.

The first recommendation was not implemented, but under the second oceanographers from Scripps Institution of Oceanography and the University of Washington on board naval vessels between 1933 and 1939 occuped over 400 oceanographic stations in waters from Panama to Hawaii and Alaska. In tho Atlantic, Dr. Vening Meinesz was enabled to carry out over 100 gravity observations aboard U.S. submarines during the same period. In the thirties, WPA projects were set up under the sponsorship of the Hydrographic Office to transfer the accumulated surface observations to punched cards in order to facilitate sorting and compiling of the data. 
During World War II, the need for a much more rapid rate of analysis of the available oceanographic data very soon became apparent. Oceanographic problems entered into every phase of warfare. Ocean waves were important in seaplane landings, and in refueling operations at sea. Surf was critical in amphibious operations. The propagation of sound in sea water was the limiting factor in detection of submarines and it in turn depended on the character of the bottom, particularly in shallow water. Mining and mine countermeasure operations required knowledge of a variety of factors, such is water transparency, nature of the bottom, waves, currents, the magnetic and acoustic picture, and even the growth of barnacles. Search and resene operations depended heavily on a knowledge of ocean currents. Marine animals had to be studied to determine which ones made noise, which ones might be dangerous to swimmers, which ones could be eaten by survivors. I could extend this list greatly, but these items will serve to show the variety of oceanographic factors that affect military operations.

In June 1943, under the Joint Chiefs of Staff, the Navy was given responsibility for furnishing the oceanographic information required by all the armed services, and the Oceanographic section of the Army Air Forces Weather Information Service was transferred to the $\mathrm{Hy}$ drographic Office as the Oceanographic unit, pilot chart section, Division of Maritime Security. This unit produced a number of basic publications, such as Current Atlases and Sea and Swell Atlases, using the WPA punchcard data. It also was responsible for products of more direct military significance, such as sonar charts and submarine supplements to the sailing directions, much of the work on which was carried out on contract at Woods Hole Oceanographic Institution and Scripps Institution of Oceanography.

At the end of the war, it was realized that the accumulated oceanographic know-how was in danger of being lost unless some firm steps were taken, since the Reserve officers would be returning to civilian pursuits, and the institutions would tend to withdraw from classified contract work. A series of interdepartmental meetings in late 1945 resulted in the recommendation that a Division of Oceanography be established in the Hydrographic Office, and a detailed proposal for this was formally approved by Secretary Forrestal on January 26, 1946.

The proposal called for the Hydrographic Office "to act as a central clearing house for oceanographic work, to prepare oceanographic charts and manuals, and to sponsor and conduct oceanographic research as a part of its general program of service to the maritime interests of the United States."

Great difficulty was experienced in obtaining qualified personnel (and in retaining them in competition with other Government agencies, universities, and private industry), and the Division of Oceanography of the Hydrographic Office at first grew slowly. At the end of fiscal year 1947 it had only 15 employees, and it had to enter fiscal year 1948 with a 27 percent reduction in force under the first postwar economy budget. This state of affairs did not continue long liowever, and the outbreak of hostilities in Korea in $\mathbf{1 9 5 0}$ found the Division with a staff of 73 and with two oceanographic survey vessels, the USS San Pablo and Rehoboth, in commission in the Atlantic. 
The great demand by the fleet for oceanographic information during the next few years led to a further increase in the staff of the Division, which reached a high figure of 235 employees in 1953 . The present onboard count is 237 , representing a recent increase from 220 .

The oceanographic missions assigned it in 1946 have been carried out by the Hydrographic Office in varying but generally increasing degrees of intensity. Sponsoring of basic or fundamental oceanographic research by the Navy was assumed by the Office of Naval Research, after that organization was created by Public Law 588 on August 1, 1946. Although oceanographic research and derelopment has always been carried out within the Hydrographic Office, when necessary to supply information needed for its product, the Hydrographic Office has not until recently been considered formally a research and development agency since its efiorts have been directed more toward the application of ocemographic knowledge. The Hycirographic Office expects to play a large and expanding role in the national oceanographic program.

The major portion of the oceanographic effort of the Hydrographic Office has been devoted to the preparation of oceanographic charts and manuals. We have turned out a wide variety of items in this category. 'They include funclamental tables of sea-water density, handbooks of methods of forecasting waves and breakers, glossaries of sea-ice terminology, and manuals on how to take oceanographic observations and process data. These have been widely accepted not only nationally but internationally, and some have been translated into Spanish, Portuguese, and Japanese. Collectively they constitute a singularly useful contribution to the science. Less basic, but of more immediate military importance, are regional descriptions of oceanographic conditions of all the waters of the globe, giving the information needed for general strategic planning or for conducting specialized types of military operations, such as mining, mine countermeasures, amphibious operations, submarine operations, icebreaking, convoy routing, or antisubmarine warfare.

To collect the necessary information, our oceanographers participate in operations all over the world. When the Shate surfaced at the IGY ice-floe Station Alpha last summer, an oceanographer from the Hydrographic Office stepped ashore from her to be greeted by another Hydrographic Office oceanographer stationed on the ice-floe. At the same time, another oceanographer from the Hydrographic Office was in charge of the wintering-over party at Wilkes Station in Antarctica : two more were steaming south in the Atlantic on the flagship of project Argus; another group had just returned from the Hardtack tests at the Pacific Proving Ground; another group in the U.S.S. Rehoboth were conducting oceanographic surveys in the Pacific Missile Range; another group were observing a mine-sweeping exercise in Danish and German waters; still another group were aboard the YF-854 (now the U.S.S. Littlehales) surveying in the Canal \%one; and another oceanographer was attending an IGY meeting in Moscow.

In producing oceanographic charts, the Hydrographic Office has gone even farther in meeting the operating needs of the fleet. As already mentioned, numerons atlases are available showing average oceanographic conditions for varions oceans in appropriate seasons. These include charts of ocean surface temperatures, currents, wave 
conditions, and ice conditions, as well as factors of purely military significance. This type of chart can be called hydroclimic, in contrast to a chart which shows conditions as they exist on a particular day, which we call a hydroptic chart. But we can go even further, and prepare a chart showing conditions as we predict they will exist tomorrow, next week, or (in some cases) even next month. These are prognostic charts, and our first large-scale prooduction of them was to show predicted ice conditions during the 1952 Arctic supply missions of the Military Sea Transportation Serive. By proper use of this ice-forecasting service, which the Hydrographic Office has continued to provide, ice damage to ships and costs due to delays have been cut from $\$ 17$ million in 1951 to less than $\$ 1$ million in 195\%. And I would like to add, not in this paper, sir, that the anmual cost of this effort rounds out at something less than $\$ 200,000$, a very fine return on our investment indeed.

Another type of prognostic chart that has proved very valuable is the wave chart. In Maury's time, sailing vessels were routed according to expected winds and currents. Modern steamers, of course, more independently of the wind, and ship speeds are now so much greater than current speeds that, apart from exceptional cases, currents can be ignored as a factor in ship routing. IVaves, however, are quite another story. Our studies show that adverse wave conditions make necessary quite appreciable reductions in ship speeds, and therefore it pays to send ships where waves are least detrimental.

For the past 3 year's we have provided the Military Sea Transportation Service with recommended rontings based on the prognostic wave charts. The results were so favorable that MSTS cut one day off its transatlantic passenger schedules at the beginning of 1958, and not a single ship failed to meet the schedule that year. Besides this saving in time and fuel consumption, there is increased passenger comfort and reduced cargo damage. Over the past year for an expenditure of $\$ 45,000$ the Hydrographic Office has been able to save MSTS over $\$ 1$ million. Oceanography can be profitable.

By a directive of the Secretary of the Navy in January 1956, these prediction systems, as they are developed, are to be integrated into the fleet weather central system. The Hydrographic Office will thus be freed of the day to day preparation of routine forecasts and will be able to concentrate its efforts on the development of new systems.

The system most needed at present is for forecasting sonar conditions. Research and development funds are currently being used in this program, and we are confident of obtaining support in future years on a level that will yield useful results within a reasonable time. The availability of a sonar forecasting system in wartime is a matter of great significance, since on it will depend much of the success of our defenses against submarines, and this in turn will affect the rate of merchant ship losses and the conduct of convoy operations.

The prediction of movement of radioactive substances in the sea, whether from tests, from peaceful applications such as the proposed Plowshare operations, or from nuclear weapons or disasters to reactors, is another field that we are entering and in which we believe that our accumulated know-how gives promise of early obtainment of useful results. 
Finally, in acting as a central clearinghouse for oceanographic infolmation within the Defense Establishment, the Hydrographic Office has played a major role and is in a position to expand its service greatly. I have mentioned the application of punchcard techniques to the storage and analysis of surface oceanographic observations which began in the WPA days. We have extencled these techniques to the analysis of subsurface data as well, and by the use of adranced electr'nic computers have greatly reduced not only the labor required to work up the data of an oceanographic cruise but the time needed to publish a complete report. Whereas by the traditional methods it usually requires at least 6 months and not uncommonly as long as 7 years after a cruise before the data are published in a form suitable for other oceanographers to use, one oceanographic laboratory in this country sends a portable cardpuncher to sea on its cruises, the oceanographer brings ashore not data sheets but a box of cards, and the fully computed results, reproduced by facsimile from the machine tabulations, are ready for circulation in less than a month.

I understand that the Coordinating Committee on Oceanography is now considering a recommendation by one of its working groups that the Hydrographic Office, which now has over a million subsurface oceanographic observations, and is the largest collection of its kind in the world, be converted into a national data center for oceanography, such as the National Weather Records Center at Asheville, N.C., which provides a central meteorological data service for the country. Such a center, once space and machines are made available, can be operated on a self-supporting basis.

I would like to extend a cordial invitation to this subcommittee, or any of its members, to visit the Hydrographic Office at any time that may be convenient to them and to observe the processes involved in production. Besides our oceanographic activities, we are engaged in a number of programs in direct support of merchant shipping that I am sure you would find of interest.

In conclusion, may I take this opportunity to state that the Hydrographic Office greatly appreciates the support which the Congress has given it over the past 12 years for developing its oceanographic organization. Without this support, we would have been unable to attain the present state of development, which we feel enhances our defense posture and offers a firm base for future expansion. It is an effort which has and will continue to contribute to our defense and which measurably assists our merchant marine.

Mr. Milles. Thank you, Captain, for a very enlightening statement. I think that the Hydrographic Office of the Navy is to be congratulated for the work that it has done. I know it appreciates the desirability of expanding this work and coordinating it with other agencies of Government.

Have you any suggestion as to what this committee can do to further this work?

Captain Munson. I have, sir. My answer must necessarily be incomplete becanse we believe that the national effort in oceanography must be well planned.

We realize that the complete report of the committee working under the National Academy of Sciences, headed by Dr. Harrison Brown, of the California Institute of Technology, has not been issued. In- 
doubtedly the justifying reasons which back up the expanded efforts in surveying and in oceanographic research will come out of this report.

On the other hand, we are fully appreciative that oceanography is an expensive science. 'This is brought about by the fact that your collecting tool is a ship and ships are very expensive. The rest of the process, strange to say, is rather inexpensive once the data is in hand.

Now, viewed, of course, primarily from the military standpoint, we have a number of competing and very serious problems. We have the antisubmarine problem which is largely a matter of engineering and science in other directions than oceanography. We have the air defense problem. We have the need for faster ships, more sophisticated and frightfully expensive missile systems. The national economy can stand, of course, but so much expenditure per year.

Therefore, what we are going to do in oceanography must be carefully weighed and balanced against the competing needs of the other systems which we are dependent upon for our defense.

Certainly we are going to have to have increased appropriations in R.\& D. for oceanography.

One cannot say whether or not any national supervisory body would be required. For the time being we are firmly convinced that the manner of doing business established by the National Academy of Sciences, vigorously supported by the Office of Naval Research and with very excellent field work being performed by Dr. Brown's committee and by the informal Coordinating Committee on Oceanography, is the best answer for the time being. Perhaps enabling legislation will be required later.

To answer your question categorically, it is too early to state what the nature of the help would be. Perhaps the present arrangement, given somewhat more authority, let us say, to divert funds, will be the answer.

Mr. Minfer. Of course, we realize that, if we can get away from having to set up some overall committee or agency officially, perhaps we can best serve.

Captain Murson. We believe that, sir, if we can escape it.

Mr. Milrer. I am not going to commit myself on that at this time. This committee is a waiting the issuance of the report of the committee of the National Academy of Sciences headed by Dr. Brown. We realize that what has been released so far is merely the first section and the preliminary report and that the details are to follow. Until we get them, there is not very much that we can do other than to familiarize ourselves with the problem, and I want to assure you that, if it is a fact as stated here that people who have long been in this business and devoted themselves to it as you have know very little about that which is below the surface of the sea, what this committee and what the average layman know about that which is below the surface of the sea is meager.

We have been trying to perfect ourselves and get this information so that, when the Brown report is finally issued, we will be in position to interpret it and perhaps be a year or more ahead, having initiated the work of the committee at this time. 
We have found it most interesting and, of course, I appreciate that it is rery expensive. It is going to be expensive. It is suggested by Dr. Brown that it be on a 10-year period, but when you realize that the savings to the Government that you have set forth for the MSTS and this lather startling fact that by applying data developed in the Hydographic Office you could cut the cost of ice damage and delays of ships from $\$ 17$ million to $\$ 1$ million a year, it indicates that here is a field where real savings have been effected and can continue to be effected and this work through your good offices can be self-supporting. If this goes on now it will be a continuing thing, so that we have a little more to offer in that respect that $I$ am confronted with in another committee that deals in science and astronautics, where, when we spend a couple of million dollars to send up a missile and get back fragmentary information from it and still have to spend more money, that in no way replaces itself and is a total contribution to science.

I am not questioning the necessity for that. You and I lnow that that is the only way we are going to get to know these things, but probing the hearens is much more expensive, apparently, than probing the bottom of the sea.

I feel that we have to carry this fight and be the spokesmen for those people who are interested. We have to be the spokesmen and champions of oceanography in the Congress.

I notice you said here that there was a report in 1928 of the first Committee on Oceanography. I wonder, Mr. Counsel, if we can get that? I suppose it is in the Library or it might be published.

Captain Munsox. If I may volunteer, sir, we did not bring it with us but it is very likely that the Hydrographic Office would find it easiest to retrieve it, and, if you would like to see it, I will procure it.

Mr. Minfler. I would like to see it.

Captain Mosson. Historically it might be a very fine document to air. I might say we have all the papers, including the order signed by Secretary Forrestal. It is a very interesting paper with the original signature.

Mr. Mrtler. Mr. Curtin.

Mr. Cuntin. Thank you, Mr. Chairman.

I want to say, Captain, that I think this statement is extremely enlightening and helpful to us. I notice that you say that in 1950 there were two oceanographic survey vessels.

Captain Munson. Yes, sir.

Mr. Curtin. How many are presently in use?

Captain Munson. Of course, your question is addressed to the $\mathbf{H y}-$ drographic Office alone?

Mr. Curtin. That is right.

Captain Munson. We are still operating these same ships, one very small one which is used to gather a particular type of inshore data, and six other vessels primarily configured to perform hydrographic work but which can and do double in brass to conduct oceanographic surveys.

It is not a situation which we are particularly happy about because recent developments have indicated that we nust enlarge modestly our own effort and we are making representations to the proper authorities in the Navy to add one more surveying ship, possibly two more of a very peculiar nature, and soon, and we certainly are going to have this request granted, an oceanoglaphic survey plane. 
We have been successful, and primarily the work has been carried out by the technical bureaus of the Navy, in developing a series of instruments which permit us to probe the ocean from an aircraft flying over it at high speed. You can appreciate that our coverage will be expanded enormously when this plan matures and I think we can say that we will have this plane in commission and configured within the year.

This will take care of our immediate foreseeable needs. As we study the problem of the demands of the merchant marine as they come within the scope of the Hydrographic Office and as the military requirements which you will understand primarily guard our thinking over this matter, we will ask for appropriate additions to our fleet.

MIr. Curtin. Thank you. That is all.

Mr. Minler. How big is the San Pablo?

Captain Munson. Those, sir, are small converted AUP's. Their tonnage is around 2,800 . 'They are not perhaps the best ships in the world that one can use but we are perfectly happy to compromise with them. Since they are old they have outlived any military usefulness. They are World War II babies. Their original use was as a small adranced base for seaplane operations. They have little use in the modern naval picture and we are happy to use them.

The Coast and Geodetic Survey has been using one for many years.

Mr. Milleer. Have you a ship in this year's budget?

Captain Munsox. No, sir. The first vessel for the Hydrographic Oflice will occur in 1961. I have been advised by an informative authority that I will have one hydrographic survey ship and one oceanographic survey ship programed for 1961. Up to that time we shall have to make do with conversions which are quite efficient. Actually, if you want the entire truth about the difference between a conversion and a new construction survey vessel, in the long haul they seem to be convinced that the new ressel is cheaper. Momentarily, of course, you make savings by converting. The requirements for a survey vessel, either oceanographic or hydrographic, are modest. It is not a sophisticated ship. There are a number of standard ships that readily adapt themselves to it.

Our two big overseas hydrographic vessels that are equipped to do a complete cartographic job even to lithographing the chart on board are medium size, small, one-shot transports left over from World War II. They have a number of years of life left in them and we find them extremely productive and quite well fitted for the job.

Mr. Minler. How about this plane? Is that programed or is that taken care of within the budget?

Captain Munson. That is not programed because the requirement has not yet been formally laid out, but it has been discussed with the proper authorities orer in the Pentagon and we are assured of complete support on it, and its need has now been shown to be unquestionable.

Mr. Miller. Mr. Dingell.

Mr. Dingell. I have no questions, Mr. Chairman.

Mr. Millek. Counsel. 
Mr. Drewry. Captain Munson, in your statement in regard to the question of savings in costs as a result of avoidance of ice damage, that related to Ms'Ts ships?

Captain Munsux. That is correct, sir.

Mr. InEwry. I was going to ask you a question to try to show that perhaps those bald fignues did not reflect a good average, but I take a look at some charts which Admiral Will presented last year when we had the hearings on the icebreaker and I woukd like to read them into the record becanse it at least eliminates the question I had in my own mind.

In 1951 there were 144 ships in the Arctic supply and resupply; in 1952,$1 ; 4 ; 1953,116$; in 1954,63 ; in 1955,126 ; in 1956,122 ; and in 1957,105 , which I think more supports than otherwise the difference between the $\$ 17$ million and the $\$ 1$ million.

The Admiral was making a point that he was changing from the use of Government-owned ships to purely commercial ships.

Captain Mussox. You understand, of course, sir, that the supply of the middle section has now been passed to the Canadians. We are assisting and collaborating with them.

Mr. Drewry. Yout went down to 1957.

Captain MIunson. Yes. I intended my contrast, which, of course, was the most startling thing we could find, to apply really to the first year's operation in which we applied ice forecasting techniques which have been subsequently perfected, but one would have to make some sort of an adjustment for the number of ship years to get a true figure.

Perhaps it would be more honest now to reduce it to a savings of dollar's per ship per' year.

Mr. Drewry. Captain, in mentioning the savings to MSTS, do you know whether the same or similar type of routing has ever been tried with the SS United Strites, for instance?

Captain Murson. To our knowledge, no, sir. The reason is this: The very large, very fast ships are somewhat independent of weather and may be sailed along what you conld call the navigationally most direct route. This is true of ships of the class of the United "States. the America to a certain degree the Constitution, and certainly of the Queens and the other larger Cmard liners.

They tend to follow the organized North Atlantic track lanes which represent a minimum geodetic distance laid ont with respect to safety for ice which would be the controlling factor.

Mr. Dlewry. Would there be matter's of savings in cost through not having to battle as heary weather as they would normally?

Captain Munsos. In certain periods of the year you would recover some but there would be a neat balance of forces that would have to be examinerl.

I believe the economics of the operation of some of the ships indicate that it is best to maintain your schedule and take some damare lather than incur the expensive delays attendant. upon a markedly late arrivil.

Mr. Drewry. Or it could be costly to get there ahead of time?

Captain Munson. This is true. MSTS finds it to be very true that you could cost yourself a lot by too early arrival.

Mr. Driwny. On the general subject of what we can do, which Mr. Miller bronght up, you mentioned that this is a costly sitnation. You mentioned that within the Navy budget there have to be various 
priorities among the different systems involved. That is readily recognized but the Hydrographic Office, in fact all of this oceanographic effort as I understand from all the testimony we have had so far, will be available, for the use of all who might be interested in it whether it be in the fisheries or merchant marine.

Captain Munson. This is true, sir.

May I make one reservation there? There are a number of facets of it which are so closely and tightly related to the operation of some secure weapons systems that it is not releasable at present.

Mr. Drewry. I understand.

Captain Munson. We are learning however, to a certain degree, to generalize it, extract and otherwise safeguard it.

Mr. Drewry. My point is that what is being learned right now is still a very elemental and fractional part of the total knowledge that will ultimately be extracted from it.

Captain Munsox. It certainly is. We know little more about the ocean than where it is.

Mr. Drewry. In any complex scientific development, the greater cost is in the initial stages; is that true?

Captain Munson. Usually, sir, it is particularly in an operation of this sort where I have explained that the principal tool of oceanography is a ship. Your processing cost to tarn this data into the usable system is very modest compared with the data collection effort.

Mr. Drewry. 'Then, as you develop the basic data in several fields, they each will have a relation to the other that will make future information easier to acquire?

Captain Musson. 'This is true. There seems to be a very fine cross fertilization. We are gesting benefits in oceanography from the literally explosive effort in missiles and the electronic art because we are taking advantage of developed engineering components that are perfected in these other fields.

Mr. Drewry. The point I am trying to develop is, is it not true that this coordinating effort which has been recommended by the National Academy of Sciences and which is being worked on through this informal group is a case of where, however the appropriations might have to come, the whole picture is being benefited by the money that is put into it?

Captain Muxsor. It certainly is, sir.

Mr. Drewry. So that, per dollar spent, it is not merely a question of the Navy or the Burean of Commercial Fisheries but for every dollar that is spent on this the benefit is distributed to a number of other Government agencies and ultimately to industry?

Captain Murson. We most certainly agree to this, sir. It is proving, is products come out, to be extremely beneficial to our whole economy.

Mr. Irewry. That is all, Mr. Chairman.

Mr. Milder. Mr. Chairman, I welcome you here.

Hare you any questions?

The Cirammax. No, sir.

Captain Musson. Mr. Miller, if there are no further questions at this time, if I may, we would like to present some of the products of the Office. It would take but a few minutes.

Mr. Miller. Do youl want to do that in executive session? 
Captain Munson. It is not at all necessary. The matter we have brought up is not classified. We think it will be of general concern and help to focms our minds on precisely what oceanography turns out.

This chart [exhibiting H.O. Miscl. 8514] usually brings a laugh particularly when you examine the date on it. It is a whale chart. Who ever heard of charting whales? It is a product originally compiled over a century ago, but the information contained on it is of military significance today. There is not the slight est use of attempting to conceal it. IIundreds of thousands have been distributed worldwide. It was obtained, of course, by careful researching of the records of whaling ships. Catches per square mile was the index to the whale production.

Today our approach could be more different as we have more knowledge of the ocean and what whales eat and where the food goes.

This chart is, as I say, important militarily today as reflected in another product.

The Sonar operator has to know where interfering marine bodies are which show on Sonar as a submarine. Hence, the density, the probability of locating a whale when you are looking for a submarine is a very valuable point. It may affect the routing of ships.

This next chart grew out of this data. This is a formalized military operational chart. It is dated 1954, 103 years later.

Mr. Miller. And it is from the data projected in the earlier chart?

Captain Munson. Yes, sir.

Now, sir, if we can project ourselves 100 years hence, this chart will be republished but instead of whales you will have tuna, halibut, and other edible fish. Maybe it will not be one chart but a series, showing where to go to catch the food which will be necessary to support an expanding population.

Oceanographic science will provide this information.

Mr. Minler. I wonder if the press would like to take a look at this?

Captain Munson. This one is so old that it is completely forgotten.

We talked about the pilot charts of Maury and we should like to offer one to each member of the committee, probably our best-known product.

'This chart is published monthly for the North Atlantic, the North Pacific, and additionally a somewhat smaller one for a portion of the Arctic Ocean. For the southern oceans we find that the information changes so infrequently and with the traffic being so much lower we publish that in atlas form. It is an expensive thing. It represents the accumulated know-how of 130 years. Hundreds of thousands of observations are averaged out on this, much of it supplied through the weather service.

Mr. Milirir. Do these show the currents?

Captain Munsox. Some are currents, some are meteorological factors, an amazing lot of information.

On the back you will find the chart of the world eurrents still of vital importance. We acknowledge Lientenant Maury's or'igin on the (hairt. We will not take that off.

It this time I would like to ask the Director of the Division of Oceanography to display some of our standard oceanographic publications. 
STATEMENT OF JOHN LYMAN, DIRECTOR, DIVISION OF OCEANOGRAPHY, U.S. NAVY HYDROGRAPHIC OFFICE

Mr. Lrman. My name is John Lyman, Director of the Division of Oceanography in the Hydrographic Office.

Captain Munson gave you a brief description of some of the types of publications that we produce.

We have actual samples of them here which I would like to show.

The first thing you need to do is to get oceanographic data. This book [exhibiting H.O. Pub. 607] is an instruction manual of oceanographic observations. It is a complete cookbook on how to obtain all types of oceanographic information, currents, water samples, bottom samples, and wa re observations.

Then for ships that are not completely fitted for oceanographic collections of all kinds but may have a simple instrument like the bathythermograph on board, we have pamphlets describing how to take bathythermographic observations, for example [exhibiting H.O. Pub. 606ic].

The next step in the problem is to process the data. Here is a publication, Processing Oceanographic Data [exhibiting H.O. Pub. 614]. This is one of those that is internationally accepted as a standard treatise on the subject. It has been translated into Spanish and it has been circulated by the International Association of Physical Oceanography.

Then once you have the information the next step is to put it into useful form.

Here is an atlas of the polar regions [exhibiting H.O. Pub. 705], two sections, Arctic and Antaretic, which display all the known oceanographic conditions for the areas. This makes use of such recent findings as Operation Deep Freeze in which our oceanographers have participated, and even some of the early IGY results from the Arctic are incorporated in this volume.

Then we have published a book that is a catalog of all the oceanographic data available in our punch-card files. Copies of these data can be obtained by anybody on a reimbursable basis and this book tells the areas in which the information was collected and how much is available.

Then for the forecasting problem, we have reports on forecasting Arctic ice, the growth and formation of sea ice.

We have a treatise on forecasting waves [exhibiting H.O. Pub. $604]$. It is a good sized book. It turns out that forecasting ocean waves is a fairly formidable problem and it takes a fat little book and a lot of training to do efficiently.

This is the book that forms the basis for our prediction system for ocean waves that in turn is the foundation for the ship routing.

Here is another example of information from a specific cruise, the report of the oceanographic observations on one of the Deep Freeze operations, and then, to show that we do not neglect biology completely, here is a report on the growth of barnacles and other fouling organisms on steel plates in Norfolk harbor over a period of a year.

This is a problem of great interest to the Navy from the standpoint of what happens to a mine, but it also has considerable implications from the fisheries point of view because it gives an idea of fertility of the water at different seasons of the year. 
This is a quick rundown of what we have.

I brought with me a list of our publications which I can append to the record, and I would be happy to answer any questions on these. Mr. Miller. If you will supply that list, we will be very happy to have it. We will make it a part of the record at this point. (The document referred to follows: )

Oceanographic Publications

\begin{tabular}{|c|c|c|}
\hline $\begin{array}{l}\text { Publi- } \\
\text { cation } \\
\text { No. }\end{array}$ & Title of hook & Price \\
\hline & MANUALS & \multirow{5}{*}{$\begin{array}{r}\$ 0.75 \\
.40 \\
.50 \\
2.80\end{array}$} \\
\hline SP-1 & Application of Wave Forecasts to Marine Navigation. (R. W. James.) 1957... & \\
\hline $\begin{array}{l}234 \\
601\end{array}$ & $\begin{array}{l}\text { Breakers and Surf, Principles in Forecasting, } 1944 \\
\text { Wind, Sea, and Swell: Theory of Relations for Forecasting. (II. U. Sverdrup and }\end{array}$ & \\
\hline 602 & $\begin{array}{l}\text { W. H. Munk.) 1947. } \\
\text { Wind Waves at Sea, Breakers and Surf. (H. B. Bigelow and W. T. Edmonson.) } 1947 .\end{array}$ & \\
\hline 603 & $\begin{array}{l}\text { Wind Waves at Sea, Breakers and Surf. }(H . \text { B. Bigelow and W. T. Edmonson.) } 1947 . \\
\text { Practical Methods for Observing and Frecasting Oceanwaves by Means of Wave } \\
\text { Spectra and Statistics. (W. L. Pierson, Jr., G. Neumann, and R. W. James.) } \\
\text { 1955. }\end{array}$ & \\
\hline 604 & 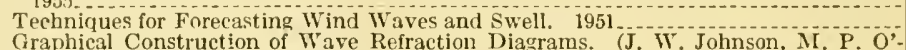 & $\begin{array}{l}3.80 \\
1.20\end{array}$ \\
\hline 605 & $\begin{array}{l}\text { Graphical Construction of Wave Refraction Diagrams. (J. W. Johnson, MI. P. O'- } \\
\text { Brien, J. D. Isaacs.) 1948. }\end{array}$ & .50 \\
\hline $606 \mathrm{C}$ & Bathythermograph Otservations. $1956 \ldots$ & .15 \\
\hline $606 \mathrm{D}$ & Ice Observations, $1956 \ldots$ & .15 \\
\hline $\begin{array}{r}606 \mathrm{E} \\
607\end{array}$ & $\begin{array}{l}\text { Sea and Swell Observations. } 1954 \\
\text { Instruction Manual for Oceanographic Observations. } 1955 \ldots\end{array}$ & 12.00 \\
\hline \multirow[t]{2}{*}{614} & Processing Oceanographic Data. (E. C. La Fond.) $1951 . . . . .$. & 7.00 \\
\hline & ATLASES & \\
\hline 225 & $\begin{array}{l}\text { World Atlas of Sea Surface Temperature Charts.- Paperbound copies of monthly } \\
\text { temperature charts for all oceans showing mean sea surface temperatures over a } \\
\text { leriod of } 30 \text { years. Size } 26 \text { by } 38 \text { inches printed on hoth sides of sheet. 1944 }\end{array}$ & \multirow{3}{*}{$\begin{array}{r}2.50 \\
.30\end{array}$} \\
\hline 236 & $\begin{array}{l}\text { Currents in the South China, Java, Celebes, and Sulu Seas. A pamphlet containing } \\
\text { chartlets showing the relation between currents and winds for every month. } 1945 . \text { - }\end{array}$ & \\
\hline 237 & $\begin{array}{l}\text { Ocean Currents in the Vicinity of the Japanese Islands and the China Coast.-A } \\
\text { pamphlet containing chartlets showing the relation between currents and winds } \\
\text { for every month. } 1945\end{array}$ & \\
\hline 550 & Ice Atlas of the Northern Hemisphere. 1946 . & 8.00 \\
\hline 566 & $\begin{array}{l}\text { Atlas of Surface Currents, Indian Ocean, Also Shows Sea Surface Temperatures (for- } \\
\text { merly II. O. Misc. 10057). 1914. }\end{array}$ & 2.40 \\
\hline 568 & Atlas of Current Charts, Southwestern Pacific Ocean (formerly H. O. Misc. 10058). & 2. 40 \\
\hline $54 i 9$ & $\begin{array}{l}\text { Atlas of Surface Currents, Northwestern Pacific Ocean, Also Shows Sea Surface Tem- } \\
\text { perature (formerly II. O. Misc. 10058A) 1944 }\end{array}$ & 2.40 \\
\hline $5 i 0$ & $\begin{array}{l}\text { Attas of Surface Currents, Northeast Pacific Ocean, Also Shows Sea Surface Temper- } \\
\text { atures. 1947 }\end{array}$ & \multirow[t]{2}{*}{ 2. 40} \\
\hline 571 & $\begin{array}{l}\text { Atlas of Surface Currents, North Atlantic Ocean, Also Shows Sea Surface Tempera- } \\
\text { tures (formerly H. O. Misc. 1968s) }\end{array}$ & \\
\hline $\begin{array}{r}705 \\
799 \mathrm{~B}\end{array}$ & $\begin{array}{l}\text { Oceanographic Atlas of the Polar Seas, Part } 1 \text {, Antarctica. 1957 } \\
\text { Atlas of Sea and Swell Charts, South Atlantic Ocean (formerly } \mathrm{I} . \mathrm{O} \text {. Misc. 10712B). }\end{array}$ & $\begin{array}{l}2.40 \\
2.50\end{array}$ \\
\hline & Atlas of Sea and Swell Charts, South Atlantic Ocean (formerly H. O. Misc. 10712B). & 1. 30 \\
\hline $799 \mathrm{C}-\mathrm{E}$ & $\begin{array}{l}\text { Atlas of Sea and Swell Charts, Northwest Pacific Ocean and Solthwest Paeific Ocean } \\
\text { (formerly H. O. Mise. } 10712 \mathrm{C} \text { and portions of If. O. Misc. } 10712 \mathrm{E} \text { ). } 1943 .\end{array}$ & 1.60 \\
\hline $799 \mathrm{D}$ & $\begin{array}{l}\text { Atlas of Sea and Swell Charts, Northeastern Pacific Ocean (fornierly H. O. Mise. } \\
\text { 10712D). 1944 }\end{array}$ & \multirow{4}{*}{$\begin{array}{l}2.00 \\
1.20 \\
1.20 \\
1.20\end{array}$} \\
\hline $\begin{array}{r}7990 \\
10057 \mathrm{~A}\end{array}$ & $\begin{array}{l}\text { Atlas of Sea and Swell Charts, Indian Ocean (formerly H. O. Misc. 10?12G). } \\
\text { Atlas of Current Charts, Japanese Theatre of War. 1941. }\end{array}$ & \\
\hline $10712 \AA$ & $\begin{array}{l}\text { Atlas of Current Charts, Japanese Theatre of War. } \\
\text { Atlas of Sea and Swell Charts, Nortl Atlantic Occan. } 1943.1\end{array}$ & \\
\hline & TABLES & \\
\hline SP-11 & $\begin{array}{l}\text { Tables of Rapid Computation of Density and Electrical Conluetivity of Sea Water } \\
\text { (formerly H. O. Pub. No. 619) 1956. }\end{array}$ & \multirow{2}{*}{.30} \\
\hline $\begin{array}{l}615 \\
619\end{array}$ & $\begin{array}{l}\text { Tilbles for Sea Water Density. } 1952 . \ldots \\
\text { 'Tahles for Rapid Computation of Density and Electrical Conductivity of Sea Water. }\end{array}$ & \\
\hline & $\begin{array}{l}\text { 'Tahles for Rapid Computation of Density and Electrieal Conductivity of fea water. } \\
1956 . . . .\end{array}$ & \multirow[t]{2}{*}{.30} \\
\hline & MISCELLANFOUS & \\
\hline $\begin{array}{l}219 \\
239\end{array}$ & $\begin{array}{l}\text { Climatology, Aslatic Station, } 1911 \text {......... } \\
\text { References nut the Physical Oceanoeraphy of the Western Pacific Oceatl. } 1\end{array}$ & $\begin{array}{l}1.00 \\
2.40\end{array}$ \\
\hline 240 & $\begin{array}{l}\text { References nu the Physical Oceanoeraphy of the Western Pacific Oceat. 1 } \\
\text { 13il)lingraphy on lee of the Northern I Iemlsphere. } 1945 .\end{array}$ & \multirow{2}{*}{$\begin{array}{r}2.40 \\
.80\end{array}$} \\
\hline 609 & A Funetional Glossary of Ice Terminology. 1952 & \\
\hline
\end{tabular}


Mr. Miller. I have no further questions.

Are there any other questions?

Thank you very much, Doctor, and thank you very much, Captain. We shall avail ourselves of the opportunity of the nice invitation that you extended to visit you when it is mutually convenient.

The rest of our meeting will be in executive session. ness.)

(Whereupon, at $11: 15 \mathrm{a} . \mathrm{m}$., the committee proceeded to other busi- 



\title{
OCEANOGRAPHY IN THE UNITED STATES
}

\author{
FRIDAY, APRII 24, 1959 \\ Hodse of Representatives, \\ Spectal Subcomitteee ox Oceanograpity, \\ of the Committee on Merchant Marine and Fisheries, \\ Carderock, $M d$.
}

The subcommittee met at $10: 25$ a.m., pursuant to recess, in the auditorium, Darid Taylor Model Basin, Carderock, Md., Hon. George P. Miller (chairman of the subcommittee) presiding.

Present: Representatives Miller, Oliver, and Tollefson.

Present also: Representatives Casey and Van Pelt.

Staff member present: John M. Drewry, chief counsel.

Mr. Miller. The committee will be in order.

I want to say on behalf of the committee and the members of the full committee who took advantage of your invitation to come out here that we are very happy to come out to this great naval installation to hold this phase of our hearings on oceanography.

I am doubly happy to be here to see my good friend, Admiral Mumma, in the audience, whom I have just reprimanded for leaving the Navy. It is going to be the Nary's loss.

I want to recognize the fact that some of the members of the interagency informal committee on oceanography are here and to tell you that we are happy to know that this committee has been created. At a later date we expect to call on you. The fact that we have not become too well acquainted with you yet is merely because of the press of time in the work of both this committee and other committees on which the members of this committee have to serve.

We appreciate the value of the contribution that you will make on this all-important subject.

There is no question but that one of the great problems confronting us today nationally, economically, is a better, more comprehensive knowledge of the sea and that which is beneath the surface of the sea.

The Navy, Coast Guard, the Fish and Wildlife Service have all done a great deal of work and are to be congratulated upon the work that they have done in this field. We have to coordinate it. We have to go further.

At this time I am sure that I reflect the thinking of the committee when I say that we do not know whether it is going to be necessary to have additional legislation or not. Maybe we have all the legislation that is necessary presently on the statute books. What we are going to need is money to implement the very fine programs that have been laid out and that can be done within the framework of present law. 
I do not know whether my good friend and ex officio member of the committee, Mr. Tollefson, has anything to add to what I have said. We would be very happy to hear from him.

Mr. Tollefsox. Mr. Chairman, thank you very much.

I had nothing particularly in mind to say except that after six terms in Congress, one of the things I have learned is how little I know.

I am glad to know that there are those agencies of Government that do know things and are seeking to find them out.

I might say that this is my first trip out to the David Taylor Model Basin area. I had no idea there was such an establishment here as I have seen thus far. 'That is not surprising.

Yesterday, Mr. Chairman, I had a meeting with Senator Magnuson and members of his committee in room P-54, in the Capitol, and I had to have a guide lead me there because I did not know where it was.

I am looking forward to the testimony today and look forward to seeing as much of your establishment as you have planned for us to see.

Mr. Mrluer. Thank you.

Admiral Mumma, I understand that you are to be our first witness today. Would you care to take over?

\section{STATEMENT OF REAR ADM. ALBERT G. MUMMA, USN, CHIEF, BUREAU OF SHIPS, DEPARTMENT OF THE NAVY}

Admiral Mumma. If I may defer a moment before testifying in the official fashion, I would like to, on behalf of the Bureau of Ships and the Navy Department, welcome the committee and its members and the guests of the committee here to this Bureau of Ships establishment. We are exceedingly proud of this establishment and we feel very honored that you have seen fit to hold your hearing here because I have had the privilege myself of appearing before the Merchant Marine and Fisheries Committee in many locations but this is the first time at this location. I feel it is the type of inquisitve searching for knowledge that has made this committee such a fine committee over the years in finding out what is good for the Government in this field, and I think the legislation that has resulted has been most enlightened, certainly, from the Navy's point of view, Mr. Chairman.

$\mathrm{I}$, therefore, thank you for the kind remarks you made about me personally but I would like to return them with interest because of my association over the last 4 years with members of the Merchant Marine and Fisheries Committee.

This will be my first and, I think, last appearance before the committee this year, and I would like very much to say how much I have appreciated and enjoyed the association.

I would also like to say just a little about the history of this establishment. I know that Captain Wright is going to give you a complete fill-in but, in view of the fact that I spent about 7 years of $m y$ technical career in this establishment and its predecessor, I feel that I would not be doing justice to some of our predecessors in this field if we did not, just say a few words about it.

One of them is, of conrse, the genius who started the whole business, David Watson 'Taylor, who was then a leutenant, had just come from postgracluate education in Europe, and in 1898 was 
successful in pressing the Congress personally to start authorization for construction of an experimental model basin down at the Washington Navy Yard.

This was a great step forward in fundamental research in this country. 'The Congress showed the wisdom of this course in authorizing this establishment at that time to do not only work for the Government, not only work for the Navy, but also work for any activity, any person, subject only to the priorities existent on the military work, upon the reimbursement to the Govermment for the cost of the work so that it has also served as a springboard from which research in science has penetrated into industry, not only shipbuilding but the industry of the whole country.

'This was the Government's first real scientific laboratory in 1898, so that, with the results that started to stem from that laboratory, it was not surprising in 1913, when Admiral Taylor became extremely interested in the then infant aviation industry which at that time consisted of nothing but a few wooden crates flying around the country, that he interested himself and built the first real research wind tumel in the country at the old model basin site. At that wind tunnel grew up a group of people then called the Advisory Committeo for Aeronautics and which then became the National Advisory Committee for Aeronautics when the Congress recognized the official stature of that group and formed this research institution.

It stemmed from the experimental model basin and Taylor was one of the first and charter members of this organization.

Then following those early years in aviation, of course, came rapidly things like the first flying of the Atlantic by the NC-4. The model was tested down in that basin. The wings of the plane were tested in that wind tumnel and you find this sort of nascent state of development of research and experimentation in this very complicated field, aerodynamics and hydrodymamics going along together.

This is true today in this establishment. You have the aerodynamics in this laboratory and the hydrodynamics in the other laboratories and the structural mechanies and the techniques have been added to form a scientific whole that is just testimony to the vision of a man like David Watson Taylor.

Of course, I know you, Mr. Chairman, are also a member of the new Space Committee.

Mr. Mrlukr. Mr. Van Pelt is also a member.

Admiral Mumas. We find that this again is an outgrowth of the work that was done by the NACA that has now become the National Aeronantics and Space Administration, so that we have in this field gone all the way from fundamental hydrodynamics into space with a very directly traceable line of research interest and expansion of knowledge with great vision. The Congress has played a very important part in this, and I think it is well that some of us who have to do with the research side of the business occasionally pause and pay tribute to the Congress in their wisdom in setting up these advanced thinking activities so that we can move ahead in these great fields.

Mr. Chairman, with those preliminary remarks which I wanted to get into the record before leaving, I would like to proceed to the subject at hand with your permission, sir. 
Mr. Miluer. Thank you very much, Admiral. We appreciate those remarks.

Admiral Mums. I appreciate this opportunity to outline the relationship of oceanographic research to the Bureau of Ships. Admiral Hayward and Admiral Bennett have previously outlined the history and the scope of the Nary's program on oceanography.

The Bureau provides modest direct support to oceanographic research, as its primary concern is in the application of the results of such research. 'The Burean is a user-consumer of oceanographic research. For example, in designing the Oceanographic Research Ship (AGS) in the Navy's fiscal 1960 shipbuilding program, the Bureau consulted various interested research organizations and other Government agencies for advice and assistance. However, the Bureau does contribute to the oceanographer and oceanographic research in three ways:

(1) By building equipment which is useful in delineating the ocean ;

(2) By assisting in the development of instruments which give us the limiting factors controlling design of military equipment and weapons which we must build; and

(3) $\mathrm{By}$ providing direct research support in the case of certain priority items, such as in $\mathrm{AST}$ warfare where the situation demands accelerated effort as at present.

In providing equipment for delineating the ocean, we have built echo-sounding equipments which can probe to all depths of the ocean. TVe have made echo-sounding equipment standard on all Navy ships so that, through records submitted to the Hydrographic Office by these ships, the picture of the ocean bottom is continually being defined and redefined. In addition, through research supported both by the Office of Naval Research and the Bureau of Ships, special recording equipment capable of giving the ocean depth accurately to within 6 feet out of 18,000 feet has been designed and built by Bureau of Ships research contractor's, and has become commercially a vailable for precise ocean surveys.

In instrumentation, Bureau of Ships supported research has provided aboard ship precise methods for determining the salinity of seawater.

I might add there that we also run the complete gamut of instruments for the determination of salinity of seawater. In the nuclear field we go all the way from fractions of a part per million of salinity in water all the way up to salinity of seawater which, as you know, increases the density of the water by about $2 \frac{1}{2}$ percent.

This prevents the necessity of research ships carrying tons of water samples back to the laboratory for tedious analysis. This instrumentation permits the oceanographer on the ship to determine this variable oceanic factor while at sea, and thus to arrange his cruise plan accordingly.

An example of Bureau-supported oceanographic research, which was of vital importance to our war eflort in Trorld War II, was a study of the fonling of ships' bottons by barnacles and other sea life. Results of this research are estimated to have reduced the Nary's total fuel costs in the war by about 10 percent by reducing the drag and the anount of ships' power normally needed to compensate for fouling. 
Of primary importance today, because of the cold war threat and the Russian submarine buildup, are our antisubmarine and submarine warfare developments. 'This area of accelerated research has been given high priority. Bureau-managed laboratories, such as the U.S. Navy Electronics Laboratory, San Diego, Calif.; the U.S. Navy Underwater Sound Laboratory, New London, Conn.; and the U.S. Navy Mine Defense Laboratory, Panama City, Fla., are actively engaged in this ASW and mine research which is extremely difficult to separate from oceanographic research.

Oceanographic research has been of great importance in the development of the high-speed characteristics of our nuclear-powered submarines. In this respect I would like to draw a comparison between the development of stratospheric research and the development of oceanographic research. In the early 1930's the Piceard brothers, through use of specially designed ballons, began their probe of the upper atmosphere. It is truly remarkable that one of these brothers has also developed the bathyscaph, now owned by the U.S. Navy, which is leading the research in the ocean depths. Thus, the same men have provided the means for probing both the stratosphere and the ocean depths. Much of the research that has gone into airplane design is equally applicable to submarine design. The submarine Albacore and the muclear-powered submarine Skipjack, for instance, both incorporate the airplane-type stick control.

I just returned from a nearly 24-hour period in Skipjack in operations at depth and at full power. I would like to announce to the Atomic Energy Committee that we beat their record made during their trip. We went faster again than man has ever gone submerged and we were extremely snceessful in observing the effect of the research that has been done not only in hydrodynamics but also in aerodynamics because those models were tested in both air and in water in order to insure that the proper relationship of the two media could be analyzed in getting the optimum form.

The Skipjack herself is a practical application of research at a very early date of the fundamental things learned from the research ship Albacore and, as a result, I think we will find that the pride of our Navy in having pioneered in this field only tends to emphasize the magnitude of the problem we have in comntering such a threat providing the Russians ever get to that state of the art themselves so that the importance of the oceanographic research that this committee is invesigating to the antisubmarine problem is emphasized by the very strides that we make on the other hand.

In fact, it can be said that these new submarines fly through the ocean much as planes fly through the atmosphere and this is literally true.

We observed in the proper operation of the sail planes, the proper operation of the ster'n planes, the rudders, and so on, that you must operate these ships as a freely moving body in a medium and not as a surface ship that is submerged.

With the recent trips under the Arctic ice pack by the submarines Nautilus and Skate. a new and better operational platform for oceanographic research has been unveiled. Oceanographers now can obtain a great cleal of information about the ocean from inside these underwater research platforms without leaving the 70 -degree comfort 
of the submarine, and by surfacing through the sea ice, the submarine has become completely useful as an oceanographic research vessel. Ian can now fly below the weather of the worst sea of all, the Arctic. He is definitely on his way into the oceanographic stratosphere. But our ship and equipment development can advance no faster than new research information can be provided by the oceanographers. In fact, it is the experience of the Bureau that pertinent environmental information must precede equipment development by 10 to 15 years. The shorter this period, the better, of comrse. Oceanographic research is, and will continue to be, of vital importance to the Navy.

Captain Wright, commanding officer and Director of the David Taylor Model Basin, is prepared to discuss the operation of the model basin, as you will see it today, in relation to applied oceanography.

Mr. Miller. 'Thank you, Admiral, for that precise and very interesting statement, and one that will contribute a great deal to our work.

I have had the privilege of spending the night on the Nautilus. I hope that with the Shate and Skipjack that she has not become so obsolescent already because I still like to brag about the time we went down.

Admiral Mumas. We will get you on Skipjack, Mr. Chairman.

Mr. Miluer. I know that people asked me what it was like. I sid that when we started down it was like going down to make a landing in an airplane. I am glad that you confirm my thinking as to the way we went down.

Admiral Mumin. Yes, sir.

Mr. Miller. Mr. Tollefson.

Mr. Tollerson. I have no questions.

Mr. Miller. Mr. Oliver.

Mr. Oliver. Mr. Chairman.

I have just one short question that I would like to address to the admiral. That you have just stated, Admiral, it seems to me points up the need for urgency in this oceanographic research program not only of the Navy but of all other agencies of the Government that are interested, and I feel personally that perhaps we are not moving ahead with such a sense of urgency minder present conditions. 'That is merely a personal opinion. I do not ask you to confirm it.

I was tremendously interested in what you had to say and I join with the chairman in expressing my own personal regrets that we aro not going to have your services too much longer. That is all.

Admiral Muma. Thank you, Mr. Oliver.

Mr. Millar. Mr. Van Pelt.

Mr. Van Perit. I have no questions.

Mr. Mirluer. Mr. Casey.

Mr. Casey. I have no questions.

Mr. Millek. Mr. Drewry.

Mr. Iliswry. I liave no questions.

Mr. Mister. 'Thank you very much, Admiral.

Captain Wright? 


\section{STATEMENT OF CAPT. E. A. WRIGHT, USN, COMMANDING OFFICER AND DIRECTOR, DAVID TAYLOR MODEL BASIN, DEPARTMENT OF THE NAVY}

Captain Wright. Mr. Chairman, the entire staff of the Darid Taylor Model Basin joins Admiral Mumma in welcoming you here today.

The David Taylor Model Basin, as Admiral Mumma has pointed out, is under the management control of the Bureau of Ships of the Navy Department and the technical control of both the Bureau of Ships and the Bureau of Aeronantics. In addition, because of our unique facilities, the model basin has a national responsibility and so serves all departments of the Govermment, as well as the merchant marine industry and private parties.

Admiral Mumma has described to you many aspects of applied oceanography. The David Taylor Model Basin is one of the Navy laboratories making such applications. It will be our pleasure today to show you some of this research and development on a tour through the David Taylor Model Basin. As a preview of your tour, I shall outline briefly some of our work in applied oceanography.

Laboratory research requires that test conditions be reproducible over and over again so that systematic design variations in models can be compared quantitatively. This slide [shide 1-full-scale pneumatic wavemaker] shows the large pnemmatic wavemaker here at the David Taylor Model Basin. Air through the ducts alternately creates a pressure and vacuum on the water surface, generating a series of parallel-crested waves which move down the model basin.

Wavemakers of this type will be used in the large seakeeping basin now under construction here at Carderock. In this slide [slide 2$1 / 10$ scale seakeeping basin] is a $1 / 10$ scale model of the new facility. Eight pneumatic wavemakers line one sicle of the basin, and 13 pneumatic wavemakers the adjacent side. Intersecting wave trains create short-crested seas and the wafle pattern shown in the photograph.

As shown in this model [slide 3-model of seakeeping facilities], the seakeeping basin will have over it a bridge, 376 feet long weighing 230 tons, with a car running on its underside to carry instrumentation and personnel. Housed under the same roof will be a circular basin with a rotating arm for research on the steering and turning of ships.

The seakeeping basin [slide 4-construction of seakeeping basin] will be larger than a football field, including the end zones, and will be covered by a roof with a 374 -foot clear span and 700 feet long. Over 32,000 cubic yards of concrete are being poured during const ruction.

The bridge spanning the basin [slide 5-interior of seakeeping basin] can be rotated so that ship models can encounter the waves from any direction. In one side of the seakeeping basin is a deep trench for free-rumning submarine models, which can be observed and photographed throngh windows in the wall of the basin.

In collaboration with the Maritime Administration, and in reparation for experiments in the new seakeeping basin, the Davir Taylor Mortel Basin has been conducting comprehensive observations at sea on two Liberty ships [slide 6-seakeeping research on Liberty ships], one with a lengthened and finer bow. Instruments measure the am- 
plitudes and accelerations of ship motions in roll, pitch, and heave, together with the hull strains, under different sea conditions.

The wave patterns are measured by this shipborne wave recorder [slide 7-shipborne wave recorder]. It measures the instantaneous height of the water alongside the ship and corrects for ship motions by double integration of the acceleration.

To measure sea conditions clear of the influence of the ship, the model basin has developed a cheap expendable wave recorder [slide 8-splashnik wave recorder]. The vertical motions of the buoy are telemetered to the ship by a miniature frequency modulated radio transmitter in the buoy.

Another oceanographic instrument [slicle 9-oceanographic survey instrument] being developed here is designed to measure very accurately ocean currents at great depths, both in speed and direction, together with the water pressure and temperature. The ability to measure water salinity and the speed of sound at various depths down to 10,000 feet will next be incorporated.

This ship model representing the M ariner class [slide 10--segmented Mariner model for hull strains] has been cut into sections and held together by a flexure beam along the keel. When the model is tested in waves, the bending and shear forces are measured which then indicate the hull strains to be expected under various sea conditions.

Full scale measurements of hull strains are made in merchant and naval ships at sea, such as in the aircraft carried Essex here shown in the roaring 40's [slide 11-U.S.S. Essex entering the roaring 40's].

Oceanographic research, both basic and applied, creates masses of scientific data highly time consuming to analyze. Here in the Applied Mathematics Laboratory of the David Taylor Model Basin highspeed general-purpose digital computers [slide 12-high-speed computer IBM 704 ] save thousands of man-years in data reduction.

Whereas our present computers operate at speeds up to 15,000 multiplications per second, there is being developed by the Bureau of Ships for installation at the David Taylor Model Basin this computer [slide 13-ultra-high-speed computer LARC] which will make 100,000 multiplications per second. It will open up new frontiers in the analysis of ocean wave spectra, the undersea transmission of sound, and the behavior of ships and submarines at sea.

Into such computers can be fed oceanographic observations, both surface and subsurface, together with ship information, forming an integrated source, fully antomated, for sea surveillance [slide 14 -operations research]. This iș a part of operations research at the model basin.

'The behavior of the sea surface is of direct interest in connection with is water proximity vehicle [slick 15 -water proximity airborne vehicle being developed by the Aerodynamies Laboratory of the David Taylor Model Basin. Under this vehicle an annular air stream is produced which greatly augments the lifting power when near the water surfare.

The David 'Taylor Morlel Basin coordinates the acoustic measurements [slicle 16-acoustic measurements on ships at sea] on all new sulmarines, such as Skate and Skipjack. 'The submarine noises as transmitted through sea water, against a background of sounds from the ocean and marine life, are recorded through hydrophones to a listening ship, by shore stations, and by other submarines. 
The design of submarine hulls to resist sea pressure is evaluated on model scale in test tanks [slide 17-submarine test tank] such as this one. Pressure is applied increasingly to the model and strains in the structure are measured and recorded mntil finally the hull collapses.

In this photograph, a structural model of a deep diving submarine [slide 18-structural nodel of deep diving submarine] is being readied for test. Compared to the bathyscaph, the submarine is fully mobile which has important military and scientific advantages.

Oceanographic research is important to miderstanding the effects of underwater explosions. In this photograph Model Basin engineers are simulating a mine being fired arainst a nommagnetic minesweeper [slide 19-minderwater explosion against minesweeper].

Shock waves from underwater explosions [slide 20 -oceanographic paths of shock waves] such as nuclear blasts are transmitted directly, reflected from the sea surfice, reflected from the ocean bottom, and transmitted through the bottom. Searching oceanographic research is essential to a more complete understanding of these phenomena.

In addition to direct investigations here at Carderock, the David Taylor Model Basin supports fundamental programs in oceanography, such as theoretical methods of describing a seaway at New Fork University, techniques for measuring the directional spectra of the sea at Scripps Institute of Oceanography, measurement of twodimensional spectra of ocean waves at Woods Hole Oceanographic Institution.

At each of the research and development projects which you will see on your tour, a model basin scientist or engineer will describe in detail the oceanographic aspects. The tour will be ready to start upon the direction of the chairman.

Mr. Miller. Thank you very much, Captain. We have enjoyed and appreciated your discussion.

For the sake of the record, I would like to ask you: Do you feel that there is a real need for the work undertaken by this committee, a need to go into the field of oceanography for the purpose of coordinating them and familiarizing the Congress with the importance of this field?

Captain Wrigrit. Mr. Chairman, a labor"itory such as the David Taylor Model Basin literally exists on fundamental research and knowledge. It is the application of that knowledge into the design process in the Bureau of Ships and the Burean of Aeronautics and the merchant marine that makes possible our developmental work and progress here.

We feel that in oceanographic research in particular the attention of the Congress will be a great inspiration to us here in an area which is so important in all of our work and in the application of it to the future of our technical responsibilities.

Mr. Miller. Thank you.

Mr. Tollefson?

Mir. Tollefson. I have no questions.

Mr. Miller. Mr. Oliver?

Mr. Oliver. I have no questions?

Mr. Milleer. Mr. Van Pelt?

Mr. VAN Pelt. I have no questions.

Mr. Miller. Mr. Casey?

$$
38171)-59-15
$$


Mr. Cisey. I have just one question. Is your work limited to that in the nature of hull designs and the nature of things other than the ocean minerals and things of that nature?

Captain Wrignt. We deal largely with ships, aircraft, and the sea as an entity. 'Therefore it is necessary for us to have the environmental aspects such as sea configration, pressure, salinity, and all the factors including chemical, physical and biological. In that it is inevitable that we are engaged in those supporting fields, and the Chief of the IBureau of Ships now provides that approximately one third of their overall research effort is reaching down into those supporting funclamental fields. As such, sir, it is an integral part of our mission.

Admiral Muxina. Mr. Chairman, may I elaborate on that point just a little?

Mr. Milifer. Yes, sir.

Armiral Muma. I believe it would be wise to say that we do not anticipate usurping the prerogatives in other areas in this field particularly of minerals and the ocean depths, and so on.

Anything that we happen to run across in connection with our research is, of course, immediately available to any other activity of the Government or otherwise for exploitation. 'The classified aspects of our own designs, of course, are the only things that we really hang on to.

The fundamental knowledge broad base on which we build is generally available to the whole country on a free basis.

Mr. Miller. Following Mr. Casey's statement, you, too, have an interest in some of the biology of the sea as it direetly affects someling with submarines?

Admiral Mumar. We certainly do, Mr. Chairman.

Mr. Mnime. Unfortunately, you cannot divorce yourself from the whole field because, in trying to determine causes for that, it naturally means the whole gamut is open to you and you have to go into it. Is that correct?

You may call upon the Fish and Wildlife Service for technical service or advice where you have an ichthyologist or marine biologist in it, but nevertheless the door of science beneath the sea is opened by everything you are doing. Is that correct?

Adminal Mfuma. I would like to answer that by further adding to your previous question to Captain Wright, Mr. Chairman.

iI]. Mnt,kr. I was going to ask that same question of you, Admiral, becanse we want it in this record before you get out of the Navy.

Admiral Muma. I would like to say, sir, that I feel that this area involves so many agencies and it is so broad in its scope that it is just like stratospheric research. We know far less abont the bottom of the ocean than we do about any other part of the world and, this being so, and everyone in the world being interested in it to an increasingly greater degree, I think guidance by the Congress will be extremely beneficial and it has a tendency to forus the attention of, say, some folks who might not be immediately alert to these problems.

We have always found that the Congress is surprisingly alert in these areas and ready to pick up the new ideas and go ahead into new fields as evidenced by the long history of the support of the Congress in these researches going back to the earliest days and carrying right through with the growth from one to the other aspect that we are now experiencing. 
I think it is extremely timely, Mr. Chairman.

Mr. Miller. I want to say that we in Congress like to take up unto ourselves credit for everything that is done so that we can go out and tell our constituents how good we are. Nevertheless, in this particular instance, I would be remiss if I did not say that it was this fine Committee appointed by the Academy of Sciences headed by Dr. Harrison Brown that brought to the attention of Congress the necessity for work in this field.

I want to pay my compliments to Chairman Bonner of the full Committee who, when this first report was shown to him, immediately grasped its significance and, as a result, this subcommittee was created.

We hope to work with the Committee and the thing that I know strikes me and I am certain strikes the other member's of the subcommittee and the members of the committee who have shown an interest in this work is that we walked into a room of which we thought we knew the dimensions and have found ourselves almost lost in a maze of the different facets of the work, the importance of each of which cannot be underestimated.

It is just a little bit confounding but we are going to see it through and try to support good people like yourself who have done so much.

May I say, Captain, after 15 years in Congress and 8 year's' service on the Committee on Armed Services where I thought I knew at least some of the functions of that great Defense Department that I was surprised to learn that you had wind tunnels out here.

I think inasmuch as time is an element, if there are no questions, we will let Captain Wright show us through some of this wonderful institution.

(Whereupon, at 11:10 a.m., the subcommittee proceeded to a tour of the facility during which the following statements were presented:)

\section{One-Tenth Scale Model of TuB Seakeeping Basin Exhibit and} Presentation

\section{(By Wilbur Marks)}

The action of waves on ships at sea has always been of concern to the designe-, the builder, and the operator of ships. The advent of the towing tank, some 80 years ago, permitted a medium for testing ships before they were built as well as romparing the performance of existing ships. Such tests were, at first, made in still water; the derelopment of wavemakers increased immeasurably the potential of the laboratory tank. These artificial waves, however, were consistently equal in height and length - not at all like waves in nature, which are irregular in all respects as well as variable in direction of travel. In addition, tanks were long and narrow so that tests could only be made in head and following seas, lea ving much information on ship behavior in waves still unknown.

Present operational requirements of commercial and military ships require unch more exacting information on existing and new designs. The Burean of Ships recognized this deficiency in tank testing and instructed the Taylor Model Basin to build a reakeeping basin that would permit the testing of ships in environments that duplicated, as nearly as possible, that which occurs in nature. The result is the Taylor Basin Seakeeping Basin which is now under construction on these grounds and a one-tenth scale model of the same tank which will now be demonstrated to you.

The prototype basin is 240 feet wide by 360 feet long and 20 feet deep, except for a 35-foot deep channe!, running the length of the basin, designed for submarine tests exclusively. Instead of the traditional 1 wavemaker, we have $21-8$ along one side and 13 along an adjacent side. These wavemakers, as rou shall see, are the essential ingredients in bringing the sea surface into the laboratory, in a realistic way. The beaches opposite the two banks of wavemakers prevent 
the waves from reflecting back into the tank. A rotating brirge spans the basin and permits testing of ship models at all relative headings to the waves.

Whatever sncesss we ma enjoy in reproducing the state of the sea in this tank will be due to the oceanographers who labored long and painstakingly to learn how nature produces waves by wind blowing over the sea surface.

Consider a stone dropped into still water or a puff of wind on a ealm sea surface. The waves rarliate out from this source of energy. Any one of our 21 wavemakers, as you see. has the same effect. As the wind blows over a wider area and for a long time. the sea builds and produces the waves you see-some short. some long, some hi $\quad$. and some low. Long waves overtake short wares and give the surface the alpleallance of irregularity. In nature, the waves travel in a band of directions giving the illusion of short-crestedness; that is, one cannot follow along a crest very fiur before it disappears into a trough. This is accomplisherl in our tank, by providing individual antomatic instructions to each wa remaker so that it operates independently of its neighbors. Often there is swell from a distant storm mixed with locally generated waves. We simulate this by waves profluced lig the other hank of wavemakers.

It is believed that this tank has the potential to reproduce the characteristics of almost any kind of wave conditions observed at sea. As surh, it is the only one of its kind in the world and there are no precedents for making waves in it and no techniques for testing ship models. This tenth-scale model affords research and development apportunities that would have cost us as much as 2 jears of experimentation in the prototype, if all such work were to wait until it was built and available.

\section{Storas and Silps, A Mutual Problem of Naval Architecture.} AND OCEANOGRAPHY

\section{(By W. E. Cummins)}

Until recently, it was the practice to design ships, both military and commercial, to conform to certain idealized conditions. Model tests were carriet out in smooth water, and only rarely were tests performed in wares, completely regular. and very unrealistic waves. Structural design took into account the fact that ships would encounter storms, but this was done by assuming the ship to be balanced on a certain hypothetical wave, which might or might not oceur in service. We must admit that these methods were generally adequate. If ther had been unsound, we would have experienced many spectacular failures. Vevertheless, in recent years more and more stringent operational requirements are being placed on the ships of the Nary as well as on the merchant marine, and it has become necessary for proper design to relate the ship to its artual environment. For instance, such military cperations as searching for eneny sulmarines, launching aircraft, or launching missiles are affected very much by the state of the sea, and the environment becomes a determining factor in the design of the vessel.

To show you what this environment can be, I would like to project a short film strip. It will tell much more effectively than many thousants of worls. just how violent this environment can be. (There will follow a 3-minute film showing a gromu of United States crnisers riding out a storm off cape Horn.)

MIr. Marks lias told you how we are attempting to simulate this enviromment in the laboratory. I will very briefly tell you of certain resenrei going on in relation to the ships themselves, in which the enviromment is taken into acconnt.

As I mentioned carlier, structural design has loen based on a highly idealized (alenlation of the furces acting on a ship in relation to a certain wave. Before the effect of the true enviromment can be considered, a better knowledge is required of the forees acting on the ship in waves. 'The model you see here was (onstructed for use in a researeh program with this as its of jective. The ressed is of an injertant commereial trie, the Mariner, It has been ent into seven segments, and ratch sexment is monted independently on a central girder, or hacklome. 'Tlue moled lats heren instrumented so that it is possible to determine the instantaments forces aleting on eareh segment as it. moves through the wares. It

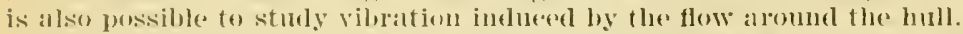

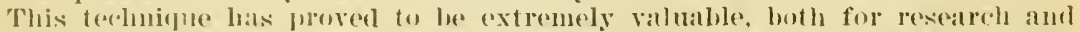

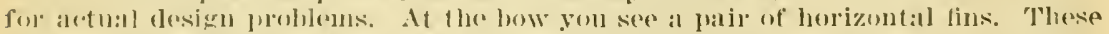
fins are iutenterl to redluce the pilehing motions of the vessel, and hoth model

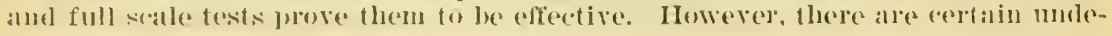


sirable effects which have been noted, specifically a serious vibration problem. This phenomenon can be studied very well by means of this model.

We also do a large amount of full scale work, in order to determine the actual responses of a vessel to the environment in which it is forced to live. For instance, we are carrying out jointly with the Maritime Acministration an extensive investigation of the motions of commercially operated vessels and the seas which they encounter. You see here models of two vessels which were used in this proglam. The first of these is a Liberty ship, of which there are hundreds in existence, many of them tied up in mothballs. This ressel has a poor reputation for its behavior in a seaway. The Maritime Administration would like to make it more attractive to the operators by improving its performance. This second model, which is almost identical, is also a Liberty Ship. Howerer the bow has been rebuilt, and lengthened about 25 feet. As you can see, the change is not great.

Two winters ago, we carried ont trials on these ressels while they were being operated by the United States Lines in the North Atlantic service. We participated in a number of round trips on both vessels, and accumulated an enormous amount of rers valuable data. The analysis of this data has not yet been completed, but we know that the slight change in ship form improved the behavior of the ressel greatly. The average speed of the modified vessel is 1 to 2 knots better than that of the ummodified vessel, under all conditions. Under adrerse storm conditions, the difference is even more spectacular. Under conditions in which the original ressel would barelc be able to maintain headway, the lengthened ressel would be able to maintain steadr progress. We are continuing our close relations with the Maritime Administration, and in the near future we intend to carry out further trials on selected commercial vessels. These studies will provide a basis for better design, thus making it possible to move cargoes faster and theaper.

Finally, I would like to mention a development project which in a sense is more or less routine, but which deals with a subject very close to our hearts, and which I think will be of very great interest to this committee. We were asked to inrestigate the behavior in waves of an oceanographic research vessel. We lirelared a terhnical report in the form of a motion picture, and I would like to show you a portion of this film. (The film includes a statement of the operational requirements for a ressel designed for oceanographic purposes, and a few runs of the model in waves.)

\section{ON tile Strength of SHIPS AT SEA}

\section{(By N. H. Jasper)}

The ship structure, machinery, and shipboard equipment must be designed to pelform their functions under all sea conditions encountered, particularly in very lough seas.

is illustrations of what can happen if the structural strength is inadequate we could recall that $(a)$ the Pittsburgh lost its bow in rough seas, (b) Liberty ships have fractured luring lougl sea conditions, (c) a number of aircraft carriers of the Esse.c class have suffered najor damage to the main luull girder, the last example being the buckling of the main deck of Ticomderoga during a passage around Cape Horn, (d) numerous instances of local how damage suffered in rougl seas occur.

The David Taylor Model Basin has carried out a continuous program to eraluate the relative significance of the various sources of stresses, and the mechanism by which they may be predicted. As the stresses induced by wave action are, very roughly, most severe in heavier seas, particular attention has been devoted to tests of ships at sea.

The ship, though built of steel, is quite flexible and for purposes of visualizing the deformation under load mav be thought of as made of rubber, fairly stiff rubber to be sure. When forces are applied to the ship it tends to viblate and these vibrations set up stresses in the ship structure. When the stresses exceed the strength of a structure it may collapse or deform excessively and thus fail to serve its purpose. Even if structural failure does not occur the environmental ship vibrations may be severe enough to cause maloperation or failure of shipboard equipment, such as fire control or navigational equipment. 
To find ont what ships are subjected to under realistic operating conditions we hare developed simple apparatus for antomatic collection of stress and motion data on ships at sea. We have found, as a result of these tests, that stresses arising from temperature changes in the structure, and stresses associated with slamming of a ship in a seaway can be as important, or more so, than stresses associated with bnoyancy and weight forces acting on the ship, which are the only forces entering into the traditional structural hull design procedure.

As an illustration of the value of full scale sea tests I will mention the ineasurements made by us on the carrier Lssex during a storm passage around Cape Hor'n in 1957. The main purpose of these tests was to explain the extensive structural damage suffered by Ticonderoga during a similar passage. The tests showed that severe vibratory whipping of the entire ship could be associated with deep immersion of the bow in an oncoming ware. The resultant vibritory stresses were several times as large as the ordinary slowly varying wave-induced stresses. We thus have here a mechanism of loading and stressing which undoubtedly eaused the damage of Ticonderoga, and which should be taken into account in ship design. It is very likely that this phenomenon (slamming) is a prime factor limiting the speed capabilities of ships in rough seas.

Ship type developments are underway for very high speed ships; here we will be faced with problems of devising structures to withstand the serere water impact loarls expected in rough seas as well as hydrostructural problems not experienced in the past.

Technological improvements, especially the advent of nuclear power, will permit high sustained ship speeds, provided that the structural strength of the ship is adequate to withstand the loads imposed by the sea. I am sorry to say that lack of adequate structural strength does limit the operational speed capabilities of a surface vessel in rough seas. Submarines do not have this limitation. Consequently, the ability of a surface vessel to maintain sustained high speed in order to keep up with the enemy submarines is of prime importance in antisubmarine warfare. Other reasons for requiring sustained sea speed can easily be developed.

To make reasonably valid predictions of strength requirements requires a fair estimate of the wave conditions expected by ships in service and the relative exposure of ships to these conditions. With the wave conditions specified it may be possibie to develop model test procedures and analytical means for estimating the structural strength requirements together with the vibratory conditions to be expected on shipboard.

The Significance of Oceanograptiy to tule Underwater Acoustics I'rogram at tile David Taylor Model Basin

\section{(By Mark Harrison, Ph. D.)}

In order to properly depict the significance and relevance of oceanograplic studies to the underwater acoustics program at the David Taylor Model Masin. it is desirable to give a brief sketch of what we do.

The underwater aconsties program at the David Taylor Model Basin is princilally concerned with noise generated by submarines and surface ships. We are interested in two aspects of this noise. One aspect is the noise which is propagated through the ocean to large distances and which can be detected by enemy ships. The other aspect of this noise is that it interferes with the operation of the ship's own sonar and thereby inhibits the ship's offensive capabilities.

In the prosecution of this program we encounter many problems that have oceanographic aspects. B, and large, hovever, we are a consumer of the information that comes from our oceanographic institutions rather than a creator of such information. For example, in measuring the noise propagated away from our ships, it is necessary to use data on the thermal structure and the bottom topography of the ocean. To a large extent such data is fairly well known though there still exists many large gaps in existing knowledge. Sperifically, we need much better data on the small inhomogenities that scatter sound. These small inhomogenities are local tenperature fluctnuations, marine life, and local currents. 
In other cases, however, the oceanographic aspects of our problem are quite novel and we are accordingly in a position to see the need for oceanographic data that is incomplete. This can be illustrated by one of our current projects.

We are engaged in choosing a site for what is called a sound range. This is to be a facility for measuring ship noise. The facility consists of a number of moored and anchored hydrophones along a course followed by the ship whose noise is being measured. The site chosen for this facility must meet certain oceanographic requirements. It must be quiet. That is to say there should be a minimum of ship traffic, the sea state should be low, there should exist a minimum of noisy marine life such as snapping shrimp and croakers, the microscopic marine life should not fluctuate, and we do not want our otherwise welcome friend the playful porpoise and his ilk.

Of course, we have other requirements besides quietness. We are interested in the currents that cause our hydrophoines to drift and thus make uncertainties in the range with resultant errors in the measurement of the ship's noise. We are interested in the thermal structure of our site and its daily and seasonal variations, the bottom topography and its constitution, and many other properties of the ocean.

Some of the properties of the ocean in which we are interested are, of course, rather peculiar to the science of underwater sound. For instance, we are very much interested in seatters of sound. These scatters may be small bubbles that exist in the surface layer or they may be small marine life. Their effect is to scatter the ships radiated sound into the sonar system and thereby increase the background noise.

We understand that some research is in progress at our oceanographic institutions on this small marine life that scatters sound. Our interest in this aspect of the ocean is somewhat specialized and no donbt there are greater needs than our own for this fundamental data. Yet, there is pointed up here again the familiar fact that fundamental data can be used for a wide diversity of purpose.

Taylor Monel Basin Disposable Waye Buoy (Splashikik)

\section{(By Wilbur Marks)}

You have heard that we sometimes are compelled to develop our own instrumentation, in order to force the sea to give up some of its secrets. This is especially true in dealing with the sea surface. Strangely enough there have been more different ware measuring instruments developed than hare been devised for measurement of ans other oceanographic parameter. The reason for such a wide variety of instruments, all designed to measure waves, relates almost entirely to the circumstances governing the experiment. In our case, we wanted an instrument that would be easy to handle, would permit the ship to go on about its business, would send information on the state of the sea back to the ship, and would be cheap enough to eliminate the effort and cost (esperially to merchant ships) of seeking it out and retrieving it, after the experiment was over.

No existing instrument met all these requirements so we designed and built the TMB Disposable Ware Buoy ourselves. As you can see, from its size and shape, it is easily launched from the deck of a ship. Its development at the time of the launching of the Russian Sputnik led to its nickname of Splashnik. the seagoing satellite. Once it is afloat it bobs up and down like a particle of water, responding to the motion of the waves. As the ship starts its experiment, the vertical motions experienced by the buoy are telemetered to the ship via a miniature FM radio transmitter in the buoy. This information is returned to the TMB analysis center where it is converted into a quantitative description of the state of the sea. No matter how violent the sea, Splashnik is quite at home in its environment. Its range is estimated at 11 nautical miles and 8 hours of life. The cost per instrument is now $\$ 125$ and expected to go still lower as components are simplified. This nominal cost permits it to be considered expendable compared with the cost of locating and retrieving it.

Our success with Splashnik has generated interest in oceanographic circles. The U.S. Navy Hydrographic Office has expressed a desire for some Splashniks to be used in a particular wave survey problem. The Dutch Government work- 
ing from a set of our wiring diagrams, developed a wave buoy almost identieal with ours, which is now in operation.

We are satisfied that our instrument is not only useful for our problems but has some apleal as a standard oceanographic instrument.

\section{OCEANOGraphic Survey Instrument}

\section{(By J. J. Nelligan)}

Considerable interest has been shown in an underseas weapon evaluation activity by the Office of Naval Research, the Bureau of Ships, and the Bureau of Ordnance. The possibility of combining a system of hydrophones and an airtracking network that could be used for weapon evaluation as well as acoustic evaluation of ships and submarines holds great potential. Since the oceanogralhic information necessary to design and install such a range is not available, it was necessary to design and construct a device for this specific purpose.

On oceanographic survey instrument is being developed to proride a means of measuring ocean currents at great depths. Ultimately, it is expected that the instrument will measure the speed (from 0.1 to 5.0 knots) and direction of eurrents, water temperature, pressure, degree of salinity, and the speed of sound at various depths down to 10,000 feet below the surface.

This first protoype is being instrumented to measure only current speed and direction, water pressure, and temperature. Now in the development and test stage are two methorls of measuring current speed; A strain-gaged eantilever flexure, sensitive to the drag force produced by flow past il flat plate, and an a.c. powered magnetic $\log$ which utilizes the electrical eondueting properties of water. The flexure system has been tested in the basin and appears to have the necessary sensitivity at very low speeds. The speerl-sensing derices are mounted in the free flooding nose section of the model. The construction of a magnetic compass to provide measurement of current direction is nearing completion.

The various measurements are transmitted to the receiving station on the surface through a single conductor cable on a cyclic basis by means of telemetering circuitry housed in the cylindrical pressure vessel. The original circuitry incorporated in the model and tested at sea last November has been simplified in design, and the revised design is now under construction. It is expected to be ready for basin tests by May 1 .

Calibration of the instrument will be completed in the DTAIB deep water basin in May prior to sea trials in the Tongue of the Ocean, Bahamas, in June.

\section{Tile Role of the Applied Mathematics Laboratory in tile Solution of Oceanograpiitc Problems}

\section{(By J. W. Wrench, Jr.)}

Two basic problems have confronted oceanographers as their research has broadened its scope through the use of far-ranging research vessels and ingenious instruments for extracting information from the sea, in fulfilling the need and desire to know more of the physics, chemistry, and biology of the oceans. The first of these problems is simply how to reduce liuge volumes of oceanographic survey data and to present the results in a form that can be made generally available to scientists who require certain information on the structure and behavior of the oceans. 'The second problem involves the performanee of thousands and even millions of arithmetical operations on a set of oceanographie data in order to extrict therefrom information about the sea. It is easy to see that oceanographic research would soon bog down if high speed computational facilities were not available for these mammotl tasks.

The Applied Mathematics Laboratory of the David Taylor Model Basin is erpuipned for the handling of just such problems. At present our basie facilities include a Univae and an IBM 704, which is seven times faster than Univae in the solution of such problems. Preparations are being made for installation of a LARC, which is faster yet. Such machines are eapable of handling the type and volume of data collected by oceanographers. 
Certain problems submitted to the Applied Mathematics Laboratory by the Bureau of Ships, the David Taylor Model Basin and some of its private contractors are purely oceanographic, and illustrate the points just mentioned. One such problem is to define the wave conditions in the vicinity of a ship that is undergoing extensive structural and seaworthiness tests in order to relate ship behavior to the state of the sea. Such ware data sent to the Applied Mathematies Laboratory are subjected to hundreds of thousands of caleulations before the resultant numbers will define that particular state of sea. Since this problem was submitted several years ago, a total of 902 cases have been handled. Several minutes are required for the computer to perform the arithmetical operations in the solution of one case. If all 902 cases were run consecutively, perhaps 5 weeks would be involved. The computation of one case, by hand, on a desk calculator, took 2 months for one man to complete. If one man worked on all 902 cases, about 150 years would elapse before the work was completed. For a crude comparison, then, 5 weeks of computer time is equiralent of 150 manyears, in the solution of typical oceanographic problems. The greater speed of LARC should appreciably decrease the requisite computer time, when that machine becomes arailable in about a year. Another problem of oceanographic origin involves the theory of sound propagation in surface sound channels. Sound wave potentials were calculated on Univac for a wide range of acoustic frequencies, denths, and horizontal distances. The purpose of this work was to verify new theory on sound-channel propagation.

Iodel basin experiments in producing irregular seas in its towing tanks center about the ability to reproduce in the laboratory phenomena occurring at sea. It is necessary, then, to compare model tank waves with real wares. Wave measurements made in the basin are analyzed by the IBM 704 , and the results are used to verify or to modify techniques for artificial wave generation.

The behavior of sound at all depths in the ocean depends on the physical structure of the water; in particular, its changing temperature characteristics. Sound transmission through a warm water mass and a cold water mass successively may be further complicated by internal waves at the boundary. In order to investigate the behavior of sound under such conditions, a set of three simultaneous differential equations, of a highly complex nature, have been developed. In order to solve them, the computer numerically traces an acoustic ray through such an ocean system. This is accomplished for rays of many different frequencies until a complete description of sound transmission under such conditions is evolved.

The problems discussed here relate to the oceanographic aspects of Navy work. It is not necessary to stop there. The continually increasing capabilities of modern electronic digital computers are of such iiiagnitude as to peruit the prediction that collection of oceanographic data, no matter how great, will not exceed the ability of such calculating machines to process it.

\section{The Interrelation of Oceanography and Submarine Operation}

\section{(By E. E. Johnson)}

As demonstrated by the sustained submergence of Seawolf, the modern submarine is no longer tied to the surface or near surface for operations as were the air-breathing submersibles of the prenuclear era. Indeed, the flexibility and mobility of nuclear-powered submarines is virtually unbounded-except for the lack of oceanographic information to guide their operations-and the ability to provide structural integrity at greater depths.

Because the lead time between research and reality of a machine as complirated as a submarine is long, the Structural Mechanics Laboratory of the model lissin is now engilged in research to provide the basis for the structural design of submarines capable of descending to depths several times deeper than current submarines can. These ships will be capable of collecting oceanographic data during their normal operations just as every existing naval ship now does. Naval ships today collect and forward to the Hydrographic Office information as to depth, temperature, currents, salinity, and general weather for each ocean passage. Nautilus and Skate have expanded this function during their transpolar expeditions. The circle is endless: As more is learned, new developments are required. 
The structural research is being conducted on a series of small machined models one of which is here in the laboratory being instrumented with wireresistance strain gages. After instrumentation, it will be inserted in a tank and the oceanographic environment which is significant for the structure, pressure, will be exerted on it to the point of collapse. During the application of the pressure, readings will be taken from each of tliese gages to determine structural behavior and correlation with theoretical predictions. The mode of failure will also be observed so that the structural behavior may be compared with the appropriate theories for collapse which are concurrently being developed at the morlel basin.

structural adequacy is of primary concern to the Burean of Ships which has the responsibility for design of such vehicles and to the David Taylor Model Basin which lias the responsibility for conducting research on which such designs can be based and of later validating the adequacy of the structural design by mockel testing. Oceanographic information is an integral lart of the chain that links research to operations.

No olverator will invest time, money, resonrces, and manpower into a venture unless the advantages are clear. So it is with submarines. The flexibility and mobility offered by greater operating deptlis can become advantages when the characteristics of these depths (oceanography) are known and the wherewithal for attaining them (structural research and design) are also known.

But here the two fields coalesce. There can be no real oceanographic research at great depths without a vehicle capable of leaching and staying at them safeiy. Fortunately, with the availability of the bathyscaphe, much information ('an be obtained to delineate clearly the characteristics of great depths, so that modes of operations can be developed to exploit these advantages. Then-and only then-will deep-diving submarines be necessities, not interesting toys. Aud when that time comes, the deep-diving submarines will be wanted overnight. 


\title{
OCEANOGRAPHY IN THE UNITED STATES
}

\author{
MONDAY, JUNE 1, 1959
}

House of Representatives.

\author{
Special Subcommittee on Oceanograpiy
}

of the Committee on Merchant Marine and Fisheries,

Boston, Mass.

The subcommittee met, at $11: 25$ a.m., pursuant to notice, in room 406, State House, Boston, Mass., Hon. George P. Miller (chairman of the subcommittee) presiding.

Present: Representatives Miller (chairman), Oliver, and Flynn.

Also present: John M. Drewry, Esq., chief counsel, Congressman Hastings Keith, Ninth Congressional District, Massachusetts, and William J. Donahue, national representative, American Federation of Government Employees (AFL-CIO).

Chairman Mrluer. The meeting will please come to order.

This is a subcommittee of the House of Representatives Committee on Merchant Marine and Fisheries, which has been especially charged with the study of oceanography. A part of that study embraces the work pertaining to biology at sea and the work of the fishing industry.

We have had rather extensive hearings on many phases of this work in Washington. The committee was appointed as the result of a comprehensive study made by a committee of the National Academy of Sciences, headed by Dr. Harrison Brown, of the Califormia Institute of Technology, an outstanding authority in his field. Incidental to this work is the jurisdiction which we exercise over the Fish and Wildlife Service authorities to reactivate the research vessel A7batross III.

The report of the committee was transmitted to the Congress. The Speaker of the House of Representatives referred it to the Merchant Marine and Fisheries Committee, where it was in turn given to this special subcommittee.

Mr. John McCormack, majority leader of the House of Representatives is extremely interested in the subject as is Mr. Keith, sitting on my far left; who represents the Ninth Congressional District of Massachusetts and is very much concerned, not only with this particular phase of it, but as an old naval man is very much interested in the subject of oceanography.

On my right is Mr. Oliver, from your great sister State of Maine. This is Mr. James C. Oliver.

Further over on my right is Mr. Flynn, Gerald T. Flynn, who comes from the middle section of the country, the north central section of the country, the great State of Michigan.

Congressman Flynn. I am sorry, Mr. Chairman, that is the State of Wisconsin. 
Chairman Mrluer. Oh, I am sorry, he comes from the great State of Wisconsin.

On my immediate left is Mr. Drewry, who is the counsel for the Committee on Merchant Marine and Fisheries, and he works with our subcommittee.

I am George Miller, Congressman from California.

Unfortunately we were somewhat delayed in getting here so our time has to be somewhat curtailed. So I am going to ask you gentlemen who appear before the committee to be as brief as possible; ire want to hear all of you. Cumulative evidence is not something we need. We have heard the stories of the Albatross. We want your opinions. We have heard the charges and countercharges that go into it. We did come here, however, to hear you gentlemen and give you a chance to register your opinions. Mr. William Donahue, national representative of the American Federation of Government Employees, is here, and I am going to ask him to assist us. I understand Miss Leonard is going to make the opening statement.

Mr. Donamoe. That is right, Mr. Chairman, our first mitness will be Miss Leonard.

\section{TESTIMONY OF MISS ELIZABETH B. LEONARD, SECRETARY-TREAS- URER, LOCAL NO. 1729, AMERICAN FEDERATION OF GOVERN- MENT EMPLOYEES, AFFILIATED WITH THE A.F.L.-C.I.O.}

Mrs. Leonard. My name is Elizabeth B. Leonard. I am secretarytreasurer of Local No. 1729, American Federation of Government Employees, affiliated with the AFL-CIO. My oflicial position is librarian at the Woods Hole Laboratory.

At this time, the lodge would say "thank you" to this subcommittee for granting us this opportunity to be heard.

Mr. Ross Lefller, Assistant Secretary of the Interior, Fish and Wildlife Service, in a letter dated February 18 and addressed to the Secretary of this lodge, stated, and I quote:

In the future we plan to make greater use of the Delancare and of charter vessels to provide for research purposes. While there will be some loss of sea time, essential parts of the biological program will be accomplished.

The Albatross III is an old ship. Maintenance and operating costs are very high and have reached the point where her continued operation gires too little return per research dollar expended. Thus we believe it best to deactivate and sell her. Our action is based upon the needs for both economy and efficiencr.

In a letter to Senator Magnuson, chairman of the appropriate committee in the Senate, and dated March 5, Mr. Leffler stated, and I quote:

Starting this rear it became evident that the Bureau of Commercial Fislieries could not longer finance two offshore research ships in the New Fngland area. After careful consideration i decision was reached to deactivate the Albatross III. She is an old ship, built in 1926, and is costls to operate. In fart, higher than normal maintrinace costs for the Albatross III were one of the major contributing factors to the eontinual budget slortage.

The operating budget of the Albatross III for fiscal 1960, is $\$ 152,000$ for 180 days at seal, giving a per diem cost of $\$ 1,000$.

In fiscal 1960, the Woods Iole Laboratory will apparently have to contribute considerably toward the operating budget of the Delaware. The Delawore is not equipped to do research that the Albatross is equipped to dlo. 
In response to these statements, we would like to pose the following salient points on the Llbatross III deactivation.

(1) On whose authority was the Albatross adjudged unseaworthy?

(2) Is fishery research essential?

(3) Why do away with a research tool?

(4) We feel deactivation of the Albatross was unjustified for reasons of economy.

(5) Why is a price put on research?

(6) How much money is being saved by the deactivation of the Albatross?

(7) If economy should prevail, why keep the Delaware and deactivate the only fully rigged oceangoing fishery research vessel on the east coast?

We stand ready to answer your questions, and await your pleasure.

Chairman MrrLer. I want to congratulate you on a very fine statement. Of course we are here to try to solve the very questions you ask in your statement. We are not in a position at this time to answer them. Mr. Oliver I think has a question.

Mr. Ounver. In the interests of brevity, Mr. Chairman, I would like to withhold questions. But I would like to supplement what you have said regarding these questions, that they were raised by Congressman McCormack. I would also like to say he has had a very intense interest in the Albatross and I think his feeling is more like mine, that the reactivation of the Albatross is more an administrative decision. I am sure he feels as I do, and I want you to know it.

Mr. Drewry. Just one question. How many people were put out of a job when the Albatross was deactivated?

Miss Leonard. Seventeen.

Mr. Drewry. Seventeen crew members?

Miss Leonard. Yes, sir.

Mr. Drewry. They were all crew member's, rather than scientists?

Miss Leonard. That is right, they were just the crew members of the Albatross.

Mr. Drewry. What is their present state of employment?

Miss Leonard. I understand some of them have jobs on fishing vessels ont of Boston, but I have no really definite information.

Chairman Miller. Thank you very much.

Mr. Dovanue. Mr. Chairman, we would like to present Dr. Lichtman, a representative of the Governor's office, who lias a statement to make on behalf of the Governor.

\section{TESTIMONY OF DR. MARTIN LICHTMAN, RESEARCH DIRECTOR, FROM THE OFFICE OF GOVERNOR FURCOLO}

Dr. Lichtran. Mr. Chairman and Congressmen, I am Dr. Martin Lichtman, research director from the office of the Governor. I have a statement which I had prepared and would like to present on behalf of Governor Furcolo on the matter of the deactivation of the Albatross.

The Commonwealth of Massachusetts is deeply disturbed by the present deactivation of the Albatross III. The importance of giving 
every aid to the commercial fishermen of New England, at least, cannot be overemphasized. We are faced with serious competition by foreign vessels, whose efficiency and new construction give our vessels serious competition. We can only by vigorous research and development work hope to overcome some of these disadvantages.

The decision to deactivate the only ressel equipped for such research will seriously imperle our program. The draft study would indicate the loss of this vessel will indeed curtail this activity. The statement that the Delaware, plus hired commercial vessels, will make up for the loss of the Albatross is hedged by many qualifications.

The testimony offered your honorable subcommittee is that the $A l$ batross is too costly to operate. Even if one grants that an efficient research operation might be carried on by a new vessel, it would appear until such a vessel is available the services of the Albutross are vitally neederl. Here is a craft which, on the basis of all the evidence presented to your honorable subcommittee, is better equipped than any of the other vessels available. It had a trained and efficient crew. The loss of that crew cannot easily be replaced.

According to the evidence of the commercial fisheries, the statement that the operating costs of the Albatross are unduly high is uncertain. How can you determine that research is carried on at a deficit? Funds to operate the Albatross are available, and we urge the committee, therefore, to give consideration to the continued use of this ressel.

I would like to add before I stop that I endorse completely the statement that Congressman McCormack is vitally concemed with this project. He has been in frequent touch with the Governor's office and ures the continued operation of this vessel. Senators Kenmedy and Saltonstall are also continually interested in this problem.

Chairman Mrluer. I think there is no doubt that Congressman McCormack is deeply concerned and the Senators from Massachusetts as well. They have been in touch with us on this matter. Thank you very much.

Mr. Drwwry. I have no questions.

Thank you very much, Dr. Lichtman.

Mr. Donamue. 'The next witness we would like to present is Capt. Emerson Hiller, who was master of the Albatross at the time of her deactivation.

Chaiman Mrduk. Thank you very much, Mr. Domahue. Will you give your name, Captain Hiller?

\section{TESTIMONY OF CAPT. EMERSON H. HILLER, OF FAIRHAVEN, MASS.}

Captain IInder. My name is Emerson H. Hiller. I live at Fairhaven, Mass., which is the center of the fishing fleet which works ont, of New Bedford and Fairluaven.

I havent come with any prepared statement, but I have more questions to which I would like some answers.

'The information which we grleaned was put into a memo which was sent down to Washington, and I am quite certain you gentlemen have received a copy of this report. 'This is a letter dated March ?, 1959; subject, "The Report on Denctivation of Albatross III," submitted by U.S. Fish and Wildlife Service, dated February 25, 1959. It was 
concerned with Mr. McKerman's report to Senator Saltonstall's statement allegedly giving the reasons for the deactivation of the ship.

Chairman Mrluer. I don't know that we have a copy of that. Would you make sure we have a copy of it?

Captain Hituer. I have a copy here.

Chairman Miluer. Who was it addressed to?

Captain Huscer. It went to Mr. John McCart, legislative director, American Federation of Gorernment Employees, and I think a copy was sent to your.

Chairman Muster. Will you see that we gret a copy of it, or will you summarize it for us?

Captain Hulcer. There is too much in it to summarize. It was in answer to the report made to explain the reasons for the deactivation of the ship. To a layman that was a full and complete answer, but to those of us who worked on the ship and men in the fishing industry, there were statements which were not true inserted. They were on the cost of operating the Albatross, the increased cost of operating the ship and questions of the seaworthiness of the vessel.

I have written letters, and many other people from allied industries have written letters to Senators and Representatives. All the replies are in the same category, they can't understand it, and there are no reasons given to show why the ship was laid up. They were told it was due to lack of funds. I know from my own experience the Woods Hole operation has always been short of funds. The have had adrice from Washington that there is money available. That may or may not be true.

I have heard also because of conditions on the ship, the ship became unionized, and that was one of the reasons why the ship was laid up. I know from working with the management in Woods Hole they have been disturbed by reason of the fact the union got on the ship. I was briefed before I went on the ship that the mion had moved in, causing management some concern ; they were asking for exorbitant wages, and there were a lot of hard feelings. I felt during the year I was on the ship it was my job to act as an impartial liaison between the employer and employee becanse there were feelings between the crew and the management.

When we took scientists ont on the ship there was also bad feeling between the scientists and management. This surprised me very much because the people I did business with at Woods Hole were very nice, but I understood from the crew, who had been on the ship longer than I, and the scientists, there was considerable discontent. I did feel during the time I was on the ship that they went along as well as could be expected. The men on the ship were excellent fishermen, and as such excellent fishermen you don't find other qualifications. They had always done their work this way, and they didn't want to do it the other way. This was a research boat, and there is quite a bit of difference between the way you do things on a research vessel and a fishing boat.

I realized they were excellent fishermen who knew more abont the job than I did, and I felt toward the end of the vear that they were coming around to the view of operating the ship different from a fishing vessel. I was encouraged.

Another thing I didn't understand was the abruptness with which the ship was laid up. The men were given a pay raise in one breath 
and in the next breath they were told the ship was to be laid up. 'The very next day we were given a communication from the National Academy of Sciences, telling us how backward the United States was in ocean research, how far behind other countries we were in the United States, but we were not told why the ship was laid up.

Chairman Mrbler. I don't know, captain, if we can give you that answer until we have all the data before us.

Captain Hinler. I wrote to Rear Admiral Momsen, who is retired from the Navy. He is very much interested in oceanography and ocean research. His answer was that laying up the ship was wrong, and he could not see any justification for it. Thas has been the voice of everyone I have talked to. I don't see any reason for it and have never heard any answer to it.

I am wondering if this committee is the ultimate one to make any decision on it.

Chairman Mituer. We have jurisdiction on legislative matters so far as they pertain to the work of the Fish and Wildlife Service. There are other committees which handle the finances for this agency. I do not know if this committee is in a position to say to the Fish and Wildlife Service that we are a court of appeals and we can override one of their administrative decisions. Of course, I don't need to tell you that decision is an administrative matter.

Captain Hiller. Yes.

Chairman Miller. If they have the money which has been directly appropriated for the Service it should be used for the Service. Of course, we are trying to deteminine on our own, just what the facts are, and out of these facts make some representation to them, to the Fish and Wildlife Service. I don't think I can say if the Fish and Wildlife Service can justify its decision, but I don't think they will disregard any recommendations we might make after weighing all the facts.

Captain Hiller. There has been some talk about a new ship, but I can't see that a new ship will solve any of the problems or the reasons given for taking this one out of service. I don't think the reasons given, that she is unseaworthy, the unseaworthiness of the ship, or the erew, I don't think they will solve the problems. I think they will be increased, because in breaking in a new ship there are several years before you get the ship the way you want it. There will be several years lost before you get a new ship where you have the Albatross.

'The reasons given for the wage increase, as I unclerstand it, and it was a surprise to the members of the erew, a surprise to them as it was to me. I understood the Wages Reviewing Board would make the annual survey and possibly this year there would be a little decrease, but all of a sudden there was a substantial increase.

We can, of comrse, all use the money, we need it, but it hasn't helped anybody yet.

Chairman Miderir. Four statement that labor trouble contributed to the laying up of the ship is new to ns. That is ent irely new to us.

Captain Hnusr. I have also some of the comespondence on it. I think some of the difliculties attributable to the fact that the union moved in is correct. I have seen letters, I camnot quote them, but I have seen letter's from some higher-mps in the Burean of Commercial 
Fisheries that the union was in now and there would be trouble with them. There is always apt to be a few radical men on the ship to keep things stirred up, but this was an opportunity to the Service to set up standards that would be fair and just. But that isn't what happened. From my own experience it did work out nicely. But one of the reasons I liked it, I can see a smooth operation could be conducted if there was a man in charge of the ship who had a background in ships and fishing, and could correlate the operation of the two vessels.

Chairman MuLer. The Fish and Wildlife Service is operating other vessels, of course.

Captain Hiller. Yes.

Chairman Mirler. I wonder if you can identify this as a copy of the letter you wrote for us [indicating document]?

Captain Hiller. Yes.

Chairman MiLLer. I think you can say that is your signature?

Captain Hiller. Yes.

Chairman Miller. Give it to the reporter and he will make it part of the record.

Captain Hiller. There seems to be one supplement missing. I don't have one here. Oh, yes, it is in here. It is a comparison, a comparison of the costs of operating the two vessels.

Chairman Mrlcer. Will you attach that to the evidence for us?

Captain HiLLer. There is also another letter here.

Chairman Miluer. Give it all to the reporter and he will make it part of the record.

Mr. Oliver would like to ask a question of you.

Congressman Oliver. You are not employed now by the Government in any capacity?

Captain Hiller. No, I am not.

Congressman Oriver. How long had you been with the Fish and Wildlife Service when the vessel was deactivated?

Captain Hiluer. About 2 weeks short of a year.

Congressman OrIVEr. Has there been any effort or offer made by Mr. McKernan or anybody representing Mr. McKernan, to help you get a replacement?

Captain Hiller. Yes, I had a note from Mr. McKiernan thanking me for my efforts and also explaining they would do everything they could to help me find a job.

Congressman OLIVER. Did you take advantage of that?

Captain Hiluer. No, I haven't asked them for it yet. I also had a note from Dr. Graham which came on my separation papers.

Congressman Oliver. I particularly asked that question when Mr. McKernan was before the committee and I specifically asked him if his department was going to bo of any help to you people who lost out by way of the deactivation.

Captain Hiller. Yes, I think they have been very good. But in fact, I don't know if I want another job with the Service mnder the circumstances. I thought this was a job in the Government service, I wasn't away from home for long periods on it, and my family was very happy with it. I have a son who is now in high school and is very much interested in marine biology. I thought it was just the sort of job I had been looking for all my life. 
Congressman Oriver. Do you know whether or not there has been any offer of assistance from the Department to other people thrown out of employment by reason of this deactivation?

Captain Hilcer. Yes, I believe there were arrangements made, I know my crew members were contacted and given the first refusal on the jobs on the Delaware when it makes a trip requiring two or three more men. I know they have gone out on her.

Congressman Ouiver. So there have been attempts by the Department to help these men?

Captain Huncer. Yes, there has. I learned this morning the men who were on the crew list were getting social security, against leave, and they will no longer get that. The job is strictly from dock to dock and they no longer get civil service benefits at all.

Congressman Obiver. Has the crew been dispersed so it is no longer available?

Captain Hiruer. I know they are all out trying to get jobs. I have been down in New York for the past several weeks. I have a good contact with Tidewater Oil and others, but I haven't been able to get a job. This is the first vacation I have had in a long time, and I have been painting my house, but pretty soon I will have to knuckle back lown. It has been my personal hope they would get this Albatross going again.

I don't want to take too much time, but this report answers many questions raised by Mr. McKernan and it shows how the Albatross can be operated much more economically than the Delaware. If one of the ships had to be laid up I don't see why it would be the Albatross.

There is one other question I would like to ask. I happened to see "Meet the Press," maybe you gentlemen did last night, but John L. Iewis was the witness, and he mentioned the Department out in Califormia had 200 men laid off.

Chairman Mrumer. The Department of the Interior is a very large office, it has some 1,200 people in it.

Captain Hiluer. I am sure it is, and I am sure this little Fish and Wildlife incident at Woods Iole is a very small part of it. But to me, living in Massachusetts all my life, and having known about it, we are told the economy is being rebuilt, but it seems to me we are going downhill. They have lost their vessel and it seems to me perhajs they won't have the laboratory there any more.

Congressman FuYN. You are raising for the first time possible economical measures. However, that is more in the nature of hearsay, because it has not been documented and this committee has not been able to make any finding of fact on the evidence before us. I think we would appreciate if you have such evidence it should be offered. Because we can't make any finding of fact on it.

Captain InsLre. I can't say that is the reason, but I know when I first joined the ship they had had considerable difficulties between the crew and the shore installation. I think partly because of the fact that nembers of the crew were earning more money than the scientists who came out on the ship. On the surface it seemed wrongr that a common lowly fisherman should receive more money than a professor of biology, but below the surface the fishermen worked 12 hours a day, around the clock. 'They put in more hours, and I think 
it was fairly well agreed by both parties that their wages should be based on a like industry, which was the fishing fleet, and that is the way it has been done.

I think if you gentlemen will get right at the merit of the statements given to the men on the ship as the reasons they were laid off, the fact that the ship came under the Coast Guard requirements, it seems to me there is a thread lunning all through the story that can be traced to the fact that the union came in. I don't know if that is a fact, but I think if I was a Senator and got a letter about it I would say lay up the Albatross, I have heard too much about this already.

I think there was a letter written to the Senators, and so forth, also to the Coast Guard in Boston, stating because of poor seamanship and poor handling the lives of the crew aboard were put in jeopardy due to the fact that we got a net caught in one of our screws while out at sea. It was during my experience with it and certainly I know I called the Coast Guard myself and had them on the way while we were dead in the water before we cleared it ourselves. But someone wrote a letter and signed it, "The crew of the Albatross," and a gentleman was sent up from Washington and spent 2 days in Woods Hole talking to every member of the crew. I was the last one he talked to and when I told him my story he said he had heard the same thing from every member of the crew, that catching a net was one of the hazards of the game. He said he was convinced no one on the ship wrote the letter and someone else wrote it. But there was a crowd all over the ship and someone said we weren't going out until an investigation was held, and it was clear that someone outside wrote that letter. If they had gotten the truth they might have kept the ship going. I don't think it was clear in Washington that letter would not have been written unless something was done about wages prior to that.

That is about all I can say, but I could keep talking for hours, maybe because I know so little about it.

Mr. Drewry. Captain Hiller, what union is it you are speaking of?

Captain Hrucer. I am speaking of the Government Employees" Union. Incidentally, I am not a member, I can tell you I have been asked to become a member. But the old skipper was a member, and when I went aboard the ship I decided I conldn't join unless all the crew members, the scientists and all, joiner the union becanse I couldn't fairly represent everybody. I felt I could act as a more effective and impartial liaison between the management and the crew, and as such I did not join the mion. I felt that I would be able to fulfill my obligations to both parties better if I was not too closely allierl to either one. I believe I was to some extent successful in my attempt to bring about a close cooperation between the ship and the laboratory. I felt I had gained the confidence of both my superiors and my crew, and of course this a first requisite for the smooth running of a ship.

I had a chap on several times, you hear about Jimmy Hoffa, and he thought when the union took over the ship it was having a terrible operation, but this isn't so. I think that is one of the best operated local unions I ever heard of. They hold meetings once a month and I could say it was felt the union was well run. There are civil 
service laws and their only operation has been to see that these rules and regulations were enforced, and I don't think they have gone beyond that. I know it is a finely operated thing. Some of the scientists belong to it. I felt it was well organized, and the unions are here to stay and you have to get along with it.

Mr. Drewry. Do you have an ocean-going master's license?

Captain Hilder. Yes, I do, I have been going out as master.

Mr. Drewry. How long have you been going to sea?

Captain Hiller. I graduated from the Massachusetts Institnte in 1940. I have been going to sea since then.

Mr. Drewry. Are you a member of the Masters, Mates, \& Pilots Union?

Captain Hrbler. No, I was during the war, but since the war I have not been reinstated.

Mr. Drewry. How were the pay scales worked out for the crew?

Captain Hiller. I can't tell you, I don't know exactly what they were before. In my own case, the master's pay, I believe is considerably less than the skipper gets on a commercial fishing boat. I haven't complained about that, but I know it is considerably less than I would get in the merchant marine. But in a merchant ship you are out to make money and the pressure is considerably more than it is on a fish and wildlife vessel.

Mr. Drewry. When was that raised?

Captain IILLer. I can't give the date exactly, but I think about the last week in January. We were out at sea and got back and were told the vessel was to be laid up March 9. Then the next day there was a pay raise. We were told the wage board had made a study of boats doing comparable work and they came up with a new wage scale. My own went up from $\$ 7,500$ to $\$ 9,000$.

Chairman Miluer. Was this increase the result of any pressure on the part of the union?

Captain Hiller. To my knowledge, no, because the union members on the ship had told me I had better be prepared for a little cut, because some of the Hiliners in Boston had not done so well. I don't think even with the new wages the fishermen were overpaid, considering the time they put in. If they are going to base it on the fishing industry, and that is what it would be, it should be based on the formula comparable to the fishing fleet.

Mr. Drewry. Is the work of the crew on a research vessel comparable to that on a commercial fishing vessel?

Captain Hilurer. It is much different than commercial fishing, you handle much more than just fish nets. TVe go for scallops, plankiton, and it calls for a wider knowledge tham just commercial fishing. But when we are in port here and we pick up a fisherman in New Bedford to make a trip with us, he is good on the fishing, but not good on handling the other material the scientists use. Our men are not moler the same strain a commercial vessel is beanse we are not out catching fish to make a living. Their pay check is there if they just sit on the dock. I don't have it here, but I have a schedule of the trips made this year, and there were very few days in port. When we were scheduled to go ont we went out. 'I believe the Woods Hole men have made two trips on the Delaware, but I know some research men have been dropped because no ship was available. 
Mr. Drewry. Is the pay scale the same on the Delaware as it was on the Albatross?

Captain Hiller. Yes, they are. Because in order to do the job, in order to bring the Delaware up to the Albatross, they hire just for the trip on the Delaware. I suppose that saves some money.

Mr. Drewry. The crew on the Albatross has been with it for some time?

Captain Hicler. Most of them had been on there several years. You probably know the ship has quite a history of laying up due to lack of money. When I went on a year ago in March, I was told we might. have to lay up due to lack of money to run the ship for the rest of the year. That wasn't done because maybe they borrowed from the next year. But my understanding is the scientists doing the research work shouldn't be worrying abont money. But our' men at Woods Hole have spent 50 percent of their time scratching their heads to find out where the money is coming from.

When we run ont of money, maybe we have broken the underwater television, we take $\$ 500$ ont of the scallop fund and put it in the underwater television. I got the feeling the scientists felt we were a great steel monster, using up their money and the Albatross had lost it. I don't think that is true. I believe a reasonable budget could be worked out for the ship, and we could live in it.

I was given a budget in March, just before we went off and I was well within the budget and in fact was going to have money left over. Asking in the oflice about that they said that was just a paper budget, actually there was no money. I was given a paper budget but was well within it.

We had a job done in the shipyard last year that might be called a major job. We put on a new deck that was $\$ 4,200$, but actually more than that is spent on a commercial ship every year. You saw the rust on her this morning, but we rere going to bring it up.

Mr. Drewry. Just one more question. You have been going to sea about 18 or 19 years. Would you say the Albatross handled satisfactorily at sea?

Captain Hiller. Oh, yes; she is a fine ship. The first trip I made on her we hit hurricane winds off Halifax, 83 miles an hour, and she handled fine. Her length was increased to 184 feet and she is still only 23 feet wide. There are many refinements you would like if you are building a new vessel, but she never gave us any trouble.

Mr. Dreivry. Were there ever any complaints from the scientists about the laboratory facilities?

Captain Hiller. Not from any that had been out on a commercial ship or the Delaware. We have facilities the others don't have. I don't remember any complaints about the facilities. They have spacial rooms for the scientists, and they have ample heads. They have a wet lab and a dry lab. They have space where the scientists can do their work. I mean there was no comparison between the two ships, the Delaware and the Albatross. The ship was ample and sufficiently seaworthy to do the job.

Mr. Donaroe. I want the captain to read this into the record in regard to the handling of the vessel. 
Captain Hiller. I will read it. This is a letter from James S. Munro of Chelsea, Mass. :

You have asked my opinion as to the seaworthiness and mechanical equipment of the Albatross III. To answer your question I can tell you we have worked on the vessel on numerous occasions. The hull and the engine room are in excellent condition. We have also drydocked the vessel in the last 6 months and have made all the changes necessary to put the vessel in good mechanical condition. It is my present impression she can operate for several years without major repairs.

That is signed "James S. Munro, Drydock and Ship Repair Business, Chelsea, Mass."

Chairman Miluer. We will receive that letter into the record.

Mr. Donahue. Mr. Chairman, next I would like to present Capt. Walter Beatty, who was the master of the Albatross in the period prior to Captain Hiller.

Chairman MrLcer. Give your name and address and identify yourself, please, Captain.

\section{TESTIMONY OF CAPT. WALTER E. BEATTY, FORMER MASTER OF THE "ALBATROSS"}

Captain Beatrx. Mr. Miller and gentlemen, this is a pleasure to be here today. My name is Walter Edward Beatty. I was master of the Albatross from January to October 1956. I have been going to sea for 26 years. I graduated from the Massachusetts Maritime Academy, the old training ship Nantucket in 1937. Subsequently I went in the merchant marine for several years and in the fisheries. Upon leaving the merchant marine I returned to the fisheries and went through the ranks as fisherman, mate, and master. The last ship I was on I served on her for 3 years. I had three of my own trawlers; I had an interest in them.

During the war I served in the Navy and retired from the Navy in 1947 from combat activity in the Pacific.

Chairman Mruler. I should say, Captain, you have qualified very well.

Captain BeATTY. The only time I have not been to sea has been for about $2 \frac{1}{2}$ years in the naval hospital from action in the Pacific.

When I went aboard the Albatross, I didn't go for the money, but I was interested in fishery research. I did a good bit of it on my own vessels. As I feel there is a great need for fishery research, I told Dr. Graham I was interested in it.

When I went aboard the Albatross at that time there was a great need for bringing the vessel into a seaworthy condition. She was not in the best shape at that time. Moneys were tight at the time. I felt there were two things involved, it was Govermment property and the safety of the personnel working on her.

We proceeded to IIoboken, N.J., in the latter part of January or the first part of February, to bring the ship in a more seaworthy condition. There we had lifeboats installed and many items which did help improve her seaworthiness. Wo did have many items done, but some were not completed. I felt very strongly for the protection of the Government and the safety of the men aboard these things should be done as soon as possible. 
We returned to Woods Hole in 1956, and we had a record of continued activity in fishery research, and I felt many things were accomplished.

Due to the men's wages and conditions of employment, which I felt were the worst I had seen in many years of going to sea, I talked with the officials, but had difficulty in accomplishing anything. I felt for their safety, and the safety of the Government equipment. I felt it was desirable that there be cooperative agreements between the Government and the union. 'The men asked me if I would join the union, and I saw no reason why I shouldn't. From that time on there was a hostile attitude toward me and the Aibatross.

As to the seaworthiness of the vessel-

Chairman Mrrler. Before you go into that, Captain, what form did this hostile activity take; can you give something specific?

Captain Beatry. Yes, sir. On occasions when I went to the office I couldn't be seen except by the second in command and secondly he told me as master I should have set an example to the men by not joining this organization. 'Thirdly, he stated the boss, meaning Dr. Graham, didn't think too kindiy of it, and he questioned whether I should stay on.

However, up until October we did a good job, from January to October. In August I had a chance to go back to the merchant marine. I went to the office and told them since I was not on a steady appointment I thought I should leave. They told me, "Don't leave, Captain ; the job is yours."

In January I got a 3-month extension of my appointment. We proceeded to sea and in October 1956 were ordered to the shipyard in Chelsea for further work to make the vessel seaworthy. There it was anticipated a Coast Guard certificate of seawothiness would be issued so the vessel would come under the American classification. In Chelsea I went through the work list and left some out for budgetary reasons.

But there is one item that stands in my mind today. I was concerned with the misuse of funds, or waste of money for the installation of a winch, which I strongly advised the office not to install, although it had been bought a year prior to that and paid under notes.

On the installation of the winch, that cost several thousands of dollars, they pulled the decks out and installed it in the hold. 'The winch itself was very costly, and furthermore, to be installed in the forehold, which violates every safety practice I have known since I have been going to sea, I told them that would render the vessel unseaworthy. They also decided to cut down the coaming to 3 inches, which would automatically make the vessel unseaworthy, to run wires out of a hold, because quite often we have heavy seas which come aboard and fill the foredeck completely. The Coast Guard came aboard and said the forehold coaming could not be cut down, and I told them the winch could not be operated due to the length of the wire and the number of turns that would be involved.

I told the Coast Guard the vessel did not comply to the international rules. I mentioned this twice and I was told by the office I was never to contact the Coast Guard relative to the vessel or the personnel.

However, we went to the shipyard and in order to comply with law and maintain the integrity of the vessel the Coast Guard did agree 
to come down, and it was necessary to change the entire navigation light system on the vessel to meet the international rules.

There was a further hostile attitude because I brought this up. They were going to sail without it, but finally they had to comply, but within a week or two I had my final notice.

Chairman Milder. Do you think the vessel is seaworthy now?

Captain Beatry. Yes; I do, Mr. Miller.

Chairman Mrluer. Was this winch installed?

Captain BEAтTY. It was installed right after I left.

Chairman Milcer. Was the hatch coaming reduced?

Captain BeAtrT. No, sir; they would not come under the Coast Guard inspection if they reduced the size of the coaming on the hatch.

Chairman Miluer. Did they put the winch on the foredeck?

Captain BEatTr. No, sir, way down in the forehold where you couldn't see it.

Chairman Mrluer. How did it work out?

Captain BEATTY. It didn't work out. I think the thing was never used.

Chairman Mrluer. The decision to make the installation was management's decision?

Captain BeAtry. Yes, sir. I protested it and tried to prevent it, but got in difficulty on account of it. Senator Saltonstall and his able administrator, Charles Colson, tried to get me reinstated several times and were always given diversified reasons for my not being reinstated. Charles Colson had felt very bad about my not being reinstated. Several months ago a letter was written to the Chief of the Bureau o. Fisheries, asking if there wasn't a just reason why Captain Beatty was not reinstated. He was going to the Department of the Interior and expose the whole thing of what happened since February 1956. However, it was not convenient then because the vessel was tied up.

Congressman Ourver. One other thing I would like to get clear for the record, is the I) claware operated by persomnel associated with the Government Emplovees' Union?

Captain Bratry. I believe so, I think she was. I can't answer that, because I haven't been in her, but it is the same men.

Congressman Obiver. Is the pay scale on the Delaware the same as on the Albatross?

Captain BEatTy. Yes, sir" and the reason we thought a union would be eflective would be to put all of om troubles in a package and be able to sit down with management and discuss them with a ninimum of objections.

Congressman Ourek. Why is it that this attitude of hostility which you mention does not carry over to the Delazvare with relation to the crew?

Captain Brarty. I couldu't answel about the Detarare. sir, I have not been on her; I have been on the ressel only a comple of times.

Congressman Ostrer. From your experience in the fishing industry, you have been associated with it in private enterprise, is there any indication that the Fish am Wildife Service costs muder these private chinter agreements womld be less?

Captain Bestry. I cannot see how they would be less for what you are groing to gain. Most of these private charfer boats are very small boats, they ale very inconvenient for scientists and biologists, and what they will get for their dollar I question sincerely. 
Congressman Otiver. And, if the private fishing vessels they say are available, you are going to have to go to the bottom of the barrel to get even one?

Captain Beatтr. The only thing they have left is the culls.

Congresman Ourer. Not only that, but they do not do a good job, is that correct?

Captain BEATtт. Yes, sir; some of these boats are not sea worthy and they do not meet the American Burean standards.

Congressman OLrver. And these men would not be trained men in the specialty field of oceanic research?

Captain BEstTr. Yes, sir; I sincerely believe the money the U.S. Government spends on research work on those vessels will be money wasted, whereas you have the Albatross and the Delaware set up for that purpose, and, with them, you will get a dollar for a dollar.

Mr. Ḱ̈гт. I was interested, Captain, in seeing if you have been back on the Albatross, have you seen any improvement?

Captain Beattr. Yes; there has been a noticeable improvement since I left it. However, a little dressing up with paint and some minor things would make her a better vessel until such time as the Government can replace it.

Chairman Mrler. Of course, you know all ships eventually have to be replaced. They are not good for an unlimited time. And her life cycle is near its end. if it has not been reached now. And our present authority is to inquire not only about this boat but others, if we are going to catch up with the rest of the world in oceanography.

Captain Beattr. Yes, sir.

Chairman MiLler. That is in the future, rather than the present day. I am very much interested in the union, and while the Government requires private industry to deal with unions, it does not impose this condition on itself. There are numerous bills which would require the Government to give official recognition to these unions, to speak for them, but they have not yet become law. But the time is not far distant when union recognition bills will be passed, and management within the Government will be required to deal with these unions.

Captain Beattr. Yes, sir.

Chairman Mrleer. Now it might be good to say this, that certain departments of the Government anticipate our doing it now, particularly the Department of Health, Education, and Welfare. Those who are responsible for management in. Government are going to have the same restrictions imposed on them that those outside the Government have, because, whether we like it or not, if we are going to say to one group of people, you are required to deal with organizations of employees chosen by them in democratic elections, you should do the same thing in Government. That may be a question of philosophy. I am not pleading one side or the other, but I am saying the drift is that way. So far as the Goverment employees in the American Federation of Government Employees are concerned, I know they have done a great job, and, as an old post office and civil service member, I would say, if it were not for their work, the Government employees in general would not receive increases in wages. They have to go through the same procedure that private industry does. 
Do I understand you to say you were under orders not to go to the Coast Guard while you were on the Albatross?

Captain Beattr. Yes, sir; I had specific orders never to contact the Coast Guard under any conditions.

Mr. Drewry. This boat under the law did not have to be certified by the Coast Guard?

Captain BEATTY. That is right, sir; under the law they do not have to come under the Coast Guard registration, but it was recommended. Mr. Drewry. Whom did you contact in the Coast Guard?

Captain BeatTr. It is the duty of the master to contact the Coast Guard.

Mr. Drewry. You contacted them anyway?

Captain Bentry. Yes, sir; and I was fired.

Mr. Drewry. Was that one of the reasons for the firing?

Captain Beatтr. I suspect so, Mr. Drewry, that was relative to complying with the international law.

Mr. Drewry. What I am getting at is, if you had not gone to the Coast Guard, would anyone else have gone to them?

Captain Beatty. It was my responsibility as master to do it, Mr. Drewry.

I spoke of a determination of many factors involving the ressel, its equipment, the personnel, the answer's to which could only come from the Coast Guard. I never heard from them again. This would also involve a master's responsibility to the union and the Government, because the law was being violated.

Mr. Drewry. There was nobody on the staff at the institution who would correspond to a port captain?

Captain BeatTy. No, sir; that is one of the weak links in the system. There is need for a man who has specialized training. The man who replaced me never went to sea in a beam trawler in his life. Maybe he is qualified in other fields, but this takes training over some years.

Mr. Drewry. Just one more. Do you have any opinion as to why the Albatross is being deactivated?

Captain Bедтту. I have none. Senator Saltonstall said if I wasn't replaced by January 1960 it would be released. Inasmuch as Senator Saltonstall's office had very poor relations with the Department, they told him I could go.

Mr. Drewry. You don't mean to imply they deactivated the vessel because management was mad at the crew, do you?

Captain BEATTY. There is a possibility of that, but I don't know what reason they had in their minds.

Chairman Miluer. Captain, as a qualified master, having worked on research ressels, do you know of any reasons why these ressels should not be required to meet all the requirements of the Coast Guard?

Captain Beatтr. Mr. Miller, I think, inasmuch as the United States vessels do not have to comply, I think there is a moral obligation to make them comply.

Chairman MuLfer. Do you think the requirements of the Coast Guard are too severe?

Captain BEATYY. No, sir; I do not, not only for the safety of the ships, but for the persomnel they should comply.

Chairman Mruser. Do you think the Government should be less restrictive than they like private ship owners to be? 
Captain Beatry. No, sir, I believe they should toe the line.

Chairman MIrler. In other words, if you go out and run into one of those severe hurricanes, it is not going to be any easier on a Govermment boat?

Captain BEATTr. The elements respect no one, sir.

Congressman OLIvER. I would like to thank the captain for being here and giving us the benefit of his wide experience.

Captain BEATTY. Thank you, sir.

Chairman Miller. Who is next?

Mr. Donahue. Mr. Chairman, next we would like to present Mr. Austin J. Powers, who was second mate aboard the Albatross III at the time in which the vessel was in commission.

Chairman Miller. Thank you; will you give your name and address, Mr. Powers?

\section{TESTIMONY OF AUSTIN J. POWERS, OF DORCHESTER, MASS.}

Mr. Powens. My name is Austin Powers; I live at 40 Bellevue Street, Dorchester.

Chairman Miller. You have heard the testimony of the people who testified before you, you know there is in the record certain documents given us today and find we have others. We are sorry to find that time is running a little short. However, you have heard the testimony and I would like to ask you to just try to give us your own ideas. If you take issue with any of the testimony that you have heard today, we would like to have you tell us that, too.

MIr. Powens. I would like to go into the labor angle right away.

Chairman Mfluler. All right, sir.

Mr. Powers. I am the original organizer of that lodge, No. 1729. I am the man who organized that union on board the Albatross. We formed the union and got along for about 2 or 3 months, and everything was all right, but on the Sth day of August I got a notice that my services were no longer required. That was 3 months after I formed the union.

Chairman MrLLer. What year was this?

Mr. Powris. In 1956, the year the union was formed. I immediately filed a protest and also Senator Kennedy and Senator Saltonstall, and I contacted Mr. Johnson of the Post Office Department. We went along writing letters back and forth concerning my layoff, but eventually they did have a hearing on my layoff in Washington. I attended that meeting. They said then my layoff was due to budgetary reasons. That also led up to other men who were laid off at the same time. One went back on later. However, the boat went in drydock in 1956 and while it was in drydock I had to get off. But, before the boat made another trip, they hired two men in the places of the men let go. The reasons for it I don't know.

I kept on in the argument about it, and in the long run I got back on the boat on the 17th of March 1957. I was put back on orders or Mr. Leffler, Assistant Secretary of the Interior.

The reasons they gave was budgetary reasons, and they wanted to curtail the operation of the ship. Then they bought a $\$ 12,000$ piece of junk, which, in my opinion, is the most ridiculous thing you can think of putting on a research boat. They made a few trips, and the scien- 
tists told me the thing was not working, they couldn't do their work. But the fact remains I got through 3 months after I started the union. It is my opinion and the opinion of the men $I$ was fired as a result of union activities.

Now, let's get to the wage side of it. Some people are mixed up, but the way to do that is by a survey of the wages in the industry. There was no survey of wages until I got through, and then they came out the following March with a survey, when orders came out to hold both boats at the dock until they made a survey. Then everyone got a substantial pay increase, $I$ believe it was $\$ 1,000$; and some, instead of getting a big raise of $\$ 1,000$, said they had to get $\$ 500$ each year. Now, if the fishermen's salary is decreased down to below what they are getting now, we would be decreased. There is no other way around it. If they do decrease, or if they do take a cut, we will take a cut, too, and we are willing to do that.

Chairman MilLer. That is the basis of the so-called uniformity in the Government pay. They are paid on that basis and apply the same theory.

Mr. Powers. Well, the wage scale, the way it was handled the last time was on what they call two scales, one while at sea and one while in port. That is how they handled that. But, anyway, they came up with another raise in February, this year, amounting to about another $\$ 1,000$. But the crew of the Albatross did not request any raise of wages in 1958. We didn't request any raise, they just shipped that order out to us in line with a deactivation notice, both on the same day. If you want to go back to 1955 , I can, but I know you men don't have the time. I can go back to 1950 and compare both the Albatross and the Delaware.

Chairman Miller. Would you want to prepare a little memo on it and submit it to us?

Mr. Powelis. Yes, sir.

Chairman MrlLer. And we will make it part of the record.

(The following was furnished for insertion:)

Dorchester, Mass., June 3, 1959.

Hon. George P. Miller,

House Offlce Building, Washington, D.C.

DEAR SIR: I want to thank you for the opportunity of appearing before your subcommittee.

There is a few things that stick out in my mind that was not brought ont at committee hearing. One was the labor relations. It's impossible to hare good relations with department head. Ever since I started the mion there is a feeling that union should not be in there. I cannot understand Dr. Graham's attitude. I was told he is class conscience. I was also told on several occasions he was a labor hater. I know it was common knowledge in Woods Hole that getting rid of erew was the first order of business.

I am convincel he was and is against me.

I started the union in June of 1956 and got fired with two other men in September of 19;i. Short time after I was through on the boat they shipped two men. I think that's proof enough of discrimiuation. 'The lay the boat left Woods Hole for the scrapyard Mr. Macksey said it was a victory to get rid of boat and crew. In April of 1958 a brazen conspiracy was started on me by trying to give me a bad performance rating. In fact I termed it a smear. I appealed it and had them change it. Dr. Graham signed it.

Waste of funds such as spending $\$ 15,000$ on installing a winch on Albatross that never worked and was not necessary in the first place. Spending thousands on a boat called T-boat that was on loan from the Army. This boat lay at the dock for months at a time with a crew on board; sometimes as much as three 
men was on board. The boat was of no use for research. Still they kept her for a long period of time.

When Albatross was in service, they went ahead and hired boats, some at the rate of $\$ 500$ per day and some at $\$ 350$ per day and Albatross lay at the dock ready to do the work that was required. Strange situation to let their own lay at the dock and hire old boats with no equipment to do a good job. We spent $\$ 23,000$ - in October of 1958 on the Albatross and deactivated her on March 9 , 1959. Strange economy. If the Albatross is too old in March 1959 she must be too old in Uctober of $195 \mathrm{~s}$, or if she was unseaworthy at that time, as Department would make us believe. why did she go to sea for Bell Telephone after some Department man called her unseaworthy? Are they qualified to make such statements? I doubt very much. We all know the boat got Coast Guard certificate and Bureau of American shipping certificate. I don't know of anybody is better qualified than U.S. Coast Guard to inspect a ship. I say it's bungling all along on the lart of Burean of Commercial Fisheries. If we had time to dig up all the evidence, I believe we would find that it is lack of experience and appeasement and unionbusting.

The most glaring discrimination I ever saw was what they did to Captain Beatty. A fully experienced trawler man was cast aside for an inexperienced man that was not qualified for the job. When Captain Frederksen resigned they could have shipped Captain Beatty then. But what happened? They shipped a man that was never on a trawler in his life and in no way was le qualified for the joh. We had two captains that couldn't stand a fishing watch. Result was myself and Captain Bruce had to work 84-hour week at sea. (Mr. Bruce was (hief mate.)

Apart from everything I beliere research should be carried ont on a larger scale. It's unbelievable that we got to deactivate the only research vessel we got.

Here is how I feel about the fisheries. I helieve we all should get together such as seafood workers, fishermen, boatowners, and Burean of Commercial Fisheries and form a committee to discuss the best way to help both research and commercial fisheries. W'e cannot expect the Government to do everything. I believe if we all pull together we can do a good job, but we must forget ancient quarrels and petty bickering and outbursts of childish temper if we are going to do a good job.

Sincerely,

Austin J. Powers.

Mr. Powers. Then they talk abont the age of the boat. The only thing you can check that against is the Coast Guard and the American Bureau of Shipping. I don't think anybody is better qualified than those two organizations, and, if they say the boat is seaworthy, I don't think any argument can be had on that, that the boat is seaworthy.

Now, I am going back to a statement here from Woorls Hole, and the anmual report signed by Mr. MacKesy. This says

Major repairs and installations aboard the Albatross $I I I$ included inspections, overhauling main engine, auxiliary engine, installation of new fire hydrants, extension of propeller shafts, installation of new dredging and oceanography winch-

And the boat now has got that Coast Guard certificate and I think the boat is very seaworthy.

Now, we have mentioned this winch here. This winch has not worked since it has been installed in the boat. There is a mechanical defect in that winch, and it does not work. We know the thing was costly and it wasn't necessary in the first place. We had a No. 1 winch on the deck, and it did the work on any trip we ever made on the boat.

Chairman Minuer. You say this winch never worked because of a mechanical defect?

Mr. Powers. Some mechanical defect, the engineers know more about than I do, but it does not work. 
Now, take a look at the expenses. This is from the Department of the Interior. There is one here I am concerned about, that is the year 1957 in here for $\$ 51,000$ for a shipyard job on repairs. Then the Delaware is mentioned in it, but there is no mention of a third boat, the expenses on a third boat known as the T-boat, which is a little boat they borrowed from the Army to do some work, but she wasn't successful. Nothing in here about her, but I am wondering if the expenses of the T-boat and the Albatross were added together for the year 1957.

We could take a look at the age of the boat. The boat is old, no question about it, and it is my opinion, if we are to keep up with the rest of the countries in the world doing exploring, it is necessary to have better boats, but I do think it is necessary to keep those boats in operation until you people in the Government can get around to building a real research boat. If the scientists are going to be able to do a better job, they should be able to go anywhere the rest of the world goes. But they haven't got that kind of a boat now. I read a report this morning that a Russian submarine returned to Russia after doing 24 days of exploring underwater with television equipment. They are all over the world, they are on the Grand Banks and they are on the Georges Bank. We had two little boats, but now we don't have sufficient funds to operate one little vessel. It seems ridiculous to me, but, if they haven't got the money, there is nothing we can do about it.

I went over all this from their own statements and found out there are at least five research vessels operating out of Labrador and what we call the Flemish Cap. The Norwegians have built a boat for 31 men; Canada also built a boat for research; and besides that, Canada hired four trawlers this year to kill dogfish. But they are going to save the liver and pay 11 cents a pound for the liver. This is all for research, and I say, again, if we cannot afford to operate the Albatross for $\$ 193,000$, it seems ridiculous to me.

Congressman Ourver. You mentioned that the Albatross is an old vessel, but on the other hand hasn't she been converted from time to time?

Mr. Powers. Yes, sir.

Congressman OLIver. To bring her up to reasonable competence?

Mr. Powers. Yes, sir, and I can give you everything they did. They drilled the plates and they found the plates were in good condition. They put a new deck on her last October. They put new fire hydrants on her. They put a new galley in, practically one end to the other, in stainless steel. They put in a good fish freezer and the boat already had two or three freezers on her. The boat is now a much better boat than she was in 1955 .

The reason I said I could go back to 1955 was because I could show she was seaworthy then. We did not have lifeboats on her in 1955, but we had four or five dories. That was bad, because a dory can carry only 4 or 5 men, and we always carried 25 or 30 men. I thought it was a menace to go out on a boat like that. I filed a complaint about it, and the Coast Guard came aboard and said there were 43 items that had to be correeted before that boat came up to their standards to be certified as seaworthy. We made an attempt at it, and went to a shipyard but we didn't get the work done such as lifeboats, and an escape hatch forward, which they recommended. But in 1956, we did go to 
Hoboken and the boat was brought up to very seaworthy condition. That is the way she is now. She is an old boat, but she is seaworthy. However, I would like to repeat, if we are going to compete with other countries, we are going to have to have a new boat.

Chairman MrLler. I agree with you, and we are glad to have the testimony of a man of your experience. Do you have any more questions?

Mr. Drewry. I have no questions.

Chairman MrLler. I want to thank you for your constructive suggestions, but we are a little pressed for time. We have to fly over to Woods Hole very shortly, but, if you will prepare that memo you spoke about, we will be glad to have it.

Mr. Powers. I will do that.

Mr. Donshue. The next witness I would like to present is somebody who perhaps can give you some idea of the utility of the vessel from the Fish and Wildlife Service viewpoint. This will be Mr. Robert R. Marak.

\section{TESTIMONY OF ROBERT R. MARAK, BIOLOGIST, FISH AND WILDLIFE SERVICE, FAIMOUTH, MASS.}

Mr. Marak. My name is Robert R. Marak, and I live in Falmouth, Mass. I am a biologist for the Fish and Wildlife Service and a union member, a member of the American Federation of Government Employees.

I think it would probably be somder to tell you why we think research is necessary, but you have heard all that from the National Academy of Sciences. One of the reasons I am here today is becanse I have spent considerable time on the Albatross in the last 6 years. All of the work that I have done on her is work I have been doing for the last 6 years. It is through the efforts of the research boat that have made it possible for me to do these things.

Getting back to some of the things these other men mentioned, I recently spent 7 days on the Canadian research boat, which Mr. Powers had mentioned, and which cost $\$ 2$ million. It is a good boat, a beautiful boat, but the Albatross, and I have spent as much time on her as any biologist at Woods Hole, and I would say the Albatross, as she stands now, can do the work the Cameron can. She can remain at sea longer, and this is important because sometimes when you are out, things come up and you have to stay ont longer than you had intended. The boat is seaworthy, and, unless she was, I don't think the Woods Hole oceanographic people would have used her on some of the occasions they have. They took her over to England and some of the men here served in her crew. They took her practically around the world.

I am not a sailor, and some of the men know more about it than I do, but when you get back from a trip which had 70- or 80-mile winds, you feel more confident about going out the next time. I don't see why a man, if he is going to give his time, should work under adverse conditions. If we use charter fishing boats, we have to rerig them, and spend money to put the boat in shape for our type of work.

As to living conditions, charter boats and the Albatross should be compared to coming up here in a 1910 coach as compared to coming ur 
on a jet airliner. I don't see why we should be subject to that. If you have a boat which is good already, I don't see any reason why we should work under those conditions. The Cameron is a plush boat, but the Albatross is a very comfortable boat and a rery workible boat.

Chaiman Mrmens. Are the laboratories on the Albatross well arranged?

Mr. Minak. Yes, the laboratories are very good on the Albatross. I said to the other men at Woods Hole when I came back that the Canadian boat's laboratories were poorly placed. We have done many chemical analyses on the Albatross III. Much work has been done for the Institute and the work layouts on the boat are all good. Granted, we may be a little crowded, but everything isn 't perfect on any boat or in anything you do.

If we don't have a boat, we will have gaps in our data. A lot of data comes up and, if you don't continue to go out and get it, you have a hole in your program. In 1954 we didn't have a boat and we conldn't have a program. What happened to us in 1954 is the same as it would be if the Congressional Records were burned for that year. Then you would be in the same position that I am now. I don t know what happened in 1954, we can summarize and correlate different statistics, but we don't know what happened in that year.

Chairman Muller. If you don't go to sea, there is a gap in your records?

Mr. Marar. There is a gap in the records, not just in mine but other people's records also. Some of the work we do is used by the Navy. The temperatures, and so on, are all given to the Nary. This is a matter of providing records for other people, not just ourselves. It is incidental to our main objectives.

We have a new building going up now, just under construction; we have a new dock, a hurricane-proof dock, but we don't have any boat. It looks nice, but the boat is missing.

In summing up, I could give you many reasons why we need to collect this data, but having no boat is just like being a carpenter without a hammer.

Congressman Ouiver. Are you currently employed by the Fish and Wildlife Service?

Mr. Marak. Yes, I am.

Congressman OLIver. Is it your opinion we should hatre the Albatross reinstated, put back to work?

Mr. Marak. Yes, it is the current olservations that are going on that we don't have, and also these galps are present. If you put a dollar price on it, it might not he worthwhile, but you won't know, because you didn't go out.

Chairinan Mutuer. Thank you very much, Mr. Marak.

Mr. Donamue. For a short statement, Mr. Chairman, I would like to int roduce Mr. Sam Nickerson.

\section{TESTIMONY OF SAMUEL NICKERSON, OF CENTERVILLE, MASS. EMPLOYED BY FISH AND WILDLIFE SERVICE}

Mr: Nirkmens. T live in ('enterville, Mass, and work for the Fish and Wildlife Service at Woxds Hole. 
I have made every trip on the Albatross since August 1956. Мy job is to assist all the biologists with what they do, whether it is tagging fish, putting out television gear, or making BT's anything like that I do. I have a little statement here, maybe some of the other boys have stolen my thunder, but I will give it to you anyway.

Gentlemen, the reasons are numerous for having research vessels as well as other vessels engaged in oceanographic work. Other countries have ressels built for research alone, and why not the United States, the greatest country in the world. We have a fishing boat, 30 years old, and that is the only research boat on the east coast, a boat built for fishing.

However, the fishing boats which you may charter have neither the space nor accommodations to carry on oceanographic work. 'The Albatross was a fishing boat, but it was rebuilt for the Oceanographic Institute and Fish and Wildlife Service. As to accommodations, it can handle 10 scientists. It has a wet laboratory and it has a dry lab where the scientists can sit down and analyze the data or just read or listen to the radio. Some of these other boats, fishing boats, there is only one place where yon can sit down, in the galley or your bunk. The Albatross also had two wing platforms with gear for taking BT's, one on each side of the pilothouse where you conld choose the leeward side for protection from the wind and spray. One man can do this job on the Albatross. whereas it would take two men on other vessels. Back aft there is storage for your gear. On the Albatross there is a bunk and a private head for the master.

Scientific personnel on the Albatross have cabins amidships which hold 10 men, and they have their own private head and shower, two mess tables, one for the oflicers and the biologists and one for the men in the crew. Contrast this with fishing boats which have one shower, no mess table, poor accommodations for the biologists near the main engine, full of the smell of diesel oil. Some biologists do not have very good sea legs, and they really need better accommodations. If you gentlemen who hold the purse strings could do it, we would like to have a new vessel, but until that time comes we would like to have the A7batross put back in service.

Congressman Oliver. Let's say we do hold the purse strings, but many others hold them, too. Are you through with your statement?

Mi. Nickerson. Yes, sir.

Chairman Mrluer. I do want to say we on this committee feel there is more need for money for research, and you are in sympathetic hands on that score. I notice in the testimony Mr. McKernan gave us in Washington, he was talking about converting ships, and he says for oceanographic purposes it became a little bit difficult to get the conversions made in such a way that it would be a good job for research efficiency. The Albatross has already been converted, has it not?

Mr. MLarak. It is already fitted ont.

Chairman Mruer. On what you tell ns, you qualify as something of an expert on the conversion difficulty ; is that right?

Mr. Nickerson. Well, I have heen ont on numerous fishing ressels. I have been on every trip the albatross made since I have been with them.

Chairman Mrluer. But you feel the Albatross is already equipped for oceanographic work? 
Mr. Nickerson. Yes, sir.

Chairman Mrluer. How about this winch we were talking about, has it ever been used?

Mr. Nrckfason. They never asked me about it, and probably at the time I wasn't qualified anyway.

Chairman Mrlber. Have you ever used it since you have been on the boat?

Mr. Nrckerson. We made an attempt to use it. I think we set out the gear and had an awful time getting it back again, so we quit using it.

Chairman Miller. What seems to be the trouble?

Mr. Nickerson. I don't know if it does not have enough power or what, but it won't haul back the gear. We had the Chief Engineer down there tinkering with it so we could get back a few fathoms at a time.

Mr. KeItr. I would like to know, and perhaps you are not the person to whom I should direct this, but how often does the management side of the Oceanographic Institute go out on these trips?

Mr. Nickerson. Probably half a dozen times, but when they were doing that work with the buoys there was one man out on every trip that we made with Jack Colton. That would be maybe a month, altogether. Then they are always sending out drift bottles. I believe the Fish and Wildlife Service has a contract with the Oceanographic Institute to work on drift currents. And all of our temperatures, things like that, they get all that. We are actually doing the work for them as well as everybody else.

Mr. Kerrt. I mean in the chain of command, how many people you actually work for, Dr. Graham, not scientists, but people who represent the Bureau of Commercial Fisheries, how often do they go out?

Mr. Nickerson. How many men do we have?

Mr. Kerth. I am wondering if Dr. Graham and his staff go out so they may adequately understand the problems of the Albatross. How often do they go out?

Mr. Nickerson. He does not go out on long trips since I have been there. Sometimes a 2-day trip off Provincetown, and he goes on a demonstration trip, one a year of 1-day duration.

Mr. KeIтн. As to other members of his staff, does Mr. McKerman ever go out on the Albatross?

Mr. Nickersox. No: I don't know if he was ever aboard the Albatross or not. The only ones who go are project leaders at Woods Hole. And maybe once in a while a visitor.

Mr. Drewry. Aside from this one winch that has caused so much trouble, are the other winches satisfactory?

Mr. Nickerson. Yes; very satisfactory. There is a regular fishing winch on the main deck which works very well.

Mr. Drewry. Was that added as part of the conversion?

Mr. Nicklarson. Yes, sir.

Mr. Drewny. How inany winches are there on deck?

Mr. Nickerson. There is just one fishing winch on deck which has two reels on it. 'Then we had two $B T$ winches and we had one winch on the boat deck we used for hating back the television cable.

Mr. Durwer. They are all working sat isfactorily? 
Mr. Nickerson. Yes, sir, the BT winches were built especially for BT work, and the fishing winch is the same as you find in any fishing vessel.

Mr. Drewry. Thank you.

Mr. Donahoe. Our next witness I would like to present is Mr. Gerhard Paulsen, one of the men who served on the Albatross and who can give you some information. He lives at Mattapoisett, which is close to New Bedford.

\section{TESTIMONY OF GERHARD PAULSEN, OF MATTAPOISETT, MASS., EMPLOYED ON THE "STANLEY BUTLER"}

Mr. Paulsen. I was employed on the Delaware in June of 1957. Before then I had been a fisherman, crew member, mate, and skipper for the past 25 years on this coast and also on the Iceland and Norwegian coasts and so forth in the North Sea. At the present time, I am employed on the Stanley Butler, which is a large dragger out of New Bedford. I am employed there as mate.

I came up here today because I am interested in what is going on and what is to be done on the boat being laid up. I was employed about a year on the Delaware and then changed over to the Albatross. Naturally I wouldn't have changed over if I knew what was going to happen, but I did it because it would be closer to home and more convenient than traveling to Boston.

I have a little knowledge of both vessels, and I will say the Albatross is a better boat to do the scientific work in than the Delaware. I will say she is just as good a boat to do commercial fishing, that is, to use commercial fishing gear as any. I have worked on all types of them in the last 25 years. In fact, that is one of the reasons $I$ got the job.

The first thing that surprised me when I was employed in Boston was the feeling between the crew of the Delaware and the skipper and the officer. Naturally, I stayed for awhile and finally they got all the hands together, and I found out it had to do with the pay. And it also had to do with the titles they call the help in the office. They are called gear and equipment specialists. I was surprised to find out how little they knew. One man comes on board as a project chief and he carries the title of project chief. And he doesn't do anything, but he is going to tell the crew that has been going fishing for 40 years what to do. Naturally they resent that. Because he doesn't know, and that is one thing.

Then, after awhile I noticed a lot of waste due to the fact that the one in charge doesn't know anything about equipment, how to take care of it. I can show you equipment laying around on the dock there for scallop boats. They used one or two of them, but the rest is laying on the dock and has been there for 2 years. It is equipment which, if you leave it outside, it is going to go bad, and it will take a couple of hundred dollars to fix it up in shape. And they are laying outside.

I noticed, when you went a certain kind of fishing, such as scalloping, there wouldn't be anyone on board who has ever been scalloping except me. When I made a suggestion, naturally being a crewman, they didn't like it. However, I did suggest putting guards on the equipinent because they were losing equipment. They did lose 
one, and naturally they resented that and then went ont for 16 days and lost another one. I suggested to them what should be done, but nobody would do it.

Then my chief suggested that I go in for a job as equipment specialist. Natmally, my knowledge is limited. I couldn't sit down and write the way this man here is writing, but I do have equipment qualifications, and I figure you need one or two men around the dock to take care of it, replace it, and you will save in the end. They need somebody to look after the equipment, fix it up, and take care of it, instead of buying it new. I conld show you some stufl laying on the docks that they bought from Paseagoula rumning into thousands of dollars, but nobody is there to look after it.

So I went ahead and applied for this position and got a classification GS-7 on my education. Well, the job came up to be filled, but I understand they did not want fishermen in the station, nobody who has been commercial fishing who could give them a suggestion to take care of the equipment. So, when the job came open, I thought it was a pushover, but I didn't get it. They took in somebody else, and the one they took in I had to show him how to tie a bowline. He couldn't tie his shoelaces.

Naturally, I got a little sore, and I talked to Mr. Linehan. From then on, the ball got rolling, and I was a troublemaker. I was called in and asked why I was going to private industry and told not to go toprivate industry about anything going on in this ontfit. I said, if I can't go to private industry but have to keep quiet about what we do. here, not looking at in a commercial way, I don't belong liere. Naturally, since then I have been in hot water ever since. And I am sure. I was one of them that could have been in trouble with it once but, when you have to work under those conditions, you can't do anything abont it, there is nothing you cam do abont it. Even if you have a radical man on the boat, maybe two or three fellows might well join the rest of them because they are working against something. you can't lick.

As far as the boat's seaworthiness goes, and the way the boat is rigged ont for the crew and the scientists, I don't see any good reasoll why it should be tied up.

So far as putting a scientific crew on the Delaure to either make up for lost work on the Albatross by being tied up or do other work, they are all cramped up so they can't do it. We have had people from the Institute come out and try to live on the boat, and they couldn't do their work. One of them told me when he went ashore he could do a lot of things out there that would be good for his work, but he couldn't do it. I will make it a little quicker, but I think the facilities we have on the boat are certainly usable until it can be replaced. I think they need both boats, and I think they need men ashore.

That is just about what I have to say.

Chairman Mithar. 'Thank you very much for' your contribution.

Mr. Donamer. May I make a short statement to watp this up?

Chairman MıLlek. Yes, sir; I want youto. 


\section{TESTIMONY OF WILIIAM J. DONAHUE}

Mr. Donahue. I gathered these notes on the questions you asked as I went along. I don't know the answers to all of them, but, as you know, I have been with these people and I am familiar with how the crew was paid under the wage-board setup. Prior to the formation of the minion, the wage board was not followed in this installation or in the Boston installation. I might say Under Secretary Chapman said this was a very, very fine agreement written up between the employees and the orgamization of the Department of the Interior. As a matter of fact, he said, if we can get as good an agreement as that to put in eflect, we will have made a great step forward toward solving the problem of the formation of unions clealing with the Department. That was in 1957.

So we sat down and negotiated the wages of these men on this basis, on the basis of wages paid to fishermen, accepted as competent, and these are statistics derived from the North Itlantic Fishermen's Union as to their pay.

Chairman MinckR. It is a very definite formula.

Mr. Doxnhes. Yes, it is.

Chairman Miller. All right, go ahead.

Mr. Dona Hue. Similarly, the vessels, as you pointed out, you developed the point that the Government ressels do not come under the inspection of the Coast Guard. I think the Committee on Merchant Marine and Fisheries should think about getting some real law that would compel the Coast Guard inspection on Government vessels. I don't speak of naval vessels, but other's, such as these in question here. There are loopholes where you find a man got in hot water with a vessel running under Coast Guard recognition as provided for private fisheries.

The third point I want to bring up, Ir. Graham is here, and I cannot believe these men want to deactivate the Albatross III because of some rumor from some members of the crew. I would like to know how you can operate a laboratory without the means of going out and bringing the stuff into your laboratory. I don't think these gentlemen would accomplish anything by being a party to the deactivation of the tools they have work with.

I know it is impossible sometimes to get at the bottom of these rumors. The Department makes their ruling which cannot be overturned, and people who have no idea of what has been determined cannot do anything about it. So that this ruling came from someone higher up in the Fish and Wildlife Service. 'These men can't buck city hall. I think, if we can get to the bottom of it and find out how much money it will cost, and knowing that, you gentlemen may get a Senate bill written to show some funds in there specifically for tho operation of this vessel and for the other vessel, too.

You have been told the vessel is unseaworthy. I think we have shown that is not so. I wonder if the telephone company would like to know their personnel is going out and chartering a vessel for the telephone company which is not seaworthy. I wonder if they would like to know during the last 30 days their personnel has been in an operation with the Navy and the telephone company out doing this research work on an unseaworthy vessel. I wonder what kind of Gov- 
ernment we have had when we not only expose our personnel or employees to an unseaworthy vessel, but take private industry and put them over the barrel, too. I understand that argument was refuted by this testimony that the vessel is fit and seaworthy.

You will go down and see Woods Hole, see some nice gear all polished up and bright. I worked in the Navy, and I know how the Navy polishes up when the admiral is coming around. You will also see some gear that was used on the Albatross III and you will also see gear that could be put back on board again. You will see the laboratories and specimens taken by the scientists. What you see down there is not going to be used again, because you have no Albatross to use it, and that gear can't be used by commercial vessels. So I hope you will have that thought in mind.

In conclusion, I would like to thank Chairman Miller and the members of his committee for coming up here and hearing this testimony, and I sincerely hope you can find good reasons for those responsible for getting this vessel back in operation again, so that it may assist a dying industry, so that we can have an industry which will be in competition with the people coming in here.

Chairman Mrluer. I might say that this entire committee, not only the subcommittee, but the entire committee is quite conscious of the plight of the fishing industry. If you could be down in Washington and see my colleagues, not only from this coast but from the State of Washington, you might be sure you have some good champions down there. My good friend on my right has some bills in. We are al? quite concerned about it, but that is a major problem which is very much in front of this committee at this time. But I am very glad to see you are here, and I want to thank you for the way you have presented the evidence at this hearing.

Is there anything else?

Mr. Charles L. Wireeler. I am representing Commissioner Foster, of the Commission on Natural Resources. I want to go on record as being in favor of keeping the Albatross or having another vessel.

Chairman Miller. We hope we can have a vessel continuously working out of this area. We know there are factors which are not readily apparent as to why sometimes you can't keep a ressel going, but we know you can't collect your data unless you can continue it. Perhaps the only way of doing it is what we are doing now, to spotlight it and hope we can come to some farorable conclusion on it.

If there is no one else, the hearing will stand adjourned.

(Hearing adjourned at $1: 45$ p.m.)

Mr. JoIrn MCCART,

FAIritaven, MASs., Murch 9, 1959

Legislative Director, American Federation of Government Employecs,

Washington, D.C.

DEAr Mr. MCCART: I am forwarding herewith, a two-page comparison of the facilities of the Albutross III and the Delaure. This should be attichel to the sumniary of information being forwarled to you todas, nnder separate cover, by Mr. Austin I'owers.

I hope that with the information we have furnisled, sou will at least be able to get a thorough inrestigation of the Albatross III deactivation.

Very truly yours,

F. H. Hiller. 
Comparison of facilities

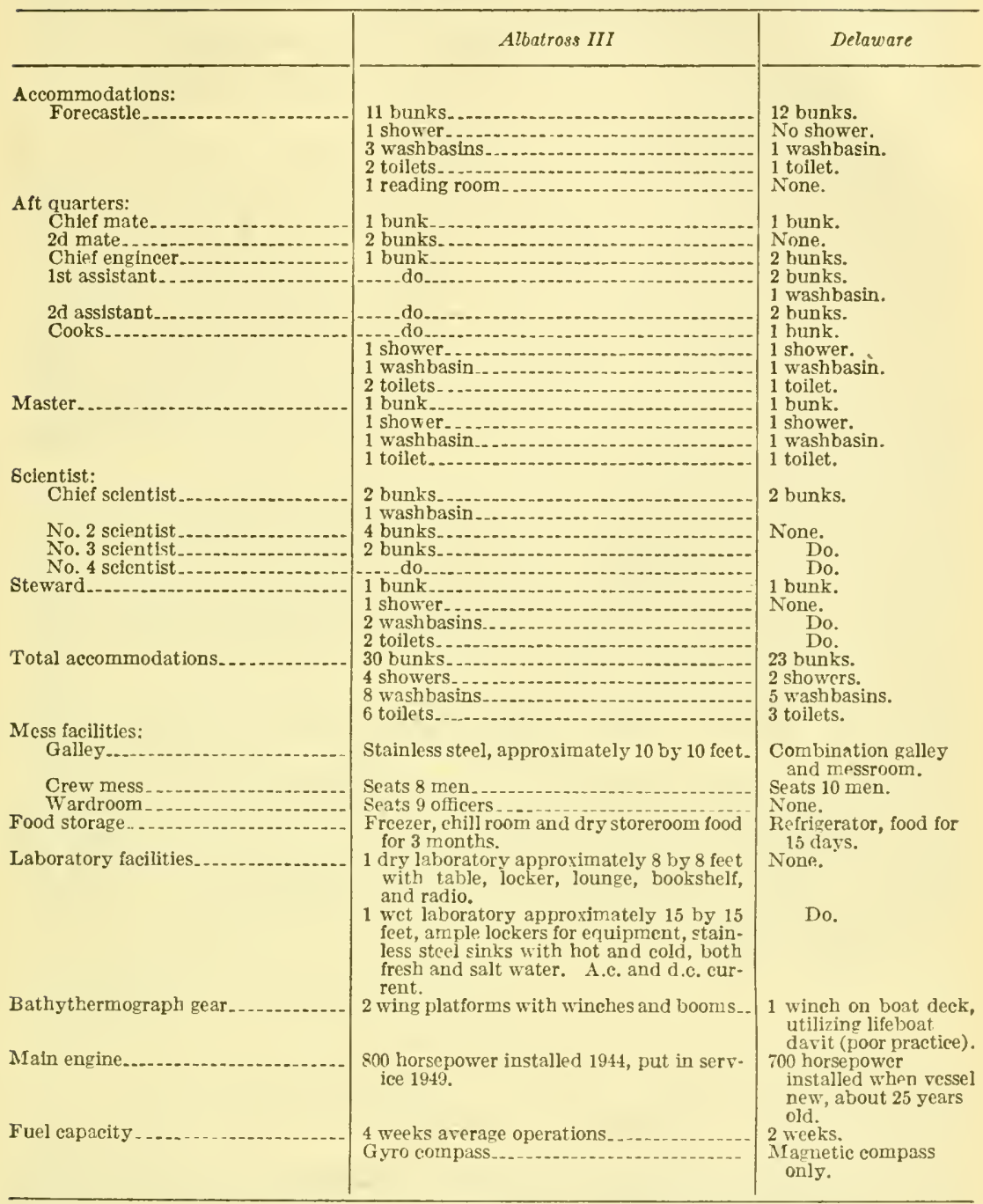

Mr. Donald L. MicKersan,

Fairhaven, Mass., March 10, 1959.

Director, U.S. Department of Interior, Bureau of Commercial Fisheries, U.S. Fish and Wildlife Service, Washington, D.C.

Dear Mr. McKernan: I have this date forwarded to Mr. John McCart, legislative director for the American Federation of Government Employees, pertinent information concerning the deactivation of the Albatross III.

As master of the Albatross III for nearly a year, I tried to act as an effectire and impartial liaison between the employer and employee, and as such, I did not join the union. I felt that I would be able to fulfill my obligations to both parties better if I was not too closely allied to either one. I beliere I was, to some extent, successful in my attempt to bring about a closer cooperation be- 
tween the ship and the labolatory. I felt that I had gained the confidence of both ny superiors and $\mathrm{m} y$ crew, and of course this is the first requisite for a smooth running ship.

Then came the order to lay up the Albatross III. I was not taken into the confidence of the Service on this action, nor was I subsequently consulted concerning the condition of the vessel or the estimated financial requirements for the balance of the year.

The budget which I was giren at the start of the fiscal sear 1959 was adequate to carry the ressel through the year with a minimm of maintenance and arelage repair bills. Monthly budget sheets, issued by the laboratory, show that we were operating the Albutross well within the appropriation. The latest figures, dated Janmary 31,1959 , show us to be a little on the plus side, with ample funds for the remainder of the year.

When the ressel was hauled out last smmmer for annual inspection, I was entrusted with full responsibility for the repairs and maintenance work, American Bureau of Shipping surves, and U.S. Coast Guard inspection. Not oue U.S. Fish and Willlife Service official came near the ressel. Yet, as a result of reports originating within the Service, marine interests and the public alike have been given the impression that the Aluatross $I I I$ is excessively expensive to operate and hadly in need of major repairs. This is not true, and I wonder if sou are aware that this is not true.

Furthermore, if it became necessary to lay up one of the ressels due to lack of funds, who could have made the decision that the Albatross be the one? I did not, and I am fairly certain that Captain IIayes of the Delavare was not consulted. A comprehensive study of the overall operations of the two vessels: work accomplished at sea, scientist accommodations, research facilities, laboratory space, condition of the main engine and hull, navigation equipment, fuel and water capacity, cruising range, ses and even toilet facilities, all add up to but one possible conclusion, that the Albatross III is by far the best equipped gnd most economical to do the work.

If there is some other reason for deactivating the Albatross, I have been unable to learn what it is, and I believe such information should be made available.

Only the union, representing the Gorernment employees at the Woods Hole Laboratory, has seen fit to consult me on the condition of the Albatross $I I I$. I hare replied with all the information I could glean from my own experience and that of the officers, crew, and biologists who know the vessel as no one else does. Sonie of this information is at considerable variance to that contained in your report of February 25, 1959, to Senator Saltoustall.

Sincerely yours,

F. H. Hiller,

Master, Formeriy of the Albutross $I I I$.

Fairhaven, Mass., March 9, 1959.

Mr. JoH McCarT,

Legislative Director, American Federation of Government Employees, Washington, W.C.

Dear Mr. McCart: Attached is a summary of information furnished by the mastel, chief officer and second officer of the research ressel Albatross III which is, in effect, a rebuttal to the report issued by the U.S. Fish \& Willlife Service, concerning the deactivating of the Albatross $I I I$.

This sumnary represents the beliefs of the crew of the vessel, some of whom have been attached to the Albatross since it was activated in 1949. It is not intended as a per:sunal gripe of one or more crew memhers, hut rather a desire to make known all the facts by persons genuinely concerned and critically involved in an action effecting the v'ly cconomy of om comntry. 
Not having access to Service files, it is not possible to substantiate all the figures contained in this summary. They are however, to the best of our knowledge, true, and of such variance to the Fish \& Wildlife Service report that we feel that a complete and exhaustive investigation is warranted. Very truly yours,

\title{
E. H. Hiller, \\ William J. BRUCE, Chief Officer. \\ Austin J. Powers,
} Second Officer.

\begin{abstract}
Sumarit of Information in Rebuttal to Rfport on Deactivation of "Alb1tross III" Subuitted BY U.S. Fisil and Wildlife Service, Dated February 25, 1959
\end{abstract}

The statement on the conditions of the Albatross $I I I$, contained in subject report, is very misleading and, in part, something less than factual. Talie the very first statement in the report, for instance: "As a result of continued repairs and shipyard work the Albatross $I I I$ is in safe operating condition." It is only as a result of continued maintenance and annual orerhauls that any ressel is kept in a safe operating condition. Repairs and shipyard work is not unique in the case of the Albatross $I I I$, as this sentence would have you believe.

It is a provable fact that considerably less than arerage amounts of money have been spent on repairs to keep the Albatross III at sea. A recent check of Boston shipyards indicates that the annual orerhaul costs for a 100 font towboat ranges between $\$ 30,000$ and $\$ 40,000$. Yet subject report, which shows an annual outlay of $\$ 33,000$ for Albatross $I I I$ "Overhaul costs," would have yuu believe this is exorbitant.

Eren if the figures shown for shipyard repairs, on page 3 , were accurate and actually represented expenditures made solely for repairs and maintenance, this would still be well below the amounts spent by other Government services and private companies to keep their vessels in shape.

But these figures are misleading. During the years 1955 through 1957 the records will show that a considerable portion of the money, itemized as "sbipyald repairs" in the report, actually was spent on structural changes and safety equipment to comply with U.S. Coast Guard and American Bureau of Shipping recommendations. Some of these items, which run into many thousands of dollars, include two new metal lifeboats and launching equipment, an escape hatch from the crew's quarters forward, extra fire hydrants, a new general alarm system, and other items totaling 42 reficiencies found to exist on the Albatross III. Ironically, most of these deficiencies have never been corrected on the Delaware, which the Service proposes to continue operating with a double workload.

Also included in the "shipyard repairs" must be the several thousand dollars put into designing, building, and installing a new winch for the scallop project. Due to faulty design, this winch las never been operated, nor will it ever be operated without extensive and expensire alterations. There she sits, "a $\$ 20,000$ piece of ballast."

No; if the actual upkeep costs of the Albrtross $I T I$ were itemized for all the years she has been operatin: since 1949 , the results would be so low as to he downright embarrassing to the Fish and Wildlife Service. For actually it was other Government services and a private institution that have over the years realls put the money into the Albatross $I I I$.

The Woods Hole Oceanographic Institution spent some $\$ \$ 0,000$ on her in 1951 , making extensive alterations and improvements. When the ressel was drafted into military selrice during the war, she was refastened from stem to stern, a new powerplant was installed, bottom plates replaced where necessary, and frames and longitudinal members reinforced throughout the vessel. It was due to these repairs, made by others, that the Albatross III met classification requirements of the American Bureau of Shipping in 1957. It is for the same reason that she is in a seaworthy condition today-not because of exorbitant repail bills paid by the Fish and Wildlife Service.

In all the rears she has been operated by the Fish and Wildlife Serrice, the Albatross $I I I$ has experienced but one major breakdown. That was when her main bearings burned out in 1957 . This can happen to any ship, old or new, and certainly should not be construed to indicate old age and high upkeep costs. 
Referring again to page 1 of subject, the new deck installed in $195 \mathrm{~s}$ was a job that should have been done a year or so earlier. It would have been too if it had not been for the engine breakdown, which fact shows that the expense of engine repairs came in lieu of annual upkeep ensts, not in addition to them. The deek job, which eost $\$ 4,200$, did not, of course, consist of new deck plates, but rather the replacement of the old wool sheathing with a modern, waterproof, nonskid deck emulsion. When the steel deck plates were bared during this work, they were test-drilled by ABS representatives and found to be in excellent condition. There are no new leaks in the deck, contrary to the report.

During the past 12 months the schedule of the ressel has never been delayed, nor have any seheduled eruises been omitted, due to breakdowns or other eauses which could be attributed to the ressel's condition. In years past, certainly the engine breakdown caused considerable delay, but beyond that there have been no major repairs or out of the ordinary repairs or layups eausing undue delays in the work sehedule. Indeed, no condition exists aboard the ressel today to keep her from going to sea for 300 days per year, if the work schedule required it. According to subject report, the Albatross III has been at sea for 102 days during the first half of fiseal year 1959. This, of course, equals an annual rate of 204 days. And this rate was aceomplished with a scheduled idle period of 25 davs orer the Christmas holidass. The figures in the report just do not add up to the conclusion that the Service draws from them.

On page 5 of the report, it is stated that costs for the Delaware run about $\$ 10,000$ per month, compared to $\$ 14,000$ per month for the Albatross $I I I$. From these two eold, uninformative figures, someone would infer that the Delaucare was more economieal to operate $-\$ 4,000$ per month cheaper, if you please.

A look at the attached sheet, showing a comparison of research facilities and personnel accommodations aboard the two ressels, and considering the faet that the Allatress $I I I$ has been working almost entirely on a 24-hour, round the clock, watch and watch basis, whereas the Delauure has been operating on a strietly daylight basis, then these figures present a different picture:

\section{Albatross III:}

Carries average of 6 scientific personnel each working an arerage of-

Hours per day

Days per month at sea_._. 15

Hours per month_-_-_.-180

Scientists _.....-_- 6

Researeh hours per month._._._.

$\$ 14,000 \times 1,080$ hours $=\$ 13$ per hour of scientific research done on the Albatross III.

\section{Delaware:}

Carries average of 2 scientists, each working an a verage of-

Hours per day

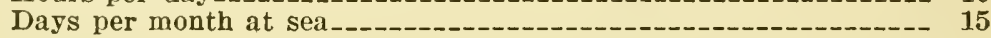

Hours per month

Scientists _....

Research hours per month

$\$ 10,000 \times 300$ hours=0ver $\$ 33$ per hour of scientific research done on the Delaware.

On a typical fishing cruise the Albatross III will average better than 10 tows per day, fishing round the elock. On a recent cruise report, figures show that the Delaware averaged less than four tows per day. If the Albatross III can accomplish more than twice as much work for less than one-third more operating cost one might expect to believe she would be judged more economical. The fact is that not one man aboard either of the two vessels, or the biologists and technicians who go out on them, not one experienced seaman, given a similar choice would choose the Delaware. It is a most illogical move. It is a decision arbitrarily made by someone totally unfamiliar with the operation of the two vessels.

The statement of increased costs shown on page 5 of the report certainly represents a drastic increase in the wages of ressel personnel. But here again the figures lead you astray. There was no review of wages made until 1957 
and the results of that survey showed that the men were drastically underpaid. Hence the increase. During the period 1957 through November 1958 , subsequent surveys resulted in a slight increase. In February 1959 the Wages Reviewing Committee again reviewed the wages, and in a surprise move, instituted, in record time, another substantial par raise. And, incidentally, they advised the Albatross crew of the new wage rates at the same time that they announced the deactivation of the vessel. In the same breath, literally, the crew were given a substantial wage increase and fired. Actually, in the case of the Albatross III, it has been pointed out that as a result of a drastic reduction-in-force order, reducing the number of crew members substantially, the subsequent pay increases affected the overall salary budget for the ressel considerably less than the report would tend to make us believe.

The lay up of the Albatross on such short notice is a real catastrophe for some of the men involred. Sure, they can find other work, in time. But they have gotten away from commercial fishing, lost their contacts, and passed up higher paying jobs for the ultimate security and satisfaction that they expected from Government service. Several men who have been hospitalized for injuries or illnesses suffered in Government service now find themselves out of a job and owing the U.S. Government several hundred dollars for advanced sick leave. They have been ordered to sign releases permitting the Government to withhold accumulated retirement benefits and annual leare parments.

In one instance, a man sick in Brighton Marine Hospital was mailed papers to sign permitting the service to advance him sick leave to cover his extended period of illness. He signed them in good faith, not expecting the ressel to be laid up scarcely 2 weeks after he returned to work. Certainly responsibile men within the service contemplated the deactivation of the Albatross months before the erew and public were advised. This being the case, it seems highly illogical and most careless of those in management to encourage the man to take advanced sick leare.

When the vessel's crew were called together to receive their final separation papers, men owing sick leave were requested to sign away their pension fund and accumulated annual leave. This is money they will need to support their families while looking for work. In the case noted above the man was told it would go lard with him if he did not sign the release on the spot, after he had requested permission to take the form home to discuss with his wife a method of paying over $\$ 400$ back to the Government. After signing away all the benefits he had coming the man admittedly could not give the Gorernment a check or money order to fulfill the claim. But he was forced to sign the release over a handwritten statement, dictated by regional administrative officer, to the effect that he needed additional time in which to pay the Gorernment claim.

At this same separation meeting each of the crew members was handed a blue form No. 52 and told to sign his name anywhere on the back. In response to questions about the form, the regional administrative officer said it was not important, "Don't bother to fill it out"-."Just sign your names on the back, so we'll know where to send your checks and how to reach you in the event we have a job for you." On closer inspection, it was discovered that form No. 52 is a request for personnel action, in short, a resignation form. When several men questioned the signing of this form, all were told they did not have to sign the form, plain paper would do as well. Was this subterfuge?

In the case of the chief officer of the Albatross, the arbitrary action of deactirating the Albatross came less than a month before the completion of his fifth year of service, thus depriving him of his right to a future annuity. This injustice is even more odious when considered in the light of the man's age, which is 6.5. Certainly arrangements could have been made to keep this man on duty for another month.

The master of the ressel is 2 weeks short of completing a full year of active duty. His retention points are 1-plus. He has not received a performance rating, although this could conceivably increase his retention points to 3 . Why?

The statement on page 10 of the report to the effect that the Delaware will be able to accomodate additional crew members without difficulty is a strange and irresponsible one. A poll of the officers and crew of either vessel, the reasearch biologists, or any impartial observer would belie the statements most emphatically. A rast amount of money must be spent to increase her accommodations and install the most meager facilities. No amount of money could make her equal to the Albatross as a research vessel. 
Certainly the Service needs new research ressels. Attempting to conrert a naval ship, except in an emergency, as a stopgap measure, would be too costly and rery unrewarding. But on second thought, does the Service need research vessels at all? Or, indeed, is it equipped with the know-how to operate oceangoing ressels? The largest and best equipped, ves, the only fully found deep sea research ressel the Government owns is now being dismantled in Bostnn, for lack of foresight. And this action is taking place at the very time men who know, men of vision the world over are emphasizing the importance of undersea research. Says the National Academy of Science, "a greatly expanded undersea research program is needed." And, "ocean research is as important to us as space research." "Deactivate the Albatross III," echoes the Fish and Wildlife Service.

Perhaps the Albatross is too large a ressel for the Woods Hole Laboratory. Perhaps an 80-foot inshore trawler will meet their requirements. If so, the Albatross should be operated as an oceangoing research vessel at large, to be put at the disposal of any laboratory on the Atlantic or gulf or Pacitic coast, Alaska, or anywhere else that a properly oriented program can justify her use.

Perhaps a whole new research program should be built around the Albatross III to utilize her exceptional facilities, extended cruising range and experienced crew. She should be made a railable for specific types of offshore research in any area of the world. Certainly she should not be taken ont of service.

The Service proposes to use fishing ressel charters wherever necessary to augment the work of the Delavare. This has been the policy in the past, even when the Albatross was operating. In an effort to save money, this way, the Service accepted bids from the boatowners and invariably the boats quoting the lowest prices were those that wele either unsuccessful for fishing, or laid up with engine trouble, or at best, were the lowest of the lowly craft. As a result, the research biologists have been sent to sea in inferior boats, not at all representative of the commercial fishing fleet. And it is a known fact that the best of the boats do not meet the minimum standards for lifesaving equipment, manning or seaworthiness as set up by the U.S. Coast Guard. In addition, the facilities offered our biologists in the way of accommodations and research equipment are inadequate. One gear and equipment specialist reported he had to sleep on the lower shelf of a food locker on one chartered ressel.

The fishing ressel Dartmouth, chartered for scalloping, found it was losing monej on the charter, so requested permission to fish commercially, at night when the scientists were not working. This request was granted. The Dartmouth crew cast aside the Fish and IInillife Service scallop dredges, stating that they were rigged wrong and did not fish well. They rigged up their own gear and used it. The expressed purpose in using the Dartmouth on this project was that a typical commercial scalloper was needed to give the scientist an authentic sample of scallops and scalloping operations. It has been inferred by the Fish and Wildlife Service project leader that the Albatross was too large for the work and would not produce realistic results. Fishermen contend that, using the proper gear, the Albatross would be ideal for the work.

Because they are small and ill equipped for research and above all, uncertlfied by the U.S. Coast Guard, the commercial fishing boast are often held in port by the weather, thus tying up the time of several biologists, awaiting better conditions. Even under idenl weather conditions, such boats are uncomfortable, so it is questionable if the scientists can accomplish as much work as they would on the Albatross.

If a commercial vessel is in good condition, such as a well found Hiliner, fishing regularly with an experienced crew, it can ill afford to accent a charter from the Fish and Wildlife Service. They are earning too much money on their own.

It is in fact, false conomy to lay up the Albatross III. It is possible that what is neerled at this time is a complete and thorough investigation of management operations of all of the Service ressels. A research biologist should not be expected to be an expert out of his own fielel. He has hat no marine ellueation or experience required to operate a vessel, manage its schedule, or to understand the problens-- fishing and slipping. Responsibility for research vessols for each region slould be segregated under an authority completely separated from laboratory aministration. If the maintenance, provisioning, manning, and budgeting of ressel uperations weres put in challue of a competent marine suluerintemient "hargerl with keeping the ressels in shape and reacly to meet the work sehedules required by the rarious laboratories, then there would be no occasion to call the Albatross 111 "a $\$ 175,000$ healache." Operating a 
vessel is not a "headache" to men experienced in handling seamen or conversant with the costs of various phases of ship maintenance and management.

Thousands of dollars' worth of equipment-nets, trawl doors, wire, and other gear have been damaged or destroyed entirely for lack of proper care or stowage. On the dock at Woods Hole is a mountain of fishing equipment rusting and rotting away for lack of proper care and protection from the weather. Perhaps enough of this equipment has been carted away to the dump already to cover the salary of a competent marine superiutenctent for a sear.

A closer cooperation between the activities of the two research ressels in this region would lesult in lower costs of gear and a more integrated work schedule. In some few instances, one research vessel could do the work of two, if care were taken in planning the cruises. One or two competent maintenance men, working in a single gear shed to serve the two vessels, would save countless hours of delay aboard the vessels by mending nets, repairing gear, and making up new equipment. Money is needlessly being spent to purchase conıleted nets and trawl gear, whereas the required materials could be bought in bulk quantities and made up by our own maintenance men, or equipment specialists.

This term "equipment specialists" should be scrutinized. It is the title of numerous classified emplorees connected with our laboratories. Sone of these employees are truly expert gear specialists and many are not. Our real specialists are aboard the vessels, working at their trade, 12 hours a day. But these men who have been working at their trade for 40 years or more, are never asked for advice, never cousulted about new gear or contemplated fishing activities. They have, in many cases, reached a point where they will not even offer unsolicited suggestious, for experience has taught them that their ideas are not wanted. Many thousands of dollars' worth of equipment has gone by the board for lack of proper rigging, or understanding of the ordinary practices of seamanship.

The men on the Service's research vessel are not encouraged to offer their ideas aud suggestions. In many instances they have been discoulaged from taking any interest in the development of new gear. And this within the branch of fisheries called "exploration and gear research." Even private industry has found it profitable and to its advantage to encourage employee interest in improving equipment and operations.

We have mell on our vessels who have spent hours of their own tine and many dollars of their own money in pursuing an idea for new equipment, only to find their superiors ashore uninterested and unenthusiastic, probably because of their lack of understanding of the problem.

Men, and most especially fishermen, with their heritage of independence and self-sufficiency, do not like to be supervised by shoreside personnel totally unfamiliar with ship gear and equipment. It is like throwing salt on an open wound when such shoreside personnel are rated as gear and equipment specialists.

The budget set up for the Albatross $I I I$ at the start of the fiscal year 19.59 was sufficient to operate the vessel for a year, with a minimum of maintenance work and average repairs. Each month the vessel has received a budget sheet showing expenses to date and balance in the appropriations. The last such sheet received was dated January 31, 1959. It showed that the vessel was ojerating well within its budget and had sufficient funds to operate the rest of the year. If the Service is in fact without funds, then where did these budget figures come from?

Although the welfare of the actual men involved in the deactivation of the Albatross $I I I$ is of little importance when compared to the jeopardization of the country's research program, America has had a long background of standing for and fighting for the value and dignity of each of its individual citizens. To summarily deactivate the Ablatross III without careful examination of all the ramifications of the situation cau only be called a blunder. It is untlinkable that this vessel should be deleted from our already insufficient research program, curtailing the biological research so important to our national welfare at this critical time when maritime nations the world over are exploring the waters washing our very shores in ultramodern research vessels.

It is the recomnendation of the undersigned, that before the U.S. Gorernment's ouly major research vessel is taken out of service, further study by responsible and impartial authority be undertaken, to determine the truth of the myriad claims and counterclaims, reasons, and excuses put forth to justify this action. 



\title{
OCEANOGRAPHY IN THE UNITEI) STATES
}

\author{
MONDAY, JUNE 1, 1959
}

House of Representatives,

Spechal Subcomintetee on Oceanograpity

of the Committee on Merchant Marine and Fisileries,

Woods Hole, Mass.

The subcommittee met, pursuant to notice, at Woods Hole, Mass., Hon. George P. Miller (chairman of the subcommittee) presiding. Present: Representatives Miller, Oliver, and Flynn.

Also present: John M. Drewry, Esq., chief counsel and Congressman Hastings Keith, Ninth Congressional District, Massachusetts.

Chairman Mrluer. The meeting will please come to order.

We will now hear from member's of the Woods Hole Oceanographic Institution.

The first witness will be Paul M. Fye, director.

\section{STATEMENT OF PAUL M. FYE, DIRECTOR, WOODS HOLE OCEANOGRAPHIC INSTITUTION}

Mr. Fye. The Woods Hole Oceanographic Institution was founded in 1930 as a direct result of a recommendation of a National Academy of Sciences' Committee on Oceanography which had been studying the status of marine science in this country for $21 / 2$ years prior to the submission of its report in 1929. The effects of this report three decades ago were vast and far reaching, not only in the establishment of this Institution but also in the expansion of the teaching of oceanography in several miversities throughout the country and in the extension of the work of the Scripps Institution of Oceanography at La Jolla, Calif.

In spite of the fact that these 30 years have seen this Institution grow into a full-fledged, energetic research institution and that oceanography has become a science well recognized by each school child and now commonly mentioned in newspapers, magazines, and by the man on the street, we find ourselves today urged by another National Academy of Sciences Committee on Oceanography to once again expand greatly our research effort in oceanography and related sciences. The increased appreciation in recent months for the urgent need to increase rapidly our stake in the ocean frontier has been a direct result of the work of your committee and the recent work of the Harrison Brown group. We hope that an examination of our Institution, its nature, history, how it came into being, the science it has done and is now doing will assist you in your appraisal of oceanography and in your evaluation of the Nation's requirements for the futture. This task which you have set for your subcommittee is of 
great importance to science, civilization, and our country's welfare and security. We at Woods Hole are indeed grateful for your interest and consideration.

\section{STAFF}

The Woods Hole Oceanographic Institution was chartered to prosecute the study of oceanography in all its branches; to maintain a laboratory or laboratories, together with boats and equipment, and a school for instruction in oceanography and allied subjects. We are a small research institution with a staff of 130 technically trained and approximately 300 regular employees. In the summertime our work is substantially increased by the addition of about 125 people who are generally faculty members of universities, graduate students, and college students. We have 40 research associates on our staff from 27 colleges and universities. As you well know, relatively few people are trained in our universities as oceanographers but most we recruit people with training in fundamental disciplines such as chemistry, biology, physics, mathematics, geology, and meteorology. At the present time our research staff has a composition shown on the following table.

TABLE I.-Rescarch staff of the WHOI

\begin{tabular}{|c|c|c|c|c|}
\hline \multirow[b]{2}{*}{ Category } & \multirow[b]{2}{*}{ Number } & \multicolumn{2}{|c|}{ Degrees } & \multirow[b]{2}{*}{$\begin{array}{l}\text { Bachelor of } \\
\text { science }\end{array}$} \\
\hline & & $\begin{array}{l}\text { Doctor of } \\
\text { philosophy }\end{array}$ & $\begin{array}{l}\text { Master of } \\
\text { science }\end{array}$ & \\
\hline $\begin{array}{l}\text { Biolooists } \\
\text { Ch imists } \\
\text { Mathematicians. } \\
\text { Ehysicists. } \\
\text { marinc, etc.) } \\
\text { Geologists } \\
\text { Oceanographers } \\
\text { Metcorologists. }\end{array}$ & $\begin{array}{r}29 \\
13 \\
7 \\
19 \\
26 \\
14 \\
16 \\
10\end{array}$ & $\begin{array}{r}16 \\
5 \\
2 \\
6 \\
\\
6 \\
6 \\
2 \\
4\end{array}$ & $\begin{array}{l}4 \\
1 \\
3 \\
6 \\
4 \\
2 \\
6 \\
2\end{array}$ & $\begin{array}{r}9 \\
7 \\
7 \\
22 \\
6 \\
8 \\
4\end{array}$ \\
\hline
\end{tabular}

The complex nature of the ocean systems requires that our scientists have a sound basic training in one of the fundamental sciences with a broad interest in related sciences. They must have some special training in the problems relating to science at sea and, above all, a keen interest in the scientific problems of the oceans compled with an intense desire to go to sea to solve them.

From its inception the Institution has taken a strong interest in the training of oceanographers and we are now most conscious of the importance of attracting and training brilliant young people in the fields of marine sciences. The founders were all attached to academic institutions and viewed the Woods Hole Oceanographic Institution as a logical extension of their miversity research and an excellent facility for fulfilling their desires to study the ocems. Over the years many fellowships have been awarded-often from funds urgently needed for research projects. Table II shows something of the results of this fellowship program. Woods Hole-trained people are now working almost everywhere that oceanography is in progress in this country. Recently we strengthened om summer fellowship program by increasing the stipend and received over 10 times as many excellent candidates as we could appont. 
TABLE II.-Summary

GRADUATE STUDENT FELLOWS AT THE WOODS HOLE OCEANOGRAPHIC INSTITUTION

\begin{tabular}{|c|c|c|c|c|c|c|c|}
\hline & $1930-34$ & $1935-39$ & $1940-44$ & $1945-49$ & $1950-54$ & $1955-58$ & Total \\
\hline Number granted. & 36 & 39 & 12 & 26 & 39 & 45 & 197 \\
\hline Number of fellows & 26 & 24 & 9 & 23 & 29 & 37 & 148 \\
\hline Further history unknown & 5 & 9 & 2 & 7 & 11 & 7 & 41 \\
\hline Higher degrees earned: & & & & & & & \\
\hline Master of arts & & & 1 & & 3 & 1 & 5 \\
\hline Doctorate & 14 & 13 & 5 & 13 & 10 & 3 & 58 \\
\hline Medical doctor & 3 & 2 & 1 & $\ldots$ & $\cdots$ & & 6 \\
\hline Present position: & & & & & & & \\
\hline & 1 & 1 & - & 2 & 5 & 2 & 11 \\
\hline $\begin{array}{l}\text { Academic } \\
\text { Industry }\end{array}$ & 9 & 11 & 5 & 6 & 7 & 5 & 43 \\
\hline 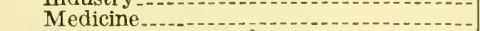 & $\begin{array}{l}4 \\
2\end{array}$ & $\begin{array}{l}1 \\
1\end{array}$ & 2 & 2 & & & 9 \\
\hline Government research & 2 & & 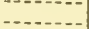 & 4 & & & \\
\hline Unrelated to oceanography & 3 & 1 & $-\ldots . . .-1$ & 2 & 2 & 1 & 9 \\
\hline Deceased & $-\ldots . .-1$ & $\mid-2-1-1$ & 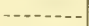 & $-\ldots . . .-1$ & 2 & & 2 \\
\hline Students_... & 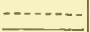 & - n.... & $-\ldots+\cdots$ & $\cdots$ & 2 & 22 & 24 \\
\hline $\begin{array}{l}\text { Total } \\
\text { Associates at } \mathrm{W} \text { HOI }\end{array}$ & 21 & 15 & 7 & 16 & 18 & 30 & 107 \\
\hline Number granted postdoctoral fellowships at & & & & & & & \\
\hline WHOI $\ldots \ldots$ & 1 & 3 & 1 & 1 & 2 & 1 & 9 \\
\hline
\end{tabular}

POSTDOCTORAL AND FOREIGN FELLOWSHIPS AT WOODS HOLE OOEANOGRAPHIC INSTITUTION

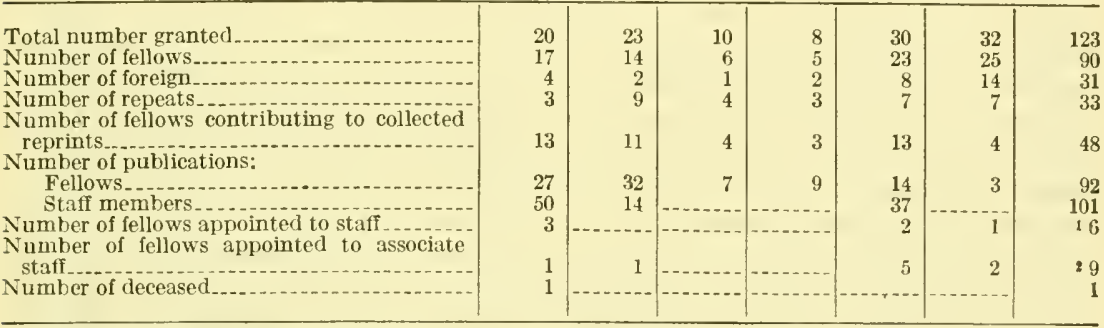

1 Includes 1 also listed as student fellow.

2 Includes 3 also listed as student fellows.

\section{Ficilities}

In the two laboratory buildings at Woods Hole, one of which was completed in $195+$ by the U.S. Navy and has been occupied by our staff since that time, we have a total of 58,500 square fleet of floor space. These waterfront laboratories furnish excellent working space for our staff but are now overcrowded and our administrative staff, together with much of our specialized electronies work, is poorly housed in temporary structures. The original investment in shore facilities of $\$ 325,000$ in 1930 was increased by $\$ 800,000$ by the U.S. Navy in 1954. Scientific equipment valued at over half a million dollars is currently in use by our oceanographers. Much of this is of such a special nature that it must be designed by our own engineers and built in our own shops.

The most important asset of an oceanographic institution in addition to its staff is its research fleet. At present our fleet consists of five deep-sea vessels and two small inshore boats. From time to time these vessels have been supplemented by naval vessels on special detail. Logistic support of our expeditions is on occasion furnished by 
the U.S. Navy. The composition of the WHOI fleet is shown in table III.

TABLE III.-WHOI research fleet

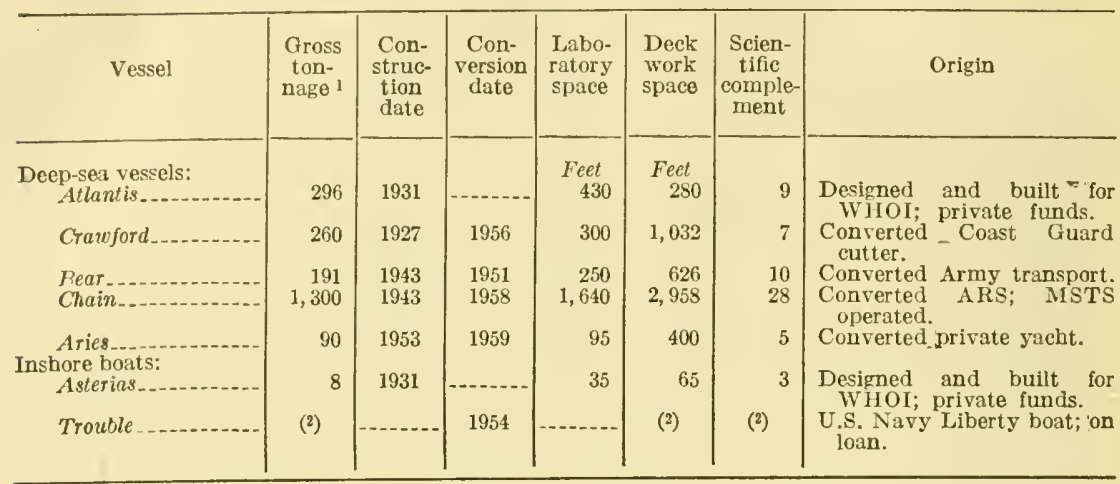

1 For total displacement see table in "Short History of WHOI" by Dr. Iselin.

2 Open day launch.

It has been repeatedly stated that the research vessel Atlantis is the only oceanographic research ship in this country specially designed for research at sea. She was built for $\$ 218,000$ in $1930-31$ and has proved to be a most capable vessel. Oceanography has, however, grown along with other sciences over the intervening years and now the use of modern electronics, isotopes, and the like have outgrown the capacity of sailing ships such as the Atlantis. Our best marine advisers indicate for reasons of safety and efficiency that it will be necessary to lay up the Atlantis in June of 1960 . We have made an intensive study of research vessels and our specific requirements. It is our hope that the artist's conception shown on the frontispiece of this statement can be implemented into a vessel on the building ways before the Atlantis is decommissioned.

The rest of our fleet over the years has been made up of converted yachts and military vessels. Its present composition is shown in table III. These have been of invaluable assistance during war emergencies and when no other means were available for research. But they are indeed poor substitutes for vessels specially designed for our work. The USNS Chain recommissioned in November 1958 is proving to be an excellent addition to our fleet and the present extended cruise to the eastern Mediterranean is an indication of her capabilities. Her capacity for 28 scientists is a welcome innovation in U.S. research 
ships-though still small in comparison to the berths for 70 scientists on both the Vityaz and Michail Lomonossow of the U.S.S.R. It is a salutary fact that all the oceanographers in the United States put together could not fill the scientific berths a vailable in the Soviet research tleet.

The research vessel $C$ rawford and the research vessel Bear have performed magnificiently for small ships; but it has been constantly necessary to overextend their capabilities in order to do some essential piece of research. The Crawford made 8 of the 13 trans-Atlantic crossings we have made in connection with the International Geophysical Year and her scientists sampled the ocean in 6,100 spots. This is a fair proportion for 1 small ship of the 24,000 samplings this Institution has made in the Atlantic Oceans during the IGY alone.

The implementation of the recommendation of the National Academy of Sciences' report for an expanded research fleet of modern ships is one of the key facets of the proposed program which is completely essential if this country is to maintain its necessary stature in the science of the world. Naturally the construction of ships requires expanded shore facilities and they should be closely coordinated. Accomplishment of one aspect without the other would be fruitless and unwise.

\section{BUDGET}

This Institution was founded on the concept that science should be largely funded by private means and was provided with a private endowment of $\$ 2$ million in addition to money for the land, the laboratory and the research vessel Atlantis. Today the market value of our endownment is estimated at $\$ 5$ million. There have been no substantial gifts for endowment since the first year. These funds were sufficient to meet the needs of the small staff during the 1930 's, but with the onset of World War II and its attendant urgent requirements in oceanography it became necessary to supplement the operating funds by money from the Federal Government-largely through the Office of Scientific Research and Development and the Navy.

Today about 90 percent of our annual budget is obtained from Federal funds. The remaining 10 percent is available from private funding-endowment income, industrial grants, and WHOI Associates. During 1959, our estimated expenditures of $\$ 31 / 2$ million will almost double the original endowment figure. Without question oceanography is one of the more expensive sciences when the cost per single datum point is considered. But the total expenditures are insignificantly small in comparison to the need. A breakdown of our budget for 1959 is shown in table IV. 
TABLE IV.-Revised budget for year 1959

[Dollar amounts in thousands]

\begin{tabular}{|c|c|c|c|c|c|c|}
\hline & & & & & & Total \\
\hline $\begin{array}{l}\text { Income: } \\
\text { Government contracts: } \\
\text { Navy } \\
\text { National Science Foundation } \\
\text { Atomic Energy Commission } \\
\text { Air Force } \\
\text { Fish and Wildife Service. } \\
\text { Weather Bureau..... } \\
\text { Public Health Service }\end{array}$ & 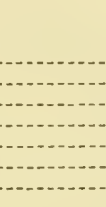 & - & 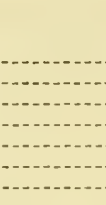 & 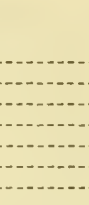 & - & $\begin{array}{r}\$ 2,722.4 \\
623.2 \\
137.7 \\
59.7 \\
40.0 \\
15.0 \\
12.3\end{array}$ \\
\hline $\begin{array}{l}\text { Commonwealth of Massachusetts } \\
\text { Endowment } \\
\text { Associates }\end{array}$ & - & 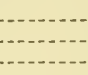 & 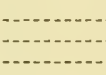 & 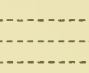 & & $\begin{array}{r}20.0 \\
133.0 \\
12.0\end{array}$ \\
\hline & $\begin{array}{l}\text { Direct } \\
\text { labor }\end{array}$ & $\begin{array}{l}\text { Vessel } \\
\text { opera- } \\
\text { tions }\end{array}$ & $\begin{array}{l}\text { Supplies } \\
\text { and } \\
\text { equip- } \\
\text { ment }\end{array}$ & Travel & $\begin{array}{l}\text { Indirect } \\
\text { costs }\end{array}$ & Total \\
\hline $\begin{array}{l}\text { Expenses: } \\
\text { Biology } \\
\text { Chemistry } \\
\text { Geology } \\
\text { Geophysies. } \\
\text { Meteorology } \\
\text { Physical oceanography } \\
\text { General }\end{array}$ & $\begin{array}{r}\$ 105.5 \\
89.7 \\
25.1 \\
415.0 \\
109.0 \\
478.2 \\
\end{array}$ & $\begin{array}{r}\$ 85.8 \\
27.7 \\
37.7 \\
389.3 \\
387.8 \\
25.0\end{array}$ & $\begin{array}{r}\$ 21.7 \\
18.4 \\
4.6 \\
358.9 \\
35.7 \\
196.1 \\
93.0 \\
\end{array}$ & $\begin{array}{r}\$ 3.9 \\
3.5 \\
1.8 \\
70.2 \\
10.6 \\
35.0 \\
5.0\end{array}$ & $\begin{array}{r}\$ 54.2 \\
55.5 \\
19.0 \\
253.8 \\
44.8 \\
285.5 \\
28.3 \\
\end{array}$ & $\begin{array}{r}\$ 271.1 \\
194.8 \\
88.2 \\
1,487.2 \\
200.1 \\
1,382.6 \\
151.3\end{array}$ \\
\hline $\begin{array}{l}\text { Total budget for year } 1959 \\
\text { Percent } \\
\text { Actual costs, year } 1958 \\
\text { Percent }\end{array}$ & $\begin{array}{r}\$ 1,222.5 \\
32 \\
\$ 1,043,1 \\
34\end{array}$ & $\begin{array}{r}\$ 953.3 \\
25 \\
\$ 593.3 \\
19\end{array}$ & $\begin{array}{r}\$ 728.4 \\
19 \\
\$ 662.9 \\
22\end{array}$ & $\begin{array}{r}\$ 130.0 \\
4 \\
\$ 132.7 \\
4\end{array}$ & $\begin{array}{r}\$ 741.1 \\
20 \\
\$ 625.9 \\
21\end{array}$ & $\begin{array}{r}\$ 3,775.3 \\
100 \\
\$ 3,057.9 \\
100\end{array}$ \\
\hline
\end{tabular}

Here it is shown that the largest source of funds is the U.S. Nary with the National Science Foundation second and the Atomic Energy Commission third. The breakdown of expenditures in the several areas of science is also shown in the table. Our greatest efforts are related to military oceanography and the problems of naval warfare. These, though of paramount importance, should not overshadow the other important problems awaiting solution. I refer here to research areas such as marine meteorology, ocean resources of food, minerals and energy, sea-keeping for merchant ships, atomic waste disposal, pollution of coastal waters and even more important those areas wherein our knowledge is insufficient to identify them.

\section{TIIE FUTURE}

We at Woods Hole endorse heartily and fully support the report of the National Academy of Sciences' Committee on Oceanography and the TENOC program of the U.S. Navy. We are well aware of the responsibilities it imposes upon us and our colleagnes. Wre, too, have been looking into the future and projecting our needs as we see them. We have completed preliminary design on a number of types of research vessels and selected the one most suitable for an Attantis replacement. On the basis of this, a proposal has been submitted to the National Science Foundation for funds to the extent of $\$ 3,750,000$ for such al vessel. (See p. 271.) Unless final design and model testing can begin immediately an unseemly gap will occur after the Atlantis layup in June of 1960. 


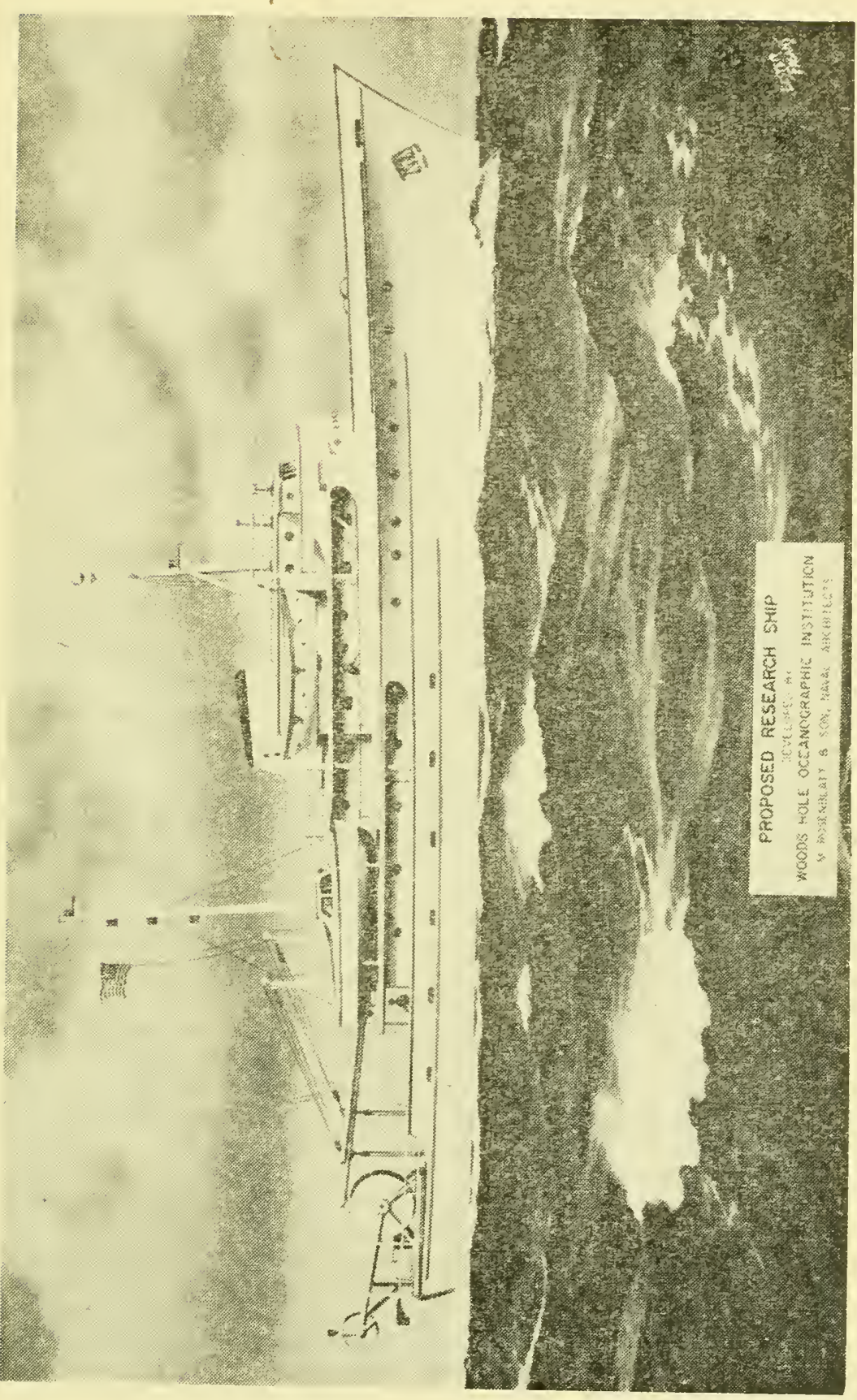


Our immediate needs also include more laboratory space. Our architects presently will complete plans for a new laboratory having approximately 45,000 square feet of space. Additional land must be procured for later expansion and equipment must be available for proper exploitation of these facilities.

With an expanded fleet our docks will be completely inadequate and must be rebuilt and extended.

These are only the needs that are urgently upon us within the coming year. Clearly this will be just a beginning and the more complete program as detailed by the Brown Committee and in TENOC must be fully implemented in the coming decade. We will continue to work energetically for private support of our research work but the fulfiillment of such programs cannot be done without Federal funds, the support of Congress and the understanding and support of all the people of this great land. Because of this we once again applaud your sincere interest in oceanography.

'The details of our current scientific program are given in the following statements prepared by senior members of our staff.

The Cramrman. And now we will hear from Mr. Columbus O'D. Iselin.

\section{STATEMENT OF C. O'D. ISELIN}

\section{Mr. Iseurn. This is a short history of the Woods Hole Oceanographic Institution.}

The concrete events that led to the establishment of the Woods Hole Oceanographic Institution were, briefly, the appointment by the National Academy of Sciences of a Committee on Oceanography; the presentation by the latter, in the autumn of 1929 , of a report on the scope and problems of oceanography and on the status of this science in North America; the adoption of this report by the Academy, with recommendations to the Rockefeller Foundation that an independent oceanographic institution be established on the east coast of North America; and the action of the foundation in granting a sum of $\$ 3$ million for building a laboratory and a ship and for endownment.

It was decided to establish the new facility at Woods Hole, and, with the help of the Carnegie Corp., a piece of waterfront was acquired from the Marine Biological Laboratory.

The institution, incorporated under the laws of Massachusetts, received its charter on the 6th of January 1930. The act of incorporation states as purposes: "To prosecute the study of oceanography in all its branches; to maintain a laboratory or laboratories, together with boats and equipment and a school for instruction in oceanography and allied subjects ***."

By the summer of 1931 the institution was a going concern with a brick laboratory, a seagoing vessel-the Atlantis-and a small parttime staff recruited largely from eastern university campuses. Dr. Henry I3. Bigelow was the distinguished first director. He had served as the executive secretary of the National Academy of Sciences' cominittee, and his book, "Oceanography," published in 1931, summarizes the hopes and expectations of oceanography that had stimulated the Rockefeller Foundation to "prime the pump." Its success is indicated by the fact that today the annual budget of the institution is equal to the original Rockefeller grant, which covered building, ship. and endowment. 
Woods Hole was chosen as the site of the newly established institution. Its objectives: The study of the oceans as a whole, their physics, chemistry, geology, meteorology, and biology, in particular ecology. Practical and intellectual considerations covered this choice: Nearness to Boston and Cambridge with their miversities and libraries; the existence of the Marine Biological Laboratory with its excellent library and which has long been a headquarter's of marine biologists; and the existence of the Bureau of Commercial Fisheries laboratory. Furthermore, Woods Hole is close to the open sea, which, in our region, provides a sudden transition of cold coastal waters to tropical oceanic conditions in the nearby Gulf Stream.

Now what has been accomplished during the last 26 years and what have been the canses of our growth? We started as a summer laboratory with one full-time ship but only a few full-time scientific staff members. We have come to acquire five more or less adequate seagoing vessels and a year-round payroll of about 350 people, augmented in summer by more than 100 students and visiting investigators.

Until the Second World War the growth was gradual. Although our original building was always full in summer, there were seldom more than three to six investigators carrying on research in winter. The Atlantis, our fine new research vessel, cruised widely, and for the most part carried ont three-dimensional surveys of the currents, biology and chemistry of the water. Occasionally cruises were made whose primary objectives were the study of marine sediments, and a beginning was made in the development of geophysical techniques for exploring the underlying structure of the North Atlantic basin. The microbiology of the sea was developed to some extent and a few cruises were devoted to the collection of the larger deep-sea forms.

$\mathrm{By}$ the end of 10 years we had made considerable progress in understanding the currents of the western North Atantic. In short, after the Atlantis had cruised for 10 years, we felt generally at home in most of the North Atlantic, both physically and chemically, and to a lesser extent geologically and biologically.

When the war clouds gathered, it was the many measurements of temperature and salinity and their study that chiefly paid off. As early as 1937 the Atlantis had made observations on sound transmission off Cuba. This opened our eyes to the fact that physical oceanography plays a significant role in subsurface warfare. With the early emphasis of the Office of Scientific Research and Development on problems of undersea warfare, for the first time oceanographers found themselves consulted on matters of national defense by the scientific community of the Nation as a whole. Woods Hole was visited by many scientists and engineers who previously had thought that this was strictly a biological center. We taught a considerable number of naval officers the sorts of oceanography that play a part in both prosubmarine and antisubmarine warfare. We acquired machine shops and electronic shops. Gradually our full-time scientific staff" came to include a hundred or so people, most of whom had previonsly had little or no comnection with the sea. By the end of the war our annual operating expenses had increased from ronghly $\$ 150$,000 per year, the approximate income from endowment, to about $\$ 1$ million per year. The Federal Government had suddenly become a major source of support for our oceanographic laboratories. 
This has continued to be the case in the postwar years, both at Woods Hole and elsewhere in the United States of America. We now not only have research contracts with the Navy but also with the Atomic Eneroy Commission, with the Weather Bureau, the Fish and Wildlife Service, other Government agencies, and research grants from the National Science Foundation. There is worry that this form of support may not remain sufficiently stable over the years to build up a strong scientific staff, but to date, with few exceptions, the policy in Washington has been remarkably liberal and understanding. Meanwhile, our own uncommitted income has grown to abont $\$ 300,000$ per year. At the present time this is about 10 percent of the total cost of our operations, but it is the key to their success.

So far as the naval applications of oceanography are concerned, we have been principally engalged in charting the ocean in ways that can be helpful to a modern Nary. Formerly, navigation was a twodimensional problem. With the advent of nuclear-powered submarines the Nary is face to face with three-dimensional navigation. In detection of submarines we are concerned with the physics and chemistry of the whole water column, and with the character of the bottom well below its upper surface. Underwater acousties has become a vigorous branch of physical oceanography and submarine geology, which is intimately bound up with the changing internal structure of the sea and its boundaries. As the instrumentation of warfare at sea has evolved, more and more nature has become a critical factor in its successful operation.

From 1942 to 1946 the top floor of the lahoratory was turned over to the Underwater Explosives Research Laboratory, a group under the leadership of our present Director. In this regard it should be mentioned also that we have continued to provide quarters for the oceanographic division of the International Ice Patrol.

It is not feasible to list all the projects that were being studied : the importance of our wartime work mat be emphasized by the award of the Legion of Merit to the Director, with the citation "**** as having saved many of our ships," and the acknowledgment that our antifouling studies "saved 10 percent of the Nary's fnel bill."

In the years immediately following World War II the Institution faced a sharp decline in its annual budget. Government contracts continned, but on a reduced scale. Those years were difficult for the Director who had to find the funds to keep the staff and the ships going, but they were exciting days for the scientists. Relieved from immediate pressures in the demand for practical applications and aided by new instruments and methods, we were able to learn that the Gulf Stream and other currents were much more complex, swifter, and narrower than was formerly believed. The new knowledge led to a most successful multiple-ship survey in 1950 (known as Operation Cabot). The geophysicists learned to operate two vessels working jointly and ranged ahead in the systematic program of measuring the aconstical reflectivity of the bottom in deep water.

Other programs also were productive. More than 40 staff members made oceanographic investigations during the first Bikini bomb tests, while in 1946 we started our meteorological observations in the tradewind areas which became so fruitful in the development of a strong meteorological group at Woods Hole. Another investigation which 
was to have great influence on marine investigations was the study of the pollution of sea water. This led to new knowledge of coastal and harbor hydrography with many practical applications.

The wartime acquisition of qualified engineers and electronics specialists was of great importance to oceanography. Many instruments designed at the institution are now in use by oceanographer's throughout the world, including the Russians.

In 1954 the Laboratory of Oceanography, built by the U.S. Navy for our use, was dedicated and provided much needed "breathing space." Since then our staff and facilities have continued to expand until we again are badly in need of additional shore facilities. 'The fleet, now consisting of five seagoing vessels, three inshore craft, and three planes, also is entirely inadequate for our needs. Other facilities acquired since 1952 are the 10-acre "Challenger" property with residences, apartments, and dormitories, two adjacent parking lots, property on the Eel Pond, and a dock for expansion purposes.

During recent years Government contracts have increased considerably from all sources. The institution's endowment, although increased through capital gains, never received additional funds. However, one most important contribution to our free moneys for basic research has come from the associates of the Woods Hole Oceanographic Institution, a group of private individuals and corporations interested in aiding our work. This fund has been instrumental in providing support for investigations which otherwise could not be carried on.

A glance at the list of more than 1,000 scientific contributions made by our staff will provide a knowledge of the extreme variability of our program and the important role the institution has played in the development of oceanography. Although mitil recent years we worked chiefly in the western North Atlantic Ocean and the Caribbean Sea, our ships now have ranged the North and South Atlantic Oceans, the Indian Ocean, Red Sea, Mediterranean Sea, and the Pacific Ocean. The International Geophysical Year gave us the opportunity, together with our colleagues of the (British) National Institute of Oceanography, to make an unprecedented survey of the North and South Atlantic Oceans which should become as classic as the famed Challenger and Meteor surveys. Our chemical and biological programs have greatly expanded and are extending their observations over progressively larger areas.

Oceanography does not fit well into the organization of our universities. There are economies to be gained by having one facility serve the needs of the relatively few students and faculty members of nearby universities and colleges. Our educational activities have increased markedly in recent years, and the universities realize the importance of our facilities, as may be indicated by the recent appointment of six of our staff members to professorships at the Massachusetts Institute of Technology.

Nearly all problems in oceanography are rather intimately connected with the movement of the waters. Thus, the many aspects of the circulation problem in the sea form a central core of knowledge that all marine scientists need to draw on. Oceanography, which may seem at first glance a most diffuse object, does, indeed, have a certain unity. At least, this is our experience at Woods Hole to date, and the 
development of similar centers of research, both in this country and abroad, seems to indicate that the original concept of our laboratory was sound.

(Matter referred to follows:)

DiRectors

1930-40: Dr. Henry B. Bigelow 1940-50: Dr. C. O'D. Iselin 1950-56: Rear Adm. Ed. H. Smith 1956-58: Dr. C. O'D. Iselin 1958-present: Dr. Paul M. Fry
Presidents of the Corporation

1980-40: Dr. Frank R. Lillie 1940-50: Dr. Henry B. Bigelow 1950-56: Dr. Arnaud C. Marts 1956-present: Mr. Raymond Sterens

\begin{tabular}{|c|c|c|c|c|}
\hline Shlps & Year acquired & $\begin{array}{l}\text { Tear dis- } \\
\text { posed }\end{array}$ & $\begin{array}{l}\text { Length } \\
\text { (feet) }\end{array}$ & $\begin{array}{l}\text { Displace- } \\
\text { ment in tons } \\
\text { (approxi- } \\
\text { mate) }\end{array}$ \\
\hline $\begin{array}{l}\text { Atlantis. } \\
\text { Asterias. } \\
\text { Aries } \\
\text { Albatross } I \bar{I} I \\
\text { Anton Dohrn } \\
\text { Ralanus. } \\
\text { Bear. } \\
\text { Caryn } \\
\text { Chain } \\
\text { Craword } \\
\text { Mentor. } \\
\text { Mytilus } \\
\text { Physalia } \\
\text { Reliance } \\
\text { Reliance } I I \\
\text { Trouble. } \\
\text { Yamacrawo }\end{array}$ & $\begin{array}{l}1931 \\
1931 \\
1959 \\
1951 \\
1941 \\
1946 \\
1951 \\
1947 \\
1958 \\
1956 \\
1945 \\
1943 \\
1944 \\
1943 \\
1943 \\
1958 \\
1957\end{array}$ & $\begin{array}{c}1952 \\
1950 \\
1951 \\
1958 \\
1950 \\
1954 \\
1946 \\
1951 \\
1946 \\
1958\end{array}$ & $\begin{array}{c}142 \\
40 \\
93 \\
1631 / 2 \\
70 \\
72 \\
110 \\
98 \\
2131 / 2 \\
125 \\
127 \\
41 \\
64 \\
78 \\
38 \\
30 \\
189\end{array}$ & $\begin{array}{r}560 \\
8 \\
95 \\
700 \\
45 \\
50 \\
250 \\
100 \\
1,800 \\
300 \\
200 \\
7 \\
42 \\
75 \\
7 \\
3 \\
1,200\end{array}$ \\
\hline
\end{tabular}

With the exception of the Atlantis and Asterias all craft were conversions. The Albatross III was on loan from the Bureau of Commercial Fisheries and the Yamacraw on loan from the U.S. Coast Guard. The Chain is on loan from the U.S. Navy.

Aircraft:

PBY 1952-57 (on loan from the U.S. Navy).

R4D 1957 ; present (on loan from the U.S. Navy).

Stinson Voyager 1954 ; present.

The Chamman. Next will be Mr. William S. voln Arx.

\section{STATEMENT OF WILLIAM S. VON ARX}

Mr. von Arx. Physical study of the ocean has been developed for the most part from economic or industrial necessity. Some of the first systematic deep-sea soundings were made in connection with the laying of the North Atlantic telegraph cables. Intensive studies of the circulation and water temperatures have been prompted by a desire to improve the yield of fisheries in many parts of the world. Other studies of the oceans have been made for reasons of military necessity. Only a few great expeditions have been prompted by simple inquisitiveness. Except for the latter, each of these endeavors has been approached in a relatively single-minded fashion so that the yield beyond the questions initially asked has been smaller than it might have been.

In the years since the last war Federal support of oceanographic research has been broadly administered with the result that, after a lapse of over a century, undirected human curiosity has led to the 
discovery of two new major ocean currents in the past decade, one by accident and the other through theoretical prediction. New understanding has also been gained of, among other things, the nature of subsurface waves and of the role of sea salt in rainfall. This knowledge is of clear benefit to our national economy even though such, or any, applications were far from uppermost in the minds of the discoverers.

Since the time of the American Civil War many nations hare contributed to a systematic description of the physical geography of the seas by sending out major expeditionary ships for periods of several years. This accumulation of information has provided most of the basic knowledge we have of the steady or climatological mean distribution of oceanic properties. Three of the most searching studies of the architecture of the oceans were made by the British in the Antarctic waters in connection with the whale fishery, by an American expedition extended over the whole globe under the sponsorship of the Carnegie Institution of Washington and by the German Meteor expedition which concerned itself mainly with the south and equatorial Atlantic Oceans. During the International Geophysical Year the area of the Meteor expedition was resurveyed and extended into the North Atlantic. The results of these recent studies show that the mean distribution of oceanic properties has not changed appreciably in the course of three decades.

This information is of fundamental significance because it is the steady component of the circulations of the oceans that have, in common with the atmosphere, an important role to play in the maintenance of the climates of the earth. As study advances it is becoming increasingly clear that the ocean-atmosphere system will one day be considered as a single problem for investigation. While the atmosphere is the principal avenue along which the excess of heat supplied by the sun to the equatorial regions of the earth is exported toward the poles, it is the water eraporated from oceans that makes this possible. Water evaporated from the sea permits the atmosphere to carry heat to high latitudes in a latent rather than sensible form. The efficiency of the latent heat process is approximately 50 times greater than would be the case in the absence of water vapor transport. The oceans also influence the atmospheric circulation directly through their enormous heat storage capacity.

Lately the center of gravity of research interest has shifted from global surveys to a more analytical approach in which ships and men go forth to find answers to carefully stated questions which their research has led them to ask. Some of these concern the details of the processes by which water vapor is exchanged between the oceans and the atmosphere. Other's relate to the unsteady motions of the sea: the phenomena accompanying internal waves, the meandering, pulsation, and tidal modulation of strong currents such as the Gulf Stream and the dynamics of the circulation far below the surface. These problems are being studied primarily because of their scientific interest but they also have important bearing on the industrial and military uses of the ocean in much the same way that knowledge of the storms and winds of the atmosphere are of importance to aviation. 
Exploitation of the oceans must be based on fundamental understanding of the physical nature of the environment. A pragmatic approach or the mere collection of data, gathered in the hope that somehow, sometime these may be fitted together, will lead nowhere. Meteorology has, since the time of the Battle of Balaclava, been forced by the demand for weather predictions into routine data collecting and pragmatic interpretation to such an extent that an approach to fundamental understanding of the process of the atmosphere has been left in the hands of relatively few men. These men work on basic problems in spite of, rather than because of, the pressures to advance the applied problem of prediction. This uncomfortable situation has improved in recent years through a growing awareness that it is these men who are most likely to produce the economically desirable result. This lesson should be borme in mind if and when it becomes necessary for oceanographers to enter the field of prediction or to participate to a greater extent than they now do in the problems of marine technology.

The Champuar. Now we will hear from Mr. Henry Stommel.

\section{STATEMENT OF HENRY STOMMEL}

Mr. Stonmes. The following are theoretical studies at the Woods Hole Oceanographic Institution.

Of the stafl at Woods Hole, about six of us are engaged in purely theoretical studies. Dr. Veronis and I have been concemed with developing a theoretical basis for understanding the circulation of the water in the currents of the ocean. How much of this circulation is due to the action of winds, how much is due to heating by the sum, or by evaporation or rain? What is the mechanism by which the ocean currents are maintained, and can it be shown that the forces involved are quantitatively sufficient to explain the magnitude of observed effects? The theory must be mathematical in form and is developed as a special class of problems in hydrodynamics-the branch of theoretical physics which treats the physics of fluids in motion. A way has been found leading to a preliminary theory of the ocean circulation. This theory enables us to compute many features of the ocean currents which at present cannot be directly observed. For example, it permits us to deduce theoretically the pattern of slow average drifts in deep water which at present, except in certain favorable localities, camnot be measured directly.

Drs. Bryan, Faller, and Stern are engaged in studying the general properties of rotating fluids by means of theoretical studies of laboratory experiments on rotating models. 'Their work is rather general and its applicability is not limited to the ocean but bears also upon the interior of the earth and the atmosphere. 'They are not part of a team but work as individuals, and their studies are guided by their own initiative and by interaction with colleagnes at Harvard University, Massachusetts Institute of 'Technology, Johns Hopkins University, and the University of Chicago who have embarked upon parallel investigations.

Some of the rotating basins which you will see when you look around our laboratory have been designed to simulate the ocean in some detail. For example the basins with the recognizable geographical features, 
made by Dr. ron Arx, are meant to exhibit realistic circulation patterns as they might appear from a very high altitude above the real oceans on a very clear day. Other rotating basins clo not bear any recognizable similarity to the earth but are used in checking and rerifying theoretical studies. Experiments in rotating basins can be controlled and conditions varied. In the real ocean, of course, we simply have to measure things as they are-even this is a diflicult task-and there is no immediate possibility of controlling or changing the ocean circulation to check our theories.

Theoretical considerations enter into the work of many people at Woods Hole other than those who make it their primary concern. In order to illustrate what is being done here I will conclude with one outstanding example-the work of Drs. Malkus and Veronis on the theory of turbulence.

You have all noticed how there are, in nature, two kinds of fluid flow: laminar flow and turbulent flow. A thick oil, poured slowly out of a bottle, flows in a laminar fashion. Each particle moves in a smooth curve or trajectory. If the fluid is thin and poured quickly there are many eddies and irregular motions-we call such flow turbulent. A theoretical understanding of turbulence is very important for all kinds of practical things besides oceanography; for example, in the design of aircraft and ships. Because there has never been a sufficiently general theory of turbulence, engineers have had to employ large and expensive wind tunnels and towing tanks to obtain the necessary information to allow for turbulence when designing new aircraft and ships.

Now that engineers are planning nuclear rockets and investigating the hydrodynamics of plasma in thermonuclear reactors, the need for a basic theoretical understanding of turbulence is once again being felt. Ten years ago Dr. Malkus set himself the ambitious task of working out a basic theory of turbulence, and when he began there were several of us who thought he had bitten off quite a bit more than he could chew. After all, it is a field in which many great scientists over the past 50 years have made such very limited progress that they soon turned to other subjects. But Malkus, by a series of remarkable insights, has succeeded in paving the way to a general theory of turbulence. Already he has been able to deduce theoretically many of the features of fluid flow which hydraulic engineers have previously had to discover by tedious and expensive experiment. Much remains to be done, but engineer's, astrophysicists, rocket designers, and others besides meteorologists and oceanographers a re beginning to take a deep interest in his work. That he is contented to stay at Woods Hole, despite offers from industry, is a measure of how much he values the freedom of inquiry which he enjoys here.

What I mainly want to convey to you is the diversity of the theoretical studies that are underway here: theories of specific oceanographic phenomena such as ocean currents, of more general hydrodynamical problems involving rotating fluids, and very general investigations like Malkus' theory of turbulence which is of interest to all areas of science where liquids are involved.

Mr. Champman. And next will be Miss Joanne S. Malkus. 


\section{STATEMENT OF JOANNE S. MALKUS}

Miss Malisus. Marine meteorology is not just the study of weather over oceans, nor is its role at an ocenographic institution restricted to aiding oceanographers understand how the winds drive ocean currents or how storms stir up waves.

First of all, the ocean is the source of energy for the entire atmosphere heat engine; the fuel driving tropical hurricane and northern jet stream, midwestern cyclone and New England rainstorm has been supplied to the air not directly by the sun, but indirectly via the oceans, largely in the form of so-called latent heat in water vapor.

If we wish to understand the operation of this huge heat engine which is our atmosphere or of any of its component wind systems, storms, or raining clouds-if we dream of eventual human control of these phenomena, both to inhibit those that are destructive and regulate those which are beneficial, we must first understand something about what is their driving power or energy source and what are the inhibitors, just as to operate an automobile we must know where are the accelerator and brakes, what fuel is needed, and how to locate a gas station. 'The atmosphere is nature's product and not man's and is thus far more mysterious and complex than an automobile, but recently we have begun to pry from it some information about its fuels and their sources, and briefly, this is the first role of marine meteorology. Marine meteorology is best carried out at an oceanographic institution not only because the proper ships and facilities are available, but because to explore the air-sea boundary and its vital energy exchanges the talents of oceanographers and meteorologists together are required.

Second, the air and the sea are both fluids and obey the same laws of fluid mechanics. Jet streams, wave motions, turbulence, are displayed in both but on different space and time scales; gaining insight into the meanders of the Gulf Stream could lead to a breakthrough in understanding or predicting the behavior of the high-level atmospheric westerly jet stream and its cyclonic storms.

Similarly universal is the phenomenon called convection, or the rising of heated parts of a fluid because they are higher or more buoyant than their surroundings. Examples of convection are the tropical cumulus cloud, the thunderstorm, the solar flare, the motions in the earth's core creating its magnetic field. Convection also frequently goes on in liquids, such as Vineyard Sound; the Pacific Ocean, and your coffee cup (where the luexagonal, square and triangular cells of adjacent up and down motions are made visible by dark lines just after you pour in your cream.)

It is an oversimplification, but not a criminal one, to say that convection drives the atmosphere, in part and at large. In the tropies, over the warm seas where the atmosphere's energy is supplied, invisible convective bubbles carry the gaseons water vapor fuel from the sea surface, where it first enters the a ir by evalporation, upward to at level where some of its is condensed ont into liguid water droplets to form a cumulus cloud, the prototype example of the convective process. Myriads of cumulus clouds forming day and night over these sun-warmed, low-latitude oceans carry aloft the water vapor. Some of the heat which is released in these clouds where a fraction 
of the water vapor condenses into liquid water is used to drive the vast and steady easterly trade-wind systems on both sides of the equator. Most of the remaining water vapor (which in energy content is enough to maintain all the global winds several hundred times over) is carried equatol-ward by these trade winds to the so-called equatorial trough zone-tropical storm and hurricane factory-upon which our marine meteorology studies have recently shed some rather exciting light.

Here the real fuel combustion of the atmosphere is done, as the accumulated water vapor is raised in towering thunderhead and anviltopped cumulonimbus, condensing and thereby releasing "sensible heat"-available to be exported poleward, much later to drive midlatitude cyclone and jet stream, and balance the spaceward radiation losses of the long polar night.

What is most remarkable, however, about the atmosphere's equatorial "firebox" is that this energy conversion and release takes place in a very small number of "cylinders"-10 percent of the equatorial trough area is occupied at any one time by vortical storms (of which, incidentally, maybe 1 in 50 becomes a hurricane), 10 percent of the area of these is experiencing active rain, while only 10 percent of this, or 0.1 percent of the total trough zone, is occupied by the giant cumulonimbus whose intense updrafts convert the latent heat and propel it to great heights. Just 1,500 to 5,000 runaway cloud towers around the globe are enough to drive the engine, to combust the vast amount of water vapor fuel accumulated from the oceans and shipped in by the trade winds-and elevate the product to great heights where it is available to be exported to distant regions: later a small fraction is used to maintain high-level jets, form eyclones and drive the Gulf Stream. If man dreams of ever controlling or regulating the largescale behavior of his atmospheric heat engine, he would do well to look for those links in its operation where much is done in restricted regions, such as the equatorial trough, by relatively few elements, such as the giant clouds, and attempt to understand these rather thoroughly. He must seek to isolate key processes and key problems and pursue them with every possible form of attack-theoretical, with equations and high-speed electronic computers; observational by instrumenting aircraft, helicopters and balloons to penetrate the active heart of the phenomenon; experimental by designing simplified models in the laboratory, and by all these approaches jointly and together, interchanging questions and knowledge.

Convection is a key problem and has a direct practical impact on man. A major fraction of the world's rainfall, all its hail, lightning, and tornadoes are convectively produced and convection forms the driving power of the destructive tropic-born nemesis, the hurricane. That it is a key problem to progress in understanding and eventually influencing the overall behavior of the atmosphere, we have seen by the brief picture just painted.

Ten years ago this picture could not have even been sketched. It has been put together, in considerable part here at Woods Hole, due in good measure to the long-sighted support of governmental agencies such as the Office of Naval Research. Research is a long, slow process, and sudden insights and turning points often occur when least expected. For example, some of our work on individual cumulus cloud 
towers, both with theory and aircraft observations, has quite surprisingly led to a sharp jump in our knowledge and understanding of the tropical hurricane. It has long been suspected that the hurricane runs on the heat released from water vapor condensing into clouds and rain, but the relationship of this energy source to the actual driving of the winds has been obscure. 'This mechanism is at last beginning to be understood, and jointly, with the University of Chicago's meteorology department, we have recently evolved a theoretical model of how the spiral bands of towering clonds maintain in the storm core the "pressure head" that powers the raging winds. We are now in the process of testing these theories in collaboration with the Weather Bureau's national hurricane research project. Their aircraft made motion pictures inside the hurricanes, and from these we are laboriously making cloud counts, maps, and calculations. It is hopeful that, if these studies are carried on here and elsewhere, we may learn more of how the formation and motion of these menaces to mankind are brought about. Regardless of immediate practical results, however, the hurricane study expenditures have already paid off multifold in taking us nearer eventual comprehension of the atmosphere's basic processes.

We are also developing theories of individual convection elements by equation and electronic computer, by testing them with field observation and laboratory data, and by flying our Nary-loaned calibrated and instrumented aircraft into actual clouds. This aircraft is also used to explore incipient tropical storms, to measure the heat input from the ocean to the air mder varions conditions, and to seek out those situations where nature herself is performing relatively controlled convection experiments, as often occurs over nearby Nantucket and Martha's Vineyard Islands.

Thus the subject of marine meteorology is a broad one, and our understanding of it may be advanced by some equations describing the motions in a coflee cup, from experimental measurements on ink blots in a rotating laboratory basin, or from an aircraft flight at 50,000 feet photographing a clond. We are doing all these things here at the Woods IIole Oceanographic Institution, not at random but with the basic motivation of learning how heat is transformed into fluid motions in man's atmosphere and oceans, how he may best understand these processes, avoid their evil consequences, and profit from those which are beneficial.

The Cimarman. Next will be Mr. Bostwick H. Ketchum.

\section{STATEMENT OF BOSTWICK H. KETCHUM}

Mr. Kercnum. The following are biological and chemical investigations:

Thirty-six scientists of the Woods Hole Oceanographic Institution are engaged in the study of the biological and chemical aspects of the ocean. The program is a broad approach to the basic problems concerning the distribution and life cycles of plants and animals in the sea. 'This includes the dynamies of their growth and the variations in the fertility of the oceans, both of which depend upon the essential fertilizing chenicals in the water.

These investigations cover all aspects of life in the sea, and include such sturlies as sunlight and its penetration into the water; the microscopic marine plants called phytoplankton; the varied forms of life 
making up bottom communities; the first step in the animal food chain, the zooplankton; and the larger forms-fish and whales. The distribution of interest and eftort of these scientists is shown in table $I$.

'These basic biological processes are studied primarily because of the interest and the curiosity of the scientists on our stafl. 'There are also eminently practical reasons for understanding the biological cycle in the sea. 'These basic studies are necessary before we can understand, much less modify, the yield of edible species of fish and other sea food. Also, the living organisms in the ocean will limit the amounts of radioisotopes which we can safely add to the ocean, either as a waste-disposal measure or inadvertently as a result of accidents.

The cycle of life in the sea, just as on land, depends upon the process of photosynthesis which converts the energy of the sun to living organic matter. In the clearest ocean water sufficient light to permit photosynthesis may penetrate to depths of 300 feet. Here, however, the bottom is perpetually in the dark and the microscopic phytoplankton, which float freely in the water are the only plants which can live in the upper, illuminated zone. The seaweed, so common along shore, is limited to depths of 100 feet or so in our turbid coastal water by lack of light.

The essential fertilizing chemicals, such as phosphorus and nitrogen, are greatly reduced and sometimes completely exhausted throughout the illuminated zone. However, about 90 percent of the ocean water is at greater depths and a tremendous reservoir of these essential elements is stored in these cleep waters. In the higher latitudes, winter cooling and strong winds mix the waters deeply and these fertilizers are returned to the surface. In spring, as sunlight increases and the water warms, the phytoplankton have a rich medium in which to grow and produce a spring bloom. In the tropics mixing occurs less deeply and the surface waters are always low in nutrients. However, the plants grow slowly throughout the year. Here the biologist and physical oceanographers face common problems since it is the turbulence and the rate of exchange of materials between layers in the sea which keep this system going.

The animals of the sea depend upon this plant production as their sonrce of food. The tiny zooplankton animals filter the microscopic plants from the water, using the most intricate arrangements of modified limbs and mouthparts. The variety of zooplankton is remarkable. All of the major groups of invertebrate forms of life are represented, and many different feedings types are frequently found in a single sample obtained with a fine mesh net. To date we have studied the food requirements of only a few species of this enormous community. Some depend entirely on the plants they can filter from the water while others consume these plant eaters, to be eaten in turn by larger animals, including fish. There is a loss in energy at each step in this food chain. When many steps are involved the final animal product may be a small fraction of the organic production by the plants. It has been estimated for one of our great fishing grounds, Georges Bank, that about a thousand pounds of organic material must be produced by the microscopic plants to provide one pound of fish for the table.

Several estimates have been made comparing the fertility of the oceans with that of the land areas of the earth. Beyond the shallow 
coastal waters where seaweeds are found, the sea never supports the dense populations found in forests or grasslands, let alone those artificially developed through agriculture. 'The forests represent an accumulation of 50 years or more of growth, while even grasslands and farm crops accumulate over one entire growing season. In contrast, maximum populations in the ocean can develop in a few days when the conditions are right. When we compare the rates of production, therefore, the total photosynthesis taking place in the ocean is approximately equal to that which takes place on land.

This brief summary of our activities omits many of the problems being studied by our biologists and chemists. For example, what is the vertical distribution of animals in the sea? We know that populations migrate upward to the surface at night and downward during daylight. Presumably this is a response to sunlight, but what organisms are involved and what is the physiological control of this migration? What effect does this migration have upon the distribution of the essential nutrient chemicals in the sea? Especially how will this migration affect the distribution of radioactive elements added to the sea, through fallout, waste disposal, or accidental additions? These and many other questions will require a complete understanding of the biology and chemistry of the sea before answers can be given.

(Matter referred to follows:)

Fields of study of the biologists and chemists on the resident staff of the Woods Field of study: Hole Oceanographic Institution

Penetration of light_-_-_-_-_-_- 2

Bacteriology

Phytoplankton:

Photosynthesis and culture_-_-_-_-_-_- 5

Distribution and composition.

Zooplankton :

Feeding and nutrition

Distribution and migrations

Fish: Distribution and life cycles

Mammals: Whales and porpoises_-

Bottom populations:

Distribution and ecology-_-_-_- 3

General physiology

Nutrient chemistry and fertility:

Seasonal cycles

Geographical distribution

Geochemistry and radiochemistry

Mr. Cirairman. The last witness will be Mr. Earl E. Hays.

\section{STATEMENT OF EARL E. HAYS}

Mr. Hays. The underwater acoustics and geoplysics group at the Woods Hole Oceanographic Institution numbers about 50 people, of whom about one-half hold college degrees in scientific curricula. This is the largest group in the institution working on a common problem: the problem being such that it requires a large number of people to make the necessary measurements, reduce the data, and maintain the equipment. 'The group is primarily interested in the propagation of 
sound in the ocean and the ocean bottom. In some cases the studies are directed toward a more complete understanding of the mechanisms of sound propagation; in others the known facts of sound transmission are used as tools to study the structure of the ocean bottom.

The most pressing problem in the underwater acoustics field today is the detection of submersibles. The state of this art at the present seems to indicate that only by overall study and detailed understanding of sound transmission in the ocean will the ranges of effective detection be substantially increased. Advanced schemes and novel ideas to solve the problem are always being presented, but whether they will work or not depends upon the accurate prediction of sound transmission. The size of the oceans automatically implies that any detection method will be very expensive and we can ill afford to invest in systems which are not based on careful experimental measurements made under the actual working conditions. Therefore, our efforts have been to make measurements of sound transmission in various typical parts of the ocean during different seasons of the year. These measurements are related to such controlling factors as the water temperature structure and bottom topography and analyzed in terms of these factors. The ultimate aim, of course, is to be able to predict sound transmission conditions anywhere at any time with reasonable accuracy. One can scarcely work in such an undertaking without thinking of particular techniques or methods for detecting submarines. As an institution of oceanography it is hardly in our realm to pursue such ideas to a final completed weapon, but we do follow such ideas through feasibility studies or interest the proper people into doing the same.

Sound is a wave disturbance that is propagated with different relocities in different materials and is analogous to light undergoing reflection and refraction. These characteristics make sound a most useful tool for studying the structure of the ocean bottoms. The answer to the song "How Deep Is the Ocean" is being answered by just such means. A sound pulse travels from a ship to the bottom, is reflected, and returns; the travel time is a measure of the depth. Instruments working on this principle are so highly developed that the major problem is knowing the ship's position accurately enough to match the precision in the depth measurement. These instruments do more than just measure the depth of the water; they show the presence of the deep scattering layers, the presence of fish and whales, and under certain conditions enough penetration of the bottom occurs that reflections from subbottom layers are detected. We have developed an instrument for the specific purpose of detecting these subbottom layers (the sound spectrum of the source is different from that of a conventional echo sounder), and it is fascinating to see the layers beneath the sea bottom appear on the record in their many forms. Unfortunately such reflection techniques do not give the complete answer as to depth and thickness of the layers. Sound refraction work in which the source and receiver are separated by appreciable distances permit us, however, to infer layer thickness and sound velocities. Laboratory measurements and field measurements correlated with coring and dredging relate the sound velocities 
to types of materials. Such studies provide important information on the structure of the ocean bottom and from this hypotheses and theories of general geophysical interest concerning the information of the oceans and the continents can be made.

In addition to these two major concerns many other interesting related problems are being investigated. 'The deep scattering layer is being studied acoustically and photographically; photographs of the bottom are taken, ambient noise is measured, and specific noisemakers are identified. 'Thank you.

Mr. Cramman. This will conclude the hearings on Woods Hole, Mass.

(The following matter is presented for the record:)

\section{Whol Participants in the House Subcommittee Hearing}

\section{Paul 15. Fye}

Director, Woods Hole Oceanographic Institution since 1958.

Ph. D. (physical chemistry), Columbia University, 1939.

In charge of the Underwater Explosives Research Laboratory at WHOI during World War II. Previously with the Naval Ordnance Laboratory as Associate Technical Director for Research. Taught at Columbia University, Hofstra College, University of Tennessee.

Member: Amer. Geophys. Union; Amer. Phys. Soc.; Amer. Chem. Soc.; NAS Cmt. for Dept. of Comm.; Corp. Mem. Mar. Biol. Lab.; trustee, Bermuda Biol. Sta.; Sigma Xi ; Phi Lambda Upsilon.

\section{Columbus O'D. Iselin}

Henry Bryant Zigelow oceanographer, Woods Hole Oceanographic Institution.

D. Sc., Brown University, 1947.

Associate professor of physical oceanography, Harvard University; professor of oceanography, M.I.T.; Director of WHOI, 1940-50 and 1956-58.

Staff member WHOI since 1932.

Member: Amer. Acad.; Geophys. Union; Philos. Soc.; fellow N.Y. Acad.; Cmt. Undersea Warfare, Nat. Research Council ; Civilian with Office Sei. Research \& Develop.; IGY Nat. Acad. Tech. Panel on Oceanog. ; Nat. Acad. Cmt. on Oceanog. ; Spec. Cmt. for Oceanog. Research (SCOR).

\section{William S. von Arx}

Physical oceanographer, Woods Hole Oceanographic Institution.

Ph. D. (meteorology), Massachusetts Institute of Technology, 1955.

Professor of oceanography, M.I.T. Previously with ONR. Taught at Yale University, Harvard University, and M.I.T. Staff member WHOI since 1945.

Member: Geophys. Union; Amer. Soc. Limnol. \& Oceanog.; Meteorol. Soc.; Univ. Cmt. for Atmos. Research; Panel on Terrestrial Heat \& Water Budget, Cmt. on Polar Research, Nat. Acad. ; Panel on Earth Sci. ; Nat. Sei. Fdn.

\section{Henry Stommel}

Physical oceanographer, Woods Hole Oceanographic Institution.

Professor of oceanography, Massachusetts Institute of Technology. Taught at Yale University, Harvard University, and M.I.T. Staff member WHOI since 1944.

Member : Astron. Soc.; Geophys. Union; Amer. Soc. Limnol. \& Oceanog.

\section{Joanne S. Malkus}

Meteorologist, Woods Hole Oceanographic Institution.

Ph. D. (meteorology), University of Chicago, 1949.

Staff member WHOI since 1955. Taught at Illinois Institute of Technology,

Imperial College (England), University of Chicago, New York University.

Previously with U.S. Weather Bureau.

Member: Phi Beta Kapla ; Sigma Xi ; $\Lambda$ m. Meteorol. Soc. 


\section{Bostwick H. Ketchum}

Senior oceanographer, Woods Hole Oceanographic Institution.

Ph. D. (biology), Harvard University, 1938.

Staff member WHOI since 1940. Taught at Harvard University, Long Island University, and Marine Biological Laboratory.

Member": Amer. Assoc. Adranc. Sci.; Amer. Soc. Limnol. \& Oceanog.; Ecol. Soc. Amer.; Amer. Geophys. Union; NAS Cmt. Biological Effects of Atomic Radiation in Oceanog. and Fisheries; AIBS Adr. Cmt. on Hydrobiol. in ONR; Sci. Research Adr. Cmt. for Bimini Mar. Labs.; Corp. Mem. Mar. Biol. Lab.; Bermuda Biol. Sta.

Earl E. Hays

Physicist, Woods Hole Oceanographic Institution.

Ph. D. (physics), Northwestern University.

Previously associate scientist, Brookhaven National Laboratories. Taught at University of Toledo.

Member: Am. Phys. Soc.; Sigma Xi ; Amer. Assn. Physics Teachers. 



\title{
OCEANOGRAPHY IN THE UNITED STATES
}

\author{
TUESDAY, JUNE 23, 1959
}

House of Representatives,

Special Subcomaittee on Oceanography

of the Committee on Merchant Marine and Fisheries,

Washington, D.C.

The subcommittee met at 10 a.m., in room 21 7 , Old House Office Building, Hon. George P. Miller (chairman of the subcommittee) presiding.

Mr. Miluer. The committee will be in order.

The Subcommittee on Oceanography of the House Committee on Merchant Marine and Fisheries is convening today.

We have the privilege of having Mr. Gordon Lill and Mr. Willard Bascom talk about the Mohole project.

This is a research project in which we are all interested because this is the first attempt to get down into the ocean floor.

Do you want to read your statement?

\section{STATEMENT OF GORDON G. LILL AND WILIARD BASCOM}

Mr. LrLL. We have a prepared statement which Mr. Bascom will read, and I would like to make some extemporaneous elaborations, after which he would like to show some slides.

Mr. Mrller. We will be happy to have you proceed in that fashion. Before you do that it might be well to insert at this point in the record a résumé of your backgrounds.

('The résumés referred to follow:)

Résumé of the Professional Activities of Willakd Bascom, Technical DIRECTOR FOR THE AMSOC COMMITTEE

Born November 7, 1916, in New York City.

Educated as a geological engineer at the Colorado School of Mines (1942).

Worked as mining engineer in several States (to 1945).

Research engineer on oceanographic projects in the engineering department of the University of California at Berkeley, Calif. (1945-51).

Research engineer at Scripps Institution of Oceanography at La Jolla, Calif. (1951-54).

Joined staff of National Academy of Sciences in 1954 as technical director of several advisory committees including those on civil defense, meteorology and maritime research.

Technical director for AMSOC, January 1959 to present.

U.S. delegate to IGY Conference on Oceanography in Sweden.

IGY field engineer (South Pacific) on wave observations, 1957.

Consultant to industry on oceanographic instrument development.

Author of many articles on oceanographic subjects including: "The Mohole," Scientific American, April 1959; "AMSOC's Mohole," Nature, July 1959 (with Lill) ; "Ocean Waves," Scientific American, August 1959. 
Résumé of tile Professional Activities of Gordon G. Lill, Chatrman of the AMSOC COMMITTEE

Born February 23, 1918, in Mount Hope, Kans.

Edueated at Kansas State University (M.S., 1946).

Conducted geological studies on Bikini Atoll (1947).

Joined Geophysics Branch of the Office of Naral Research in 1947.

In 1919-50 took year's leave of absence to conduct a mineralogical survey in Liberia, West Africa.

Head of Geophysies Branch of ONR, 1951 to present.

U.S. delegate to CSAGI conference in Brussels (1955) (Commite Special Annee Geophysique Interuationale).

U.S. delegate to CSAGI conference in Moscow (1958).

Chairman of U.S. IGI Technical Panel on Oceanography.

Member of U.S. IGY Arctic Panel.

Recipient of Distinguished Service Award in Science, Kansas State University (1957).

Author of numerous articles including: "The Earth's Mantle," Science, May 1959 (with Maxwell), "AMSOC's Mohole," Nature, July 1959 (with Bascom).

Speaker on the Deep Hole project at the Undiscovered Earth Conference in Birmingham, Ala., June 1959.

Mr. BAscorr. Thank you, Mr. Chairman.

A complete roster of the members of the AMSOC Committee is inserted at the close of this prepared statement.

I would like, also to introduce two members of our panel and our Committee who are present here. One is Captain Harry Hess, who is present today and who is a member of the AMSOC Committee and one of the originator's of the idea.

The other is John Lyman, of the Hydrographic Office, a member of one of our panels.

Mr. Miller. We want to welcome Captain Hess and Mr. Lyman here. We are happy to have them with us.

(Submitted statement of AMSOC Committee follows:)

1. The AMSOC Committee is composed of distinguished earth scientists whose names and organizations are given on the attached roster. AMSOC is the abbreviated form of the American Miscellaneous Society which, although it selected its name in a moment of whimsey, takes the Mohole project seriously. The National Academy of Sciences is a private nonprofit organization of scientists chartered by Congress in 1863 to advise the Government on scientific matters.

The AMSOC Committee is at present operating with funds supplied by the National Science Fonndation under Research Grant NSFG5731 which requires that a study be made of the feasibility and desirability of drilling a hole to the Mohorovicic aiscontinuity.

2. The Committee has completed that study and is now preparing a final report to the National Science Foundation on the findings. These include the opinion that such an exploratory hole is both feasible and highly desirable.

This is only the heginning of the Committee's work. So many scientists and technicians of different diseiplines and from different institutions are involved that the NAS itself is decmed the most appropriate organization to manage this complex project. Moreover, the academy is organized in such a way that it is a convenient mechanism for integrating the varions forms of public and private support. Therefore it has been decided to consolidate the management of the project under this Committee and an appropriate staff is now being assembled.

3. A concept of the earth is necessary in order to understand the menning of the Mohole projeet. The earth has a radius of about 6,400 kilometers and is divided into two main zones, the core and the mantle. Although the mantle represents about 84 percent of the enrth by volume we are not sure of its composition. Alove the mantle is a thin slaglike crust of light rocks and over part of that crust there is a fim of water called the ocean.

The continental crust averages about 33 kilometers thick; the oceanic erust about 12 (including the water). The boundary between the erust and the 
underlying mantle was first defined bF Prof. A. Mohorovicic in 1912 as the deptl at which earthquake waves showed a marked change in velocity. This boundary is commonly called the Moho. There are intermediate lasers in the crust which also are identified by their seismic relocities.

4. The feasibility of clrilling to the mantle depends on two things: (1) the depth to the Moho; (2) the maximum reach of drilling tools.

Thus our study looked rarefully at both. We find that there are places both in the Atlantic and the Pacific basins where the total distance from the water surface to the mantle is less than 9.5 kilometers (about 31,000 feet). We also find that leading members of the oil industry believe that "a 50,000 foot hole would be possible if there were any reason to drill it and if the best of deep-drilling equiment and technology were assembled." (The deepest hole to date is $25,3+0$ feet.) This is on dry land.

Drilling from floating platforms anchored in shallow water is becoming routine; four large vessels and a dozen small ones have built up a backlog of experiences hoth in the Gulf of Mexico and off the California coast. Two of these vessels, C'uss $I$ and Nola $I$ (made from Navy freight-barge hulls), are completely self-sustaining and have successfully ridden out storms. They are designed to drill holes 12,000 feet deep in water as much as 500 feet deep.

5. The average depth of the ocean (aud the depth at which it will be necessary for us to drill) is about 4 kilometers or 13,000 feet.

The ocean floor is pared with soft sedimentary material whose usual thickness is about 1,600 feet. Beneath that is a "second layer" 3,000 to 6,000 feet thick which may be hardened sediments, limestone, basalt, or more soft sediments screened by a harl rock lașer above. The do not know. Beneath the second layer is a third layer of even more uncertain composition, and beneath that is the Moho and the mantle. Table 1 shows that a drill capable of reaching 18,000 feet below the sea surface will simple all of the intermediate lasers.

6. It is thus evident that, if one of the existing rigs can be modified so that it (1) will reach 18,000 feet and (2) maintain its position abore a deep-rvater hole site, we will have made a great step forward. It is the opinion of the operators of both the Cuss and the Nola drilling ships that this is feasible and both groups are now making studies of exactly how their ships could be modified to do this job.

Phase I of the Moho project involves modifying a drilling vessel and testing it out in deep water to see how it performs mechanically. This will give us much valuable engineering information which can be used in the design of the ultimate vessel.

7. Although phase I is not intended to reach to the Moho, it is man's first attempt to drill or to do any heary work on the bottom in leep water. The implications of thls on oceanic work are enormous. But besicles obtaining design data and practical experience it will return scientific data of great importance.

As seen in table 1 , the experimental holes of phase I will reach completely through the sedimentary layers and sample the second and third lavers. By so doing, scientists expect to uncover a great deal of otherwise unobtainable information about the history of the ocean and the earth (both biological and physical).

$\mathrm{S}$. When the test drilling has been completed we will go back to the drawing boards and design a phase II floating drilling rig capable of reaching to at least 31,000 feet. It will be built, tested, and taken to a site where it appears that the most valuable information about the deep crust and the mantle can be obtained. There it will drill to the Moho.

If phase I is largely completed by July 1 of 1960 (which is possible if we can get the money to proceed at once) the phase II Mohole rig could be ready in another year (July 1961) and the mantle reached by the end of 1962 .

We hare tentatively estimated the cost of this project at about $\$ 15$ million, broken down as follows:

Preliminary and phase I Million

Phase II drilling $\$ 3.0$

Scientific work 
We ask that this committee take whaterer steps are appropriate and within its power to further this imaginative project which will so greatly advance man's understanding of the oceans.

TABLE I.-Reach of drill required to achieve various objectives

\begin{tabular}{|c|c|c|c|c|c|c|c|c|}
\hline & \multicolumn{6}{|c|}{ Pacific } & \multicolumn{2}{|c|}{ Atlantic } \\
\hline & \multicolumn{2}{|c|}{$\begin{array}{l}\text { Clipperton } \\
\text { Island area } \\
10^{\circ} 53^{\prime} \mathrm{N} \\
105^{\circ} 09^{\prime} \mathrm{W}\end{array}$} & \multicolumn{2}{|c|}{$\begin{array}{l}\text { Guadalupe } \\
\text { Island area } \\
28^{\circ} 45^{\prime} \mathrm{N} \\
117^{\circ} 31^{\prime} \mathrm{W}\end{array}$} & \multicolumn{2}{|c|}{$\begin{array}{c}\text { Due south of } \\
\text { San Diego, Calif. } \\
5^{\circ} 47^{\prime} \mathrm{N} \\
123^{\circ} 59^{\prime} \mathrm{W}\end{array}$} & \multicolumn{2}{|c|}{$\begin{array}{l}\text { North of } \\
\text { Puerto Rico } \\
20^{\circ} 40^{\prime} \mathrm{N} \\
66^{\circ} 30^{\prime} \mathrm{W}\end{array}$} \\
\hline $\begin{array}{l}\text { Phase I: } \\
\text { Depth of water........ }\end{array}$ & $\begin{array}{r}\text { Kilo- } \\
\text { meters } \\
3.1\end{array}$ & $\begin{array}{l}\text { Feet } \\
10,100\end{array}$ & $\begin{array}{l}\text { Kilo- } \\
\text { meters } \\
3.5\end{array}$ & $\begin{array}{l}\text { Feet } \\
10,700\end{array}$ & $\begin{array}{c}\text { Kilo- } \\
\text { meters } \\
4.3\end{array}$ & $\begin{array}{l}\text { Feel } \\
14,000\end{array}$ & $\begin{array}{l}\text { Kilo- } \\
\text { melers } \\
5.5\end{array}$ & $\begin{array}{l}\text { Feet } \\
18,000\end{array}$ \\
\hline Depth to bottom of sedi- & 3.3 & 10,400 & 3.6 & 10,900 & 4.8 & 15,700 & 6.0 & 19,600 \\
\hline $\begin{array}{l}\text { Depth to bottom of } 2 \mathrm{~d} \\
\text { layer } \\
\text { Phase II: Depth to Moho... }\end{array}$ & $\begin{array}{l}4.2 \\
8.6\end{array}$ & $\begin{array}{l}13,800 \\
28,100\end{array}$ & $\begin{array}{r}5.2 \\
10.8\end{array}$ & $\begin{array}{r}17,000 \\
135,500\end{array}$ & $\begin{array}{l}5.5 \\
9.7\end{array}$ & $\begin{array}{l}18,000 \\
31,800\end{array}$ & $\begin{array}{l}\text { 8. } 0 \\
9.6\end{array}$ & $\begin{array}{l}26,200 \\
31,500\end{array}$ \\
\hline
\end{tabular}

SodRCE,-Pacific data from R. W. Raitt, Scripps Instltution of Oceanography. Atlantlc data from J. Worzel, G. Sutton, et al., Lamont Geological Observatory. 


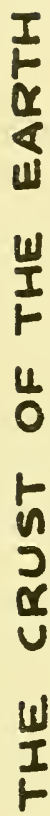
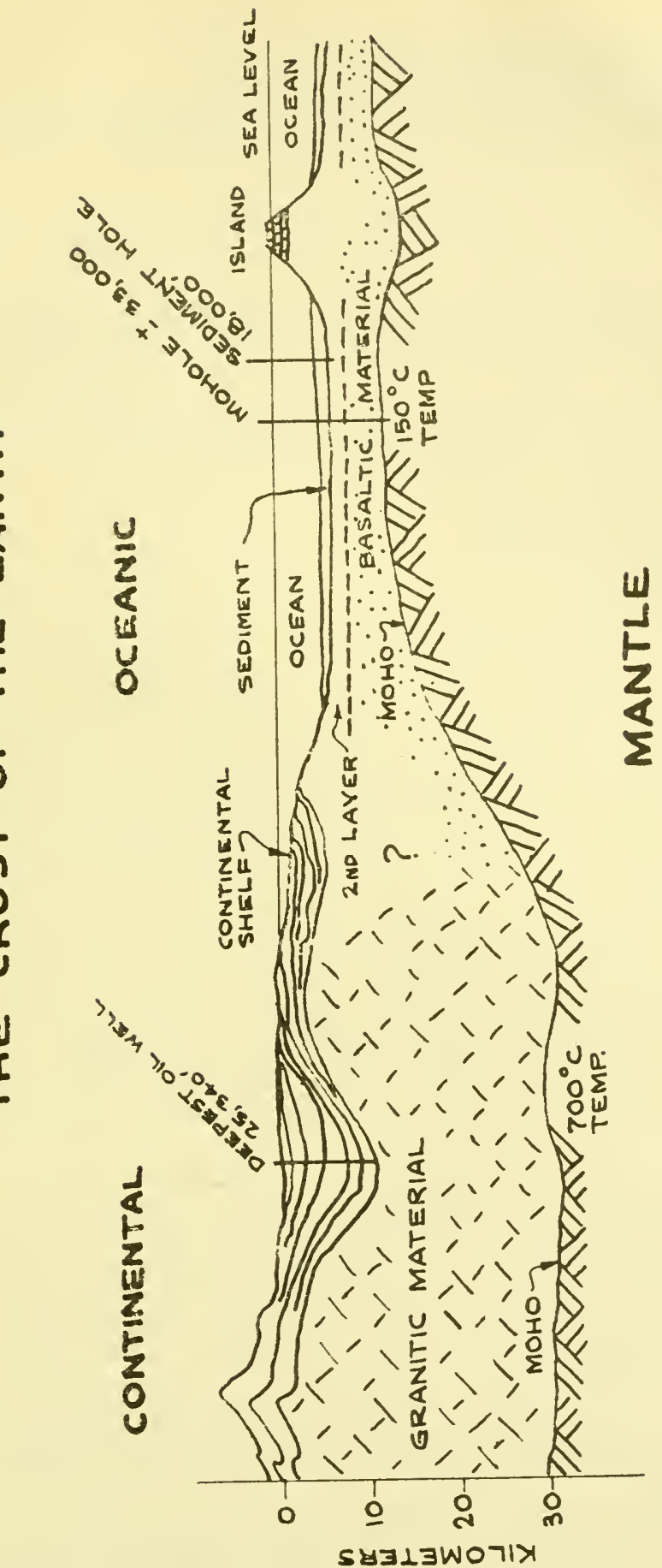
MEMBERS OF AMSOC COMMITTEE

Gordon G. LILL, Chairman of the AMSOC Committee; Geophysics Branch, Office of Naval Research, T-3, Washington, D.C.

WILLARD BASCON, technical director for the Committee.

Dr. MaUrice Ewing, Lamont Geological Observatory, Palisades, N.Y.

Dr. William B. Heroy, the Geotechnical Corp., Dallas, Tex.

Dr. Harri H. Hess, Department of Geology, Princeton University, Princeton, N.J.

Di. Harry S. LAdd, U.S. Geological Survey, U.S. National Museum, Washington, D.C.

Dr. Arthur E. Maxwell, Geophysics Branch, Office of Naval Research, Wash. ington, D.C.

Dr. Walter Munk, Scripps Institution of Oceanography, La Jolla, Calif.

Dr. Roger Revelle, Scripps Institution of Oceanography, La Jolla, Calif.

Dr. Whllialr W. Rubey, U.S. Geological Survey, Washington, D.C.

Dr. Joshua I. Tracey, U.S. Geological Survey, U.S. National Museum, Washington, D.C.

Dr. LeONARD S. Wrison, OCRD, U.S. Army, the Pentagon, Washington, D.C.

George Colchagoff, Major, USAF, Astrodymamics Section, Headquarters, ARDC, Andrews Air Force Base, Mid.

Mr. BAsconr. Might I call your attention to table 1 and figure 2 which follow thereafter.

Looking at table 1 you will see it is divided between the Atlantic and Pacific Oceans.

Under phase 1, taking the first column, one of the best sites we know about so far is the so-called Clipperton Island area.

At that point the depth of water is approximately 10,000 feet.

The depth to the bottom of the sediment is 10,400 feet.

The depth to the bottom of the second layer is 13,800 feet.

Henceforth, we are in the third layer which is unknown, so it means a rig which could at that particular point reach downward something on the order of 15,000 feet conld, in effect, sample all of the layers, including the third layer, and tell us considerable about the crust of the earth.

I will not go through the rest of the items on that table since that is only an explanation of how it looks.

On figure 2 we see the crust of the earth so that we can compare the continental depths with oceanic depths. The deepest oil well is shown. as being drilled in a sedimentary basin to 25,000 feet.

You can compare generally the chances of getting through the continental crust with the chances of getting through the oceanic cl'ust.

Perhaps now we should hear what Mr. Gordon Lill would like to tell us about the scientific part of the project.

Mr. Luls. I wanted to make a few remarks, Mr. Chairman, and I have prepared here some rather pretty pictures.

In the first place, I wanted to emphasize again that the project we are talking about, the Mohole project, is purely a scientific project. It has no other implications so far as we know at the moment other than scientific.

In this connection the AMSOC Committee, and various earth scientists interested in this project, look upon our earth as a prototype planet. We feel it behooves us to find out as much abont this planet as we can.

Practically all the physical information we have about the interior of the earth is contained on this chart. Here you see the earth is cut 
in sections. We have the very thin crust, the thick mantle which is about 1,800 miles thick, the outer core, about 800 miles thick, and lately we have found an inner core, and the inner core and outer core are taken to be some mixture of nickel and iron, quite dense, quite heavy, and probably quite hot, about 4,000 degrees centigrade, and magnetic.

Some of the scientific reasons we want to drill this hole and obtain a sample of the mantle is that everything we see on here has been obtained in an indirect fashion.

The temperature information perhaps was obtained not quite so indirectly but it was deduced from the surface down to the interior by shallow probes which have been stuck into the ocean bottom and other places on the continents.

The structure we see here has been obtained from observing earthquake shock waves as they passed from the point of origin through the crust to the point of observation, by studying the travel times and the velocities of these waves. They have been able to figure out that the earth generally is made up of these various layers. They are really not layers but for lack of a better term we call them layers, these various boundaries which probably grade into each other.

The densities have been obtained generally from laboratory studies and from making gravity observations around the earth, and the pressures have been deduced lately principally from laboratory observations at General Electric.

We find, then, that everything we know is indirect. What we propose to do is to drill as deeply into this crust, through the crust and as deeply into the mantle as we can, get a sample of the mantle, find out what it is really made of, and we hope to end part of the speculation about what the mantle is.

One of the striking features about the difference between continents and the ocean basins is that in the ocean basins there is no granite. In the continents everywhere you find a large mass of granite which you will see on figure 2 in our prepared statement.

This means that the granite under continents has bent down the earth's crust, pushing it down through sheer weight, so we cannot possibly hope to reach the mantle under the continents.

Under the oceans there is no granite. This is the principal difference between ocean basins and the continents.

We also find under the oceans a thin layer of sediments averaging from 1,000 to 600 feet in thickness.

Actually we should find a layer of sediments many times that thick. One of the big problems is what happened to all the ages of sediments. There should be an accumulation of about 500 million years of sediments in the oceans. Actually all we can find so far is about 100 million years worth of sediments, so there must be somewhere beneath the ocean bottom some sediments. If the sediments are missing then this will give us some reason to think that perhaps the ocean basins are not as old as we think they are.

We have no idea what the second layer and third layer are composed of. Some people say it may be limestone and it also may be basalt. It also may be that there is a high velocity layer of basalt in the second layer which masks everything below it.

If we find a tremendous thickness of sediments in the basins containing a great deal of limestone we will have to then go back and 
reexamine all the chemical knowledge we have, work out a new geochemical balance in nature because we already have all the limestone we need based on the geochemical studies that have been made.

This second layer also shows some possibility it could be composed of volcanic material. The question then is why is it the same thickness nearly everywhere that it is observed.

One might think that if it is lava spewed out on the ocean floor it might vary in thickness from place to place but it does not seem to vary very much.

The two basins are indeed of volcanic regimes. Both ocean basins studied show volcanos which rise to within a few hundred fathoms of the ocean bottom, and we find them almost everywhere.

We know, too, about 100 million years ago there was a good deal of volcanic activity.

Another thing we wish to study is exactly what takes place at this boundary between the third layer and the mantle. It is a very puzzling layer. There is some evidence we get seismic scattering in that layer. One could dream a little bit and suppose that that zone might be an old earth surface before it was covered by sediment or lava. This is only a very slight possibility, but if it turns out we found meteoric material in that layer then it might be an old earth surface.

The major aim is to bring up a sample of the mantle after we have been through all these various layers above the mantle.

I think that is all the explanation I have to offer. If there are any questions, both Mr. Bascom and I would be happy to answer them.

At one point in the proceedings Mr. Bascom would like to show some slides of actual drilling operations.

Mr. Mruler. Has any governmental agency assumed the sponsorship of this project?

Mr. LiLu. The National Science Foundation has assumed responsibility thus far for the operations of our committee. They have given us a grant of about $\$ 30,000$ for the committee.

In addition they have made some grants for exploratory work in the area just north of Puerto Rico which now is going on and just about finished.

Mr. Mrluer. Has any approach been made to any of the foundations for money to assist in the drilling of this hole?

Mr. Lill. Not thus far.

Mr. Miller. In other words, when your findings are complete you then have to look to the Government to get the money to implement the project?

Mr. Lird. We have plans. We would like to get both Government and private money into this project.

We have indications from the National Science Foundation that they plan to budget something on the order of $\$ 5$ million in their 1961 budget. This is only a plan thus far in so far as I know.

We have officially but not formally been notified by General Motors Corp. that they will give us for our use all the diesel electric power equipment that we need. They estimate the total value of this equipment is on the order of $\$ 1$ million. 
We have had various hints from other private sources that they are interested but we have no concrete evidence as yet that they are.

This is essentially where our finances stand.

As soon as we can enlarge our staff, the Committee staff, we will go to work on these various sources.

Mr. Minler. Has the oil industry come forward in any way in offering to give you any assistance?

Mr. LiLl. So far just oil industry suppliers. We have had no direct approach unless Mr. Bascom can recall some. I do not think we have had any direct contact with the oil industry.

Mr. Bascon. They certainly have not made us any cash offers to date. We have every hope that in one way or another they will be persuaded that this is a very good thing for the oil industry to participate in, and that they will make various kinds of offers before long.

Mr. Miller. Anything that has to do with expanding the earth's sciences certainly should be of material interest to the oil industry you would think.

Mr. Basconc. Yes, sir. There are several possible ways that they might gain from a project such as this, both fundamental and direct.

First of all, the origin of petroleum still is a great question and it is possible there may be keys which would help solve that problem found in the deep sediments. It is even possible there might be oil in the sediments although there is no evidence of that, either. It is certainly an open question.

The other major way in which the oil industry might gain is that we are bound to develop something new in the way of drilling technology just by the mere fact of having to go at least a mile deeper than the deepest hole so far and having to do it at sea and having to do it in deep water.

All of these things together certainly are bound to bring about various kinds of technological advances which the oil industry can cash in on, all the way from new kinds of bits, new kinds of coring, new metallurgy, special strings of pipes, all these things.

Mr. Mrluer. Would it be necessary to expand the field of seismographic exploration or have we developed that to a point where it would be helpful?

Mr. BAsconr. It is a very complex matter. Development on such a thing never ceases. I do not think any direct development will be needed for this project although it is always possible that in the course of our work something new will turm up which has not previously been known.

Actually the methods we use, although they are generally similar to those used by the oil industry, are not directly interchangeable with their systems.

Mr. Miller. Mr. Chairman, I am happy to have you with us.

Have you any questions you would like to ask?

Mr. Bonner. No.

Mr. Militer. Mr. Dorn?

Mr. Dorn. I have no questions.

Mr. Miller. Mr. Oliver?

Mr. Oliver. Mr. Chairman, I must confess that I am very insuffciently equipped to ask questions on a subject such as this. From a practical standpoint I expect this has to do with basic research, looking for information. Is that correct? 
Mr. LiLL. That is right.

Mr. Oliver. Concerning information we might hope to get from a project of this kind, we have heard you say something about the practical applications that might be made of that information which we expect might be gotten from this exploration, can you amplify further as to what practicability any information we get here might have?

Mr. Lind. Other than those mentioned by Mrr. Bascom, benefits to the oil industry, it is quite difficult to say what will come out of this.

My attitude toward the thing is more or less a scientific one. I feel in the face of the competition for funds for science these days, which all of us see going on, the earth sciences have really suffered.

Dr. Harry Hess, Dr. Walter Munk, and Dr. Frank Estabrook, among others, have been scouting about for something exciting for the earth sciences to do which would attract attention and money, and at the same time be highly worth while and exciting, scientifically.

The reason for this was that the earth sciences were falling behind in getting funds for science. Space scientists were forging ahead. Rocket sciences were forging ahead, and earth science was falling even further behind.

As a matter of fact, by this project, if we drill to the mantle and get a sample of it, chances are that the rest of the planets in our solar system might have a structure considerably like that of the earth.

If the rocket scientists and spacemen want to go to other planets they can find out a great deal of what will confront them there by studying the earth. We have scarcely begun to study it.

This project will open up a host of new scientific questions.

Practically speaking, I think Mr. Bascom has covered nearly all the benefits that we have thought of thus far. There certainly might be other things showing up as we go along.

Mr. Oliver. In a recent visit we made to Massachusetts it was indicated last year in IGY activities that many samples of sediment were procured from the ocean bottoms. I expect that a sampling of those deposits would show the texture of those deposits.

What you are thinking about is going even deeper into the earth's structure and from that gaining some knowledge and information which might give you an idea as to what makes this earth click. Is that right?

Mr. Irllu. So far sediment samples taken from the bottom of the ocean are only a few meters in length. They have been taken by these coring devices dropped down from ships, fall from the force of gravity through the ocean, they pull them out and they find they have collected perhaps 10 meters of sediment.

The age of these sediments generally goes back a little bit, perhaps, beyond the begimning of the last ice age.

In other places in the ocean, in digging in Bikini and Eniwetok, we find sediments which go back 100 million years.

On the tops of some of the sea mounts we have collected sediments that go back 100 million years.

We foel there must be more ancient sediments than these and to find out we propose to drill through whatever is on the ocean bottom and see if there are ancient sediments there.

Mr. Ondver. Is there any indication there are any other governments of the world who are moving into this area of activity? 
Mr. LiLl. We suspect the Russians are. We have no direct evidence, however, that they are. They expressed a great deal of interest in this project at a scientific meeting in Toronto in 1957.

They announced they had the equipment to drill to the mantle and that they had the capability of using the equipment.

Since that time we have discovered that the Soviet Academy does have a branch located out in the center of $\Lambda$ sia which is dedicated to the problems of deep drilling. How old this branch of the academy
is I have no idea.

It may be a number of years old, and it might be a brandnew branch.

They have also carried out seismic explorations in the Sea of Japan which might be connected with the deep drilling project in some
fashion.

In the Sea of Japan they find a depth to the mantle is roughly 10 kilometers, which means it is oceanic.

This would be a good site for the Russians to drill if they propose to drill. We don't really know.

Some scientists in Great Britain are quite interested in the project. We have no evidence they plan to do any drilling.

As far as the nations are concerned that is about the size of the interest. I have no knowledge of any other nations proposing a project of this kind.

Mr. Otiver. That is all I have, Mr. Chairman.

Mr. Pelly. You stated that phase 1 is expected to be completed by July 1 of 1960 , which leads me to inquire as to whether or not you have anything concrete to propose in the way of legislation to enable the committee to carry on from that point?

Mr. Lilf. We have no concrete proposals to make in this connection. Probably the best assistance the committee can give us would be to back up whatever requests come from the Government agencies
in this regard.

I do not really think this project requires any special legislation. If there were special legislation announcing that the program was to be financed by the Federal Government it would certainly put the
show on the road.

Mr. Pelly. I suppose the entire cost of the project would not be much more than the cost of firing one rocket.

Mr. Lill. I would guess, without being too firm in my knowledge on what rockets cost, that it would be the cost of about two big

Mr. Pelly. I understand a rocket costs something over $\$ 10$ million. Mr. LiLl. One and a half rockets, then, just the cost of the rocket
itself and no development costs.

Mr. PELLY. I think you certainly have a very inspiring and imagina-
ve project.

Now that you mention the Soviet Union's interest, I am sure that competitive spirit would probably be helpful in getting support.

Mr. IILL. I don't know what their intentions are, and I probably never will know unless they actually drill a hole.

It seems to me they would take considerable delight in beating us to this project, since drilling is something we are rather proficient in.

Mr. Pelcy. We are always apathetic until we get something like
sputnikup in the air.

$38170-59-20$ 
Mr. LiLl. We have to be truthful about it, however, and state that, so far as we know, we are not in a race on this project. We just don't know.

Mr. Pelly. Sorry we cannot use some of the $281 / 2$ percent depletion allowance. If it was indicated there was some oil down there, I am sure there would be considerable interest from a purely profit motive and incentive.

Mr. LiLL. The oil industry is one up on us in that respect. Almost everyone assumes now that hydrocarbons which form petroleum probably do not accumulate in the deep ocean basins.

This is only probable, but it is a large probability. All the indications seem to be that the hydrocarbons accumulate in shallow seas.

Some hydrocarbons perhaps could be carried off to the bottom of the deep sea on sediments, but I do not think it is very likely.

I think the farthest out from the continents you likely would find oil would be on the edge of the continental slope, where sediments accumulate and perhaps do form a petroleum trap. This also is only a probability.

Mr. Pelly. From a practical standpoint it always seems to me we should investigate our own earth rather than space and other planets so far off. We would get a better return on it from our effort much more rapidly and serve the purpose of humanity much better.

Mr. LiLt. We think it is at least as important. There are many reasons why it is more important.

Mr. PeLcy. There are many hidden secrets in the depths of the earth. I am very much interested and I want to express my pleasure at being able to hear your testimony.

Thank you, Mr. Chairman.

Mr. Miller. Mr. Curtin?

Mr. Curtin. I have no questions.

Mr. Milumer. Committtee commsel?

Mr. Drewry. Mr. Lill, in the list of members of the AMSOC Committee, I notice you have representatives of the ONR, Geological Survey, the Army, and the Air Force.

Is there official interest in those branches of the Government in seeing this project carried out?

Mr. Litu. In the Office of Naval Research we have established a small study contract with the Global Marine Research Corp. in Los Angeles to see how they would go about modifying their rig, Cuss I, to get through the first two sediment layers at least in the deep ocean.

$\Lambda$ s part of that contract, the Office of Research and Development, Army, transferred to the Office of Naval Research a small amount of money to help us get this study going.

The total cost of the stndy, I think, which will be paid off this coming fiscal year, will be about $\$ 65,000$.

These two agencies are the only two that have done anything about the program.

Mr. Drewry. The Geological Survey has not taken any oflicial position with regard to this program?

Mr. Lils. No, sir. I imagine the Geological Survey, howerer, will provide geologists if they are needed, who are not otherwise provided, in overall help in collecting the cores, sediments, and so on, presumably without cost to the project. 
Mr. Drewry. The net findings might be of considerable value from a biological standpoint, too?

Mr. Lill. Yes, sir.

Mr. Drewry. So there possibly would be some net gain to marine biology?

Mr. LiLl. Scientifically, yes. If we find ancient sediments and are able to bring up cores it will give them a much greater background on the history of life on the planet.

Mr. Drewry. I notice you say there are so many scientists and technicians from different institutions.

What I was trying to get at is this: This apparently is mostly a basic research matter where there are a number of different interests who will stand to gain either actually or possibly.

I am trying to grope around for an approach which best can be taken to push this project forward, either with Government support, inclustry support, or both. of cost.

You need some $\$ 15$ million according to your present estimates

What is your thought as to where that $\$ 15$ million will be sought and by whom?

Mr. LiLl. The committee will be seeking the funds. We will seek them probably from the National Science Foundation and from industry wherever we can.

So far as industry is concerned, we have fond hopes that at least some of the oil well suppliers will come forth, such as General Motors has, and say "We will donate such and such equipment to your project

Unless the material is disposable, unless it is used up in the drilling, we would expect to give it back to these corporations.

I would anticipate that about half of the cost of this project would come from private sources and about half from the Government.

Except by personal contact the only way we know of getting private sources interested is through the marvelous publicity the program has
had.

We have had much more publicity at the moment than the situation actually warrants.

None of it has been solicited.

In any case, this publicity is stirring up a great deal of interest thronghout the country, and we have had many contacts from oil well suppliers and various other types of industry who seeni to want to do something about this project, but we are not quite prepared to take them all on. We are not quite organized to that point.

Mr. Drewry. It would occur to me that the problem would be somewhat similar to the problem we were confronted with generally on how to decide upon an overall oceanographic program and then keep it
moving forward on a solid front.

Here with a large number of people interested we have this focused on the National Association of Scientists, and they can apparently provide the push with a combination of themselves and the National

I am wondering if we are seeing some light as to how we might solve this question of the broader study. 
Mr. Lill. I think before the end of the year is out we will see a great deal of light on the financing and the development of this project.

At the present time, Mr. Bascom is the only full-time person working on the program. He is really swamped with inquiries, talking to the press, writing letters, and answering inquiries, gathering information on drilling techniques, and so on, running three panels on the subject, as well as looking after the interests of the committee.

As soon as we can get two or three more assistants for Mr. Bascom, put them out chasing up the interested parties in the program, then I think at least part of this will take place before the end of the year and we will be able to get the first phase of the program underway.

TVe really have been operating on a shoestring up to this point.

Mr. Miller. I want to congratulate you on the very fine way that you have operated on a shoestring.

I think you and Mr. Bascom deserve to be commended.

It is always difficult to initiate a project of this type.

Of course, I personally feel it would be well worth the money to the Federal Government. In fields of science we cannot say we always get quid pro quo for every nickel we spend because if we can do that there would be no necessity for doing research work. Research work itself implies you are looking for the unknown, and when we have found it it makes this country ever greater.

Although at the moment we might say there is no practical advantage to be gained, who can say that when you dig this hole down here you might not open vistas which are just as great as any which have been opened in the past in other fields of scientific research.

This is a project which is merely in its infancy, and as in other projects scientists have no idea of what will be developed.

As recently as building of the first cyclotrons no one knew where they were going. We were plotting strange and new paths and we came up with atomic energy. It may be our salvation for the future.

Mr. Dorn. Concerning this hole which you contemplate drilling, will the width and circumference of the hole be as round as a person's pinkie at its deepest point? What would the circumference of the hole be at the deepest point?

Mr. Lilu. We would like to have it so we can retrieve at least a 3-inch core.

Mr. Bascom has looked into this and perhaps can answer it a little better and in more detail.

Mr. Basconr. First of all, oil well holes, and this is essentially the same as an oil well hole, are different depths. As they go down they become smaller and smaller. Since we do not know how far we will go we don't know where we will get stopped in this particular case.

As Mr. Lill says, we would like to have a 3-inch core.

This means at the maximum reach of the drill we might be drilling, say, a 6 -inch hole.

However, when you start the hole you have to have a preconecived idea of how many times you will have to set casing in the hole, that is, to set a protective string of pipe around the outsicle of the hole.

Every time you set casing you have to reduce the size of the hole, so since we do not know right now what the characteristics of the 
material will be, and consequently cannot guess at how many times we set casing, we can neither quite tell you the beginning of the hole nor the end of the hole. We have to do some experiments first.

Mr. Dors. What do you contemplate as the width at the beginning of the hole?

Mr. Bascom. That is what I say. The ultimate hole we cannot tell you. In our experimental work at first we will probably start with a hole something like 18 inches in diameter, although that is certainly a wide open question, too. It might be much less, something like 10 or 12 inches in diameter.

You have to go out and get some information about the character of the strata first, and then you come back and revise your ideas about how often you will have to set casing, and so forth.

It may be that these dense rocks which give us the high seismic velocities and depths will be so rigid they will stand up very nicely without casing, in which case we can go on for quite a long way with a slim hole.

This will speed up the drilling considerably.

If I may amplify some things that were said earlier.

Mr. Miller. Yes.

Mr. Basconr. You asked about the many kinds of technologies and scientific disciplines that were involved in this.

On our central committee it seems as though we have a large selection of people from the local Geological Survey, and the Office of Naval Research.

Actually we have these three other panels which spread out much wider into the entire fields of geophysical sciences.

Among others, the kinds of people we have to ultimately draw on for advice and information and assistance in this project we have to talk to, for example, astronomers and people who know about meteor studies because the qualities inside the earth are probably similar to those of other planets.

It seems to us a little strange to go off 350,000 miles to the moon to get a sample of what may likely be 30 miles beneath our feet.

WTe have to talk to people who know a lot about volcanoes because obviously you get some idea of the interior of the earth from what comes up from volcanoes.

We have to be involved with various other kinds of geologists, including paleantologists who trace out the evolution of history on earth through changes in fossils and also to stratigraphists who know something about the qualities of the layers in the earth who essentially designate the various periods of geologic time.

We have to deal with gravity people who study the earth's gravity at many places and from this partly determine the thickness of the crust.

We have to talk to seismologists, both the earthquake type seismologists and those who shoot off their own explosions and measure the character of the crust.

We have to know something also about the earth's magnetic properties. Each of these takes a highly specialized person, and so for our committee to have all the competence needed we just could not do it with the Central Committee, and we have panels which deal with these various aspects of scientific work. 
Besides all this we have the laboratory work associated with it, testing of materials, both real and hypothetical, for the qualities they will have under the deep heats and pressures, and the analysis of the cores when we get them back.

Besides the scientific things, there are two technologies, really; one of them would be drilling technology and the working at sea and the other would be the oceanographic type technology, both of which stand to gain tremendously from this particular project.

It is our hope that we will have at least consultants from all of these fields somehow represented in our group, because we would like to see a great many people in the geophysical business and the oil business involved in this project.

I might say a little bit more about the practical aspects of this.

I was specifically asked about the influence of this on the oil industry, but there are other people who stand to gain in a more practical way from what we are going to do. As scientists we do not like to talk about the practical outcome of this because we are mainly looking forward to the scientific objectives that will be accomplished.

So far, the heaviest work that has been done on the bottom of the ocean has been essentially with a half-inch cable. This has essentially a working stress of 5 or 6 tons. Oceanographers have traditionally worked with tools and equipment too light and cheap to do the job they have to do at sea. They always work a little too small and consequently are always right on the limits of what they can do.

When we have at least reached the bottom with, let us say, a $31 / 2$ inch drill string, we have increased the capability for doing heavy work on the bottom and perhaps oriented work on the bottom by a factor of 50 to 100. This has tremendous implications for anybody who is going to do heavy work at sea, such as might be involved in various problems of submarine hunting, for example. We do not intend in any way to get involved in classified projects, I should say, but there is no way we can do this without having a great deal of meaning for people who have the problem of locating things on the bottom of the deep ocean, knowing what the stresses are for both shallow and deep water, and for placing things where they need to be put on the bottom.

As you perhaps are aware, there seem to be great possibilities in the mineral deposits on the bottom of the ocean, both phospates in fairly shallow water, a thousand feet deep, and in so called manganese nodules which are also rich in nickel and chromium and cobalt.

Of course, that wonld also include manganese, all of which certainly look as though they are groing to be one great sonrce for these materials in the future. There are probably other things on the bottom that we do not know about because it has not been surveyed as well as it should have been.

In order to do this we have to develop our technologies for our own use there. For example, it might be useful in some way for us to have a television set working in very deep water which would inspect what we are doing, and take a look at the instrumentation which we put on the bottom. No such instruments now exist. 'The deepest ones go to about a thousand feet.

If such a device were developed in some way and tried out and used with this project, it would be a tremendous step forward in inspecting 
the bottom of the ocean which we cannot do very well at the moment. The deepest cores to date, as Mr. Lill said, average about 30 feet and occasionally one gets up to a little bit more. These reach back in geologic time but beyond that the depths of the ocean are a complete mystery to us. Since virtually all, or, at least, a great deal of the undersea evolution took place roughly 400 million years before that, obviously there is a great deal missing in our records of geologic occurrences. If this is going to be found anyplace on earth, it is ver.y likely to be found in the deep sea.

We have this combination of objectives which are both scientific and technical and which have some practical applications as well as a great many scientific implications involved in all of the things that we scientists need to know.

Mr. Miller. I think that is a very fine statement.

Of course, if we seem to stress what practical application may come of this, it is really because when yon go before the Appropriation Committee of Congress to get money, it is very hard to sell them on the idea of pure science. Somebody is going to want to know what are we getting out of it?

I am satisfied personally that there is a lot to learn.

Mr. Bascom. I do not know.

Mr. Mircer. We have great salt beds out in San Francisco Bay that Westvaco is developing. 'They are sources of non-ferrous metals and chemicals there.

How do we know that after you get down to the bottom of this think we may find new deposits of minerals. Certainly they are in the sea water, but where do they come from? Do they ever precipitate?

Who knows till we get down and take a look at them?

Anyway, it might be very valuable.

I was just wondering whether Captain Hess would like to say anything on that.

Mr. Oliver. Mr. Chairman, before that, I would like to make this comment: I, too, join with you in your commendation of this statement which Mr. Bascom has just made.

You have indicated that in appearing before an Appropriations Committee of the Congress, it is a very practical matter and I am sure that you appreciate that.

Mr. Bascour. Yes, sir.

Mr. OtIver. I think that what you have said is going to be very helpful to those of us who would like to encourage this project.

Mr. Mrller. Captain, would you like to say anything?

\section{STATEMENT OF DR. HARRY H. HESS, DEPARTMENT OF GEOLOGY, PRINCETON UNIVERSITY, PRINCETON, N.J.}

Mr. Hess. I think really what we should stress is how little we know about the earth or any celestial body. This is probably the best way to find out and at the present time we are dragging along on a hypothesis that the earth is like a meteorite. Maybe meteorites are only the outer skin of the moon or some other celestial body, but there is a great advance to be made in science if we know what these planets are made of. 
The astronomical theory of abundance of elements is based almost entirely on the gases that you see in the sun or the stars. You can use spectography but the heavier elements do not show up very well. We do not know their abundance and really we are trying to find out what the universe is made of and what the earth, in particular, is made of. That is the primary objective. No doubt, a great many interesting things will come out of this but, practically, I do not see very much coming out of it. You can grab for various odds and ends that might be practical, but aside from technology, I do not think it is going to be very much.

Mr. Miller. Thank you very much, sir.

Mr. Basconr. Mr. Chairman, may I say that I probably should have said Professor Hess, chairman of the Geology Department of Princeton University, who is now on 2 weeks' Naval Reserve duty.

Mr. Mrluer. Dr. Lyman, would you like to express yourself on this?

\section{STATEMENT OF JOHN LYMAN, DIRECTOR, OCEANOGRAPHIC DIVISION, U.S. NAVY HYDROGRAPHIC OFFICE-Resumed}

Mr. Lrman. Thank you, Mr. Chairman.

I am Dr. Lyman, of the Navy Hydrographic Office.

It is a great pleasure to have this opportunity to speak before this committee again this morning. I do not think that I ean add much to what has already been said on the chemistry of water and what is under the ocean, but I think that I could second Mr. Bascom's remarks that if this project goes through to completion it will certainly contribute greatly to the technology of oceanography and increase our ability to handle heavy weights on the ocean floor. It would be a great step forward in the U.S. oceanographic program.

Mr. Miller. Thank you very much.

Do any of you gentlemen have questions of any of these gentlemen?

(No response.)

Do you want to add anything more?

Mr. Lill. We have some slides we thought maybe you would be interested in seeing.

Mr. Millefr. Please proceed.

Mr. Bascom. In the prepared statement, I noted that there were two principal barges which are at least self-contained and are now capable of doing drilling in shallow water to fairly large depths.

This first slide shows the Nola $I$.

At this time I gness it still is drilling off the delta of the Mississippi River in quite shallow water, about 35 or 40 feet deep. 111 of the elements of a deep drilling rig are present in this one and it seems as though it would be possible to modify either this rig or the other one in such a way as to hold it still in deep water and go on down and drill into the sediments.

The Nola $I$ is now set up and designed to drill 15,000 feet. Obviously, if we could get it out into water only 12,000 feet deep, we would have some kind of a capability for going as much as 3,000 feet into the bottom of the ocean.

'The Nola I has the curious eharacteristic in that it drills over the side. It looks unstable although it really is not. As you see in this 
particular system shown there, their casing really projects up out of the bottom and they drill clear out over the side and then, to counterbalance it, you can see we have a low dark spot on the side. Here is essentially a closeup view of the bottom of the drilling platform and the rig as it rises.

The advantage of this, from the point of view of these operators, is that they can simply pull away from the completed hole when it is finished whereas the other vessels drill down through the center and they require a bottom completion. 'This has no bearing on the drilling capability, but only on the oil production and consequently does not influence us very much.

This is a picture [indicating] of the so-called draw works. A draw works is, is a hoist. The capability for going deep with one of these rigs is very largely dependent upon the size of this particular machine. I will not go into the details of it now, but there [indicating] is the drilling platform and the rotary table of the Nole $I$.

Wre are now in California, Mrr. Miller, and this is the Cuss $I$ [indicating] as it is drilling not far from Santa Barbara.

Mr. Mil Ler. You can see how much bluer the water is there.

Mrr. Basconr. Actually, these are really monstrous rigs and you do not realize the scale of them until you get aboard them.

This is the center of the anchoring system of the Cuss $I$ in which they have six anchors leading oft' the heary cable like a cat's cradle in all clirections to work in the deep sea. This is the part that we will have to modify in this particular vessel. We have got to arrange the hole when it gets in deep water. 'There you start to get some idea of the scale of this thing when you get aboard and see that the pipes in the foreground are what are called triples.

In other words, three joints of pipe for a total of about 60 feet in length.

The big yellow block in the lower part of the block and tackle weighs 6 tons by itself and is capable of handling weights up to 500 tons. This is a pretty good-sized piece of machinery.

This [indicating] is looking up a little more steeply into the upper part of the derrick. Yon see that same yellow block and beneath it is the so-called swivel in which the mud is circulated through that hoist on the right [indicating] and down through the drill pipe which is exactly the center.

This is a picture [indicating] of the complete controls of the $C$ uss $I$ when it is drilling. This man stands at that platform and operates the whole thing.

This particular operation [indicating] is setting pipe. You can see the size of the drill pipe and in this case they are using $41 / 2$-inch pipe to drill holes about 7,000 feet deep in about 300 feet of water at the time of this operation.

Here [indicating] is a view of how the pipe is racked horizontally and this particular joint of pipe has just been lowered from this double rod on the left part of the elevator and it lowers it into this rack where it automatically slides out through that trough and is picked up by chains and set off to one side. This is all done antomatically.

This is the part [indicating] where the drill stem goes down through the ship and looks like this [indicating]. There is a big wheel in the middle of the ship and once you are on board you very soon forget 
you are out at sea at all. Everything is so monstrous and large and everything goes on just about the way it does on land.

Here is a picture of the kind of bits [indicating] that are used. This is on the bottom of this drill pipe and the mud is pumped down through these at high velocity and then the pipe and these bits are rotated in the bottom of the hole at several hundred r.p.m. and they grind their way down. This particular kind of bit is only good for making holes.

This [indicating] is a diamond bit intended for coreing. As this bit is put on the same piece of pipe it grinds its way down and leaves a piece of the bottom rock standing up through the middle of that hole. This bit is upside down, but these are diamonds, the little black spots. It is possible, by putting what is called a core-catcher in the bottom of the pipe, to trap this material from the bottom as it comes into this thing [indicating] and when you retract the pipe, you get a sample of the bottom back again.

This is a picture [indicating] of the same ship doing another kind of operation. 'This is setting casing. You ask, how big is the hole going to be? The hole will be just as big as the outside of this casing. As you are drilling, you stide the casing down the side, and I believe this is 14-inch casing we are running here, but I am not sure at the moment; they are hoisting it into position with the casing elevator and here they are setting it [indicating].

You can see that it is a pretty good sized operation going on here.

At this particular moment, they are tightening a new piece of casing on the old one and they are lowering it down and holding it in some spiders and swinging up another piece and setting it on. It is possible in the oil business to run as many as 10,000 feet in this pipe at one time if the hole is that deep.

Here is simply another view of that operation [indicating] and to give you a little better perspective of the situation. The men are dwarfed by the size of this rig. With Cuss and certain modifications it probably needs a little bit larger draw works.

That [indicating] is the hoist with the cable on it that I showed you before and with some device arranged for holding it into position at sea.

We have studies going on as to how this might be done and there are several possible ways that look promising. It would be possible to make these modifications in a vessel like the Cuss in a matter of a few months. We are talking about maybe 3 or 4 months beyond the design work and after that, our general plan, assuming that we raise the money and are able to do that-the vessel is for rent at a price of approximately $\$ 5,000$ a day, complete with everything, crew and everything that goes with it - we probably will take it in near the shore off California and drill a few of these test holes in the bottom just to see what the difficulties are.

At this moment we do not know what the forces will be due to currents acting on a string of casing like this. It will be 10,000 feet long extending from the surface of the water down to the bottom, and the only way we know to find this out is to try it out.

There are many other things that have to be solved, such as the question of how one cores in soft bottom, how you hold still in deep water, how the wave forces are acting on it, and so on. Once we have 
solved these kinds of problems with this interim ship, as we are calling it, or we might call it a phase one ship, then we come back to the drawing board and design a really large drilling ship, build it, and take it out to a spot selected by Professor Hess' site selection committee and go on down to the bottom.

I thank you.

Mr. Millek. Thank you very much, Mr. Bascom.

Are there any questions?

(No response.)

I want to thank you, Mr. Bascom and Mr. Lill, for coming down today. This has been a very interesting presentation, and it gives us an idea of the work that you are doing and the contribution you are making in the field of earth science.

I want you to know-I think some of us have expressed ourselves pretty well on this--we are very much concerned with the progress that will be made in this field.

Mr. Pelcy. Mr. Chairman, I wonder if it would be well for us to express what you know we all feel. That is, we would like to have continuing reports.

Mr. Miller. Yes; I am very happy that you brought that up.

We would like to have continuing reports and to work with you in this project. I am certain that the members individually-I know our reaction here-we might be very happy to help you in any way we can.

Mr. Lic.. Thank you very much, Mr. Chairman.

We would be very glad to keep the committee informed.

Mr. Miller. Thank you.

If there are no other questions, the committee will stand adjourned until the call of the Chair.

(Thereupon the committee adjourned at 11:20 a.m.) 



\title{
OCEANOGRAPHY IN THE UNITED STATES
}

\author{
MONDAY, JUIY 13, 1959 \\ House of Representatives, \\ SubcomartTee on OCEanography of tile \\ Commititee on Merchant Marine and Fisheries, \\ Washington, D.C.
}

The subeommittee met at 10 a.m., in room 429, Old House Office Building, Hon. George P. Miller (chairman of the subcommittee) presiding.

Mr. Miller. The committee will be in order.

This is a meeting of the Subcommittee on Oceanography of the House Committee of Merchant Marine and Fisheries.

We are met this morning as the result of a report gotten out by the Committee on Oceanography of the National Academy of Sciences on the radioactive waste disposal into the Atlantic and gulf coastal water's, and other oceanographic activity.

The first witness I want to call on this morning is Hon. Thomas $\mathrm{N}$. Downing, of Virginia.

I want to say before you start, for the benefit of the witnesses, that when this report was circulated, many of the people from the coastal areas, such as Mr. Downing, became very much concerned with it, and rightfully so.

We have therefore asked them to be here to give us their views or express their apprehension relative to the subject of the disposal of raclioactive waste.

Mr. Downing.

\section{STATEMENT OF HON. THOMAS N. DOWNING, A REPRESENTATIVE IN CONGRESS FROM THE STATE OF VIRGINIA} men.

Mr. Downivg. Thank you very much, Mr. Chairman and gentle-

My name is Thomas N. Downing. I represent the First Congressional District of Virginia.

This district includes the entire eastern seaboard of Virginia from Maryland on the north down to North Carolina on the south.

It includes portions of the Chesapeake Bay and the tributaries of many rivers.

I do not have a prepared statement, Mr. Chairman. I just want to give the committee my thoughts and express my concern over the recent suggestions of the National Research Council that certain sites along the Atlantic seaboard be used as possible dumping sites for atomic waste materials. 
I read their report very carefully, and in it they suggest that 28 sites along the Atlantic and gulf coasts could be used as possible dumping sites for atomic material.

Three of those sites are located off the coast of Virginia, and one of which is located only 35 miles from Little Creek, Va., which is approximately 25 miles off the coast of Virginia Beach, which is one of the greatest resort areas on the eastern seaboard.

This has created great concern among my people in this area, and with some justification.

Mr. Chairman, this site 35 miles off Little Creek is known as Site No. 4 in the report put out by the National Research Council.

That site is the location of a sunken ship, and it is in the middle of a great fishing area in my area, sport fishing as well as commercial fishing.

The thought of having this waste material in 55 feet of water, if that is correct, and with the commercial and sport fishing area which exists there, it causes me great concern.

Doctor Hargis, who is the head of our Virginia Laboratories, says that his information is that the drift currents there are toward the Capes.

He is very much opposed, in behalf of the Laboratory of Virginia, to this particular site.

In addition to possible harm that this may bring not only to the marine life but to other industries, it is a great psychological thing down there, with the resort areas so close, with people coming down by the thousands in the summertime, so that there is perhaps a reluctance, and perhaps there is a slight fear which would develop if this material were allowed to be dumped so close to the shore.

Speaking very frankly, I know practically nothing about the effects of atomic radiation. I do not know that anybody knows the complete story, but it seems to me, Mr. Chairman, that rather than take any chance at all, the authorities should consider dumping this material further out at sea where they can be more assured that there will be no danger from radiation and remove any psychological danger that might exist.

I am told that the reason they are trying to get close into shore sites is because they contract the hauling of this material, and the people with whom they contract do not have the equipment to carry this out to sea.

I am not too impressed with that argument. With something so dangerous as what we are dealing with, it seems to me that people who are contracting to haul it should have the equipment necessary to take it way out to sea, or if they do not it should be hauled out by one of the services, the Navy or the Coast Guard.

As to these contract haulers, I am wondering whether they dump this dlangerous waste material exactly where they are supposed to dump it or not, and whether there is any adequate check on where they dump.

It is possible they could take it out beyond sight of land and dump it and nobody would know about it.

Mr. Chairman, perhaps it would be wise for this committee to consider criminal legislation for the misplacement of atomic waste material. In other words, if it is not dumped in the prescribed area which is deemed safe, then that would constitute some form of a crime. 
It is important enough to warrant consideration along those lines in my opinion.

$\Delta$ Iready, and for some time, I understand since 1955 , they have been dumping this atomic waste material at certain sites approximately 100 miles off the shore.

I would like to be reassured as to just how safe this dumping is. I would like to know whether there are controlled checks made at periodic intervals to see whether this material is kept intact and is not radiating into the waters there.

I would like to know if this dumping is supervised by the Atomic Energy Commission.

I would like to know if drift or if storms would cause that material that is dumped to move in closer to shore, or possibly to break the containers and allow harmful radiation to escape.

These are some of the things that I would like to know.

I would also like to file with this committee, if there is no objection, a letter dated July 10, 1959, from Dr. William J. Hargis, the director of our Virginia Laboratories, to Dr. Dayton E. Carritt, chairman of the special working group on disposal of radioactive waste into the Atlantic and gulf coastal waters.

Dr. Hargis has gone into the matter pretty thoroughly, and in this letter he cites specific objections to site No. 4, which is the one located just 35 miles off of Little Creek.

I think it would be interesting for the committee to have this in its files.

In conclusion, Mr. Chairman, I would like again to say that I must protest against any further consideration of dumping of atomic waste materials so close to our shores of Virginia as 35 miles, not only because of the harmful effect it might have on marine life and human beings but also the psychological effect which could hurt the economy of this area.

I appreciate the opportunity of appearing before you.

Mr. Miller. I will be happy to have filed the letter to which you referred, written by Dr. Hargis. It will be made part of the record.

(The letter referred to follows:)

Dr. Dayton E. CarritT,

JULY 10, 1959.

Chairman, Special Working Group on Disposal of Radioactive Waste Into Atlantic and Gulf Coastal Waters, Chesapeake Bay Institute, Johns Hopkins University, Baltimore, $M d$.

Dear Dr. Carritt: After careful study of Publication No. 655 "Radioactive Waste Disposal Into Atlantic and Gulf Coast Waters" and consideration of the sites proposed to serve Norfolk, Va., we have come to the conclusion that although the amounts to be disposed of are small, the containers will hold the material for some time, and the hazard from radioactivity probably slight, we cannot approve site 4 . As you recall, site 4 is $36^{\circ} 49^{\prime} \mathrm{N}$ and $75^{\circ} 27^{\prime} \mathrm{W}$, near the location of a wreck which is in 11 fathoms of water. Our objections are as follows :

(1) We believe that the net circulation over this site is into Chesapeake Bay. Drift bottle experiments seem to indicate a shoreward movement, particularly toward the Capes, in this area. We anticipate further observations of the currents in this area in connection with another problem.

The committee, itself, has stated several times in the report that it is advisable to avoid contaminating estuaries and shallow places where there is a significant shoreward water movement.

(2) According to our information, trawlers frequently work in the vicinity of this particular site. Even though the committee has attempted to avoid 
this possibility by selecting a site near a wreck, we doubt that any disposal contractor whose operation is too small to permit him to carrs wastes out to deeper water will either be equipped for, or prone to pinpoint bombing. Since trawl nets might occasionally be destroyed by the bulky waste disposal containers and since it would be bad psychologically if containers were to be trawled up, we believe that they should not be dumped at this site.

(3) The wreck and lumps, indeed the wlole flat, constitute a good sport fishing area whose use might be discouraged should it become known that radioactive wastes are being dumped nearby.

(4) Unfortunately perhaps the word radioactivity and the phrase radioactive wastes evoke an enotional reaction from the mblic. The nse of a dumping site so close to the Virginia beach resort areas mas have an adverse effect on their habitues.

Aside from stating that at this time we are in cautious agreement with the National Pureau of Standards Handbook $58^{\circ}$ s 1,000 fathom rule of thumb we can offer no alternative for site 4 other than $4 a$ or $4 b$, which seem much more suitable to us. Our knowledge of the circulation pattern is unfortunately scanty.

May I make several pertinent comments? I liave found it quite interesting that neither the precise amounts nor kinds of radioactive materials already deposited in the sea are known despite Handbook $\check{5}$ 's recommendations (p. 4) that accurate records be kept. Slipshod record lieeping should not persist. All of us are aware of the myriad unknown factors inrolved in the biological activities of raclioactive substances and the possible effects of these materials on the marine system and it seems absurd to compound these nukuowns unnecessarily.

We believe that there are so many unknowns involved that choice of disposal sites slould not be linited to the distance a small contractor can take lis boat and return in 1 day. As a matter of fact, if a contractor's equipment is too small to travel beyond the 1,000 fathou (urve, his navigational ability might be somewhat limited and his accuracy impaired. If time is important, perhaps a helicopter or a blimp might be used to slorten travel time. Disposil sites should not be selected on the basis of cost or travel time.

We have all heard rumors of irresponsible actions by disposal contractors in dumping radioactive materials in manthorized areas. While they may be no more than rumors, we believe that some who may be chosen, such as garbage haulers, etc., are and will continue to be ignorant of the possible serious effects of irresponsible disposal practices. We believe it poor policy to entrust disposal of radioactive materials to civilian contractors unless precise control of their activities can be assured and unless they are adequately equipped and avare of their responsibilities. Perhalus in order to have proper control over disposal an agent of a regulatory bods slould accompany each load.

Mr. Haven, of this laboratory, observes tlat according to extrapolation from data contained in page 6 of Publication (3.j.) about 1,000 drums of low-level radioactive wastes a year have been dumped into the Atlantic since 19.71 and suggests that dumping of this small volume could be done by the A $\mathrm{EC}$ in deep) water at relatively little expense. Lsers could ship wastes to several collection points along the coast and the AlC could dispose of them at regular inter. vals, perhaps monthly. One thousand barlels amounts to little more tlan a good-sized bargeload.

The amounts of money involved in disposal contracts must be relatively small and their contibution to the general economy slight. Though we are lefinitely not oplosed to encomragement of private enterprise we believe that a rosponsible Guverument disposal unit should be established immediately. In any case, we are olposed to the notion of allowing eost to have any liniting influence on solertion of disposal sites. The safest, most infallible nethod, from every present and future standpoint, must be employed. Igmoranco of possible effects is too great to have it otlerwise.

In closing naly I say that our laboratory is extremely interested in any "preuse, during-use, post-use" survers that miglit he conducted in Virginia waters or offshore. We will make our laboratory facilities, vessel, persomel, and data avaliable, conduct coordinated studies and even mulertilie contract res search should the neel and opportunity arise. We are also interesterl in corollary research into the various aspects of rablioartivity as it is commected to marino biolog. Please connt us in on all deliberations, survers, etc.

With best regarls to you and your associates, I am, Cordially yours, 
Mr. Miller. I might say that all of us are concerned, and naturally somewhat confused, concerning this problem. We realize the necessity of getting rid of this material. We have confidence in the Oceanography Committee of the Academy of Sciences, and I think they are very frank in their report.

Part of it is not readily understood by the layman, but I am concerned with one section of it, and I think it is one of the things that is bothering you.

On page 16, this page deals primarily with the movement of bottom sediment and bottom water circulation.

Evaluation of bottom circulation must be inferred from observations of salinity and tenperature distributions, and measurements of surface drift, the latter largely from drift bottle experiments. A few direct measurements of bottom currents have heen made from light ships.

Our knowledge of bottom water circulation along the Atlantic coast may best be summarized by the following four items-

Then they give you those four items, as I interpret them, in effect, saying that this is an area of oceanography, the matter of these bottom drifts, which must be studied. We must spend some money on it because we don't know a lot about it.

Maybe I interpret this report wrongly, but I have tried to go into it and frankly that is one of the things that concerns me, as I know it concerns you.

Mr. Doñing. I agree with the Chairman.

Mr. MiLler. I want to thank you for testifying here.

IVe appreciate the time you have taken from a very busy schedule to be here.

Mr. Downing. Thank you very much.

Mr. Miluer. Any questions, gentlemen?

Mr. Pelcy. I would just like to say that I share the concern of our colleague, Mr. Downing. I do not know what the final answer will be, but very recently, in the Pacific Northwest, a container was found on the shore marked "Danger", and it was marked to indicate that it had some dangerous waste material in it.

Whether it was a hoax or whether it was actually the Atomic Energy Commission's own container, I do not know.

However, I think this is something that you are certainly properly concerned about in your district, and I would be very much interested in supporting any measures that are taken to be sure of the safety of the people.

Mr. Downisg. I thank the gentleman.

Mr. Miller. Thank you very much, Mr. Downing.

Our next witness is the Honorable Bob Casey, of Texas. We are happy to welcome our colleague from 'Texas, who also has expressed great concern about this problem.

\section{STATEMENT OF HON. ROBERT CASEY, A REPRESENTATIVE IN CONGRESS FROM THE STATE OF TEXAS}

Mr. Caser. Mr. Chairman, and members of the committee, I first became concerned about the matter of disposal of radioactive waste when a corporation in my home city of Houston, Tex. was licensed by the Atomic Energy Commission to dispose of such waste. 
Of course, I, as most laymen, was a little afraid of radioactive materials, being ignorant as to their effects and how safely they might be handled.

In particular that is so in our area because of the fact a little over a year and a half ago we had a little unfortunate experience where some employees were working in an industry which used radioactive materials in their work, and we had contamination not only of the plant but of these employees' homes.

Therefore, any mention of radioactive materials in our area naturally causes quite a disturbance.

Recently, a new industry, Industrial Waste Disposals, Inc., was licensed to dispose of radioactive waste, and the license provided that they would dispose at a site in the gulf coast approximately 180 miles off the coast in 1,000 fathoms of water.

I did not become too concerned about that anthorization due to the fact I felt that the safeguards they had placed in the license indicated that they who had knowledge of these materials were taking proper precautions, and also I know that in our own medical center they use a considerable amount of radioactive materials in medicine and research which under proper precautions is bound to be safe, and if it were not I am sure the men who know the uses of this material would never allow it to be right in the heart of our medical center.

Also, I thought our people were about to accept these pronouncements as being proper, when along came the National Academy of Sciences report in which they recommended a location just 20 miles off the coast in 54 feet of water.

I am very familiar with the spot they located just off Galveston because I have personally caught many a red snapper, and many fish of various varieties and species there, and it is quite a popular place to fish.

I began to see what the basis of these recommendations were.

Of course, immediately the National Academy of Sciences comes back and says "We made these recommendations subject to studies."

I want to point out to the chairman that I think the National Academy of Sciences was a little presumptuous in making definite site locations at this time because in the very forward part of their report they state they were supposed to make a detailed study.

I do not think they have made such a detailed study, if they are just going to pick out sites, because they can easily pick out any point just a few hundred feet off the coast, so far as that is concerned, if the location is subject to detailed study.

That was not my understanding. My understanding was that the report was to have included a detailed study to begin with, and I think they have certainly harmed the program of meeting this problem we have. I say "we" because it is a problem that the whole Nation will have from now on, this disposing of these waste materials.

'They have not helped this thing at all by coming out in this manner, with definite spots picked out where there has been no study.

The National Bureau of Standards put out a handbook No. 58 in 1954, entitled "Radioactive Waste Disposal in the Ocean."

In this booklet they moved with caution, and properly so.

'They recommended disposal, if it should be in ocean waters, to be in depths where the water exceeds a depth of 1,000 fathoms. 
They also made the observation that disposal by pipeline was undesirable.

I understand that Great Britain has been disposing of some of these radioactive materials by pipeline, and you will hear a lot of fine talk about how successful that has been and how it empties into a kelp bed and they harvest this kelp. They have made all sorts of studies, and the pipeline operation works fine. There is proper dispersal, and there is no after effect either on marine life or plantlife.

I think again you have to take into consideration the currents, sedimentation, and so forth, on each particular location.

The original recommendation of the National Bureau of Standards did not recommend a pipeline at all.

They state on page 4 of that publication:

Disposal of radioactive waste through pipelines is considered undesirable.

That is very flatly stated.

We have no definite studies which have been made with reference to the maximum permissible concentration, and in none of the publications has there been a study with reference to maximum concentration, nor has there been a study made with regard to dispersion, either in the upper layers or lower layers of the ocean. I think that is something your committee perhaps should be very much concerned with, detailed studies which will bring about a proper guide as to dispersion and disposal of radioactive waste materials in the ocean.

Another thing that will concern us all is the control of dumping these materials in the ocean.

After all, we have control of our waters only a certain distance from our shores, and the oceans are free, and there is a good possibility some other country might choose our offshore sites to dump materials, and I don't know how we can stop them so far as that is concerned.

By the same token, I wonder about how we are going to control our own licensed people other than by the license itself as to where they will dump this material, because once they are out into the free high seas the only control we would have would be by nature of what we can do with them when they get back to shore should they not follow the purposes of their license.

It looks like this might develop into an international question as to these disposal sites.

The National Academy of Sciences put out some other reports with reference to this subject. One of them was published in 1957, publication No. 551, and it is a very exhaustive piece of work entitled "Effects of Atomic Radiation on Oceanography and Fisheries."

In this volume they point out the hazards through recovery of containers.

In other words, they state fishermen might bring these containers up in their nets if they are not properly disposed of, and you would find fishermen exposed to this material unless it is properly placed at a depth where it would not interfere with the fishermen's nets.

It is not unusual for fishermen to bring up junk which has been dumped out in their fishing grounds, unknown to them, and it not only damages very expensive nets but in this instance it might very well mean some exposure to them which might cause injury or death.

They point that out, and it is a very practical consideration. 
In this book, which was just published by this same organization 2 years ago, they go into great detail about the fact that knowledge of radiation effects on marine organisms is inadequate for any firm conclusions.

If they had any experiments in order to reach firm conclusions they do not give indication of it in these later publications.

They point ont that sites which provide the least hazard may involve the greatest clisposal cost. I grant that may be true, that these sites isolate the materials so no part of their entry back to the land or any place which might come in contact with man is limited.

That may be true, but I think in this instance cost should not be considered when we are talking about the safety of our people and the use of our beaches not only for recreation, but the waters are also important to the harvesting of our marine life which is a strong segment of our economy, as well as a source of food for our people.

Mr: Miller. Might I point out it is a somrce of food which has a great potential as the population of this comntry increases and the population of the world increases, the importance of which will increase in proportion to that population.

Mr. Cassy. I agree with the chairman very heartily on that.

On page 21 of this report they state:

Our knowledge of most of the processes in the ocean are altogether too fragmentary to permit precise predictions of the results of the introduction of a given iuantity of madioactive materials at any particular place.

In orler to obtain the necessary knowledge, an aderuate long-range program of restirch in physics, chemistry and geology of the sea, and on the biology and ecology of its contained organisms is required. Such research must be directed toward the understanding of general principles, not simply to the ad hoc solution of a particular local problem for inmediate application.

The latter sort of study is desirable in order to provide engineering solutions to particular waste disposal problems as they arise. Sucl engineering solutious must necessarily he of limited application, and more they must always be conservative at least until sufficient broad understanding is obrained.

Then, Mr. Chairman, they follow that with a list of the major unsolved problems. I will just give you the headings of those without reading them.

They list them-one, dispersion in the upper mixed layer.

Two, circulation in the intermediate and deep layers.

Three, exchange between the surface layer and deeper layers.

Four, sedimentation process.

Five, effects of the biosphere on the distribution and circulation of elements.

Six, uptake and retention of organisms used as food for man.

Seven, effects of atomic radiation on populations of marine organisms.

As far as I know, these major problems are still unsolved because this is a publication by the same group which put out this recent publication.

'This same year, 1959, this National Academy of Sciences, the National Research Council, put out a booklet "Artificial Radioactivity in the Marine Environment."

They reiterate some of the very same things they did in publication 5.51, and that is mostly lack of knowledge, and the fact that detailed studies are needed. 
I would like to point out to the chairman that particularly in my own area, in one of these booklets they have a study with a general statement as to the tides and currents, and in those instances in my own area off the coast of Texas it is quite obvious that you have very little current, lots of sedimentation, and all these things which would lead you to be afraid to use that particular area for any disposal purposes, particularly of materials such as this.

T hope that this committee will in the first place allay the fears of my people that these specific sites as pointed out in this most recent publication will not be used as recommended here, and that the public will be protected by proper studies to gain the knowledge that is needed to meet this problem.

I will not say that I do not want any materials dumped in the waters off the coast of Texas, because I think that would be foolish. We are living in a changing world. I know that, and $I$ think the people I represent are intelligent enough to know that, but if we are going to rely on people whom we presume have the knowledge to deal with this problem I certainly think they should be cantioned not to presume that we know so much about it, and that their language should be carefully studied before they release a publication of this sort, somewhat as is referred to in the legal profession-the big words give it to you and the little ones take it away.

First they say, "These sites would be fine." Then they say, "If studies are made and are found to be acceptable."

We have quite a public relations job to do between the scientific mind and the layman's mind in understanding this tremendous problein.

I do not want any activities, scientific or otherwise, which will be beneficial to my community to be discouraged from coming into my community.

I know the field of radioactive materials in use in peacetime is growing day by day, and I want my community to share in those growths and in those developments, so I want a healthy climate and I want an understanding with my people.

By the same token, I do not want them subjected to something which on its very face shows that it would be dangerous or a wildeyed experiment or presumptuous on someone's part to just pick out a spot and use it for dumping something. It is perhaps used to dump trash, but not used to dump material such as this which can be washed back on to the beaches or can settle into the bottom of this shallow water where our marine life will pick it up.

I, too, read the article Mr. Pelly referred to. It was a matter of just about a week ago where the people were out on the beaches swimming and up floats a barrel with big yellow letters on it- "Dangerous, Radioactive."

Whether or not there was anything in it, I don't know. As I understand it, one of our agents picked up the barrel for examination, but I have heard no report on what was in it, and I don't know whether or not anyone else has. That was out on the Pacific coast.

If there is anything I can do to be of assistance to this committee, Mr. Chairman, I certainly hope you will call on me.

Mr. Miller. I want to thank you for a very comprehensive and well thought out statement, and to congratulate you on the research work you have done on this. 
I may say that as I see the picture in its broad aspect it points up the necessity for intensive studies on oceanography which has been recommended by the Academy of Sciences through the medium of the Brown Committee, its Committee on Oceanography.

I think that the academy has done a great work in advancing interest in this field.

I do not think that the oceanographers themselves will controvert what you have said throughout this report and others.

Indications are that they do not know all of these answers. They have come to us now asking for some money so that they can get the equipment with which to find these answers.

As I see the problem today, it is not too acute, not acute in this sense-most of the waste being dumped is low-level waste.

However, this will not always be the case, and we are on the threshold of this new era.

Substantially the same group, if I remember rightly, which got out this report, just 2 or 3 days ago released another report which came to my desk. It may be on your desk, too, relative to the effect of nuclear-powered ships.

A casual reading indicates you cannot have more than about 300 such nuclear-powered ships throughout the world without raising some level of contamination that will be dangerous.

I say that is a casual reading. Perhaps $I$ did not read all the fine print, but that is the summation that $I$ got out of this report, so this is another reason why we on this committee must act with some dispatch, and must appeal to the Congress to give the scientists in the field of oceanography the tools with which to work to get these facts and correlate them so they will be able to give us positive answcrs rather than some of the answers which you so aptly put here-the big words give it to you and the fine print takes it away.

I want again to express my appreciation to you, Mr. Casey, for the work you have done and the statement you have made.

Questions?

Mr. Pelly. Mr. Casey, it is very obvious that you have given a lot of thought and study to this problem we are getting into.

You made the statement early in your testimony that it looked to you as if the disposal of radioactive waste might become an international problem.

To me that is an understatement, because when you have experienced the conversations which go on and on in the United Nations, and the difficulties we encounter in arriving at any understanding, it makes you feel that that problem is right here.

Do you know of any conversations or discussions which have gone on in the realm of international agreements on radioactive waste disposal?

Mr. CASEY. No. The only reference or conference I know of where we had some discussion with any other nation has been with Mexico. Mexico has been disturbed about this proposal.

Mr. PELLY. I can understand why they would be.

Mr. Caser. One of the sites is right down near the Mexican coast, too.

Mr. Pelly. You can imagine how Canada might have an interest in this entire matter. The United States and Canada in some cases 
have an agreement on migratory fish, we each share the harvest. We have a joint commission on that.

If anything should endanger that fish migration it would affect Canada exactly as it would affect us.

I would think that your statement on the international aspects of this was certainly a master piece of understatement, because to me it is vital that we now get into the realm of the disposal of radioactive waste as it is affected by the peaceful use of the atom.

Now we in our committee have had the very interesting explanation of the first nuclear cargo vessel, the Savannah, and the way there will be disposal of the nuclear propulsion waste, and we realize that this thing is on us now, and as our chairman, Mr. Miller, has indicated, there are only a limited number of those ships which can be safely allowed to sail on our seas. Certainly we have to start to control them now because various nations are considering nuclear propulsion right now.

I certainly am very much interested in your thoughtful testimony. I think Mr. Miller has indicated that this committee feels it has a real responsibility in that field to get into oceanography. I am sure the thought you are giving us as a committee will be implemented.

Mr. Miller. Mr. Lennon.

Mr. Lenson. Mr. Chairman, I wish I were competent to comment on the testimony. I have been greatly impressed by it. It is comprehensive, thoughtful, and certainly a most intelligent analysis of the situation we are now confronted with.

I am reminded that just a few weeks ago I had a communication from the executive secretary of the North Carolina Fisheries Association. He had presumably read the bulletin which you may have referred to in your testimony, and he indicated the feeling that the people have in North Carolina with respect to a proposed site just off our coast near Morehead City, N.C., for the dumping of radioactive materials.

In his letter he called my attention to the nearness of the Gulf Stream to our entire coast. Of course, as you gentlemen know, we are in the area of the hurricane belt. We had four major hurricanes in a matter of 11 months. The eye of three of them passed within my congressional district coastwise. We know there are sediment and things on the bottom of the ocean beyond the Gulf Stream, as much as 54 miles in some spots off our coast, that the hurricane tempest brought to our shoreline. This proposal provides for the dumping of radioactive material at this possible site within a distance of less than 20 miles from the coast of North Carolina, which is between the coastline and the Gulf Stream. The Gulf Stream would of course carry anything, if it is not anchored to the floor of the ocean, from the Caribbean all the way up the Atlantic coast from one end of it to the other.

I say to you, Mr. Casey, that I am alerted by what you said, and I shall go back and not only read that again but delve into the matter, because it is of serious consequence if that develops.

Mr. Pelly. Will the gentleman yield.

Mr. Lennon. Yes.

Mr. Pelly. You mentioned the Gulf Stream. We have a Japanese Current. Anything which is done over in Asia or Japan would affect us just the same way that you are referring to. So the inter- 
national aspects of this are certainly pointed up in this testimony. Mr. Len Non. It is crystal clear, Mr. Pelly, that it is an international matter, and is becoming more so.

Mr. Miller. I may say for the benefit of my colleagues that in the short time we have been at this, from some of the information I gained at Woods Hole and talking to people in this field, I am convinced more and more that the whole field of oceanography will require a reevaluation of international law.

You speak of fisheries compacts with a neighboring country, we have one with Canada. We have a halibut compact. We have the same thing on the east coast. This was fine where only the two comntries were concerned. Recently we have found other comntries coming in and taking fish in the areas that we at one time felt were corered by these compacts. Then a third nation's fishing boats show up.

This matter of radioactive wastes is one which I think eventually will have to be dealt with on an intemational basis. As we go along, this whole field must be gone into. Ancl, sooner or later, maybe not in our day but I can foresee the time when the nations of the earth will get together and divide the oceans of the earth just as they have divided the land area of the earth for their self-preservation and self-protection. That is a little bit in the future, but I cannot see how we are going to get a way from it eventually.

Mr. Curtin.

Mr. CurTin. Thank you, Mr. Chairman.

I think the statement of both Mr. Downing and Mr. Casey are a matter of considerable concern to all of us. I note one of the proposed places for disposal is off the coast of New Jersey at Atlantic City which, as everyone knows, is one of the most popular resorts in the country. I think as a result of this disclosure, this matter requires considerable investigation.

That is all.

Mr. Miller. Mr. Counsel.

Mr. Drewry. No questions.

Mr. Milles. I may say for the benefit of Mr. Pelly and myself that Dr. Ravelle's introduction to this or foreword, if you have not read it, says :

Reports are also in progress on the disposal of low-level wastes in the Pacific coastal waters and on radioactive waste disjosal from nuclear-powered ships.

We in the Pacific coast region look forward to getting perhaps the same sort of shock that the people from the $\Lambda$ tlantic and gulf coast have had.

Mr. Cuntr. In other words, we are going to start getting some mail from home one of these days on this problen.

Mr. Milleir. I am just giving you waming.

Thank you very much, Mr. Casey.

Mr. CASEY. Thank you, Mr. Chairman.

Mr Miller. Did you have anything you wished to put in the record?

Mr. Caser. 'This is rather voluminous. Of course I recommend to the committee these other publications if you have not seen them.

Mr. Minfer. I have some notes here to get those publications.

Mr. Casly. I think you would find them very interesting. 
STATEMENT OF DR. ALLYN H. SEYMOUR, CONSULTANT, ATOMIC ENERGY COMMISSION, AND ASSISTANT DIRECTOR, LABORATORY OF RADIATION BIOLOGY, UNIVERSITY OF WASHINGTON

Mr. Miller. Dr. Allyn H. Seymour, consultant, Atomic Energy Commission, and assistant director, Laboratory of Radiation Biology, University of Washington.

Dr. Seymour, we welcome you here. We are glad to see you. I am certain I am exercising Mr. Pelly's prerogative now. We are happy to see a west coast man here in your capacity from the great university that you represent.

Mi. Pelcy. Mr. Chairman, I think the University of Washington has an actual class and study over in Hanford, Wash., where there are nuclear works. Is that not right?

Dr. Seyrour. Yes, sir, there are studies conducted at the Hanford operations plant in conjunction with the University of Washington.

Mr. Pelly. I know that in our marine studies in the nuclear propulsion field, often there is occasion to refer to the very fine work which is done at the University of Washington in that connection. I often hear from some of those who are in the shipbuilding field indicating that they desire to get it modernized and study nuclear propulsion, and the University of Washington seems to be right up in that field.

I am certainly glad you are here today.

Dr. Seymour. Thank you, Mr. Pelly. Thank you, Mr. Chairman.

Before presenting the paper which has been prepared by Dr. I. E. Wallen, aquatic biologist, Environmental Sciences Branch, Division of Biology and Medicine, a word of explanation as to why he is not here is in order. Dr. Wallen is on military leave. Since I preceded Dr. Wallen as marine biologist in the Division of Biology and Medicine and served in that capacity from October 1956 to October 1958, Dr. Dunham and Dr. Wolfe of the Division of Biology and Medicine asked me to present the statement of Dr. Wallen.

I shall now read his statement:

The Atomic Energy Commission has a limited research program in oceanography and marine biology. Although we have used Navy vessels and the ships of oceanographic institutions for limited periods of time, we do not own ships nor do we employ personnel to carry on oceanographic research. We have not considered this a handicap since it has been the general policy of the Commission to contract for research as well as services witl other agencies and organizations.

Under these circumstances the Commission's interest in open ocean research is restricted to such specialized basic problems as (1) deep ocean current as a distributive mechanism for radioactivity, (2) dispersal and distribution of fallont radionuclides through the ocean layers, (3) food web concentration of radioactive isotopes in ocean waters, and (4) mechanisms for reduction or dilution of possible centers of radioactivity in the ocean.

I have made some minor corrections in Dr. Wallen's statement, so what I read will not follow exactly the copy that you have at hand.

The Commission (Manhattan District) has been supporting research in oceanography and the marine sciences since 1943 when the Applied Fisheries Laboratory of the University of Washington was 
asked to develop information about the possible effects on the Columbia River fisheries of the building and operation of plutonium reactors. The Applied Fisheries Laboratory has continued these studies to the present time and has advised the Commission concerning the effects of the testing program on the biota of the Pacific test site. The Applied Fisheries Laboratory, which is now called the Laboratory of Radiation Biology, was recently selected as a prime contractor to evaluate the effects of the Alaska harbor project (Chariot) on the surrounding ocean environment.

Although the Commission had long been aware of the possibility of temporary contamination of land and water areas by atomic testing, the unexpectedly heavy yield from the Bravo shot of March 1, 1954, focused attention on the vital need for more adequate oceanographic data to augment the predictions of effects of nuclear detonations on living organisms. The Commission sent several scientists to Japan to discuss the radiobiological aspects of the incident with their marine scientists. A working arrangement was made permitting the exchange of duplicate samples of fishes collected before and after the 1956 and 1958 tests.

The discussion with the Japanese scientists followed the March 1, 1954 , event in which there was fallout upon a Japanese fishing vessel. Some AEC people were sent to Japan to discuss this problem with them.

By the time of the "Wigwam" detonation off the coast of lower California in May 1955, the Commission had set up a temporary fish monitoring program at the canneries on the west coast of the United States. 'The Food and Drug Administration, which conducted the monitoring, was able to assure the public that the fishes caught off the coast were not contaminated by fission products.

Because of the paucity of general oceanographic data in the Pacific test area the prediction of the distribution of radioisotopes from Eniwetok-Bikini by ocean currents was uncertain, and therefore it became necessary for the Commission to sponsor open sea oceanographic surveys in 1955, 1956, and 1958. A Coast Guard cutter was used in 1955 and Navy ships provided transport ation for the latter two cruises. Although the data collected during these cruises were favorably received, they pointed up the necessity of continued oceanographic work before a very clear understanding was possible of the environmental forces responsible for determining the effects of the detonations on the environment.

It is to be noted that in these endeavors the Scripps Institution of Oceanography has assisted the Commission greatly for a number of years in carrying out special studies related to the weapons testing program, as well as the performance of biological oceanographic surveys, especially for the "Wigwam" operation.

In addition to the release of radioactive isotopes by detonation of nuclear devices, it is obvious that other sources of radioactive materials will become more important to oceanographers. Small quantities of very low level wastes are now being packaged in concrete filled barrels for disposal at sea. Some low level (low activity) wastes are inherently associated with industrial uses as well as with the medical research uses of radioisotopes. A part of these wastes from installations convenient to the seacoast are disposed of to the oceans. 
Normally operating nuclear submarines and nuclear surface vessels generate low-level wastes in relatively small quantities. The degree of control needed over the release of these wastes to the ocean depends in large part on the ability of that environment to safely assimilate the particular isotopes. It is important that the Navy and the Commission investigate this now when the problem is a small one.

Nuclear powerplants are being used for production of electricity and for research. The irradiated fuel elements from these reactors are highly radioactive and will probably never be disposed to the ocean. However, impurities in the water which may be used in cooling such reactors may pick up a small amount of radioactivity by induction. In this way small amounts of certain radioactive isotopes are in some cases released into streams, depending again on the capacity of the environment, and may eventually reach the ocean.

Although much of the radioactivity in fallout from past testing of nuclear devices will be chemically combined into the land portion of the earth, a larger percentage should fall on the oceans, which comprise about 70 percent of the earth's surface. Likewise, the fallout isotopes may appear in fresh waters, be dissolved from soils and/or be concentrated in waste water from man or industry to eventually go downstream to the ocean, and in this way indirectly add more radioisotopes to the sea.

Although we are confident that early reports are correct that fallout isotopes are insignificant as diluted in sea water, it is necessary to continue monitoring the oceans and to continue research leading to complete elaboration of the oceanic processes that determine the ultimate fate of the long-lived isotopes that may go through the food web in the ocean and again become significant to man.

Support of oceanography is largely dependent upon Federal funds, and the research has been directed toward the programatic needs of the sponsoring agency. Most of the Navy-sponsored research is related to naval operations and is not applicable to problems of $\mathrm{AEC}$ interest. The Bureau of Commercial Fisheries program in oceanography collects some data useful to the AEC from the standpoint of location of sites for waste disposal, but seldom overlaps into the primary interests of the AEC in the health and safety aspects of irradiation. All AEC projects are considered from the standpoint of their relationship to the oceanographic programs of other agencies with which we work closely.

Contracts for research and services have been let jointly with the Office of Naval Research, with the National Science Foundation, with the Bureau of Commercial Fisheries, and with the Maritime Administration for various types of projects, sometimes to be carried out by cooperation with the Coast and Geodetic Survey, the Public Health Service, the U.S. National Museum, the Bureau of Commercial Fisheries or other governmental agencies. Naval ships and other vessels have often gathered samples for AEC analysis.

Although the Commission has a general interest, as described above, in the potential use of the ocean for disposal of wastes, it is unlikely that other than very minor use will be made of the ocean in this manner. The economics of disposal of wastes seem to point clearly to the use of land disposal sites. In any case the high level and con- 
sequently more dangerous wastes are stored in underground, steel tanks on land. Current research on processes for treating these wastes to make them safer to handle and use are all pointed to some method of storage or disposal on land. Dr. Lieberman undoubtedly will discuss the subject at greater length.

The Commission is primarily interested in the development of uses of radioactive isotopes that may contribute substantially to the fund of scientific knowledge, as well as to the production of more food from the oceans. The value of tracer quantities of radioactive materials in the solution of problems of living functions of organisms can hardly be overemphasized.

Oceanographic assistance, principally in the way of conferences, has been given by the Commission to Japan, to Canada, to the United Kingdom, to the International Atomic Energy Agency, and to other countries and groups of countries. It is anticipated that such cooperation must continue, since obviously the ocean cannot be separated into isolated compartments for study or for use.

It has been estimated that in case of a nuclear war, one of the least contaminated sources of food will be the sea because of the tremendous volume of water that, through natural mixing processes, will greatly reduce the concentration of added contaminants. It is obvious that studies must be undertaken to assess more accurately the level of radioactivity that may be absorbed by the ocean without detrimental effects.

It has been pointed ont (NAS/NRC Publication 551) that the concentration of certain elements by organisms, along with gravitational effects on their excreta and dead remains, as well as their migrations, result in a circulation of these elements that is different from the circulation of the water.

What Dr. Wallen has in mind here is that the radioisotopes could not be traced merely by following the currents. The biota play an important part in the distribution of radioisotopes in the ccean.

A number of elements are concentrated in the bodies of organisms by several orders of magnitude over their abundance in sea water. Radioisotopes of some of these elements may be concentrated in man's aquatic foods. Ion exchange and sedimentation of particulate matter will remove some radioisotopes; however, in near shore areas these may be recycled by bottom feeding organisms.

'The general outline of the Commission's research eftorts, concerned with ladioactivity in the oceans, was suggested by the National Academy of Sciences "Report on Oceanography, 1960 to 1970 " and inserted in the Congressional Record of February 17, 1959. We previously presented two papers covering the broad aspects of this program to the Joint Committee on Atomic Energy (Fallout Hearings, May 5-8, 1959). 'These two papers were, first, "The Atomic Energy Program in Oceanography and Marine Biology," prepared by Dr. I. F. Wallen, aquatic biologist, Division of Biology and Medicine, U.S. Atomic Energy Commission. This paper was presented as appendix $\mathrm{C}$ of the "Statement on Fallout" prepared by the Director of the Division of Biology and Medicine, Dr. C. L. İunham. 'The second paper" was entitled "Fallout in the Ocem," and of this paper I was the author.

'The objectives of the Commission's research program are as follows: One of the objectives is to determine the eflects of the accumulat- 
tion and retention of fission products on marine organism and their transfer along the food chain to those higher species used as food by man. Problems of the effects of severe radiation on fishes are also studied. Such studies are of considerable magnitude when one considers that there are hundreds of organisms and at least $2 \pm$ isotopes of significant occurrence as fission products.

I should like to include here a chart, which was adapted by Chipman (1958) from data of Hunter and Ballou (1957) showing the percent of total radioactivity contributed by certain fission products at different times after fission (table I). We have this table prepared and ready for presentation, but this information is also included as table I in this report. Rather than present the graph at this time, I shall make reference to the table.

'The significance of the table is that it shows the isotopes that biologists look for in contaminated organisims, and it is also significant in that it point out that the relative abundance of these various isotopes changes with time. At a certain time after the origin of the radioisotape, one isotope may be important; and some time later some other isotope may be relatively more important.

I think it obvious from the table that strontium 90, cesium 137, and cerium 144 are some of the important radioisotopes to be looked for after 3 years.

In addition to the radioisotopes from fission, other radioisotopes are also produced by the detonation of nuclear devices or the operation of nuclear reactors. These include zinc 65 , cobalt 57 and 60 , iron 55 and 59, phosphorus 32, copper 64 , chromium 51, and arsenic 76 , all of which are important biologically.

Since many of the elements are present in trace amounts we have found it necessary to study the chemical composition of biological organisms. It has been demonstrated that plankton organisms will accumulate large concentrations of mixed radioisotopes. If we were looking for an area in the ocean to see if it had been contaminated by fallout, the easiest way to do this at the present time is to collect a sample of plankton and examine the plankton for radioactivity.

As a result the Commission has developed a detailed program to discover the effectiveness of these organisms, both from the standpoint of decontamination and that of possible transfer to human food orranisms. Some expansion is necessary in the fiscal year 1959 expenditure of $\$ 170,000$ for this type of research.

A second objective is to evaluate the disposal and transport of elements by the physical processes of mixing and currents, by the geochemical processes of adsorption, sedimentation and accumulation in locations where they may be absorbed by bottom dwelling populations and finally by biological transport through accumulation in living matter and the subsequent migration, horizontal and rertical, of the populations. Many kinds of experiments must be designed and completed before the answers are known here.

When radioactive materials enter the oceans they may go into solution, they may precipitate or coagulate, they may interact to attain colloidal size, they may be adsorbed or absorbed by other particles, they may settle to the bottom, or they may be ingested by organisms and enter into the biochemical cycle.

Whatever the state of suspension or removal from the water, radioelements will be subject to physical forces that affect their ultimate 
distribution. Horizontal and vertical currents may transport the isotopes until they reach a water density level that temporarily or semipermanently stabilizes them. Diffusion processes tend to equally distribute the added elements among those already present. Migrating animals ingest the particles, excrete them, die, or are eaten by other animals to modify the tendency toward homogeneity of distribution.

Some of the radioactive elements are needed by organisms and, because the normal elemental supply is low, these radiochemicals are concentrated, perhaps 1 million times over their abundance in sea water. In other words, if the organism living in the sea has a physiological demand for an element that cannot be satisfied by the elements which are already present in the sea, and a radioisotope of this element is added to the sea, then naturally the organism will take up the radioisotope of this element.

Other elements are avoided or discriminated against by organisms.

Sedimentation processes may car'y heavier elemental particles, adsorbed radiochenicals and dead organisms with contained radionuclides toward the bottom of the sea where they may be permanently incorporated into the sediments or removed by bottom-feeding organisms.

Since research in these subject fields often requires ocean trips of some magnitude, such research is costly. The Commission is spending approximately $\$ 300,000$ on a minimum program which we propose to expand during fiscal year 1960 .

A third objective of the Commission in oceanography is to maintain a control and monitoring program to assure that the utilization of atomic energy has not resulted in dangerous contamination of the environment. "As has been previously mentioned, the Commission has made oceanographic surveys of the Pacific test site before and after each test series. Samples are also collected between testing programs as practical. A large collection of organisms was taken from the central Pacific before any testing was initiated. The Nary and the Commission have provided these organisms for the Smithsonian Institution to assemble and identify and make them available for comparison with samples collected later.

Biological samples of organisms from Thailand, Japan, Palau, Guam, and other sites have been taken frequently to docmment the distribution of radioactive isotopes from the Pacific. Samples of ocean water from the north and sonth Atlantic Ocean, from the Arctic and Antarctic Oceans, and from the Indian Ocean have been analyzed for radioactive isotopes to provide data on the minute quantities of isotopes present in the oceans from fallont. In some cases 150 gallons of water must be collected in order to locate from 1 to 30 disintegrations per minute of strontium 90-present as one part per billion billion parts of water.

Dr. Wallen wishes to point out here that the amount of contamination that is added to the water can be detected by radiochemical means, but actually in quantity, that is, in weight, it is an extremely small part of the ocean water.

Since by weight 1,000 grams of sea water normally contain an averagre of 34 grams of dissolved materials of at least 44 elements, it is no easy chore to identify and measure accurately the trace amounts of radiochemicals that appear in the water. 'The production of radiochemicals from some individual detonations can be identified, how- 
ever, and the progress of their diffusion followed across the Pacific.

Following the 1954 test series at Bikini-Eniwetok, a vessel from the Coast Gutard was sent on this sort of mission. This was about 10 months following the end of the 1954 series. At that time the highest levels of radioactivity were found about 3,000 miles to the westward of Bikini-Eniwetok off the coast of the Philippines. The levels of activity here were about one-fourth that of the naturally occurring radioactivity in sea water.

Mr. Miller. What was the last statement, Doctor?

Dr. Sermour. 'The level of radionctivity off the coast of the Philippines approximately 1 year after the end of the 1954 test series was about one-fourth that of the naturally occurring radioactivity of the water. There are naturally occurring radioisotopes in the ocean. The principal radioisotope is potassium 40, which contributes about 97 percent of the naturally occurring radioactivity in the water. This amounts to 720 distintegrations per minute per liter. A liter is slightly larger than a quart. So, if you had a quart of water, you would find around 720 disintegrations per minute per liter of radioactivity from naturally occurring potassium 40 . Off the coast of the Philippines about a year after the 1954 series, we found some added activity, and this was at a level that was about one-fourth that of the naturally occurring radioisotopes in the water.

Mr. Milren. That means, if I follow you correctly, where you had 700 naturally you would have roughly between 900 and 1,000 disintegrations per minute.

Dr. Seymour. Total.

Mr. Miller. Somewhere in that neighborhood as a result of it, which would not be at all dangerous.

Dr. Seymour. Yes. That is a correct conclusion, sir. However, to make this statement positive, you should know what isotopes are present, because the hazard is dependent upon two things: First, the amount of radioactivity present, and secondly, the radioisotope which is present. The tolerance level, the MPC value, for various isotopes may vary by a factor of a million or more. For instance, the tolerance for promethium 147 is a million times that for strantium 90 . So it is obvious you cannot say that water of certain radioactivity is or is not hazardous without knowing what radioisotopes are present.

I might further add that this was the area in which we found the highest levels of activity, too, in this 1955 survey. That is, we found some radioactivity practically all the way across the ocean from $\mathrm{Bi}$ kini-Eniwetok, but the highest levels were found near the coast of the Philippines, a distance of about 3,000 or 3,500 miles west of BikiniEniwetok.

Mr. Mrller. Why does it migrate in that direction, do you know?

Dr. Seyrrour. Yes, because the general circulation in the North Pacific is in this way. The waters in the northern hemisphere circulate in a clockwise direction. We have the Gulf Stream in the Atlantic circulating in a clockwise direction. Likewise, we have a current in the Pacific circulating in the same manner, in the same general direction.

In connection with the monitoring of fallout chemicals we expect to learn about oceanography from a number of aspects. Circulation of ocean currents can be measured directly by appraisal of directional 
differences in rates of dispersal. Questions of exchange of chemicals between thermal layers and between water and sediments may be solved using radioisotopes.

In addition to the monitoring of fallout, the AEC program is aimed at establishing operating criteria for both radioactive waste disposal (packaged low level wastes) and nuclear ship operations, and this is being done in cooperation with several other governmental and private agencies.

The investigation of waste disposal sites has been developed under close guidance of the National Academy of Sciences Committee on Oceanography. A subcommittee has just released its first report, "Radioactive Waste Disposal Into Atlantic and Gulf Coastal Waters," and a report is being prepared for the Pacific coast. In addition to these formal reports, the advice of the committee has been sought at several meetings to develop a sound program for selecting and monitoring waste disposal sites. These meetings have been held with the cooperation of the Coast and Geodetic Survey, the U.S. Public Health Service, and other interested organizations.

A study of New York Harbor to predetermine the fate and effect of any released radioactivity is now underway. It is jointly financed by the AEC (approximately $\$ 180,000$, fiscal year 1959) and the Maritime Administration (approximately $\$ 200,000$, fiscal year 1959). As an extension to the New York Harbor study, models of harbors are utilized for similar dispersion studies by the Corps of Engineers at Vicksburg, Miss. This latter work is being done in cooperation with Maritime Administration as a part of the nuclear ship project. AEC plans to expand the harbor studies in the next year or two including studies using tracers in the actual harbor's.

Similar studies may be undertaken by the Navy Bureau of Ships in connection with the nuclear ship program. During fiscal year 1959 and AEC-sponsored studies $(\$ 25,000)$ of two possible sea disposal sites; in fiscal year 1960 additional similar studies costing $\$ 100,000$ are planned. Work will be carried out by the CGS and the USPHS. Right now it is difficult to say with any precision just how much will be spent on coastal and estuarine studies in the next 2 years. It is anticipated that AEC will support approximately $\$ 200,000$ in fiscal year 1960 and the Maritime Administration approximately $\$ 115,000$ in connection with the operation of the NS Savannah. Undoubtedly the total program will be larger as other agencies undertake studies. In addition, the fallout monitoring program includes an expenditure of about $\$ 200,000$.

A fourth objective of Commission research aims to provide information concerning the natural radioactivity and normal processes of oceanic distribution of radionuclides. The uptake of radiochemicals is dependent upon the concentration of tracer chenicals and normal chemicals in the environment. Radium, uranium and thorium are normally found in ocean sedimets. Carbon 14 is a matural component of ocean waters. Potassimm to is also a nat mial component of ocean waters. The long half-lives of these radioactive chemieals permits a look backward to past conditions and thus provides data of value in predicting future distribution of elements in the seat. It has been found that rertain natumb componts which are formed in the deep sea will chelate thorium and other radiochenicals. 
Mr. Miluer. Will you define "chelate" for us, please?

Dr. Sermour. Chelation is a chemical process whereby one compound will grasp and hold onto another chemical element. In marine biology we call the pincers of a crab "chele," which means to grab and hold onto.

It has been found that certain natural compounds which are formed in the deep sea will chelate thorium and other radiochemicals. Studies of chelation shed light on the permanency of storage and future availability of radioactivity.

What Dr. Wallen has in mind here is that some of the sediments on the bottom can grasp and hold onto chemical elements, and that if this element should happen to be radioisotope, they conld hold radioactivity. For instance, clay materials have this characteristic and is a factor to be considered in the distribution of radioisotopes. That is, the clay or other sediments may remove radioisotopes from the water and hold them on the bottom. However, once they are on the bottom, they can become available to what we call detritus feeding organisms, organisims which scoop up mud and filter it. They actually eat mud and remove some organies from the mud. It this way, also, they remove radioisotopes.

Mr. Miller. They in turn enter into the general cycle of some other type eating them?

Dr. Seymour. Yes.

Mr. MLiller. On up the scale until it gets to man.

Dr. Sermork. Ies. This is what we refer to as the food web. It makes little difference how the organism acquires the radioisotope, whether it is adsorbed on the outside surface of the organism or whether it is actually absorbed within the tissues. 'The organism that feeds upon it has access to it, and in this way the radioactivity can move through the food web.

However, I think it should be kept in mind that just because a radioisotope is concentrated by one organism, it is not necessarily going to be concentrated by the organism higher in the food web that feeds upon it. Concentration is dependent upon the physiological need of the organism for the element.

Mr. Mrller. Do you know what effect this would have on the life cycle? is.

Dr. Seymour. No, we have no direct eridence as to what the effect

Mr. Miller. There may be mutations as a result of them?

Dr. Seymour. This is a possibility, but we have no direct evidence of this occurring. In our studies in the Pacific at Eniwetok-Bikini test site where the levels of radioactivity are, of course, extremely high compared to other parts of the world, we have looked but we have not positively been able to identify any mutations resulting from contamination by radioactive isotopes.

Mr. Millfer. Under controlled conditions with marine organisms, conld you find such evidence?

Dr. Sersour. Genetic studies have not been undertaken to study the effects of radioisotopes on marine organisms.

Mr. MIILLER. Would that be desirable?

Dr. Sermocr. Yes, it would be desirable. 
Mr. Miller. In other words, until we get some answer to that, we again rather bump up against a blank wall.

Dr. SeYMrour. Yes, that is right.

I wish to point out, though, that the problem here is a large one. It is a matter of determining the effect of low levels of radiation upon marine organisms. We know what the effects of high levels of radiation upon marine organisms are. Some of the early work of the Applied Fisheries Laboratory was directed toward the study of the effects of X-rays upon fish, salmon and trout, upon snails, upon plankton organisms, and other aquatic organisms. The eflects of high level radiation are well known, but the effects of low levels, the sort of levels of radiation that exists currently in the waters of the ocean, are not known. This is an area in which we need information, but it must be recognized that this is an area that will require considerable effort. It is not a problem which can be solved easily.

Mr. MiLler. Not one that can be solved overnight either? It would take a long time?

Dr. SeYmour. Yes, it will. Although I said our observations in the Pacific have not given us any positive evidence of any mutation effects upon fish populations that now occur, this does not say they might not occur in the future. This will take time.

Mr. Mrller. In connection with the work that has been done, we talked about some of the detonations that are taking place out there, we talk about these wastes going into the sea. This is a continuing process that will be cumulative, will it not?

Dr. Sermour. Yes.

Mr. Miller. Whereas, the other is something that could dissipate and there was no continuous dissipation of it, so that again this poses an entirely different problem. Whereas, the first may lead the way, it is not in any sense a solution to the problem of the disposal of radioactive wastes.

Dr. Seymodr. That is generally correct. Certainly, much of the information we learned from studies carried on in the Pacific or in Nevada also will help greatly in answering some of the questions that arise in the disposal of radioactive wastes in the sea, but this is different due to the fact that there is continuous disposal in one and sporadic disposal in another.

Mr. Mrluer. I am sorry to have broken in, but I thought this was a good place.

Mr. Pelly. Mr. Chairman.

Mr. Miluer. Mr. Pelly.

Mr. Pelly. Is there any indication that nature might provide a counterforce and immunity to radiation in the long run?

Dr. Seymour. There is no evidence that I am aware of. Dr. Dunham, Directol of the Division of Biology and Medicine, is present this morning and, I am sure, conld answer this much better than I.

Mr. Prucy. In other words, you are indicating that what we are hoping is that the radiation dissipates sufficiently so as not to become serious, is that it, rather than something off setting it?

Dr. Srymour. Yes; there are forces in the sea that dissipate radioactivity, both biological and physical. The current systems especially the surface currents, those waters that are above the thermocline, the top couple of hundred feet of the ocean, tum over and dilute radioiso- 
topes. Furthermore, organisms living in the sea pick up radioisotopes and add to the dispersion.

Mr. Miluer. We are talking about the currents carrying this out. I was surprised to learn when we got into this matter of oceanography that there are countercurrents in the sea that we knew nothing about and under the Gulf Stream there is a current moving in the opposite direction, not quite as fast. This means that the distribution will eventually be miniversal throughout the sea except in those very deep holes where water has become concentrated and moves very little; is that right?

Dr. Sermour. Yes; that is the proper interpretation, that eventually the radioisotopes will be generally distributed throughout the sea except, as you mention, in areas of the sea where there is no movement of water. These places are very few. I think another thing that this points out is that we have a lot to learn about the ocean and oceanography and the movement of currents. You mentioned the countercurrent in the Atlantic. Within the last 2 years a countercurrent of gigantic proportions has also been discovered in the Pacific which is now known as the Cromwell Current. Again I would like to emphasize the fact that this points out that we know very little about our oceans.

Mr. Mrluer. I think that is our problem, to stimulate and encourage you men of science more than we have in the past in this field so that you will be able to have the tools with which to work and safeguard us. I want to congratulate you on what you have done under very adrerse circumstances in the past. I mean the people engaged in the field of oceanography. I have come to have the greatest respect for them and I know my colleagues have.

Dr. Sermour. Thank you, Mr. Chairman.

Determination of age of ocean waters by the use of radiocarbon and other radiochemical decay increases our understanding of ocean currents and assists in prediction of the diffusion rates in the case of a nuclear accident or detonation of a nuclear device. Radiocarbon also provides a useful tool for measuring rates of production of organic matter in the sea.

Studies of the basic processes of oceanic metabolism have been extremely difficult and it is anticipated that great progress can be made by the use of radioactive tracers. 'This may be illustrated by listing some of the biological benefits which may accrue from circulation of the ocean waters. Such benefits include (1) oxygenation of subsurface water, (2) dispersal of excreta, (3) distribution of nutrients, and (4) dispersal of spores, eggs, larvae, and many adults. Controlled experiments on a sizable scale may be developed when the equipment necessary for monitoring extremely low level counting is adequately designed for oceanic use. Small experiments have been very encouraging.

Studies in the open ocem involve the use of larger research vessels. Rather than purchase its own ships the Commission considers that it should pay an operating agency-that is, Navy, Coast and Geodetic Survey, Bureau of Commercial Fisheries, or a private organization-for ship time to gather pertinent data.

The fiscal year 1959 level of Commission expenditures toward research of this nature is about $\$ 300,000$. It is planned that such expenditures will increase. 
In Dr. Wallen's statement is a fifth objective, but in view of Dr. Dunham's suggestion, I think it is not germane to this presentation. This program was carried on at the University of Washington and is interesting in itself, but in view of the discussion this morning I suggest it be deleted.

In conclusion, I should like to again call the committee's attention to the National Academy of Science Committee on Oceanography report which in chapter 1 states that-

The Atomic Energy Commission should finance the major part of the research lealing with the problems of radioactive contamination of the ocean-

and to page 30 of chapter 5 of the committee's report which I quote again:

A 5-year proglam of the magnitude described would lead to a significant advance in our understanding of the processes affecting the distribution of radioactive materials in the sea.

$W_{\theta}$ feel that competent persons have been trained to engage in this type of research and we are prepared to encourage these scientists to expand their programs within the limits set by Congress.

(The table and bibliography follow:)

TABLE 1.-Percent of total radioactivity contributed by certain fission products of biological interest at different times after fission ${ }^{1}$

\begin{tabular}{|c|c|c|c|c|c|c|}
\hline & 20 days & 90 days & 1 year & 3 years & 10 years & 20 jears \\
\hline 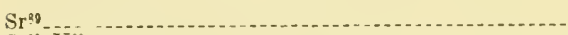 & 5. 0 & 10.5 & 2.7 & & & \\
\hline $\mathrm{Sr}^{90} \mathrm{Y}^{80}+\mathrm{C}^{90}$ & & & 3. 7 & 17.4 & 44.0 & 48.0 \\
\hline$Y q_{1}$ & 5. 6 & 12.5 & 3.8 & -- & $\cdots$ & .... \\
\hline 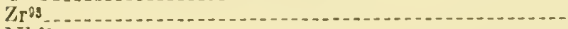 & 5. 9 & 14. 7 & 7. 2 & -...... & 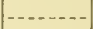 & $-\ldots$ \\
\hline$y^{2}$ & 2.3 & 18.0 & 14.7 & - . . . n. & $-\ldots-n$ & $-\ldots$ \\
\hline ( & 1.3 & & $\begin{array}{llll} & \end{array}$ &.- & - &.- \\
\hline$R u^{1030} \ldots$ & 4. 4 & 7.2 & .8 & $-\cdots$ & $-\ldots-\ldots$ & $\ldots$ \\
\hline Rh203 & 4. 2 & 7.0 & .8 & 60 & - & $\ldots$ \\
\hline Ru100-Rh196 & 50 & $\cdots$ & 4.9 & 6.0 & (.......... & $-\cdots$ \\
\hline 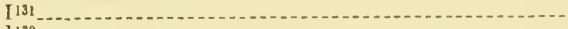 & 5. 6 & . & .....- & $-\ldots . . .$. & $-\ldots$ & - \\
\hline 1132 & 1. 1 & & & & & \\
\hline $\mathrm{Cs}^{137-\mathrm{Ba}^{137 \mathrm{~m}} \ldots \ldots \ldots \ldots}$ & 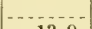 & & 2.9 & 13.6 & 36.0 & 45.0 \\
\hline 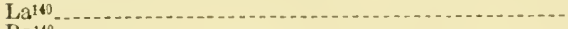 & 13.9 & 1.8 & -.......... & …....... & -......... & $-\ldots . . . .$. \\
\hline$B a^{140} \ldots \ldots$ & 12.0 & 1.6 & -......... & -........ & $-\ldots \ldots$ & $-\ldots . . . .$. \\
\hline Celt1 & 9.7 & 8.5 & 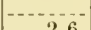 & $-\ldots . .-1$ & 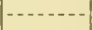 & -............ \\
\hline $\mathrm{Pr}^{1} \mathbf{6}^{3}-\mathrm{P}_{\mathrm{n}}$ & 12. 0 & 11.2 & 2.6 & 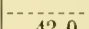 & $-\ldots . .+1$ & ............ \\
\hline $\begin{array}{l}\text { Cel14-Prit4 } \\
\text { Nd14i }\end{array}$ & $\begin{array}{l}2.6 \\
5.0\end{array}$ & 12.0 & 52.8 & 42.0 & -........... & $\cdots+\infty$ \\
\hline Pm147 & 0.0 & $\ldots$ & 5.7 & 19.0 & 16.0 & 3.4 \\
\hline Sm151 & & & & 1. 1 & 2.5 & 2.6 \\
\hline
\end{tabular}

1 Adapted from data of Hunter and Ballou (1951). Reference, Chipman (1958).

\section{Bibliograpity}

Chipman, Walter A. 1958. "Biological Accummlation of Radioactive Materinls." l'rocerdings of the first Texas conference on uses of atomic energr, 1)1. 36-41. Special publication of the Agricultural and Mechanical College of Texas, College Station, 'Tex.

Sational Academy of Sciences-National Research Council. 19.9. "Oceanography 1960 to 1970. I. Introduction and Summary Recommendations. 5. Artificial Radionctivity in the Marine Euviromment." Special publication, a report to the Commitiee on Oceanography.

National Academy of Sciences-National Research Comcil, 1957. 'The Effects of Atomic Radiation on Oceanography and Fisheries. P'ublication No. 551.

National Academy of Scicnces-National Research Comeil. 1950). Radioactive Waste bisposal Into Atlantic and Gulf Coastal Waters. Publication No. 655.

Seymour, Allyn, 195!). "Fallont in the Ocean." A statement prepared for the special subcommittee on Radiation, Joint Committee on Atomic lnergy, Congress of the United States for mblic hearings on fallont from nuclear weapous tests, May 5-8, 1959. 
Wallen, I. E. 1959. "The Atomic Energy Program in Oceanography and Marine Biology." Appendix "C" to a statement prepared for the Special Subcommittee on Radiation, Joint Committee on Atomic Energy, Congress of the United States for public hearings on fallout from nuclear weapons tests, May 5-8, 1959 .

Mr. Mulcer. Doctor, that is very fine. Our understanding is that we need more competent people in the field of oceanography, that there is a dearth in that field, and that that is one of the problems confronting us tolay. Do you agree with that?

Dr. Seriroct. I certainly do. Since I am from the University of Washington, I would like to point out what we feel is probably one of the limiting factors in the development of the program of oceanography proposed by the National Academy of Sciences and that is the training of students in oceanography. 'The University of Washington is the only university that offers course work for modergraduates as well as graduates in oceanography.

Mr. Miller. If you have time, Doctor, would you care to go into this portion of the report that you modestly deleted because it pertained to the university?

Dr. SEYmour. The part about the fish?

Mr. Mrluer. Yes. That is one of the things we are very particularly interested in; the fish.

Mr. Pelly. Mr. Chairman, I am glad you suggested that because I started to read ahead and I thought that was one of the most interesting parts of his testimony.

Mr. Miller. One of the things we are interested in is fish. Before you go on, I presume you know my friend, Dr. Dick Van Cleve at the university.

Dr. Sexroor. Yes, very well. I worked with Dr. Van Cleve and took some of my graduate work under him.

Mr. Miller. I had the privilege of working with him for 4 years on the California Division of Fish and Game. I was the layman in charge of the work and I never enjoyed anything more in my life. He is a warm personal friend of mine.

Dr. Sexmour. This work is done under the direction of Dr. Donaldson, under the sponsorship of the College of Fisheries and the State department of game and the State department of fisheries. This is an experiment in selective breeding in which Dr. Donaldson has used both rainbow trout and Chinook salmon. By selecting for certain characteristics over several generations has developed a run of salmon and trout that is mique in that more of them seem to survive than do under normal conditions and the growth rate is faster.

The important thing to note is that the return of the fish in 1958 was 3.2 percent of those released. WVith paper and pencil you can figure if you get this sort of returm on a release of salmon, you can build up a run of salmon tremendously. One pair of salmon will produce 4,000 young. To maintain the population you only need to get back 2 fish from that 4,000. If you get back 3.2 percent, which is something over a hundred, you have increased the run tremendously. What we believe has happened here is that the chameteristics Dr. Donaldson has selected for are those that are suitable for this more or less changed enviromment. Normally the Chinook salmon are found in the large streams, the large rivers, and do not usually come into small streams or up through the Lake Washington ship canal into this small tributary to Lake Washington. 
The other work on the rainbow trout has been generally of the same nature. He started with a natural stock of tront in Washington and by selective breeding has got them to grow much faster and to produce nore egoss.

Mr. Milller. Doctor, in essence, so far as the problem before us is concerned, there is a great deal to learn, perhaps the greatest contribution we can make is to furnish the tools for men to do this job, the scientists, furnish the gear, the money, so that they can get it so we can obtain more positive data, as to what can happen to the ocean when we actually get into the atomic age. Is that correct?

Dr. Seynour. That is correct, Chairman Miller. I think I might mention in that regard that just recently there has been a group organized called Fish Unlimited. This is an organization comparable to Ducks Unlimited. They are aware of the work Dr. Donaldson has done here and are providing funds for enlargement of his program, enlargement of both the physical facilities and also in providing graduate students to carry on this work.

Mr. Militer. Mr. Pelly.

Mr. Pelcy. We have an interest in this committee because we have jurisdiction over the Panama Canal, and there has been reference to the use of atomic explosives to create a harbor in Alaska and its possible dangerous effects.

We think maybe from testimony given to the committee that we may be creating a new waterway between the two oceans somewhere around the Panama Canal at some time in the future. I think we were told that thr cost of the explosive would be less than $\$ 1$ billion, whereas to use TN'T it would cost over $\$ 50$ billion. We are hoping maybe you can study the effect of that because it is one of the problems that is very definitely before our committee.

I am not going to take the time to ask more questions other than that I would like to say that that part about the fisheries interested me a great deal. I heard testimony once that if you could increase the number of salmon that go to sea by 1 percent you would double your return, because actually only 1 percent of those little fry that are hatched out and seeded in the streams ever get out, so that we have great interest in seeing that that migration of fish and that great source of food for people is protected.

I know my colleagues here have greatly enjoyed your testimony here today. I particularly probably have more than the ordinary pride in the fact that you do represent the University of Washington, and $I$ have the responsibility of representing them back here. I am always interested in hearing the number of references made to our gradiuates, the place they have in our Department of Fish and Wildlife. You always hear the University of Washington right at the top. I want to say that I am greatly interested in your references to the University of Washington. I appreciate very much your very fine testimony.

Dr. Srymouk. I would like to make one final remark. Since you have mentioned the Alaska Harbor project, the Division of Biology and Medicine of the AEC have an environmental program for study of environmental and ecological eflects associated with this experiment. Dr. Wolf, chief of the environmental sciences branch, who is present this morning, is in charge of that program. This includes 
both a marine and a land program to carry on a full-scale ecological study.

Mr. Pelly. I think the economy of the new State of Alaska is really dependent upon their great resource of fisheries. It is about a hundred-million-dollar industry and really is the only cash crop Alaska has. The effect of any experiment on their fisheries resource is very important,

Mr. Miller. Mr. Lennon.

Mr. Lennow. Doctor, I notice in your statement you say that one of the duties of the AEC program is to establish the operating criteria for the disposal of low-level wastes from industrial operations and also nuclear ship operation. That is on page 10. That is one of the duties of the AEC. That is paragraph 3 , on page 10.

You say that in addition to monitoring of fallout the AEC's program is aimed at establishing operating criteria for radioactive waste disposal, the packaging of low-level waste, et cetera. That is a function of the AEC, is it not?

Dr. Seysour. Yes; it is. Dr. Lieberman is here. Do you intend to discuss this subject?

Mr. Lennon. Keeping that in mind, go back to page 3. These lowlevel or low-activity wastes you say are committed to the ocean for disposal. They come, of course, from industrial plants located inland or ashore. You state further on that same page in paragraph 3 that nuclear powerplants are being used for production of electricity and for research. The irradiated-fuel elements from these reactors are highly radioactive and will probably never be disposed to the ocean. How are they disposed? Is it by burying?

Dr. SeYmour. At the present time they are disposed of in vaults. These are concentrated wastes that are stored in vaults underground.

Dr. Lieberman. Not unless there is some specific point.

Mr. Lennon. That is a rather expensive operation, I assume, as compared with dumping them in the ocean?

Dr. SeYmour. Dr. Lieberman of the Division of Reactor Development is here and would be able to answer this better than I.

Mr. Miller. Will you please identify yourself for the record.

STATEMENT OF DR. JOSEPH LIEBERMAN, CHIEF OF THE ENVIRONMENTAL AND SANITARY ENGINEERING BRANCH, REACTOR DEVELOPMENT DIVISION, ATOMIC ENERGY COMMISSION

Dr. Liebermax. My name is Joseph Lieberman. I am chief of the environmental and sanitary engineering branch of the Reactor Development Division of the Atomic Energy Commission.

Mr. Lennon. How are these high test and highly active wastes disposed of from nuclear powerplants and from research? Are they disposed of by burying in the bowels of the earth, in vaults, or something of the kind?

Dr. Lieberman. In connection with this whole question of radioactive waste disposal, it is important to distinguish between low and high level wastes which Dr. Wallen intended to do here. The irradiated fuel elements from the reactors he refers to are sent to chemical processing plants of which at this time there are only three major ones. They are at Hanford, Savannah River, and in Idaho. There is also a smaller scale plant at Oak Ridge. 
They take these fuel elements ont of the reactors and send them to the processing plants and in the course of this processing highly radioactive wastes are evolved. These wastes at the present time are not disposed; the way they are being handled at the present time is by storage in specially designed steel tanks underground.

It is not proposed that these highly radioactive wastes ever be disposed in the ocean, although conceivably there is that possibility or theoretically there is that possibility.

Mr. Lenvon. Do they have subsequnt use after they are sent to these laboratories and experimental stations?

Dr. Liemeriran. Yes, sir; the possible or potential use of fission products, which have been characterized in a very general way as the result of a nuclear reaction, do have potential use. This is perhaps another contributing factor or reason why one would not want to dispose of these fission product wastes into the ocean.

However, the potential or possible utilization of these highly radioactive materials in itself will not solve that particular problem becanse eventually these things will have to be disposed of some place.

The important point is that these highly radioactive wastes evolved from the processing of irradiated fuels are not now being disposed of. Speaking for our own installations-and I think this is true internationally-it is not proposed that they be disposed in the oceans.

The systems that are being worked on in our development program involve the possible safe long-term disposal-because we are thinking in terms of hundreds of years now for the effectiveness of this radioactivity - this involves disposal on land in one way or another, either by fixing the radio-activity in some kind of solid inert carrier and then disposal in some specially selected geologic formation, or direct disposal of some highly radioactive wastes in special geologie formations where we know it will stay for this long period of time.

Mr. Lennon. The low-level wastes are committed to the ocean in concrete barrels or containers for economic reasons rather than burying in the earth; is that right?

Dr. Lieberiran. These low-level wastes, which are the wastes that are evolved from the use of isotopes in research-this is essentially trash that might have some contamination-are susceptible to what we call a dilute and disperse technique or approach. In other words, specific environments have the capacity to absorb certain amounts of this radioactivity without creating any harm to the public or to its resources. These low-level wastes are susceptible to that approach.

On the other hand, the high-level wastes we talked about are handled or approached on a concentrate and contain philosophy. In other words, our contention is at this time that there is not enough dilution capacity in the environment to permit these high-level wastes to be dispersed to the environment.

With the low-level wastes, disposal into the oceans certainly seems to us to be one way of disposing or handling these low-level wastes. Burial on laud is an alternate way. As far as safety is concemed, I think they both can be considered safe under specific circumstances. I aun, of course, talking in general terms.

Certainly, under some conditions the economics of the situation would indicate that you might use one method or the other. But burial on land or disposal in the ocean could perhaps be considered alternative methods for disposal of these low-level wastes. 
Mr. Lennon. Since there seems to be some concern on the part of some of our people who live along the coasts that we shonld not continue to use these close-in shore areas for dumping of low-level wastes, I was trying to compare that with the cost of burying that low-level waste material.

Dr. Lieberman. I think again this depends on the individual circumstances. Conceivably in some situations where the installations were right on the coast it would be cheaper for them to clispose of these wastes at sea. On the other hand, at research installations evolving these low-level wastes that are located in the interior of our country, it would be more expensive for them to dispose of at sea and the burial methods would be preferable from an economic standpoint.

Mr. Lennon. You see no danger in the continued utilization of the ocean floor even fairly close in for dumping of low-level wastes?

Dr. Lreberman. If I can answer the question this way, Mr. Lennon-this perhaps relates to what I will call the AEC program insofar as it concerns to the report that has been discussed-the way we view it is that based on the best available knowledge the oceanographers and marine biologists have now, as represented by the experts involved in preparation of this report, they have indicated that it is safe, under proper circumstances to dispose of those solid, packaged wastes in inshore areas. 'They have also made it quite clear that before these areas are put into operation certain detailed studies should be made which in effect would check their general observations.

We have already started to implement this in cooperation with the Coast and Geodetic Survey, Public Health Service, and perhaps some other organizations in connection with some of the areas off the New England coast.

Before any of these suggested areas are officially designated, these preuse surveys mould be made. I feel sure that before the areas would be officially designated there would be detailed consultation with other Federal and State agencies and other gromps that are specifically concerned, and rightfully so, in this situation.

The other point that perhaps I should make here is that these preuse surveys need not be on the exact latitude and longitude indicated in this report. I think this report indicates, that these look like areas along the Atlantic and gulf coasts that could be used based on our present knowledge. But before we actually use them we propose to check the generally available knowledge.

So that conceivably, for example, the suggested areas off the New England coast, may not be the specific areas that might be designated but they might be close by.

Mr. Lenvon. I yield to you, Mr. Chairman.

Mr. Miller. I was interested in two things. First, talking of high level wastes, presently all of the high level wastes or a great percentage of them are controlled by the Goremment, are they not?

Dr. Lieberunax. I would make it more general. I think essentially all radioactive wastes are controlled by the Government.

Mr. Miller. Youl are going to build a plant, say, at Shippingport. A number of them are being built. When you have these low level wastes, these ashes you speak of, in the case of private companies and utilities, when the people at Shippingport have had to remove the fuel elements from the reactor and they have this ash, are 
they going to dispose of that or is it going to be returned to the Atomic Energy Commission for disposal?

Dr. LIEBerman. This might be a slightly involved answer.

Mr. Miluer. It is not an involved question.

Dr. Lieberman. No, sir. First I should make it clear that from a normally operating reactor such as at Shippingport high level wastes are not evolved. 'There is a solid fuel element that goes into the Shippingport reactor. When it is removed, in other words, the ashes, it is still in solid form. If it were not so radioactive, you could pick it up. It is hotter than a pistol.

Mr. Mrluer. It is still hot.

Mr. CuRtin. Is that what they call a core?

Dr. Lieberman. Yes, sir. These are solid fuel elements. At the present time all the processing plants I mentioned are owned and operated by the Atomic Energy Commission. At the present time the fuel elements from all reactors are shipped to one of the three places that I mentioned. So the high level wastes we talked about are not evolved at the reactor unless there is some kind of catastrophic accident. They are not evolved until this solid fuel element, shipped in specially designed containers, come to the processing plant and goes through the chemical process to remove the unused fuel, separate it from the fission products or ashes. The use of the word "ashes" in connection with the Shippingport plant is perhaps slightly misleading.

Mr. Miller. I confused it because you used it. I do not mean to quibble. You put a core in these things, as I understand it. After the radioactivity has been generated, the heat has been generated, and this thing has worn itself down you then have this core that must be disposed of. I suppose if you brought two of these cores into this room, one that was live or had not been used and one that was dead and had been used, the layman could not tell one from the other as far as their physical appearance goes. I assume when you use the word "ash," you use it in the effect of saying this is the one that has been utilized and the life has gone out of it. In effect, it is like the ashes in a fireplace after the coal or the wood is burned down and has no further use; is that correct?

Dr. Lieberman. Yes, sir.

Mr. Miller. Are we talking the same language now?

Dr. Imemerman. I think so. There is one big and major difference. The core that would have the ash, the fission products, would be extremely radioactive. You could not get near it. With the one that was fabricated and ready to go in service, you conld go up and touch it.

Mr. Mruler. What will happen to this hot core when it is being used by private industry?

Dr. Liejerman. At the present time and up until at least 1965 the Commission has indicated that it would supply the chemical processing service for any and all reactors, so that this core would be sent to one of the Commission reprocessing plants.

Mr. Miller. In other words, it will be returned to the Commission?

Dr. Limberman. 'This is correct.

Mr. Milfer. Then Uncle Sam will be charged with taking care of that up until 1965? I suppose the half life of some of these things 
is 1,000 or 1,200 years and the half life of others is 625 years. So for some future milleniums Uncle Sam is going to be stuck with this waste that is hotter than a pistol. We are going to have to take care of it.

Dr. Lieberman. Yes, sir; I think in general this is a fair statement. I do not see, personally, any escape from the long term cognizance over these high level wastes by the Government. I should note that the Commission is encouraging private industry to get into the chemical reprocessing business. In the absence of such commercial operations, it is making the arrangements I mentioned before.

Mr. MicLer. If they do, I hope we pass very stringent laws with plenty of teeth in them. We would not want them to say that in the interest of economy we cannot do this without affecting our capital structure and our return. We must not allow them to wantonly dispose of these things where they can be hazardous. That is not our problem in this picture, but it is one with which I am concerned.

Dr. Lieberman. Certainly, in all these waste problems, high level wastes particularly, it is quite obvious they will have to be handled in a way that there will not be a deleterious effect on the public or upon the resources and the long-term responsibilities - this is a personal observation-would have to remain with the Government.

Our record in the protection of the public and its resources in the roughly 15 years of operation of the Atomic Energy Commission is perhaps indication that it can be done.

Mr. Mrller. I have no criticism of the work done by the Atomic Energy Commission and its people. I think it has been a great job.

Dr. Liebernan. Thank you.

Mr. Miller. I think we are opening Pandora's box and we have to be very careful. We do not know where all these things are going to fly. We have to be very careful that in the interest of doing it too quickly we do not unleash a Frankenstein that will come back to ham the world in the future.

I would like to ask a couple of questions now about low level wastes. First you do dispose of some of this low level waste at sea. Do you contract the disposal of that with private concerns such as barge companies, that sort of thing?

Dr. Limerermax. No, sir. At the present time the wastes evolved from the Atonic Energy Commission operations are disposed at sea through naval facilities. There are, lowever, I think some six or seven licensed commercial waste disposers that are available to service isotope users.

Mr. Miller. Does the Atomic Energy Commission regulate the use and set down the rules for these private contractors and isotope users or are they free to go where they want?

Dr. Lieberman. This is a little outside my bailiwick, but I know they are all licensed and are subject to the licensing and regulatory requirements and inspection.

Mr. Miller. By whom?

Dr. Lierermax. By the Atomic Energy Commission through the Division of Licensing and Regulation and Inspection.

Mr. Miluer. We know where to go for that. I would like to get into that field because I am very much concerned with it. I presume those people, too, this same agency regulates the containerization and how they are disposed of; is that right? 
Dr. Lieberuan. Specifically where they should go, maximum content of radioactivity they can possess at any one time, things of that sort.

Mr. Miller. Who determines the type of container?

Dr. Limberman. The Atomic Energy Commission.

Mr. Miller. I have a report before me from the California Department of Fish and Game that is very disturbing. I do not know whether you have ever seen this report. It was made from the vessel N. B. Scofield-Doctor, you are familiar with the Scofield-July 21 and 22 of last year. 'They duplicated the type of container and put instruments on it. These were supposed to go into a thousand fathoms of water.

I will summarize it, although I will put the matter in the record. When they got down to 400 fathoms they blew the heads out of these containers and it would have released any waste in them. When we talk about dumping these things in containers into the ocean, I am concerned that the containers are sufficiently well designed so as to withstand the pressures we will subject them to.

There are parts of this report that speak of putting them into a thousand fathoms of water. What good will it do to put them in a thousand fathoms of water in old 50-gallon drums that are surplus to other parts of the Government because they are cheap and we cover them with some concrete but we lower them into this water and when they get to a certain depth they disintegrate.

I realize these are very low level wastes, the type of wastes that perhaps you could bury in the backyard. I think they have short half lives. I understand they are aprons and gloves and tools and things that are used generally around the atomic installations. But I am also concerned about the fact that we put them in containers, we put concrete around the containers to sink them, and then take them out and when we throw them overboard we have not considered very much what is going to happen to them after they get beneath the surface of the sea.

Do you know whether any followup has been taken to make sure we have containers that are proper?

Dr. Liemerman. I think it is generally recognized that the types of containers used are designed so that the weight of the container and content will be sufficient that it will sink and will withstand the rigors of transportation and will afford adequate protection to personnel during the handling from the point of origin to where they are going to be disposed of. They are not designed as tme pressiure vessels. As they sink it is certainly conceivable, and I think quite likely, that they will not maintain their complete integrity. As they sink the pressure on the outside is greater than the pressure on the inside, so leakage would tend to be into the container rather than out of it.

'There is another factor involved which I mentioned earlier, the rlispersive or diffusion and transport capabilities of the environment. In connection with both our Pacific and Allantic disposal operationsI think this was about 18 months ago but I do not remember the exact date-wo took a look at both disposal areas to see what we conld find in the way of radioactivity at disposal sites. On the Pacific through the Seripps Institution of Occanography and on the Atlantic through Woods IDole, the Chesapeake Bay linstitute, and the Coast and Geodetic Survey. 
At both these locations something of the order of 10,000 curies of radioactive material have been disposed since roughly 1949 or thereabouts. At both these places we were unable to detect any increase in radioactivity that could be related specifically to the disposal operations.

There are these two factors that play a part here, the diffusion and transport in the marine environment and the nature of the container and its contents to assure that it would not simply split open and allow the contents to come out. The way the containers are built it is conceivable they would have a leak-as a matter of fact, at a thousand fathoms it is probable that there would be means of communication between the ocean water and the interior of the drum.

Mr. MIrLer. It has been suggested here that you have an equalizing valve that would take care of those pressures with no danger of the stuff getting out. Has that type of valve been put on?

Dr. Lieberuras. This has been proposed by certain installations and can be used. I think the point to make here again relates to the capabilities of the marine enviromment to diffuse and transport these low levels of radioactivity to the point where they would not be harmful so that you are not entirely dependent on the container for the safety of the operation. I think the same sort of philosophy applies to the disposal of any type of industrial wastes. Certainly, if you exceed the safe capacity of the environment-perhaps if you look at our Potomac River right by our door-

Mr. Mircer. I would say you will find plenty of agreement on that. The loss of our fish life is well evidenced.

Dr. Limberman. I agree thoroughly with what you are saying, that in situations where you exceed the safe capacity of the environment you rum into trouble. Just as obviously, it is essential in the disposal of radioactive wastes, as in the disposal of any industrial wastes, that you make sure you do not exceed the safe capacity of the environment.

This is certainly our intention, to be sure that the safe capacity is not exceeded in any of these operations.

Mr. Mrimer. Congress and the people are becoming more conscious of pollution.

We have not done much about it here. Eventually we will get something done. Te are taking cognizance of the pollution of our waters through industrial waste, sewage disposal, and so on.

I remember when San Francisco Bay was nothing but a big cesspool.

We still have a lot of waste to take care of, but waste of this nature, becanse it is different from ordinary industrial waste brought about by concentrations of popnlation, makes us a little more cautious.

Dr. Lieberiman. I wonld agree thoronghly. This is perhaps reflected in the amount of time and in the amount of money which has been spent by the Government in connection with this specific waste problem.

Mr. Mruler. We will have to spend more. We have to go into it very thoronghly.

Mr. Cortin. You described a used core as being hotter than a pistol. Can I assume that is high level waste?

Dr. Lieberman. It generates the high level waste when it is reprocessed. 
If this core were going to be disposed of it would be a high level waste of a solid type. When it is pulled out of the reactor it still has a considerable amount of unburned fuel and therefore at that time it should not be considered a waste.

Mr. Mrlber. If in the event the milleminium were to come and we could have world peace, or we could have inspections so we no longer would need atomic weapons, then would not this core be high level?

Dr. Liebermin. The short answer to that is "No, sir." "This depends entirely on the value of the uranium that is unburned that is still in the core.

It would be a waste if it was cheaper for us to get the uranium from some other source than to recover from the core, then perhaps the core would be a waste, but this does not look like it will be the case.

Mr. Miller. Right now we have other uses for that core?

Dr. Lieberman. Other uses for the unburned fuel that is still in the core.

MIr. Cuntin. I presume that these used cores are presently being disposed of in the ocean?

Dr. Lrebenmax. No, sir. They are not disposed at sea. They are sent to the chemical processing plants I mentioned previously.

Mr. Cuntrin. Would you have of your knowledge any idea as to where this low level waste now is being disposed of in the ocean?

Dr. Lieberman. Yes, sir. There is a specific area designated in the report off the New Jersey coast.

Mr. Curtin. How far?

Dr. Lieberm.an. About 120 miles.

There is another area off San Francisco which is about 60 miles offshore.

Mr. Miluer. The depths of the waters in the two places are a little different, are they not?

Dr. Limberman. Both more than 1,000 fathoms.

The New Jersey one is about 120 miles, just off the edge of the Continental Shelf.

There is also another area off the Virginia coast which is used to a much lesser extent, which is something like 75 miles. It is also designated in the report of the National Acalemy of Sciences.

Mr. Miller. Is it off the shelf, too?

Dr. Liereman. Just off the edge of the shelf; yes, sir.

Mr. Curtin. Inas there been any investigation as to whether or not there has been any contamination of the water in the areas where they are disposing of this?

Dr. Limberman. Yes, sir. About 18 months ago, I am not exactly sure of the date, we did take a look at both the Atlantic and the Pacific areas, the two major ones where roughly 10,000 curies have been disposed of since we began operations. On the Atlantic coast the amonnt of radionctivity disposed is somewhat less than that.

We looked at both of those and in both cases we were unable to detect increases in radioactivity which conkl be attributed to these waste disposal operations.

Mr. Cuncrs. I would presume you are contiming your investigaltions as yon continne to dispose of waste in those areas?

Dr. Litibraman. Yes, sir. 
It is certainly my feeling that wherever we disperse radioactivity to the environment periodically we have to go back and make sure the capacity for that environment is not being exceeded.

Mr. Curtin. What is your opinion as to these proposed areas which are just a few miles off the coast?

Dr. Lieberman. I think I could answer the question this way, sir:

Certainly the report that the Academy group has put out has supplied what I feel is much useful and needed information.

I feel their assumptions, where they have been made, based on their present knowledge, have been conservative.

I think if the report is implemented the way they recommended it be, that the kinds of waste we are talking about could be disposed of safely in shore locations.

Mr. Lennon. These independent contractors are hauling the waste out to sea. Are they the ones pushing this project to take them just a little offshore?

Dr. Lmeberman. Not to my knowledge.

Mr. Lennon. That certainly would be an economy measure. Rather than going 60 miles offshore, as you do at San Francisco, and 120 miles offshore, as you do in Virginia, they now propose to go how many miles offshore at some of these sites?

Dr. Liebermax. Some are as close as 19 miles if I recall.

Mr. Lennon. That is certainly an economy measure, is it not?

Dr. Lieberman. That is certainly true, yes, sir. You do not need ocean-going vessels to go these shorter distances.

There is another aspect to consider. One conceivably can state that at these in-shore areas, or at an in-shore area, that the degree of continuing control in monitoring that you could maintain in these areas would be greater than that which you could maintain over a much deeper area farther ont at sea.

Mr. Lennon. You know something about the Gulf Stream as it moves along the coastline of North Carolina. It is no more than 55 miles at any one spot along our coast.

Offshore fishing is a big thing in the Gulf Stream, and between the shoreline and the Gulf Stream.

Don't you think it is practical to take this stuff out at least beyond the Gulf Stream rather than having it move back and forth with the current of the Gulf Stream?

Dr. Limberman. Certainly this is possible. Again, the only thing I can add here is that with the kinds of waste we are talking about, and this is perhaps strictly from a technical sense, and it does not mean to say I do not have an appreciation for the psychological and public relations problems involved-

Mr. Lennon. That should be considered.

Dr. Lieberman. I agree they are prodigious. With the quantities of radioactivity we are talking about this could be done safely without going beyond the Gulf Stream.

It could be done just as safely by going farther out. There are some advantages and rlisad vantages on both sides.

inr. Lencos. What are the advantages other than economics in putting it offshore 20 miles?

Dr. Limberman. I wonld not want to ascribe a specific level of intportince to this, but it would be much easier to go out and share these 
areas at shallower depths to make sure that the safe capacity has not been exceederl than it would be to go out 100 miles at 1,000 fathoms of water because of difficulties of sampling and things of that sort.

Mr. Lenvon. How long has the A EC been dumping now?

Dr. Lieberman. Roughly 10 to 12 years.

Mr. Lennox. You made a statement a few moments ago that you checked for the first time in how many years about 18 months ago?

Dr. Lieiserman. I don't follow you. We checked both of these areas about 18 months ago.

Mr. Lenson. They have not been checked since then?

Dr. Lieberman. 'That is correct.

Mr. Lexnon. When were they checked before that 18 months period?

Dr. Lifeberiran. As far as I know that was the first time they had been looked at.

Mr. Lennon. You certainly could not claim that you are spending a lot of money going out and checking them when you checked them one time in 10 years.

Dr. Lieberian. No, sir, I didn't mean to imply that claim.

Mr. Lennon. I thought you said the fact they were in closer would enable you to get out more often to check this.

Dr. Lieberinan. All I said is that this conceivably might be considered one of the advantages. I am not saying it would be an overriding advantage at all.

Mr. Lennon. Experience has not proven it to be an advantage in the last 10 year's when you check one time in 10 years.

Dr. LIEBERMAN. I think that is correct, yes.

I would say this: From conversations with oceanographers one gets the idea that it is certainly easier to do the kind of detailed sampling that would be required in the in-shore areas than in distant areas.

I do not want to leave the implication that because of this this is the reason why these in-shore areas should be used.

Mr. Lennon. I certainly would like to know the reason they propose to use in-shore areas.

Dr. Lieberman. Economics is one of the major considerations. Ocean-going vessels are not required if it can be done just as safely in in-shore areas and can be done more easily than the other way.

Mr. Iannon. AEC would have final authority to determine whether these sites are to be used?

Dr. LiEBerman. That is correct.

Mr. Lennos. I for one hope that in the interest of the general public, if for nothing else, that that decision will be long thought of before it is ever reached.

Dr. Limbiman. Before any of these areas are officially designated these pre-use surveys will be made, as they are being made ofl' the New England coast, and I feel sure all the consultation that is required with ot her agencies, States and other groups concerned with this will be done before they are oflicially designated.

Mr. Inswon. There is not a great deal of money spent in your particular agency with respect to investigating ocean sites for the disposal of waste fissionable material, is there?

Dr. Lmimmax. Not up to the present time. Dr. Seymour indicated some of the work being done. 
For example, in the next fiscal year we propose to spend something like $\$ 100,000$ to investigate two of these areas off the New England coast.

Mr. Lennon. I was impressed with the insignificant amounts being expended by the AEC in the determination of the proper ocean sites for the disposal of these materials as compared with the overall cost of this program. It is infinitesimal, is it not?

Dr. Limberican. That is essentially correct when compared to the total cost of the atomic energy program.

Mr. Lennon. Yet it is a very important part of the overall program for the future.

Thank you, Doctor. I was trying to find ont in my own mind what brought about this decision to consider these relatively close off-shore sites for disposal.

Dr. Lmebermas. I hope I have given you some additional information.

Mr. Lennow. I am convinced it is largely a question of economy from what you said.

Dr. Lieberirax. The only final remark I wonld make is that I certainly would want to emphasize so far as AEC is concerned that it would not be a question of economy overriding safety.

Mr. Milluer. Mr. Casey?

Mrr. CASEY. What would you do if you found that such a spot had been overloaded?

Dr. Lieberman. 'The short answer, $\mathrm{Mr}$. Casey, is that we obviously would have to move to another spot or do something else about it.

The important factor here, howerer, is that the maximum allowable concentrations of radioactivity discussed in these reports are those quantities of radioactivity which could get back through the marineological system to man and which he could take in over the period of his lifetime and still not cause detectable damage. So if we found we exceeded this maximum permissible concentration, if at that time we moved, this still would not result in any danger to the public.

The change conld and would be made before there was any danger of contamination exceeding the maximum permissible concentrations.

Mr. CAsEY. Do you know these maximums at this time?

Dr. Liebermax. Sir, they are recorded in a rather specific way in the Federal regulations promulgated by the AEC.

These in turn are based on recommendations by the National Committee on Radiation Protection, based on the best medical and biological knowledge available.

ITr. CASEY. I understand you base it on the best information available, but aren't there a lot of unanswered questions to be determined by lengthy studies?

You have a 5-year program recommended by the National Academy of Sciences here. Reference was made to a 5 -year program which will cost approximately $\$ 30$ million before many of these things you are talking about are determined.

Dr. Limberman. If we are talking about the maximum allowable or permissible concentrations, these are specific numbers that relate to how much radioactivity you can have in the food you eat or the water you drink or the air you breathe without causing damage. 
Those numbers are based on the best available medical and biological knowledge. Dr. Dunham I am sure could relate in detail the programs specifically related to these specific numbers.

I do not believe the Committee on Oceanography's report, in advocating the 5-year program, relates specifically to work concemed with these basic standards, these basic allowable concentrations in air and water.

Mr. Casey. I am sure they are not related to that but they are related to the study of concentration in a given area in the sea, what the fish can absorb and what would be safe in this area.

Dr. Lieberman. Yes, sir.

Mr. Casey. You do not know that yet, do you?

Dr. Lieberuran. I am not a marine biologist, and Dr. Seymour can check me on this. The conclusions that the National Academy of Sciences group came to are based on the data that they presently have.

In any scientific and technical endeavor there is always additional information that could be and should be obtained.

It is my observation that some of their assumptions they made in this area are perhaps on the conservative side.

In any case, any operation such as suggested in this report would have to be followed closely and continuously again to make sure we are not adversely affecting these resources.

Mr. CasEY. If after they do find out more, and we know they will find out more, if after their studies they find out that one of these areas 19 or 20 miles out has been overloaded, I would much rather have them overload a spot 180 miles out than 20 miles.

Dr. Lieberman. I agree with that.

The point I would make here is this: I feel that in the absence of complete and detailed information our approach has to be conservative. I feel sure the approach of this group has been conservative.

Insofar as small quantities of radioactivity involved, and with what is presently known about the concentration of radioactivity by marine organisms and the effect on marine organisms, and with the conservative assumptions and conservative bases on which this group arrived at their conclusions, it seems to me, at least, that this is a rational approach to this problem.

I would agree with you thoroughly that every detailed step should be taken to make sure that this is indeed safe.

About the only other thing I can say in answer to your question is that we propose to proceed with great care and deliberation in this sort of operation. We would lean heavily on the advice and counsel of groups like the Committee on Oceanography, the experts in the Fish and Wildlife Service, and others, to make sure that what we are doing or what we might propose is indeed safe.

Mr. Caser. Here publication after publication admonished using a site such as they propose right off the coast of Galveston.

Yet in the report in which they recommend this site they have nothing to counteract their other divisions of this same group in some of their other publications to counteract these very things that they are now going against.

Dr. Lifmerman. I feel this is the basis for much concern, and it relates back to the kinds and quantities of waste we are talking about.

Mr. Caser. I understand that. You are dealing with tho public. 
The public is dealing with something unknown to them. There is possibly not enough material released to the public on this so they can fully understand it.

We had an industrial plant in Honston which was supposed to be operating under strict supervision of the AEC.

That plant all of a sudden was found to be contaminated. 'Three of the emplovees had contaminated their own homes. There were serious effects from it, such as one man losing his sight. We have lawsuits going on.

My people are disturbed about something which was supposed to be under strict Government supervision where this sort of thing could occur.

Now you come along, and in defiance of all other recommendations they pinpoint this thing.

If they said the Gulf of Mexico could be used if certain surveys are made and a good location is found, all right. But they give you the latitude and longitude, 22 miles, less than 22 miles, 54 feet of water, right where a lot of the people fish. I fished there personally myself within the last 12 months. There is also a great deal of commercial fishing.

You got my people excited. They have done that by making a specific recommendation contrary to another group within your oreanization.

Dr. Liebermax. As far as understanding by the public is concerned, I share your concern down to the last detail. This is certainly something that I think all of us would have to acree on.

I recall in the early days of the AEC Chairman Lilienthal made the statement we will have to learn to live with radiation.

I am sure the implication was not that we wonld have to leam to live with it in any unsafe way.

The problem of getting this sort of operation in proper perspective and getting the sort of information to the public so that there is an adequate understanding of this whole situation is indeed a prodigious one and an exceedingly important one.

I am not personally familiar with the previous instant in the Houston area you refer to.

To put it frankly, the difficulty we run into, and this is common in the industry, is that as soon as you say radioactivity the first thing you conjure up in people's minds is a mushroom cloud. This is a natural reaction and if you did not recognize it would be sticking your head in the sand.

What we should do to better inform the public as to what is spefically involved in operations of this kind is something that I am not completely qualified to say, but this is certainly a big part of the problem.

You use the words curies, microcuries, and most people do not know what that means, and perhaps at this stage of the game they don't care.

I am not quite sure how to put a handle on that aspect of the problem, but I certainly agree it is an exceedingly important problem.

All I can add at this point, Mr. Casey, is that in our plans in connection with this report, we are taking these as suggestions, there would be these preuse surveys, and we would want to make sure just 
as we attempted to make sure with this industrial waste disposal application in Houston, hold public hearings and do everything that can be done to adequately inform the public as to what is involved here.

Mr. Caser. You hit on another thing I am sensitive abont, and that is public hearings.

They had public hearings in Houston. The hearing examiner in his report went to great lengths to say that no one in opposition had furmished him with sufficient proof.

I think the AEC should take more of a position of being the people's advocate rather than just a judge to sit and determine who puts up the best side.

Do you agree with me on that?

Dr. Limbermas. I would certainly say that it is the responsibility of the $A \mathrm{EC}$ to make sure that whatever is proposed is done in a safe way. I am not in the licensing or the regulatory part of the Commission.

Mr. CASEY. The examiner's wording was such that it would appear he was just sitting there as a judge to determine who put. up the best proof.

I think the AEC examiner or representative, whoever he might be, should take the attitude that he is there to see that the public is protected and not just-_

Dr. Limbermax. This is certainly a responsibility of the AEC, to make sure the public is protected.

When I mentioned hearings I didn't mean to refer to that specific case, but certainly I think the policy

Mr. CASEY. That is the only one I am familiar with.

Dr. Lrebermas. It is fair to say that in all of these operations the primary consideration of the AEC is the protection of the public health and safety.

Mrr. CASEY. I am inclined not to agree with you with reference to their being overly cautions in this last recommendation in view of the fact that they pinpoint sites and then turn around and say that studies are needed. I do not think they were too cantious in that particular instance. I trust that a great deal of cantion will be userl before any sites are pinpointed, because I think we have too much to learm abont these things yet to pick a site just 20 miles off'shore used by sports fishermen and commercial fishermen, and in an area such as the gulf coast.

In one of their other publications they point out the general features of the different coasts, and the gulf const is deseribed as it straight shoreline, a wide shelf, where the range of tide is small, the tidal currents are weak, permanent circulation is weak, and no upwelling. That is set out in one of their other reports, which would indicate to me that that stuff might stay there for you to monitor, but it also means that should it reach a density so marine life wonld pick it up, there would be no dispersion of it. Te do not know what the eflects will be until further sturly.

Dr. Lieminan. As far as the technical details of the report are concerned, I feel the committee may wish to question some of the members of the NAS group. I am neither an oreanogralpher nor at marine biologist, but in my reading of it and in my disconssions with the people involved, the sort of things you have just mentioned. 
Mr. Casey, were taken into consideration in their evaluation of the situation and in the preparation of the report.

Whether it looks as if they were being undercautious because they pointed out these specific areas perhaps is a question. It might well have been, rather than putting the latitude and longitude of specific areas, that could hare been generalized. I can say that in our approach to this and in our preuse surveys, we are not chained to these specific latitudes and longitudes.

I think they were given for what seemed to me at least to be reasonable technical grounds, and the detailed data which would be obtained in the field surveys, which in essence would check their general observation, need not be restricted to those specific areas.

Mr. Lennon. How would you restrict or patrol these close offshore areas where you dump this material? Would you buoy it? Would you have to set buoys and restrict it and patrol it?

Dr. Lmebeman. It certainly would be conceivable that these areas would be marked on the hydrographic charts, and perhaps buoyed so everyone would know what they were being used for.

Mr. Lennos. Do you know anything about menhaden fishing?

Dr. Lreberman. I am afraid not, sir.

Mr. Lennon. Or deep sea trawling for shrimp. They use ocean seines. They drag the bottoin of the ocean at that depth and that far out all up and down the South Atlantic coast, especially off my coast.

If you were 20 miles offshore, as this report suggests that you would be off Mírehead, N.C., you would be right in the lane of the trawlers for both menhaden and shrimp. I believe you would be picking up these things every time you dragged the bottom.

Dr. Lieberian. One of the considerations that was taken into account was the location of fishing areas, Mr. Lennon.

Mr. Lenvor. That is the most popular fishing area in North Carolina, off Morehead. At least that is what is claimed by both commercial and sports fishermen, but particularly commercial fishermen.

Dr. Lieberimas. I agree it would not make too much sense to go into a popular commercial or sports fishing area and stick a buoy up there and say irom here on we are going to dump low level radioactive wastes here.

Mr. Lennos. Unfortunately, the report pinpointed that area. Whether rightly or wrongly, I do not know. That is what happened.

Mr. Cuntin. Could I ask one other question, Mr. Chairman?

Dr. Lieberman, you have just stated the maximum concentration that the human body can safely absorb of these materials in food, water, and in the air we breathe. As we proceed into the atomic age, those concentrations, it would seem to me, will increase. Has your research on this subject indicated whether or not the human body can build up an immunity to these materials so the safety factor will become a higher percentage as the years go by?

Dr. Lieberman. I think I would have to defer to Dr. Dunham, who is a physician, to answer that, Mr. Curtin.

Mr. Cuntis. When you say they have carefully chosen the sites, it seems ironical that they chose one site off Atlantic City, another site off Virginia Beach, and sites where the favorite fishing sites are. I would say they have carefully chosen them. That is all. 
Dr. Seynour. May I make one comment? I know the committee deliberately asked for the guidance of the Fish and Wildlife Service in selecting these sites, and the reasons for giving specific localities were that these were selected as being places where there was not supposed to be either sports fishing or commercial fishing. Evidently they made a mistake.

Mr. CASEY. I shall be glad to show them the map.

Mr. Lenson. I wonder if the gentleman contacted the North Carolina Department of Conservation and Development, particularly the bureau of commercial fisheries, before they reached a decision with respect to the site off Morehead City, N.C.

Dr. Seynour. I do not know, sir. I know that they contacted the Fish and Wildlife Service people. I cannot speak firsthand. I have no firsthand information as to that. It is evident that they should have.

Mr. Curtin. 'That is all, Mr. Chairman.

Dr. Lieberman. Just one other point, Mr. Chaiman, which I might mention here. As most of you gentlemen know, hearings were held on the disposal of industrial radioactive wastes before the Joint Committee on Atomic Energy earlier this year. I understand that they are now in print. There are four volumes on this whole subject of waste disposal. Perhaps, Mr. Chairman, you and the other members of the committee would be interested in obtaining copies of this report.

Mr. Miller. I am conscions of them. I have not read them.

Dr. Lieberma . I do not think they are out yet, sir.

Mr. Miller. I asked Mr. Holifield about them, and he suggested that he might come over here. Whereas we recognize their authority in this field, I want to point out that we also in the Committee on Merchant Marine and Fisheries have a very definite responsibility, and we are not going to surrender that responsibility to the Joint Committee. We are not jealous of them, but in these fields we are certainly going to look very carefully before anything is done.

Of course, I realize this is something new. The AEC has been a sort of "untouchable" around here, but as far as we are concerned, this committee will accept its responsibility in this jurisdiction. We may have you up here again.

Comnsel has one question, I believe.

Mr. Drewry. Just one question, Dr. Lieberman. If this radioactivity we are discussing is artificial, do we have the means or knowledge to eliminate the radioactivity, to recombine these poisonous materials into some other form which wonld be nonradioactive, to reverse the process?

Dr. Iambramas. 'Theoretically yes, but practically no.

Mr. Drewry. Is work being done on that?

Dr. Limbrrman. I cannot say that work is being done on this. In order to transmute these radioactive elements and turn them back to something which is nonradioactive, you would be producing other radioactive elements. It would be like the dog chasing its tail or trying to pull yourself up by your bootstraps. So it looks as if it is not a reasonable or even perhaps theoretical hope that you could take the radioactive materials and turn them into something else.

Mr. Drewry. 'That is all, Mr. Chairman. 
Mr. Miller. Thank you very much, gentlemen.

Dr. Seymour, you have Dr. Innham and Mr. Loewenstein with you. The hour is late, but do you wish them to say anything? I would like to recognize their presence here. Is there anything they would like to say? As long as we can hold Mr. Curtin here, I am all right.

Dr. Dunnam. I am Dr. Charles L. Dumham, Director of the Division of Biology and Medicine of the Atomic Energy Commission.

I am very happy to be present today and to hear this very interesting hearing. I have nothing to offer at this point except in answer to Mr. Curtin, that so far as we know, the development of immunity to radiation, as one develops immunity against typhoid fever from vaccination, is impossible at the present time.

Mr. Curtin. So we have to keep those levels below what is the maximum safety level if human beings are to survive.

Dr. DunhaM. Yes.

Mr. Cuntin. Thank you.

Mr. Loewenstein. Mr. Chairman, I am Robert Loewenstein of the General Counsel's office. I have nothing to add to what has been said.

Mr. Miluer. I want to thank you gentlemen; and Dr. Seymour, I want to thank you for a very instructive dissertation on this rather involved subject. You have us rather at a disadvantage inasmuch as you know the meanings of all these words and I had to interrupt you to get very simple ones defined.

Dr. Sermour. It was not long ago that we did not understand them, either.

Mr. Mili.er. Thank you.

We will now hear from Charles E. Bennett from Florida.

\section{STATEMENT OF HON. CHARLES E. BENNETT, A REPRESENTATIVE IN CONGRESS FROM THE STATE OF FLORIDA}

Mr. Bennetr. Mr. Chairman, I appreciate this opportunity to testify today on radioactive waste disposal into Atlantic and gulf waters. My interest in this subject arises ont of the recommendation by the National Academy of Sciences that two of the disposal locations be in the Atlantic Ocean 18 and $8: 3$ miles respectively from our district's beaches. This is uncomfortably close. Not being an atomic scientist, I cannot speak anthoritatively as to whether any radioactive danger to the district which I represent would result. However, I note in the report which recommended these locations that it is axiomatic that there will be some escaping radiation. The report says at page 1:

The primary objective of the stucly has been to provide an estimate of the rate of return of radioactive substances to man, arising from stated rates of disposal into the coastal areas.

Thus, the report admits there will be some rate of return. The recommendations in the report are for the purpose of reducing this admitted "rate of return" to safe levels.

Perhaps those in charge of the program will tell you that they can easily accomplish this reduction to safe levels. Nevertheless, there is a danger that utilizing locations so close to our beaches will have a damaging psychological effect in our area. Adjacent to these lo- 
cations are our beautiful Duval County beaches, which attract large numbers of vacationers and bathers. If there should arise an apprehension concerning the safety of these beaches from a radioactive standpoint, a severe economic hardship might result, whether or not these fears are justified. Accordingly, it is my hope that these two locations near our coast can be abandoned in favor of locations at least several hundred miles from the nearest land. I will greatly appreciate any assistance your subcommittee can give toward this objective.

Thank you again, Mr. Chairman, for permitting me to express these views.

Mr. Mriller. Thank you, Congressman Bennett.

We will now hear from Paul G. Rogers of Florida.

\section{STATEMENT OF HON. PAUL G. ROGERS, A REPRESENTATIVE IN CONGRESS FROM THE STATE OF FLORIDA}

Mr. Rogers. Mr. Chairman and members of the committee, I appreciate the opportunity to offer a statement in connection with a matter of great importance to a large segment of the population comprising the Sixth District of Florida, which I am privileged to represent.

I refer, Mr. Chairman, to the recent study conducted by the Oceanography Committee of the National Acadeny of Sciences. In its report, the Committee proposed a number of ocean sites along the eastern seaboard and gulf coast which it considered suitable for the disposal of low level radioactive waste material. The distance from land of the proposed sites varies from 120 miles to 3 miles. The ocean depth at these sites ranges from 42 feet to 9,000 feet, depending on the proximity of the Continental Shelf and the configuration of the ocean bottom.

The proposed site with which I am particularly concemed, and you will agree rightfully so, lies in the Gulf Stream, 2 miles oceanward from the Port Everglades sea buoy or about 3 miles east of Fort Lauderdale, Fla.

Try as I might, Mr. Chairman, I ean conceive of no logical reason why this particular site was proposed for the dumping of this potentially dangerons radioactive refuse. The Fort Lauderdale area is one of the fastest growing sections in the country. During the winter season, literally hundreds of thousands of visitors combine with some 300,000 permanent residents to frequent the spacions beaches of the area. One of the prime attractions presented to our touring friends is the game fish which abound in abunlance in and around the Gulf Stream. Boating in small pleasure craft as a moans of recreation is enjoying mprecedented popularity. Millions of dollars have been expended by our merchants through their associations to acquaint the workl with this vacationer's' paradise.

Now, we are informed that there is a proposal under consideration, which if carried out, might result in the contamination of one of our priceless assets. Such a course seems passing strange when we spend lmudreds of thomsands of dollars annually in antipollution programs. In any event, dingerous or not, the ominons cloud of donbt connected with such a disposal program would have far-reaching adverse effects on the economy of this entire area. I hesitate to imagine what the 
result would be if a container labeled "Radioactive Waste, Dangerous" washed up on one of the lower east coast beaches of Florida.

Testimony before this committee has disclosed the fact that even our scientific minds are apprehensive as to the ultimate effect such a disposal program would have on the area concerned. This uncertainty, together with other unanswered questions involving the nature of radioactivity itself, lead me to request that further consideration of the proposed dumping site immediately adjacent to Fort Lauderdale, Fla., be abandoned.

Again I want to express my appreciation to you, Mr. Chairman, and to the members of the committee for permitting me to make a statement on this very important matter.

Mr. Mruler. Thank you, Congressman Rogers.

We will now hear from Jack Brooks, of Texas.

\section{STATEMENT OF HON. JACK B. BROOKS, A REPRESENTATIVE IN CONGRESS FROM THE STATE OF TEXAS}

Mr. Brooks. Mr. Chairman, may I first express my appreciation for the opportunity to be heard by you and your fine committee. I believe you are to be especially commended for interrupting your planned agenda of committee business at the earliest possible moment after it became evident that plans are being formulated to dispose of radioactive waste material along the Atlantic and gulf coasts within a few miles of the beaches.

As you have shown in your prompt convening of these hearings, you are deeply and properly concerned with these dumping proposals, and I want to assure you that I and the people I represent in the Second Congressional District of Texas are decidedly apprehensive abont the dumping of radioactive waste near our coast at this time.

Our immediate concern, Mr. Chairman, deals with at least one of the suggested dumping sites proposed by the National Academy of Sciences. This site is listed in the Academy's publication No. 655 4- by 9-mile area 19 miles from Sabine Pass, where the water is about 42 feet deep. Our ultimate concern is the concern of every American citizen who has the right to know whether or not the present and proposed methods of disposal of radioactive waste material are safe and who has the right to be protected from indiscriminate disposal of radioactive waste.

I have had the opportunity to sit in with several of our colleagues, including our good friend and distinguished member of this committee, Congressman Bob Casey, on an informal conference with three representatives of the Atomic Energy Commission. This was several weeks ago and we were discussing a pending license application to dump radioactive waste in the gulf off the Continental Shelf in 6,000 feet of water. I asked the AEC people for a brief, simple, and direct statement to the effect that disposal of radioactive waste material in the manner and location where they were considering would not be harmful to either the marine life in the area or our people.

To date I have not received any such assurance from the Atomic Energy Commission. And since that time the National Academy of Sciences has suggested 28 additional dumping sites. 
In the meantime, however, I have talked with other persons and agencies concerned with this problem, including the Bureau of Commercial Fisheries and Dr. Ralph Lapp, prominent nuclear scientist. Each report I receive emphasizes that our present knowledge of radioactive disposal apparently is not sufficient to determine whether or not the proposed disposal is, in fact, safe.

I have been impressed with the consistency of the witnesses from the AEC and other agencies who have testified thus far in these hearings when each of them says we need to have more study before we can know.

Mr. Chairman, if the proponents of this radioactive waste disposal program close to our public beaches are uncertain about its danger, how can the people who live near and use these beaches and fish in these waters be expected to accept this program? If the scientists declare that we need more study, it is my sincere hope that before any pernits are issued to authorize dumping of radioactive waste in coastal waters proper and comprehensive study will be made and complete factual reports will be made available to the Congress and to the reneral public.

Thank you, Mr. Chairman and members of the committee, for this opportunity to present this statement for your consideration.

Mir. Miller. 'Thank you.

The committee will stand in recess until 10 o'clock tomorrow morning, when we will meet in the hearing room of the Committee on Science and Astronautics.

(Whereupon, at 1 p.m., the subcommittee recessed, to reconvene at 10 a.m. Tuesday, July 14, 1959.) 


\section{OCEANOGRAPHY IN THE UNITED STATES}

TUESDAY, JULY 14, 1959

House OF Representatives,

SUbCOMMITTEE ON OCEANOGRAPHY OF THE

Comaititee on Mfrichant Marine and Fisheries,

Washington, D.C.

The subcommittee met at 10 a.m. in room 214B New House Office Building, Hon. George P. Miller (chairman of the subcommittee) presiding.

Mr. Muller. The committee will be in order.

I am very happy to greet the gentleman from the northernmost and westernmost State among the United States, our new brother from Alaska, Mr. Rivers.

Mr. Rivers, I believe you have a statement to make.

STATEMENT OF HON. RALPH J. RIVERS, A REPRESENTATIVE AT LARGE IN CONGRESS FROM THE STATE OF ALASKA

Mr. Rivers. Mr. Chairman and members of the subcommittee, I appreciate the opportunity to be heard on the highly important and timely subject of oceanography. Now that the West is conquered and Alaska has become a State, our thoughts of frontiers have changed from the conception of unsettled wilderness to the concept of the frontiers of science, which will certainly include exploration of the ocean, its submarine life and other resources, and its potential as a thoroughfare for enemy underwater craft which may eventually force our country to fight battles under the sea.

Not being a scientist, I am not capable of contributing technical material at this hearing. It is, however, my pleasure to submit to you a letter and statement sent to me by Mr. C. L. Anderson, the commissioner of Alaska's Department of Fish and Game. Mr. Anderson points out that his department of fish and game is already conducting oceanographic research at Kitoi Bay with operations based at its research station of Afognak Island near Kodiak, Alaska. The program of the State of Alaska has particular reference to the biological resources of the sea, which will be an important phase of any overall oceanography program. I call the attention of this committee to the fact that my State has its oceanography program underway and its research station established, and that such program and station, with Federal implementation, could be expanded and thereby serve a useful purpose toward carrying out the objectives toward which these hearings are directed.

Mr. Anderson's letter and statement, addressed to me under date of July 11, 1959, are hereby submitted as part of my remarks. 
With that I will submit those papers as part of my remarks. Mr. Muluer. Without objection, they will be made part of the record. (The attachments to Mr. River's' statement follow:)

\author{
State of Alaska, \\ DEPARTMENT OF Fisil AND GAME, \\ Juneau, Alasta, June 11, 19.5.9.
}

Hon. RAIPII J. RIVER,

House Office Building,

Washington, D.C.

DEAR RALPIJ : In accordance with our recent conversation in Washingtoll, D.C., I am forwarding the enclosed statement concerning the Alaslia Department of Fish and Game Kitoi Bay Research Station on Afognak Island near Kodiak. I hope that it may be of use to you in obtaining Federal assistance for the station's program in conducting oceanographic research with particular reference to the biological resources of the sea.

This supplements the brief description of the station forwarded through you on April 2, 1959, to Congressman George P. Miller.

With best personal regards.

Sincerely,

\title{
C. L. Anderson, Commissioner.
}

OrJectives, NeEds, and Costs of Expanded Oceanographic-Fisheries Research Program for Alaska Departinent of Fish and Game Kitor Bay Research STATION

\section{Prepared June 1959 by Alaska Department of Fish and Game}

The abundance and distribution of our marine biological resources is dictater by the environment in which these populations live, and this is true of populations now being harrested as well as those which are, at present, unexploited. 'This is true for the strictly marine forms such as halibut, cod, shrimp, and crabs, as well as for such anadromous species as salmon, trout, and smelt whose life histories involve both fresh water and the ocean. Fundamental knowledge of the complex interrelationships of fish in Alaskan waters to oceanographic factors is the key to foresight rather than handsight. With a sufficient understanding of the marine environment, management agencies can accurately predict what may be safely harvested, and keep stocks at a self-sustaining high level of productivit $y$.

A very significant facet of the life history of many of the ocean fish popmlations involves the environment over the Continental Shelf and along the shore areas. Although the seience of oceanography has advanced greatly, much of it has bcen in the open ocean and in deep sea studies. The comparatively minor fringe areas of the ocean have received the least attention. However, considering the development of marine fisheries resources, it may well be the most important part of oceanography.

It is submitted that the Kitoi Bay Research Station is in a unique position to make major contributions in oceanographic studies of the Continental Shelf and shore areas which will relate closely with the life histories and factors of abundance of the numerous fish polulations along the Alaska coastline. Tn accomplish this, however, the marine research facilities of the station lleer? expanding.

$\Lambda \mathrm{s}$ indicated in a previous report prepared in April 1959, the Kitoi Hay Research Station, already consisting of substantial facilities in buildings, laboratory and lield equipment and allealy concerned with an extensive fisheries research program, is still subject to serious limitations of capital and operations budgets. Its work in research would be considerably enhanced and a large fund of information developed if monetary assistance was given for oceanographic and fisheries work.

Kitoi loay is centrally Iocated with regard to the fisheries resources of the Gulf of Alaskal and the Bering Sea. It constitutes an ideal base Iocation for marine researcll for the entire area. Further, in the reneral region of the station itself, the sea gives promise of great future commercial production. The nearby city of Kodial uny well be the center of a future major fisheries industro, ranking high with those lishing center's of the rest of the world.

With adequate equipment and staff, long-term research could be conducted along the shoreline and over the Continental Shelf adjacent to the southern and western coastlines of Alaska. Initially, the oceanography of the Fodiak region 
could be studied to determine the marine factors of estuaries and bays involved in the survival of salmon and other species of fish and shellfish utilizing this environment. It has been recognized for many years that, while the stream or fresh water environment has frequently been the dominant natural influence in determining the abundance of the salmon species, at times unknown factors in the sea have seriously limited their abundance. The knowledge of how these marine envoronmental factors actually determine salmon survival will permit much wiser management of the stocks in the future.

The abundance of halibut, various species of cod, herring, shrimp, and crabs, as well as clams and other shellfish, is likewise intimately connected with variations of the marine environment in bays, chamnels, and estuaries along the Alaska coastline. 'The study of these factors and interrelationships will be of great assistance to the Department of Fish and Game of Alaska in the conduct of fisheries management.

Following is a brief ontline of expenditures necessary to meet this objective.

\section{STAFF AND EQUIPMENT}

For the expanded program it is anticipated that two marine scientists with a technical assistant, and a boat captain with five crew members, would be required. A capable research vessel, docking and servicing facilities for the vessel, saltwater ponds and aquaria, other marine laboratory facilities, and residence housing for the oceanographic staff at the station would also be required. The total cost of new equipment and facilities would be about $\$ 360,000$. The annual expense for operations and salaries would be about $\$ 110,000$.

VESSEL

A 75 -font boat capable of operating along the Alaskan coast in most weather would be adequate. It should have sufficient cabin and messing accommodations for the staff and crew, as well as laboratory, gear, and deck working space. A new boat built to specifications would be desirable, although there may be available some surplus ship that could be adapted to the frogram. Cost, about $\$ 100.000$ (if new).

\section{DOCK AND SERVICING FACILITIES}

The existing high-tide dock at Kitoi should be extended into deeper water so that the research vessel can tie up at ans time and receive and discharge personnel, equipment, and supplies. In addition to the dock, fuel storage and warehouse facilities are also required so that the ship may refuel and store equipment when not in use. Total cost about $\$ 60,000$.

\section{LABORATORY AND SALTWATER SUPPLY EQUIPMENT}

Saltwater aquaria and rearing ponds with adequate pumping and supply pipeline will make possible studies on living specimens with water of any desired salinity. The salt water intake will be in deep water at the end of the dock and sea water will be pumped to the saltwater laboratory. Cost of construction of concrete rearing ponds, installation of pumps and pipeline, and equipment for laboratory : about $\$ 100,000$.

\section{RESIDENCES FOR STAFF}

Residences at the station for staff members while working at the home base, and for families of married staff members will have to be provided. Bachelor quarter's will be available from the State budget. It is anticipated that five residence units of two- or three-bedroom classification will be required. These will have to be livable during all 12 months of the vear. Estimated cost of construction and furnishing five residences will be $\$ 100,000$.

\section{OPERATION AND MAINTENANCE EXPENSES (ANNUAL)}

For fuel, operation, and maintenance of vessel, dock, and service facilities, salt water laboratory, and residences; annual cost about $\$ 20,000$.

STAFF SALARIES AND EXPENSES (ANNUAL)

For nine adidtional personnel including scientific staff and vessel crew, the total annual salaries and expenses would be about $\$ 85,000$. 
TOTAL

Vessel

Dock and servicing facilities

$\$ 100,000$

60,000

Laboratory and saltwater supply equipment

100,000

Residences

Total, initial equipment

360,000

Operation and maintenance expenses per year

25,000

Sularies and staff expenses per year

85,000

Total, annual expenses

110,000

It is desirable that these funds be made directly available to the Alaska Department of Fish and Game by contract with the appropriate Federal agency or by congressional appropriation.

Mr. Mildefr. Have you anything to tell us over and above your statement? Yesterday we were holding hearings on the effect of radioactive wastes in connection with oceanography. Have you any thoughts on that?

Mr. Rrvens. Mr. Chairman, I stated in my remarks that I am not a scientist and not able to contribute any scientific material to this record. Therefore, I am going to maintain that position.

I do want to say, though, that I realize the frontiers of science are facing us on all fronts, including oceanography, and that this committee is actually among the pioneers that are doing some of the exploring in a new field. I am an old pioneer myself from Alaska.

Mr. Pelly. You are not so old.

Mr. Rrvers. Thank you, Mr. Pelly.

I commend the committee and the group for taking the initiative in connection with this program. I wish you a lot of success.

Mr. Miller. Among other things, from time to time we have discussed the cooperative effort that exists between Canada and this country with respect to certain fisheries that I know you are particularly interested in.

Mr. Rivers. We are certainly interested.

Mr. Mrluer. Through treaty we have come to some understanding with Japan, but last year certain boats from another nation that also borders on the Pacific showed up in some of the fishing water covered by our treaties with Canada and Japan. I am certain this caused you some concern, as it caused all of us concern, because there is no legal way in which we could say to them, "You can't fish here." It is open sea.

Have you ever given any thought to the necessity for some day, perhaps through the United Nations World Fisheries Convention, establishing by treaty or making by treaty arrangements for dividing the area of the sea among nations of the world for the purpose of exploiting fisheries?

Mr. Rivers. Mr. Chairman, we are watching that phenomenon of the Russians expanding their fishing exploration in the Bering Sea. We know the Continental Shelf is a long shelf that goes way out into the open ocean. We know it is high seas and that we camnot stop a foreign nation from fishing on the high seas. That is true of Japan in the North Pacific, with whom we have reached partial accord.

As to Russia, which is exploring more for ground fish up there now and for trawling operations-and the Bering Sea is very rich in 
bottom fish-the time is bound to come when we have to have conservation of such resources by treaty arrangement with all participating nations. Otherwise, if the resource is depleted and ruined, it is to the disadvantage of all nations.

Mr. Mrller. It does not pay for those nations that are conservation minded to restrict their citizens from exploiting the products of the sea if other nations that are less conscionable come in and raid those resources.

Mr. Rivers. But we must use our utmost persuasive power's, to say the least, to bring about cooperation between the nations that are harvesting the crop in the ocean.

Mr. Miller. I wanted to press this problem to you because I think Alaska by its very geographical position is one that must, of necessity, be primarily concerned.

Mr. Rivers. Yes.

Mr. Milluer. Youl are the frontier.

Mr. Rivers. That is right, Mr. Chairman.

Mr. Miller. I know it is a problem that future Congresses and future administrations will have to give very serious consideration.

Mr. Rivers. 'That is right.

Mr. Mrller. Mr. Pelly.

Mr. Pelly. I would like to say I am very much interested in the testimony of our colleague, Mr. Rivers, and share his interest in the oceanography of the North Pacific Ocean.

Does the University of Alaska have a college or department of fisheries?

Mr. Rivers. No; but plans are on the drawing board, you might say, for a fisheries school to be set up in one of the coastal cities under the jurisdiction of the university.

Mr. Pelly. The study of oceanography is certainly vital to the economy and the future of Alaska, is it not?

Mr. Rivers. Yes. I might say that this research in the biological resources of the sea is increasing our knowledge of the feeding of the Alaska salmon in the North Pacific where the Japanese fish, and the Kitoi Bay research station under the Alaska department of fisheries, under Clarence Anderson, is playing a part right now in the research which the Japanese and the Federal Bureau of Fisheries are pursuing.

Mr. Peuly. Is it not true that actually science has no boundary line and that the State of Alaska and Mr. Anderson know they can draw on the other great educational institutions, such as the University of Washington, where they have the finest college of fisheries in the United States, and our oceanography school, that we will work together regardless of any confines that might exist as to the State boundaries?

Mr. RIVERs. I subscribe to your statement.

Mr. Pelly. I think more and more as the cost of education goes up, educators are pointing out that we have to work on a regional basis. One educational institution will work in one field and one in another because these things are getting so expensive and so highly technical and require a great deal of equipment.

Mr. RIvers. You have pointed out the way to go.

Mr. PeLly. In connection with your statement regarding the problem with Japan and the Soviet Union, do you not have some feeling 
that science must work out these peaceful means of achieving conservation as against the previous doctrine of nationalism and force?

Mr. Rivers. The only way of obtaining the facts for making determinations in connection with the part each nation will play in a conservation program is through science. Part of the reason our State Department camnot agree with the Japanese Government is that there has not been enough tagging of salmon, there is not enough exict knowlerge as to how many sahmon that spawn in Alaskan streams are feeding in the gromds of the North Pacific. We are learning more every day about that. The more clearly the facts are established the easier it will be for the respective state departments of the nations involved to reach an accord. Certainly, science is going to be the basis for all such arrangements.

Mr. Pelly. Yesterday in the hearing we discussed radioactive waste and its possible danger to the fishery resources of our oceans. The matter of international treaty arrangements was pointed up. I am sure you would support my statement that with the Japanese current coming over we have great interest in any waste that the Soviet Union or Japan might dispose of in the ocean because it might have effect on not only the migrating fish that come our way but also upon other eventual situations that are purely local to us on the Pacific coast.

Mr. Rivens. I am heartily in accord with you, Mr. Pelly.

Mr. Pelly. I do not think any record, Mr. Chairman, of oceanography would be complete unless there was in there the strong emphasis that it is the belief of the people who have studied fisheries that abstention for conservation is the one principle to which we can look to preserve the fishery resources of our Pacific Northrest and the Pacific coast. Is that correct?

Mr. Rivers. 'That is as I view it. You say abstention. It might be a marked restraint, possibly a little fishing in the high seas can be done, as it is in the tuna and halibut fisheries and others under treaties.

Mr. PELLY. In other words, that would protect, abstention would protect any nation practicing conservation-I do not mean complete abstention, but it would mean not depleting the resource because one country who in her inland waters and streams and lakes was practicing conservation and disciplining her own fishing interests in preserving this resource from depletion must be protected by other nations on the high seas.

Mr. Rivers. Yes, and with that definition of the word "abstention," I am in full accord with you.

Mr. Pelly. We cannot have that doctrine really understood until we know more about our oceans, and that is why I think the work of this committee is so important. Do you agree?

Mr. Rivers. Very much.

Mr. Peldy. Thank you.

Mr. Miller. 'Thank you, Mr. Pelly. Mrr. Oliver.

Mr. Oldver. One question has occurred to me which is far afield from what the gentlemen have been discussing here, but as long as we have such a distingnished colleague from the great State of Mlaska here, I would like to get his reaction to this thought that I think many of us hatve.

Yon were speaking a moment ago about the Soviet fisheries reseatrch activity as you know it to be in your particular area. 
Mr. Rivers. I called it exploration. It is research, too.

Mr. Oliver. Do you have the feeling that I have that perhaps their activity goes beyond actual fisheries research? Do you have the feeling it is a matter of oceanographic research probably dedicated to other purposes?

Mr. Rivers. I feel they are probably on a multipurpose expedition. I can easily see they would be making all possible explorations while exploring for the quantity of fish in the bottom of the ocean.

Mr. OLIVER. Generally speaking, is there a feeling among Alaskans that this poses a challenge to us in that we should be expanding our own research programs?

Mr. Rivers. I might say the intensification by the Soviet of its activity in the North Pacific is so recent that I have not actually picked up any material reaction. I can easily see that the United States should proceed on a larger scale than it is at the present time.

Mr. Orrver. But there is no question that there is a rather large intensification of their effort in this field?

Mr. Rivers. Yes; they are inultplying their efforts manyfold just within the last year during which it has come markedly to our attention.

Mr. Ourver. Thank you.

Mr. Miller. Mr. Curtin?

Mr. Curtin. No questions.

Mr. Miller. Mr. Lennon?

Mr. Lennon. No questions.

Mr. Mrluer. I am very happy to note the presence of the chairman of the full committee here. Do you have anything, Mr. Bonner?

Mr. Bonner. I am greatly interested in the proposed program for disposal of waste material. You will recall yesterday I asked you to insert in the record here a copy of a telegram received from the Department of Conservation and Development of North Carolina expressing their interest in this matter and the concern of the State as a whole in the Atlantic seaboard as to safety and security that might be affected were this material disposed of in close proximity to the shore and just what would be the result and whether or not your committee might want to call in State officials on the Atlantic seaboard with respect to this matter.

Mr. Mrluer. Mr. Chairman, I may say I have a note here to insert your telegram in the record, which I will do at this time.

(The telegram referred to follows:)

Congressman Herbert Bon ner,

Morehead City, N.C., January 13, 1959.

Washington, D.C.:

North Carolina Denartment of Conservation and Development voted unanimously this morning to oppose dumping of radioactive materials in any form or manner or in any area that would adversely affect either commercial and sport fishing on any part of the North Carolina coast. Formal resolution follows. Your assistance in this matter will be most appreciated.

William P. SAUnders,

Director, Department of Conservation and Development.

Mr. Miller. We appreciate your being here and may I sav the welfare of North Carolina in this respect was well taken care of yesterday by our colleague, Mr. Lennon.

$38170-59-24$ 
Mr. Bonner. I am sure it was.

Mr. Miluer. We are happy to have you here, and may I say for members of the committee that I have asked counsel to get out a letter to all of the Governors of the Coastal States pointing out that particular problem and asking their cooperation, asking them if they care to cooperate through their departments of natural resources and fisheries. A few States have had cognizance of this and have been quick to tell us.

Mr. Bonner. When I first noticed this, I wrote a letter to Mr. Lefller, Under Secretary of the Interior for Fish and WVildlife, expressing my concerm about it. I have a reply from him and sometime I would like to put my letter and his reply into your record.

Mr. Mrlezer. We will put that in the record at this point.

(The two letter's referred to follow:)

JUNE 23, 1959.

Hon. Ross L. Leffler,

Assistant Seeretary of the Interior,

Department of the Interior,

Washington, D.C.

DeAr Mr. Leffler: It has come to my attention that the National Academy of Sciences and the National Research Council have suggested the use of ocean areas near Morehead City, N.C., for the disposal of low level radioactive waste. In view of the present state of knowledge conrerning the effectiveness of the means of preventing contamination, I an greatly concelned about the possible danger to the fisheries and, inclirectiy, to the people of my state.

I would appreciate som furnishing me with information concerning the possibility of any adverse effect unon either the fishery or the population by reason either of improper containment of the wastes prior to their disposition or premature destruction of the containers after disposition. In addition, please inform me what, if any, steps yonr Service prans to take to make periodic inspections of the disposal areas after they are placed in use.

Sincerely,

Herbert C. Boyxer, Chairman.

DLPARTMENT OF THE INTERIOR.

OFFice of THIE SECBetali,

Washington, IJ.C., July 2, 1959.

IIon. HerberT C. Bonner,

Honse of Representatives,

Washington, D.C.

Dear Mr. Ionner: The Burean of Commercial Fisheries has prepared a general statement on disposal of low level atomic waste materials in the sea. We hope the enclosed cony of this statement will in part answer the ruestions in your letter of Jnne $23,195 !)$.

The program of waste disposal should not be harmful to tishermen or the general mblic if it is properly corried out. Tests show that the wastes packaged in sted drums filled with eoncrete are sife for hambling. limpture of the drums is not kikely, so the wastes will be contained for long periods before heing released to the sea environment. If, however, some of the drums should release thoil contents prematurely, no ham would result. The radioactive materials moler consigeration ane low level in aletivity and the quantities to he placed in each area are to bo limited. We helieve the safety factors allowed in the stucly by the National Acallemy of sciences precelnde return of the waste materialis to man either through seafood or by heing washed in on heaches near the disposal areas.

The Atonic Energy Commission is arranging for site surveys and monitoring of disjosal areas. The Coast and Geodetie Survey is to movide slip time for the surveys and will eollect samples of the bottom and of hottom organisms for study. The Public Health Service will aualyze the samples for rabloactivity. 'The Woods IIole Oceanographic Institution will study circulation in relation to predisposal and post disposal monitoring. 
While the results of this work will be arailable to the Bureau of Commercial Fisheries, the Burean will not participate directly in the surveys and inspections requiled.

The Burean of Commercial Fisheries plan to follow the disposal operations very carefully, with the aim of protecting fishing interests should this become necessary. At present we believe there is no cause for concern if disposal is carried out in accordance with the recommendations of the National Academy of Sciences.

Sincerely jours,

Ross LeFFler, Assistant Sccretary.

Bureau of Commercial Fisheries Statement on Disposal of Low Level RadoACTIVE WASTES IN THE SEA

It is the opinion of the Burean that the ocean should be used as little as possible for disposal of atomic wastes or other unwanted materials. If the ocean is to be used for disposal, howerer, it should be done according to a rell-designed plan. Areas should be selected for disposal which will not harm other interests. 'Their' number's should be kept to a minimum, thes should be well marked, and their existence should be publicized. Furthermore, all disposal operations should be policed closels. Unless these conditions are met, this Bureau would be opposed to waste disposal at sea.

The question central to our consideration is whether or not introduction of low level radioactive substances into the marine enviromment will be harmful to marine resources. Considering sereral factors involver, particularly that the materials to be disposed of are of a vers low level of actirity and that the amount is to be limited annully, the Bureau would not object to sea disposal on the basis of harm to fishery resources as a result of raclioactivity. We would insist, however, that the operation be carefully monitored so as to insure that disposal is carrier out according to regulation.

From time to time fishermen working in the gulf have hauled up drums of nonractioactire substances in their nets. This has caused damage to gear, loss of fishing time, and alarm on the part of fishermen. Entrance of the drums into fishing nets results because they rere not placed in proper disposal areas by commercial disposal contractors. Thus similar diffeulties could arise from improper dislusal of frums containiug radioactive wastes.

Care must also be taken to insure that public misconceptions of the effect of this activity will not result in consumers shying away from fishery products harrested from this area. Important segments of our gulf fishing industry are alreads confronted with difficult narketing problems. Any act that will create public fear of radioactirity in fishery commodities will tend toward additional consumer resistance, which should be a roided.

Persons interested in studying the matter of sea disposal of unwanted materials might wish to read Publication 655 of the National Academy of Sciences-National Research Council entitled "Radioactive Waste Disposal Into Atlantic and Gulf Coastal Waters." We regard this study as an objective effort on the part of the Atomic Fuergy Commission and the National Academy of Sciences to handle disposal of low level wastes in a logical way. We will insist, though, that the requirements for pre- and post-disposal monitoring, maximum rate of disposal and policing of operations be rigidly followed in any future operations. It is important to note, that the areas proposed to receive low level wastes are suggested as tentative. Before actiration of any disposal area, detailed studies are to be made of all environmental and use conditions, to insure that the operation will be safe and will not cause conflict with fishing or other interests.

In summary, the Bureau would support the recommendations contained in this report, with the reservation that the rigid requirements for study and policing be carefully followed.

Mr. Rwers. Before departing, I would like to say I appreciate the penetrating interrogation of our colleague, Mrr. Pelly, from Washington and I want to say I have a vast respect for his special knowledge and grasp of this problem. I know he will be a great help to the committee.

Mr. Mrcler. We are happy to have Mr. McKeman and Mr. McHugh here. I believe you have a prepared statement and that you are going to show us some pictures. 
STATEMENT OF DONALD L. MCKERNAN, DIRECTOR OF THE BUREAU OF COMMERCIAL FISHERIES; AND J. LAURENCE McHUGH, CHIEF, DIVISION OF BIOLOGICAL RESEARCH, BUREAU OF COMMERCIAL FISHERIES, DEPARTMENT OF THE INTERIOR

Mr. McKernas. Thank you, Mr. Chairman. It is a special privilege to appear before you this morning and talk to you about my own specialty, biological oceanography.

Gentlemen, I wish to share my pleasant experience today with my colleague, Dr. J. Laurence McHugh, who only recently became the Chief of our Division of Biological Research. Dr. McHugh has had broad experience in marine research on both coastlines of our country, studying and obtaining his doctor's degree under a very famous oceanographer, Dr. Sverdrup, at one of the country's outstanding oceanographic institutions, the Scripps Institute of Oceanography in southern California.

Mr. Miller. Without taking away anything from Mr. Pelly, I am very happy, being from California, to welcome him.

Mr. McḰnnan. Dr. McHugh for the past 8 years has been in charge of marine fisheries research in Virginia and has contributed greatly to our knowledge of oceanography and fisheries on the Atlantic coast.

This morning we wish to talk to you about the ocean as a source of food. We think the best way to do this is to show you some of the things we are learning at the present time through our current research programs. As you will see, we are hardly splashing the surface of the ocean. We need much more knowledge before we can apply it to harvesting fully the rich food resources of the sea.

The sea is in some respects similar to the atmosphere surrounding the earth in that it has both length and width and depth. Plants and animals grow within these three dimensions most abundantly to a depth where light freely penetrates, or to about 300 feet. Unlike our land masses, the sea is not a solick ; and unlike air, it is not a gas. It is a liquid, and oceanographers have found that the movements of these vast bodies of liquid, the oceans, more closely correspond to the movements of the air above than with the time lag in the morements of the waters.

I hope other oceanographers have told you of the effect of the ocean currents on the temperatures of the coastal regions of the world. In addition to the effect of ocean currents on our coastal weather, there is, in fact, weather within the oceans themselves. Ind just as our climatic conditions determine the plants and animals which inhabit and prosper in any of the climatic zones from the tropics to the Arctic, so there are various ocean weather zones. Different plants and animals are found in these zones, and many migrate hundreds of miles through the eight ocean weather zones during a seasonal cyclic migration, just as birds and some animals move from one locality to another with the seasons.

The sea has its rich pasturages, just as has our fertile valleys on the land. In some instances these fertile pastures in the sea are caused by the wind blowing offsore from the land, bringing enriched water from the ocean bottom to the surface sunlit layers. This enriched water in the presence of sunlight forms the basis for the chain of life 
starting with the simplest plants and extending up through the fishes which are harvested by man.

Sometimes ocean currents are interrupted by islands, and the resulting turbulence again enriches the surface layers with deep, enriched water. In such circumstances, a rich ocean pasture produces an abundance of fish and various forms of plant and animal life.

The Hawaiian Islands are a good example of that. There are a number of other examples in other parts of the world.

Oceanography in the broad sense is the study of all natural phenomena that take place beneath the surface of the sea, whether they relate to the circulation of the waters, their chemical composition, the contours and structure of the bottom, or the habits and interrelationships of the plants and animals that inhabit all levels of this vast domain. A principal objective of the work of the Bureau of Commercial Fisheries is the maximum utilization of the living resources of the sea, and the Bureau's research program is essentially a program of oceanographic research.

The marine resources exploited by U.S. fishermen range over vast expanses of ocean, far broader than the narrow band that constitutes the territorial waters of our country. Our salmon resources migrate across the North Pacific and Bering Sea almost to the shores of Asia; the cod, haddock, and other species that support our great Atlantic trawl fishery are found across the North Atlantic near European shores; the great tuna stocks that are so important to our fishermen range over all the temperate and tropical waters of the world. These fisheries are subject to great fluctuations in abundance from time to time, and these fluctuations are of great concern to our fishing industry. Fishing operations and other human activities, such as dams, pollution, and the like, are responsible for some of these fluctuations, and an important part of our responsibility is to understand these manmade effects, so that their influence upon our economy and upon the welfare of our fishing industry can be minimized or eliminated. But the success of fishing is also affected substantially by natural forces, which may alter the habits of marine animals so that they fail to appear in their usual haunts at expected times, or may influence the success of spawning to the extent that a year's brood may be many times more, or less, abundant than normal. An understanding of these phenomena is essential if our ocean resources are to be exploited efficiently, and for this reason the Bureau is vitally interested in oceanographic research.

In the brief time available here, it would be impossible to describe all the oceanographic investigations of our Bureau, and I, therefore, propose to confine my remarks to a few of our major investigations.

The total landed value of U.S. fisheries is more than $\$ 350$ million. Many different kinds of fishes make up this catch, but shrimp, salmon, tuna, oysters, and menhaden make up almost 60 percent of the total value. Individually, the various species that support the North Atlantic trawl fisheries are not of primary importance, but collectively they also represent one of our major marine resources. When these are added to the five species groups named above, almost 70 percent by value of American fishery landings are included. 


\section{WHAT DO WE INNOW ABOUT FISIIERY OCEANOGRAPHY?}

Our knowledge of oceanography as it affects the distribution and survival of marine resources and the availability of these resources to fishermen is fragmentary and imperfect. The present state of this knowledgo might be compared with our knowledge of the geography of the North American Continent in the 16th century shortly after the voyages of Columbus-a few fairly well established facts pieced together with speculation and considerable myth. We know in general that temperature is important to marine life; that each species has its own optimum temperature limits which limit its geographic distribution and its distribution with depth in the sea; that seasonal changes in temperature, and deviations from the normal temperature pattem, affect the migrations of fishes; and that sudden changes in temperature may be lethal to marine life. We know that salinity influences the morement of marine animals and that unusual changes in salinity may canse death. We know that winds and currents have profound effects upon the marine environment, and influence the fisherman's catch in many ways. But these are only the most obvious of a myriad of factors in the ocean that exert an influence upon our marine resources and upon the welfare of those who depend on these resources for their livelihood.

In order to examine some of these particular features, Mr. Chairman, with your permisison I would appreciate having Dr. McHugh tell you about some of our research and some of the facts of oceanography which do influence the fisheries resources and our fishing industry.

Mr. Miller. Very well, Dr. McHugh.

Mr. McHugr. This is a simplified diagram of the major ocean currents of the world. We are concerned primarily with the systems in the North Atlantic and North Pacific Oceans, for these are the areas from which most of our fishery harvest comes. In a general way, these two great ocean systems are remarkably similar. The warm Gulf Stream flows north along our Atlantic coast, then veers diagonally across the Atlantic to divide into two main drifts, one of which modifies the climate of the United Kingdom and the Scandinavian countries, the other swings southward along the coasts of Portugal and North $\Lambda$ frica, returning toward America as the North Equatorial Current. Meeting the Gunlf Stream off our New England coast is the cold Laborador Current, and the boundary between cold and warm currents in this region separates our fisher'y resources into two main groups, characterized by such species as haddock, cod, and redtish north of the Gulf Strean system, and bluefish, tuma, oysters, shrimp, menhaden, and other warm-water species to the sonth.

Similarly, in the Pacific the warm Kinroshio flows northward off the Asian coast, then swings diagonally across the ocean as the North Pacific drift. It also divides as it approaches North America, part flowing northward as the Mlaska Current, part swinging sonth as the California Current. The water returns to the westward as the North Equatorial Curent. The Laborador Current also has its counterpart in the Pacific, the Oyashio, a cold current that flows sonthward off' Kanchatka and meets the Kuroshio off Japan. 'The boundary between the Alentian and North Pacific drifts separates rather sharply 


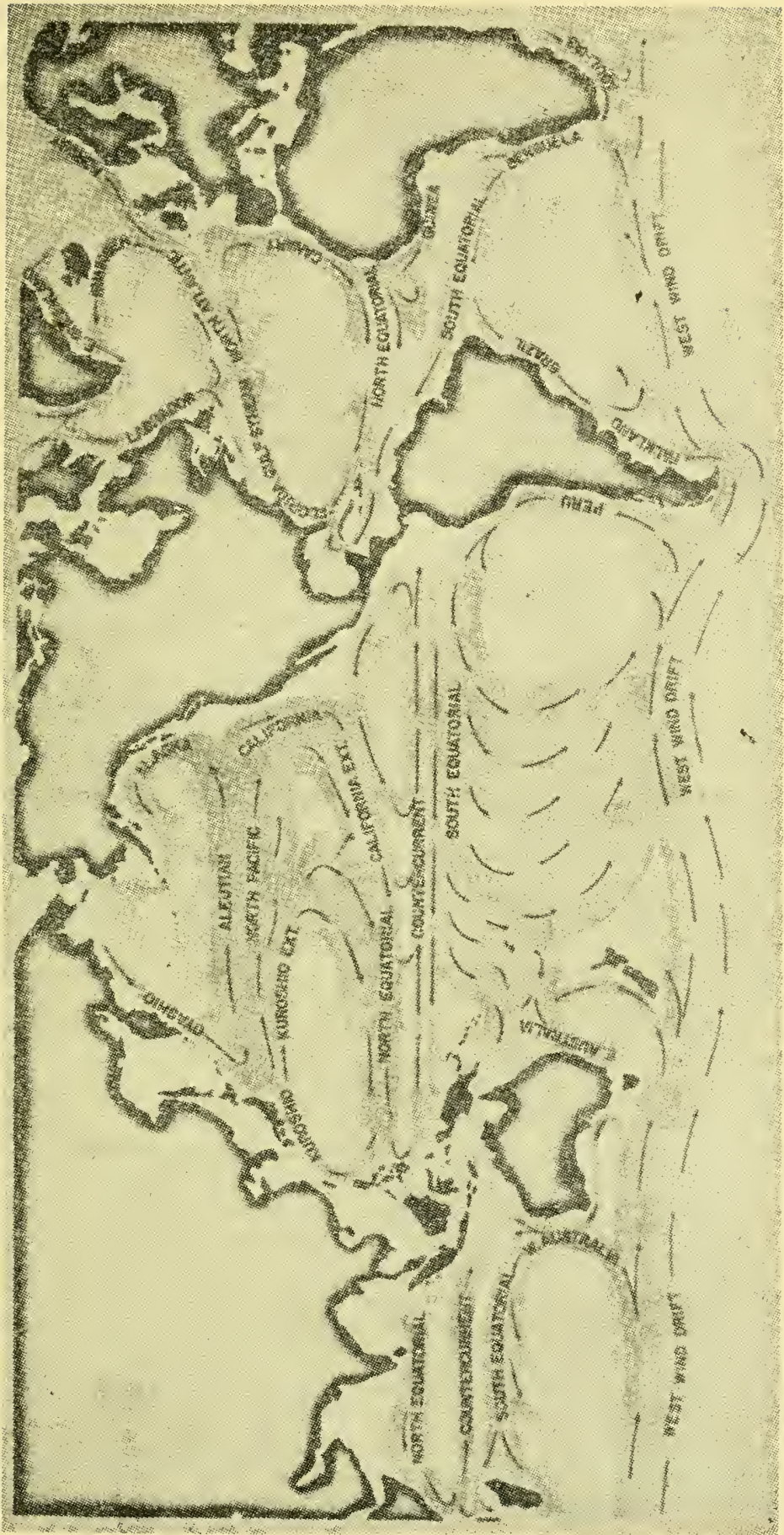


the marine resources of the North Pacific, characterized by the important salmon stocks of northern waters and the tuna resources of the tropical Pacific.

The Bureau's tuna investigations based in the Hawaiian Islands have made some significant contributions to fishery oceanography. For example, early cruises discovered a region of divergence near the equator in midocean along which an upwelling of nutrient-rich water from mid-depths occurred. Biological investigations showed that this water was rich in plankton, and it was concluded that exploratory longline fishing for tuna might be profitable here. Exploratory cruises located deep-swimming yellow fin tuna in commercial quantities in the region between the equator and the equatorial countercurrent.

Of even more far-reaching importance was the recent discovery of a major ocean current in the Pacific equatorial region. The existence of this current was first realized by a Bureau scientist in attempting to explain the contrary drift of a ship and its experimental fishing gear. Subsequent surveys revealed that this hitherto unsuspected current is one of the major oceanic currents, ranking with the Kuroshio and the Gulf Stream in magnitude. More than 3,000 miles long, flowing at more than 3 knots in its center, at a depth of 300 feet, and carrying more than a thousand times the volume of water discharged by the Mississippi River, this deep ocean river is not evident at the surface. Its discovery will lead to a vast improvement in our understanding of the circulation of the North Pacific Ocean, and so to a better knowledge of the movements and distribution of the major fishery resources. In honor of its discoverer, this has been namød the Cromwell Current.

But there is much that we do not know about the effect of currents on marine life. Our work has shown, for example, that salmon from Alaska spread throughout almost this whole region north of the Aleutian drift, intermingling with salmon from Asian streams. Yet by some unknown sense, when spawning time approaches, they unerringly find their way back in opposite directions, over thousands of miles of ocean, to streams on opposite sides of the Pacific. We are entirely ignorant of the part currents play in this almost incredible countermigration.

In the Atlantic and Gulf of Mexico, we have some equally fascinating problems. Perhaps the most famous is the story of the American and European eels, which undergo migrations even more striking than Pacific salmon. Both eels spawn in the open Atlantic in the region of the Sargasso Sea. 'Then, as delicate, transparent larvae, their progeny find their way back to coastal river's and streams, one species to American shores, one to Europe-presumably carried by the clockwise current system. Their rates of developnent are so adjusted to the timing of the current drift that the American species transforms to the elver stage just as it reaches American streams. The European species, on the other hand, takes much longer to reach its native streams, and its larval development is extended accordingly. From beginning to end of this journey, the larval cels drift with the major ocean currents.

Equally interesting are the migrations of shrimp, menhaden, and many other coastal fishery resources of the South Atlantic and gulf coasts. These species are similar in that they spawn in the ocean, usually not far offshore, and the delicate transparent young somehow 
find their way very quickly into the bays and estuaries where they penetrate well into the marshes, or up the rivers often into fresh water. How these delicate organisms perform such formidable migrations, unless they are carried by currents, is difficult to understand. Yet if they are at the mercy of ocean currents, which are known to vary in strength and direction, they may at times be carried to unfarorable areas and perish. The effect of currents on survival of shrimp, menhaden, and other important resources has an important bearing on the success of fishing at some later date.

\section{TEMPERATURE}

Our knowledge of the general distribution of surface water temperatures in the oceans is reasonably good. The boundary between what we call warm and cold waters falls somewhere near $55^{\circ} \mathrm{F}$. In the northern hemisphere in winter, this line rums from the South China Sea through Japan to the northern California coast, and from Cape Hatteras to Cape Finisterre in northern Spain.

In summer this boundary shifts to a line from the southern islands of the Kurile chain to southeastern Alaska, and from Newfoundland to the northern coast of Norway. It is interesting to see how the line falls much further north on the eastern sides of both oceans, especially in summer, and how it corresponds in general with the paths of Kuroshio and Gulf Stream.

If we now look at the worldwide distribution of one of our most important tunas, the albacore, we see how closely it matches the temperature pattern. The northern and southern limits correspond very closely to the positions of the $55^{\circ}$ isotherm, and the blank space in the tropical Pacific probably means that temperatures here are too high for this species. Note how the northern limit in the Pacific runs diagonally across the ocean, conforming very closely to the positions of Kuroshio, North Pacific drift, and Alaska current, and also to the temperature distribution. The information on which this chart was based comes mostly from records of the fishery, hence the irregularities are not too significant. We know less about tunas in the Atlantic, and this is why the pattern is less complete.

Look now at the distribution of another important tuna, the yellowfin. This species is more tropical than albacore, and its northern and southern limits are bounded by $70^{\circ}$ or $75^{\circ} \mathrm{F}$. temperatures. You will remember that the current system takes warm water north on the western sides of the oceans, and cold water south on the eastern sides. This corresponds with the broad distribution of yellowfind tuna in the western Pacific, and its absence in the eastern part, except for a narrow coastal band.

Look also at the known distribution of yellowfin tuna larvae based on the records of oceanographic cruises. This tells us things about this tuna that the commercial fisheries do not. Note particularly how it adds to our knowledge in the Atlantic Ocean. Clues to the effect of oceanographic factors upon tuna abundance must be sought by surveying these vast ocean waters.

We have a few other clues to the importance of temperature to commercial fisheries. The movements of migratory marine animals in and out of our coastal bays and estuaries, and their behavior and 
survival while there, are controlled at least partly by temperature. In Chesapeake Bay, for example, striped bass sometimes are numbed by sudden temperature drops in winter, or congregate in deep holes to escape sudden temperature changes in shallower water. In lagoons bordering the Gulf of Mexico, mass mortalities of fishes and shrimp sometimes are caused by cold weather in winter. White shrimp stop spawning and growth ceases at $68^{\circ} \mathrm{F}$. or lower.

'The most striking of all known temperature effects occurred during the warm year 1957 in the Pacific. The underlying cause of these unusual phenomena was a major change in atmospheric circulation over the North Pacific. This caused ice to go ont 6 weeks early at Point Barrow, prolonged the rainy seasons along the southern Asian coast and in southern California, brought the first recorded hurricane to Hawaii, caused a disastrous fish-killing El Niño ofl the coast of Peru, brought many southern fishes to norther'n waters where they had seldom, if ever, been seen before, and caused the highest water temperatures in 26 years off' the California coast. 'The eflects upon ocean temperatures were most striking. Along the west coast of North America and in the Gulf of Alaska, temperatures increased by more than $2^{\circ} \mathrm{F}$. and some regions as much as $8^{\circ} \mathrm{F}$. In the western Pacific, on the other hand, there were equally large temperature decreases, associated with a weakening of the current systems. Phenomenal increases occurred in sportfish catches along the California coast, especially barracuda and yellowtail; the set of Pismo clams was the best in 10 years; the location of major sardine spawning shifted from lower California to southern California for the first time in a decade; and the valuable salmon l'uns to the Fraser River changed the route of their migrations, coming round the north end of Vancouver Island, instead of through the Straits of Juan de Fuca, as they normally do. In 1958 the unusually warm conditions persisted and the sardine fishery recovered to a remarkable degree. Recent increases in the frequency of shark attacks upon swimmers in California waters may well have been caused by these oceanographic changes.

Another important feature of the distribution of ocean temperatures is the decline in temperature with depth. Usually there is a layer of more or less uniform temperature at the surface, overlying a body of colder water below. Between the two is a layer in which the temperature drops rapidly with increasing depth, and this region is called the thermocline. The average depth of the thermocline is about 200 feet, but it varies considerably from season to season, being shallow in summer, deeper in winter. Because the seasonal temperature change at the surface is greatest at high latitudes, the depth of the thermocline varies much more than it does in the tropics.

Many of our important commercial fishes, like salmon and tuma, remain in the layer above the thermocline, and the depth of the thermochine has important eflects upon the fishery. This would explain, for example, why the high-seas gill-net fishery for salmon would be more successful in summer. A long the equator in the Pacific, the thermocline is much deeper on the western side. 'This is probably why purse seines and live-bait fishing are eflective near our coast, but long lines are necessary on the $\Lambda$ sian side. 
Some fishes, like cod, usually stay below the thermocline, and their location on the fishing grounds may be determined by the depth of this layer. All fishes have their preferred temperature limits, and this may cause them to become trapped at certain times, as for example, when winter cooling of surface water sandwiches a layer of relatively warm water between cooler layers above and below.

\section{SALINITY}

We know also in a general way that the amount of salt in the water has profound influences on marine animals. Some, like salmon, striped bass, shad, and others that spawn in fresh water have a remarkable capacity to adjust to the change from salt to fresh and back to salt water again. This capacity is even more remarkable in menhaden, shrimp, and other species that spawn in the ocean, but move into brackish or even fresh water while they are still very small and delicate. Brackish water affords protection to animals such as oysters, since certain of their enemies, like oyster drills and certain oyster diseases, cannot tolerate salinities quite as low. Heary rains in early summer favor survival of shrimp in the estuaries.

In the area of the Hawaiian Islands salinity as well as temperature can be used to predict spring and summer skipjack catches. The islands come within the influence of two major currents, the relatively warm, high salinity extension of the Kuroshio in summer, and the cooler, less saline extension of the California current in winter. The time at which the Kuroshio will shift to the northward can be forecast from water salinity and temperature conditions in February and early March. On this basis the poor skipjack season of 1958 was predicted, but the forecast for 1959 was good. This has been borne out already by catch statistics for May 1959 , when almost two million pounds of skipjack were caught-10 times the catch in May 1958 .

\section{OCEANOGRAPHY AND FISHERIES}

Among the most universal characteristics of marine animals are the great fluctuations in abundance that occur from time to time. These fluctuations are not confined to those commercial or recrational resources exploited by man, although popular opinion often seems to favor this view. We have found in the Pacific, for example, that the abundance of plankton (organisms of microscopic size that drift with the currents) decreased considerably in 1957 and 1958, and that in general the amount of plankton is correlated inversely with water temperature.

Fluctuations in commercial fishery resources, however, are more obvious to man because they affect him economically. One of the most disastrous was the recent collapse of the Pacific sardine fishery, once the greatest fishery in the world in terms of annual landings, from a peak catch of nearly 800,000 tons in 1936 , to less than 5,000 tons in 1953. This completely wiped out the fisheries in the Pacific North west and the San Francisco region, leaving a relatively minor and irregular fishery off southern California and in Mexican waters.

Since 1949 we have been conducting an intensive fishery oceanographic survey of the waters occupied by the sardine, from which we have learned a great deal about the sardine and about many other 
fishes that inhabit the same waters. Major sardine spawning areas are in the Gulf of California, off the lower California coast, and off southern California. We have not studied the Gulf of Califomia intensively because the sardines there belong to a distinct subpopulation that does not intermingle with the subpopulations on the ocean coast. In the first 10 years of the surveys most spawning took place in the sonthern area, but in 1957 and 1958, as we have already said, the pattern changed, and about 80 percent of the spawning has been in the northern area. At the same time, the abundance of sardines off California has increased, so that the 1958 catch was the greatest since 1951, and could have been greater if the fishery had not been restricted.

Spawning areas and nursery grounds of other important species have been cliscovered by these surveys. Hake, anchovy, and jack mackerel inhabit the same waters as the sardine, and compete with each other for food. The eggs and larvae are small and delicate; for example, the newly hatched sardine or anchovy is only about one-tenth inch long. It must be very sensitive to changes in oceanographic conditions, and, of course, is prey to a host of diseases and predators, and subject to changes in abundance of its own food, too.

\section{SUMIIARY}

These shreds of knowledge emphasize the fact that oceanography is important in fishery investigations. How large are the tuna resources of the world, and where and how can they be fished most profitably? What governs the movements of North American and Asian salmon across the Pacific, and how can we prevent orerfishing? What causes the great variations in success of Pacific sardine spawning, so that some spawnings produce as much as 100 times as many fish as others? How do menhaden and shrimp find their way inshore so soon after hatching, and what oceanographic conditions affect their survival? Why are some ocean regions rich in marine life, others poor? These are only a few of the questions that oceanographic research can answer.

The wind pattern over the North Pacific has changed in the past decade with stronger winds off the California coast and weaker winds over the Bering Sea. What relation does this bear to the decline of the sardine fishery, and changes in other Pacific fisheries?

The temperature of the North Atlantic has increased substantially in the past 100 years. Early records showed that mackerel landings increased in warm periods, but catches dropped abruptly about 1890 and the fishery has failed to recover. Is the water now too warm for mackerel?

On a recent cruise off Georges Bank, our biologists found large numbers of dead fish larvae in plankton samples. These dead were all cold-water forms, and they were taken in an area where warm and cold water met, with a $20^{\circ}$ change in water temperature in 10 miles. Warm-water species in this same area were not affected. These kills, if they occur at certain times, can affect fishing at some later date.

Studies of shrimp migrations in the Tortugas area, using a newly developed method of marking with dyes, have shown that these ani- 
mals make remarkable migrations out to sea and back again. Oceanographic factors that influence these movements are not known, but their discovery would help to explain the reasons for variations in shrimp abundance.

Albacore are probably the most highly migratory of all the tunas, ranging from one side of the Pacific to the other. For a period of about 10 year's in the late 1920 's, they failed to appear in any numbers off the North American coast. Some change in oceanographic conditions may have caused this temporary change in habits, but we do not know the cause, although some success has been achieved in forecasting albacore runs on the basis of spring temperatures and currents.

To obtain continuous oceanographic observations to fill in the gaps between cruises, some method of automatic observation is needed. Our scientists have pioneered in the development and testing of such methods in the Pacific and the Gulf of Mexico. We are taking advantage of every opportunity to improve the methods and techniques of oceanography as applied to the fisheries and hope to place even greater emphasis on oceanography as time goes on.

The full significance of oceanography in fishery investigations has never been adequately explored. Until recently, fishery biologists and oceanographers have tended to work separately, never really planning their investigations in such a way that one would complement the other. To remedy this situation we have established two centers of ocean research within our Bureau, one at Palo Alto, Calif., and one in Washington, D.C. 'The California laboratory already has made some significant achievements, one of which was the chart of surface temperature anomalies that we showed you earlier.

Another was the publication of a wind atlas, to show fishermen where they could find fishing areas relatively free of stormy weather. Our Washington laboratory was established more recently, and its work is just beginning. We anticipate that these laboratories will be extremely valuable in analyzing our present knowledge of fishery oceanography and in pointing out gaps in knowledge that should be filled.

Mr. Milcer. Mr. McKernan, have you a further presentation?

Mr. McKernax. We have completed our presentation, Mr. Chairman.

Mr. Miluer. We were interested yesterday and are very much concerned about the recent report gotten out by the Committee on Oceanography in Bulletin 655 on the disposal of atomic wastes. Have you made any investigation into what effect this practice may have on the fisheries offshore?

Mr. McKernan. Mr. Chairman, one of our staff was a member of the committee which made this particular study, Dr. Walter Chipman, one of our staff members. We had another consultant, one of my staff members in the Washington office, one of Mr. McHugh's assistants. We have examined this particular situation as thoroughly as possible.

Mrr. Miller. Of course, laymen who read this report become quite confused, becanse at best it reaches a number of conclusions which are dicta. We continuously find very positive information.

Is it correct that this is a sort of interim thing, or is it final? 
Mr. McKernan. No, it is not. If my information is correct, I believe the areas which have been discussed in this particular report were possible areas of disposal. In so far as we are concerned, they are not final at all. In fact, it is our opinion that the oceans should be used just as little as possible for the disposal of atomic wastes or other unwanted materials. If they are to be used for disposal, it should be as the result of a well-developed plan.

With your permission, I wonld like to ask Dr. McHugh, who has been closely associated with this particular study, perhaps to comment further on this subject.

Mr. Miller. We should like to have Dr. McHugh's comment on it.

Doctor, I do not think we are too concerned about high level wastes, but with what may be low level wastes. I am somewhat worried about that.

Mr. McHugh. Dr. Chipman's laboratory, which Mr. McKernan has already mentioned, is doing work on various aspects of the effects of atomic radiation on marine life, studying fishes, shellfish like oysters and clams, and also bottom organisms. This work has been going on for several years now.

While we do not believe by any means that we have all the answers, we are very much encouraged by the work which this laboratory is doing. Dr. Chipman has an international reputation in this field and is well respected by people not only in Canada but also in Europe and across on the other side of the Pacific.

There is a great deal to be learned, of course, about the effects of radiation on marine life. Several aspects of his work, which he is doing under contract with the AEC, have been directly on this question of waste dumping. We have been concerned mostly with low level wastes, of course, because, as I understand it, the plan is not to dispose of high level wastes in the oceans.

Mr. Miller. That I understand to be the present procedure. I just wonder as we go on developing more atomic installations in the country, bringing atomic powerplants into commercial production, as the matter of disposal will become more onerous as time goes on, if the tendency will be to try to sell the people on the filct that here is the great area of the ocean, and all you have to do is take it out and dump it in the ocean and it is gone. They are disposing of high level wastes in England, are they not, in the manner of pipelines going down?

Mr. McIlugr. I am not sure abont this, Mr. Miller. I believe those are low level wastes, too, but I would not be positive about it.

Mr. Mrubre. I am not too sure, either, but I thought being liquid they were most likely high level wastes. Have we any cooperative agreement to get any of that information, or is that all handled through $\Lambda \mathrm{E}$ contractors?

Mr. MCIUGH. $\Lambda$ good deal of that is handled through $\Lambda$ EC, but of course we do have contact with our colleagnes over there in fisheries work, partly through the North Atlantic organization, as we call it, ICN $\mathrm{AF}$, the International Commission for the North Atlantic Fisheries. So any dangers of that sort conkl be quickly understood by both parties, and we would have an opportunity to complain if we felt they were threatening the fisheries in any way or dumping in the ocean wastes which we felt were harmful. 
Mr. Mrtuer. Of course, if these wastes are dumped in the ocean in any great amounts or if high level wastes are clumped in the ocean by any one country, the effect would be universal, would it not, carried by the currents and dispersed throughont the ocean?

Mr. McHugrr. Even more so, they probably are carried more rapidly by animals than by currents, because the animals can move across current patterns and go up and down in the ocean, too, you see.

Mr. Mchernan. We know, Mr. Chairman, that there is an accumulation of some of these radioactive materials, radioactive metals, in animals. They are carried some distances from the sites by animals. So our Bureau at the present time takes the view that only low-level wastes should be put into the ocean, and then only under very carefully controlled conditions and after a thorough study has been made.

Mrr. Minter. Is the Fish and Wildlife Service on its own initiative doing any work in this field, or is it only the work which is contracted to youl by $\mathrm{AEC}$ ?

Mr. Míkernan. We are doing cooperative work with AEC, a good share of it now with our own resources. This is especially true of Dr. Chipman's laboratory. So the answer is yes, we are doing work on our own initiative.

Mr. Miller. I would like to know if you are doing work and, if you are not doing work, what we can do to have you do this independently. I realize there must be cooperative effort, but the old saying is that the man who pays the piper calls the tune. I am not interested in having a thing quite so important as this filter through one agency. Although it may have the best intentions, it at least has some preconceived thoughts about these things. I think we should have a check.

Do you feel that the work which has been done in this field or that the way it is being done is sufficient at this time, or should we have it stepped up?

Mr. Mclínnas. I suspect that work at a higher level of effort would be very productive, Mr. Chairman, but my relationships during the past some $21 / 2$ years with AEC hare indicated to me that there is no intention on their part to withhold or to request us to withhold or to cut back on any particular criticisms that we might have of the disposition of wastes into marine environment. In fact, we have been critical at times of this, and have been so publicly.

Mr. Mruler. They have not tried to influence you?

Mr. McKernan. They have not. They have been very cooperative. I say in all sincerity that our relationships with AEC on this particular problem have been excellent, and the cooperative work we have carried out has left us perfectly free, with absolutely no connotation of their attempting to quiet down any criticism we might have of this particular program.

Of course they do have classified programs, and at times they have asked our review and criticisms of these programs, in fact. But with respect to this matter there has been no intention, to my knowledge, of AEC's attempting to try to get us to withhold any criticism of any procedures in that regard.

Mr. Mruler. Are any of the States engaged along with you in this work, or have you worked with the fish or conservation groups of the respective States? 
Mr. McKernan. Mr. Chairman, indirectly we have. We are the research arm of the Atlantic States Marine Fisheries Commission and the Gulf States Marine Fisheries Commission. 'This matter has come up before both of these State commissions, and there has been a rather thorough airing of this particular problem among the scientists and administrator's at these particular commission hearings. So I think you would consider this to be in a sense a cooperative venture, at least in an examination of the things that are being done in this regard.

Mr. Miller. I am concerned with two phases: One, this subcommittee or our parent committee, the Committee on Merchant Marine and Fisheries, is charged with the preservation of the fisheries of the United States, as you well know. We want to make sure that nothing will be done to destroy them. In the past, unfortunately-and I think acknowledged in your own statement, as I interpret part of it-we have seen what the effect of the pollution of some of our streams has been on our fisheries. We are now fighting to force control on industry. We know this is a long and very hard fight, but one which must be carried on if we are to maintain fish life in our streams, bays and estuaries. I think you subscribe to that statement.

Mr. McKernan. I certainly do, Mr. Chairman.

Mr. Miluer. We would not like to see this condition reproduced with respect to the atomic wastes, waiting until half the damage is done before we begin to correct it, and then be confronted with another herculean task of rolling back time. That is our interest.

We realize that our industry, and perhaps our very way of life, must depend on atomic energy in the future because other sources of heat and power can be dissipated or can give out, but falling water to generate electricity and atomic energy will be with us for perhaps a long time to come.

We are not critical, but we do want to make sure that all of the protection necessary is given to us. After all, you are the arm of the Government we have to look to for this.

Mr. MeḰernan. Mr. Chairman, I could not subscribe more fully to your statement in this regard. It is my general feeling, as a matter of principle, that right along with the development of various uses for nuclear power and atomic power should come studies into matter's of disposal of these particular wastes, just as there should have been studies by our industrial plants to develop methods of disposal of their wastes early in the industrial uses of our great water systems.

We have been through that mistake once, as you aptly mentioned. I think those of us in the Bureau believe and, in fact, it is my impression that the Atomic Energy Commission believes also that we need study and development in order to take care of these critical waste materials so we do not repeat the destruction of wreat natural resources and great natural waterways for all kinds of purposes, not only for fish but for recreation and for other human uses as well.

Wre certainly intend to practice diligence in this respect, Mr. Chairman, and we intend to look at this problem with a very fishy eye and attempt to protect the present aquatic resources to the very iniximum extent.

I do not mean to imply that there are not problems or that the whe thing is simple or ensy. To my knowlectge lhere is no complete 
answer at the present time, but I believe there is an interest by all agencies concerned to develop the very best answer to this problem that we can find.

Mr. Miluer. I am glad to hear you say that. Of course, there is the other phase, public relations, as you know. In recent months and for some continuing time there have been a number of unfortunate events in the atomic energy field, not too many but they lend themselves to great publicity. The floating ashore of a barrel or a container marked "Danger, Atomic Wastes" in Mr. Pelly"s area some time ago created in the minds of people suspicion which it is very hard to overcome. So we have this public relations problem to overcome, too.

I shall stop questioning now so others will have an opportunity, but I shall ask you to read the record of yesterday. I am certain when Mr. Lennon has an opportunity to question you, which he will have in a few minutes, he will make his position clear. Counsel will make available to you at the earliest convenience the record of yesterday. Read the questioning by both Mr. Lemnon and Mr. Casey, in whose districts some of these dump areas have been designated, which apparently are not too far offshore, at least in the layman's mind.

After you have seen that, if you would, I would like to have your comments in the form of a memorandum for inclusion in the record.

Mr. McKernan. We shall be pleased to do that, Mr. Chairman.

Mr. Miller. Mr. Pelly.

Mr. Pelly. Mr. McKeman, what organizations exist as channels of information on any possible threat to marine life by the disposal of radioactive wastes? I think there was a reference to NATO.

Mr. McKernan. You mean worldwide?

Mr. Pelcy. International organizations.

Mr. McKernan. I am probably not qualified to answer this fully, Mr. Pelly, but within the fisheries field alone several international commissions exist. Dr. McHugh mentioned the North Atlantic Commission. This is a Commission composed of 12 member nations, most of them North Atlantic nations. In fact, I think perhaps most of them are members of NA'TO, also. I do know that Russia is a member of the North Atlantic Fisheries Commission, so that is one exception, at least.

These nations get together, and scientists and technicians from these nations discuss problems of mutual concern. 'This is one body through which a discussion of this kind could easily be had and could coordinate and could disseminate the knowledge that each of the nations have.

There are other international fisheries bodies which could act in the same capacity, such as the North Pacific Commission, with which you are very familiar, I know.

Mr. Peliy. Do you not think it extremely important that these organizations communicate back and forth and exchange information and develop any knowledge and disseminate it among our various research groups?

Mr. MeKernan. Yes, I do.

Mr. Pelly. The second thing I would like to ask you is this: What would be the appropriate international organization to discuss and 
develop mutual agreements or laws on the subject of proper protection of marine life from the disposal of radioactive wastes?

Mr. McKernan. There is an arm of the United Nations, the Food and Agriculture Organization, FAO, which might be a means of getting together the nations of the world and discussing this particular matter.

Mr. Peliy. For instance, the Conference on the Law of the Sea. Would that be a subject which nations would discuss in such meetings as are held in Geneva, United Nations conferences?

Mr. McKernan. I would think not, Mr. Pelly. That particular body has been concerned really with laws governing both territorial and high seas.

\section{Mr. Pelly. Do they not develop laws?}

Mr. McKennan. 'They might set up subcommittees of technicians to study this particular matter. I can see whether that particular group could. But I think an equally or perhaps more competent body might be $\mathrm{FAO}$, with headquarters in Rome, who have on their staff competent scientists to develop all the knowledge that is available on this matter. In fact, it is in a sense also a wing of the United Nations, too.

Mr. PELLY. It would just seem to me that early in the game, before the development of the peaceful utilization of the atom is advanced, chains of communication should be open and there shonld be constant exchange of research information among nations, leading toward the ultimate control and agreement among nations on means to prevent destruction and devastation of marine life and resources for human needs.

Mr. MrKennax. I agree with you, Mr. Pelly, that concurrent with the development of the uses of atomic power and nuclear power should come discussions and agreements on how the potentially destructive wastes can be handlet.

Mr. PELLY. In other words, these suggested locations are, of course, of concern to the areas which they are near but, on the other hand, certainly as between Canada and ourselves, and as between Mexico and ourselves, we have a tremendous community of interest in working out arrangements so the resources which we share are protected. What is the good of just one nation practicing control if the other nations of the earth do not do it?

Thank you.

Mr. Millus. Mr. Oliver.

Mr. Ohrer. Just a brief question, Mr. Chairman.

This mat be ofl the track of what you have just been discussing, Doctor, but I was wondering if you are familiar with the recommendations which the Committee of Sicientists on Oceanography made for an overall budget for the next 10 years.

Mr. MrKensan. Yes. I am most familiar, Mr. Oliver, with those reconmendations pertaining to the living resources section.

Mr. Oriven. I should like to ask you this question. In that recommended buderet, was your Thureain or Department recommended for increased approp riations for oceanographic work?

Mr. MoKmenas. Yes.

Mr. Os,res. Is that reflected in the appropriations which have been mate for your Burealu for fiscal year 1!960? 
Mr. McKernan. Not in 1960. You see, our 1960 budgets were submitted a good deal before this particular study was completed.

Mr. Oliver. So, so far as the budgetary recommendations of the committee of scientists are concerned, your Bureau's appropriations for 1960 will not reflect those recommendations.

Mr. McKernas. 'The original budget for 1960 will not reflect those recommendations, but we nevertheless are attempting to work with other departments of Government to reorient our oceanographic program within the limitations of our budget and with the limitations that Congress imposes upon us for the expenditure of our funds. Within those limitations we are attempting to reorient our program to use to the maximum the recommendations which have been submitted in this report.

Mr. Oliver. Was any increased appropriation requested by your Bureau through the Department to the Burean of the Budget?

Mr. MicKensax. Mr. Oliver, I do not believe that I am permitted to disclose information on prehiminary estimates by our budget, but I think it fair to say that our Bureau has been aware for a number of yeurs of the need for increased oceanographic research, and we have been attempting consistently to reorient our program along these lines. We have done so within the limits of our authority.

Mr. Oliver. I am sure, Dr. McKeman, there is no need for me to stress to you the importance of increased oceanographic research. You are fully aware, far more than I, of the implications involved in not doing what you should be doing. What bothers me is whether or not we are waiting until 1961 or 1962 or 1972 before we do the things which we know should be done as soon as possible.

I am concerned about what I think to be the fact, that various bureaus and departments of the Government which have a direct interest in this perhaps are not doing what should be done to get the importance of these necessary appropriations stressed effectively enough to get the actual money and do the job. That is all I wanted to determine. Thank you very much.

Mr. Miller. Mr. Curtin.

Mr. Curtin. Thank you, Mr. Chairman.

Doctor, as you know, recently there was published a list of proposed disposal points for nuclear wastes in the sea and in the gulf. Was your agency contacted and did you discuss with the National Academy of Sciences these locations before this publication was made?

Mr. McKernan. Yes, Mr. Curtin. Dr. Walter Chipman was a member of the group which finally came up with those recommendations, and Mr. Howard Eckles of our staff right in the Washington office was a consultant. So our Bureau had ample opportunity to express our views with respect to those recommendations.

Mr. Curtin. Certain of the spots seem to be very close to or in the middle of rather popular fishing grounds. Was that taken into consideration when these discussions were held?

Mr. McKersan. Yes, it was. It is my understanding that these recommended locations are not final by any means. Is that correct, Dr. McHugh?

Mr. McHugh. That is correct.

Mr. McKernan. There still will be opportunity and still must be opportunity for further study and review of the possible effects on any of our resources, not only fisheries, but others as well. 
Mr. Curtin. Have you an opinion as to the feasibility of these locations in relation to the fishing grounds?

Mr. McKersix. I have great confidence in the members of this committee. Upon review and recommendations of my staff, the Bureau has generally adopted the recommendations of this particular. committee, because in a sense these are simply not finally adopted disposal areas, you see. They are suggestions which call for further study and further deliberation. So we still have an opportunity to object to any of these areas where they might have a permanent effect on the fisheries resources.

Mr. Cuntis. "They are in the nature of proposals. Are you in favor" of these proposals?

Mr. McKennax. Insofar as our information is developed so far, yes.

Mr. Cuntin. That is all, Mr. Chairman.

Mr. Miller. Mr. Lennon.

Mr. Lexwon. I believe your official title is Director of the Burean of Commercial Fisheries in the Department.

Mr. McKernan. Yes, Mr. Lennon.

Mr. Lenvon. I believe you stated in response to a question by $\mathbf{M r}$. Curtin that you are familiar with the areas recommended by the National Academy of Sciences for the disposal of low level radioactive wastes recently published.

Mr. McKernax. I may have misled you, Mr. Lennon. I am not specifically familiar with the detailed locations of these, and talked to our people only in a general sense.

Mr. Lenson. You said you had an opportmity to review that, though, and to make objections to it if there were any objections.

Mr. McKernan. Yes.

Mr. Lennon. You made no objections?

Mr. McKernan. Yes; that is correct.

Mr. Lennon. Dr. Joseph Lieberman, who I believe is a safety engineer for the AEC, testified yesterday. I think he identified himself as sanitation environment engineer of the Reactor Division of the AEC. As I recollect from his testimony yesterday, that was his identification when he testified before the committee.

He was askerl about this matter. I shall tell you in a few minutes what he had to say, as I recall his testimony.

For almost ten years we have been dumping packages, properly motected or supposedly properly protected, in certain areas of the ocean, generally beyond the continental shelf, in the deeper waters of our gulf coast and Pacific and Atlantic coasts. These are low level radioactive materials. Have we not?

Mr. MeKervan. Yes.

Mr. Lenvon. Of course, those areas were approved by the Bureau of Commercial Fisheries.

Mr. McKemis. I would not say "approved," Mr. Lemnon. We had an opportunity to object to those areas.

Mr. Ixinnos. You found no reason to object?

Mr. MeKernan. Correct.

Mr. Laxyox. Now the proposal is to dump these radioactive waste materials, low level though they may be, in spots along the gulf coast and more particularly along the North Carolina coast at a spot which, 
according to the area specified, would be about 22 miles off the coast of North Carolina, from Morehead City, N.C., in what we consider to be very shallow water. I suppose at that particular place, because of the contour of the ocean floor from the shore line out, it would not be more than 55 or 60 feet, if it is that deep at that spot.

What we are concerned about is why, except for economy reasons, rou do not move a little farther out in the sea and dump this material in deep water beyond the Continental Shelf.

Before you answer, I will tell you what I recollect Dr. Lieberman said. He said economy was a great factor in this decision; that it was just cheaper to take it out 20 -some miles and dump it than it was to take it out another 25 or 50 miles and dump it in waters where it is very unlikely it would ever do any harm. He said there was another factor, and that was being able to stay right where it was and go there and test it from time to time.

He said further that in the last 10 years the area where we have been dumping for 10 years had been tested only once, and that was about 18 months ago, to determine the percentage of contamination, if any, that was found there.

I would like you to comment on that because the board of conservation which has charge of our commercial fisheries in North Carolina has already expressed by resolution and by telegram its violent disapproval. I was amazed yesterday to learn that you people, who have been called on to make a recommendation or at least to consider this matter, had not taken the trouble to contact the State agencies which have responsibility to the commercial fisheries.

Would you please tell us how you feel about that?

Mr. McKernax. In the first place, I certainly would have no objection and would agree with you that the farther offshore we take this as a general rule, the better off we are. On the other hand, of course, these are very low level wastes, and on examining all of the information which was available, published as well as mpublished, our people felt that the sites suggested would have no adverse effect on the fisheries resources.

There again, obviously, setting aside the matter of economics, the further offshore you get this material, provided you are not going offshore into areas of use by our commercial fisheries or areas of heavy concentration of commercial fisheries, the better off you are.

I cannot explain nor do I attempt to condemn our scientists not contacting members of your department of conservation. I think we should have done that. I do not understand why we did not. We have been in contact with department of conservation officials in other parts of the country on this particular matter during other discusions and deliberations.

Mr. Lennon. We have about 360 miles of coastline. We are right in the heart of the menhaden indnstry. I suppose Morehead City has one of the largest menhaden fleets on the South Atlantic coast. We have a large shrimp industry as well.

I know you are familiar with the way they drag the ocean bottom for shrimp in that general area. They drag it out that distance sometimes, I am told. I know the menhaden fleets range out in that area. We simply cannot understand. 
I was amazed, too, to see the figures that were given to us yesterday of the small amount of money being spent by AEC, and your Department as well, in a study of this situation. It was an infinitesimal part of the overall AEC program, perhaps $\$ 200,000$ or $\$ 300,000$, if that much, on an annual basis.

I, for one, intend to ask the chairman of the Joint Committee on Atomic Energy to bring the proper officials of AEC and your Department before that committee to see if economy is the only reason. Certainly you cannot justify a situation like this on the basis of the extra cost of maybe even $\$ 200,000$ a year. These contracts are made by AEC with disposal corporations, are they not? Is that not the way it is done?

Mr. McKernan. Yes.

Mr. Lennon. I hope that in the future, before any publicity is given to where radioactive materials, even low level wastes, are to be disposed of, you would review with the departments of conservation and development, particularly the bureaus of commercial fisheries and sports fisheries, of the States and extend them the courtesy of getting their views before you publicize such a thing. It is a matter of grave concern to our people. I know the gentleman from Texas, Mr. Casey, who is certainly moderate and sympathetic and cooperative both with your Department and the AEC, is very much concerned about the decision to dump this material within 23 miles from the coastline of his district, right in the fishing grounds which he fishes himself. The sports fishing industry in the South Atlantic-certainly I can speak for my own State - as well as the commercial fishing industry are great factors in our total economy. I do not believe that you folks ought to commit yourselves and give your approval or withhold your disapproval until such time as the related counterpart agencies in the State are at least solicited for any view that they may have.

The ultimate and final decision is with AEC. I do not believe that the AEC or the National Academy of Sciences would have announced any such intention if you folks had said, "Hold this up until we can study it thoroughly." I do not believe they would have done it, because everybody wants good public relations. I should think they would, anyhow. Certainly good public relations are not gained in the way this thing was handled.

I ask you, sil, with all the sincerity that I have, to go back and review this proposed decision and see if it cannot be determined if it would be in the public interest, the psychology of the thing if nothing else, and its effect on the general public, to spend a few more dollars and go ont another 25 miles, in some instances less, and dump it in deeper water on the Continental Shelf. I hope yon will do that.

Thank you, Mr. Chairman. I have made my speech, but I was concerned about it.

Mr. Minder. All right. Counsel.

Mr. Drwwry. Mr. McKernan, yesterday when the question was asked how come certain sites were nimed, the Atomic Energy people said the selection of the sites was done by the Bureau of Commercial Fisheries. Is that correct?

Mr. McIKnrnan. Not to my knowledge.

Mr. Drewry. Did I not also understand from you that Dr. Chipman was on this group? 
Mr. McKernan. That is correct.

Mr. Drewry. Is he not one of your representatives?

Mr. McKernan. Yes, he certainly is. In fact, they also had Mr. Eckles from our office as a consultant. It was not my understanding that we had selected the sites, but we certainly had an opportunity to critically review the sites which were suggested by AEC and by this group. To my knowledge, we did not specifically select the sites ourselves.

Now I want to confess, Mr. Counsel, that there may be something here I have not been informed about, but to the best of my knowledge, we did not select the sites.

Mr. Drewry. Perhaps my recollection is faulty. Do you know how the sites were selected?

Mr. MCKERnan. I believe the general area was determined by AEC and then the specific sites were selected on the basis of all the knowledge available about the resources in that particular area, both with respect to concentrations of fish and concentrations of fishing. There were undoubtedly a great many other considerations also, but in fisheries, with respect to fisheries considerations, we considered whether there were the resources present and where they were present and where they were harvested and attempted to pass judgment on that particular basis-again, of course, being assured these were low-level wastes and being assured that they were not of a level that would have adverse effects on the aquatic resources in the region where the wastes were dumpect.

Mr. Drewry. How did you determine what resources were there?

Mr. MoKrersan. TVe have fairly broad knowledge from our own exploratory research on the rarious consts of the United States and in addition there are published records from the States and other research agencies and from the commercial fisheries themselves. Taking all these data into account, the decision was based on that.

Ifr. Drewry. Was there any actual on-site fishing done before the sites were selected?

Mr. MoKernan. In most of the areas we had fairly good knowledge. Someone might disagree with me in that regard, but we felt, that before a decision was made we had made an adequate study of the area suggested so that we did know whether or not fisheries resources, which perhaps were not as yet utilized, might be aflected or whether the fishing operations themselves might be affected. Dr. McHugh has a comment on this.

Mr. McHegri. There is one other point which is that as I understand it, these sites were chosen as far as possible in particular spots where fishing was not possible because there were wrecks or were already explosive dumping areas, or something like that. It would be difficult, in other words, if not entirely impossible, for a vessel to actually go trawling on that spot and pick up one of these containers even if they tried.

Mr. Drewry. Is that the criterion, the use of trawlers?

Mr. McKernan. Other forms of fishing gear used in that particular vicinity.

Mr. Drewry. I am not too much of a fisherman but a wreck is a rather attractive spot.

Mr. McKernan. For handline fishing sometimes. 
Mr. Drewry. Do you take the individual sport fisherman into account?

Mr. McKernan. The level of waste is so low as to not affect the fish that might come in reasonably close contact with this material.

Mr. Drewry. I understand these areas would be forbidden to fishing, that they would be marked off.

Mr. McKernan. Actually fish will and do migrate in those various vicinities. Any particular wastes that are of a level, which would contaminate either the plankton itself or the fish themselves would not be desirable nor would we want to approve such an area.

Mr. Lennon. Would counsel yield to me at that point?

Mr. Drewry. Certainly.

Mr. Lennon. Dr. Lieberman yesterday suggested the strong likelihood where this material was dumped it would have to be restricted, patrolled, or at least marked off with buoys.

Mr. McKennan. You cammot keep the fish from migrating past it.

Mr. Lennon. You can keep the fishermen out. Do you know anything of the sports fisheries along the South Atlantic coast? I know you do not spend a dime in research on it. All the fine material the doctor brought to us this morning was based on commercial fisheries. I do not know 'that the Bureau of Commercial Fisheries spends anything at all on the sports fisheries.

Mr. McKernan. A great deal of our research applies to resources harvested by anyone, commercial or recreational.

Mr. LenNos. We have in the last 2 years found white marlin and blue marlin in the very area I am talking about, a tremendous catch of them. One boat boated five about 3 weeks ago. We found out ourselves they are there. They have been there all the time but we learned how to fish them. They are in the very area where you suggest now they plan to dump this low-level waste material.

That is sort of disturbing to party boat operators and fishermen to find that they have finally discovered a fishing ground that people are coming to. The Atlantic Ocean is a mighty big place and it seems you could find a place other than 20 miles offshore for this dumping. It does not make sense to me.

Mr. McKernan. We will certainly explore those sites you suggested

Mr. Drewry. You mentioned there might be some disagreement with you as to whether these sites were presently fishable. I would say there is. We had testimony yesterday of Mr. Downing in regard to the area off Virginia Beach, and Mr. Casey as to the area off Galveston where he said some of the finest fishing he had ever had was in the exact spot.

I understand from the testimony yesterday that there were two preuse surveys under study at the present time up in New England. Upon inquiry, I find one is at a place called Browns Ledge where the Coast and Geodetic Survey, I believe, is participating with AEC. I assume you are involved in it, too, are you not?

Mr. McHugin. Yes, we are, Mr. Drewry.

Mr. Dnwnr. Has that survey proceeded to a point where you could discuss any results?

Mr. McHugn. No, sir. There was a meeting not more than 10 days ago up at Woods Hole at which some of our people were present. 
I have not yet seen a report of this meeting. I cannot tell you anything about what went on.

Mr. Drewry. In connection with Browns Ledge, which is rather close inshore and a rather shallow area, is that an area where there never had been fish before?

Mr. McHugn. No; I think, it seems to me, Mr. Drewry, that the problem here and the thing in the minds of this committee when they were determining sites was that the chief danger was actually picking up these containers in gear. I am sure the committee felt that merely the presence of fish in the vicinity would not be enough to cause any danger. So that it is my guess that what they would say would be that right in that region probably sport fishing would not cause any problem because the fish would not be contaminated.

Mr. Drewry. It seems to me, as I recall the testimony here and other testimony, that certainly this point was not made clear that it was not to interfere with sport fishing. From the list of sites, many are mentioned as sites where there is a wreck or a site which has been used as a dumping ground for explosives, or something of that sort, but the impression I received was that it was to be a forbidden area, even though it is low level waste, to be a forbidden and perhaps patrolled area.

What is the scope of the biological research functions of the Bureau of Commercial Fisheries? By that I mean are you limited to dealing with studies concerning the life cycles and abundance and locations of known food fish or commercial fish, or is it the whole field of marine biology?

Mr. McKernan. Pretty much the whole field of marine biology as it pertains at the present time or might pertain in the future to the use of the living resources of the sea for food.

Mr. Drewry. Total living resources of the sea for food?

Mr. McKennan. Yes.

Mr. Drewry. Would that include studies into various plant or animal organisms that are not themselves usable but nevertheless have a place somewhere in what was referred to yesterday as the food web of the sea?

Mr. MrKernan. Yes; we certainly study the organisms and the general chain of life in the sea.

Mr. Drewry. The development of rough fishes in certain areas, you would want to know how come they are developing? I am speaking of carp and others of that sort.

Mr. McKernan. Yes.

Mr. Drewry. You spoke of your program in relation to the National Academy of Science's suggested 10-year program. I understood you to say that you budgeted within the scope of your authority. I did not quite understand that. Or rather, you programed within the scope of your authority. How do you mean that?

Mr. McKernan. Of course, the way I understand our national budget, the President makes a decision about budgetary levels and these are passed down to the various departments of Government. Then the department applies certain limitations on each of the bureaus within the department. Our bureau budgets within these limitations imposed by the President's budget itself.

Mr. Drewry. And that is your program? 
Mr. McKernax. Within these particular limitations we devise the very best program possible.

Mr. DREwry. Your program is controlled by your departmental budget rather than by your scientific understanding of what should be done in order to gain the maximum amount of knowledge with the greatest efficiency?

Mr. MCKernax. I have misled you a little bit, because we certainly have ample opportunity to attempt to alter any departmental ceilings that are imposed in any kind of matter and we have a chance to argue for higher budgets and for new programs during these various years that I have had this responsibility. So that we have opportunity to argue our point before departmental officials who make these decisions.

Mr. Ourver. Will counsel yield?

Mr. Drewry. Yes.

Mr. Oliver. Did you argue for more funds for oceanographic research for 1960 ?

Mr. McKernan. Yes; I have generally argued for increases of various things and oceanography has been one of the programs I have pushed fairly heavily. By the way, I have obtained a great deal of sympathy and interest within departmental officials from the Secretary right on down in the Department of the Interior.

Mr. Otrver. But did you get more dollars?

Mr. McKernan. We obtained some more dollars, not a great deal more, not perhaps as much as some of us bureaucrats would like to have, you know.

Mr. Mrleer. If counsel will yield, it is similar to the case of the enthusiastic salesman who reported to his sales manager that he had had a great solicitation but not sales. I have been in your position with a smaller agency. I know you speak a lot of words but, frankly, as Omar Thayyam said, "I came out of the same door wherein I went"-unfortunately.

Mr. Drewry. My point is just this: I do not see any conflict between stating the goal even though, to borrow a phrase, it far exceeds your grasp-the grasp being the amount of money you can get-but too often we hear testimony of what the forward program is and the program seems to be limited by the budget rather than the broader goals of the agency. In this case the overall 10-year program recommended by the Academy.

As an example, I think we can bring up something we talked about before, which is that we do not need fishery research vessels becanse we have to get caught up in our paperwork, speaking of the case of the Albatross. It is disturbing to think of the budget controlling the program.

Mr. MoḰnenan. We never said we did not need research vessels in New England and we never said that we would not like to have right at the moment a good research vessel in New England. I think we have been orer that several times before. Our position with respect to the Albatross is that it is an ineflicient research vessel and that we were better advised to spend our money in analyzing the research that had been collected rather than spending an increasingly greater amount to keep this vessel at sea.

Mr. Dlinwry. I will stand corrected and not wo into the Albatross any more. 
You did in this budget ask for additional funds for development work on a new research vessel ; is that not correct?

Mr. McKernan. In which budget?

Mr. Drewky. Your eurrent budget.

Mr. McKernan. The 1961 budget?

Mr. Drewri. Is it 1961 or 1960 ?

Mr. McKennan. The budget we recently submitted to the Department and which still, insofar as I know, is a confidential departmental budget, I do not believe I am at liberty to disclose what we asked for.

Mr. Drewny. What I understood was you requested something like $\$ 100,000$ for design and development work in the 1960 budget.

Mr. McKernan. We are very thankful that this was put into our budget in the Senate, Mr. Drewry, and sustained by the House, we understand. We are very pleased and thankful for this and we have started preliminary studies leading toward design of a proper research vessel for New England.

Mr. Drewry. Will this be a prototype design or a special vessel?

Mr. McKineran. We will attempt to develop a design which might have broader application. In the case of fisheries research vessels, fisheries research and oceanographic vessels, sometimes one suited for the New England area might not be suited for the more tropical or semitropical waters either by reason of the kind of experimental fishing to be carried on in the boat or by weather itself.

For example, fishermen and research people out in New England and the North Atlantic region, the vessel has to have considerably different characteristics from those that we use in the Hawaiian Islands, for example.

Mr. Drewry. How will you proceed with this design and development work? Will you call on your own resources? I do not suppose you have any naval architects in the Interior Department.

Mr. MeKernan. No.

Mr. Drewry. Will you work with the Maritime Administration or will you go to outside contractors?

Mr. McKernan. We will work with Maritime Administration and outside architects.

Mr. Drewry. Similar to the way Coast and Geodetic Survey has done with their survey vessels; is that correct?

Mr. MrKernan. I believe that is the way they do it, also.

Mr. Drewry. Several years ago there was talk of a 10 -year program which Fish and Wildlife Service had itself. What is the status of that program at the present time?

Mr. McKernan. Yes, you had reference-and very hightly soto the matter of advanced programing and looking into the longrange needs for ocean research. We have been doing that. In fact, I was a member of a survey team back in the winter of 1956-57 which did study the long-range needs of our particular bureau. That particular program is still under fairly active consideration within the Department but has not been approved nor released by the Department yet.

Mr. Drewny. It is still within the Department?

Mr. McKernan. Yes.

Mr. Drewry. When it receives departmental approval, then what happens to it? 
Mr. McKernan. When it receives departmental approval, we will then attempt to implement the recommendations by budgetary requests. In fact, of course, in a sense we have been trying to do this at the present time. We have actually attempted to organize our program along the lines of the results of this 10-year study and within the budgetary limitations imposed upon us always.

I might add that the National Academy of Sciences Subcommittee on Oceanography had access to at least part of the recommendations in this particular report, that part dealing specifically with oceanography. So that to some extent the recommendations of the National Academy of Sciences Subcommittee on Oceanography correspond to or parallel perhaps more currently the needs as the $\mathrm{Bu}$ reau sees them, with a great many expert advisers and world famous oceanographer's that were on that subcommittee, and with that advice in a sense this portion of the program has been brought currently up to date.

Mr. Drewry. Will your program be made public when it is approved within the Department?

Mr. Mchernan. As soon as it is approved it is my understanding the Secretary will make it public.

Mr. Drewry. Without having to go to any higher or other level of approval?

Mr. Mrínernan. I did not mean to mislead you. My understanding is that departmental approval will come after the Secretary has received clearances, I presume, from the Bureau of the Budget, for example.

Mr. Drewry. That is what I was talking about. The Budget controls the program rather than the program influencing the budget.

Mr. McKersan. There is a balance. This is true to some extent but not entirely, I would not say.

Mr. Drewry. Have you given consideration to the need for revamping of your laws to fit into this? Is that included in the program?

Mr. MoKernan. Yes, we discussed that at considerable length. In fact, I believe our present authorization under the Fisheries Act of 1956 provides fairly adequate legal structure to implement the oceanographic program as it is recommended by this subcommittee, with one or two exceptions. I believe those exceptions are being taken care of by special bills that are now introduced. Those would involve the making of grants to certain oceanographic institutions or contracting on a little freer basis than we now have authority for to contract and grant money to these oceanographic institutions.

Mr. Drewry. That is all.

Mr. MoKernan. May I say that it was brought to my attention by handwriting which I readily recognize as that of Dr. Wilbert M. Chapman of California that the atomic waste disposal at sea was considered by the Conference on the Law of the Sea last year in Geneva. Dr. Chapman believes that subject will come up again. I was not at that Conference.

Mi. Minler. Before the Department of Defense dumps antiquated or old ammunition and other waste at sea, the surplus defense waste, do they consult you or do they just go ahead and dump?

Mr. McKmenas. I cannot be sure that they always consult with us, Mr. Chairman. 
Mr. Miller. I wish you would look into your records because since this matter of disposal has come up, my memory was awakened yesterday to an incident on the Pacific coast where they got rid of some mustard gas that had been stored there. They loaded a Liberty ship, took her out to sea, and sank her. 'They afterwards disposed of some 700 tons of this in containers. Some of it was mustard gas. I cannot give you the chemical formula for mustard gas, but I am certain Mr. Oliver and I at one time had to train with mustard gas.

Not being a chemist or a biologist, I have no idea what would happen 50 years from now when these containers rust through and release a lot of this stuff into the sea. What will happen to the fish life?

Mr. McKernan. I believe I remember the occasion. I want to assure you we did not give permission for that disposal. I also confess and I suspect that there is in this vast maze of Government some lack of coordination in this respect, but I might add that the activities of this committee and this report on oceanography has done a great deal to bring together the interests of the various departments of Government in coordinating their activities.

Mr. MHLwer. Without asking you to commit yourself, I would like to have you think about the introduction of a bill to give the Fish and Wildlife Service the authority to veto the dumping of wastes at sea where they were inimical to fish life and perhaps require agencies of Government and others to come to you to get that permission before doing it.

Mr. McKernan. I believe the amendment to the Coordination Act passed by Congress last year does help us in this respect. It does require other departments to consult with us on activities which affect the fish and wildlife resources. I believe that will help us in this particular problem of offshore disposition of wastes.

Mr. Miller. Are they doing it now?

Mr. McKernan. Yes. This comes slowly because these things do not filter down to people in Government too rapidly, but, in general, I get the impression that all departments are anxious to cooperate in this respect. It takes some time before this can be fully activated, I confess, but I do not see any effort in any of the departments to circumvent this particular law.

Mr. Muler. Would it not strengthen your hand if we did have very positive regulation of this matter?

Mr. Mchernan. Yes.

Mr. Miller. Are there further questions? Thank you very much, sir. I want to tell you we appreciate your being here. It is always nice to see you.

Mr. McKernan. Thank you, sir.

Mr. Chapman. Mr. Chairman, before you leave, I just wonder if the committee's work has advanced far enough that it desires receiving testimony from the fishing industry. The reason for my inquiry is that I will be in town for a week or so, and the tuna industry, of course, and all the fishing industry in the State of California have a deep and abiding interest in this program.

Mr. Mrumer. Doctor, we have in mind getting to you. wY several agencies of Government to hear from. Infortm rather handicapped. As you know, we have to go aro: hearing rooms. That has held us up some. I want $t$ 
we do not get around to it in the immediate future we certainly want to hear from the fishing industry in all of its pluases and aspects. TVe do not expect to have everybody in here, but we recognize you and the group your represent.

Without further ado, the hearing will stand adjourned, subject to the call of the Chair.

(Whereupon, at $12: 29$ p.m., the subcommittee adjourned, subject to the call of the Chair.)

('The following were furnished for insertion.)

Congress of the United States,

House of REPRESENTATIVES,

Washington, D.C., July 23, 1959 .

Hon. George P. MiLLer,

Chairman, Special Subcommittee on Oceanography, Committee on Merehant

Murine and Fisheries, House of Representatives, Washington, D.C.

Dear $\mathrm{M}_{\mathrm{r}}$. Chairian: In connection with the consideration being given by your subcommittee to the question of the disposal of low-level radioactive waste materials in the oceans, I want to go on record as registering my strong objection to this practice.

In principle, I am opposed to the contamination of the earth's water bodies with this material. I leel that the isychological reaction now and the possible physical reactions of the people of the world in future generations make denial of applications for dumping of these products imperative. The amount of radiation that sea life and the human being consuming that sea life can safely tolerate is a vital question and one which is under debate by our finest scientific minds: and there is definite doubt that those coming after us on this planet will not suffer for our present-day actions.

I personally shall carefully consider possible ill effects which might be siffered from eating shrimp or fish should more and more dumping sites for radioactire material be approved; and I'm sure all thinking Americans will do the same. Consequent dlops in consumption would be disastrous to oul entire fishing industrv.

Thank you very much for your attention to these views. Sincerely,

Dante B. Fasceli, Nember of Congress.

\section{Department of THE INTERIor,}

Fisit and IVildifife Service,

Bureau of Commercial Fismeries,

Washington, D.C., July 28, 1959

Hon. George P. Millei,

IIouse of Represcntatives,

Washington, D.C.

Dear Mr. Miller : At the hearings on July 14, 1959, you instructed me to read the questioning by Congressmen Lennon and Casey at the AEC hearings on the previous day and to prepare my comments in the form of a memorandum for inclusion in the record. I have received transeripts of the record from Mr. Drewry, and offer the following eomments.

It frobably was unfortunate that the Committee of the National Academy of Sciences did not prepare the way more carefully for public acceptance of I'ublication No. 6.5.) by issuing a series of press releases prior to its release. The chief sonrce of complaint secms to have been their listing of specific sites for disposal. By designating these sites by latitude and longitude and by stating water depths and other characteristies, the report inadvertently gives the impression that these locations were recommended, whereas it was elearly the intention of the Acadomv's Commitfe merely to pick locations for funther investigation. We suspect if locations had not been given, there would hare been less alarm. "ith the qualifications of the members of this eommittee, and the criteria stated were to he followed rigidly, no danger s or humans would ensue. If there is any criticism to be irt, it would be that the importance of recreational uses of 
